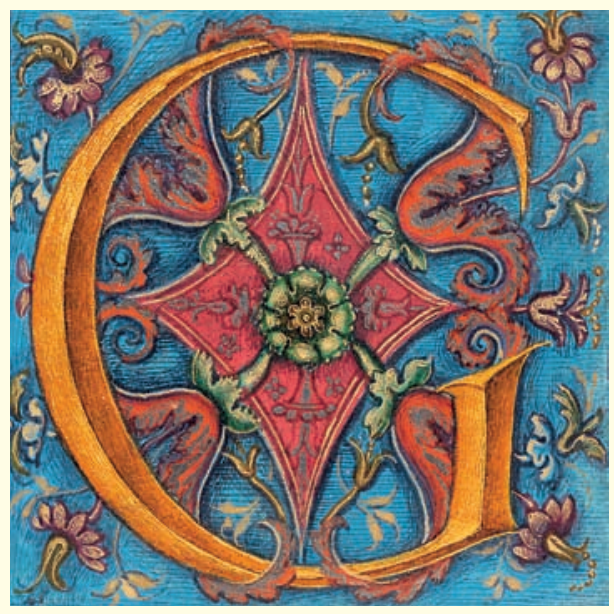

öttinger

Kostbarkeiten

Handschriften, Drucke,

Einbände aus

zehn Jahrhunderten

Göttinger Bibliotheksschriften 35

Hrsg. Elmar Mittler 



\title{
Göttinger Kostbarkeiten
}

Handschriften, Drucke und Einbände

aus zehn Jahrhunderten

\author{
Bearbeitet von \\ Silke Glitsch \\ Joachim Migl \\ Helmut Rohlfing
}

Göttinger Bibliotheksschriften 35 
(C) Niedersächsische Staats- und Universitätsbibliothek Göttingen 2006

Digital Imaging: Martin Liebetruth, GDZ

Umschlag, Satz und Druck: AZ Druck und Datentechnik, Kempten

ISBN- 10 : 3-930457-79-2

ISBN- 13 : 978-3-930457-79-3 


\section{Inhalt}

Zum Geleit

Zur Einführung Buchgeschichte und Provenienzermittlung. .................................... 6

Kapitel 1 Der Grundstock im Jahre 1734............................................... 10

Kapitel 2 Schenkungen vollständiger Sammlungen........................................ 26

Kapitel $3 \quad$ Herkunft aus öffentlichen Institutionen. ....................................... 46

Kapitel $4 \quad$ Wer bietet mehr? Ersteigert auf Auktionen.................................... 74

Kapitel $5 \quad$ Buchhandel und Antiquariat. ..................................................... 98

Kapitel $6 \quad$ Von adliger Herkunft ........................................................... 112

Kapitel 7 Göttinger Gelehrte. ................................................................... 134

Kapitel 8 Auswärtige Wissenschaftler.................................................... 174

Kapitel 9 Aus den Bibliotheken privater Büchersammler.............................. 200

Kapitel 10 In Dankbarkeit verbunden - Schenkungen Ehemaliger. ................. 220

Kapitel $11 \quad$ Autographa Lutheri..................................................................... 252

Kapitel 12 Die Sammlung Deutscher Drucke des 18. Jahrhunderts. ................ 260

Kapitel $13 \quad$ Wissenschaftliche Nachlässe. ................................................... 272

Register Verfasser, Anonyma, Drucker, Vorbesitzer und Provenienzen. ........ 282

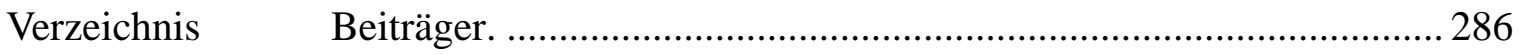




\section{Zum Geleit}

Für die neue Konzeption einer Forschungsuniversität wurde seit ihrer Gründung im Jahre 1734 die Göttinger Universitätsbibliothek mit einem schnell wachsenden Literaturbestand ausgestattet, der in liberaler Weise Professoren wie Studierenden bereitgestellt wurde. Sie diente als wichtige Grundlage für den Ruhm der Göttinger Professoren, wie Jacob Grimm einmal schrieb. Modern gesprochen könnte man „Exzellenz durch Information" als Grundsatz des Hannöverschen Kurators Gerlach Adolph von Münchhausen bezeichnen, den er insbesondere in Zusammenarbeit mit Christian Gottlob Heyne in jahrzehntelanger engagierter Aufbauarbeit umsetzte. Auf ihren unvergleichlichen Bücherschatz gestützt - Fabian sollte ihn später ein ideales Forschungsinstrument nennen wuchs die Georgia Augusta bis zum Ende des 18. Jahrhunderts zur größten und führenden Hochschule des deutschen Sprachraumes empor. Kontinuierlich wurden diese Bestände gepflegt; glücklicherweise erlitten sie kaum Kriegsverluste. Daraus sind der Bibliothek vielfältige Aufgaben u.a. als deutsche Nationalbibliothek für das 18. Jahrhundert und Sondersammelgebietsbibliothek für viele Fachgebiete innerhalb der nationalen verteilten Forschungsbibliothek erwachsen.

In Heynes Charakterisierung der Erwerbungspolitik wird das hochgesteckte Ziel formuliert, alles zu sammeln, was den Fortschritt der Wissenschaft dokumentiert. Kauf ,nach Prachtliebe“ oder „nach dem Schein des Äußerlichen“ wird dagegen ausdrücklich ausgeschlossen. Umso überraschender ist es, einen Blick in die Sondersammlungen der Göttinger Universitätsbibliothek zu werfen. Sie reichen von mittelalterlichen Handschriften von höchster Kostbarkeit über eine bedeutende Inkunabelsammlung bis hin zu vielen seltenen Drucken, die immer wieder auch mit prächtigen Einbänden versehen sind.
Handgezeichnete und gedruckte historische Karten gehören dazu ebenso wie die wissenschaftlichen Nachlässe bedeutender Göttinger Gelehrter. Das breite Spektrum sei an einigen Beispielen wie dem Fuldaer Sakramentar von 975, der zum UNESCO-Weltkulturerbe zählenden Göttinger Gutenbergbibel, reich illustrierten Frühdrucken wie der Weltchronik von Hartmann Schedel oder dem in Ulm gedruckten Weltatlas nach Ptolemaeus und der Korrespondenz Albert Einsteins mit dem Göttinger Mathematiker Felix Klein gezeigt.

Es gehört nicht zu den besonderen Kennzeichen der Georgia Augusta, dass sie ihre Kostbarkeiten prunkvoll zur Schau stellt. Und doch besteht eine Verpflichtung, einer breiteren Öffentlichkeit diese wichtigen Zeugnisse unserer kulturellen Überlieferung vorzustellen. Deshalb bin ich sehr dankbar dafür, dass meine Kolleginnen und Kollegen in der Ausstellung „Göttinger Kostbarkeiten Handschriften, Drucke und Einbände aus zehn Jahrhunderten" eine kenntnisreiche Auswahl dieser Schätze der Universität zeigen: 125 schöne, außergewöhnliche, besonders wichtige Werke vermitteln nicht nur einen Eindruck von dem erstaunlichen Reichtum und der beeindruckenden Vielfalt der Bestände der Bibliothek; sie bieten zugleich einen anschaulichen Einblick in die Erwerbungsgeschichte der Bibliothek und zeigen, auf welch verschlungenen und mitunter abenteuerlichen Wegen Handschriften und Bücher ihren Weg nach Göttingen fanden, aus welch unterschiedlichen Quellen die Göttinger Bibliothekare gezielt und systematisch einzelne Titel oder ganze Sammlungen erwarben, um in der Summe einen gut erschlossenen Bestand von erstaunlicher Dichte zu bilden. Es verwundert nicht, dass diese Bibliothek bereits im 18. Jahrhundert als Vorbild für Neugründungen und Neugestaltungen in Deutschland, in Europa und in Amerika diente. 
Ausstellung und Katalog sind das Ergebnis engagierter Mitarbeit vieler. Hier sind vor allem Dr. Helmut Rohlfing, Leiter der Abteilung für Handschriften und Alte Drucke, Dr. Joachim Migl, Leiter der Sammlung Deutscher Drucke 1701 - 1800, und Dr. Silke Glitsch, Referentin für Ausstellungen und Öffentlichkeitsarbeit, zu nennen. Weitere Exponatbeschreibungen wurden von den Fachreferenten Dr. Wilfried Enderle, Dr. Heinz Fuchs, PD Dr. Katharina Habermann, Dr. Jens Mittelbach, Mechthild Schüler, Dr. Werner Schwartz und Dr. Arnulf Timm, von den Bibliotheksreferendaren Jens Ilg und Dr. Andrea Kölbl sowie den Ausstellungspraktikantinnen Stefanie Krinninger, Kathrin Nordmeyer und Diana Walz beigesteuert. Dr. Helmut Kind, Prof. Dr. Kathryn M. Olesko, Dr. Gerd Unverfehrt und Dr. Horst Zehe waren spontan bereit, dem interessierten Besucher und Leser ihre Forschungsgebiete zu vermitteln. Den Ausstellungsaufbau hat Kathrin Sülflohn, die Digitalisierung der zahlreichen Katalogabbildungen Martin Liebetruth in gewohnter Professionalität bewerkstelligt. Ihnen allen gilt mein herzlicher Dank.

125 Göttinger Kostbarkeiten - diese nicht gerade kleine Zahl darf nicht darüber hinwegtäuschen, dass sie nur einen winzigen Teil dessen widerspiegeln, was den Wert und den Reichtum der Göttinger Bibliothek ausmacht. Viele sehenswerte Stücke mussten notgedrungen unberücksichtigt bleiben. In den Lesebereichen der Bibliothek oder in digitalisierter Form aber stehen sie dem Nutzer zum ,freyen und unbeschwerten Gebrauche" auch künftig zur Verfügung.

Göttingen, im September 2006
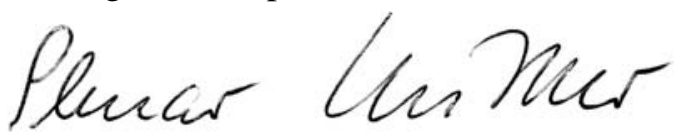

Prof. Dr. Dr. h. c. Elmar Mittler 


\section{Zur Einführung}

\section{Buchgeschichte und Provenienzermittlung}

Im Mai 1773 reiste der Bibliothekskustos Jeremias Nikolaus Eyring (1739-1803) im Auftrage Christian Gottlob Heynes (1729-1812), Professor und Leiter der Universitätsbibliothek, mit sieben Dukaten von Göttingen nach Nürnberg. Dort sollte er die Summe dem Besitzer einer spätmittelalterlichen Handschrift aushändigen, über deren Anschaffung für die Göttinger Bibliothek Heyne mehrere Wochen verhandelt und schließlich einen Abschluss erzielt hatte.

Gegenstand des Geschäftes war eine Handschrift, die heute zu den besonderen Zimelien der Bibliothek zählt, der sogenannte Bellifortis des Konrad Kyeser. Konrad Kyeser aus Eichstätt (1366-um 1405) ist der früheste namentlich bekannte Verfasser technischer und militärwissenschaftlicher Darstellungen des späten Mittelalters. Der Bellifortis gehört neben dem anonymen Feuerwerkbuch zu den erfolgreichsten Kriegsschriften seiner Zeit. Er ist in verschiedenen Fassungen in etwa 20 Papierhandschriften des 15. Jahrhunderts überliefert. Die wertvollste erhaltene Handschrift ist aber der vorliegende PergamentKodex, der König Ruprecht von der Pfalz gewidmet ist und die Nähe des Verfassers Konrad Kyeser zum Hof König Wenzels IV. von Böhmen (1361-1419) aufweist. Die zahlreichen anschaulichen Illustrationen, die auch der zivilen Technik breiten Raum gewähren, stammen aus der Prager Buchmalerschule, die von Kaiser Karl IV. (1316-1378) eingerichtet worden war. Ein Beispiel für den Bildschmuck der Handschrift ist die Darstellung der Speerspitze Alexanders des Großen mit Namen „Meufaton“, der magische Kräfte bei der Vertreibung von Feinden und Tyrannen zugeschrieben werden.

Eigentümer des Buches war im Frühjahr 1773 Johann Siegmund Stoy, ein 1745 in Nürnberg geborener Gelehrter. Nach Studien in Altdorf und Leipzig hatte er seit 1767 eine Stelle als Frühprediger inne, die er aber nur bis 1771 behielt. Seine nächste Anstellung bekam er erst 1774 als Pfarrer in Henfenfeld. Zu dem Zeitpunkt, als Heyne mit ihm über den Bellifortis verhandelte, hatte Stoy anscheinend kein regelmäßiges Einkommen und war möglicherweise gerade so knapp bei Kasse, dass er sich zum Verkauf der Handschrift genötigt sah und am Ende die finanziellen Vorschläge aus Göttingen akzeptierte. Ursprünglich hatte Stoy einmal 20 Dukaten erzielen wollen, musste seine Erwartungen aber schon bald auf zehn Dukaten reduzieren. Ende April 1773 berichtete Heyne in der Angelegenheit nach Hannover und bot schließlich am 8. Mai sieben Dukaten an, auf die Stoy sich einließ. Der Handel war perfekt, das Buch für Göttingen gekauft. Schon am 12. Mai trugen die Göttinger Bibliothekare den Titel in ihre Erwerbungsakten ein und wiesen ihm einen Platz in der Fachgruppe Militärgeschichte (Historia rei militaris) zu. Am selben Tag brach Eyring mit dem Geld nach Nürnberg auf. Den Empfang quittierte Stoy in einem kurzen Brief vom 19. Juni 1773.

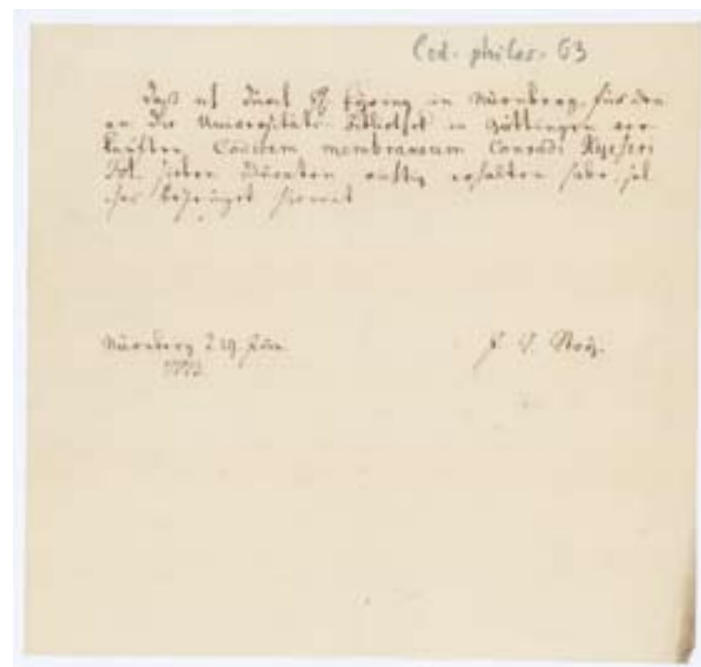

Quittung über 7 Dukaten von Johann Siegmund Stoy. 


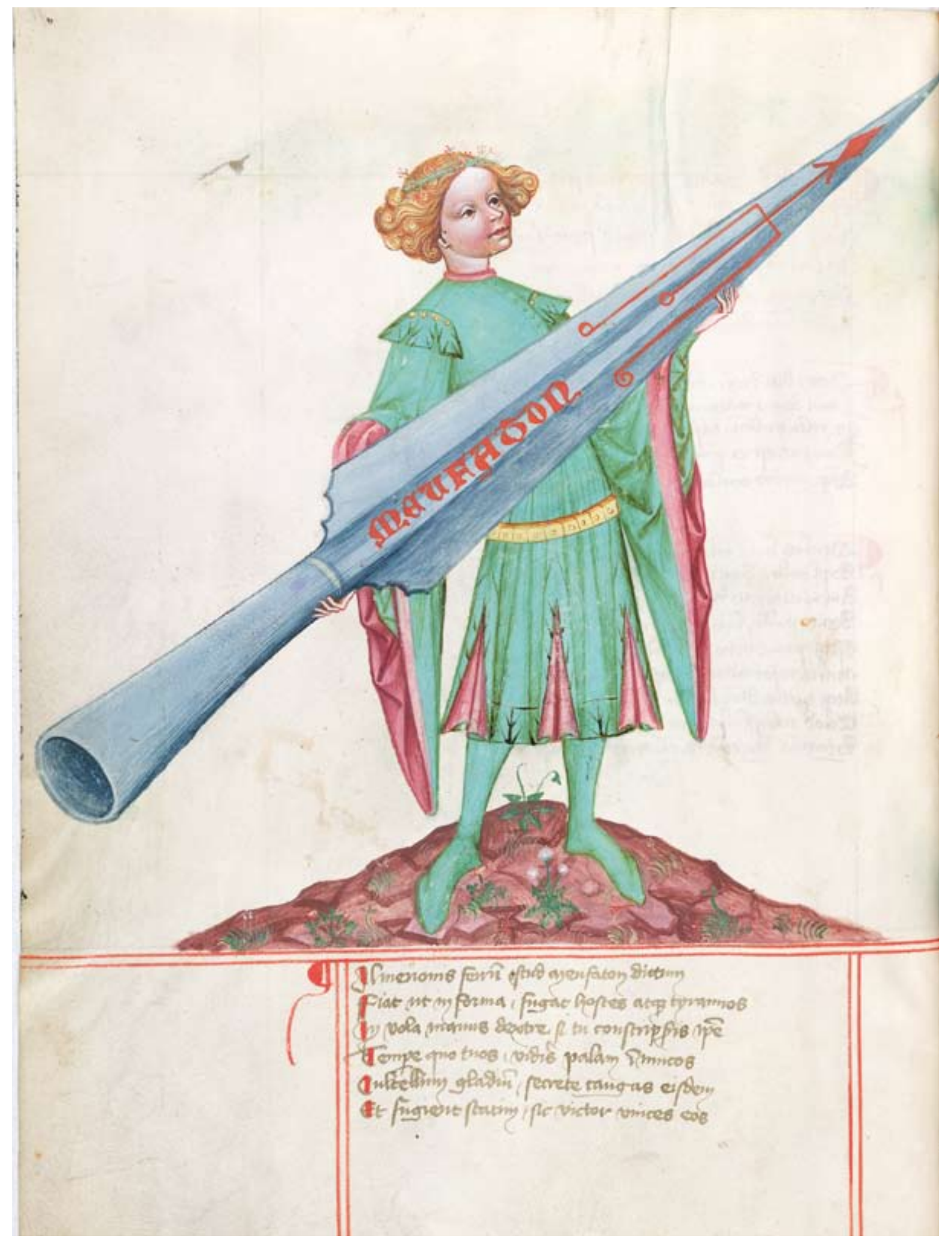


Es ist keineswegs die Regel, dass sich die Geschichten um die Erwerbungen von Büchern für die Universitätsbibliothek so detailliert rekonstruieren lassen wie im Fall des Bellifortis. Hier sind es Informationen aus mehreren Quellen, die den oben skizzierten Ablauf der Ereignisse beleuchten: Im Bibliotheksarchiv werden drei Schriftstücke zu dem Vorgang aufbewahrt, aus denen Nachrichten zu den Verhandlungen über den Kaufpreis und zur Identität des Verkäufers hervorgehen. Einzelheiten seiner Biographie wiederum sind dem vierten Supplementband zum Nürnbergischen Gelehrtenlexikon (Nürnberg 1808) zu entnehmen. Und schließlich enthält das Manual von 1773, das Zugangsbuch der Bibliothek, eine Notiz über den Eingang der Handschrift.

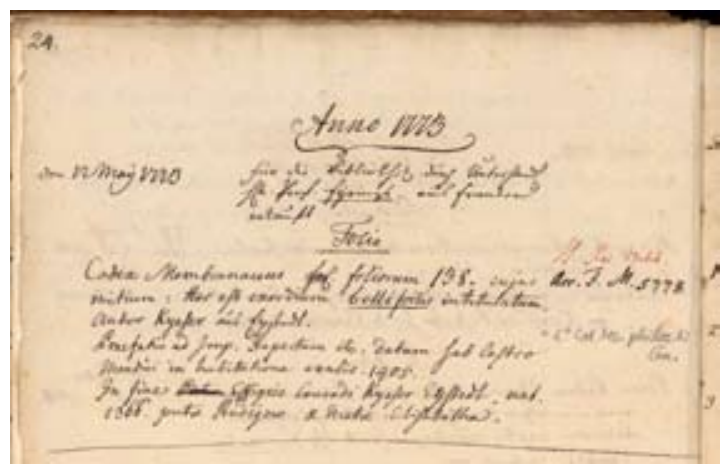

Kaufeintrag zum Bellifortis im Manual von 1773.

Wann und woher, von wem und für welchen Preis die Bibliothek ihre Bücher erwarb, erschließt sich - wie das Beispiel zeigt - zumeist erst durch Konsultation von Quellen zur Bibliotheksgeschichte und einschlägigen Hilfsmitteln. Dabei muss zunächst die Akzessionsnummer des Buchs ermittelt werden, die im Alphabetischen Bandkatalog der Bibliothek vermerkt ist. Sie bildet die Verzahnung mit weiteren Sonderkatalogen und dem Manual, das den unmittelbaren Vorbesitzer, den örtlichen Buchhändler oder die Herkunft aus einer Auktion nennt. Für Institutionen, die ihre Sammlungen über Jahrhunderte zusammentragen, ist diese Art der Bestandserschließung von besonderem Reiz, macht sie doch die individuelle Geschichte der Objekte in ihrem früheren, heute aufgelösten Zusammenhang transparent. So stolz die Bibliothek darauf ist, viele unterschiedliche Vorgeschichten unter ihrem Dach zu einem (hoffentlich endgültigen) Zielpunkt gebracht zu haben, so sehr belebt es ihre Bestandsgeschichte, in der Fülle von Büchern die Konturen vieler älterer Episoden und Geschichten erkennbar werden zu lassen. Das ist Aufgabe jeder Provenienzermittlung.

(JM/HR) 



\section{Kapitel 1}

\section{Der Grundstock im Jahre 1734}

Die Gründung einer hannoverschen Landesuniversität in Göttingen im Jahr 1734 war das Verdienst eines Verwaltungsfachmanns, des Geheimen Rats Gerlach Adolph von Münchhausen (1688-1770). Nach ihrer Gründung hielt er fast vierzig Jahre lang als Kurator die Geschicke der Georgia Augusta in seinen Händen.

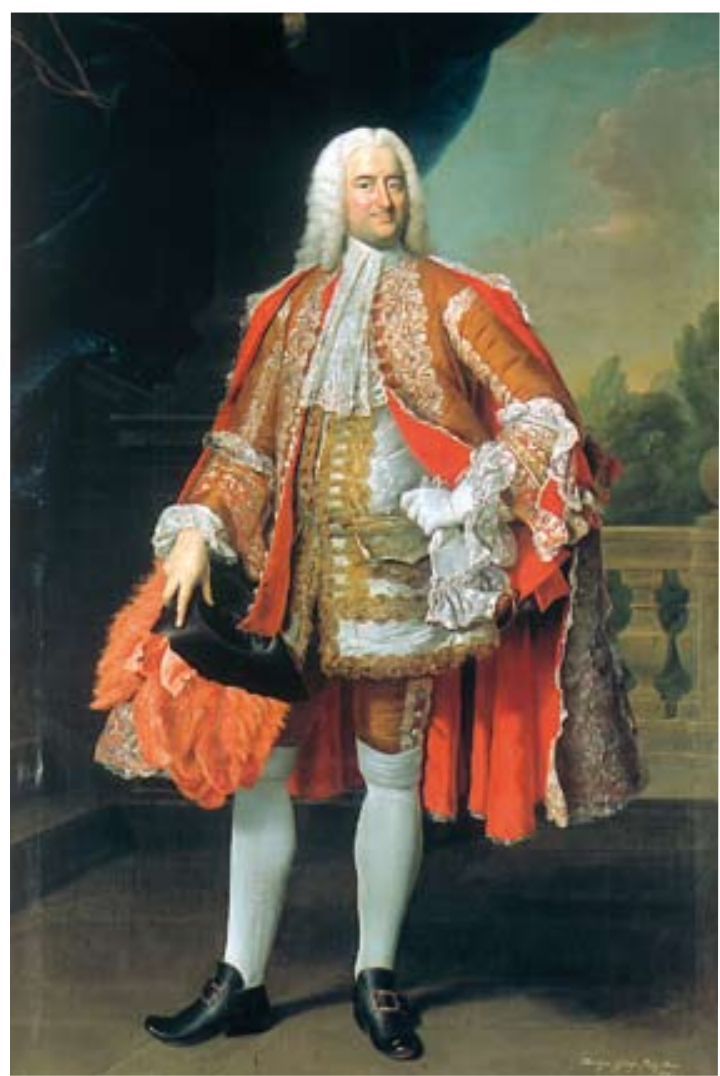

Gerlach Adolph von Münchhausen (1688-1770).

Die dynamische Entwicklung zu einer europäischen Reformuniversität mit internationaler Bedeutung war von Anfang an mit dem zielgerichteten Aufbau einer funktionierenden Bibliothek verknüpft, deren wichtigste Aufgabe in der Beschaffung und Erschließung der aktuellen wissenschaftlichen Literatur, aber auch der für die Forschung und Lehre entscheidenden historischen Quellen aus früheren Zeiten bestand. Es war ein glück- licher Umstand, dass Münchhausen die herausragende Privatbibliothek des 1724 verstorbenen Großvogtes Joachim Hinrich von Bülow (1650-1724) als Schenkung der Familie für die junge Universität erwerben konnte, eine mit 9.000 Bänden recht umfangreiche Universalbibliothek, die Münchhausen selbst in einem Brief an den König vom 6. April 1734 als „nombreuse und selecte Bibliothec“ bezeichnete. Der erste Bibliothekar der Georgia Augusta, Johann Matthias Gesner (1691-1761), bestätigte bei der feierlichen Eröffnung der Universität in seiner in der Paulinerkirche gehaltenen Dankesrede, dass in Erinnerung an den Stifter die Göttinger Universitätsbibliothek ,beständig den Nahmen Bibliothecae Bülovianae führen sollte, wie sehr sie auch durch andere Bücher künfftig vermehret werden würde.“

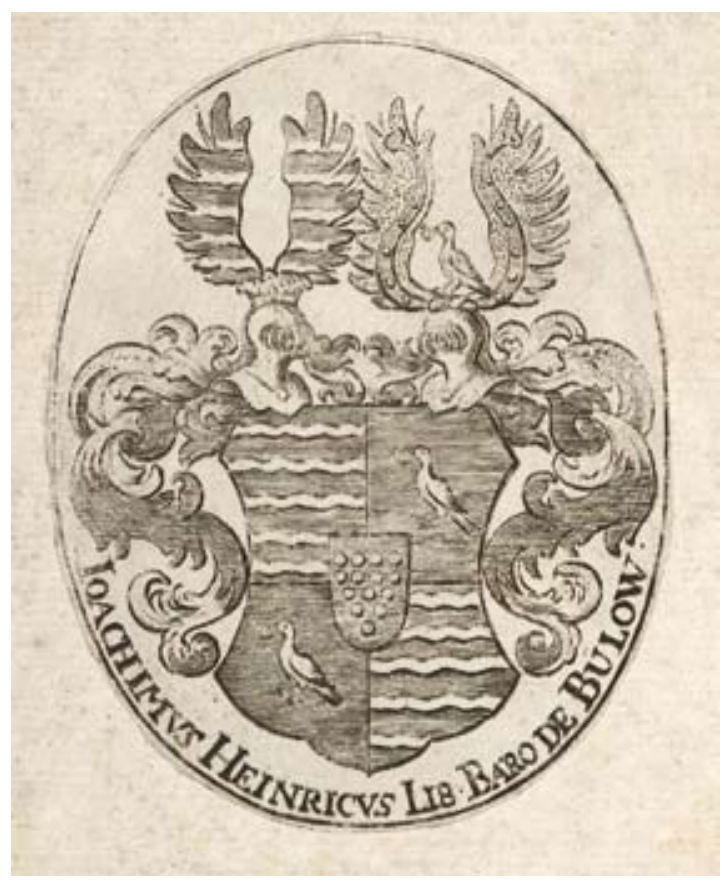

Exlibris Joachim Hinrich von Bülow.

Die ersten Kupferstiche, die uns einen Blick in den Bibliothekssaal gewähren, sind aus diesem Grund mit der Bezeichnung Bibliothe- 


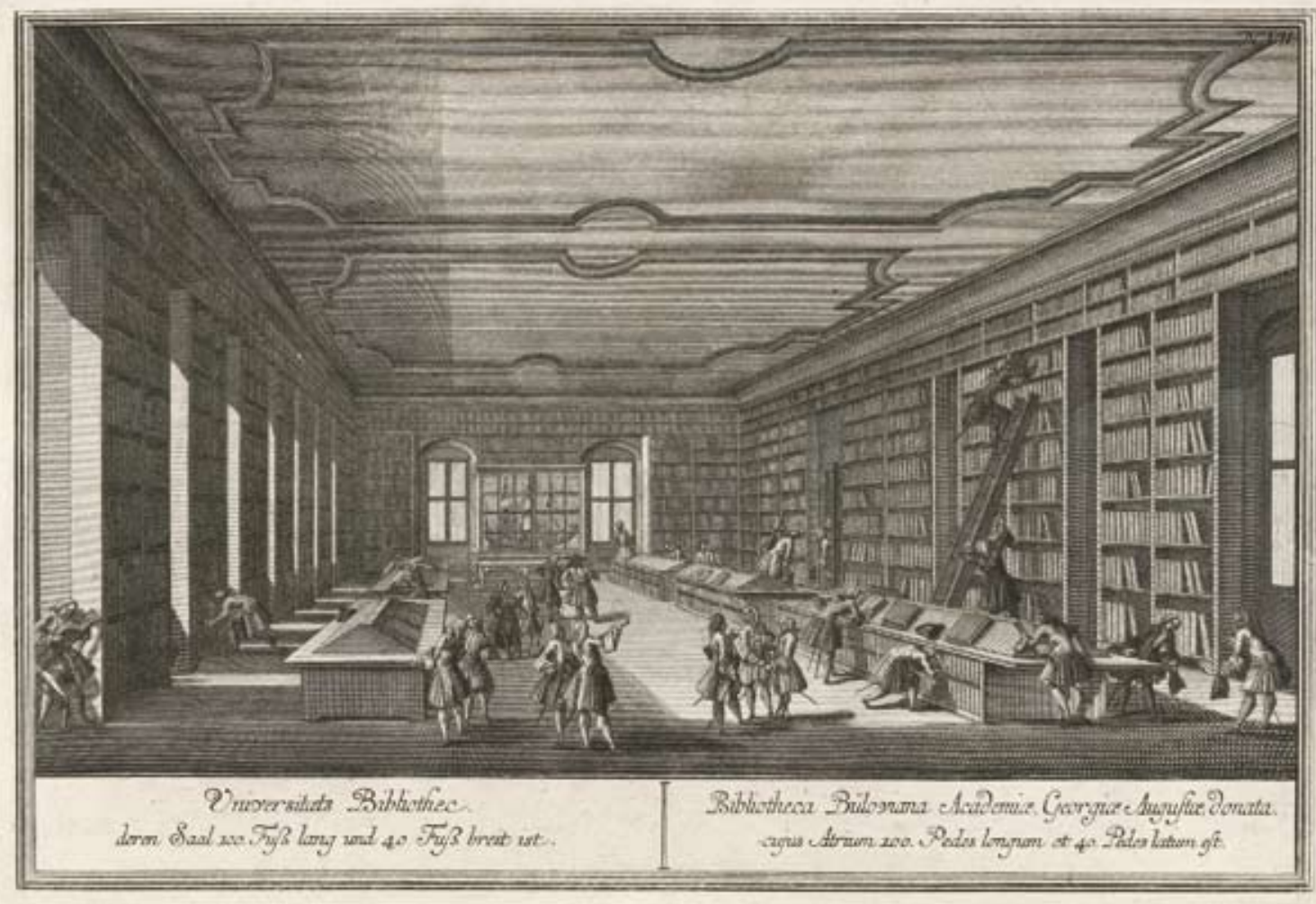

Blick in den ersten Bibliothekssaal.

ca Buloviana versehen. Der von Georg Daniel Heumann geschaffene Kupferstich aus dem Jahre 1747 gibt außerdem die Maße des ersten Büchersaals im Nordflügel des 1734 erbauten quadratischen Universitätsgebäudes mit einer Länge von 100 und einer Breite von $40 \mathrm{Fuß}$ an (was etwa 28,5 x 11,4 m entspricht). Inhaltlich waren in der Bibliotheca Buloviana alle Wissenschaftsgebiete vertreten, die an der Georgia Augusta gelehrt wurden, so dass von Beginn an nicht nur die Theologie, Jurisprudenz und Geschichte, sondern auch die Naturwissenschaften und Medizin im Bestand vertreten waren. Auch zwischen 40 und 50 Frühdrucke aus der Inkunabelzeit mit Erscheinungsjahren bis 1500 und eine Reihe mittelalterlicher und neuzeitlicher Handschriften finden sich in der großartigen Sammlung. Typisch für die Bücher aus Bülows Besitz sind große ovale
Exlibris mit dem Namen des Besitzers und mit Rautenmustern verzierte Lederbände.

Ergänzt wurde dieser Grundstock durch Dubletten aus der Königlichen Bibliothek Hannover und einen kleineren Bestand von Büchern der Bibliothek des Göttinger Gymnasiums. Alles in allem besaß die Georgia Augusta bereits im Jahre 1734 einen soliden Grundbestand von etwa 12.000 Bänden aus allen Wissensgebieten. Da Münchhausen selbst am Aufbau der Bibliothek regen Anteil hatte und mit Zahlungen von jährlich ca. 4.000 Talern für einen kontinuierlichen Bestandsaufbau sorgte, hatte die Bibliothek im Jahr 1761 bereits einen für die Zeit beachtlichen Bestand von ungefähr 50.000 Bänden.

(HR) 
Biblia, lateinisch.

Pergamenthandschrift.

Nordfrankreich, 1. Hälfte 13. Jahrhundert.

Signatur: $8^{\circ}$ Cod. Ms. theol. 5 Cim.

Provenienz: Joachim Hinrich von Bülow, 1734

Diese in Frankreich während des 13. Jahrhunderts entstandene Bibel gehörte zur Bibliothek des Joachim Hinrich von Bülow, wie das in den vorderen Deckel eingeklebte Exlibris verrät. Unter dem Wappen des im Jahre 1705 von Kaiser Joseph I. in den Reichsherrenstand erhobenen von Bülow findet sich eine handschriftliche Eintragung, die auf Philipp August Schlüter († 1761) als möglichen weiteren Vorbesitzer hinweist. Schlüter hatte bis zum Tode von Bülows im Jahr 1724 dessen Bibliothek verwaltet und wirkte in den Anfangsjahren der Göttinger Universität von Hannover aus als Bibliothekar der noch jungen Universitätsbibliothek. Der Orientalist und Bibliothekar Johann David Michaelis (1717-1791) charakterisierte Schlüter folgendermaßen: „Dieser Mann, der sein Vergnügen an der Bücherkenntniß fand, las Auctionscatalogos mit der Empfindung, mit der ein Poet Hallers Gedichte liest, und machte seine Lieblingsbeschäftigung daraus, die hießige Bibliothek vermehren zu helfen“.

Die 930 Seiten starke lateinische Bibel enthält den gesamten Text des Alten und des Neuen Testaments. Am Ende der Handschrift folgen noch ein Verzeichnis der Laster und Tugenden sowie ein Verzeichnis der Lesungen für 122 kirchliche Fest- und Heiligentage. Sie hat trotz ihres Umfangs ein handliches Format, was hauptsächlich an der in der Handschrift verwendeten zierlichen gotischen Minuskel oder Perlschrift liegt, die durchgängig von einer Hand stammt. Die in Frankreich entstandenen kleinformatigen Bibeln werden deshalb auch „Perlbibeln“ genannt. Als Beschreibstoff wurde ein ausgesprochen dünnes Pergament verwendet, das von sehr jungen Tieren stammen muss, so dass die Handschrift trotz ihres großen Seitenumfangs nur ca. 5 cm stark ist.

Der Bilderschmuck besteht aus mehr als 150 Deckfarbeninitialen, Ranken und grotesken Tierdarstellungen, die bei ihrer geringen Größe sehr sorgfältig ausgeführt wurden. Auffällig sind die länglichen Schlangen-, Drachen- und Hundeleiber, die sich um die I-Initialen herumwinden. Aber auch zahlreiche figürliche Darstellungen sind in den Initialen zu entdecken, wie ein Trommel schlagender Narr als Illustration zu Psalm 52 (Bl. 198'). Wegen der in der Handschrift enthaltenen dominikanischen Festtagslesungen könnte diese Taschenbibel im Auftrag eines dominikanischen Wanderpredigers angefertigt worden sein. Die Ornamentik der Initialen und der Figuren- und Gewandstil lassen vermuten, dass die Bibel in Nordfrankreich in der ersten Hälfte des 13. Jahrhunderts entstand. 


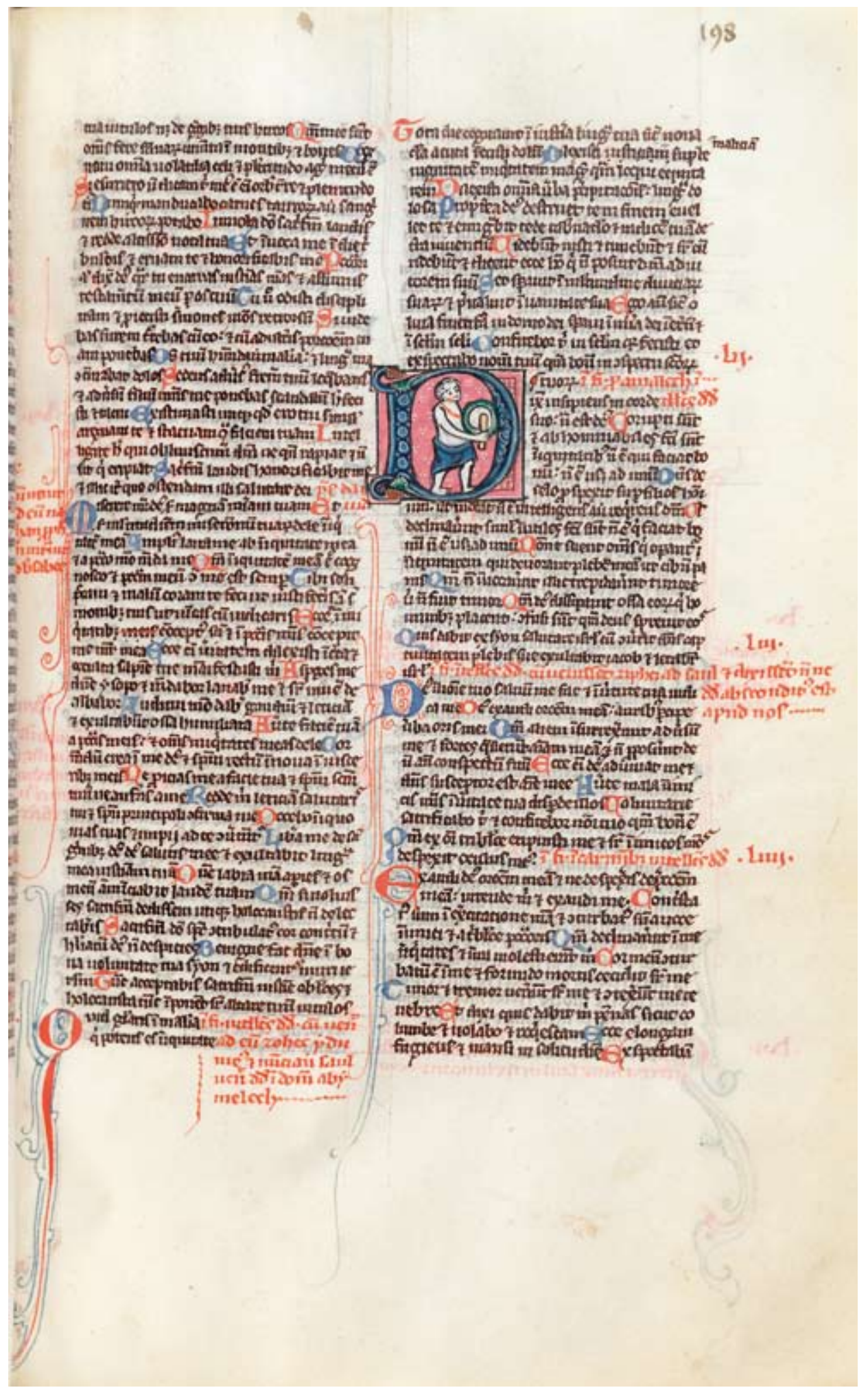




\section{Das größte Buchdruckunternehmen der Wiegendruckzeit}

Hartmann Schedel:

Liber chronicarum.

Nürnberg: Anton Koberger, 12. VII. 1493.

Signatur: $2^{\circ}$ Hist. un. II, $53^{\mathrm{b}}$ Inc.

Provenienz: Joachim Hinrich von Bülow, 1734

Im Juli 1493 erschien in Nürnberg eine lateinische Weltchronik, die zu den schönsten Holzschnittbüchern der Wiegendruckzeit zählt. Nicht weniger als 1.800 Holzschnitte von 645 Holzstöcken umfasst das Werk, mithin die bildreichste Inkunabel des Abendlandes. Erstmals wurde ein weltliches Buch so aufwändig gestaltet wie zuvor nur kirchliche Texte. Dem lateinischen Erstdruck, der am 12. Juli 1493 erschien, folgte bereits im Dezember desselben Jahres eine deutsche Ausgabe. Der Drucker der Weltchronik war der Nürnberger Anton Koberger (um 1440/45 -1513), der Pate Albrecht Dürers. Nach zeitgenössischen Berichten soll der Großverleger gleichzeitig mit bis zu 24 Druckerpressen gearbeitet und über hundert Gesellen und andere Mitarbeiter beschäftigt haben, Drucker, Korrektoren, Setzer, Metteure, Illuminatoren und Buchbinder. Für die Weltchronik reichten allerdings selbst seine finanziellen Möglichkeiten nicht aus, zumal innerhalb kurzer Zeit zwei Ausgaben zu besorgen waren: Die Druckkosten wurden von den Nürnberger Bürgern Sebald Schreyer und Sebastian Kammermeister finanziert.

Die Weltchronik stammt aus der Feder des Nürnberger Stadtphysikus Hartmann Schedel (1440-1514), der zu den größten Bibliophilen des ausgehenden Mittelalters gehört. Anregungen erhielt er aus einer 1482 gedruckten Chronik des Italieners Jacobus Philippus de Bergamo (1434-1530). Der in die christliche Heilslehre eingebundene Text beschreibt die gesamte Menschheitsgeschichte von der Schöpfung und der Erschaffung Adams und

Evas (im ersten Weltalter) bis zum Ende der Welt, der Apokalypse (im siebten Weltalter). Der Zeitraum von der Geburt Christi bis zur damaligen Gegenwart im Jahr 1493 ist dem sechsten Zeitalter zugeordnet, während das siebte eschatologischen Betrachtungen gewidmet ist. Das auffälligste Merkmal des Werkes sind die von den Nürnberger Künstlern Michael Wolgemut (1434/37-1519) und Wilhelm Pleydenwurff (um 1420-1472) geschaffenen Holzschnitte, insbesondere die großen Städteansichten. Vermutlich war auch Wolgemuts Schüler Albrecht Dürer an ihrer Herstellung beteiligt. Das Buch Kobergers erschien in einer Auflage von etwa 1.400 Exemplaren; sein buchhändlerischer Erfolg wurde freilich durch einen Raubdruck seines Augsburger Konkurrenten Johann Schönsperger (1455-1521) geschmälert, der 1497 eine kleinere, billigere - und qualitativ schlechtere - Ausgabe drucken ließ. Aufgeschlagen ist der Tanz um das goldene Kalb aus dem dritten Weltalter. 


\section{Terciaetasmundi}

Folium

$\mathrm{XXXI}$

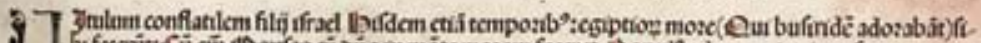

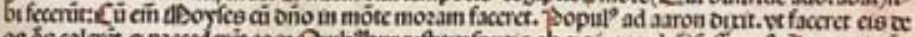

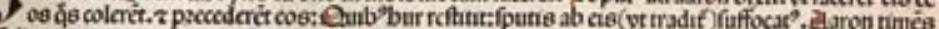

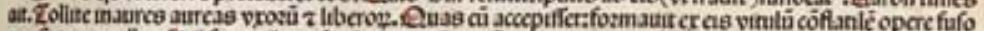

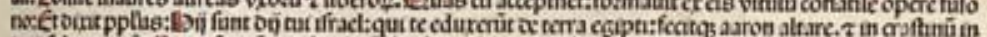

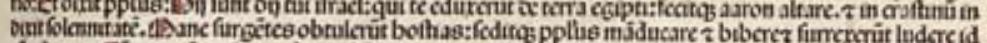

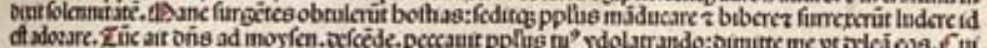

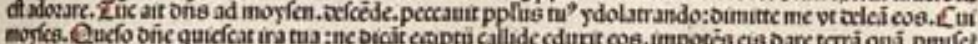

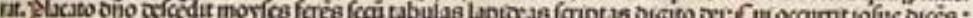

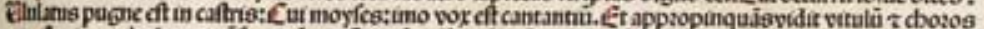

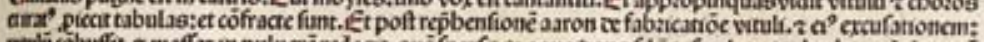

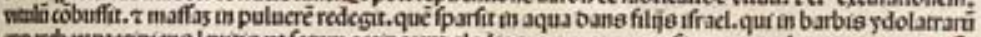

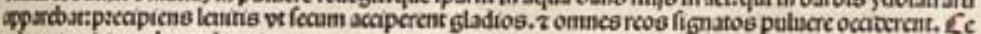
olenut $c$ bic multa mulia yorozum.

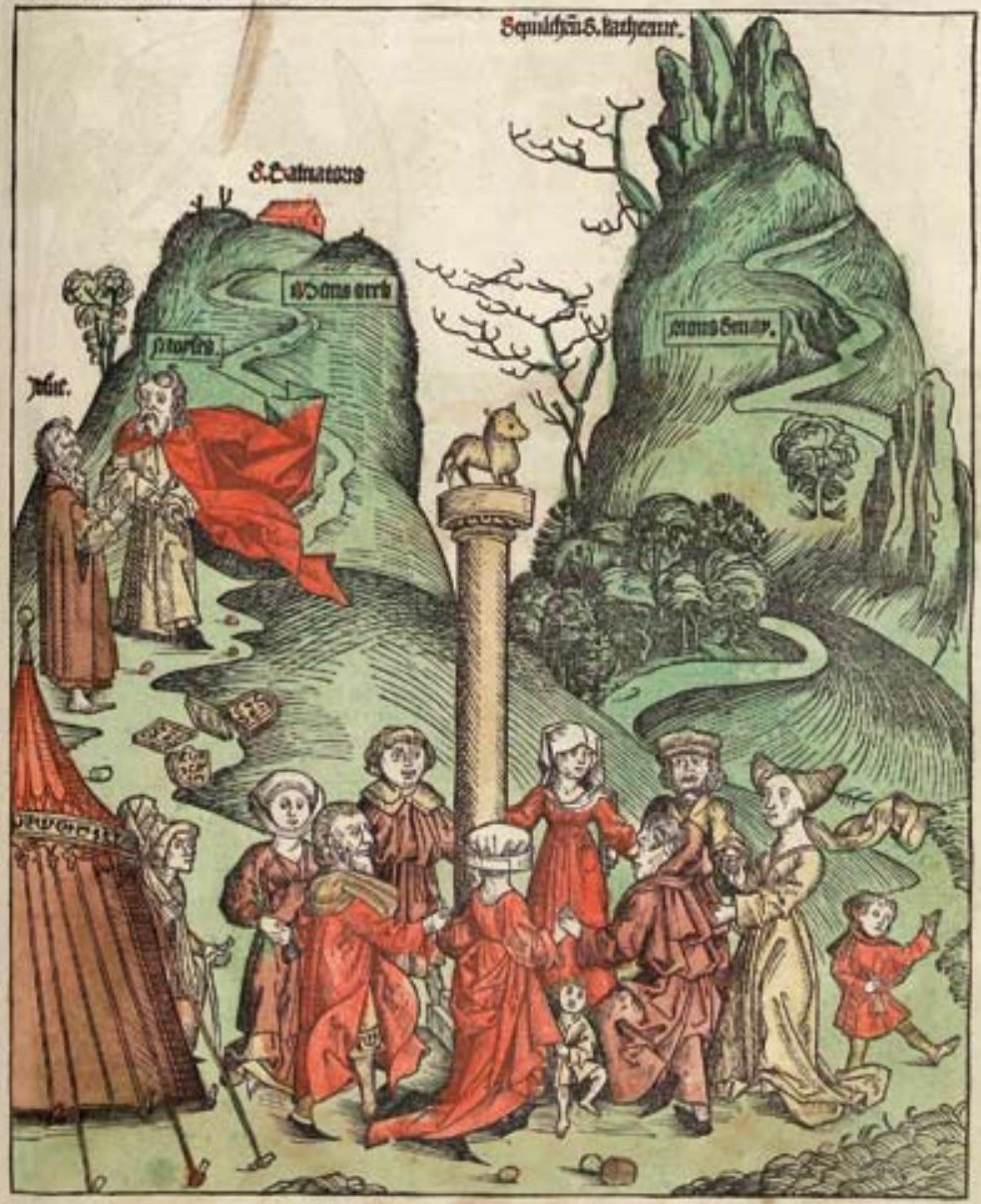




\section{Georg von Braunschweig-Lüneburg}

Stammbuch des Herzogs Georg von Braunschweig-Lüneburg mit zahlreichen Eintragungen Adliger sowie von Kommilitonen des Herzogs aus Jena.

Papierhandschrift, 1591-1611.

Signatur: $8^{\circ}$ Cod. Ms. hist. 220 Cim.

Provenienz: Joachim Hinrich von Bülow, 1734

Das Album amicorum oder Stammbuch im Sinne eines Freundschafts- oder Erinnerungsbuches entstand um die Mitte des 16. Jahrhunderts, möglicherweise ausgehend von der Wittenberger Universität und dem Brauch dortiger Studenten, sich Widmungen der dort lehrenden Reformatoren in Bücher eintragen zu lassen. Bereits in der zweiten Hälfte des 16. Jahrhunderts gibt es zahlreiche Beispiele studentischer Stammbücher. Stammbücher fanden aber auch außerhalb der Universität, zum Beispiel unter Handwerkern, Verbreitung. Formal gab es zwei Varianten: das „echte“ Album amicorum, das aus leeren, zu einem Buch gebundenen Blättern bestand, in das Widmungen und Bilder eingetragen werden konnten, und das „vorgedruckte“ Album amicorum, bei dem etwa ein Emblembuch mit leeren Blättern durchschossen wurde.

Bei dem vorliegenden Stammbuch handelt es sich um ein ,echtes“ Album amicorum. Es gehörte Georg von Braunschweig-Lüneburg (1582-1641), der von 1591 bis 1596 in Jena studierte. Auf die freien Seiten wurden Widmungen, Sinnsprüche und Zeichnungen, meist Wappen, zum Teil aber auch allegorische Szenen eingetragen. In der ersten Hälfte des Stammbuchs finden sich Eintragungen der hochadligen Verwandten und Freunde. Neben Mitgliedern der Welfen haben u.a. auch Wolfgang Wilhelm, Pfalzgraf von Neuburg, oder Herzog Johann Friedrich von Württemberg Widmungen eingetragen. Die zweite Hälfte des Stammbuchs ist den Eintragungen der meist adligen Kommilitonen in Jena vorbehalten.
Der abgebildete, 1594 in Jena erstellte Eintrag des Fabian von Kottwitz ist für die Person des Herzogs insofern charakteristisch, als er mit seiner Apologie kriegerischer Tugend auf dessen spätere militärische Laufbahn anspielt. Denn Georg, der sechste Sohn Herzog Wilhelms d. J. von Braunschweig-Lüneburg (1535-1595), der nach seinem Studium seine Kavalierstour an deutschen Höfen unternahm, konzentrierte sich seit 1604 auf eine militärische Laufbahn. Während des Dreißigjährigen Krieges (1618-1648) war er zunächst in dänischen, danach in kaiserlichen Diensten tätig und wechselte 1630 auf die Seite der Schweden. Militärisch wie politisch war er unter den damals regierenden Welfen der aktivste und fähigste Kopf. Sein Versuch, nach der Übernahme der Regierung in Braunschweig-Lüneburg 1636 das Land durch eine starke, bewaffnete Neutralität aus dem aktiven Kriegsgeschehen herauszuführen, scheiterte indes nicht zuletzt aufgrund seines Todes im Jahre 1641.

(WE) 


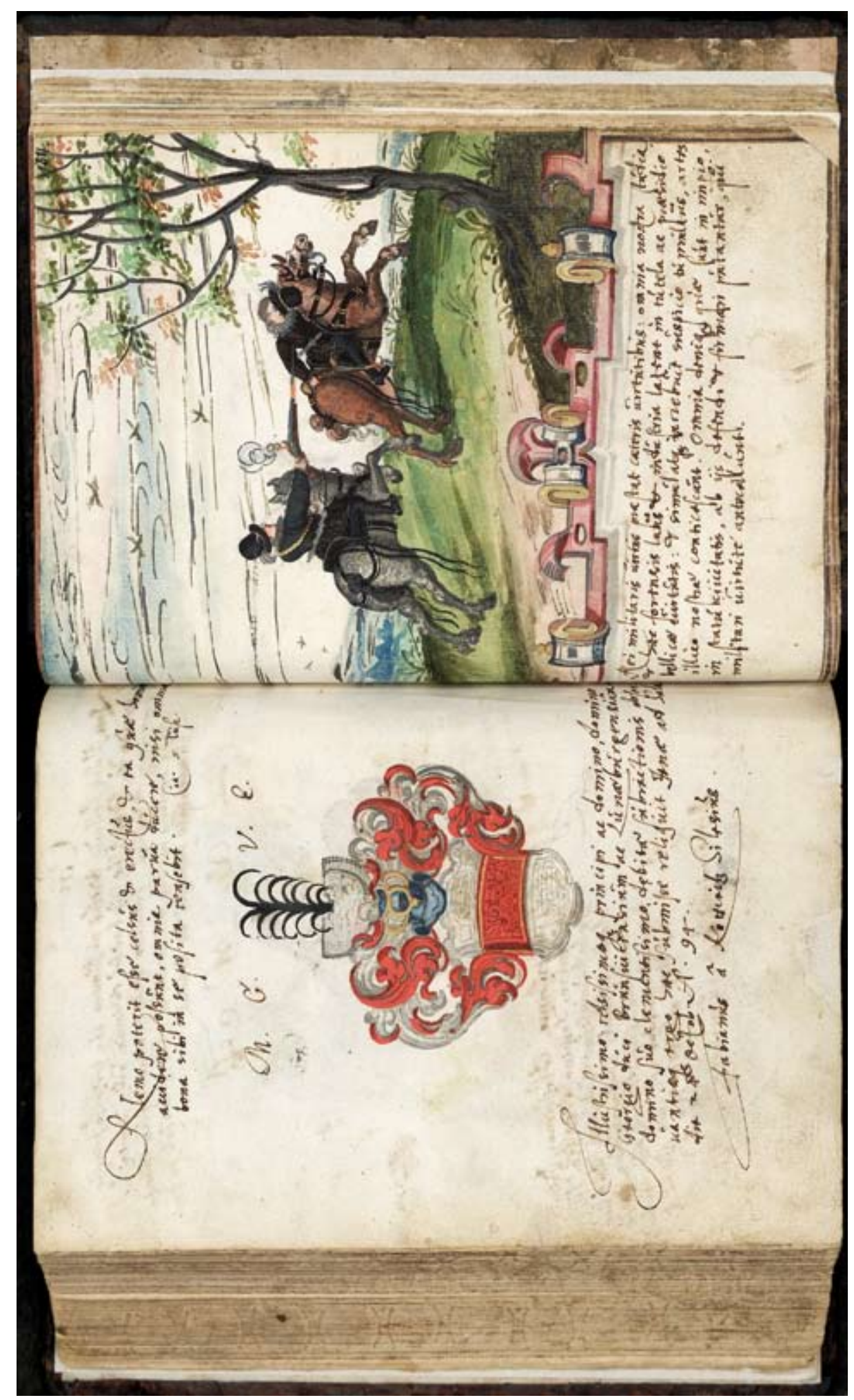




\section{$4 \quad$ Von den alten Rittern und deren Kampf}

Hans Talhoffer:

Fechtbuch mit farbigen Bildern. Landgericht der Bischöfe von Würzburg.

Ordnung des Kaiserlichen Kammergerichts.

Papierhandschrift, Ende 17. Jahrhundert.

Signatur: $2^{\circ}$ Cod. Ms. philos. 61

Provenienz: Joachim Hinrich von Bülow, 1734

Trotz der Erfindung des Buchdrucks um 1450 gab es noch fast die gesamte Frühe Neuzeit hindurch auch eine Tradition handschriftlicher Überlieferung. Das vorliegende Manuskript eines Fechtbuches bietet dafür ein gutes Beispiel. Joachim Hinrich von Bülow (1650-1724) ließ es wohl Ende des 17. Jahrhunderts nach einer Vorlage anfertigen, die ihm einer seiner Kollegen unter den damaligen kurhannoverschen Spitzenpolitikern, der Kammerpräsident Friedrich Wilhelm von Görtz (1647-1728), überlassen hatte. Dieser wiederum war über einen nicht näher zu ermittelnden Geheimen Rat und Obersten von Dieden an die ursprünglich vom Würzburger Hof stammenden Vorlagen gelangt. Möglicherweise spielten hier die Verbindungen des Kammerpräsidenten zum hessischfränkischen Adel eine Rolle, da sein Vater Johann Volprecht von Görtz (1602-1677) fuldischer Obermarschall und Direktor des Fränkischen Ritterkreises gewesen war.

Bülow ließ den Rückentitel Von den alten Rittern und deren Kampf auf den Ledereinband prägen. Dahinter verbirgt sich eine Abschrift des Fechtbuches Hans Talhoffers aus dem 15. Jahrhundert. Dieses Fechtbuch ist in sechs spätmittelalterlichen Codices überliefert; darüber hinaus sind sechs weitere frühneuzeitliche Abschriften bekannt. Das Göttinger Exemplar folgt weitgehend der ältesten Überlieferung, dem mittlerweile in der Gothaer Forschungsbibliothek befindlichen Codex von 1443. Das Werk beginnt mit Johann Hartliebs Kampfbuch (Bl. 4-15), dem sich die Kunst des langen Schwertes von Meister Liechten- auer (Bl. 16-23) anschließt. Den Hauptteil bilden Abbildungen, die weitgehend ohne Text bleiben (Kampf mit dem Stechschild, Bl. 4-49; Kampffechten, Bl. 52-75; Hellebardenfechten, Bl. 76-83; Dolchfechten, Bl. 84-105; Ringkunst Otten, eines getauften Juden, Bl. 106-129). Gegenüber der Vorlage fehlen sechs Abbildungen zum Kampf mit dem langen Schwert, allerdings wurde zusätzlich aus einem zweiten Gothaer Exemplar von 1467 der Zweikampf zwischen Mann und Frau aufgenommen (Bl. 190-195). Die ikonographische Ausführung der von Joachim Hinrich von Bülow in Auftrag gegebenen Handschrift orientiert sich - von einigen kleinen Abweichungen abgesehen - weitgehend an den spätmittelalterlichen Vorlagen. Im Unterschied zum in Tusche ausgeführten Original sind die Umrisszeichnungen der vorliegenden Ausgabe in Bleistift und die Ausmalung in Wasserfarben, die handschriftlichen Passagen in frühneuzeitlicher Kanzleischrift ausgeführt.

(WE) 


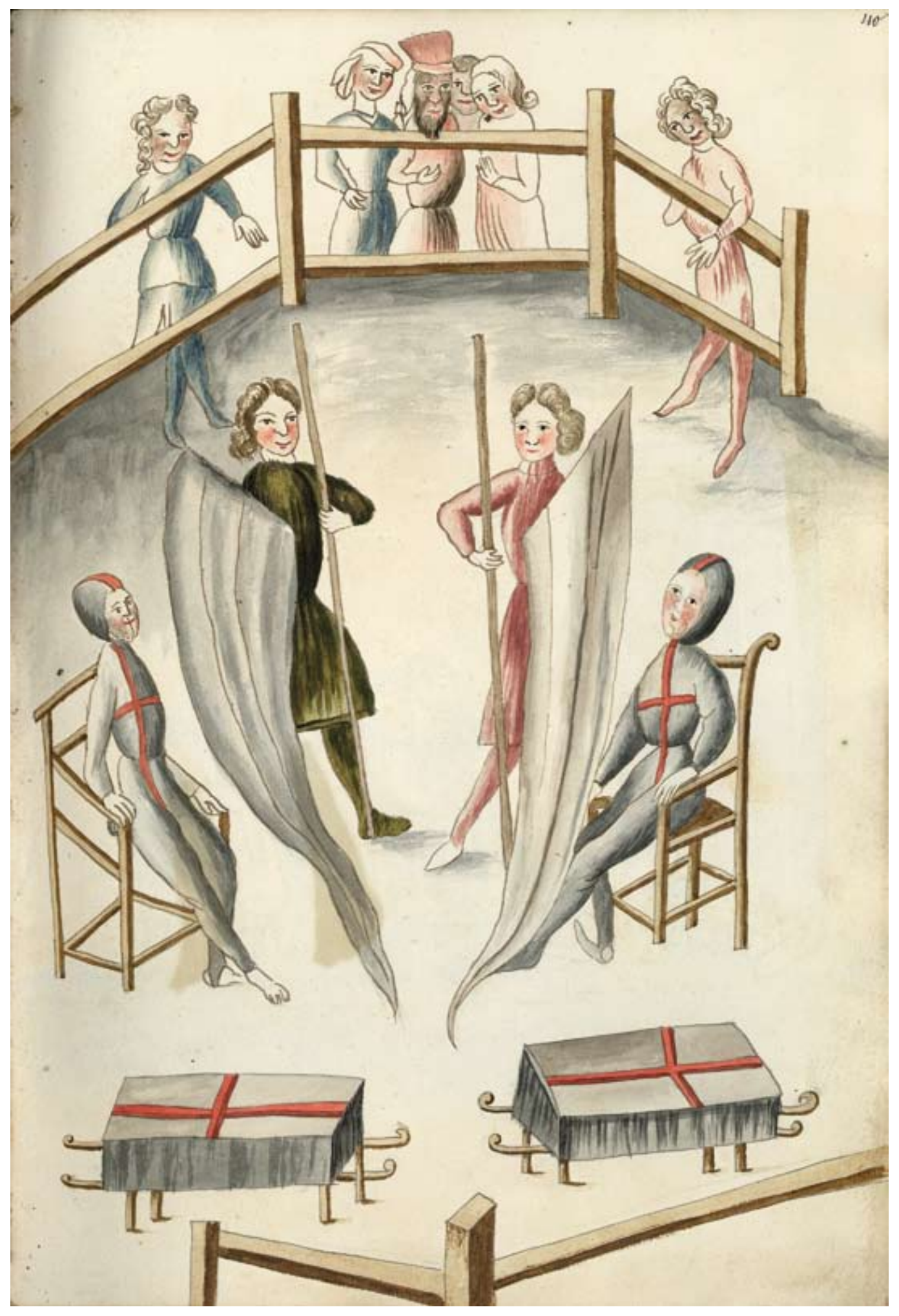




\section{Johannes Mellingers Ämteratlas}

Johannes Mellinger:

Ämteratlas des Fürstentums Lüneburg.

Papierhandschrift, um 1695.

Signatur: $4^{\circ}$ Cod. Ms. Mapp. 25

Provenienz: Joachim Hinrich von Bülow, 1734

Der Kartograph und Arzt Johannes Mellinger (um 1538-1603) wurde in Halle an der Saale geboren. Er absolvierte ein Magisterstudium in Wittenberg, fand 1568 eine Anstellung als Kantor an der Weimarer Stadtschule und wurde im Folgejahr Rektor der Lateinschule in Jena. Wie viele Gelehrte seiner Zeit befasste sich Mellinger neben seiner beruflichen Tätigkeit mit der Kartographie. In seiner Weimarer Zeit entstand 1568 seine nachweislich früheste kartographische Arbeit, eine Darstellung des Thüringer Landes. Auch Ansichten der Städte Halle und Hildesheim in dem seit 1574 erschienenen Städteatlas von Braun und Hogenberg gehen auf ihn zurück, wobei diese Arbeiten, zumindest anfänglich, der Aufbesserung seines Lebensunterhalts dienten. 1572 begann Mellinger an der Universität Jena ein Medizinstudium. Er musste vermutlich als Folge eines Richtungsstreits in der protestantischen Kirche 1573 seine Stellung als Rektor aufgeben.

1578 trat Mellinger als Hofmedicus in die Dienste Herzog Wilhelm d. J. von Lüneburg, der zu jener Zeit die ersten Symptome von Depressionen zeigte. Bis zu seinem Tode im Jahre 1603 war Mellinger dann als Leibarzt am Hof in Celle tätig, nach dem Tode von Herzog Wilhelm im Jahr 1592 auch für dessen Nachfolger Ernst II. Hier schuf Mellinger sein kartographisches Hauptwerk, den Ämteratlas des Fürstentums Lüneburg-Celle, dessen erstes Exemplar 1590 entstand. Eine im Sommer 1599 begonnene Zweitausfertigung stellte Mellinger im Jahre 1600 fertig. Der Atlas hatte für den Landesherrn einen großen Wert, denn er konnte sich mit den in den 42 Karten festgehaltenen Einzelheiten einen genauen Überblick über die Lage und Größe der in seinem Herrschaftsbereich liegenden Städte, Flecken und Dörfer machen. Ernst II. zahlte Mellinger für die Ausfertigung des zweiten Exemplars einen Vorschuss in Höhe von 100 Talern.

Aus dem 17. Jahrhundert stammen mehrere Kopien des Ämteratlasses, darunter auch das vorliegende Exemplar, das etwa um 1695 entstand. Die sehr sorgfältig mit Tusche ausgemalten Karten lassen an Exaktheit nichts zu wünschen übrig. Der Vorbesitzer Joachim Hinrich von Bülow verglich die Göttinger Kopie 1717 mit der Zweitausfertigung im Königlichen Archiv in Hannover, die seit dem Zweiten Weltkrieg verschollen ist, und stellte kaum Abweichungen vom Original fest. Eine Faksimile-Ausgabe des Ämteratlasses wurde im Jahre 2001 von Mitarbeitern des Instituts für Historische Landesforschung der Universität Göttingen als Festschrift für Ernst Schubert (1941-2006) veröffentlicht. Abgebildet ist die Grafschaft Diepholz, die vom Dümmer-See im Süden bis zur Ortschaft Hölingen im Norden reicht.

(KN/HR) 


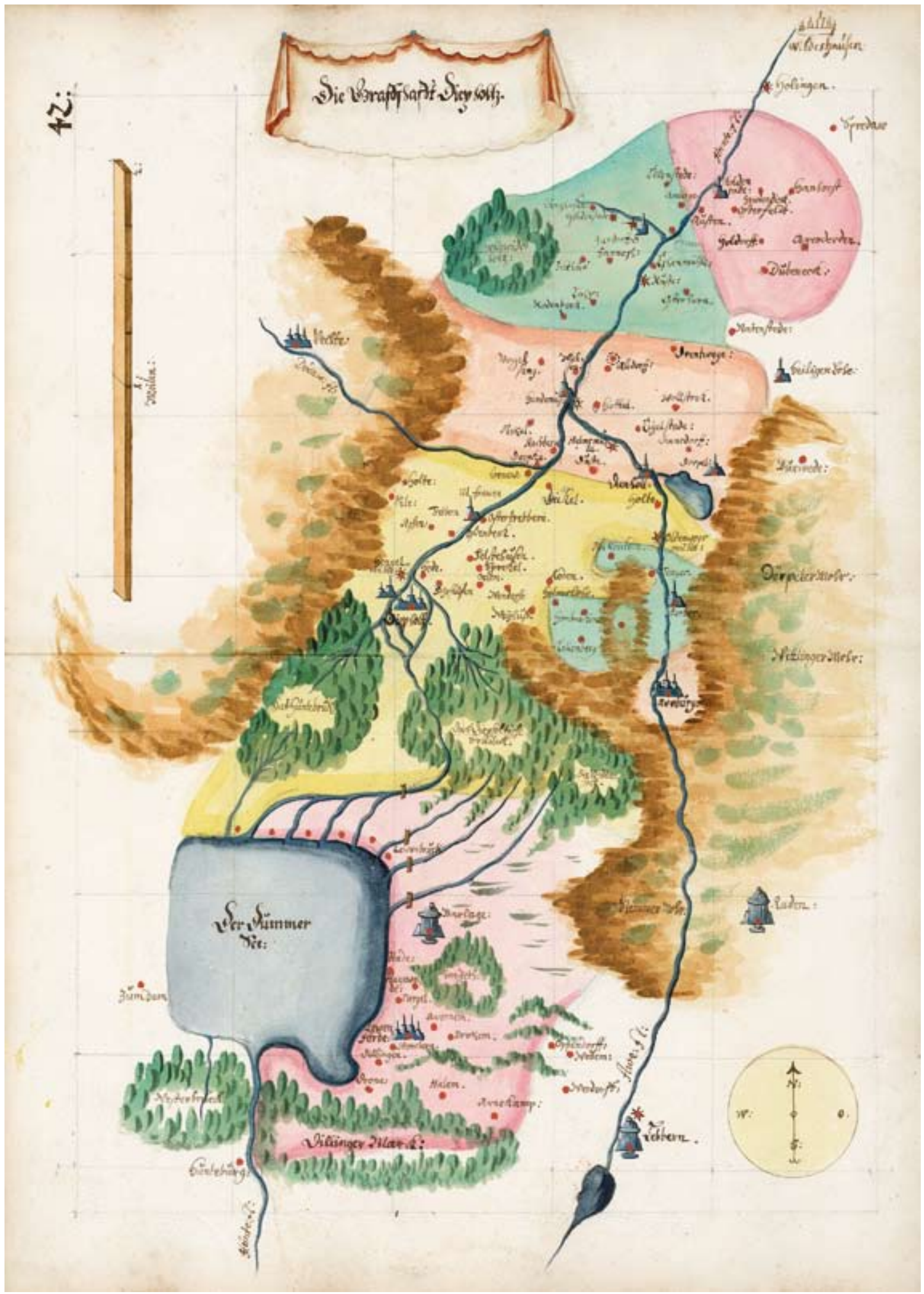




\section{von Fischen der Gewässer Ostindiens}

Samuel Fallours:

Fische des Indischen Meers und der Molukken.

Papierhandschrift, 1717.

Signatur: $4^{\circ}$ Cod. Ms. hist. nat. 108

Provenienz: Joachim Hinrich von Bülow, 1734
Nach der Erlangung der Unabhängigkeit von Spanien (1648) stiegen die Niederlande noch im 17. Jahrhundert zu einer der größten Seeund Wirtschaftsmächte auf. Auf der ganzen Welt wurden Kolonien und Handelsposten gegründet und in der Folge die fernen Länder auch wissenschaftlich erforscht. Besonderes Interesse weckten auch die fremdartigen, farbenprächtigen Fische und Krebstiere der tropischen Gewässer. Eine der ersten Darstellungen der maritimen Fauna stammt von Samuel Fallours (Wirkungsjahre 1703-1720), der in den Diensten der Niederländischen Ostindien-Kompanie stand. Auf der zu den Molukken gehörigen Insel Ambon fertigte er Zeichnungen von Fischen und anderen Meereslebewesen des Indischen Ozeans an und brachte sie 1715 mit nach Holland. Fallours ließ seiner Phantasie bei der Darstellung in vielerlei Hinsicht freien Lauf. Er versah seine Fische mit kunstvollen Mustern, gab ihnen teilweise menschliche Gesichter und verwendete fast surreale Farbgebungen. Dennoch sind die meisten der abgebildeten Fische teilweise bis zum Niveau der Species taxonomisch bestimmbar. Nur wenige Abbildungen gehören vollständig dem Reich der Phantasie an - wie etwa eine Meerjungfrau, die vier Tage in einem Wasserbehältnis in Fallours' Haus gelebt, rattenähnliche Schreie ausgestoßen, jegliche Nahrungsaufnahme verweigert haben und schließlich gestorben sein soll. Bemerkenswert ist auch, dass Fallours in seinen Kurzbeschreibungen Hinweise zur Essbarkeit einzelner Fische gibt und teilweise die beste Zubereitungsart nennt. Zu der aufgeschlagenen Abbildung 100 wird beispiels- weise angemerkt: „De Seeramse Visch; Poisson de Ceram; on l'écorche, et le découpe dans des pots, avec du sel, du poivre et du vinaigre, il est très bon.“

Das ausgestellte Werk ist eine im Jahre 1717 für Joachim Hinrich von Bülow angefertigte genaue Kopie des Originals, das sich in der heutigen Niedersächsischen Landesbibliothek in Hannover befindet (Handschrift Nr. 326). Diese Kopie enthält alle Abbildungen des Originals, dazu ein Dokument über die Entstehung des Hannoverschen Originals und der Göttinger Kopie sowie zwei Briefe des Druckers Louis Renard (1678-1746) aus dem Jahre 1718. Renard nutzte viele der Abbildungen von Fallours für sein bekanntes Druckwerk Poissons, Ecrevisses et Crabes, de Diverses Couleurs et Figures Extraordinaires, Que l'on Trouve Autour des Isles Moluques et sur les Côtes des Terres Australes (1718). 


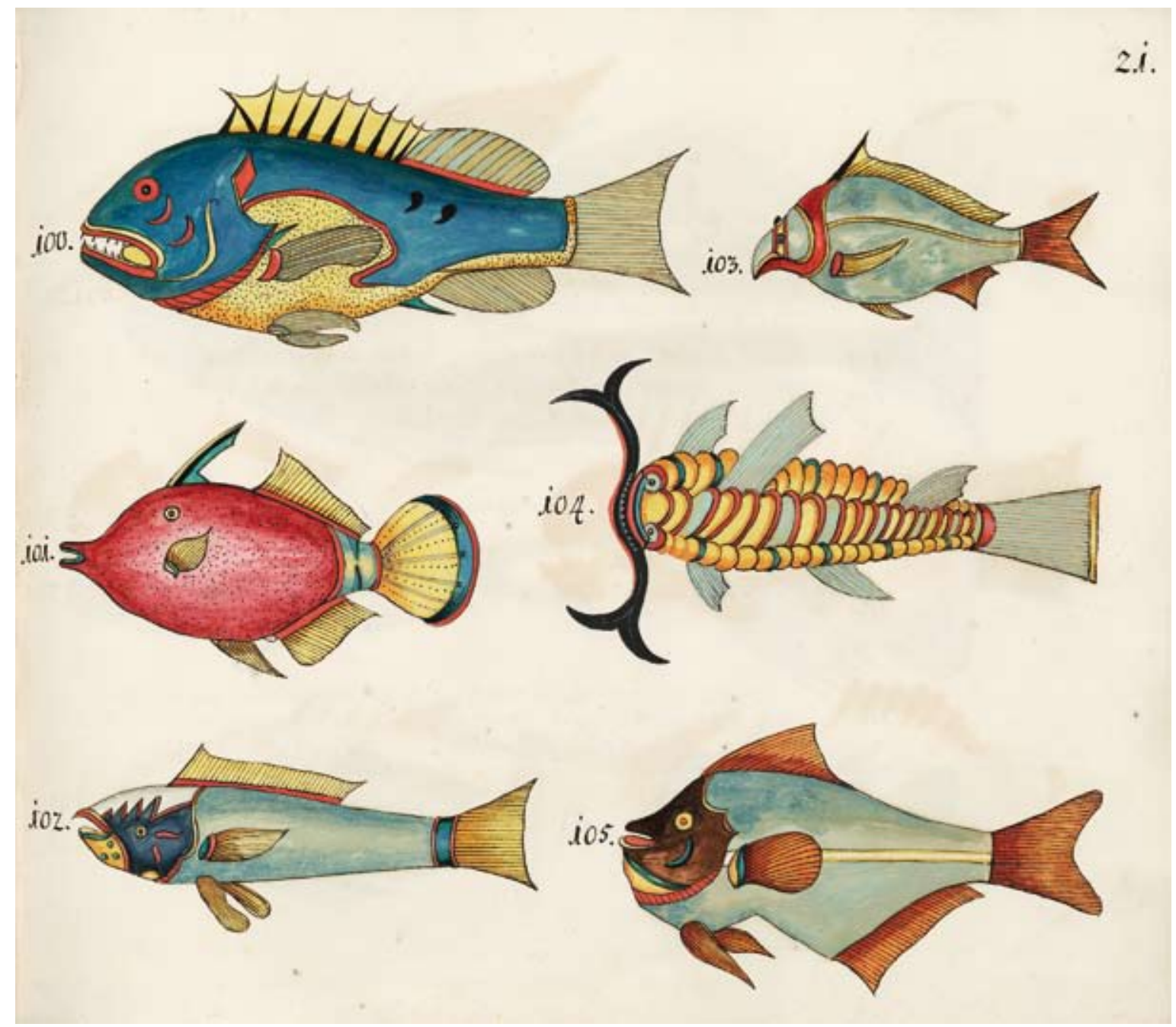




\section{$7 \quad$ Die Farbe des Lichts}

Isaac Newton:

Opticks or a Treatise of the reflexions, refractions, inflexions and colours of Light.

Also two treatises of the species and magnitude of curvilinear figures.

London: Samuel Smith and Benjamin Walford, 1704.

Signatur: $4^{\circ}$ Phys. III, 2200 Rara

Provenienz: Königliche Bibliothek Hannover, 1734

Isaac Newtons (1643-1727) Opticks hatte ein völliges Umdenken in der Bewertung von Licht und Farben zur Folge. Das Werk entstand in jenem annus mirabilis von 1666 bis 1667, als er gezwungen war, London wegen der Pest zu verlassen und auf dem Landsitz seiner Mutter Zuflucht zu suchen. Dort machte Newton drei grundlegende Entdeckungen: die allgemeine Schwerkraft, die Infinitesimalrechnung und die Zusammensetzung des weißen Lichts. Newtons Aufsatz „New Theory of Light and Colors“ über die Zusammensetzung des weißen Lichts erschien 1672 in den Philosophical Transactions. Darin beschreibt er sein berühmtes doppeltes Prismen-Experiment, in dem ein Strahl weißen Lichts auf ein Prisma trifft und mittels eines Vorgangs, der heute als Dispersion bezeichnet wird, ein Spektrum erzeugt. Mit dem Experiment bewies Newton, dass Licht aus Strahlen zusammengesetzt ist, die unterschiedlich brechbar sind.

Unmittelbar nach der Veröffentlichung traten Kritiker auf den Plan, die an der neuen Theorie zweifelten. Newton geriet in eine Krise, die ihn beinahe von einer weiteren Beschäftigung mit diesem Thema abgebracht hätte. Erbittert stritt er für seine Überzeugung und bemühte sich um eine deutlichere Formulierung seiner Forschungsergebnisse. Die Auseinandersetzungen führten zu einer Abkühlung der Beziehungen mit den führenden Fachkollegen Newtons, darunter Robert Hooke in England, Gottfried Wilhelm Leibniz in Deutschland, René Descartes in Frankreich und Christian Huyghens in Holland, die sämt- lich die Meinung vertraten, dass Licht sich wellenförmig in einem Äther ausbreite.

Mehr als drei Jahrzehnte später erschien Opticks (1704) als ausführliche Darstellung der Newtonschen Theorien über Licht und Farben. Auf sorgfältigen Experimenten basierend, definierte es gleichzeitig die Farben nach mathematischen Prinzipien und legte damit die Grundlage für eine neue Forschungsrichtung in der physikalischen Optik. Zusätzlich beschrieb Newton seine Methode in einer Reihe von Anhängen oder „Queries“. Hier verteidigte er seine Vorstellungen über die Schwerkraft gegen diejenigen seiner Gegner, die die Gravitation als „okkulte Qualität“ bezeichneten. Newtons Gesamtwerk blieb während des 18. Jahrhunderts umstritten. Zu seinen Gegnern zählte auch Johann Wolfgang von Goethe, der zu Beginn des 19. Jahrhunderts eine Farbenlehre entwickelte, die Newtons Werk in Frage stellte (s. Nr. 43).

(KMO) 


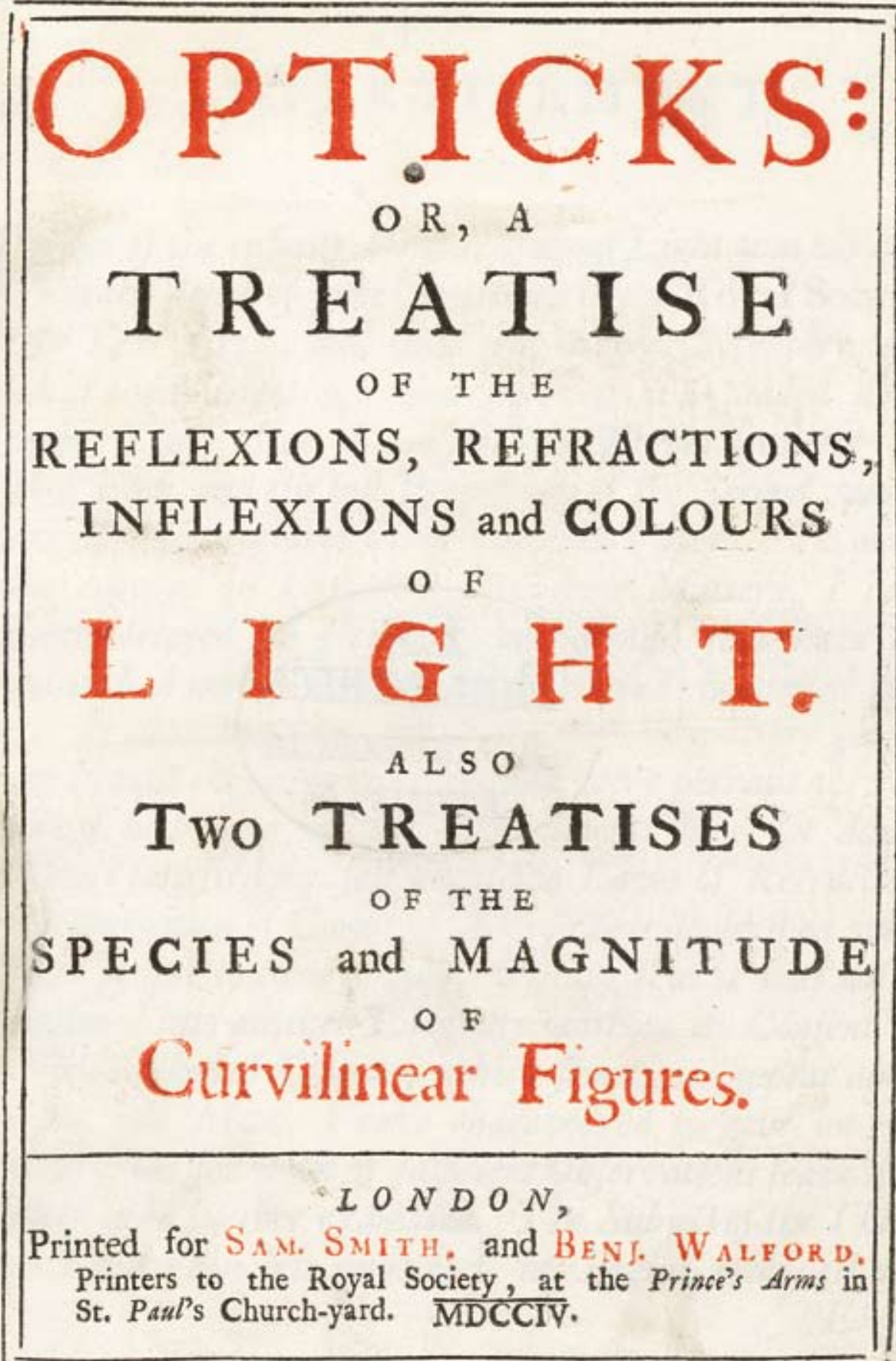




\section{Kapitel 2}

\section{Schenkungen vollständiger Sammlungen}

Auch wenn ihre Bearbeitung im Detail mitunter mit Problemen behaftet sein kann: Für Bibliotheken ist die Übernahme vollständiger Sammlungen nicht erst in der heutigen Zeit knapper Kassen eine besonders willkommene Form der Bestandsmehrung. Denn die Übernahme von Buchbeständen durch Legate aus dem Besitz eines noch lebenden oder verstorbenen Gönners verursacht in der Regel für die begünstigte Einrichtung keinerlei Anschaffungskosten. Nicht selten allerdings werden Auflagen oder zumindest Wünsche mit dem Vermächtnis verbunden, die bisweilen Abweichungen von der bibliothekarischen Praxis bedeuten. Dann muss mit aller gebotenen Sensibilität eine für alle annehmbare, pragmatische Lösung gefunden werden.

Die Göttinger Bibliothek hat im Lauf ihrer Geschichte von ganz unterschiedlichen Seiten Schenkungen erhalten. Eine erste Schenkung allerhöchster Bedeutung erhielt sie kurioserweise noch vor ihrer feierlichen Eröffnung. In den Jahren der Vorbereitung des Universitätsbetriebes wurden die Kontakte zwischen Göttingen und dem Frankfurter Patrizier Johann Friedrich Armand von Uffenbach (1687-1769) so weit vertieft, dass 1736 ein offizielles Dokument über die Donation der Uffenbachschen Bibliothek aufgesetzt werden konnte. Was war der Hintergrund? Uffenbach, studierter Jurist und ganz den Ideen der Aufklärung verpflichtet, war ein kunstsinniger Mensch. In Frankfurt begründete er eine Gesellschaft zur Pflege von Wissenschaft und Kunst, hielt selbst Vorträge über künstlerische Techniken und machte sich auch als Architekt einen Namen. Aber er hatte ein Problem: Der Rat seiner Heimatstadt drängte Uffenbach zur Übernahme standesgemäßer Amtsgeschäfte, derer dieser sich zu entziehen trachtete. Es kam zum offenen Streit. Wollte Uffenbach seine Heimat nicht verlassen, blieb ihm nur ein Ausweg: ein hohes militärisches, auswärtiges
Amt, mithilfe dessen er sich dauerhaft von seinen städtischen Pflichten befreien konnte. Eine Lösung zeichnete sich nun mittels der oben erwähnten Kontakte nach Göttingen ab. Uffenbach wurde von König Georg II. zum Königlich Großbrittanisch Churfürstlich Braunschweigisch Lüneburgischen Artillerieobristlieutenant erhoben und war für die Stadtoberen in Frankfurt damit nicht mehr zu belangen. Ein Jahr zuvor wurde im Gegenzug die Schenkung auf den Weg gebracht. Göttingen sollte nicht nur Uffenbachs 2.289 Bände umfassende Bibliothek, sondern auch sein graphisches Kabinett und seine Instrumentensammlung erhalten. Der Zuschnitt der Bibliothek schien besonders geeignet, um den noch kleinen Bestand der Universitätsbibliothek zu vergrößern, denn Uffenbach hatte Vieles gesammelt, was im vorgesehenen Grundstock der Bibliothek fehlte. Unstimmigkeiten darüber, ob die Sammlungen sofort, also noch zu Uffenbachs Lebzeiten, übergeben werden sollten, wie man es natürlich in Göttingen wünschte, oder ob die Übereignung erst nach seinem Tode erfolgen sollte, wie es der Stifter vorschlug, waren bis dahin im Sinne Uffenbachs geregelt worden. Für die Bibliothek begann damit eine nicht unkomplizierte und mit Blick auf die vorgesehene Regelung auch von Sorgen und Befürchtungen bestimmte Wartezeit von mehr als 30 Jahren. Tatsächlich kam es nach Uffenbachs Tod im Jahre 1769 zu Streitigkeiten mit den Erben. Aber noch im selben Jahr war es dann schließlich so weit: In mehreren Lieferungen wurde die der Universität zugedachte Hinterlassenschaft Uffenbachs nach Göttingen gebracht. Zahlreiche Werke zur Architektur- und Kunstgeschichte sowie mathematische, physikalisch-technische, militärische und ikonographische Titel konnten so dem Bestand einverleibt werden. Das Versprechen, die Schenkung geschlossen aufzustellen und mit einer eindeutigen Bezeichnung in der Signatur kenntlich zu machen, wurde eingelöst 
und wird bis heute gehalten: Die Bücher der Bibliothek Uffenbach stehen als gesonderte Bestandsgruppe im Rara-Magazin der Bibliothek.

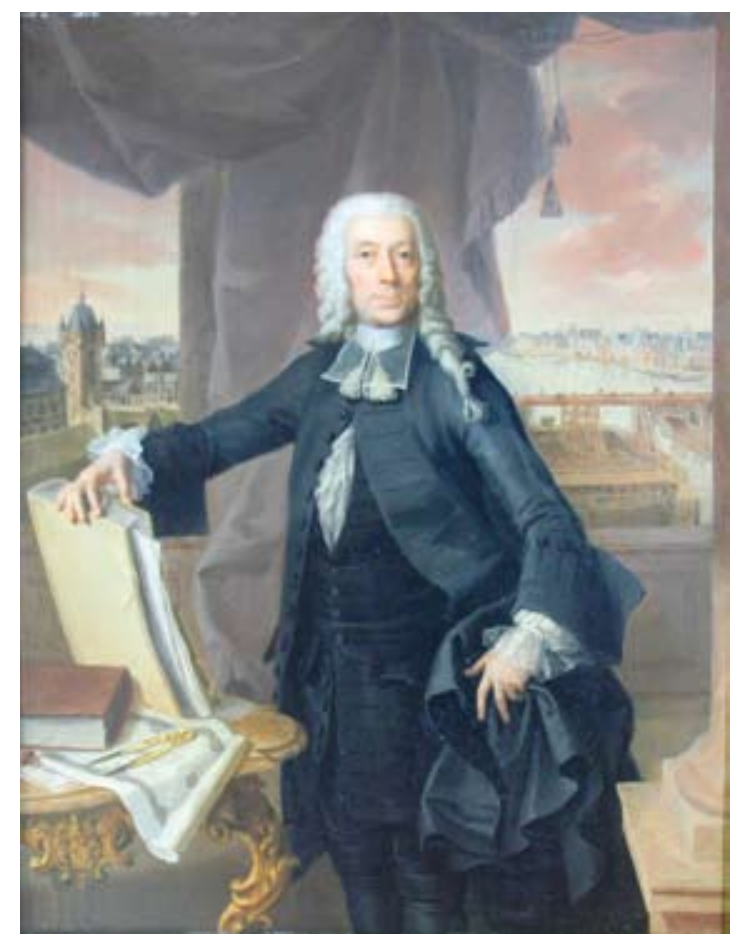

Johann Friedrich Armand von Uffenbach (1687-1769).

Auf ganz andere Art kompliziert war die Übernahme der Bibliothek von Börries von Münchhausen (1874-1945). Münchhausen, der aus dem bekannten Adelsgeschlecht stammte, war wie Uffenbach Jurist, widmete sich aber auch den Künsten und der Philosophie. In Sahlis und Windischleuba betätigte sich Münchhausen literarisch. Zwar wurde schon vor Ende des Zweiten Weltkrieges festgelegt, dass sein Nachlass der Göttinger Bibliothek überlassen werden sollte, doch nach dem Tod des Eigentümers 1945 verhinderte die deutsch-deutsche Teilung den Vollzug der Regelung. Stattdessen blieb der Nachlass in Jena, wo man allerdings um die Vorgeschichte wusste und die Sammlung mit entsprechendem Feingefühl verwaltete. Nach dem Fall der Mauer und der Vereinigung der beiden deutschen Staaten war der Weg frei, um auch diese Angelegenheit im Sinne des Stifters zu regeln. 1991 kam das Vermächtnis dorthin, wo es schon seit langem hätten stehen sollen, in das Sondermagazin der Göttinger Bibliothek.

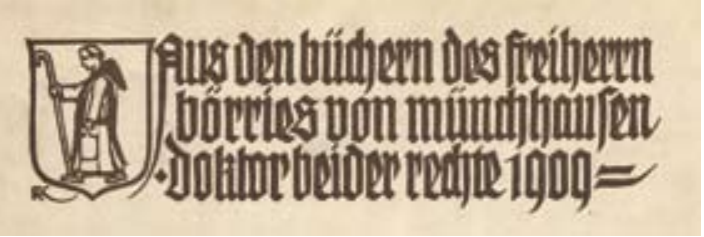

Exlibris Börries von Münchhausen.

Der dritte in diesem Kapitel illustrierte Fall eines Legates trat gänzlich unerwartet im Jahre 2003 ein. Diesmal ging alles sehr schnell. Wenige Telefonate und Besuche vor Ort genügten, um die Übernahme der Bibliothek Klammer aus Marburg in die Wege zu leiten. Sie ist das Ergebnis der Sammlungstätigkeit des Ingenieurs Gerhard Klammer, der lange im Ausland, insbesondere in Südamerika, lebte und bis zu seinem Tode hauptsächlich Literatur zum Thema Brasilien erwarb. Ohne dass die Göttinger Bibliothek etwas davon gewusst hätte, bestimmte Klammer sie als letzten Aufbewahrungsort seiner Bücher. Grund dafür war ein Gefühl von Dankbarkeit gegenüber der Georgia Augusta, deren Ausbildungsangebot unmittelbar nach dem Zweiten Weltkrieg den Grundstein für Klammers berufliche Karriere gelegt hatte. Einige Jahre nach seinem Tod wurde dieses Vermächtnis nun erfüllt. Auch diese Sammlung wurde vollständig und geschlossen in den Bestand übernommen. 
Melchior Pfintzing:

Theuerdanck.

Nürnberg: [Johann] Schönsperger, 1517.

Signatur: $2^{\circ}$ Bibl. Uff. 355

Provenienz: Johann Friedrich Armand von Uffenbach, 1769/70

Kaiser Maximilian I. von Habsburg (1459-1519), Kaiser des Heiligen Römischen Reiches Deutscher Nation, war ein gebildeter Mann: Er beherrschte sieben Sprachen, hatte Humor, war sehr fromm und ein bedeutender Mäzen und Stifter der Künste und Wissenschaften. Zugleich war er aber auch auf den Ruhm seiner Person und seines Hauses bedacht und dabei ganz den Idealen des Rittertums verpflichtet. An der Epochenschwelle zwischen Mittelalter und Neuzeit nutzte er zu diesen Zwecken das neue Medium des Buchdrucks. Charakteristisch für Kaiser Maximilian I. ist ein Nebeneinander von Gegensätzen: Geldnot und Repräsentation, feudale Hofhaltung und Interesse an Humanismus und Renaissance. Als „letzter Ritter“ begründete er eine eigene Memorialkultur. Sein Name sollte ewig im „gedechtnus“ der Menschen fortleben. In diesem Zusammenhang ist auch der Auftrag für den Theuerdanck zu sehen.

Die Attraktivität dieses Druckes besteht in den meisterhaften Holzschnitten von Hans Leonhard Schäufelein (1480-1540), Hans Burkmair (1473-1531) und Leonhard Beck (1475-1542), die in jedem der 118 Kapitel die Schlüsselszenen aus den 80 Abenteuern des Ritters Theuerdanck zeigen. Die Holzschnitte sind zeitgenössisch von Hand kräftig koloriert und gelten als Meilensteine in der Entwicklung der perspektivischen Darstellung. Die Schrift wurde eigens für den Druck entworfen; es handelt sich dabei um eine an der deutschen Kanzleischrift orientierte, berühmte frühe Frakturtype. Sie ist durch reiche Verzierungen, An- und Abschwellen der
Buchstaben und mannigfaltige Buchstabenvarianten gekennzeichnet.

Der Theuerdanck erzählt in Reimpaaren die abenteuerliche und gefahrvolle Brautfahrt Maximilians I. zu Maria von Burgund (der Ehefrau des Kaisers von 1477 bis 1482). Die Personen tragen allegorische Namen: Kaiser Maximilian I. ist „Ritter Theuerdanck“, sein Schwiegervater Herzog Karl der Kühne „Ruhmreich“ und seine Gemahlin Maria von Burgund Königin „Ernreich“. Seine Gegenspieler „Fürwittig“ (Fürwitz), „Unfalo“ (Unfallgefahr) und „Neidelhard“ (Neid) symbolisieren die gegen Maximilian I. gerichtete niederländische Opposition. Die Erstauflage bestand aus nur 40 Exemplaren, die erst nach dem Tode des Kaisers von seinem Enkel Karl V. an die Würdenträger des Reiches verteilt wurden.

$(\mathrm{KN} / \mathrm{JM})$ 


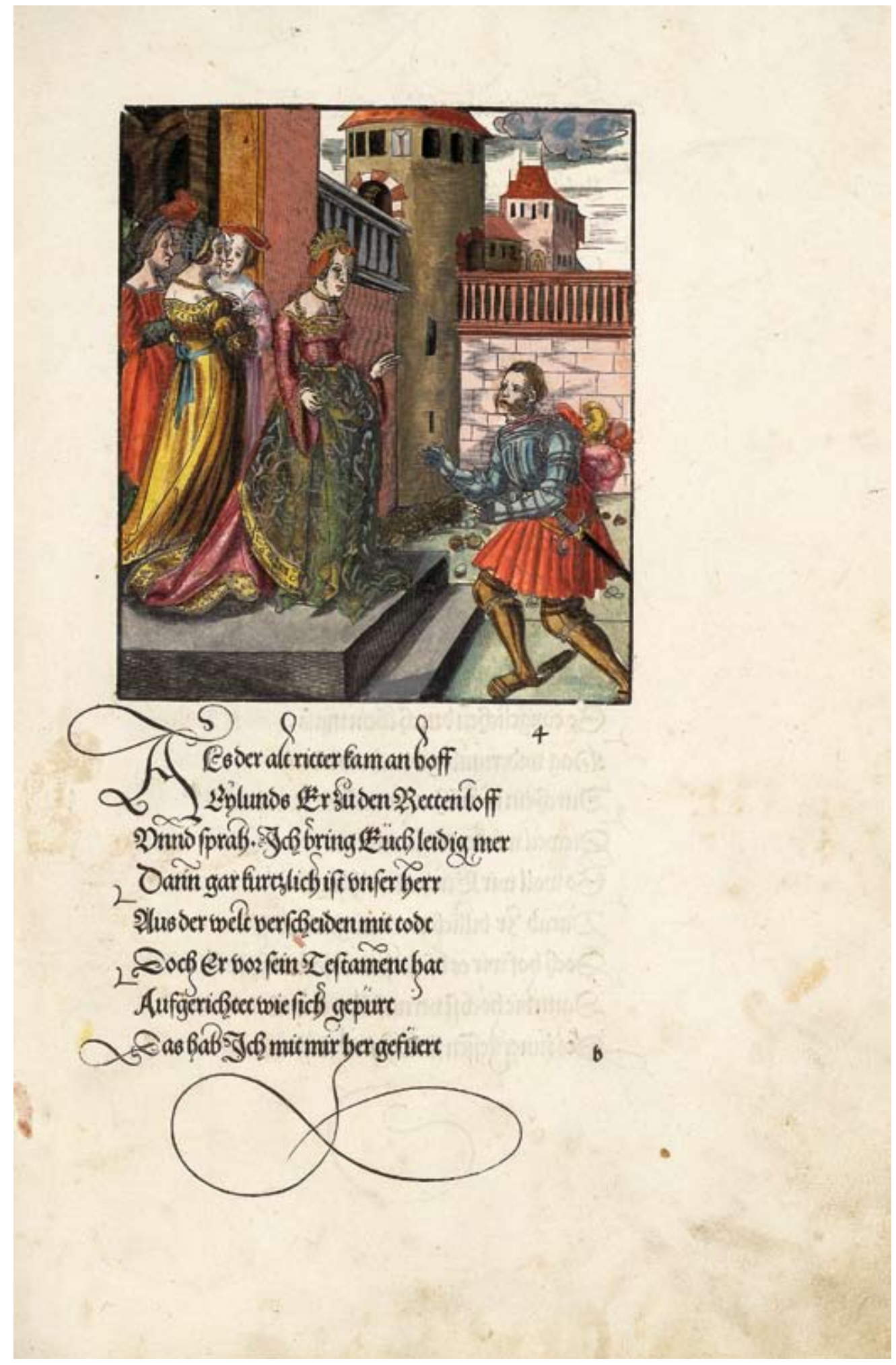


Martin Luther; Lucas Cranach d. Ä. [mutmaßl.Verf.]:

Passional Christi und Antichristi in Holzschnitten.

[Wittenberg:] [Johann Rhau-Grunenberg,] [1521].

Signatur: $4^{\circ}$ Bibl. Uff. 639

Provenienz: Johann Friedrich Armand von Uffenbach, 1769/70

Im Jahre 1521 erschien in Wittenberg, dem geistigen Zentrum der Reformation, zunächst in lateinischer, dann in deutscher Sprache ein Werk, das bald eine Schlüsselstellung innerhalb der antipäpstlichen polemischen Druckgraphik des 16. Jahrhunderts einnehmen sollte. Als „das erste Bilderbuch der Reformation“ (Kumer), eine Holzschnittfolge, die von kurzen Texten begleitet wird, sprach das Passional Christi und Antichristi nicht nur ein gebildetes Publikum an, sondern war auch dem Leseunkundigen unmittelbar verständlich. Die Entstehungszeit des Werkes fällt zwischen den endgültigen Bruch Martin Luthers (1483-1546) mit Papst Leo X. (Ende 1520) und die Verhängung des Wormser Edikts über den Reformator (im Mai 1521). Es ist vermutlich ein Gemeinschaftswerk Luthers, seiner Mitstreiter Philipp Melanchthon (1497-1560) und Johann Schwertfeger sowie seines Freundes und „Reformationsmalers“ Lucas Cranach d. Ä. (1472-1553). Auf einander gegenüberliegenden Seiten vereint das Werk in lehrhafter Manier dreizehn einprägsam gestaltete, antithetische Bildpaare. Sie stellen Szenen aus dem Wirken und Leidensweg Christi und aus einem mit dem Antichristen gleichgesetzten Papsttum dar, das sich über Gott und die weltliche Obrigkeit erhebt und durch rein materielles Macht- und Besitzstreben charakterisiert ist. Unter den Bildern sind Zitate aus der Bibel und der römischen Kirchengesetzgebung sowie Glossen der Verfasser angeordnet, die zentrale reformatorische Anliegen transportieren. Die Schlussantithese wird durch eine Darstellung der Himmelfahrt Christi und des Höllensturzes des Papstes gebildet. Das Werk führt transformierend eine Fülle von religionsgeschichtlichen, literarischen und ikonographischen Traditionen und Impulsen zusammen (mittelalterliche Passionalliteratur und Antichristlegenden, Biblia Pauperum, Schriften John Wyclifs und des Hussitentums). Es erfuhr eine weite Verbreitung und wurde im 16. Jahrhundert in verschiedensprachigen Ausgaben nachgeschnitten und nachgebildet. Eine interessante Aktualisierung fand es 1873 im Kontext des Kulturkampfes mit der Herausgabe einer Faksimileausgabe des Wittenberger Drucks: Ihr waren zwei aneinander gerichtete Briefe Wilhelms I., König von Preußen, und Papst Pius IX. vorangestellt, die den Konflikt zwischen dem Königreich Preußen und der römisch-katholischen Kirche widerspiegeln.

Aufgeschlagen ist ein Bildpaar, das einen zentralen, bereits in den 95 Thesen des Jahres 1517 manifesten Kritikpunkt Luthers zum Inhalt hat: den Ablasshandel. Einander gegenübergestellt sind die Vertreibung der Händler und Wechsler aus dem Tempel durch Christus und der Ablassverkauf durch Papst und Klerus. 


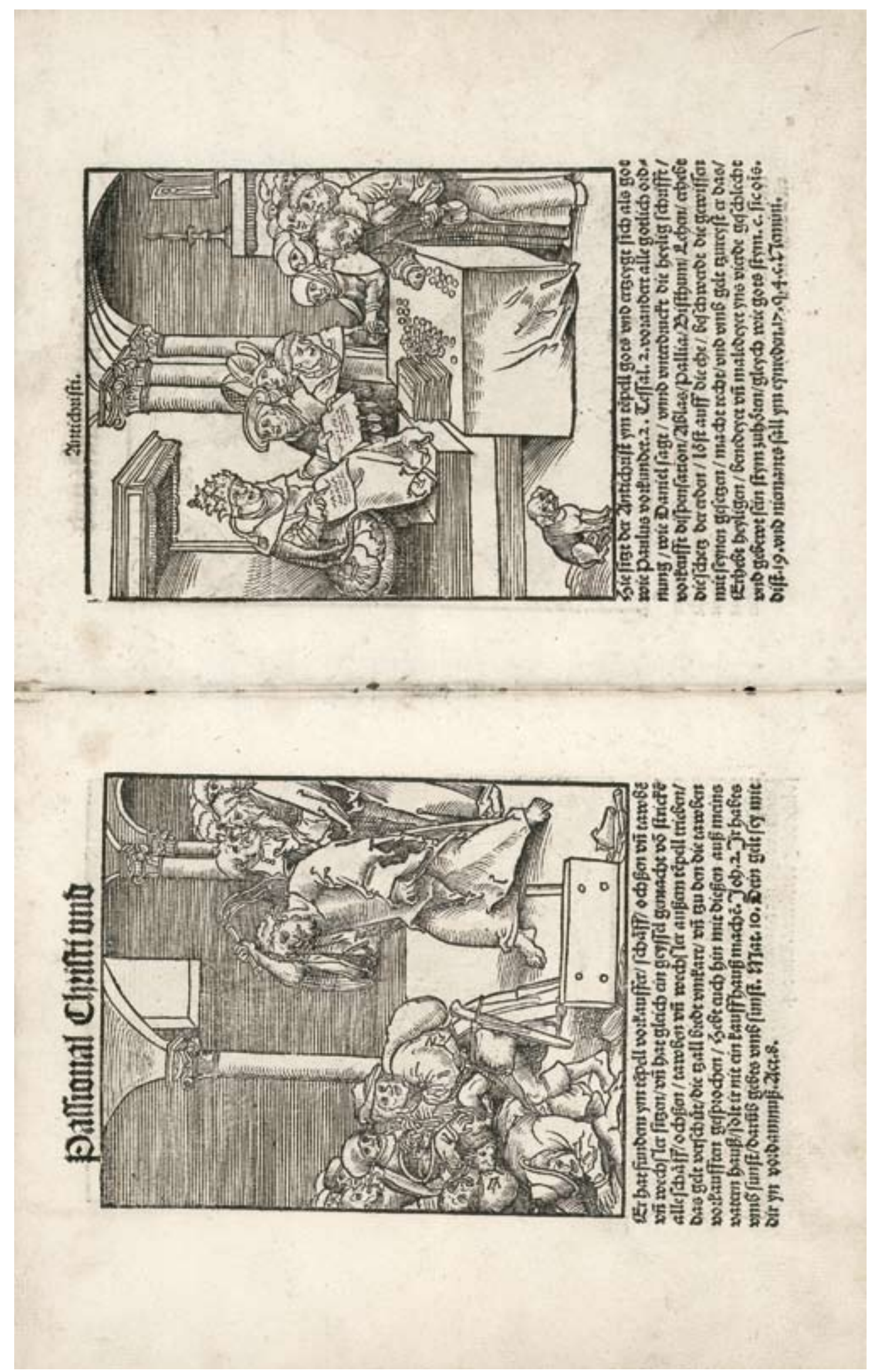




\title{
10 Kunst als mathematische Wissenschaft
}

\author{
Albrecht Dürer: \\ Underweysung der messung mit dem zirckel und richtscheyt. \\ Nürnberg: Hieronymus Andreae, 1525. \\ Signatur: $2^{\circ}$ Bibl. Uff. 183 (1) \\ Provenienz: Johann Friedrich Armand von Uffenbach, 1769/70
}

Die Kunst der perspektivischen Zeichnung war in Italien bereits fast ein Jahrhundert lang bekannt und in der Praxis verbreitet, als Albrecht Dürer (1471-1528) sie 1525 mit seinem bahnbrechenden Werk Underweysung der messung mit dem zirckel und richtscheyt in Nordeuropa bekannt machte. Dürer lernte das „Geheimnis der Perspektive“ zu Beginn des 16. Jahrhunderts auf seinen Italienreisen kennen. Frühere Arbeiten zur Perspektive wie Leon Battista Albertis Trattato della Pittura (1435/36) hatten die perspektivische Zeichnung als Problem der Optik dargestellt, wie es bereits in der Antike üblich gewesen war. Im Gegensatz hierzu wandte Dürer Euklids Geometrie auf die Darstellung von Gegenständen auf einer zweidimensionalen Ebene an. Sein Buch stellte so die erste vollständig ausgearbeitete mathematische Theorie der linearen Perspektive dar. Um Perspektive in geometrische Begriffe zu „übersetzen“, musste Dürer neue Termini schaffen. Der erste neue Begriff erscheint im Titel des Werks: „Messung“ statt „Messkunst“ (was Landvermessung bedeutete). Da keine deutschen Entsprechungen für die Bezeichnungen der drei Kegelschnitte (Ellipse, Parabel und Hyperbel) existierten, nannte er sie „Eierlinie“, „Brennlinie“ (da ein Parabolspiegel benutzt werden kann, um ein Feuer zu entfachen) und „Gabellinie“.

Dürers „Kunst des Messens“ war für Maler, Handwerker, Steinmetze und Zimmerleute bestimmt. Erst gegen Ende des letzten Teils des Werkes erörtert er das Problem der Perspektive, und dies erst nachdem er Anweisungen zur Konstruktion von Sonnenuhren auf der
Basis der Geometrie gegeben hat. Kunsthistoriker sind sich uneins über den Einfluss, den das Werk auf die europäische Kunst, ja selbst auf diejenige Dürers, ausgeübt hat. Dürer stellte stets ästhetische Grundsätze über rigorose mathematische Prinzipien. Dies ist etwa in seinem Bemühen erkennbar, einen perspektivischen Schatten darzustellen, der von einem Kubus auf einer quadratischen Oberfläche erzeugt wird, oder in der unterschiedlichen Verwendung des Fluchtpunkts bei der Darstellung von Gebäuden im Gegensatz zu menschlichen Figuren. Im Anhang seines vierten und letzten Buches stellt Dürer Zeichenapparate zur vollkommenen Abbildung von Gegenständen und Personen vor. Die Abbildung zeigt verschiedene Kegelschnitte, darunter auch rechts unten die „parabola“ als Brennspiegel.

$(\mathrm{KMO} / \mathrm{KN})$ 


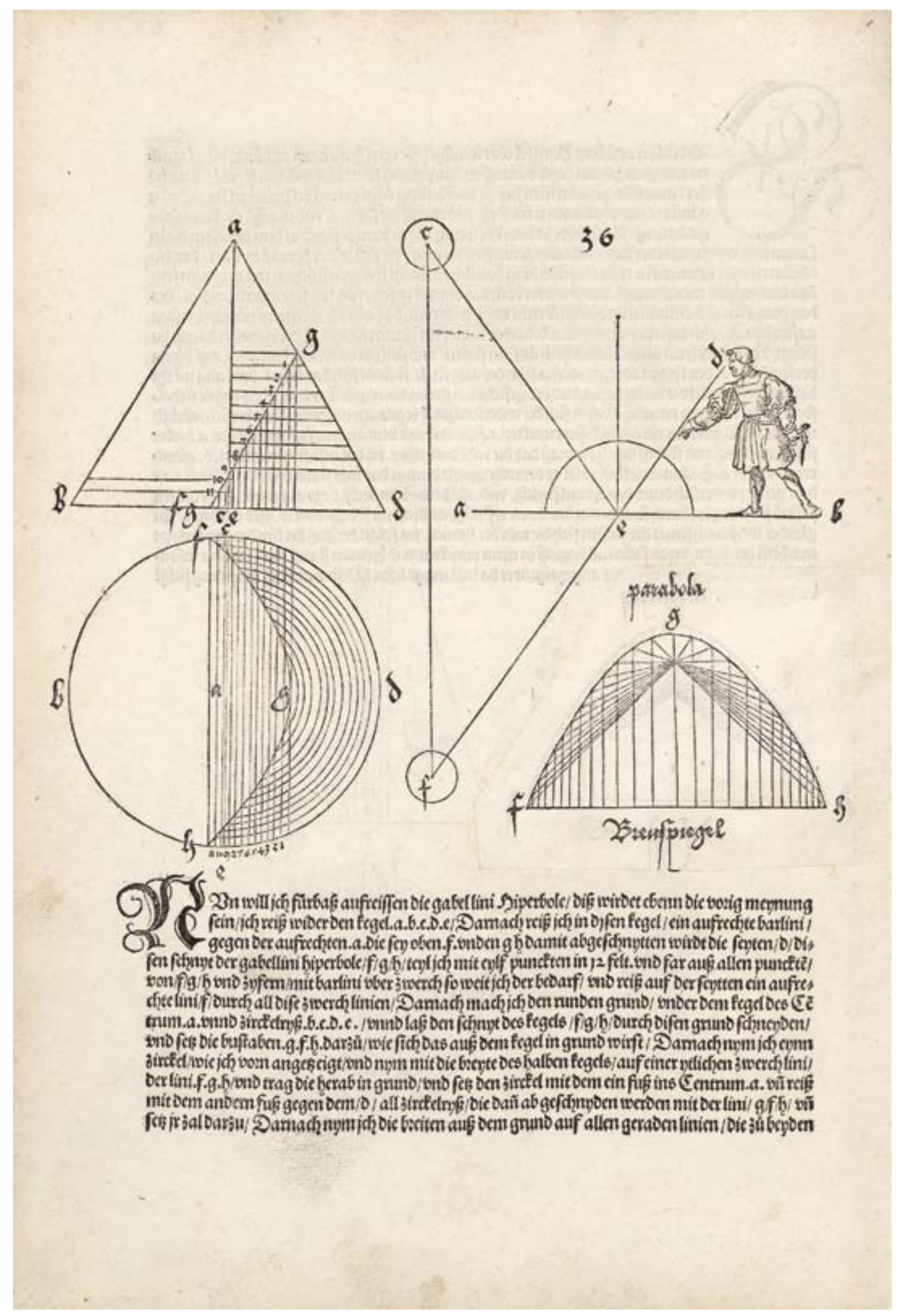




\section{Blumen aus dem markgräflichen Lustgarten}

Johann Bartholomäus Braun:

Flora Picta, oder Sammlung aller Blumen, so ehedeßen im Garten des Markgrafen von Baden Durlach geblühet, nach dem Leben gemahlt. Papierhandschrift mit eingeklebten Pergamentblättern, Durlach, um 1660.

Signatur: $2^{\circ}$ Cod. Ms. Uff. $40^{\mathrm{e}}$ Cim.

Provenienz: Johann Friedrich Armand von Uffenbach, 1769/70

Seit der Mitte des 16. Jahrhunderts gelangten über Spanien nicht nur die ersten amerikanischen Pflanzen nach Europa, sondern auch die für die Epoche typischen Zwiebelgewächse aus Südosteuropa und dem Vorderen Orient eroberten die Gärten. Bis zum Dreißigjährigen Krieg (1618-1648) ist ein massenhaftes Aufkommen von Hyazinthen, Narzissen, Kaiserkronen, vor allem aber von Lilien und Tulpen charakteristisch. Sie zogen im Triumphzug von Ost nach West und verdrängten die schlichten einheimischen Blumen und Arzneipflanzen aus den Gärten, die sich zu Zier- und Lustgärten wandelten. Die Vorliebe für die großblumigen Zwiebelgewächse trieb die Preise für Blumenzwiebeln in die Höhe und gipfelte schließlich in dem Spekulationsfieber der „Tulpomanie“. Sie ist bezeichnend für den Geschmackswandel, der sich seit der Mitte des 16. Jahrhunderts allmählich auf allen Gebieten Geltung verschaffte und bis zum Hochbarock entwickelte. Im Dreißigjährigen Krieg wurden im deutschsprachigen Kulturraum zwar etliche Lustgärten zerstört, aber für die Oberschichten war eine verschwenderische Prachtentfaltung auch vor dem düsteren Hintergrund des Krieges weiter möglich. Mancher Adliger war somit bald nach seiner Rückkehr aus dem Exil damit beschäftigt, einen Ziergarten wieder herzurichten oder neu anzulegen. Die Blumen- und Gartenliebhaberei war so groß, dass es verbreitet war, Maler in Dienst zu nehmen, die die wertvollsten und schönsten Blumen ,nach dem Leben“ abmalten. Das Jahresgehalt eines Blumenmalers des Grafen von Nassau-Saarbrücken betrug 50 Gulden, während eine Kiste Blumen- zwiebeln aus Amsterdam 167 Gulden kostete. In dieser Zeit entstanden nicht nur bekannte und prachtvolle Werke wie der Hortus Eystettensis der Fürstbischöfe zu Eichstätt, sondern auch kleinere, künstlerisch einzigartige Blumen- und Gartenbücher.

Zu den künstlerischen Unikaten der Gattung gehört auch die um 1660 entstandene Flora Picta, die Pflanzen im Ziergarten des Markgrafen von Baden-Durlach abbildet. Das Werk umfasst 190 Blätter mit größtenteils farbigen Illustrationen, die von dem Künstler Johann Bartholomäus Braun (Wirkungsjahre 1636-1674) stammen. Sie zeigen Blumen nicht weniger als 50 Blätter sind Tulpen gewidmet - aber auch Vögel, vereinzelt Schmetterlinge, Hirschkäfer und Libellen. Gezeigt werden auf Pergament gemalte Tulpen. 


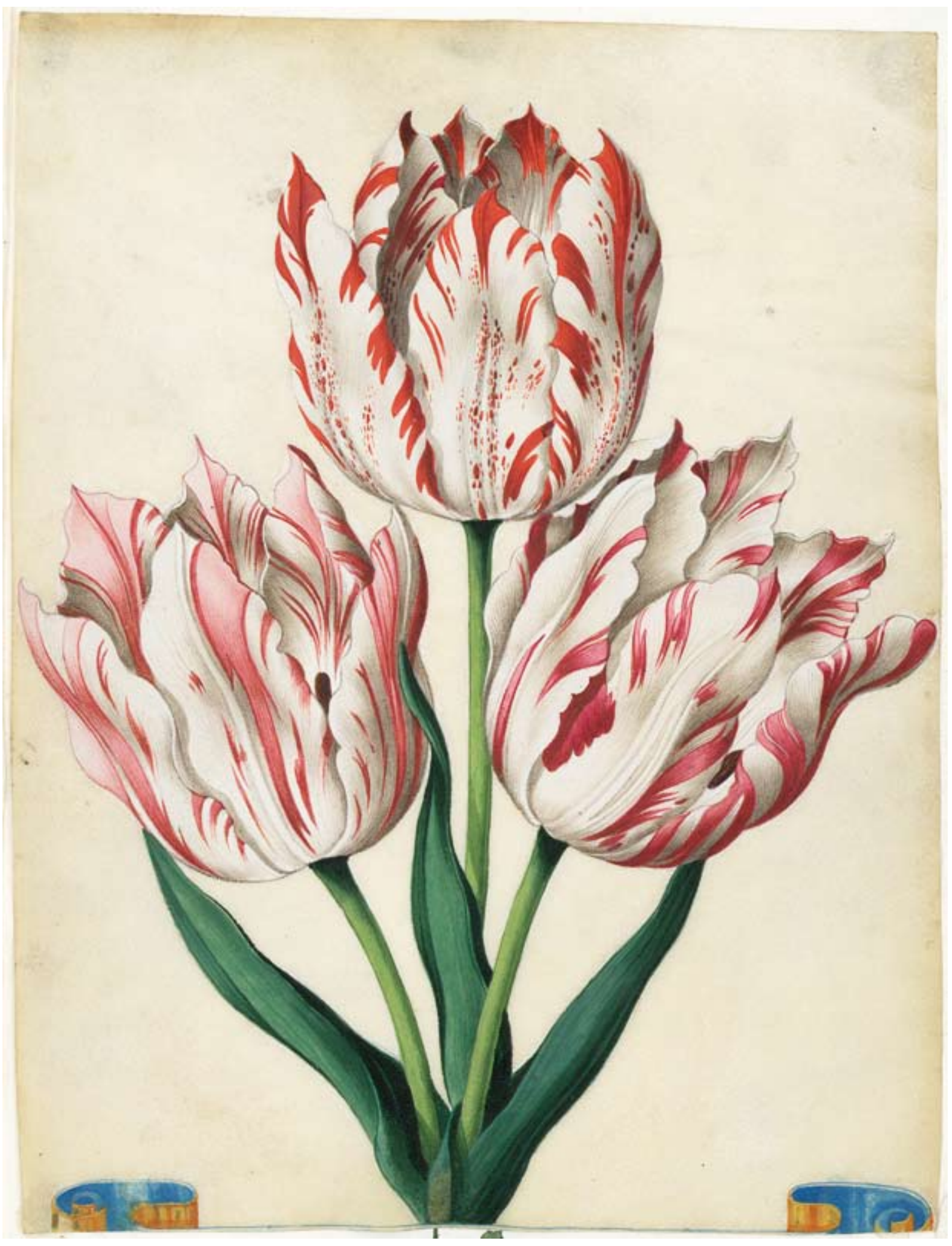




\section{Je einfacher, desto besser}

Sitzungsberichte der Wissenschaftlichen Gesellschaft Frankfurt. Band 2.

Frankfurt, 18. VII. 1727 - 30. VII. 1728.

Signatur: $2^{\circ}$ Cod. Ms. Uff. 13: 2

Provenienz: Johann Friedrich Armand von Uffenbach, 1769/70

Johann Friedrich Armand von Uffenbach (1687-1769) war der jüngere Bruder des in Europa weithin bekannten Bücher- und Handschriftensammlers Zacharias Conrad von Uffenbach (1683-1743). Die Familie gehörte seit mehreren Generationen dem Frankfurter Patriziat an, und Johann Friedrich von Uffenbach bekleidete zu verschiedenen Zeiten hohe Ämter in der Stadt, war Mitglied des Rates, Schöffe und 1762 auch Bürgermeister von Frankfurt. Nach Beendigung seines Studiums in Gießen und Halle ging Uffenbach 1714 auf eine zweijährige Grand Tour durch die Schweiz, Italien, Frankreich und die Niederlande. Der junge Privatgelehrte interessierte sich insbesondere für Opernhäuser und Theater, für Kirchen und Paläste, besuchte aber außerdem die öffentlichen Bibliotheken, Galerien und Sammlungen. Er erwarb auf seinen Reisen zahlreiche Bücher, Graphiken, Gemälde sowie musikalische und wissenschaftliche Instrumente, die mit seinem Vermächtnis 1769 nach Göttingen gelangten.

Im Jahre 1725 gründete Uffenbach in Frankfurt eine Gesellschaft zur Pflege von Wissenschaft und Kunst, eine der frühesten bürgerlichen Gesellschaften dieser Art in Deutschland. Zu Beginn bestand sie aus nur sechs Mitgliedern, von denen drei dem akademischen Bürgertum, drei der Frankfurter Geschäftswelt angehörten. Der Verein trat alle vierzehn Tage zusammen, zunächst ohne Protokolle der Sitzungen anzufertigen. Erst 1726 übertrug man Uffenbach „,das Ampt des Schreibers“, um die Inhalte der Treffen zu dokumentieren. Das Ergebnis waren fünf in grünes Leder gebundene Protokollbände mit dem Titel Wochentliche Sammlung der in Nützlichen Neben Stunden angestellten Untersuchungen der Natur und Kunst, welche zu einer vernünftigen Gemüths Ergötzung diejenige Gesellschaft veranlasset, deren Denckspruch ist Quo simplicius eo perfectius [Je einfacher, desto besser]. Die Themen der Zusammenkünfte waren äußerst vielfältig; oft wurden neue Maschinen, Musikinstrumente oder auch seltene Bücher vorgestellt, und regelmäßig versuchte man sich in Diskussionen und Anwendungen von Kunst- und Maltechniken.

Der in das Protokoll vom 9. Dezember 1727 eingeklebte Kupferstich wurde von Johann Friedrich von Uffenbach gezeichnet und gestochen. Er zeigt einen Blick in die Bibliothek seines Bruders Zacharias Conrad, damals mit 40.000 Bänden eine der größten Privatbibliotheken Deutschlands, die in acht Zimmern aufgestellt war. In dieser Sitzung präsentierte Uffenbach außerdem ein Schrankschloss mit zweifacher Verriegelung. 

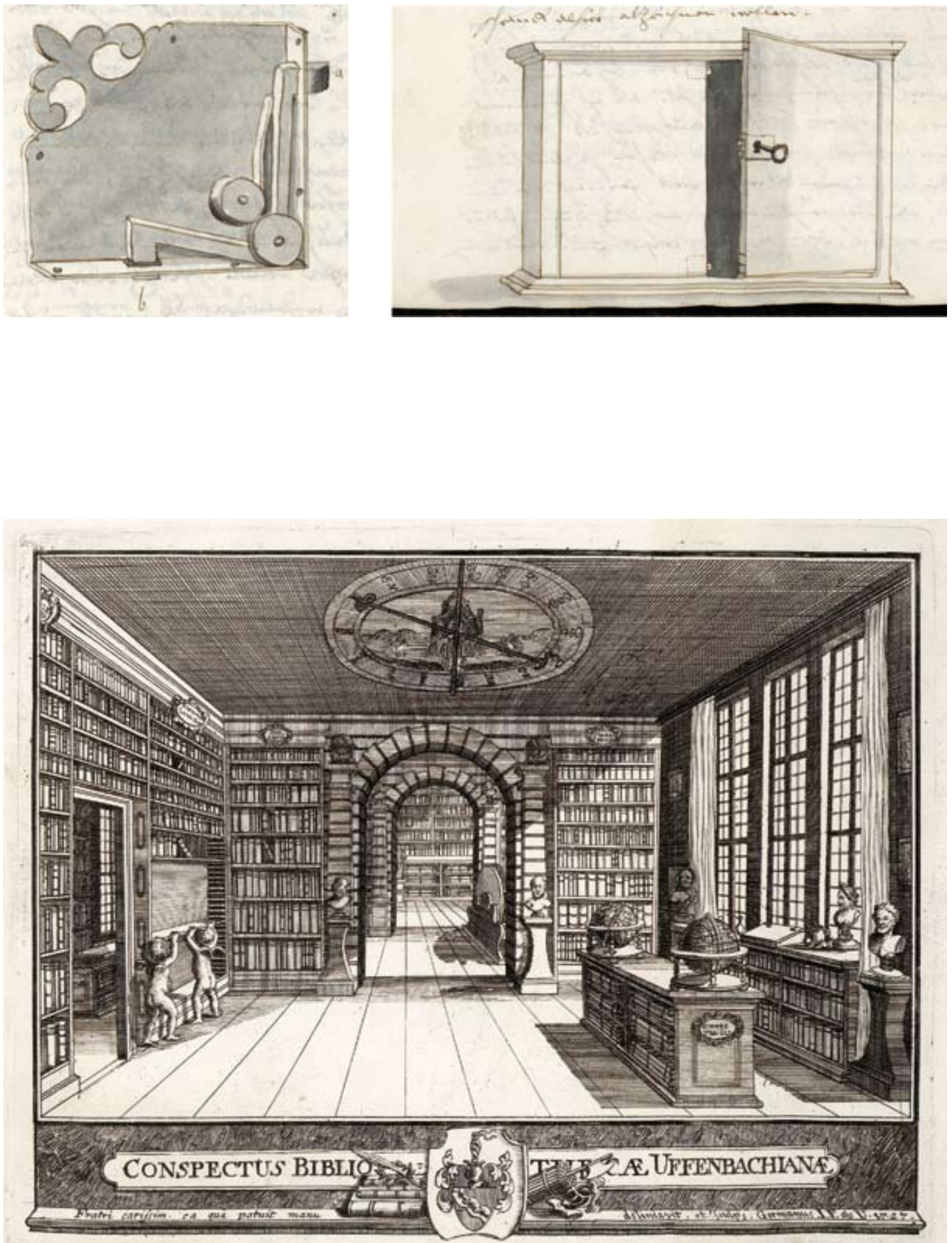


\section{des Freiherrn von Münchhausen}

[Rudolf Ernst Raspe; Gottfried August Bürger]:

Wunderbare Reisen zu Wasser und Lande, Feldzüge und lustige Abenteuer des Freiherrn von Münchhausen, wie er dieselben bei der Flasche im Zirkel seiner Freunde selbst zu erzählen pflegt. London [i.e. Göttingen: Johann Christian Dieterich], 1788.

Signatur: Münchhausen Bibl. 3170

Provenienz: Börries von Münchhausen, 1991

Mit den Worten „Der Freyherr von Münchhausen, dem diese Erzählungen größtentheils ihr Daseyn zu danken haben, gehört zu einer der ersten adeligen Familien Deutschlands ... “ beginnt die Vorrede der Wunderbaren Reisen des Freiherrn von Münchhausen. Der deutsche Gelehrte Rudolf Ernst Raspe (1737-1794) legte 1786 in England mit der anonymen Veröffentlichung seiner Erzählungen von den Abenteuern Münchhausens den Grundstein für deren Welterfolg. Als Vorlage dienten ihm vermutlich die 1781 anonym im VadeMecum für lustige Leute in Berlin erschienenen „Erlebnisse eines Herrn von M-h-s-n”. Raspe übertrug die Anekdoten ins Englische, erweiterte sie und verzierte den Band mit Kupferstichen. Mit seinem Verweis auf die Person des Hieronymus Carl Friedrich von Münchhausen (1720-1797) aus Bodenwerder erhielten die phantastischen Erzählungen einen Realitätsbezug. Bereits ein halbes Jahr später erschien eine deutsche, anonyme Fassung der Geschichten. Für den realen Münchhausen bedeutete diese Veröffentlichung einen deutlichen Eingriff in sein Leben. Bis zu jenem Zeitpunkt galt der ehemalige russische Offizier in seinem Umfeld als geistreicher und kurzweiliger Geschichtenerzähler. Auch in Göttingen war die Erzählkunst des Barons, der das Hotel „Zur Krone“ frequentierte, beliebt. Rasch wurden die Lügengeschichten der Wunderbaren Reisen mit ihm in Verbindung gebracht und führten dazu, dass ihm der Spottname „Lügenbaron“ verliehen wurde.
Die Identität des deutschen Bearbeiters der Erzählungen wurde 1798 aufgedeckt. Der Göttinger Gelehrte und Dichter Gottfried August Bürger (1747-1794) übersetzte das englische Büchlein und fügte 16 neue Geschichten hinzu, darunter den „Ritt auf der Kanonenkugel“ und die „Rettung am Zopf aus dem Morast“. Die Erstausgabe erschien 1786 mit der fingierten Druckortangabe London in der Dieterichschen Verlagsbuchhandlung in Göttingen. Zwei Jahre später wurde die vorliegende zweite Ausgabe veröffentlicht. Ihre 15 Illustrationen stammen vermutlich von dem Göttinger Universitätskupferstecher Ernst Ludwig Riepenhausen (1765-1839). Die dargestellten Zeichnungen sind den Erzählungen „Rettung am Zopf aus dem Morast“ und „Sprung durch das Fenster“ zugeordnet.

(DW) 


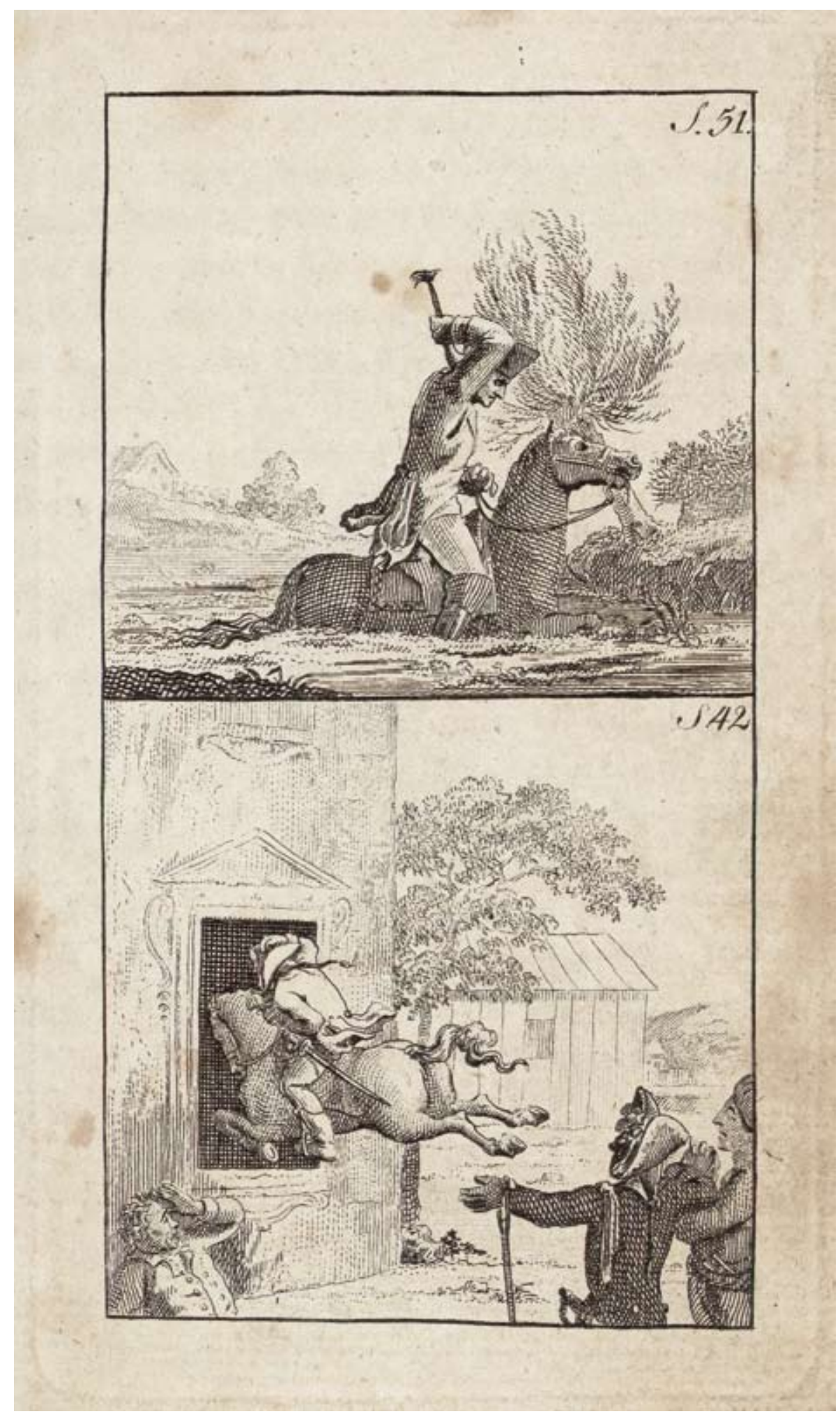




\section{Portugal und Holland im Streit um Brasilien}

Francisco de Brito Freire:

Viage da armada da companhia do commercio, e frotas do estado do Brasil.

Lissabon: Joam Galram, 1655.

Signatur: Bibl. Klammer 102

Provenienz: Gerhard Klammer, 2003

Bis weit in das 17. Jahrhundert hinein blieb Brasilien ein Machtvakuum und Schauplatz rivalisierender Kolonisierungsversuche. Portugal zeigte sich zunächst wenig geneigt, die neu entdeckte Region einer intensiven Kolonisierung zu unterziehen, da sich das Hauptinteresse auf den Orienthandel richtete. Erst als portugiesische Hegemonialansprüche durch holländische Kaufleute und Siedler gefährdet waren, wurden verstärkte Anstrengungen unternommen, das Gebiet militärisch abzusichern. Die Herrschaft der Niederländer in Brasilien stellt ein kurioses Kapitel der Kolonialgeschichte des 17. Jahrhunderts dar. Recife, eine kleine Siedlung in Pernambuco an der Nordküste Brasiliens, wurde zwischen 1630 und 1654 als Hauptstadt NiederländischBrasiliens in die größte und fortschrittlichste Stadt des ganzen Kontinents verwandelt. Nach einer kurzen Blütezeit wurden die Niederländer 1654 in der Schlacht von Guararapes jedoch endgültig von den Portugiesen aus Brasilien verdrängt.

Francisco de Brito Freire († 1692) war als Admiral der portugiesischen Flotte maßgeblich an der Rückeroberung Nordbrasiliens beteiligt. 1654 wurde er außerdem Gouverneur von Pernambuco. Aufgrund seiner Position konnte er als sachkundiger Berichterstatter einen guten Einblick in die wirtschaftliche Situation Brasiliens geben. Seine Schriften gelten als die besten portugiesischen Quellen über die wirtschaftliche und militärische Situation Brasiliens um die Mitte des 17. Jahrhunderts. Nachdem auf dem Land die Vormacht der Portugiesen gefestigt war, sollte mit Hilfe der 1649 gegründeten Companhia Geral do Comércio de Brasil der Seeweg zwischen Brasilien und Portugal vor holländischen Kaperversuchen geschützt werden. Brito Freire schildert die Reise einer großen, 170 Schiffe umfassenden Handelsflotte, die erstmals nach der Rückeroberung Brasiliens reich beladen nach Portugal zurückkehrte und die er als Gouverneur und „General-Kapitän“ in einer Person befehligte. Für die Seefahrt gibt das Werk wichtige Informationen über die Navigation zwischen Brasilien und Europa.

Die großzügig gedruckte Publikation mit Holzschnitt-Initialen und -Vignetten stammt aus der Offizin Joam Galram in Lissabon und sollte mit den holländischen Veröffentlichungen der Zeit konkurrieren. Da die Portugiesen an den Verhältnissen in Südamerika jedoch kaum interessiert waren, blieb die Verbreitung der Schrift gering.

(MS/KN) 


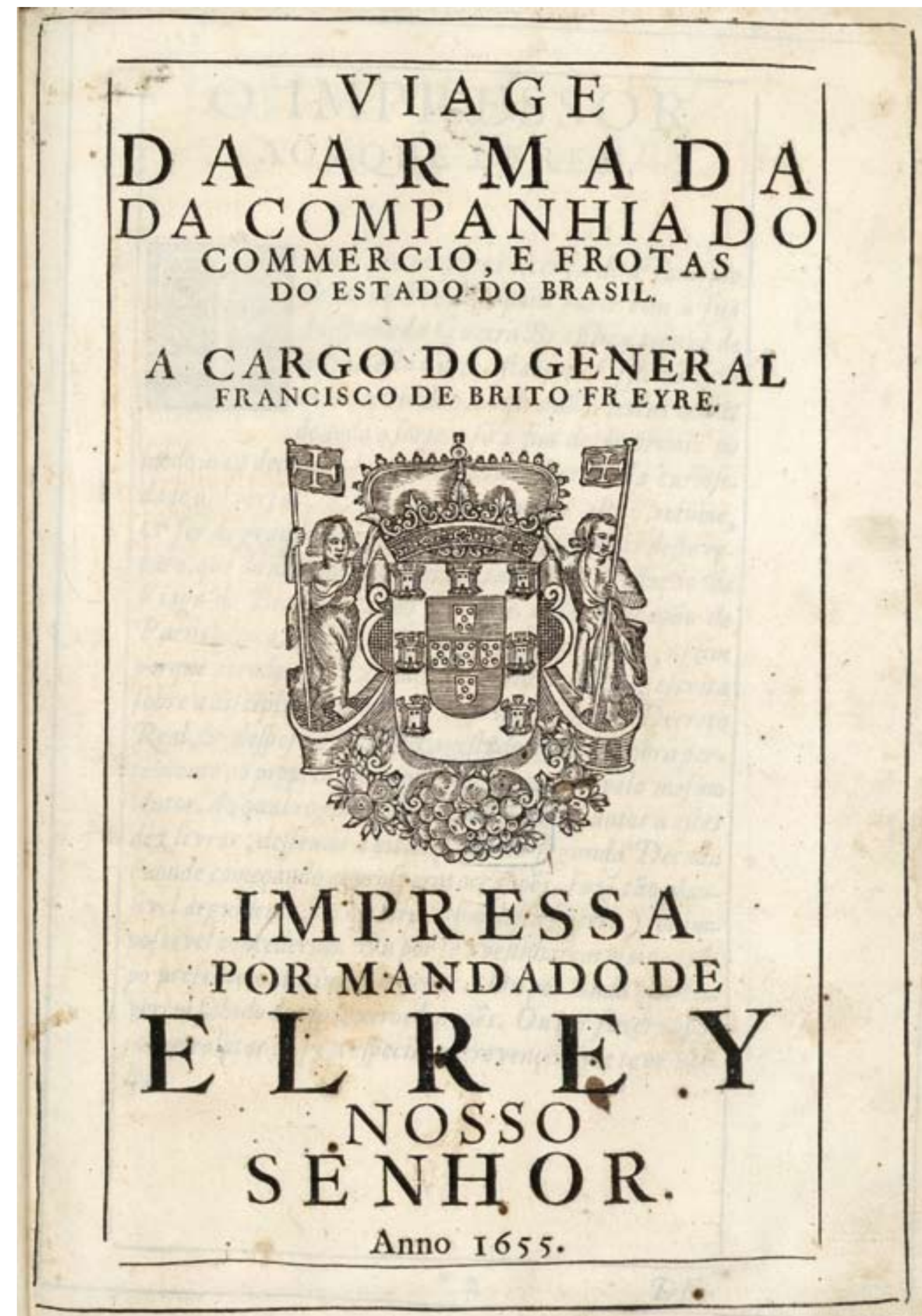




\section{Die Erlebnisse eines Weltenbummlers}

Joan Nieuhof:

Voyages and Travels into Brasil and the East-Indies, Containing an Exact Description of the Dutch Brasil, and Divers Parts of the East Indies. London: Awnsham and John Churchill, 1703.

Signatur: Bibl. Klammer 182

Provenienz: Gerhard Klammer, 2003

Joan Nieuhof (1618-1672) stammte aus einer angesehenen Familie aus Ussen in der Grafschaft Bentheim. Sein Vater, Bruder und Schwager waren Bürgermeister des Ortes. Im Alter von 22 Jahren trat Nieuhof in den Dienst der niederländischen West-Indischen Compagnie und kehrte lediglich zu zwei kurzen Familienbesuchen $(1658,1671)$ in seine Heimat zurück.

Das vorliegende englischsprachige Werk ist eine Übersetzung des 1682 veröffentlichten niederländischen Originals. Wie die beiden weiteren unter seinem Namen erschienenen Werke wurden auch die Voyages and Travels into Brasil nicht von Joan Nieuhof selbst verfasst, sondern auf der Grundlage seiner Aufzeichnungen von seinem Bruder Hendrik ausgearbeitet und herausgegeben. Das Buch besteht aus drei Teilen: aus einem Bericht über den neunjährigen Aufenthalt Joan Nieuhofs in Brasilien (1640-1649), über seine Reise nach Indien und Indonesien und aus einer äußerst kurzen, auf einem Logbucheintrag seines Schiffes basierenden Darstellung seines plötzlichen Verschwindens anlässlich eines Landganges auf Madagaskar. Vermutlich wurden Nieuhof und seine Begleiter von kriegerischen Einheimischen getötet.

Nieuhofs Reise nach Brasilien fällt in eine Zeit, in der die Niederländer danach trachteten, den Portugiesen Handelstützpunkte abzunehmen. Die diplomatischen und kriegerischen Auseinandersetzungen werden in seinem Bericht ausführlich beschrieben und mit Auszügen aus Dokumenten belegt, um die
Authentizität und den Wahrheitsgehalt seiner Schilderung hervorzuheben. Es geht Nieuhof aber auch darum, dem interessierten Leser landeskundliche Kenntnisse von Brasilien zu vermitteln und diese durch eine Reihe von Abbildungen, Karten und Stadtplänen zu veranschaulichen. Eben dieses Konzept der Information aus erster Hand wird auch in der Schilderung seiner Reise nach Indien und Indonesien verfolgt. Dabei ist Nieuhofs Beschreibung der bedeutenden niederländischen Handelsniederlassung Batavia (heute Jakarta) die wohl umfangreichste und genaueste seiner Zeit. 


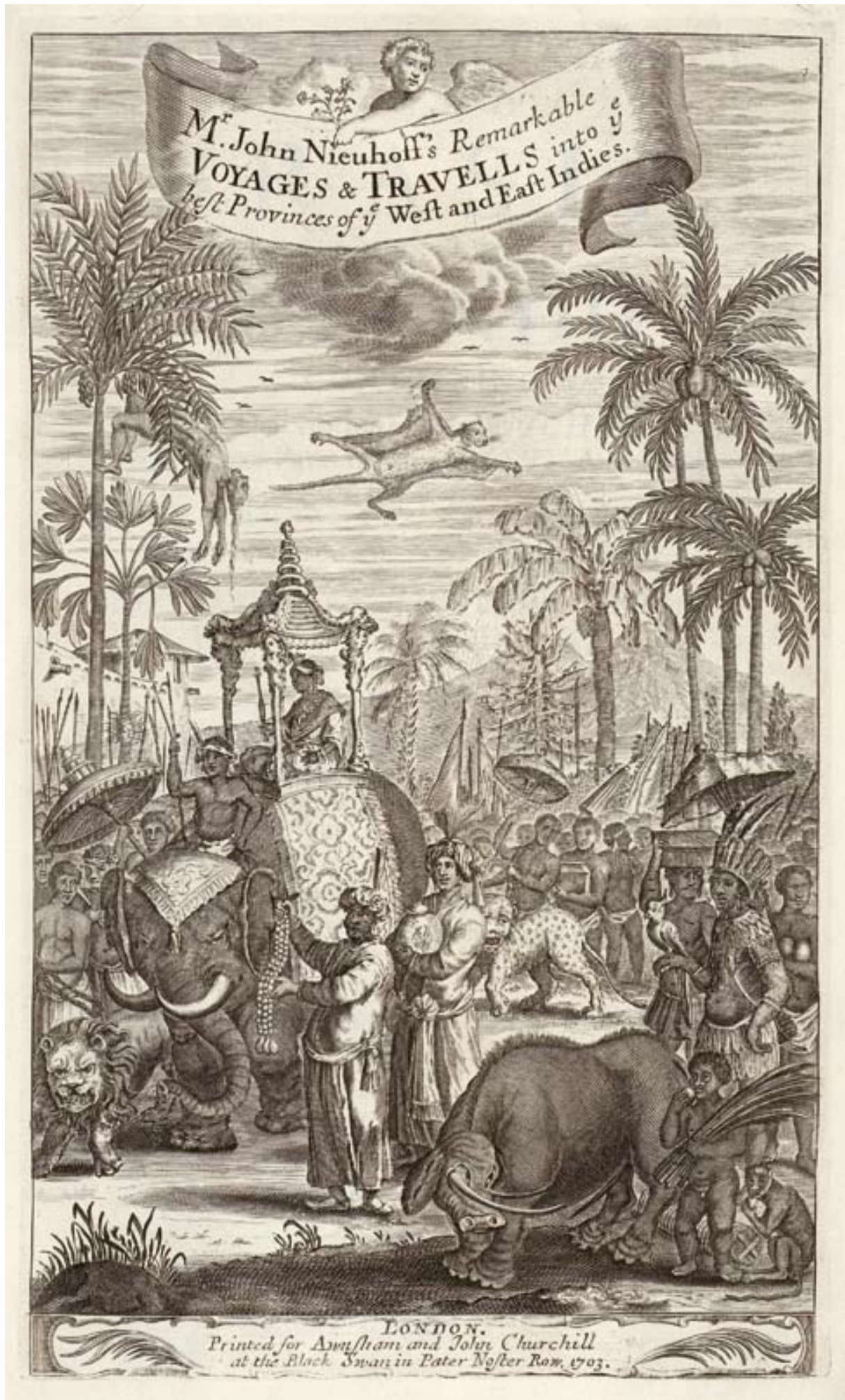




\section{Der französische Humboldt}

Alcide Dessalines d’Orbigny:

L’Homme Américain (de l’Amérique Méridionale) considéré sous ses

Rapports Physiologiques et Moraux. Atlas.

Paris: Pitois-Levrault et Cie, Libraires 1839.

Signatur: Bibl. Klammer 183: Atlas

Provenienz: Gerhard Klammer, 2003

Alcide Charles Victor Marie Dessalines d’Orbigny (1802-1857) war einer der bedeutendsten französischen Naturwissenschaftler des 19. Jahrhunderts und sowohl auf den Gebieten der Zoologie, Paläontologie und Geologie als auch in der Archäologie und Anthropologie zu Hause. Er gilt als Begründer der Mikropaläontologie und veröffentlichte eine umfangreiche und systematische Beschreibung von Fossilien, die zwischen 1840 und 1860 unter dem Titel La Paléontologie Française in acht Bänden erschien. 1826 nahm d'Orbigny an einer achtjährigen Forschungsreise des Muséum National d'Histoire Naturelle nach Südamerika teil und bereiste die südlichen Länder Lateinamerikas, die zuvor kaum von europäischen Forschern erkundet worden waren. Da seine finanziellen Mittel äußerst dürftig waren, bewältigte er große Distanzen überwiegend zu Fuß. Der Gelehrte identifizierte während seines Aufenthaltes 6.900 Tier- und 1.500 Pflanzenarten und zeichnete erstmalig eine präzise Gebirgskarte der Region. D’Orbignys Entdeckungen wurden in den neun Bänden der Voyage dans l'Amérique Méridionale (1835-1847) publiziert.

Im Jahre 1839 erschien das anthropologische Werk L'Homme Américain, das d'Orbigny Wilhelm von Humboldt (1767-1835) widmete. D’Orbigny beschreibt und vergleicht auf der Basis damals üblicher Kriterien die Indianerstämme Perus, Boliviens und Brasiliens und weist u.a. den Einfluss des Klimas und der Lage über dem Meeresspiegel auf den Menschen nach. Neben anthropologischen
Charakterisierungen liefert d’Orbigny auch ethnographische Beschreibungen der Sprachen, Sitten und Gebräuche, der Religion, Kleidung und des Handwerkes. Der Franzose, der neben Humboldt zu den großen wissenschaftlichen Erforschern Südamerikas zählt, sammelte zahlreiche aufschlussreiche Informationen über die südamerikanischen Indianer. Sein Eintreten für die Befreiung der Urbevölkerung von den Weißen trug ihm in den modernen südamerikanischen Staaten einen guten Ruf ein.

In dem gezeigten Atlas ist auch ein eindrucksvolles Porträtgefäß aus der so genannten Moche-Kultur abgebildet, die bis etwa $600 \mathrm{n}$. Chr. existierte und die nach dem Ort Moche in der Nähe der heutigen Stadt Trujillo (Peru) benannt ist. 


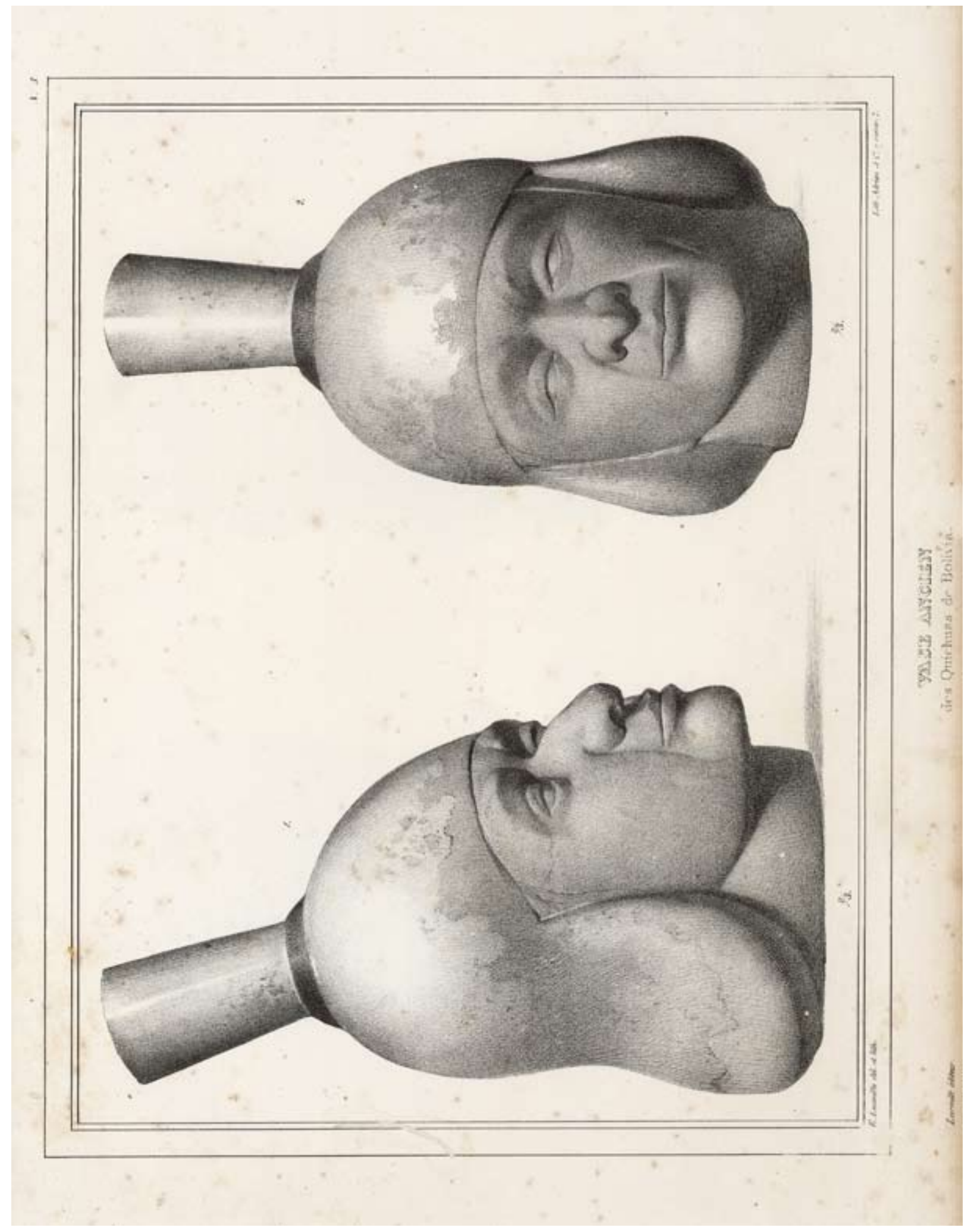




\section{Kapitel 3}

\section{Herkunft aus öffentlichen Institutionen}

Neben dem regelmäßigen Erwerbungsgeschäft und dem Bezug einzelner wertvoller Drucke und Handschriften aus dem Antiquariat und bei Auktionen des In- und Auslandes gelangten häufig Stücke in den Bestand der Göttinger Universitätsbibliothek, die zuvor im Besitz öffentlicher Einrichtungen gewesen waren. In jeder Bibliothek war und ist es trotz großer Sorgfalt unvermeidbar, dass Drucke erworben werden, die bereits im Bestand vorhanden sind, so dass Doppelstücke oder Dubletten nebeneinander existieren. Dies kann durch ungenaue Angaben im Verkaufskatalog eines Antiquariats geschehen oder durch unzulängliche Verzeichnung der Drucke in den älteren Bibliothekskatalogen, um nur zwei der offensichtlicheren Ursachen zu benennen. Bereits seit dem 18. Jahrhundert veranstalteten öffentliche Bibliotheken deshalb größere Dublettenverkäufe, um sich dieser unnötigen Exemplare zu entledigen. Ein typisches Beispiel hierfür ist ein Dublettenverkauf der Stadtbibliothek Nürnberg aus dem Jahr 1777, der in erster Linie zum weiteren Aufbau der Göttinger Inkunabelsammlung beitrug.

Als Göttingen 1807 dem Königreich Westfalen einverleibt wurde, schienen sich für die Bibliothek beim Erwerb älterer Literatur Aussichten besonderer Art zu eröffnen. Im Zuge der von Frankreich übernommenen Zentralisierung wurden neben der Universitätsbibliothek Helmstedt zahlreiche Stifts- und Klosterbibliotheken im Bereich des neuen Königreichs aufgelöst, deren Bestände 1812 nach Göttingen gelangten. Nach dem Zusammenbruch der Napoleonischen Herrschaft musste jedoch nach 1814 der größte Teil dieser Bestände wieder an die Vorbesitzer zurückgegeben werden. Damit war die Möglichkeit, dem Zentrum für alte Drucke und Handschriften im Süden Deutschlands eines im Norden gegenüberzustellen, geschwunden, kaum dass sie entstanden war. Doch sind zwei herausragende Bücher aus Helmstedt in Göttingen geblieben: das Fuldaer Sakramentar aus dem 10. Jahrhundert und eine der schönsten und frühesten Inkunabeln, die von Johannes Gutenberg in Mainz 1454/55 gedruckte 42-zeilige Bibel.

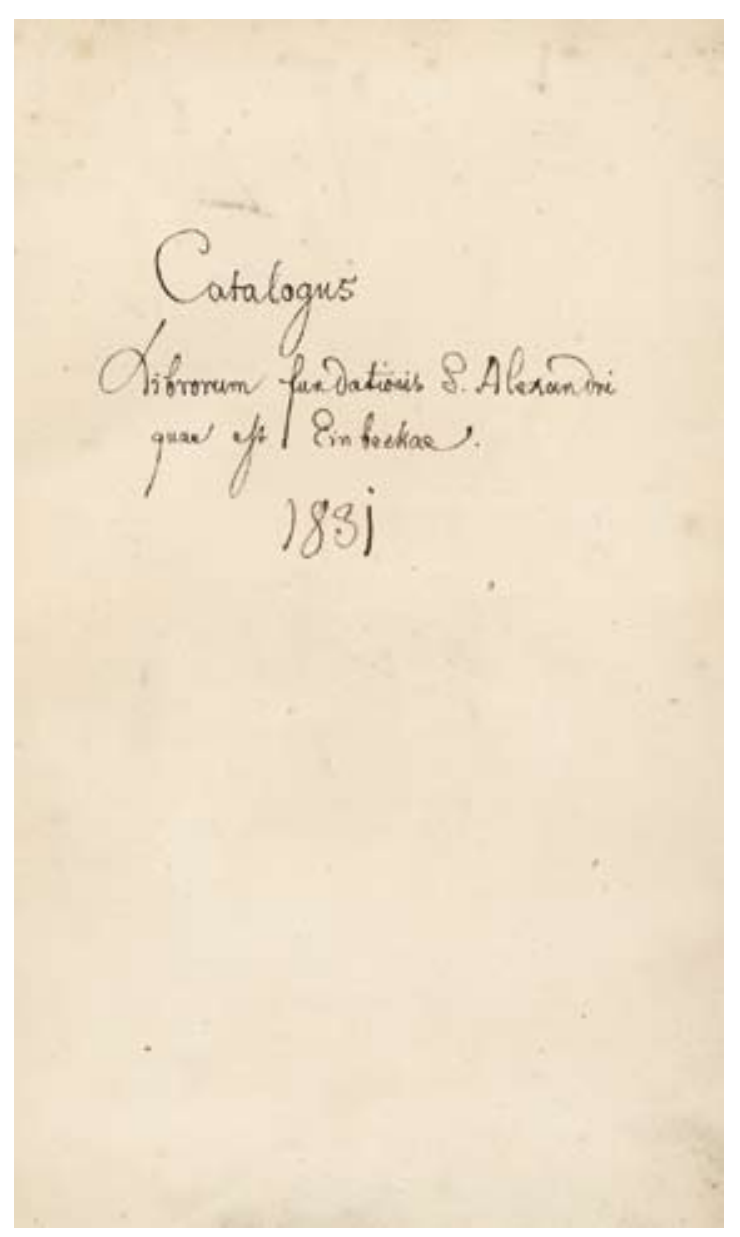

Katalog zur Bibliothek des Alexander-Stifts Einbeck.

Die Aufnahme von Bibliotheken aufgelöster Institutionen ist ein willkommenes Instrument des Bestandsaufbaus, insbesondere in Zeiten, in denen Mittelkürzungen die antiquarische Erwerbung im Handel schwieriger gestalten oder gar ganz ausschließen. Im 
19. Jahrhundert flossen auch die Göttinger Erwerbungsmittel spärlicher, so dass die Übernahme der Bücher des Alexander-Stifts zu Einbeck im Jahre 1831 sowie die 1853 zugewiesene Bibliothek der aufgelösten Ritterakademie zu Lüneburg, des ehemaligen Michaelisklosters, zu den wichtigeren Ereignissen in der Erwerbungsgeschichte zählen. Unter den Büchern des Einbecker AlexanderStifts befanden sich 81 Inkunabeln, großenteils aus dem juristischen Bereich. Ein handschriftlicher Sonderkatalog der aus Einbeck erhaltenen Werke wurde von Jacob Grimm (1785-1863) angelegt, der seit 1830 als Bibliothekar und Professor in Göttingen tätig war und möglicherweise auch die Erwerbung selbst veranlasst hatte.

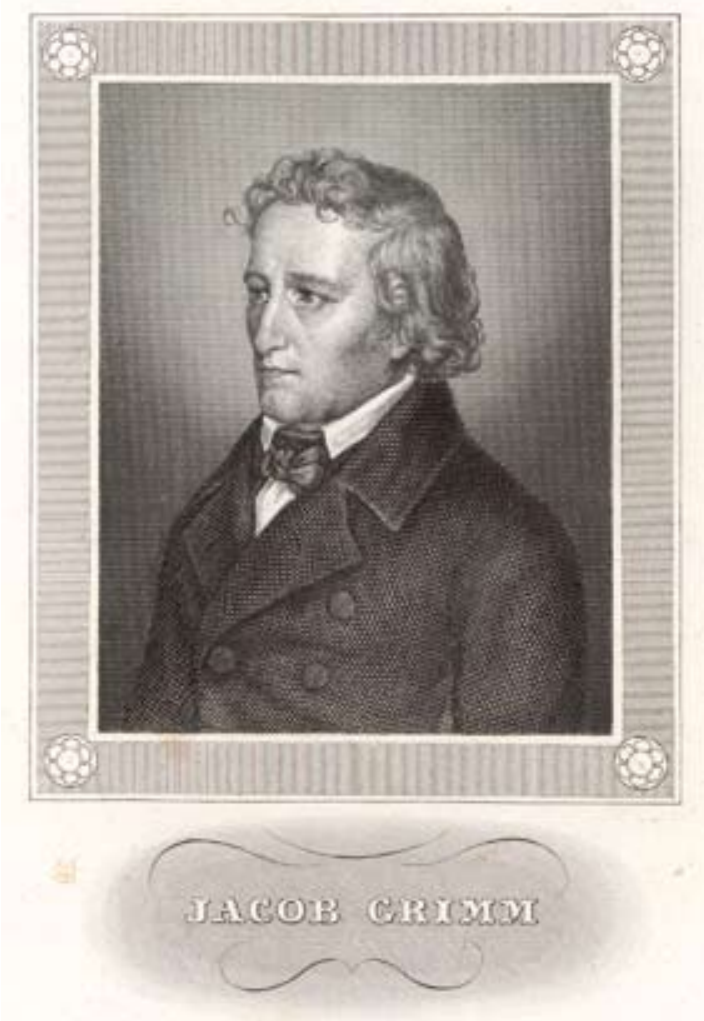

Jacob Grimm (1785-1863).

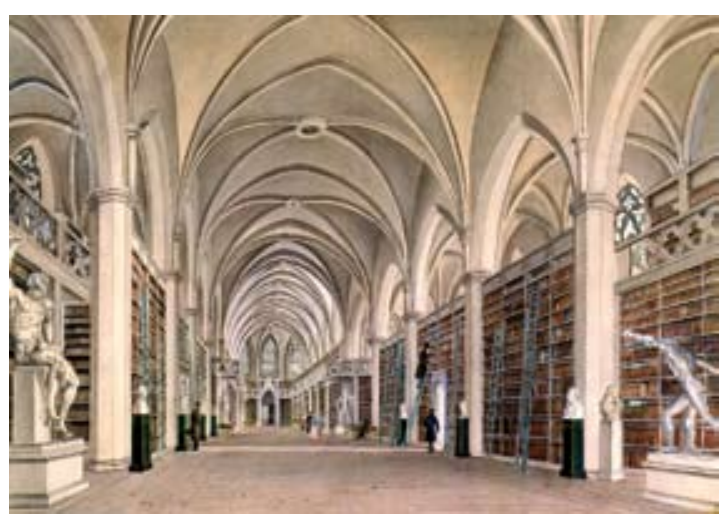

Der Historische Saal in der Paulinerkirche.

Im Jahr 1853 wurden 3.500 Bände der aufgelösten Ritterakademie zu Lüneburg nach Göttingen überwiesen. Die Ritterakademie hatte den Bestand des ehemaligen Klosters St. Michaelis in Lüneburg übernommen, und man erwartete von der Erwerbung eine große Zahl von Kostbarkeiten. Tatsächlich war die Sammlung als Ganzes nicht so bedeutend wie angenommen. Unter den neueren Titeln gab es einen Schwerpunkt zur niedersächsischen Geschichte, der doch eine willkommene Ergänzung darstellte. Zu den wertvolleren Stücken zählten aber die mittelalterlichen Handschriften des Klosters, 54 Inkunabeln und zwei klassische Werke der Architekturgeschichte: Wendel Dietterlins Architectura (Nürnberg 1598) und Andrea Palladios I quattro libri dell' architettura (Venedig 1570).

(HR) 


\section{Die erste gedruckte Bibel: Die Gutenbergbibel oder 42-zeilige Bibel (B 42)}

Biblia, lateinisch.

[Mainz: Drucker der 42-zeiligen Bibel (Johannes Gutenberg, zusammen mit Johannes Fust und Peter Schöffer), um 1454, nicht nach August 1456]. Signatur: $2^{\circ}$ Bibl. I, 5955 Inc. Rara Cim.

Provenienz: Universitätsbibliothek Helmstedt, 1812

Obwohl Gutenberg - wie bei allen ihm zugeschriebenen Drucken - als Drucker nicht namentlich genannt ist, gilt es heute als gesichert, dass dieses erste große Werk nach der Erfindung des Buchdruckes von ihm in der Gemeinschaftsdruckerei mit Fust und Schöffer geschaffen wurde. Es stellt mit der eleganten Form der Typen (Missalschrift, Textura) und der harmonischen Geschlossenheit des Satzbildes ein unübertroffenes Meisterwerk der Druckkunst dar. Die Bindung an das handschriftliche Vorbild zeigt der von Gutenberg geschaffene umfangreiche Apparat von Typen nicht nur für Buchstaben, sondern auch für Abkürzungen und Ligaturen. Man schätzt, dass die Auflage etwa 180 Exemplare (150 Papierund 30 Pergamentexemplare) betragen hat. Heute sind weltweit - zusammen mit den beiden noch verschollenen Leipziger Exemplaren - 49 vollständige und unvollständige Stücke bekannt, darunter 12 auf Pergament gedruckte Bibeln. Zu den vier vollständigen Pergamentdrucken gehört auch das Exemplar der Niedersächsischen Staats- und Universitätsbibliothek; die übrigen befinden sich in London (British Library), Paris (Bibliothèque Nationale) und Washington (Library of Congress).

Im 15. Jahrhundert wurden Werke dieser Art meist erst auf Veranlassung des Käufers rubriziert (mit roten Einzeichnungen versehen), illuminiert (mit Verzierungen und Bildern ausgemalt) und gebunden. Jedes Exemplar der Gutenbergbibel ist deshalb (ähnlich den Handschriften) als ein Unikat anzusehen.
Das Göttinger Exemplar ist durch vielfältige Formen der Einzeichnungen und Ausmalung gekennzeichnet: Seitenüberschriften in roter Missalschrift, Kapitelzahlen, Kapitelanfänge abwechselnd rot und blau, große Initialen reich in Gold und Farben mit anschließendem Blattwerk an den Rändern, vor allem der großartige Schmuck des Bibelanfangs sowie der einzelnen Bücher mit Blattwerkinitialen und Ranken in Akanthus, Farn- oder farbigem Dornblatt. Als Vorlage für diese Illuminierung hat wohl das Göttinger Musterbuch gedient (s. Nr. 18).

Ursprünglich gehörte das Göttinger Exemplar einem Kloster, das wahrscheinlich im Calenberg-Göttingischen Teil der Welfenlande gelegen war, und kam dann in den Besitz der Herzogsfamilie. Über Wolfenbüttel (1587) gelangte die Bibel 1614 an die Universitätsbibliothek Helmstedt und von dort nach Göttingen. 


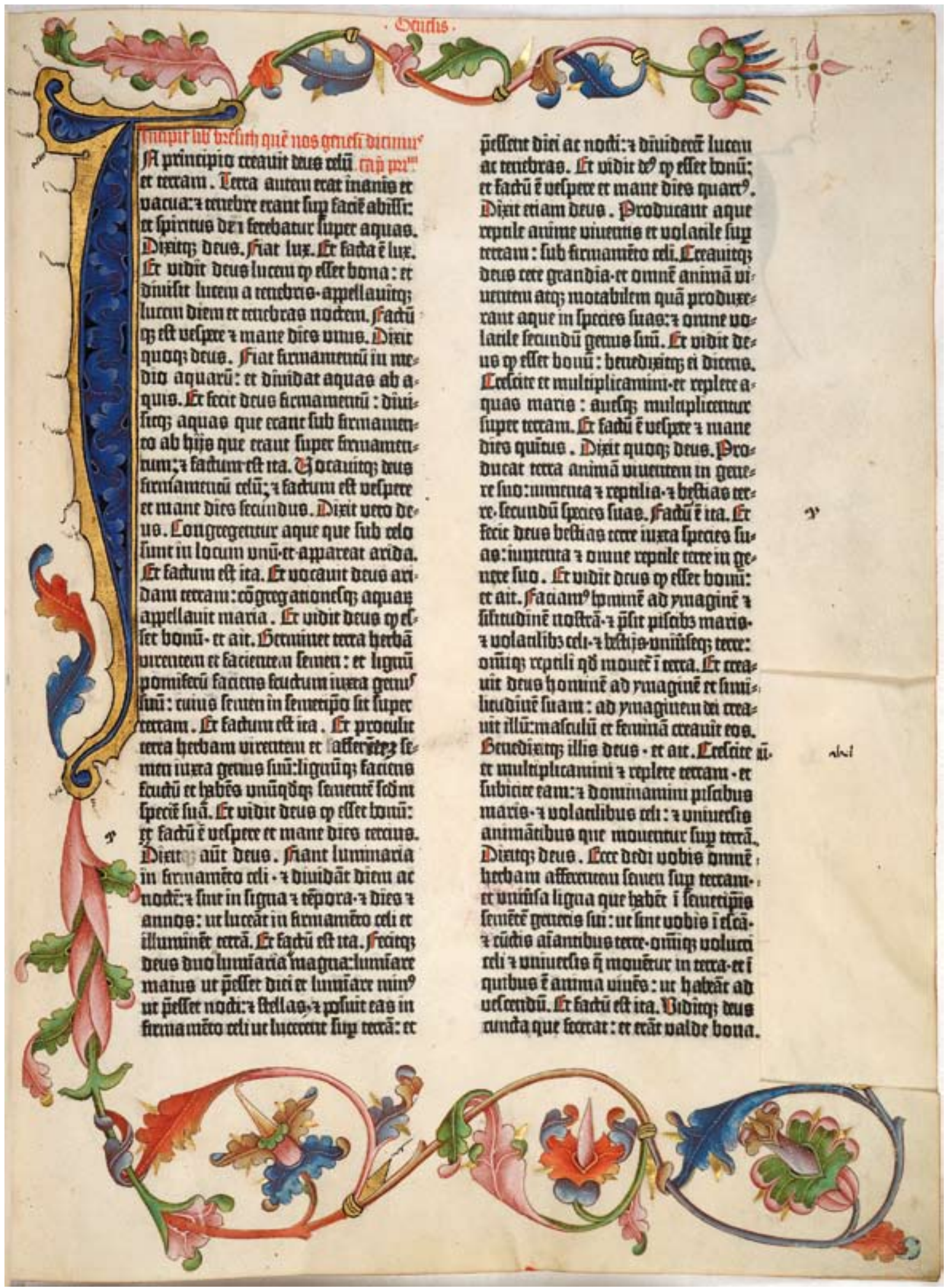




\section{Bibeldruck und Buchschmuck: das Göttinger Musterbuch}

Göttinger Musterbuch.

Pergamenthandschrift, um 1450.

Signatur: $8^{\circ}$ Cod. Ms. Uff. $51 \mathrm{Cim}$.

Provenienz: Johann Friedrich Armand von Uffenbach, 1769/70

Das Göttinger Musterbuch ist ein Malerbuch für die Herstellung von Laubwerk, Initialen und gemusterten Gründen in verschiedenen Farbzusammenstellungen. Der in dieser Handschrift von nur 22 Seiten Umfang erläuterte Buchschmuck findet sich in der Zeit des frühesten Buchdruckes in mehreren Gutenbergbibeln, darunter auch im Göttinger Exemplar der B 42. Vorgestellt werden nur ornamentale und florale Verzierungen, Anleitungen für die Gestaltung von Hintergrund und Ausmalung von Initialen, aber keinerlei figürliche Darstellung von Tieren oder Menschen. Eine Besonderheit besteht darin, dass in einer Abfolge von Abbildungen der allmähliche Arbeitsfortschritt an Beispielen gezeigt und auch textlich beschrieben wird. Originell ist das Musterbuch nicht. Seine Vorschläge zur Illumination entsprechen ganz dem üblichen Kanon dekorativer Elemente. Seine Aufgabe bestand aber auch nicht darin, innovativ zu sein, vielmehr sollte es Konventionen und Ratschläge der technischen Umsetzung vermitteln. Und genau das tat es in beachtlich hoher Qualität und größtmöglicher Klarheit. So beginnt etwa der Text zur Verwendung von Mennige (Bleioxid) und Purpur auf der Mitte der linken Seite: Beide Farben sollen auf einem mit Blei und einer Feder vorgezeichneten Blatt verwendet werden, eine Farbe für die Oberseite, die andere für die Unterseite. Als nächster Schritt seien die Blattkonturen und -strukturen einzuzeichnen, danach die Schatten durch Auftrag von verdünntem Rot. Abschließend könnten mit Weiß und Gelb die Lichter gesetzt werden.
Mit seinen Qualitäten ist das Musterbuch ein einzigartiges Dokument zur Buchgeschichte und Geschichte der Buchkultur des 15. Jahrhunderts. Es ist sehr wahrscheinlich, dass dieses Musterbuch, zu dem nur eine einzige Parallelhandschrift bekannt ist, als Vorlage für die Ausschmückung des Göttinger Exemplars der Gutenbergbibel (und weiterer Bücher) gedient hat (s. Nr. 17). Mit seinen recht exakten Anweisungen zur Gestaltung und Intensivierung von Farben hat das Musterbuch überdies eine bedeutende Rolle für die Erforschung der Techniken der mittelalterlichen Buchmalerei gespielt, die in einem gemeinsamen Projekt der Deutschen Forschungsgemeinschaft und der Volkswagen-Stiftung in Göttingen untersucht wurden.

(HK/JM) 


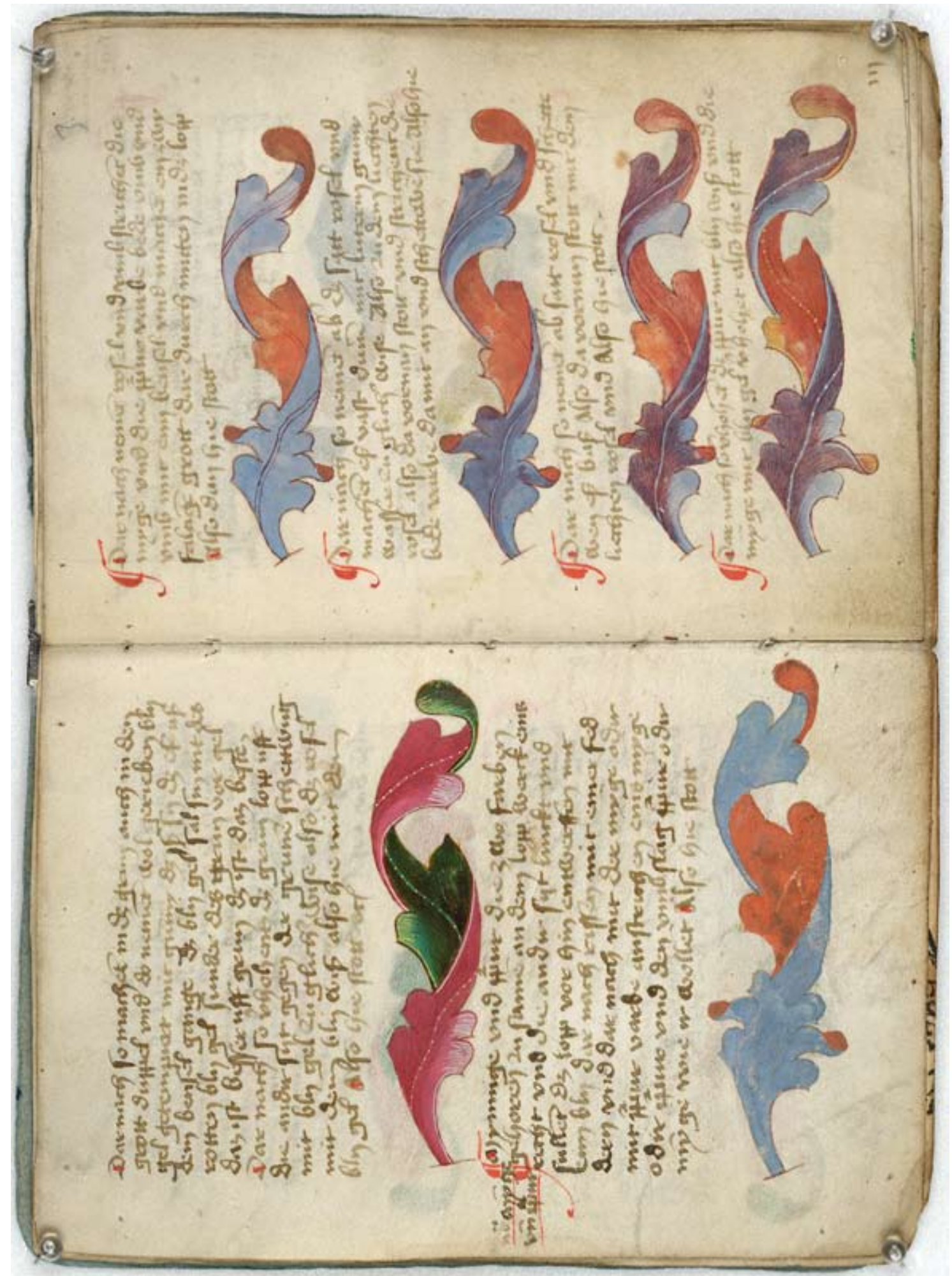




\section{Das Fuldaer Sakramentar - Göttingens wertvollste Handschrift}

Sacramentarium Fuldense.

Pergamenthandschrift, Fulda um 975.

Signatur: $2^{\circ}$ Cod. Ms. theol. $231 \mathrm{Cim}$.

Provenienz: Universitätsbibliothek Helmstedt, 1812

Sakramentare sind liturgische Handschriften der römischen Kirche, die die Gebete und sonstige heilige Texte enthalten, die während eines Gottesdienstes von dem Vorsteher der Messe verlesen wurden. Unter Karl dem Großen wurde der von Papst Gregor I. (540-604) geschaffene Sakramentartypus, das Sacramentarium Gregorianum, in die fränkische Kirche eingeführt. Wegen ihres Inhalts und ihrer sakralen Funktion zählen die Sakramentare zu den prächtigsten illuminierten Handschriften des frühen und hohen Mittelalters.

Auch im Fuldaer Sakramentar findet sich reichhaltiger Buchschmuck: goldene Unzialschrift, abwechselnd auf purpurnem und blauschwarzem Untergrund, nahezu 500 Initialen, bestehend aus goldenem oder farbigem Rankenwerk auf blauem oder grünem Grund, und mehr als 30 überwiegend ganzseitige Miniaturen, die Szenen aus dem Neuen Testament, aus Heiligenviten sowie von liturgischen Handlungen darstellen. Die Prachthandschrift gilt mit Recht als das Hauptwerk der Fuldaer Schreib- und Malschule, aus der neben dem Kilians-Margarethen-Kodex in Hannover der Kodex Wittekindeus in Berlin sowie die Sakramentare in Bamberg, in Udine und im Vatikan hervorgingen. Das Fuldaer Sakramentar ist eines der wichtigsten Denkmäler der ottonischen Buchmalerei und gleichzeitig eine der bedeutendsten Quellen zum Verständnis der Liturgie des hohen Mittelalters. Die aufwändige bildliche Ausstattung der Handschrift, an deren Ausschmückung vermutlich vier Buchmaler beteiligt waren, zeigt sich unter anderem in den Purpurzierseiten (z.B. Pater Noster, Agnus Dei) und in den Illustrationen zu den Festen des Kirchenjahres (Allerheiligen, Pfingsten). Am Ende der Handschrift findet sich ein Kalendarium, das mit einer ganzseitigen Jahresdarstellung abgeschlossen wird. Die konzentrisch angeordneten Elemente zeigen die zwölf Monate, die vier Jahreszeiten, die Elemente Feuer, Wasser, Erde, Luft und im Zentrum eine Darstellung des römischen Jahresgottes Annus, der mit Sonne und Mond versehen ist. Die Entstehung des Sakramentars im Kloster Fulda belegen die häufigen Erwähnungen des Heiligen Bonifatius und des Ortes im Text sowie der paläographische Befund, der eine besonders enge Verwandtschaft mit dem Kilians-Margarethen-Kodex in Hannover erkennen lässt.

Um die Mitte des 16. Jahrhunderts ist die Handschrift im Besitz des lutherischen Theologen Matthias Flacius, genannt Illyricus (1520-1575), nachweisbar, und etwa um das Jahr 1600 muss sie im Besitz der 1576 gegründeten Universität Helmstedt gewesen sein. Nach Auflösung der Universität unter König Jérôme Bonaparte gelangte sie wie die Gutenbergbibel in den Besitz der Göttinger Bibliothek. 


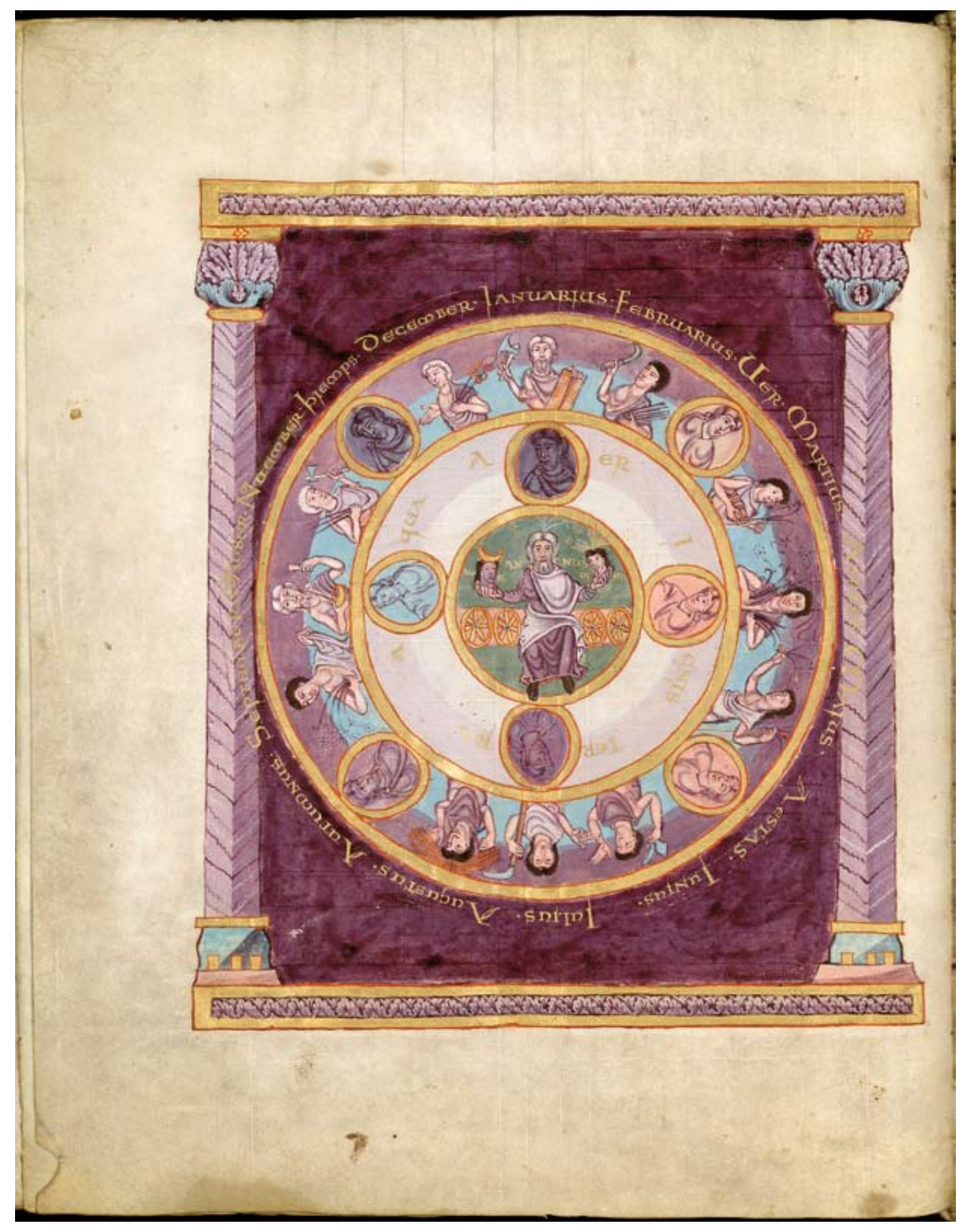




\section{Das erste gedruckte Buch mit mathematischen Figuren}

Euklid:

Elementa geometriae, lateinisch.

Venedig: Erhard Ratdolt, 25. V. 1482.

Signatur: $4^{\circ}$ Auct. Gr. IV, 3743 Inc.

Provenienz: Stadtbibliothek Nürnberg, 1777/78

Die Elemente der Geometrie sind das älteste mathematische Lehrbuch der Welt, das noch heute im Gebrauch ist. Sein Verfasser war der in Alexandria lebende Mathematiker Euklid (um 365-um 300 v. Chr.), der das gesamte mathematische Wissen der Griechen seit Pythagoras in ein System brachte, bei dem jedes Theorem logisch aus dem vorhergehenden abgeleitet wird. Die dreizehn Bücher der Elemente behandeln die Geometrie der Flächen $(1-4)$, die Verhältnislehre nach Eudoxos und ihre Anwendungen (5-6), die Zahlentheorie (7-9), quadratische Irrationalität (10) und schließlich die Geometrie der Körper (11-13). Das grundlegende Werk wurde im frühen Mittelalter ins Arabische übersetzt. Seine Verbreitung im Abendland basierte auf lateinischen Übersetzungen dieser arabischen Fassungen, die von Adelard von Bath (um 1150) und von J. Campanus (um 1260) angefertigt wurden. Die von Campanus herausgegebene Version liegt auch dem Erstdruck zugrunde, den Erhard Ratdolt (1442-1528) 1482 in Venedig veröffentlichte. Erst im 19. Jahrhundert gelang es, einen Teil der von Euklid durch bloße Anschauung gewonnenen Voraussetzungen zu analysieren. Die entscheidende axiomatische Neugestaltung der Euklidschen Mathematik vollzog der Göttinger Mathematiker David Hilbert (1862-1943) in seinem Werk über Die Grundlagen der Geometrie (1899), in dem er ein vollständiges System voneinander unabhängiger Axiome aufstellte.
Erhard Ratdolt, der Sohn eines Augsburger Holzbildhauers, ließ sich 1476 in Venedig nieder, wo er eine der bedeutendsten Offizinen der Stadt begründete. Er wurde bekannt als Drucker mathematischer und astronomischer Werke, vor allem von Johannes Regiomontanus (Johannes Müller aus Königsberg in Franken), der selbst als Drucker wirkte. Ratdolt übernahm vermutlich von Regiomontanus eine wichtige Neuerung im Inkunabeldruck: einzigartige Initialen (weiße Buchstaben auf schwarzem Grund, von Rankenwerk umschlungen), Tiefschnittumrahmungen und Zierleisten. Die Zierelemente sind in ihrer äußeren Form ganz dem Stil der italienischen Renaissance verhaftet. Euklids Elemente zeigen auf ihrem ersten Blatt eine weitere Neuerung Ratdolts: Die Erstausgabe ist das erste gedruckte Buch mit Holzschnitten mathematischer Figuren. Ratdolt kehrte im Jahre 1486 nach Augsburg zurück. 


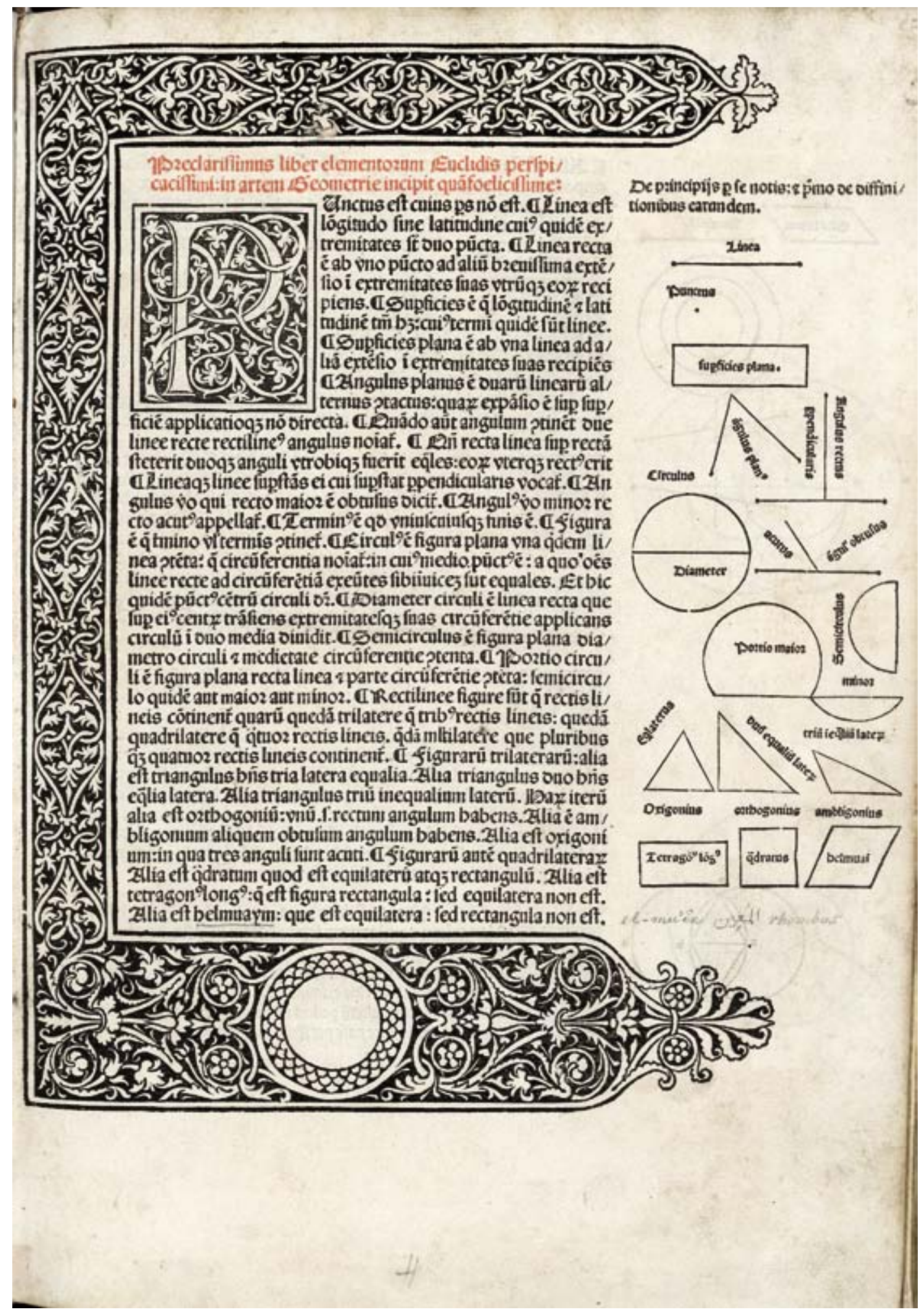




\section{Tycho Brahes Widmungsexemplar für Kaiser Rudolph II.}

Tycho Brahe:

Astronomiae instauratae mechanica.

Wandsbek: Philip von Ohrs, 1598.

Signatur: $2^{\circ}$ Cod. Ms. philos. 28 Cim.

Provenienz: Schulbibliothek Hildesheim, 1816

\section{Ein Geschenk für Herzog Heinrich Julius}

Tycho Brahe:

Stellarum octavi orbis inerrantium accurata restitutio.

Papierhandschrift, Wandsbek 1598.

Signatur: $2^{\circ}$ Cod. Ms. philos. 28a Cim.

Provenienz: Schulbibliothek Hildesheim, 1816

Der Däne Tycho Brahe (1546-1601) gehört zu den berühmtesten und verdienstvollsten Astronomen der frühen Neuzeit. Aufgrund seiner Beobachtungen und Tafeln gilt er gemeinsam mit Kopernikus, Kepler und Galilei als Mitbegründer der modernen Astronomie. Bereits als Student der Jurisprudenz erwachte Brahes Interesse an der Astronomie. 1572 wies er bei der Beobachtung eines ,neuen Sterns“ im Sternbild Cassiopeia nach, dass sich der neue Himmelskörper außerhalb der Mondbahn befinden muss. Da der dänische König Frederik II. Brahes Forschungen finanziell unterstützte, konnte der Astronom 1576 die damals größte europäische Sternwarte Uraniborg und die Sternwarte Stjerneborg errichten, die sich noch heute auf der dänischen Insel Ven (damals Hven) befindet. In den darauf folgenden 20 Jahren führten Brahe und seine Mitarbeiter eine große Zahl präziser, rein visueller Positionsmessungen der Gestirne durch. Differenzen mit dem neuen dänischen König Christian II. veranlassten ihn, Dänemark zu verlassen. Nach einem zweijährigen Aufenthalt beim Grafen Rantzau in Wandsbek trat er als Kaiserlicher Astronom in die Dienste Rudolphs II. ein. Brahes Astronomiae instauratae mechanica (Nr. 21) erschien 1598 in Wandsbek bei
Hamburg. Das Buch enthält eine illustrierte Beschreibung des Baus und der Handhabung der wichtigsten auf Ven neu gebrauchten Instrumente. Außerdem beinhaltet es einen kurzen Lebenslauf Brahes, eine Zusammenstellung seiner verschiedenen Forschungsarbeiten auf Ven, eine Beschreibung der Insel sowie Pläne und Ansichten der Sternwarten. Das Buch schließt mit einer Erörterung der verbesserten Visiere und der Transversalteilung (Schrägteilung der Messskala) der Instrumente. Diesen Druck und die Handschrift mit dem Titel Stellarum octavi orbis inerrantium accurata restitutio (Nr. 22) widmete er 1599 Kaiser Rudolph II. Gleichzeitig sandte er beide Bände an Heinrich Julius, Herzog zu BraunschweigLüneburg (1564-1613). Ein aufwändiger grüner Seideneinband, in den auf dem vorderen Deckel Brahes Bildnis eingeprägt ist, die sorgfältige Kolorierung, das Kupferstichporträt Brahes und seine eigenhändige Unterschrift zeigen den besonderen Charakter der beiden Geschenke für einen adligen Gönner. Heinrich Julius hat sie vermutlich der Gymnasialbibliothek in Hildesheim übergeben, von wo aus sie 1816 in den Göttinger Bestand übergingen.

(KN/HR) 


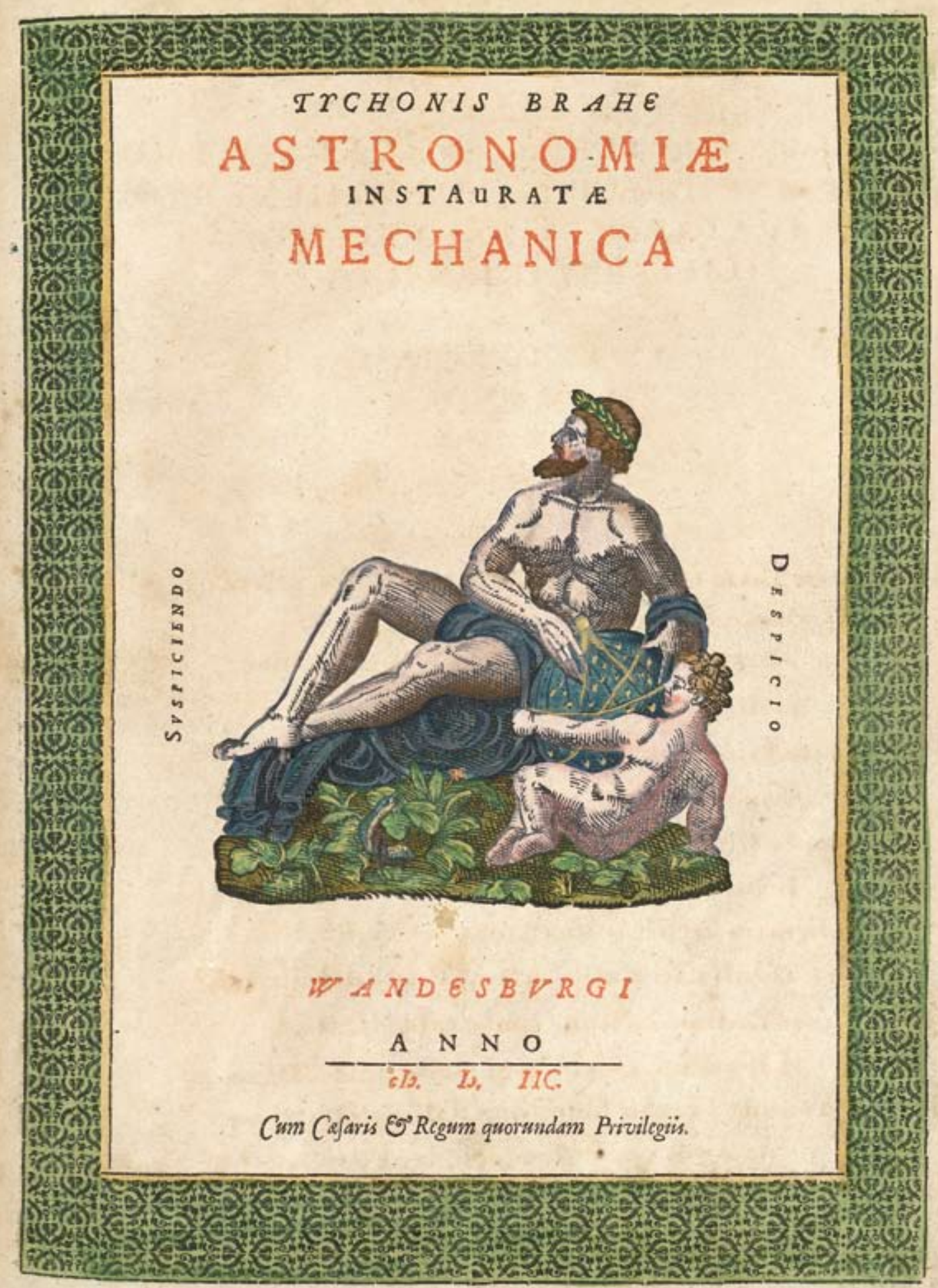




\section{Jüdische Geschichte in einem Lübecker Druck}

Flavius Josephus:

De bello Iudaico, Antiquitates iudaicae, lateinisch.

Lübeck: Lukas Brandis, um 1475.

Signatur: $2^{\circ}$ Auct. Gr. V, 2145 Inc.

Provenienz: Alexanderstift Einbeck, 1831

Joseph ben Mathijahu (37/38-ca. 100)

stammte aus einer hoch angesehenen Familie in Jerusalem. Während des jüdischen Aufstandes gegen die römische Besatzung wurde er im Jahre 67 gefangengenommen und diente seitdem den Römern als Ratgeber u.a. bei der Belagerung seiner Vaterstadt. Nach der Eroberung Jerusalems ging Joseph mit Vespasians Sohn Titus nach Rom. Erst jetzt erhielt er den römischen Namen Flavius, zusammen mit dem römischen Bürgerrecht. Seine Loyalität gegenüber den Kaisern in Rom sicherte ihm ein gutes Auskommen, während er allerdings in der Heimat seinen Kredit verspielt hatte. In Rom, wo er bis zu seinem Lebensende blieb, schrieb er im Bellum Iudaicum zunächst über den jüdischen Kampf gegen die Fremdherrscher und seine eigenen Kriegserfahrungen. Anschließend verfasste er ein Kompendium zu jüdischen Sagen und jüdischer Kultur: die Antiquitates Iudaicae. Josephus hat seine jüdischen Wurzeln niemals verleugnet, aber mit griechischer und römischer Tradition und Kultur verbunden. Seine Leistung als Historiker ist beachtlich. Als glaubwürdige und verlässliche Quelle zur jüdischen Geschichte genoss er bereits im Mittelalter und in der Frühen Neuzeit hohes Ansehen. Seine Werke konnten nach der Erfindung des Buchdrucks noch weiter verbreitet werden und gehörten im Humanismus zu den nach der Bibel am häufigsten aufgelegten Texten.

Der Drucker des gezeigten Werkes, Lukas Brandis (1450-nach 1500), stammte aus einer Familie von Buchdruckern (sowohl der Vater Markus als auch seine Brüder Moritz und Matthäus gingen diesem Gewerbe nach) und war der erste Drucker, der sich in Lübeck niederließ. Lukas hatte seit 1465 in Leipzig studiert und in der Offizin von Johannes Fust und Peter Schöffer in Mainz den Buchdruck erlernt. Über Merseburg ging er nach Lübeck, wo er bis 1478 blieb. Wie aus einer zeitgenössischen Werbeanzeige zu entnehmen ist, muss er um 1478 sechzehn verschiedene Drucke im Angebot gehabt haben. Insgesamt druckte Brandis in den fünf Jahren seines Aufenthaltes in der Hansestadt mindestens 45 Bücher, löste dann aber seine Werkstatt auf und ging nach Magdeburg, wo er als Typograph an der Herstellung mehrerer Messbücher beteiligt war. Als er um 1483 wieder nach Lübeck zurückkehrte, gelang es ihm nicht, an seine wirtschaftlichen Erfolge der Anfangsjahre anzuknüpfen. Um 1500 befand er sich wie so viele seiner Berufskollegen nachweislich in wirtschaftlichen Schwierigkeiten, später verliert sich seine Spur.

Die Abbildung zeigt den Beginn des Vorwortes zum Bellum Iudaicum in einem Sammelband mit den beiden Hauptwerken des Josephus in einer lateinischen Übersetzung von Rufinus Aquileiensis. 


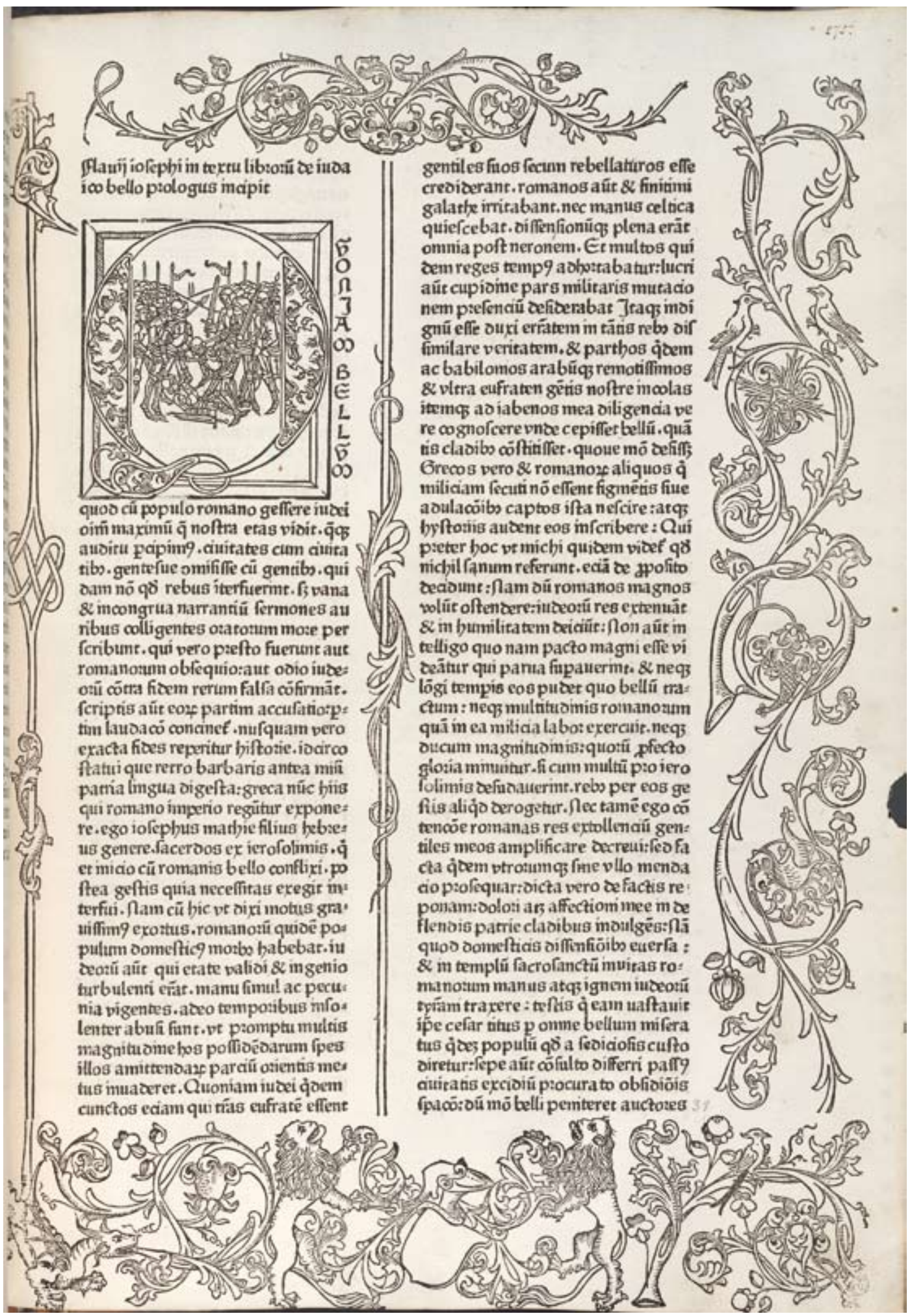




\section{Eine Abhandlung über Verwandtschaftsverhältnisse}

Stephanus Costa:

Tractatus de consanguinitate et affinitate. Pavia: Martinus de Lavalle, 3. VIII. 1489.

Signatur: $2^{\circ}$ Jus Canon. 33/65 Inc.

Provenienz: Alexanderstift Einbeck, 1831

Von Stephanus Costa wissen wir nicht sehr viel mehr, als dass er Jurist für kanonisches Recht in Pavia war. Die Schlussschrift seines kurzen Traktates über Blutsverwandtschaft und Verwandtschaftsbeziehungen, gedruckt 1489 an seiner Wirkungsstätte, nennt ihn immerhin ,subtilissimus“, also sehr scharfsinnig. Auf der Abbildung sind in graphischer Form die Bezeichnungen von Blutsverwandten und die Grade ihrer Verwandtschaftsbeziehung wiedergegeben. Ausgangspunkt ist das nicht ausgefüllte Feld in der Mitte. Von dort ausgehend sind nach unten die Nachkommen dargestellt: Tochter bzw. Sohn (filius, filia), Enkel (nepotes) usw. Nach oben reicht die Reihe der Vorfahren, beginnend mit den Eltern (pater, mater), den Großeltern (avus, avia) usw. Nach den Seiten folgt die Auflistung der nach Lebenszeit jeweils am nächsten stehenden Verwandten. Auffallend ist, dass es im lateinischen Sprachgebrauch schon seit der Antike sehr viel mehr Differenzierungsmöglichkeiten gab als in der heutigen Praxis geläufig (und erforderlich). Wo etwa die Geschwister der Eltern heute summarisch als Onkel und Tante bezeichnet werden, kennt das Lateinische die Unterscheidung nach Geschwistern des Vaters und denen der Mutter: Erstere sind patruus und amita, letztere avunculus und matertera.
Der Text des Rechtsgelehrten umfasst insgesamt nur zehn Blätter und ist mit drei anderen juristischen Abhandlungen zusammengebunden, die sämtlich aus dem Venedig der 90er Jahre des 15. Jahrhunderts stammen. Die Verzierungen des Einbandes - Streicheisenlinien und blind geprägte Stempel - verweisen auf eine Erfurter Buchbinderwerkstatt. 


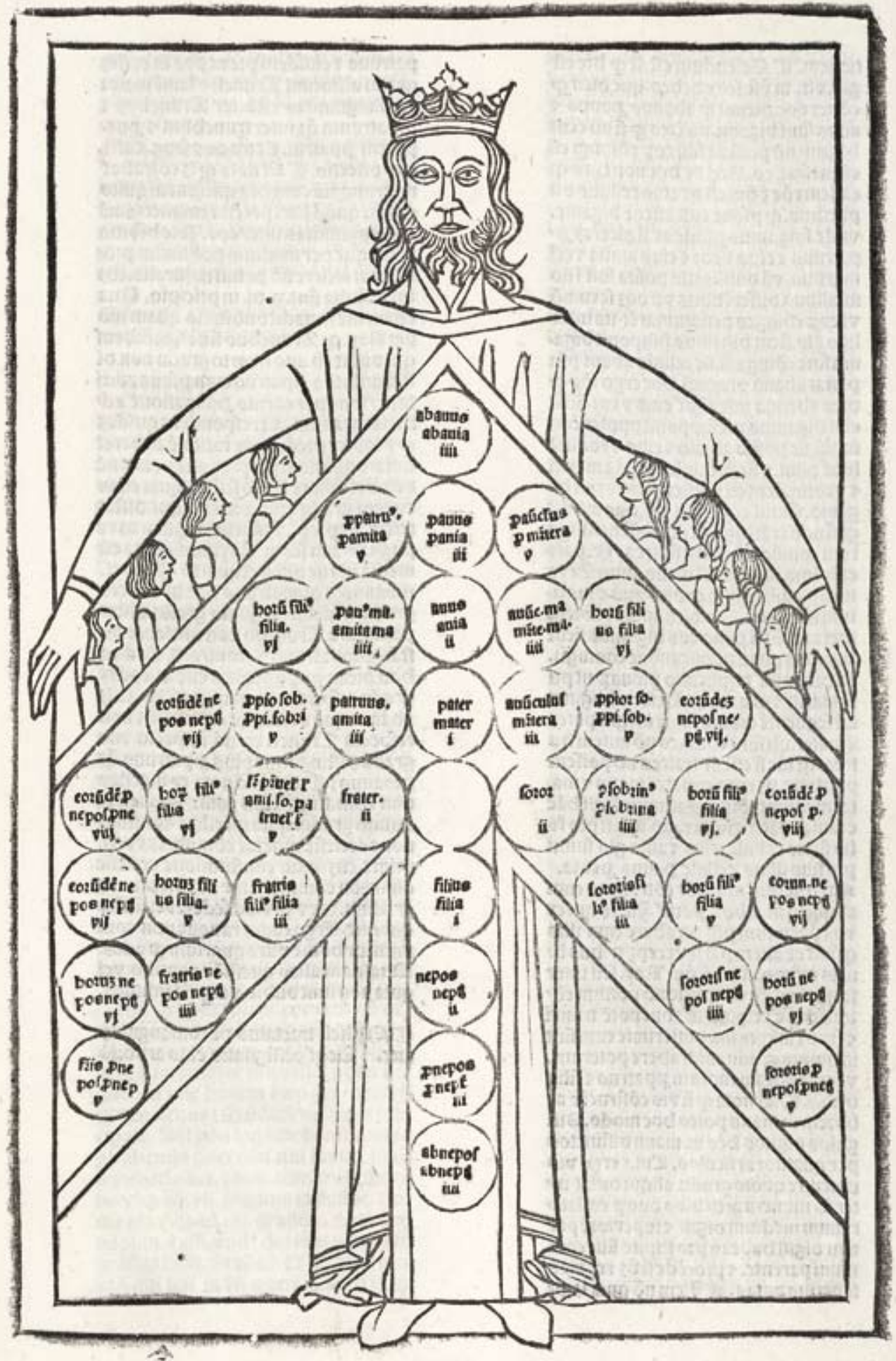




\section{5 Über das richtige Beichten und Büßen}

Libellus de modo confitendi et penitendi. Deventer: Jacobus de Breda, 11. VI. 1491. Signatur: $8^{\circ}$ Theol. Mor. 122/41 Inc. Provenienz: Alexanderstift Einbeck, 1831

Der Text dieses anonym erschienenen Beichtund Bußbüchleins war im 15. Jahrhundert weit verbreitet und kursierte in mehreren Ausgaben. In Deventer war Richard Paffraet der erste Drucker des Werkes, nach ihm druckte Jacobus de Breda mehrere Auflagen der kurzen Abhandlung über das rechte Verhalten beim Büßen und Beichten. Aus seiner Werkstatt stammt auch dieses Exemplar. Vor den Beginn des Textes hat der Drucker eine Abbildung des Heiligen Lebuin gesetzt, der u.a. auch Schutzheiliger der Stadt Deventer war. Lebuin kam im 8. Jahrhundert als Missionar aus England nach Utrecht und begann von dort aus mit der Missionierung der Friesen und Sachsen. In Deventer baute er die erste Kirche, hatte aber mit dem zunehmenden Widerstand der Germanen zu kämpfen. Wirklich durchsetzen konnte er den neuen Glauben nicht; nach wenigen Jahren wurde er von wütenden Sachsen getötet und in Deventer bestattet. Neben seinem Schutzpatronat für die Stadt wurde ihm auch eine besondere Sorge für die Sterbenden zugeschrieben.

Schon seit dem frühen Mittelalter gab es Bußbücher in der Form, dass je nach Vergehen ganz kasuistisch ein differenzierter Strafenkatalog vorgelegt wurde. Vielleicht liegt ein zweiter Grund für die Abbildung des Heiligen Lebuin vor dem Text darin, dass derartige Traktate ursprünglich aus England und Irland kamen? Ausführungen dieser Art enthält der kleine Libellus allerdings nicht. Vielmehr versucht er, das Empfinden der Zeitgenossen für den Sinn von Buße und Strafe und die Begleitumstände zu schulen. So wird etwa die
Tötung eines anderen Menschen nach Ansicht des Verfassers durch Trunkenheit nicht entschuldigt. Wenn schon nicht die Tat selbst gewollt gewesen sein möge, so sei es doch sicher der Entschluss zum Trinken gewesen, so dass die Schuld eher vermehrt denn verringert werde. 


\section{Jincipit libell9 oe mõ cõfitêdí et.penitendi}

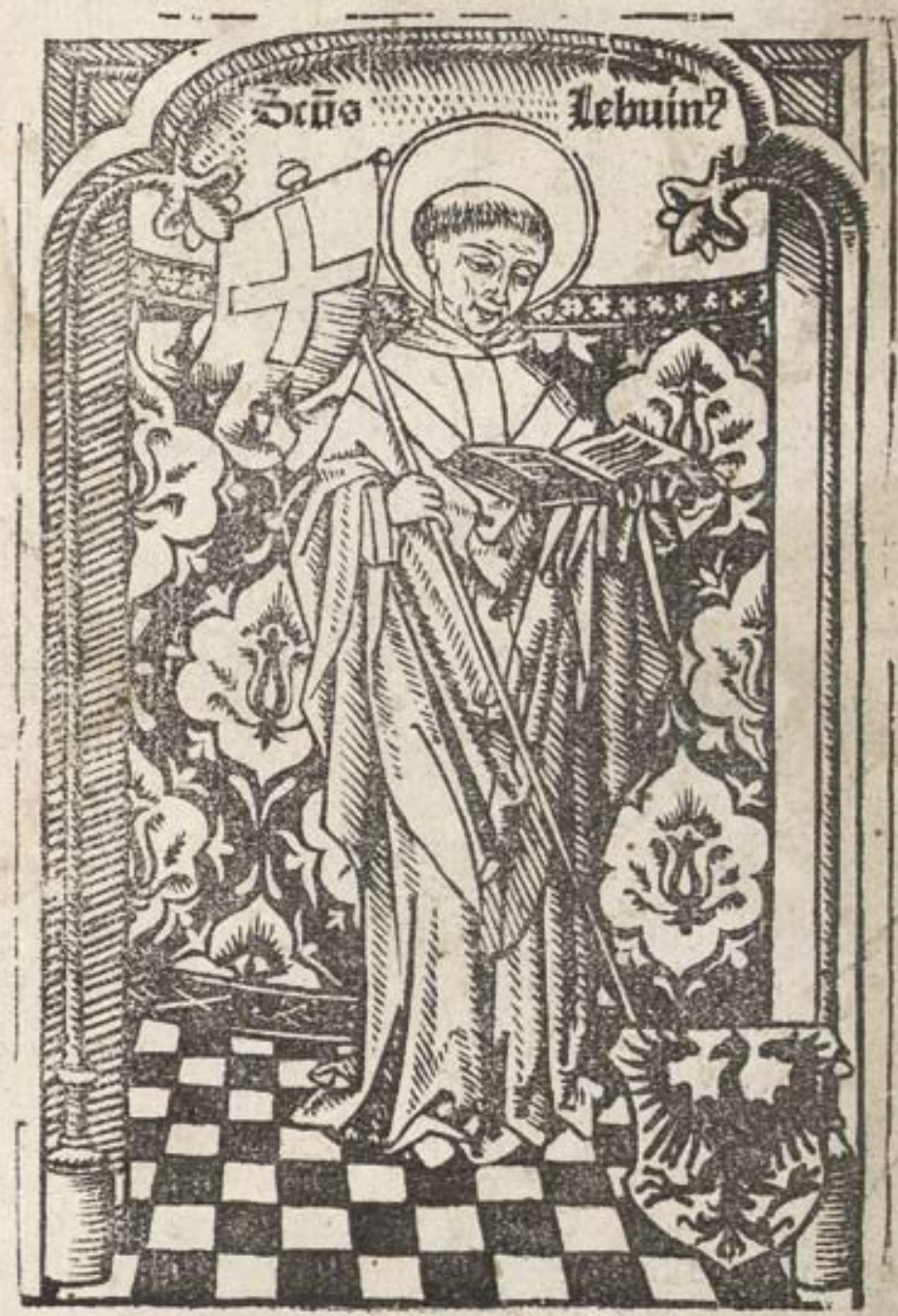




\section{Briefe des Tyrannen?}

Pseudo-Phalaris:

Briefe, lateinisch.

Leipzig: Jacob Thanner, 31. V. 1498.

Signatur: $8^{\circ}$ Auct. Gr. II, 3506 Inc.

Provenienz: Alexanderstift Einbeck, 1831

Berühmte Legenden und Erzählungen ranken sich um die Gestalt des Tyrannen Phalaris, der im sechsten vorchristlichen Jahrhundert in der sizilischen Stadt Akragas (Agrigent) herrschte. Kurz nach der Gründung der Stadt um 580 durch griechische Kolonisten schwang sich Phalaris während eines Festes zum Tyrannen auf und führte der Überlieferung nach ein grausames Regiment. Ob ihm diese Charakterisierung gerecht wird oder ob auch hier wie so oft bei der Beurteilung der älteren Tyrannis die in der späteren Literatur gängigen Topoi vorherrschen, sei dahingestellt. Immerhin förderte Phalaris die Kunst und Philosophie, auch wenn die bekannteste Erzählung, die sich mit seinem Namen verbindet, ein ganz anderes Bild vermittelt. Der Tyrann soll dem Künstler Perillos den Auftrag erteilt haben, einen ehernen, im Inneren hohlen Stier herzustellen, um darin seine Feinde lebendig rösten zu können. Perillos soll der erste gewesen sein, der auf diese Weise den Tod fand. Angeblich hätten die Schreie der Sterbenden von außen wie das Gebrüll des Stieres geklungen. Die Geschichte könnte auf zwei historisch gesicherte Tatsachen verweisen, einerseits auf die Herkunft des Phalaris aus Kreta (kretischer Stier), andererseits auf Kontakte zwischen Akragas und Karthago in Nordafrika, wo Menschenopfer auf ganz ähnliche Weise dargebracht wurden.

Welchen Charakter auch immer Phalaris gehabt haben mag, die Briefe, die in einer kleinen Sammlung unter seinem Namen kursierten und die im hier gezeigten Druck ediert wurden, hat er nicht geschrieben. Am Ende des 17. Jahrhunderts entlarvte der englische Gelehrte Richard Bentley (1662-1742) die Texte als Fälschung: Sie sind in attischem Griechisch geschrieben, nicht im sizilischdorischen Dialekt, den Phalaris gesprochen haben muss. Zudem werden Städte erwähnt, die zu Phalaris' Lebzeiten noch gar nicht existierten. Die Briefe stammen vermutlich von einem Sophisten des zweiten Jahrhunderts. All das wussten aber weder Franciscus Aretinus, als er die lateinische Übersetzung anfertigte, noch der Leipziger Drucker Jacob Thanner, als er das Buch 1498 produzierte. 


\section{Ifpitale Shalatiois pet Frattif́ctutatetimumttra intrtt.}

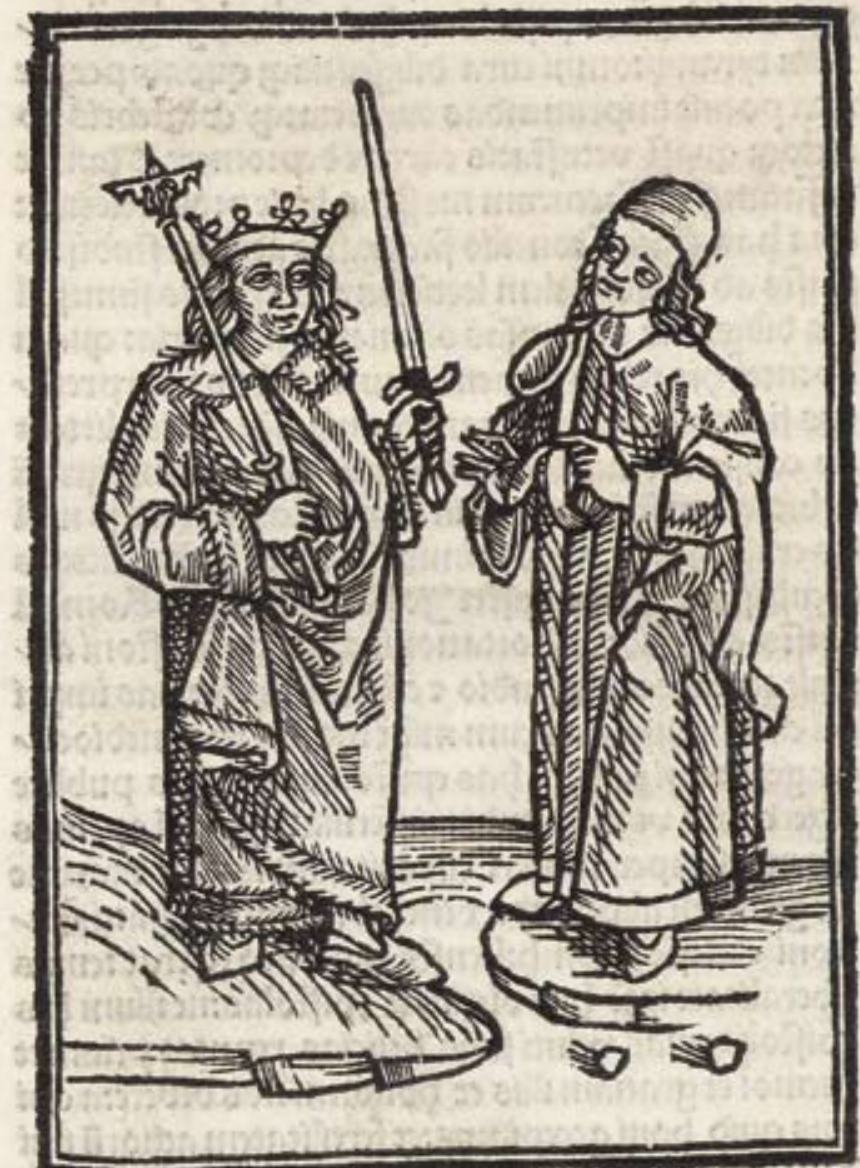




\section{Die Offenbarungen der Heiligen Birgitta}

Birgitta:

Revelationes.

Daran: Vita abbreviata S. Birgittae.

Lübeck: Bartholomäus Ghotan, 1492.

Signatur: $4^{\circ}$ Hist. eccl. Sanct. 176/32a Inc.

Provenienz: Michaeliskloster Lüneburg, 1853

Die als Birgitta Birgersdotter geborene Birgitta von Schweden (um 1303-1373) war die Tochter des Lagmanns von Uppsala. Bereits im Kindesalter hatte sie religiöse Visionen. Als 13-jährige heiratete sie den späteren Lagmann von Närke Ulf Gudarsson, dem sie acht Kinder gebar. Nach dem Tod ihres Ehemannes 1344 erfuhr sie immer häufigere Offenbarungen. Mehr als 600 Visionen wurden von ihrem Sekretär festgehalten, später aus dem Schwedischen in verschiedene Sprachen übersetzt und verbreitet. $\mathrm{Zu}$ ihnen gehörte der himmlische Auftrag zur Gründung des Birgitten- oder Erlöserordens. 1349 reiste Birgitta nach Italien, um die päpstliche Anerkennung ihres Ordens zu erwirken, die jedoch erst nach ihrem Tod, im Jahre 1378, erfolgte. Birgitta wurde 1391 heiliggesprochen. Sie wird heute als Schutzheilige Schwedens und seit 1998 als Patronin Europas verehrt.

Der lateinische Text der Revelationes basiert auf einer Übersetzung aus dem Schwedischen, die von Birgittas Beichtvätern angefertigt wurde. Birgitta beschreibt, wie sich Gott, Jesus Christus, die Jungfrau Maria und verschiedene Heilige ihr offenbarten. Außerdem berichtet sie als Zeugin von Gesprächen anderer, etwa von einem Dialog Christi mit einem ketzerischen Mönch. Schließlich finden sich in der Sammlung an verschiedene Personen gerichtete Briefe und Botschaften. Das durchgehende Thema der Revelationes aber ist ihre Kritik am moralischen Verfall der Kirche. Den Erstdruck besorgte der Lübecker Drucker Bartholomäus Ghotan im Jahre 1492 für das Kloster Vadstena am Wettersee, das

\begin{abstract}
Mutterkloster des Birgittenordens. Er hatte bereits um 1485 in Lübeck eine niederdeutsche Fassung der Revelationes gedruckt; 1486 und 1487 ist er als Drucker in Stockholm nachweisbar. Ghotans weitreichende internationale Beziehungen sind ihm möglicherweise zum Verhängnis geworden: In zeitgenössischen Quellen wird berichtet, dass er vom Großfürsten Iwan II. zur Einrichtung einer Druckerei nach Moskau gerufen wurde. Vermutlich verlor er im Zusammenhang mit den Nowgoroder Unruhen das Leben. Die 23 bemerkenswerten Holzschnitte in Birgittas Revelationes sowie Ghotans großformatige figürliche Initialen machen das Werk zu einem herausragenden Beispiel der norddeutschen Druckkunst.
\end{abstract}




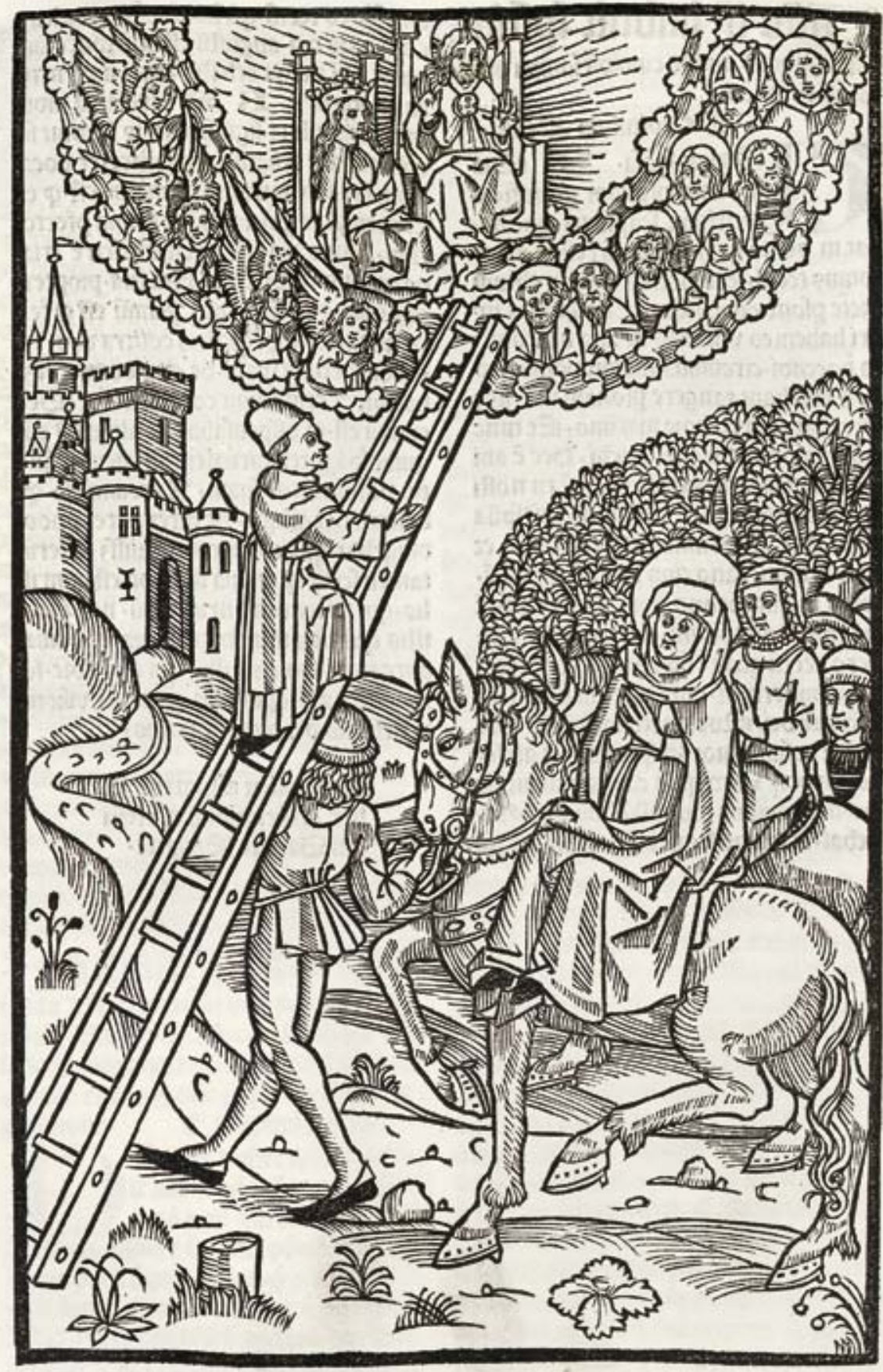




\section{Zwischen Spätrenaissance und Barock}

Wendelin Dietterlin:

Architectura: de constitutione symmetria, ac proporzione quinque columnarum.

Nürnberg: Caymox 1598/99.

Signatur: $2^{\circ}$ Math. Arch. I, 1365 Rara

Provenienz: Michaeliskloster Lüneburg, 1853

Das Werk des Straßburger Architekten, Malers und Radierers Wendelin Grapp, genannt Dietterlin (1550-um 1599), ist das wohl bedeutendste Druckwerk der deutschen Spätrenaissance. Dabei fällt die Architectura im Vergleich zu den architekturtheoretischen Arbeiten der Zeit insofern aus dem Rahmen, als Dietterlin in erster Linie Maler und nicht Architekt oder Mathematiker war. Die auf den Studien des antiken Architekturschriftstellers Vitruv basierende Säulenordnung hat Dietterlin als erster auch auf die Malerei und die angewandten Künste übertragen. Sie stellt den Rahmen für phantasievolle, reichhaltige Ornamentik dar. Ein derartiger Einfallsreichtum war singulär im ausgehenden 16. Jahrhundert und weist in seinem nahezu impressionistischen Ausdruck, in Körperlichkeit und Belebtheit voraus in die Formensprache des Barock. Die von Dietterlin ausgeführten Innenausmalungen von Gebäuden sind leider sämtlich untergegangen, doch existieren zum Teil noch Vorzeichnungen bzw. Nachstiche. Dennoch beruht Dietterlins Ruhm ganz wesentlich auf der Architectura mit ihren über 200 radierten Tafeln und den aufwändigen Entwürfen für allerlei Bauteile, Säulen, Wandgestaltungen, Portale, Tore, Grabmale, Wappen, Fenster, Kamine oder Brunnen. Zielgruppe des Werks waren Maler, für die Dietterlin Anregungen und Vorlagen bereitstellen wollte, weniger Bildhauer und Baumeister, für die die Entwürfe dann doch zu elaboriert gewesen sein dürften. In der Tat scheint Dietterlins Werk auch entsprechend rezipiert worden zu sein: Anhaltspunkte dafür gibt es in Wolfenbüttel, Bückeburg und Paderborn, aber auch in Süddeutschland. Die Editionsgeschichte der Architectura ist kompliziert und erstreckt sich über die gesamten 1590er Jahre. Die Zusammenstellung der 209 Tafeln der Endfassung scheint 1598 erfolgt zu sein, die Publikation 1598/99. Mit den zahlreichen Abbildungen ist das Buch das erste in dieser Größenordnung durch Radierung illustrierte Werk und kann - angesichts der Abnutzung der noch unverstählten Platten beim Druck nicht in einer sonderlich hohen Auflage hergestellt worden sein. Die bei der Ausführung der Drucke bewiesene kunsthandwerkliche und technische Perfektion zieht den Betrachter bis heute in ihren Bann. 


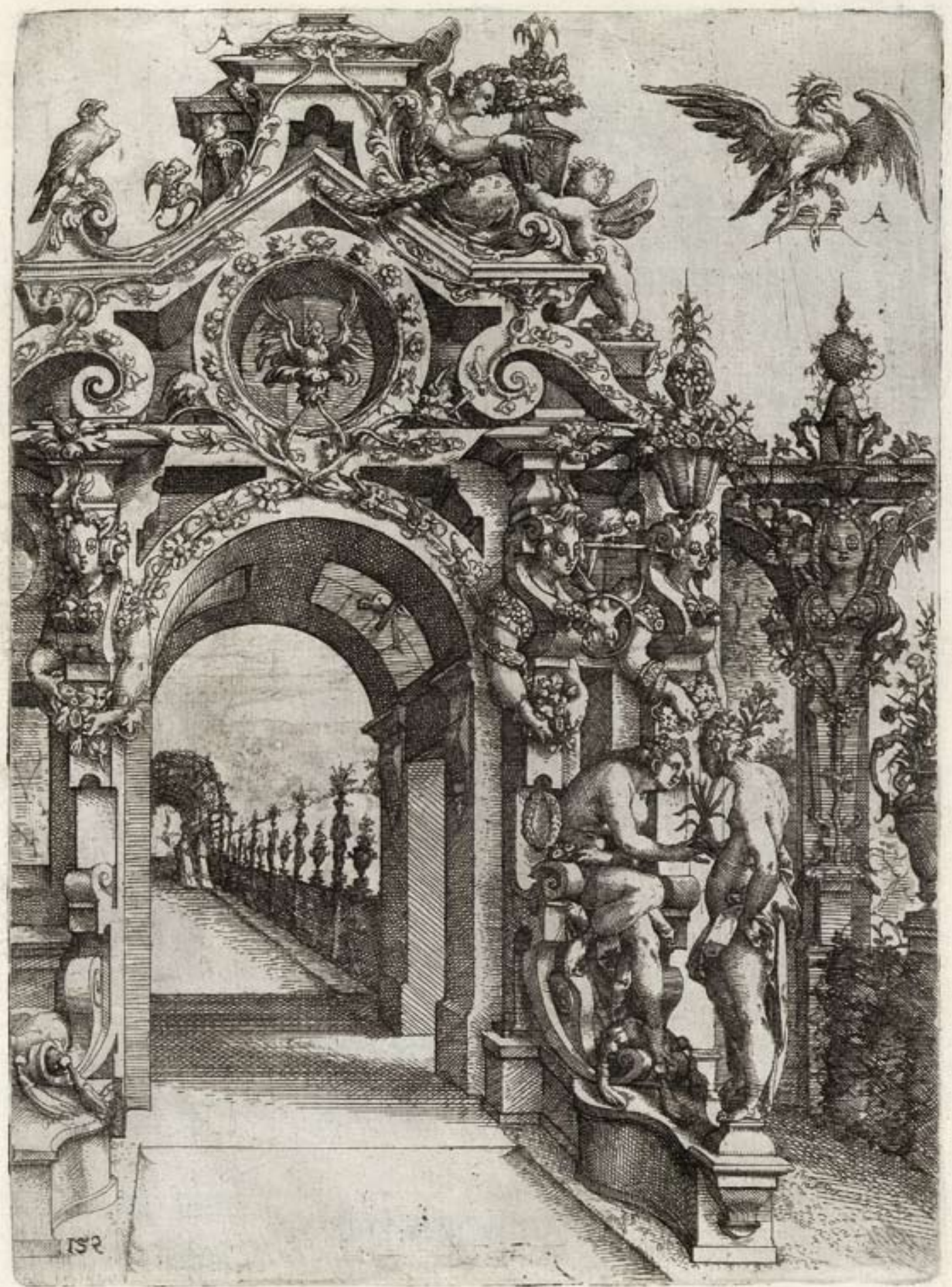




\section{Ein Standardwerk der}

\section{neuzeitlichen Architekturgeschichte}

Andrea Palladio:

I quattro libri dell'architettura.

Venedig: Franceschi, 1570.

Signatur: $4^{\circ}$ Math. Arch I, 1293 Rara

Provenienz: Michaeliskloster Lüneburg, 1853

Wohl kaum jemand wüsste etwas mit dem Namen Andrea di Pietro della Gondola anzufangen. So aber hieß der unter seinem Künstlernamen Andrea Palladio (1508-1580) berühmt gewordene Architekt eigentlich. Seine Benennung verdankte er dem Vicentiner Adeligen Giangiorgio Trissino, dessen Bekanntschaft für den jungen Palladio nicht nur wegen der Namensgebung schicksalhaft war. Bis dahin hatte Palladio das Maurer- und Steinmetzhandwerk erlernt, nunmehr kam er in den Genuss humanistischer Bildung und beschäftigte sich mit antiker Architektur und Architekturtheorie. Mehrfach hielt er sich in Rom auf und erschloss für sich die Überreste der antiken Bauten. 1554 publizierte er sein so erworbenes Wissen in einem Führer mit dem Titel Le antichità di Roma. 1556 steuerte er seine Kenntnisse für eine Ausgabe des römischen Architekturschriftstellers Vitruv bei. Der größte Wurf aber waren die vier Bücher über die Architektur, die Palladio 1570 herausbrachte. Das Wesentliche beinhalten die exakten Zeichnungen, auf wortreiche Erläuterungen verzichtete Palladio und zeigte sich so auch im Edieren als ein Praktiker, dessen Arbeit sich von der vieler Fachschriftsteller seiner Zeit abhob. Sein Thema war die Zivilbaukunst. In verschiedenen Schnitten und Aufrissen sezierte Palladio gewissermaßen jedes Gebäude und vermittelte eine bislang unerreichte Anschaulichkeit. Im vierten Buch seines Werkes beschäftigte sich der Meister mit den Bauwerken der Antike, so auch mit dem Pantheon, zu dem er u.a. nebenstehende Ansicht fertigte. Vorbildcharakter kam der antiken Hinterlassenschaft aus der Sicht des humanistisch gebildeten Architekten in mehrfacher Hinsicht zu: Dauerhaftigkeit, Zweckmäßigkeit und Schönheit waren die Eigenschaften, die es auch für die gegenwärtige Architektur wiederzugewinnen galt. Die Wirkung Palladios in der europäischen Kunstgeschichte kann gar nicht hoch genug eingeschätzt werden. Jede Epoche griff bei der Ausformulierung ihres Architekturstils immer wieder auf ihn zurück. Palladio ist in der höfischen und adeligen Baukunst ebenso anzutreffen wie in der bürgerlichen Architektur. Auch wenn sein Werk bisweilen als eine Art Musterbuch für den Architekten benutzt wurde, so beeindruckte er doch alle späteren Generationen mit der Geschlossenheit seiner Entwürfe, in der die Lösungen untereinander stimmig sind, Tradition und Innovation vereint werden, ein angemessenes und in jeder Beziehung ,passendes“ Ergebnis entsteht. 
Q V A R T O.

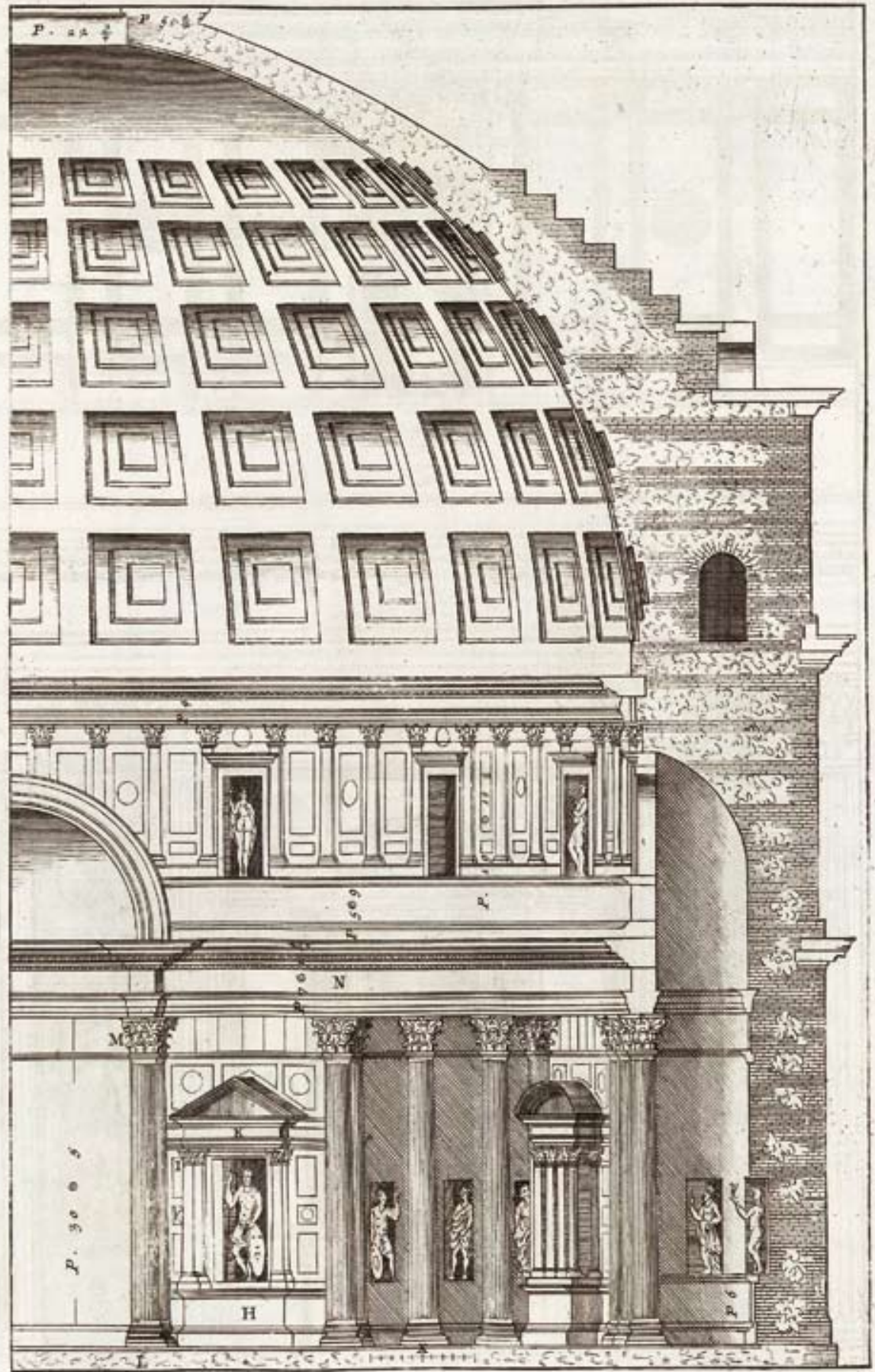




\section{Bilder von Amerika in der Frühen Neuzeit}

Johann Ludwig Gottfried:

Historia Antipodum, oder Neue Welt (und americanische Historien), das ist, Natur und Eigenschafft des halben Theils der Erden, so West-Indien genannt wird.

Frankfurt/Main: Meriansche Erben, 1655.

Signatur: $4^{\circ}$ Hist. Am. I, 310 Rara

Provenienz: Michaeliskloster Lüneburg, 1853

Das Amerikabild, die visuelle Vorstellung, welche Europäer der Frühen Neuzeit von der Neuen Welt besaßen, wurde stark von den großen illustrierten Sammelwerken des Frankfurter Verlegers und Kupferstechers Theodor de Bry (1528-1598) oder des Engländers Richard Hakluyt (um 1551-1616) geprägt. 1590 erschien bei de Bry der erste Band der Sammlung von Reisen in das westliche Indien und das östliche Indien, die bis 1630 auf 14 Bände anwuchs und die nach dem Tode de Brys von seinem Sohn Johann Theodor $(1561$ - 1623) sowie dessen Schwiegersohn Matthäus Merian d. Ä. (1593-1650) weiter herausgegeben wurde. Trotz des verlegerischen Erfolgs dieser monumentalen, mit zahlreichen illustrierten Kupferstichen versehenen Ausgabe konnten sich natürlich nur einige vermögende Sammler und größere Bibliotheken diese Bände leisten.

Aus diesem Grund beauftragte Matthäus Merian d. Ä. den calvinistischen Pastor und Gelehrten Johann Ludwig Gottfried (um 1584-1633) mit der Erstellung einer kompilierten und günstigeren Ausgabe des großen Sammelwerks de Brys. Gottfried, der nach einem Theologiestudium in Heidelberg seit 1603 als Diakon und Pastor in verschiedenen Gemeinden der linksrheinischen Kurpfalz und in Offenburg tätig war, wirkte seit 1625 als Schriftsteller und Gelehrter. Er verfasste unter anderem eine Weltchronik, die noch zu Zeiten Goethes oft gelesen wurde. Die Gottfriedsche Historia Antipodum erschien in der ersten Auflage 1631. Der hier vorliegende Nachdruck - sowie eine weitere 1663 in Nürnberg erschienene Ausgabe - zeugen vom Erfolg des Werkes. Erst die Gottfriedsche Neubearbeitung begründete die Popularisierung und breitere Rezeption der Kupferstiche de Brys.

Einer der zeitgenössischen Reiseberichte, den Gottfried in seiner Darstellung paraphrasierte, war die erstmals 1557 in Marburg erschienene Warhaftig Historia und Beschreibung eyner Landschafft der Wilden, Nacketen, Grimmigen, Menschenfresser Leuthen, in der Newenwelt America gelegen des Hans Staden $(\dagger 1556)$. Es handelte sich dabei um den ersten deutschsprachigen Bericht aus Amerika, in diesem Falle aus Südamerika, da Staden zwischen 1547 und 1554 zwei Brasilienreisen unternommen hatte. Die vorliegende Abbildung bezieht sich auf seine Gefangennahme durch Indianer vom Stamm der Tupinamba. Nach der Gefangennahme wurde er mit einer Federkrone geschmückt und in einem rituellen Tanz von Indianerinnen umringt.

(WE) 


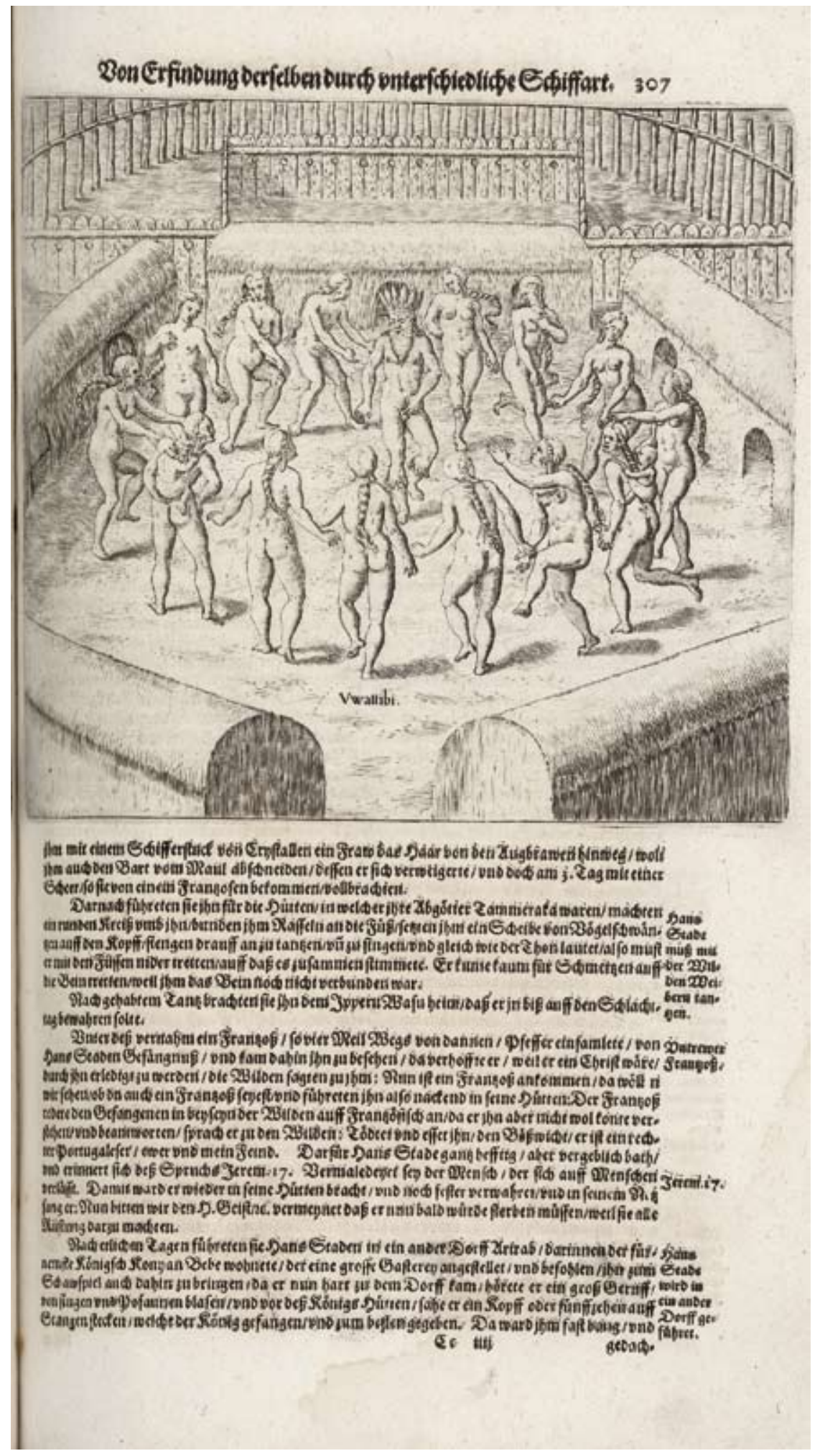




\section{Kapitel 4}

\section{Wer bietet mehr? Ersteigert auf Auktionen}

Bereits in den ersten Jahrzehnten ihres Bestehens entwickelte die Göttinger Universitätsbibliothek eine differenzierte Erwerbungspolitik, die nicht nur auf den Kauf der aktuellen deutschen Neuerscheinungen bei lokalen und regionalen Buchhandlungen konzentriert war, sondern die benötigte Literatur auch direkt im Ausland zu erwerben suchte. Bereits in dieser Phase wurde angestrebt, durch antiquarische Erwerbungen den Grundbestand der Bibliotheca Buloviana zu ergänzen. Christian Gottlob Heyne erläuterte dies rückblickend in seinem Rechenschaftsbericht aus dem Jahre 1810: „Die Ausfüllung der Lücken aus frühern Zeiten ist meistens nur von einem glücklichen Zufall und aus Bücher-Auctionen zu erwarten“. Die Prinzipien der Erwerbungstätigkeit beschreibt er zusammenfassend: „Also werden in der Regel nur solche Bücher gesucht und gewählt, worin die menschlichen Kenntnisse, wissenschaftliche, technische, practische, ein Fortrücken, Fortgang, oder auch nur einen einzelnen Schritt vorwärts, gemacht haben.“

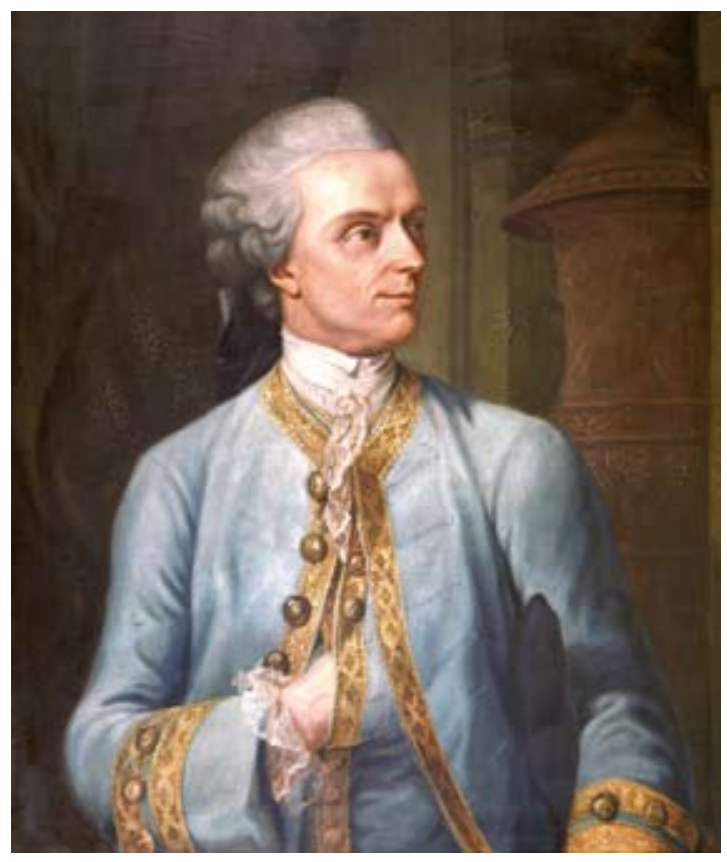

Christian Gottlob Heyne (1729-1812).
In London unterstützte der hannoversche Diplomat Wilhelm Philip Best (1712-1785) die Bibliothek, indem er ihr das Kaufangebot des Buchhändlers Thomas Osborne (getauft 1704?, † 1767) übermittelte, der 1742 die große Büchersammlung von Robert Harley, des ersten Earl of Oxford, erwarb. Bei der Herstellung des fünfbändigen Auktionskatalogs zur Harley-Bibliothek versicherte sich der geschäftstüchtige Osborne der Mithilfe von Samuel Johnson (1709-1784), dem berühmten Verfasser des Dictionary of the English Language (1755). Die Zusammenarbeit zwischen Osborne und Johnson war nicht konfliktfrei, und es wird berichtet, dass eine der Streitigkeiten damit endete, dass Johnson seinem Auftraggeber einen Band an den Kopf schleuderte und ihn damit zu Boden streckte. Die Göttinger Bibliothek erwarb zwischen 1749 und 1755 bei jeder OsborneAuktion Hunderte von Titeln, so dass sich bereits zwanzig Jahre nach ihrer Gründung ein Schwerpunkt in der englischen Literatur entwickeln konnte.

Bereits im 18. Jahrhundert begann man im In- und Ausland, Gelehrtenbibliotheken auf Auktionen zu veräußern. Auch diese Quelle nutzte die Universitätsbibliothek für den zielgerichteten Bestandsaufbau und zur Schließung noch vorhandener Lücken (s. Kap. 7 und 8). Die in diesem Abschnitt vorgestellten Auktionskäufe des 18. Jahrhunderts stammen aus den Bibliotheken von Büchersammlern verschiedener Länder:

Petrus Meerman, Auktion Den Haag 1754 Johannes Nettis (1707-1777), Augenarzt in Leiden, Auktion Leiden 1774

Pieter Burman d. J. (1713-1778), Philologe und Dichter, Auktion Leiden 1779 Pastor Pappe aus Pechau bei Magdeburg, Auktion Magdeburg 1786 


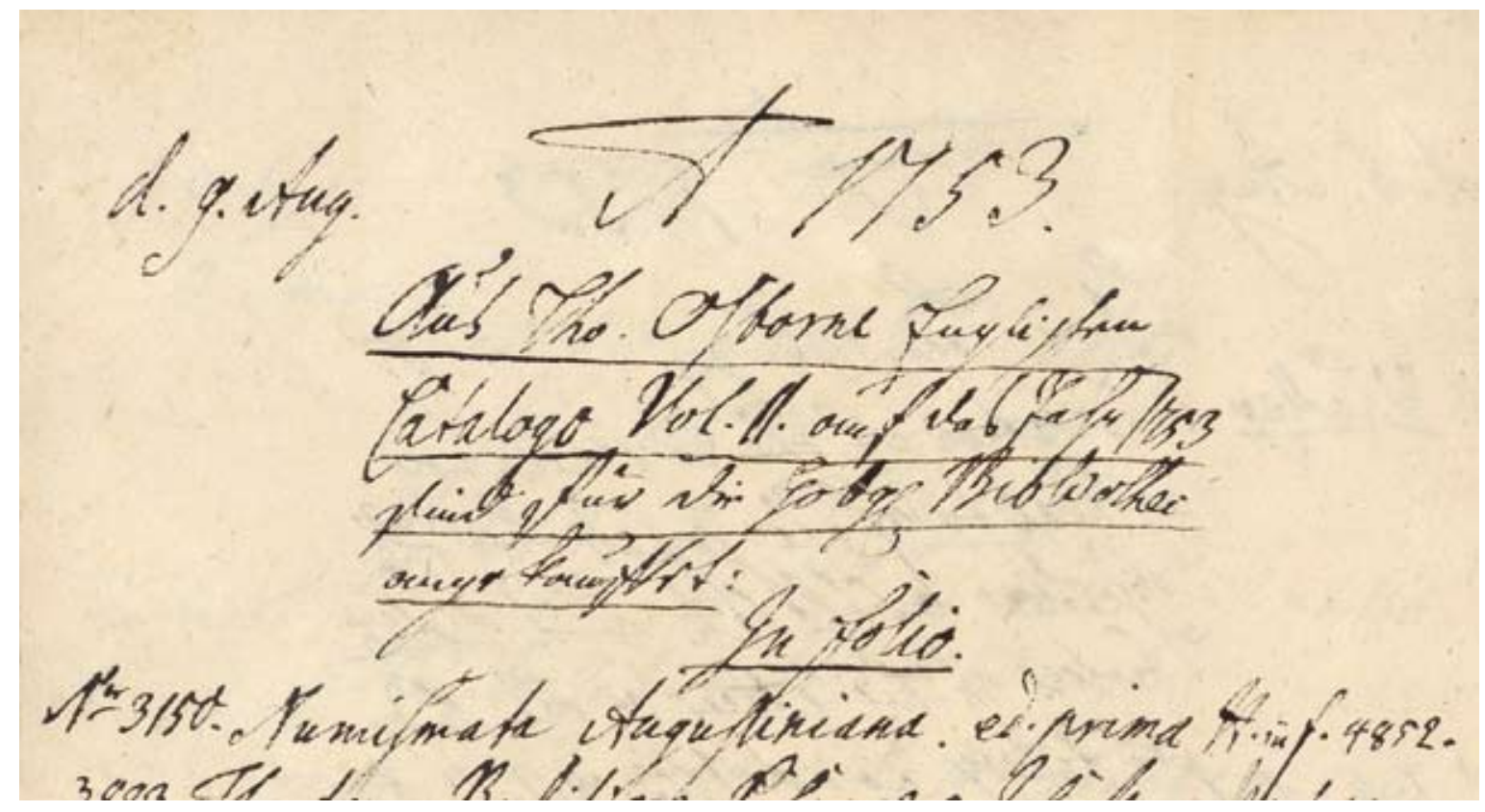

Erwerbungen auf einer Auktion Thomas Osbornes (1753).

Die aktive Teilnahme an Auktionen hatte einen weiteren Nebeneffekt: Die Bibliothek erwarb eine Vielzahl an gedruckten Auktionskatalogen des 18. Jahrhunderts, in denen Anstreichungen und Notizen den einzelnen Erwerbungsvorgang dokumentieren. Erst seit Beginn des 20. Jahrhunderts entstanden in Deutschland Auktionsfirmen, die in regelmäßigen Abständen ihre Versteigerungen abhielten und zu diesem Zweck gedruckte und bebilderte Kataloge vorlegten. Zwei Beispiele aus dem 20. Jahrhundert beschließen dieses Kapitel: die Ersteigerung eines Rechenbuchs von Adam Ries beim Auktionshaus Gerda Bassenge in Berlin (1968) und die einer frühen Eulenspiegel-Ausgabe bei Hartung \& Karl in München (1974).

(HR) 


\section{Der Ploetz des 15. und 16. Jahrhunderts}

Werner Rolewinck:

Fasciculus temporum, niederländisch. Utrecht: Johann Veldener, 14. II. 1480.

Signatur: $4^{\circ}$ Hist. un. II, 40 Inc.

Provenienz: Auktion Thomas Osborne, 1751

Werner Rolewinck (auch Rolevinck, Rolvinck, Rovelink) wurde 1425 als Sohn wohlhabender Bauern im münsterländischen Laer geboren. Nach dem Besuch der Domschule in Münster begann er 1443/44 ein Studium der Rechte an der Universität Köln. 1447 trat er in die berühmte Kartause St. Barbara in Köln ein und legte im Folgejahr das Ordensgelübde ab. Als Mönch begann er eine umfassende literarische Tätigkeit und verfasste in den Folgejahren mehr als 50 Werke, die entscheidend zum Ansehen des Konvents beitrugen. 1502 starb Rolewinck an der Pest. In den Klosterannalen heißt es über seine Person: „Gelehrsamkeit und Tugend besaß er in solchem Maße, dass man ihn den erleuchteten und heiligen Pater nannte. Er war ein ausgezeichneter Geschichtsschreiber, ein guter Kenner des Kirchenrechts, ein gründlicher Theologe, ein hervorragender Erklärer der Heiligen Schrift und, was die Hauptsache ist: ein tiefinnerlicher Mensch.“

Der Fasciculus temporum stellt einen knappen synoptischen Abriss der Weltgeschichte dar. Mithilfe graphischer Mittel, des Schriftbildes und zahlreicher Illustrationen war er als gut benutzbares Nachschlagewerk für Daten, historische Personen und Ereignisse gestaltet. Der „Ploetz des 15. und 16. Jahrhunderts“ erschien erstmals im Jahre 1474 bei Arnold Therhoernen in Köln; bis 1500 wurden nicht weniger als 35 Ausgaben veröffentlicht, darunter zwei deutsche, fünf französische und die vorliegende niederländische Übersetzung, die einzige niederländische Ausgabe des 15. Jahrhunderts. Der Drucker des Fasciculus temporum, Johann (Jan) Veldener, stammte aus der Diözese Würzburg und ließ sich 1477/78 in Utrecht, dem frühesten holländischen Druckort, nieder. Der sorgfältig kolorierte Fasciculus temporum zeigt eine Vielzahl von Holzschnitten, die Veldener zum Teil mehrfach in seinem Werk verwendete. Sie sind Kopien aus der Kölner Erstausgabe. Der niederländischen Ausgabe der Welthistorie ist ein Supplement beigefügt, welches Ereignisse aus der jüngeren Geschichte der Stadt Utrecht behandelt. 


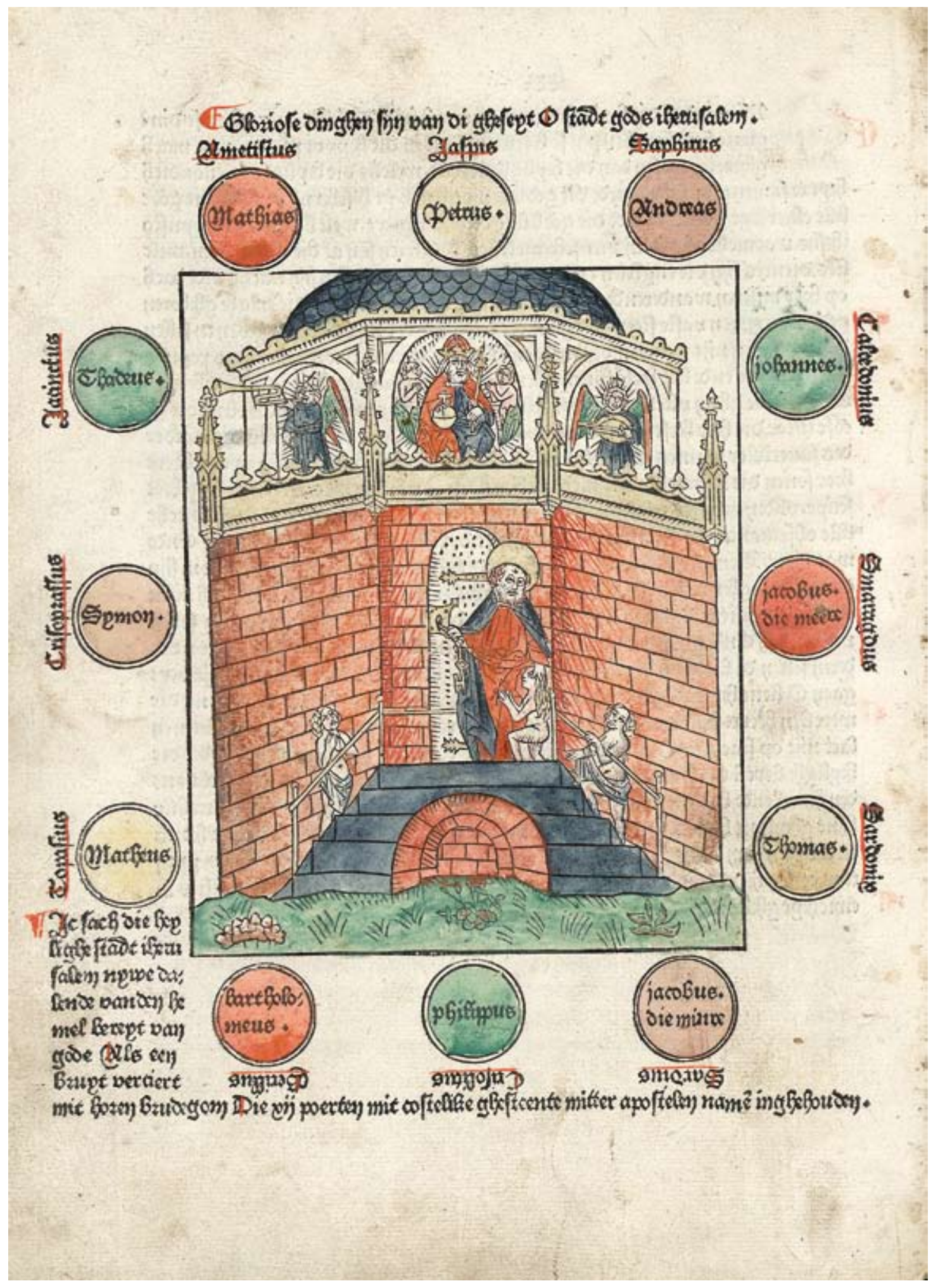




\section{Die Reise ins Heilige Land als Bildreportage}

Bernhard von Breidenbach:

Peregrinatio in terram sanctam, französisch. [Lyon:] [Gaspard Ortuin,] 18. II. 1489/90.

Signatur: $4^{\circ}$ Itin. I, 2297 Inc.

Provenienz: Auktion Thomas Osborne, 1749

Der Mainzer Domdechant Bernhard von Breidenbach (um 1440-1497) unternahm vom 25. April 1483 bis Ende Januar 1484 gemeinsam mit dem jungen Grafen Johannes von Solms und dessen Lehnsmann und Beschützer, Ritter Philipp von Bicken, eine Pilgerfahrt nach Jerusalem und auf den Sinai. Der aus Utrecht stammende Maler Erhard Reuwich schloss sich der Reisegruppe an und erhielt die Aufgabe, die wichtigsten Eindrücke von Städten und Gebäuden, von Menschen und Kulturdenkmälern in Bildern festzuhalten. Nur zwei Jahre nach der Rückkehr erschien am 11. Februar 1486 der von Reuwich geleitete deutsche Erstdruck des Reiseberichts in lateinischer Sprache in Mainz, eine deutsche Ausgabe folgte ganze vier Monate später und am 4. Mai 1488 auch eine niederdeutsche Version. Graf Johannes von Solms erlebte das Erscheinen des Buches, das eine Verbindung von Pilgerführer, Reisehandbuch und geographischer Beschreibung darstellt, nicht mehr: Er starb kurz nach Antritt der Rückreise in Alexandrien.

Der große Erfolg des Reiseberichts ist in seinem Inhalt und seiner künstlerischen Ausstattung begründet. Bernhard von Breidenbach ergänzte den eigentlichen Reisebericht durch eine Beschreibung Palästinas, eine Biographie Mohammeds, Berichte über Belagerungen von Konstantinopel und Rhodos sowie Notizen über Recht und Sitten der Bewohner des Heiligen Landes. Reuwich selbst übertrug seine Skizzen in den Holzschnitt und überwachte den Druck des Buches. Das reich ausgestattete Werk ist das erste Holzschnitt- werk, dessen Illustrator namentlich bekannt ist, und das erste topographische Werk, dessen Städteansichten weitgehend der Wirklichkeit entsprechen. Reuwichs Holzschnitte sind von starker malerischer Ausdruckskraft und gelten als Höhepunkt der Mainzer Buchillustration; sie haben unter anderem die Ausstattung der Schedelschen Weltchronik (s. Nr. 2) beeinflusst. Das Frontispiz zeigt eine allegorischheraldische Darstellung mit den Wappen der drei Reisenden; es war vorher bereits in den lateinischen, hochdeutschen und niederländischen Erstausgaben des Reiseberichts verwendet worden und gilt als das älteste Frontispiz im Buchdruck. 


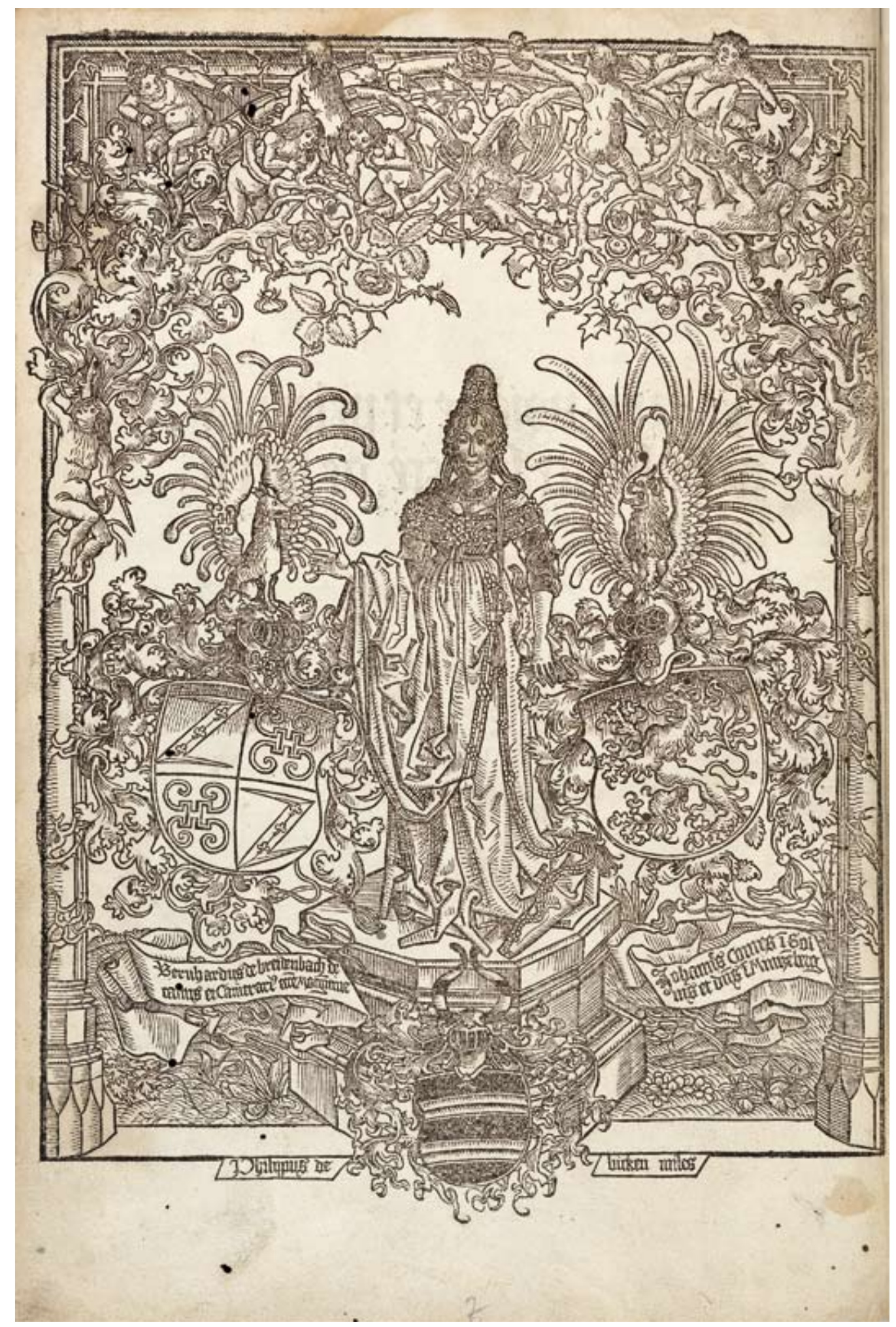




\section{Das schönste Buch der Renaissance}

Francesco Colonna:

Hypnerotomachia Poliphili.

Venedig: Aldus Manutius, Dezember 1499.

Signatur: $4^{\circ}$ Fab. Rom. I, 7351 Inc. Rara

Provenienz: Auktion Thomas Osborne, 1753

Der Roman mit dem merkwürdig klingenden griechisch-lateinischen Titel, den man im Deutschen vielleicht mit Poliphilos Erzählung vom Kampf zwischen Liebe und Schlaf wiedergeben könnte, erschien 1499 anonym in einem berühmt gewordenen Druck des Aldus Manutius (1450-1511). Die 38 Kapitelinitialen bilden ein Akrostichon, das den Verfasser preisgibt: POLIAM FRATER FRANCISCUS COLUMNA PERAMAVIT. Es handelt sich um den Dominikanermönch Francesco Colonna (1433-1527) vom Kloster SS. Giovanni e Paolo in Venedig, der zwischen 1455 und 1472 als Lektor der Rhetorik und Grammatik sowie fremder Sprachen tätig war. Die Traumerzählung schildert, wie Poliphilo auf der Suche nach seiner Geliebten Polia, von wechselnden Personifikationen menschlicher Eigenschaften und Ideen geleitet, eine utopische Kunst- und Architekturlandschaft durchwandert, bis er schließlich der als Nymphe verschleierten Geliebten begegnet. Im Tempel der Venus gibt sich Polia endlich ihrem Geliebten zu erkennen. Nach dem Verlöbnis des Paares und einer Wanderung durch eine alte Nekropole werden die Liebenden von Amor zu Schiff auf die Insel Cythera gebracht, wo sie den Nymphen berichten, welche Hindernisse sie zu überwinden hatten, bis sie endlich glücklich vereint waren.

Wichtiger als der Inhalt des Romans ist jedoch die druckgeschichtliche Bedeutung dieses Buches, das wegen seiner überragenden Typographie und der hohen Qualität der Holzschnittillustrationen als eines der schönsten Bücher aller Zeiten gilt. Textblöcke und Illustrationen sind auch bei wechselnden Bildgrößen der Holzschnitte durchgängig harmonisch aufeinander abgestimmt. Durch Einzüge und trichterförmig auslaufende Abschnittsenden sowie durch Einsatz von Versalien und Einfügen von Initialen wird der streng aufgebaute Satz aufgelockert und wirkt dennoch immer ausgewogen und ruhig. Für die Hypnerotomachia Poliphili entwickelte Aldus Manutius eine eigene Antiqua-Type, die auf künftige Antiquaschöpfungen von Schriftkünstlern wie Collines, Garamond oder Caslon einen deutlichen Einfluss ausübte. Der Künstler der großartigen Holzschnitt-Illustrationen konnte bislang nicht bestimmt werden; er wird dem Umkreis von Mantegna und Bellini zugerechnet. Unter den zahlreichen Druckwerken aus der Offizin des Aldus Manutius nimmt dieses einzigartige Buch auch deshalb eine Sonderstellung ein, weil Aldus nur wenige mit Buchschmuck ausgestattete Werke herausgegeben hat. 


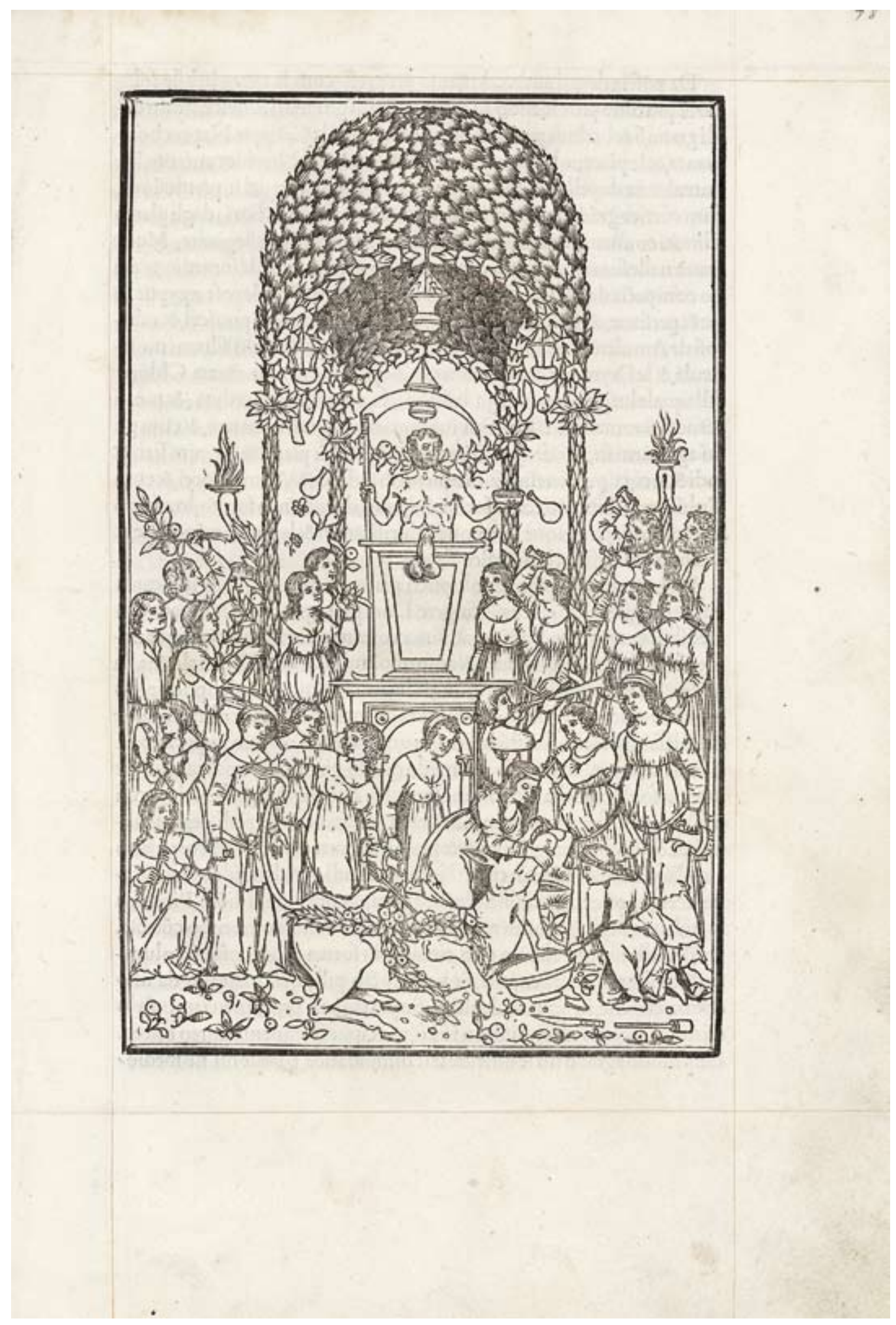




\section{Die Vermessung des Menschen}

Albrecht Dürer:
Vier Bücher von menschlicher Proportion.
Nürnberg: Hieronymus Andreae, 1528.
Signatur: $4^{\circ}$ Art. plast. III, 515 Rara
Provenienz: Auktion Thomas Osborne, 1754

Albrecht Dürer (1471-1528) wandte jene Prinzipien der geometrischen Messung, die er im Jahre 1525 in Underweysung der messung mit dem zirckel und richtscheyt (s. Nr. 10) entwickelt hatte, auch auf den menschlichen Körper an. Vier Bücher von menschlicher Proportion ist sein letztes und bekanntestes Werk. Während Andreas Vesalius' Verständnis von den Oberflächenmerkmalen des menschlichen Körpers auf den inneren Beziehungen und Formen basierte (s. Nr. 40), beruhte Dürers Darstellung der Oberflächenmerkmale auf Idealisierungen, die er von den äußeren Merkmalen des Körpers abgeleitet hatte. Dürer war von den Proportionen und den Symmetrien des menschlichen Körpers fasziniert und vermaß von Kopf bis Fuß zahlreiche Längen zwischen spezifischen Punkten, um typische Werte zu ermitteln. Als er aber feststellte, dass nicht alle Körper diesen typischen Werten entsprachen, demonstrierte er zusätzlich, in welcher Weise die menschlichen Proportionen bei sehr dünnen oder sehr dicken Körpern ausfallen. Die Regelmäßigkeit, die Dürer in den menschlichen Maßen erkannte, drückt er in seiner Proportionslehre folgendermaßen aus: „Dann warhafftig steckt die kunst inn der natur / wer sie herauß kann reyssen der hat sie / ... vnd durch die Geometria magstu deins wercks vil beweyssen.“

Obwohl Dürer als Künstler die Perspektive in der Kunst und in der Mathematik von Italien aus im übrigen Europa einführte, wandte er sie merkwürdigerweise nicht auf die typischen Proportionen und Symmetrien an, die er am menschlichen Körper feststellte.
Kunsthistoriker sind der Ansicht, dass eine gewisse visuelle Verzerrung den ästhetischen Reiz ausmacht, den die Betrachter von Dürers menschlichen Figuren empfinden. Das Werk ist bekannt für seine große Anzahl von Holzschnitten - es sind mehr als 100 - und für die Innovationen, die Dürer in diese Drucktechnik einbrachte. Der letzte Abschnitt des Buches über die menschliche Bewegung enthält die ersten Holzschnitte mit Kreuzschraffierung, die der Erzeugung von Schatten und Schattierungen diente. Wenige Monate vor Dürers Tod am 6. April 1528 begann der Druck der Vier Bücher von menschlicher Proportion, aber sein Verfasser erlebte das Erscheinen nicht mehr.

( $\mathrm{KMO} / \mathrm{KN})$ 

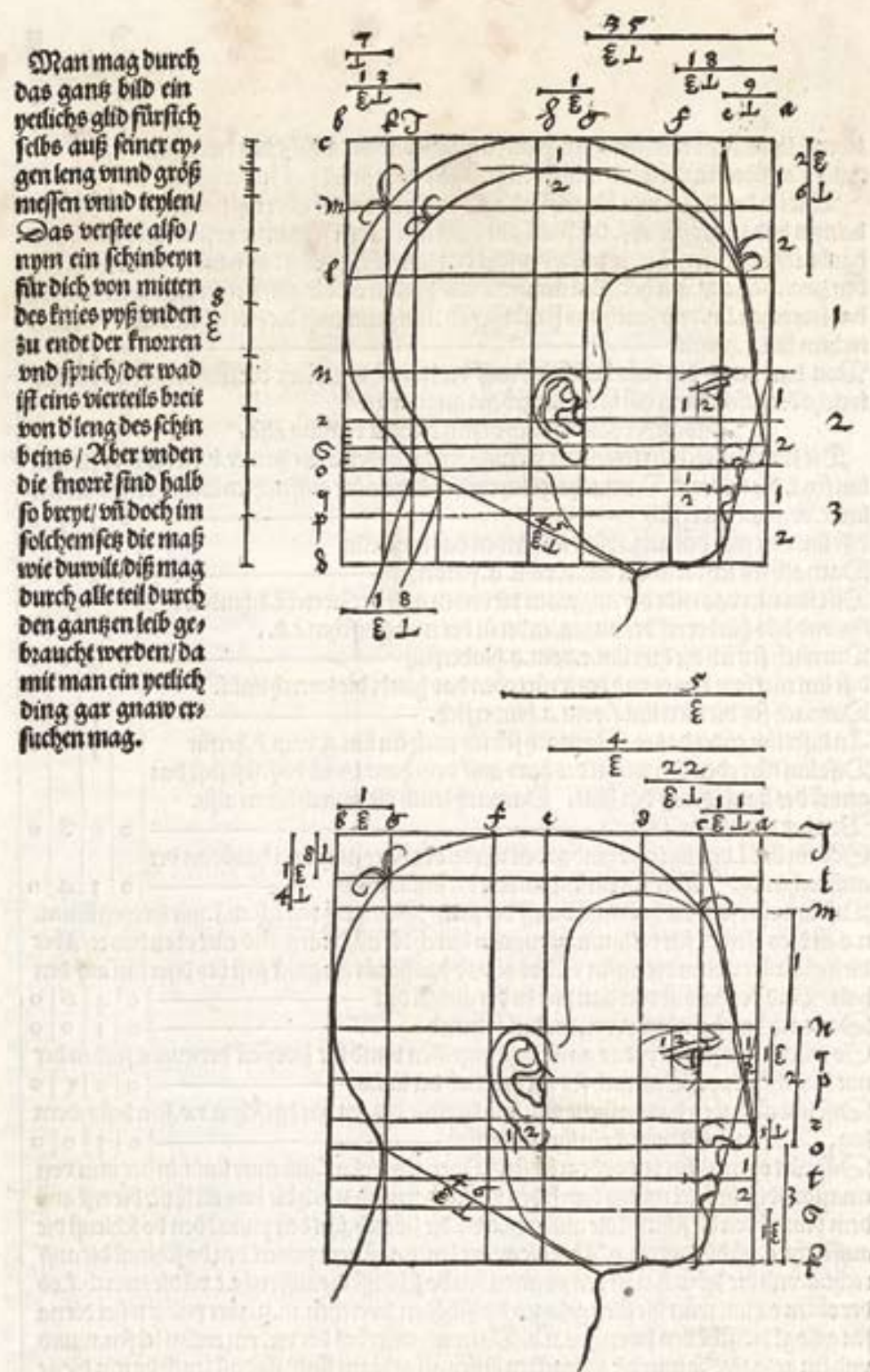

\&notoes antern butḩต. 


\section{Das erste in Spanien gedruckte Offizium}

Officium Beatae Mariae Virginis.

Valencia: [Drucker des Officium BMV,] 7. XI. 1486.

Signatur: $8^{\circ}$ Hist. eccl. Rit. I, 8158 Inc. Rara

Provenienz: Petrus Meermann, Auktion Den Haag, 1754

Für das gemeinschaftliche christliche Gebet zu bestimmten Tagzeiten oder Stunden bildete sich früh eine relativ feste Form, deren Hauptbestandteile Psalmodie, Lesung, Hymnus, Canticus und Gebet sind. Die Stundengebete (Horen) heiligen den Tagesablauf und stellen ihn zugleich in den Kontext der Schöpfungswoche und des Kirchenjahres. Da der Beter, der Forderung „Betet ohne Unterlass“ (1 Thess. 5,17) nachkommend, Gott schuldige Dienste erweist, wird der Tageskreis der Stundengebete Offizium (officium divinum) genannt. Mit der durch das Mailänder Toleranzedikt des Jahres 313 eingeleiteten konstantinischen Wende entwickelten sich die beiden Formen des monastischen Offiziums (als Gebet der Gemeinschaft der Mönche) und des kathedralen Offiziums (als Gebet der Gemeinschaft der Gläubigen). Aus den verschiedenen Prägungen des Mönchtums entstanden verschiedene Varianten des Offiziums, die in vielfacher Wechselwirkung zueinander standen; eine weitgehende Einheitlichkeit des Stundengebetes wurde durch die Ordnung der Regel des Benedikt von Nursia (480-547) erreicht.

Seit dem 8. Jahrhundert entstanden für das Laientum bestimmte Gebetssammlungen, die anfänglich vor allem das Sünden- und Trinitätsbekenntnis, seit dem 11. Jahrhundert zunehmend Betrachtungen der jungfräulichen Geburt und der Passion Christi enthielten. Die aufkommende Marienfrömmigkeit manifestierte sich in einem eigenen Marianischen Offizium. Dieses wichtigste Nebenoffizium gibt die Stundengebete für Marienfeste sowie für verschiedene Anlässe zur Ehre der Gottesmutter wieder. Seit dem 13. Jahrhundert wurden für das wohlhabende, lesekundige Laientum Stundenbücher gefertigt, die, häufig mit Miniaturen versehen, je nach Aufwand ihres Buchschmuckes durchaus auch als Prestigeobjekte gelten können. Ihre auch künstlerische Blütezeit erlebten die Stundenbücher im späten 14. und beginnenden 15. Jahrhundert. Dieser Zeit entstammt auch das ausgestellte Buch, die erste Ausgabe eines Offiziums in Spanien. Äußerlich unterscheidet es sich kaum von zeitgenössischen Handschriften, ein Phänomen, das für die zwischen 1450 und 1480 gedruckten Bücher charakteristisch ist. Ein handschriftlicher Eintrag im Buchdeckel weist als mögliche Drucker Gabriel Luis de Arinyo und Lope de la Roca aus. Das Exemplar ist mit prächtig ausgemaltem Rankenwerk und in Blattgold gefassten Initialen geschmückt. Aufgeschlagen ist das Mundöffnungsgebet.

(SG/KN) 


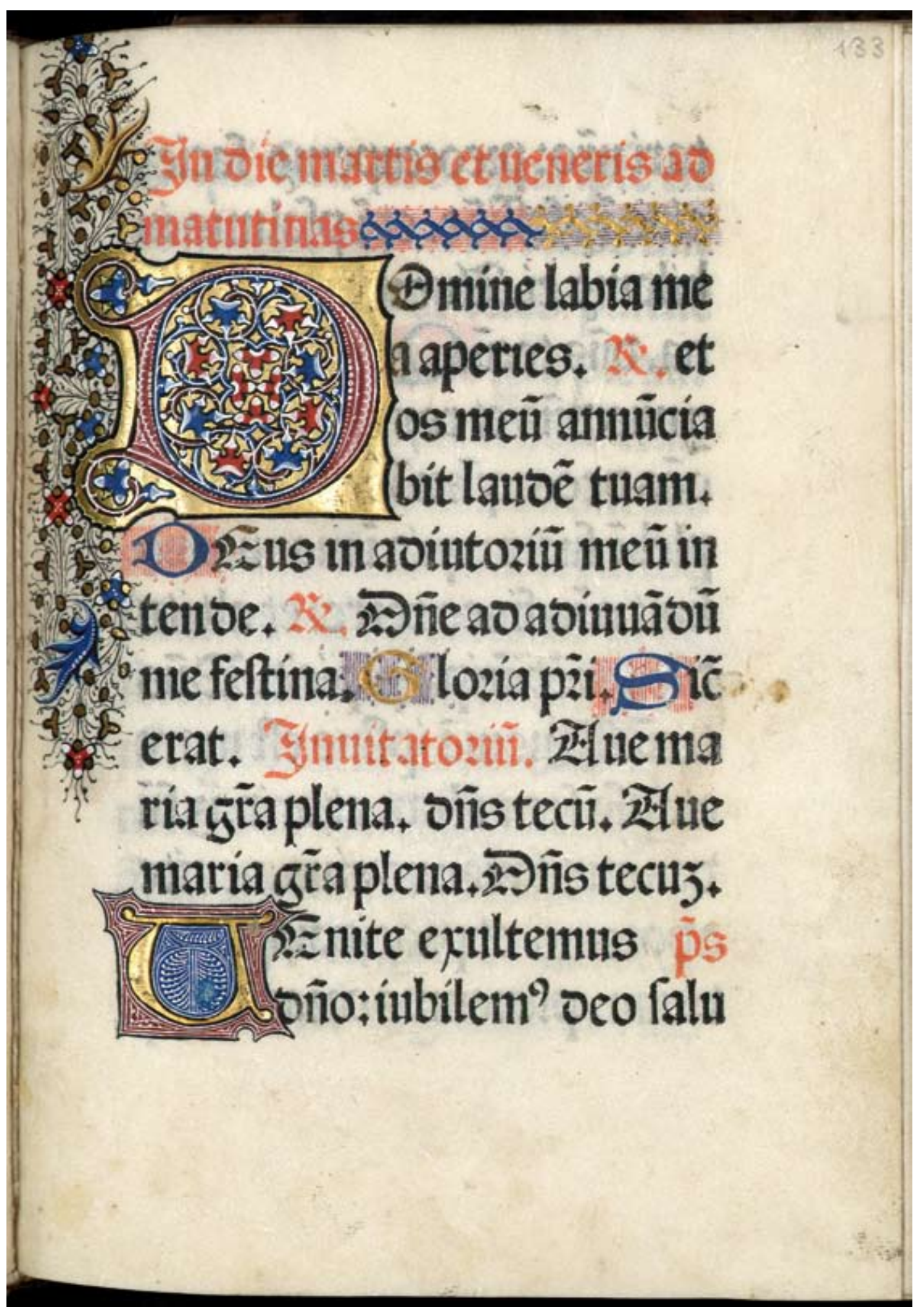




\section{von der Entdeckung Amerikas}

Christoph Kolumbus:

Epistola de insulis repertis de novo, lateinisch.

Paris: [Guy Marchant], 1493.

Signatur: $8^{\circ}$ Hist. Am. I, 502 Inc. Rara

Provenienz: Pieter Burman d. J., Auktion Leiden, 1779

Den jungen italienischen Seefahrer Christoph Kolumbus (1451-1506) beschäftigte der schon von Aristoteles erörterte Gedanke einer Westfahrt nach Indien. Die geographischen Vorstellungen von Kolumbus beruhten zunächst auf denen der Antike und des Mittelalters, die vielfach die Existenz von Kontinenten in den westlichen und südlichen Meeren annahmen. Vor allem aber war Kolumbus von der Kugelgestalt der Erde überzeugt und hoffte, mit seiner Westfahrt den Ostrand der Alten Welt zu erreichen. In diesem Plan bestärkten ihn ein Brief und eine Karte des italienischen Astronomen und Arztes Paulus Toscanelli um so mehr, als darin die Entfernung zwischen dem Westen Europas und dem Osten Asiens über den Atlantik angegeben war - viel zu kurz, wie sich zeigen sollte. Von Isabella und Ferdinand II. von Spanien unterstützt, brach Kolumbus mit drei Schiffen zu seiner ersten von vier Fahrten gen Westen auf (3. August 1492-5. März 1493). Zuvor bekam er besondere Rechte zugesprochen: die erbliche Würde eines Großadmirals, das Amt des Vizekönigs der zu entdeckenden Länder und ein Zehntel aller Handelseinnahmen dieser Länder. Auf dieser Fahrt entdeckte Kolumbus Guanahani (Watlingsinsel), Kuba und Haiti. Er starb in der Meinung, Inseln vor der eurasischen Ostküste betreten und den Westweg nach Indien entdeckt zu haben. Die Einlösung der ihm zugesagten Sonderrechte hat Kolumbus nie erlebt. Erst nach seinem Tode hat sich die ganze Tragweite seiner Entdeckung erschlossen: Mit seiner nautischen Pionierleistung und der Entdeckung des neuen Erdteils hatte sich das mittelalterliche Weltbild endgültig überlebt.
Der von Kolumbus auf der Rückreise seiner ersten Entdeckungsfahrt auf den 15. Februar 1493 datierte und mit einer Nachschrift vom 14. März 1493 versehene Brief, in dem er über seine Entdeckung berichtet, ist nicht im Original erhalten. In seinem Schreiben gab Kolumbus einen Rechenschaftsbericht an Raphael Sanchez, den Schatzmeister des spanischen Königspaares, und bestätigte, dass das von ihm gefundene Land allen Hoffnungen und Erwartungen entspreche. Er schildert eine paradiesische Natur, Reichtümer an Gold und freundliche Eingeborene, die unschwer zu guten Christen und gefügigen Arbeitskräften zu erziehen seien. (Bereits die zweite Reise, die Kolumbus von 1493 bis 1496 unternahm, sollte freilich den Traum von einer friedlichen Koexistenz zerstören.) Der Kolumbus-Brief mit seiner sensationellen Nachricht wurde bereits im April 1493 in spanischer Sprache in Barcelona gedruckt. Die europäische Öffentlichkeit erfuhr von der Entdeckung durch die lateinische Übersetzung des Briefs, die noch im selben Jahr in Rom, Antwerpen, Paris und Basel erschien. Der hier abgebildete Vorabdruck in lateinischer Übersetzung erschien in Paris und ist nur in einem weiteren Exemplar nachgewiesen.

(KN) 
Epiftola Chsiftofori Co

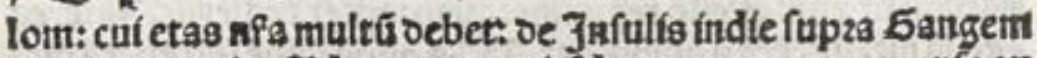
nuper inuentis. Zd quas perquirêdas octauo antea menie as fpicijs z ere inutctifini fermand toípaniarum Regts miffus fuerat: ad magnificú oñ 3 Rapbaelem Santíts: eiufdé ferenifini

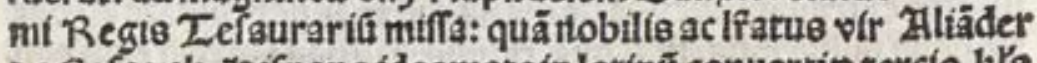
se Corco ab bifpano ideomate in latinu conuertit: tercio $\mathrm{kl}$

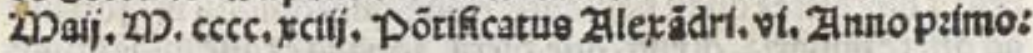

\section{uoniăfufcepteprouin}

๑ cierê perfectă me confecuțí fuifie gratú tibifoze fcio: bas oftitui exarare: que te vufuicuiuf $\$$ s rei in boc nfo

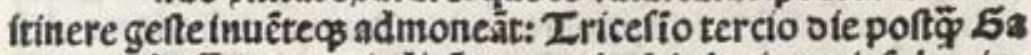
oibus oifceffitin mare indicí peruent: vbiplurimas infulas in: numeris babitatas boibns repperi: quarí oim pzo felicflimo Regenfo preconio celebsato $\tau$ vexillis extêfís côtradicẻtene: mine pofteftioné accepí pzimeq earú ofuint Saluatozis nomẻ

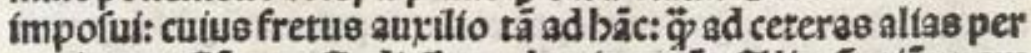
uenimus. Eä vero Jndi Suanabantinvocät. Zliarú etiā vinam

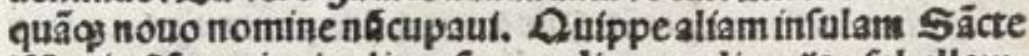
2Darie Cóceptionis aliam fernandinam. aliam "o ýabellam. sliam Jobanam, et fic oerelfquis gppellarifufít. Q uãpzimum in eāinfulam quä oudum Jobansm vocari oíxi appulínus:í: xta eius littus occidenten verfus alfquätulum pzocefí: tamos eam magnā nullo reperto fine inueni: vr non infulam: fed cötik nētem Cbataí pzouinciam efle crediderim: nulla trí videns op: pidamunicipisue in inaritimis fira côfinibus preter aliquos vi cos z predia ruftica: cú quop incolís loqui nequibam quarefí mul ac nos videbät furriptebant fugam. p2ogrediebar vitra: exfitimans aliquä me vrbem villafuc inusenturí. Dentiç vidēs $\varphi$ löge admodū pzogreffus nichil noui emergebat: $\tau$ bmōi via nos ad feptêtrionem veferebat: $q$ ipfe fugere exoptabam: ter

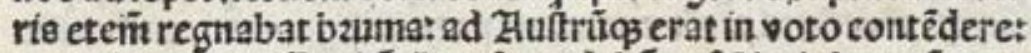
nec minus ventif lagitätibus fuccedebät. côftitư alı lios nö ope: virt fucceffus: et fic retrocedēs ad poatú quendă quem fignaue ram fum renerfus: vnde suos boies ę noftris in terră muf qui

q. if 


\section{Die Kunst des Destillierens}

Hieronymus Brunschwig:

Liber de arte Distillandi de Compositis.

Straßburg: [Johann Grüninger], 1512.

Signatur: $4^{\circ}$ Med Chem. 72/7 Rara

Provenienz: Auktion Ansbach, 1776

Hieronymus Brunschwig wurde 1450 in Straßburg geboren. Er studierte Medizin in Bologna, Padua und Paris, vermutlich aber ohne einen Magistertitel zu erlangen, da ihn keines seiner Werke mit einem akademischen Titel erwähnt. Als praktizierender Arzt wagte er gegenüber den klassischen und arabischen Autoritäten der „Schulmedizin“ gelegentliche Abweichungen. Vorbildlich wurden seine Behandlungsweisen von Schusswunden. Nachdem er einige Jahre als Wundarzt und Chirurg im süddeutschen Raum tätig gewesen war, kehrte er am Ende des Jahrhunderts nach Straßburg zurück, wo er schließlich Stadtarzt wurde und um 1512 verstarb. Seine Bücher, darunter zwei Titel über das „Destillieren“, waren in deutscher und lateinischer Sprache abgefasst und wurden zuerst bei Johann Grüninger gedruckt. Sie fanden große Verbreitung.

Das Destillieren ist nichts anderes, als das Subtile vom Groben und das Grobe vom Subtilen zu scheiden, das Zerbrechliche oder Zerstörbare unzerstörbar, das Materielle unmateriell, das Leibliche geistig, das Unschöne schöner zu machen. (Hieronymus Brunschwig, 1512)

Das Destillierbuch ist eines der frühesten Bücher über die Chemie und Pharmakologie und basiert auf der Untersuchung von 3.000 Pflanzen und ihren Bestandteilen. Erstmalig macht sich sein Autor Gedanken über chemische
Prozesse und essentielle Pflanzenöle. Die Beschreibungen der Experimente und der dazu notwendigen Versuchsaufbauten und Gerätschaften sind mit mehr als $200 \mathrm{Holz}$ schnitten, darunter allein 130 Abbildungen von Destillierkolben, illustriert. An der Schwelle zur beginnenden Neuzeit verfasste Brunschwig damit ein pharmazeutischtechnisches Handbuch, dessen Einfluss weit in das 16. Jahrhundert hineinreichte.

Im ersten Teil seiner Arbeit referiert Brunschwig Methoden und Apparate und berichtet über seine Beobachtungen der Destillation (hauptsächlich durch Dampf) von pflanzlichen oder tierischen Produkten. Der zweite Teil des Werkes, der eine Besprechung und Beschreibung von Heilpflanzen und ihrer Attribute enthält, ist eine Zusammenfassung der traditionellen Kräuterkundebücher mit Illustrationen. Auch der dritte Teil folgt der Gestaltung eines Kräuterkundebuches und gibt eine Liste von Heilmitteln und Rezepten, die nach den jeweiligen zu behandelnden Leiden geordnet ist. Dem vierten Teil, einem chirurgischen Arzneibuch, folgt im fünften ein Arzneibuch für arme Leute. Damit stellt Brunschwig sich in die Reihe jener Ärzte, die sich dem Berufsethos verpflichtet fühlten, kranken Menschen ohne Standesunterschied zu helfen. 


\section{Daserft 20̌ch}

Dar inacb foltu baben ofen oar in mä Gèneine waffet

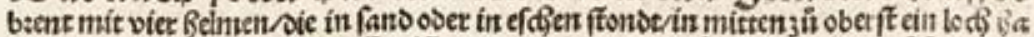

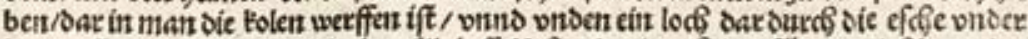

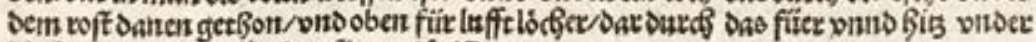
Die Belun gesogent witur. Des figur alfo ift.

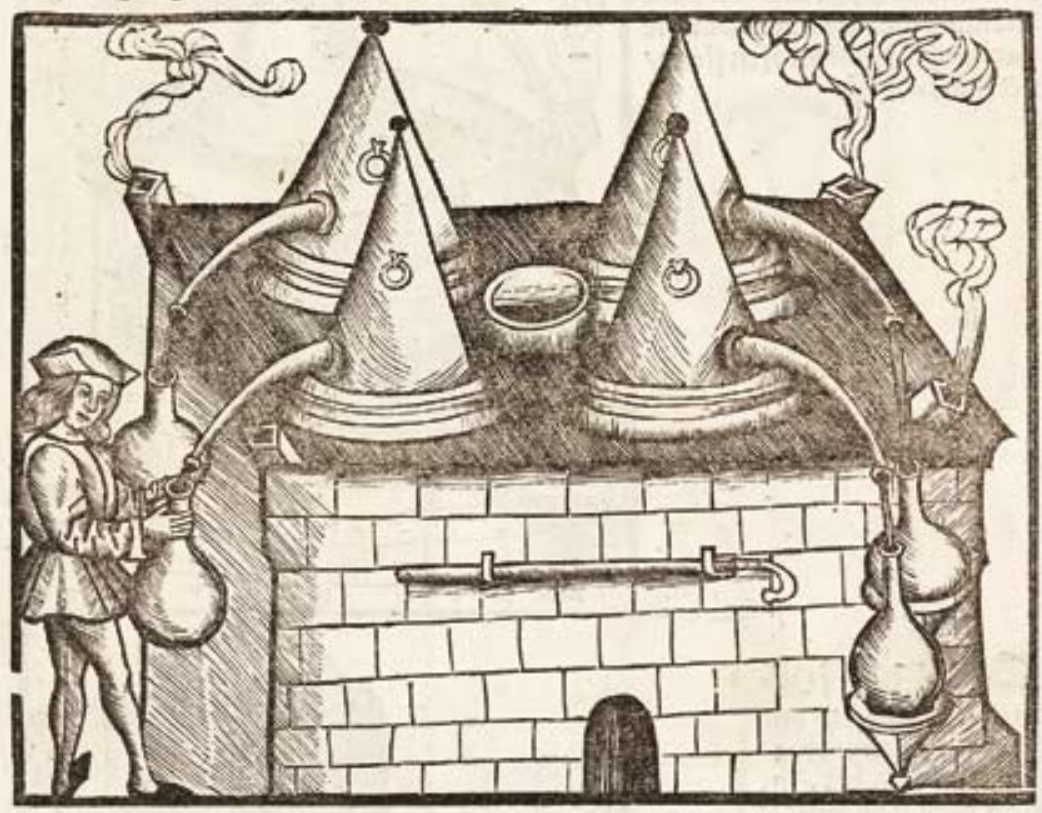

Du folt ouchbaben recíf,

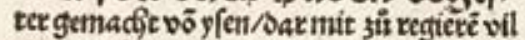
oserwentig/gro/3 oberclein nods oymbege/ renserfigurallo ift.

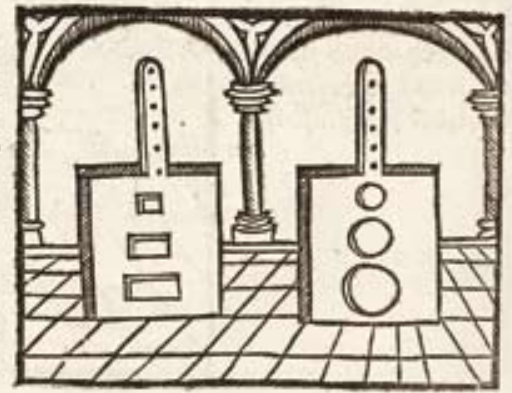


Eucharius Rösslin:

Der schwangeren Frauen und Hebammen Rosengarten.

Straßburg: Martin Flach, 1513.

Signatur: $8^{\circ}$ Med. Chir. III, 61110 Rara

Provenienz: Pastor Pappe aus Pechau bei Magdeburg, Auktion Magdeburg, 1786

Eucharius Rösslin (1470-1526) war ein angesehener Mediziner, der seit 1493 als Apotheker in Freiburg im Breisgau, seit 1506 als Stadtarzt in Frankfurt am Main und in Worms wirkte. 1508 war Rösslin als Leibarzt der Herzogin Katharina von Sachsen und Braunschweig in Lüneburg tätig. Ihr widmete er seinen 1513 bei dem Frühdrucker Martin Flach (um 1440-um 1510) in Straßburg erschienenen Rosengarten. Sieht man von Ortolff von Bayerlands Frauenbüchlein, einem um 1495 in Ulm gedruckten kleinen, nur 13-seitigen Bändchen ab, so handelt es sich bei Rösslins Werk um das erste gedruckte Handbuch zur Geburtshilfe. Auf der Grundlage antiker Texte, vor allem der Werke des Epheser Arztes Soranos (um 100 n. Chr.), verfasst, ging es weit über diätetische Vorschriften für werdende Mütter hinaus, indem es Beschreibungen von Kindsstellungen im Uterus mit Anweisungen darüber verband, wie das Kind im Falle von abnormen Lagen oder Geburtsschwierigkeiten zu wenden sei und welche Instrumente zu verwenden seien. Dem aus 13 Kapiteln bestehenden Buch sind 25 einprägsame Holzschnitte beigegeben, die verschiedene Kindsstellungen und die Konstruktion eines Gebärstuhls illustrieren. Wie Rösslin selbst in seiner dem Rosengarten vorangestellten „Ermahnung“ berichtet, reagiert er mit seiner Schrift auf die „Rohheit und jämmerliche Unwissenheit der Hebammen“. Tatsächlich führten in einer Zeit, die durch eine hohe Sterblichkeitsrate der Kinder bzw. ihrer Mütter gekennzeichnet war, insbesondere abnorme Lagen nicht selten zum Tod von Kind und Mutter. Wie groß das
Bedürfnis nach einem solchen Werk war, zeigt die außerordentlich hohe Zahl von mehr als 100 Druckausgaben (einschließlich seiner Übersetzungen), und die mehr als 200-jährige Wirkungsgeschichte, die der Rosengarten erlebte. Rösslin selbst ging als „Hebammenlehrer Europas“ in die Wissenschaftsgeschichte ein.

Das Göttinger Exemplar wurde 1786 auf einer Magdeburger Auktion der Bibliothek des Pastor Pappe aus dem nahegelegenen Pechau erworben. Die Bibliothek des verstorbenen Geistlichen umfasste mehrere tausend Bücher, darunter vor allem Bibelausgaben, theologische, philosophische, historische und philologische Titel. Wie gut die Göttinger Bibliothekare auf dieses Ereignis vorbereitet waren, zeigt der Auktionskatalog, der noch heute im Besitze der Bibliothek ist. Ein Bibliothekar hat offenbar die für Göttingen interessanten Titel am Katalog geprüft und mit Bleistift angemerkt, ob der Titel vorhanden war oder nicht. Im Bestand vorhandene Titel tragen den Vermerk „ad“ für „adest“, fehlende Titel eine kleine Null. Der Titeleintrag des Rosengartens findet sich auf S. 76 unter Pos. 565 und ist am Rande handschriftlich ,abgenullt“.

(SG/KN) 


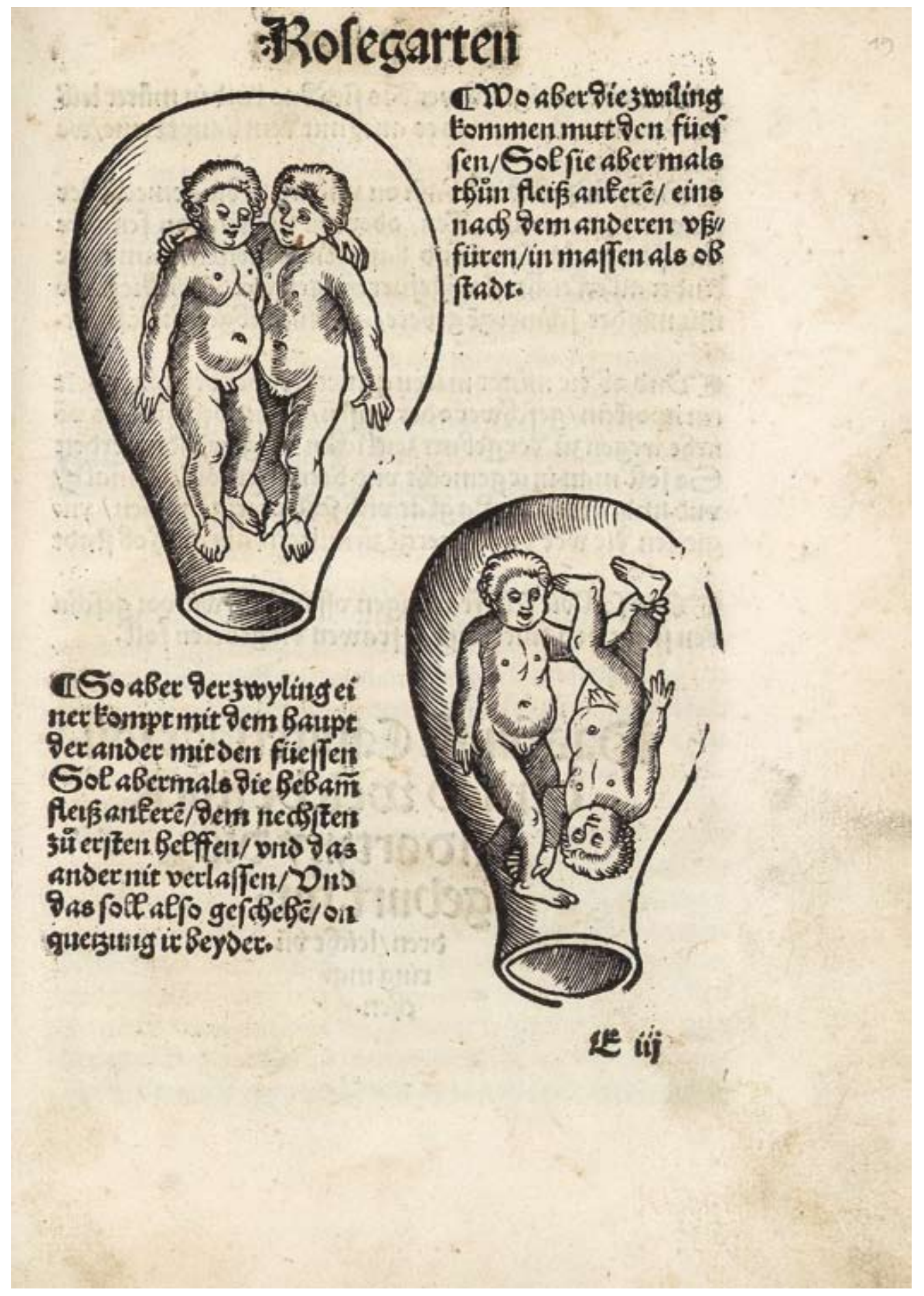




\section{Ein Rechenbuch für Schüler und Kaufleute}

Adam Ries:

Rechnung auf den Linien und Federn.

Erfurt: Melchior Krause, 1531.

Signatur: $8^{\circ}$ Math. II, 1282 (1) Rara

Provenienz: Auktion Berlin, 1968
Adam Ries (1492-1559) hatte zunächst - wie damals üblich - auf Märkten und Messen seine Rechenfertigkeiten vorgeführt und sich dabei bereits als junger Rechenmeister einen Namen gemacht. Nach seinen Wanderjahren ließ er sich um 1517 in Erfurt nieder und eröffnete eine Rechenschule, in der er angehende Kaufleute und Handwerker im kaufmännischen Rechnen unterrichtete.

Rechenschulen traten im deutschen Sprachraum seit dem 16. Jahrhundert in Erscheinung. Der Unterricht an diesen Schulen erfolgte in deutscher Sprache und vermittelte wichtige Rechenfertigkeiten sowie Grundkenntnisse der Algebra. Das kaufmännische Rechnen spielte vor dem Hintergrund der ökonomischen Entwicklung, die von einem beachtlichen Aufschwung des städtischen Handels und Gewerbes geprägt war, eine immer größere Rolle.

In seinem ersten, 1518 verfassten Rechenbuch beschreibt Adam Ries das „Rechnen auf den Linien“, ein damals verbreitetes Rechenverfahren auf Rechentischen und Rechentüchern: Rechenpfennige wurden auf Linien gelegt und mittels geeigneter Aktionen, die der Durchführung der vier Grundrechenarten entsprachen, verschoben, aufgelegt und entfernt. Dem Titelblatt des Buches ist zu entnehmen, dass es damals üblich war, diese Art von Rechenbuch für den Unterricht an Rechenschulen einzusetzen.
Das zweite, hier vorgestellte Rechenbuch, das in erster Auflage 1522 erschien, führt nach einer kurzen Darstellung des „Rechnens auf den Linien“ didaktisch geschickt in das uns heute vertraute schriftliche Rechnen (,mit der Feder") mit arabischen Ziffern ein. Gemäß dem Titelzusatz auff allerley Handthirung gamacht enthält es ausführliche Anleitungen, Beispiele und Aufgaben, die auch ein selbständiges Durcharbeiten, Nachvollziehen und Aneignen des Stoffs ermöglichen. Das Werk hat maßgeblich dazu beigetragen, dass die römischen Zahlen in der Folgezeit in der alltäglichen Anwendung immer mehr an Bedeutung verloren und sich das Rechnen mit arabischen Ziffern etablierte. Das Buch erlebte schon zu Ries’ Lebzeiten zahlreiche Auflagen. In deutscher Sprache und allgemein verständlicher Form geschrieben, fand es weite Verbreitung und begründete so den Ruhm seines Verfassers. Das Buch hat über die Jahrhunderte nichts von seinem Reiz verloren und eignet sich als Quelle anwendungsbezogener Aufgabenstellungen.

Die damals hochgeschätzte Rechenkunst erlebte mit Hilfe der arabischen Ziffern, der Schreibfeder und dank Adam Ries eine überzeugende Vereinfachung, die sie einer breiten Schicht zugänglich machte. Noch heute ist die Redewendung ,nach Adam Riese“ geläufig, welche die Richtigkeit eines Rechenergebnisses unterstreicht. 


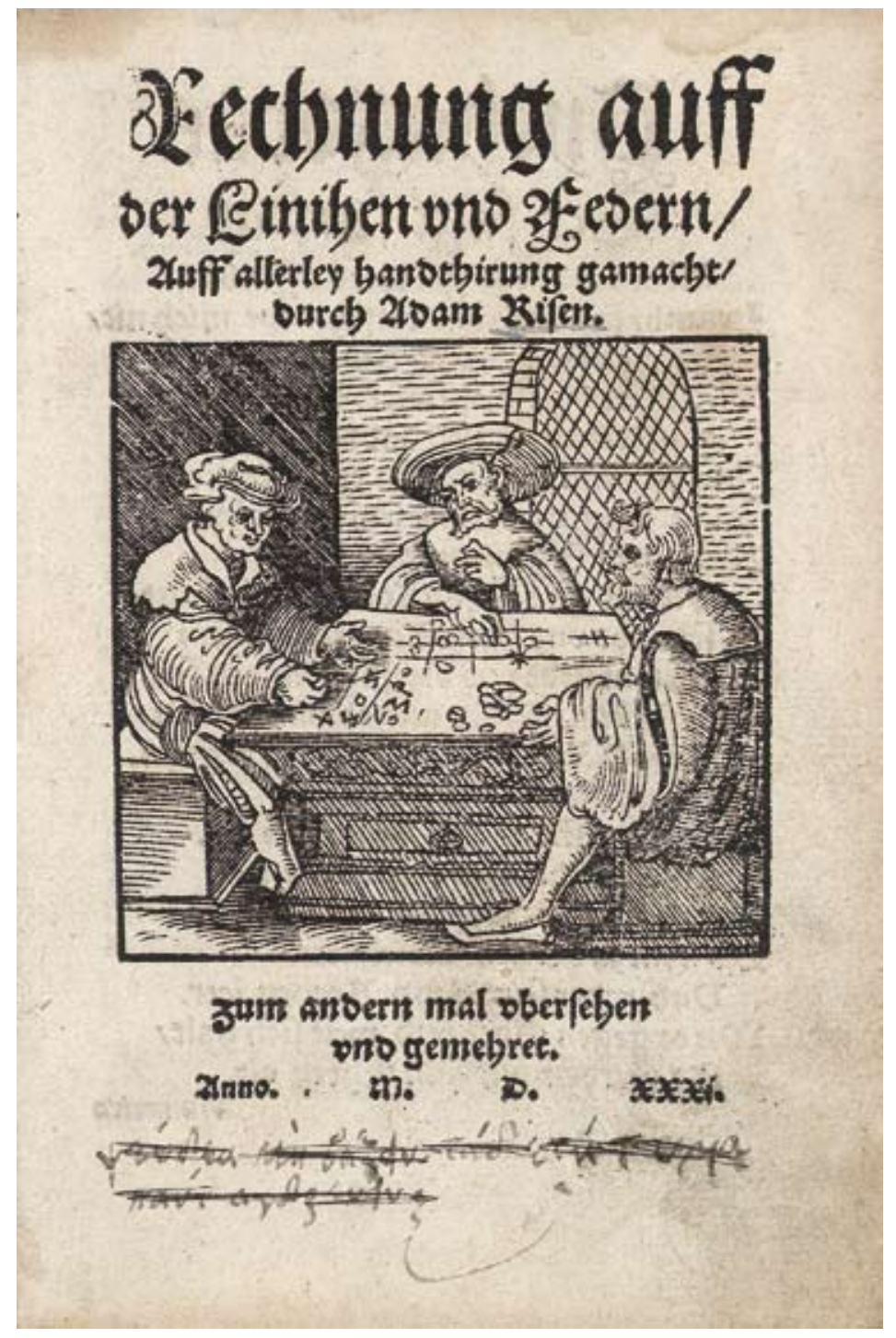




\section{Begründer der modernen Anatomie}

Andreas Vesalius:

De humani corporis fabrica libri septem.

Basel: Johannes Oporinus, 1543.

Signatur: $2^{\circ}$ Hist. nat. zool. XI, 4420 Rara

Provenienz: Johannes Nettis, Auktion Leiden, 1774

Andreas Vesalius' (1514-1564) Hauptwerk De humani corporis fabrica wurde ebenso wie Nikolaus Kopernikus’ De revolutionibus orbium coelestium im Jahre 1543 veröffentlicht. Es hatte eine völlig neue Sichtweise des menschlichen Körpers und physiologischer Systeme überhaupt zur Folge. Während $D e$ revolutionibus die Astronomie des Aristoteles in Frage stellte, beseitigte De humani corporis fabrica überkommene Vorstellungen zur Anatomie und Physiologie, die noch von Galen (um 129-um 199) und anderen antiken Medizinern stammten. Beide Werke waren somit für die „wissenschaftliche Revolution“ der frühen Neuzeit von entscheidender Bedeutung, weil beide die wissenschaftliche Beobachtung der natürlichen Welt an die Stelle des Studiums antiker Texte setzten.

Der aus Brüssel stammende Vesalius machte seine ersten Erfahrungen in der Kunst des Sezierens an der Pariser Universität. Zuvor war es üblich gewesen, während des Sezierens die klassischen medizinischen Texte vorzulesen. Als Vesalius 1537 eine Anstellung als Chirurg an der Universität Padua erhielt, reformierte er den anatomischen Unterricht, indem er die vormals getrennten Funktionen des Vortragenden, des Vorführenden und des Sezierers in seiner Person vereinigte und für die Studenten anatomische Zeichnungen drucken ließ, die auf faktischer Beobachtung basierten.
De humani corporis fabrica präsentierte Vesalius' anatomische Beobachtungen auf systematische Weise. Durch seine zahlreichen detaillierten Darstellungen reformierte das Buch Forschung und Lehre gleichermaßen. Besondere Berühmtheit hat das Frontispiz erlangt, das eine Sektion in einem anatomischen Theater zeigt. Umgeben von Studenten und Ärzten, von Vertretern der Universität, der Stadt und der Kirche steht Vesalius an einem Operationstisch und untersucht eine geöffnete weibliche Leiche. Das in der Bildmitte oberhalb der Zuhörer angebrachte Skelett repräsentiert die Grundlage der neuen Anatomie, die Osteologie oder Lehre vom Knochenbau des menschlichen Körpers. Die in dem Bild zu sehenden Tiere, ein Affe am linken Bildrand und ein Hund im Vordergrund rechts, weisen auf die überkommenen Studienobjekte der Anatomie, mit denen Vesalius’ Vorgänger Galen arbeitete. Die einzige weibliche Person im Auditorium ist links von der Bildmitte zu sehen: eine Hebamme und somit Vertreterin eines medizinischen Standes, für den das Studium der Anatomie von Bedeutung war. Vorn rechts wendet sich ein älterer Besucher vom Betrachten der Sektion ab, vermutlich ein Vertreter der antiken medizinischen Tradition.

(KMO) 


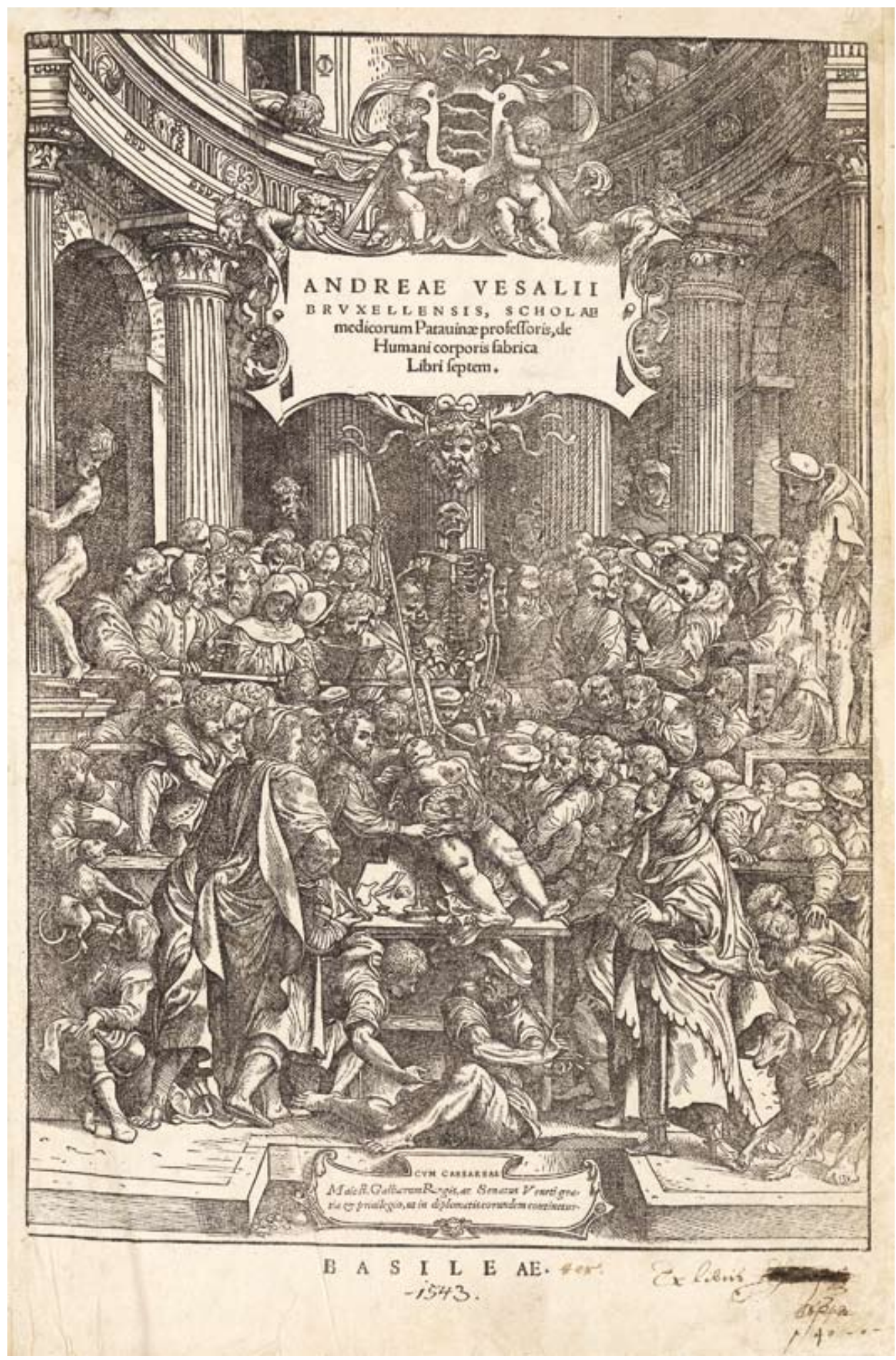




\section{Ein seltener früher Eulenspiegel-Druck}

Eulenspiegels wunderbarliche, abenteuerische und gar seltsame Historien.

Frankfurt am Main: Sigmund Feyerabend (?), 1569.

Signatur: $8^{\circ}$ Fab. Rom. VI, 1201 Rara

Provenienz: Auktion München, 1974

Zum ersten Mal gedruckt wurde der spätmittelalterliche, biographisch angelegte Schwankzyklus Eulenspiegel 1510/11 in Straßburg. Die vorliegende Ausgabe ist mindestens der 25. Druck des Werks - und damit zwar keiner der frühesten, immerhin aber noch ein früher. Die große Anzahl der Auflagen schon in der ersten Hälfte des 16. Jahrhunderts deutet auf eine hohe Popularität des Eulenspiegels hin, darf aber nicht darüber hinwegtäuschen, dass es bis zu diesem Zeitpunkt weniger ein „Volksbuch“ als vielmehr ein Buch für ein humanistischgelehrtes Publikum war. Über den Kompilator der wenigstens schon 100 Jahre vor dem Datum des Erstdrucks bekannten Schwänke ist nichts Sicheres bekannt; es wird im Allgemeinen angenommen, dass es sich dabei um den Braunschweiger Chronisten und Zollschreiber Hermann Bote (um 1467-um 1520) handelt. Wirkliche Belege für diese Hypothese gibt es jedoch nicht. Ob die Titelfigur Till Eulenspiegel auf eine historische Person zurückzuführen ist, die zwischen 1300 und 1350 lebte, kann ebenfalls nicht nachgewiesen werden. Der ambivalente Charakter Eulenspiegels sein Handeln bewegt sich zwischen erzieherisch-entlarvend und boshaft-zerstörerisch hat Anlass zu widersprüchlichen Interpretationen gegeben. Es ist jedoch anzunehmen, dass die Figur bewusst mehrdeutig gestaltet worden ist, um den Leser zum Nachdenken anzuhalten. Das genaue Abwägen des Für und Wider einer Sache galt im rhetorisch geprägten Zeitalter des Humanismus als eine besondere, immer wieder zu übende Kunst.
Aufgeschlagen ist das Titelblatt mit einem Holzschnitt, der Eulenspiegel in einem Bienenkorb zeigt. Der gut erhaltene Druck hat einen Umfang von 168 ungezählten Blättern, die recht knapp beschnitten und zum Teil von Hand foliiert sind. Im Text finden sich weitere 100 Holzschnitte in vielfach variierten Zierrahmen, in denen Eulenspiegel beim Ausüben seiner Späße zu sehen ist. Hinzu kommen zwei Schmutzblätter, deren vorderes handschriftliche Bemerkungen zu den Vorbesitzern in Tinte und Blei enthält. Der Text bricht in der Historie $\mathrm{C}$ ab; das hintere Schmutzblatt trägt von Hand hinzugefügte Textergänzungen zu den fehlenden Historien CI und CII sowie den Eulenspiegel-Epitaph. Dem Titelblatt ist ein Holzschnitt des 19. Jahrhunderts vorgebunden, auf dem Eulenspiegel zu Pferd mit einer Eule und einem Spiegel in den Händen abgebildet ist. Die Ausgabe ist äußerst selten und wurde mit dem Ankauf durch die Niedersächsische Staats- und Universitätsbibliothek erstmals bibliographisch nachgewiesen.

(JMb) 


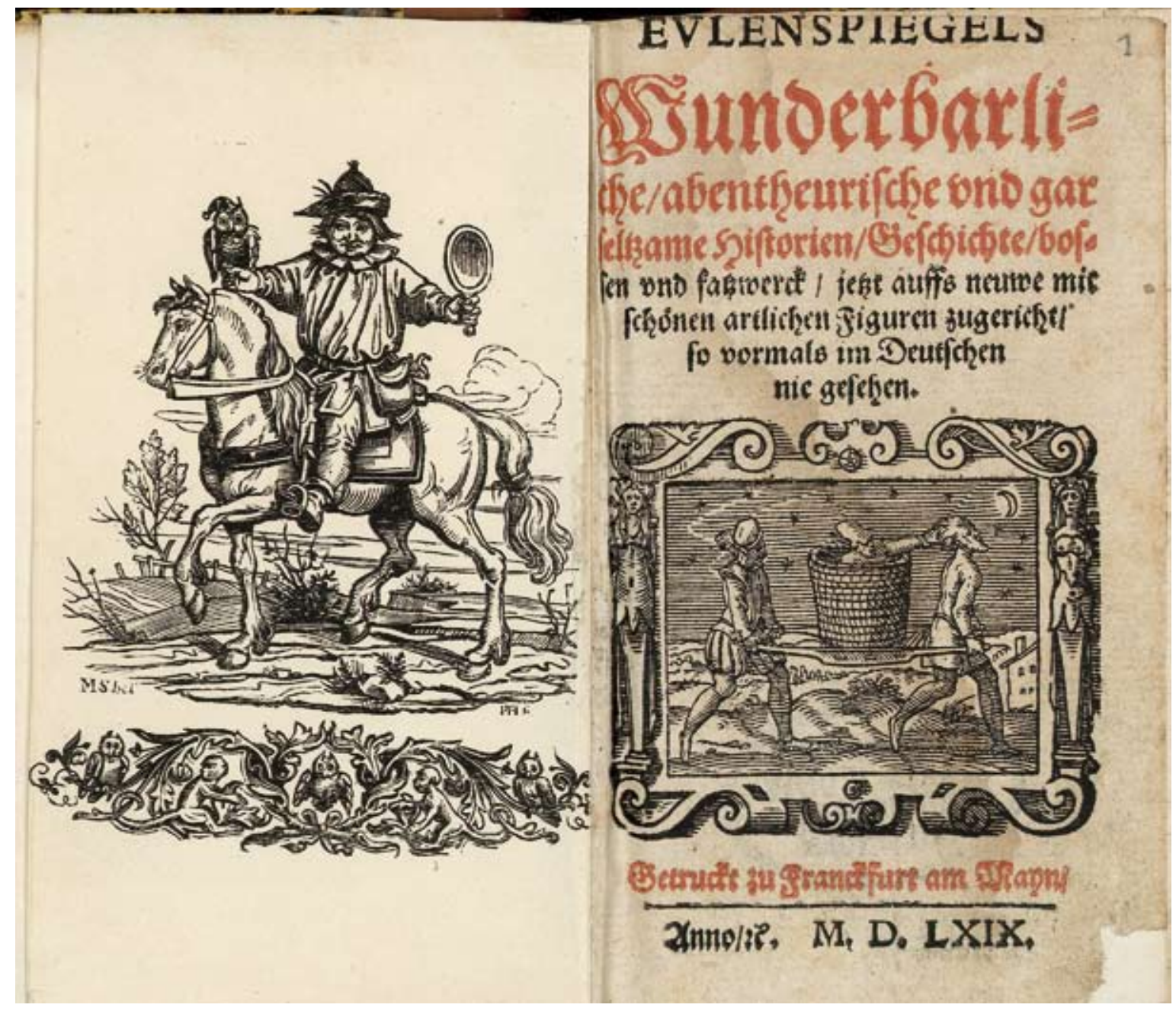




\section{Kapitel 5}

\section{Buchhandel und Antiquariat}

Die natürlichen Ansprechpartner bei der Beschaffung von Literatur waren und sind für die Bibliothek seit jeher jene Unternehmen, die den Medienvertrieb gewerbsmäßig betreiben: Buchhändler für verlagsfrische und im Sortiment vorgehaltene Titel, Antiquariate für ältere und bereits benutzte Bücher. Noch im 18. Jahrhundert war freilich der übliche Weg für die Veräußerung gebrauchter Werke die Auktion (s. Kap. 4). Eine Festigung des Tätigkeitsbereiches der Antiquare und ihre uns heute ganz geläufige Funktion im Buchhandelsbetrieb begannen sich damals gerade zu entwickeln und erlebten erst am Beginn des 19. Jahrhunderts einen Aufschwung: Voraussetzungen der Existenz von Antiquariaten waren zum Einen die immer größer werdenden Mengen neuer Bücher, die über den Sortimentsbuchhandel verkauft wurden. Vor dem Hintergrund neuer Buchherstellungsverfahren, eines veränderten Leseverhaltens, eines wachsenden Informationsbedürfnisses und des sprunghaft anwachsenden Wissens der Zeit wurden mehr Bücher hergestellt, waren aber viele Bücher auch schneller inhaltlich überholt und wurden ausgesondert. Zum Anderen gewann die funktionale Trennung zwischen Buchhandlung und Antiquariat erst mit der Einführung von Festpreisen für verlagsfrische Bücher so viel Schärfe, dass sich getrennte Geschäftsbereiche entwickeln konnten.

Einer der wichtigsten Partner der Universitätsbibliothek für Literaturbeschaffung vor Ort war in Göttingen die Dieterichsche Buchhandlung, über die die Bibliothek auch so ungewöhnliche Produktionen wie Goethes Farbenlehre beziehen konnte. Johann Christian Dieterich (1722-1800) besaß bereits eine Buchhandlung in Gotha, als er in Göttingen sein Geschäft eröffnete, das nicht zuletzt durch die Universität gut lief, zum ersten Haus am Platz wurde und ihn alsbald zur Aufgabe seiner Buchhandlung in Gotha veranlasste.
Nachdem er seine Tätigkeit auch auf den Druck von Büchern ausgedehnt hatte, veröffentlichten namhafte Universitätslehrer bei Dieterich. Wichtige und angesehene Periodika aus seinem Hause trugen ihren Teil zum Renommee des Betriebes bei. Im 19. Jahrhundert liefen die Geschäfte zeitweise weniger gut. Der Insolvenz von 1865 folgte jedoch eine Neugründung als Dieterichsche Universitätsbuchhandlung und Antiquariat. Das Verlagsgeschäft ging 1897 nach Leipzig und ist heute in Mainz angesiedelt.
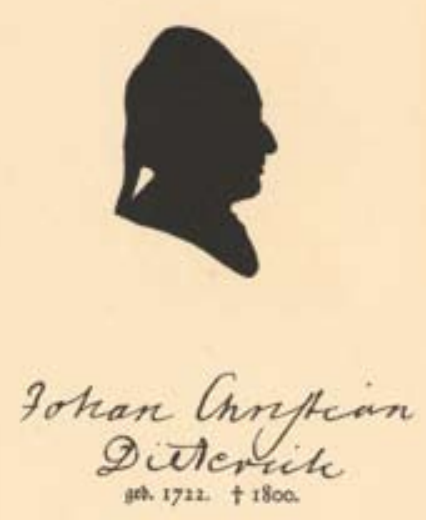

Johann Christian Dieterich.

Zu den selbst gesteckten Zielen der Göttinger Bibliothek gehörte es von Beginn an, die zur Anschaffung vorgesehenen Titel in ihrer jeweiligen Originalausgabe zu besitzen. Bei fremdsprachiger Literatur bedeutete dies in der Regel die Beschaffung aus dem Ausland, da die Infrastruktur für den Vertrieb von Büchern in jenen Zeiten bei weitem nicht so 
leistungsfähig war wie heute. In der Praxis bedurfte es also eines Netzes von Kontakten zu auswärtigen Händlern, die die gewünschten Werke besorgen und nach Göttingen liefern konnten. Für Titel aus dem französischen Sprachraum übernahm diese Funktion die Buchhandlung Treuttel in Straßburg. Johann Georg Treuttel (1744-1826) stammte aus dem Elsass, widmete sich nach einem Studium der Theologie dem Buchhandel und übernahm in Straßburg das Geschäft des Buchhändlers Bauer. Bedingt durch die Wirren der Revolutionszeit gelangte Treuttel nach Paris und eröffnete auch dort eine Buchhandlung. Wie viele seiner damaligen Berufskollegen sah Treuttel im Buch nicht nur das Handelsgut. Vor allem die Bildung seiner Mitmenschen im christlichen Sinne lag ihm am Herzen. Dennoch war er ein erfolgreicher Geschäftsmann und darüber hinaus ein zuverlässiger Lieferant französischer Werke nach Göttingen.

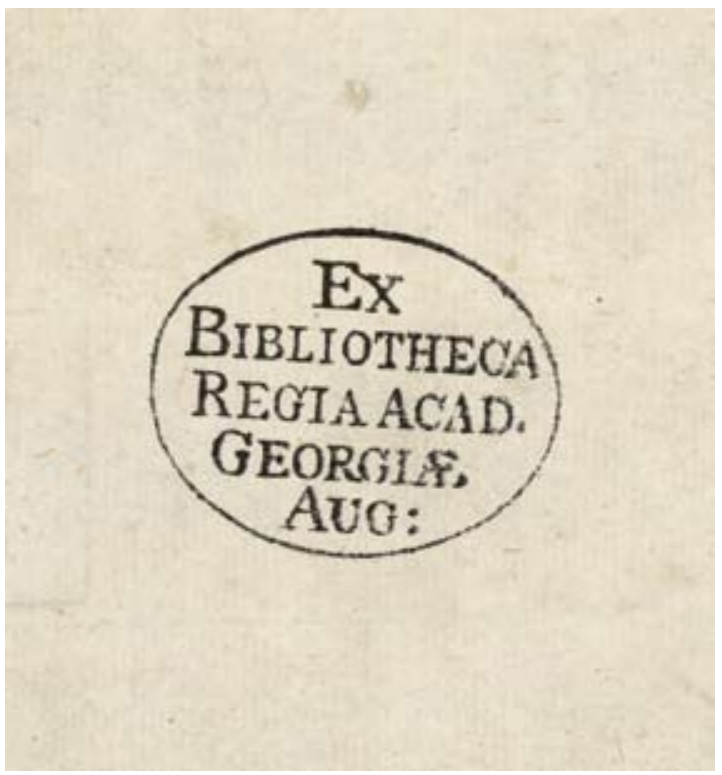

Besitzstempel der Bibliothek.

Für antiquarische Erwerbungen sind die internationalen Kontakte zu Händlern bis heute entscheidend geblieben, auch wenn
Online-Kataloge und internationale Messen die Marktbeobachtungen inzwischen sehr erleichtern. Die Herkunft mancher Bücher aus namhaften Antiquariaten im In- und Ausland belegen die weltweit geknüpften Erwerbungskontakte der Bibliothek. 


\section{Vulkanologische Lusterscheinungen}

Sir William Hamilton:

Campi Phlegræi : Observations on the volcanos of the two Sicilies:

As they have been communicated to the Royal Society of London.

Neapel [1776].

Signatur: gr. $2^{\circ}$ Min. II, 556: Tafelbd Rara

Provenienz: Bauer \& Treuttel (Buchhandel), Straßburg 1778

„Am Sonntag, den 25sten [1766], regnete es zu Neapel den ganzen Tag über kleine Asche:

Sie schoß aus dem Crater des Vulkans empor.... Aus der schwarzen Säule schossen unaufhörlich Strahlen eines blitzförmigen Feuers ... . Ich ergötzte mich ungemein an dieser Lusterscheinung.“ Diese und andere Beschreibungen wurden von ihrem Autor, dem britischen Gesandten Sir William Hamilton (1730-1803), Berichten aus Neapel angefügt, die er seit 1764 regelmäßig der englischen Regierung schickte. Mit der Zeit wuchsen sie sich zu eigenständigen vulkanologischen Reportagen aus, die Hamilton, zu diesem Zeitpunkt bereits Mitglied der Royal Society, ihrem Präsidenten, dem 14. Earl of Morton, zusandte. Die Schilderungen galten bald als die besten ihrer Zeit. Hamiltons insgesamt sechs Briefe aus dem Zeitraum von 1766 bis 1771 wurden schließlich in den Philosophical Transactions, den wissenschaftlichen Jahresberichten der Royal Society, veröffentlicht und stießen auf so großes Interesse, dass der Verleger und Buchhändler Thomas Cadell d. Ä. sie gesammelt in Buchform herauszugeben beschloss: 1772 erschienen die Observations on Mount Vesuvius, Mount Etna and other volcanos in zwei Bänden; im Folgejahr wurde bei Hermann Heinrich Holle in Leipzig auch eine deutsche Ausgabe gedruckt.
Der Golf von Neapel galt als ,ideale Landschaft", der Tourismus dort florierte und der Absatz von Hamiltons Buch ebenso. So lag die Entscheidung nahe, aus den Observations einen Prachtband zu machen. 1776 erschienen die Campi Phlegrcei zweisprachig in englischer und französischer Sprache. Sie waren mit 54 handkolorierten Tafeln von vulkanischen Landschaften aus der Umgebung von Neapel, Vesuvausbrüchen, Gesteinsabbildungen und Kraterseen versehen. Der englische Maler Pietro Fabris (1756-1792) fertigte die Zeichnungen, die als Vorlage für die Stiche dienten, und aquarellierte sie. Stecher der Tafeln war der bekannte Landschaftsmaler und Kartenzeichner Paul Sandby (1725-1809). Er ist berühmt für seine beispiellose Beherrschung des damals noch neuen Aquatinta-Verfahrens, einer Methode des Tiefdrucks, die flächige Tonabstufungen ähnlich der Tuschezeichnung möglich machte. Fabris' Naturwiedergaben faszinieren durch ihren Dokumentarcharakter und die Intensität der Darstellung, die die farbmächtigen Szenerien nahezu sinnlich erlebbar werden lassen. Sie machen die Vulkandarstellungen heute noch zu dem, was die Vulkanausbrüche selbst vor über 200 Jahren für Hamilton waren: eine „Lusterscheinung“. 


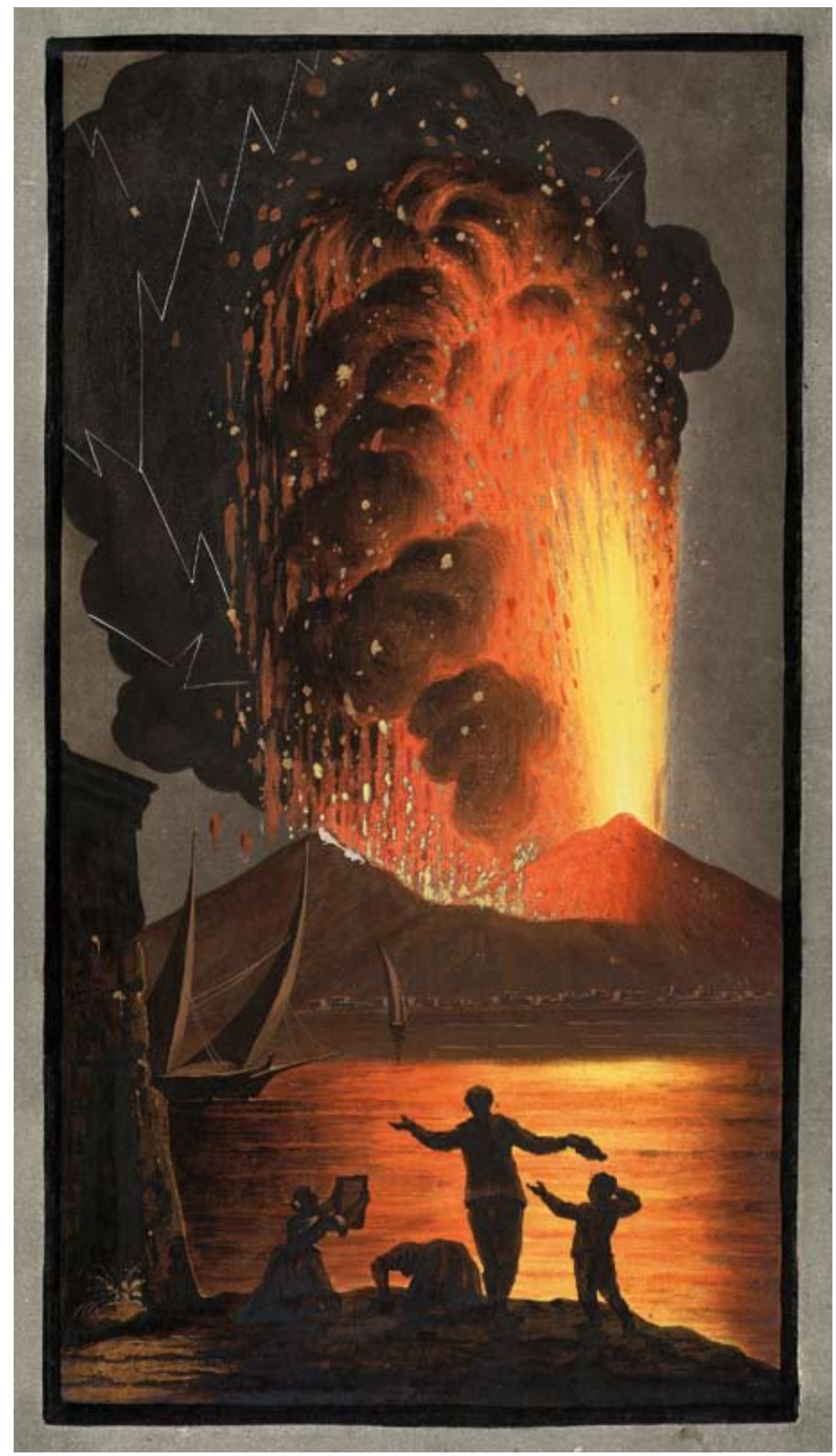




\section{Göttingen und Goethes Farbenlehre}

Johann Wolfgang von Goethe:

Zur Farbenlehre. Erster Band. Nebst einem Hefte mit sechzehn Kupfertafeln, Tübingen, in der J. G. Cottaschen Buchhandlung 1810. Entwurf einer Farbenlehre. Des ersten Bandes, erster, didaktischer Theil. Enthüllung der Theorie Newtons. Des ersten Bandes zweyter, polemischer Theil. Zur Farbenlehre. Zweyter Band. Tübingen, in der J. G. Cottaschen Buchhandlung 1810. Materialien zur Geschichte der Farbenlehre. Des zweyten Bandes Erster, historischer Theil.

Signatur: $8^{\circ}$ Phys. III, 4127 Rara

Provenienz: Dieterichsche Buchhandlung, 1810

„Wann der Blick an heitern Tagen

Sich zur Himmelsbläue lenkt, Bey'm Siroc der Sonnenwagen

Purpurroth sich niedersenkt, Da gebt der Natur die Ehre, Froh, an Aug' und Herz gesund, Und erkennt der Farben Lehre Allgemeinen ew’gen Grund.“

Diese Verse sandte der fast 78-jährige Goethe (1749-1832) einem jungen Bewunderer seiner Farbenlehre, nicht ohne hinzuzusetzen: „Ich brauche nicht zu sagen: halten Sie fest daran; es hält Sie fest, Sie werden nicht loskommen.“ Wie auch Goethe nicht davon losgekommen ist: Von dem Augenblick an, da er, durch ein Prisma auf eine weiße Wand blickend, Newtons Lehre für falsch befand, hielt ihn das „Farbenwesen“ bis in seine letzten Lebenswochen gefangen. Was er erkannt zu haben glaubte, hat er der Nachwelt in seinem Opus magnum Zur Farbenlehre überliefert, das er für wichtiger hielt als sein poetisches Schaffen. Für Goethe war das Licht einfach und homogen, es konnte weder in farbige Bestandteile zerlegt, noch aus solchen zusammengesetzt werden. Alle Experimente, die das Gegenteil zu beweisen schienen, waren in seinen Augen falsch. Als er den renommierten Göttinger Physiker Georg Christoph Lichtenberg (1742-1799) davon zu überzeugen suchte, als er „das ekelhafte Newtonische Weiß mit Gewalt verfolgte“, brach Lichtenberg ab „über diese Dinge zu schreiben und zu antworten. “ Kurz zuvor noch hatte er mit großem Interesse und Vergnügen Goethes

Untersuchung der farbigen Schatten verfolgt und mit ihm darüber korrespondiert. Hatte Goethe auch vergeblich um Lichtenbergs Beifall geworben, so fand er doch später in Göttingen Beistand und Hilfe. Als er im Sommer 1801 nach Göttingen kam, hatte er eine Liste von Büchern bei sich, die er in der Bibliothek zu finden hoffte. Und er wurde von dem,,allgelahrten Göttingen“ nicht enttäuscht. „Zur Geschichte der Farbenlehre habe ich auf der Bibliothek recht viel und glücklich zusammengearbeitet“, kann er dem Freunde Meyer nach Weimar melden. Und die Göttinger Bibliothek kann sich rühmen, dass sie Goethe aus ihren Schätzen einen großen Teil der Materialien zu dieser Geschichte hat präsentieren können.

Die Tafel XII aus dem Hefte mit Kupfertafeln soll Newtons Experiment 14 von Bk. I. Pt. I der Opticks illustrieren. Newton demonstriert dort, dass Fliegen oder kleine dunkle Körper, durch ein Prisma betrachtet, klar und deutlich erscheinen, wenn sie mit homogenem (monochromatischem) Licht bestrahlt werden, dagegen undeutlich und verschwommen, wenn sie mit Tageslicht beleuchtet werden. Goethe moniert, dass Newton „bloß dunkle Körper in dem sogenannten homogenen Licht beobachtet und beobachten kann, dass unser Versuch hingegen eine Mannichfaltigkeit von Fällen darbietet.“ Schon die Beschriftung der Tafel mit „Newtonische Mucken“ (eigensinnige Launen), zeigt Goethes polemische Absicht. 


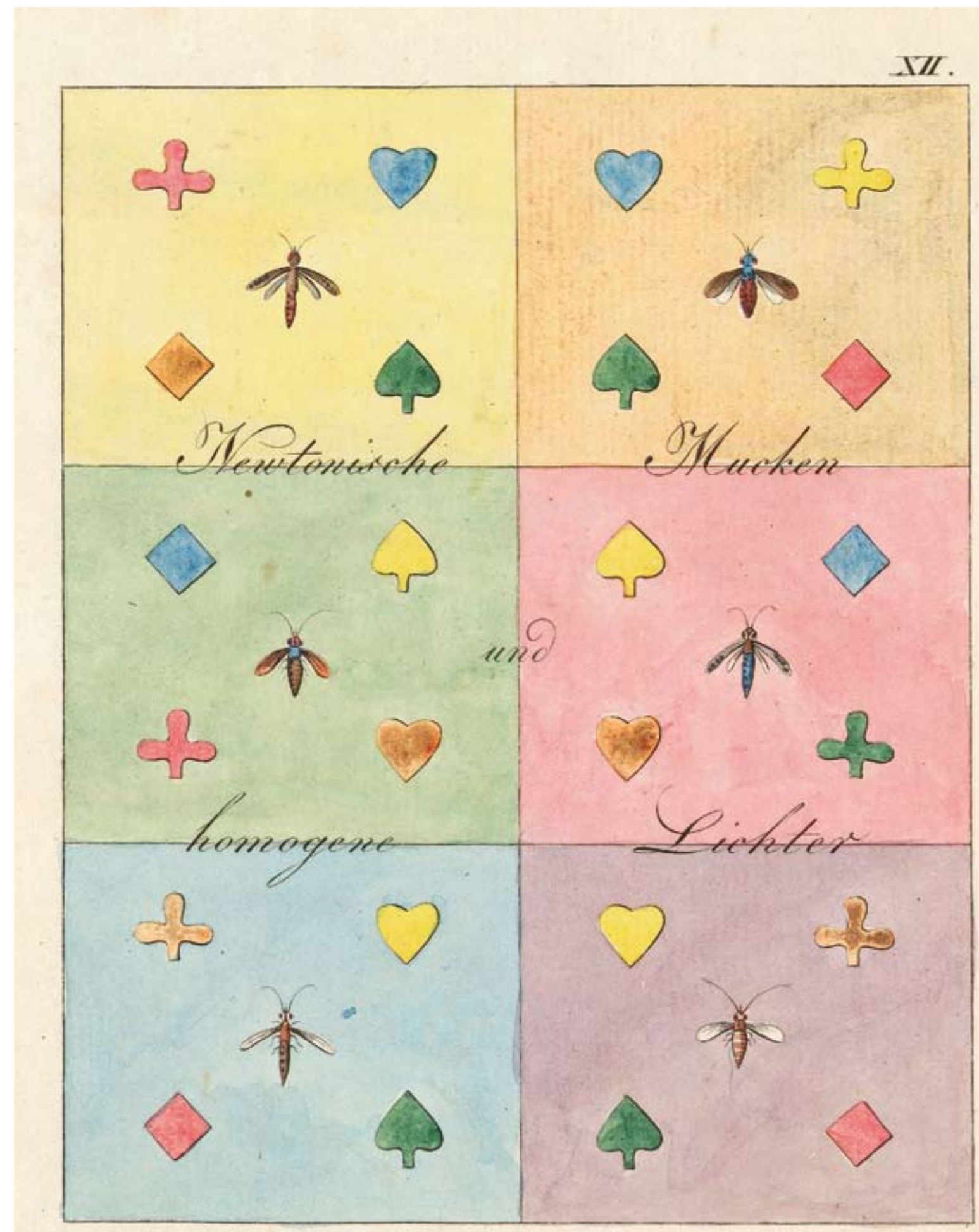




\section{Die Rosen von Redouté}

Pierre-Joseph Redouté:

Les roses. Text par Claude-Antoine Thory. Paris: Firmin Didot, 1817, 1821 und 1824.

Signatur: gr. $2^{\circ}$ Hist. nat. bot. IV, 7860 Rara

Provenienz: Buchhandlung Treuttel (Straßburg); 1817, 1821 und 1824

Pierre-Joseph Redouté (1759-1840) zählt zu den bedeutendsten Blumenmalern Frankreichs. Er wuchs in einer Künstlerfamilie auf und begab sich in seiner frühen Jugend als Wand- und Porträtmalergeselle auf Wanderschaft. In Holland entwickelte sich sein besonderes Interesse an der Blumenmalerei. 1782 ging Redouté nach Paris, der Hauptstätte seines Wirkens, wo er sich neben seiner Tätigkeit als Kulissenmaler am Théatre Italien dem Blumenzeichnen widmete. Der Botanische Garten des Biologischen Instituts „Jardin du Roi“ bot ihm ideale Arbeitsbedingungen. Vor allem begegnete er dort Gerardus van Spaendonck (1746-1822) und CharlesLouis L’Heritier de Brutelle (1746-1800), die ihm bei seiner Ausbildung zum botanischen Illustrator sehr förderlich waren. Von van Spaendonck erlernte Redouté die Technik des Aquarellierens und den Farbpunktstich, für deren Meisterschaft er berühmt wurde.

Unter den zahlreichen Veröffentlichungen Redoutés war und ist das dreibändige Werk Les Roses am berühmtesten. Kurz nach der Erstauflage 1817 wurde in der kaiserlichen Porzellan-Manufaktur in St. Petersburg ein Service mit Redoutés Rosenmotiven angefertigt. Das Werk umfasst drei Text- und drei Tafelbände und erschien 1817, 1821 und 1824 in Paris. Der Textautor Claude-Antoine Thory (1759-1827) schrieb im Vorwort, es sei sowohl für Rosenliebhaber als auch für Botaniker bestimmt. Die Abbildungen, welche einheimische und fremdländische Arten umfassen, stützten sich auf Rosensammlungen in Paris und Umgebung. In den
Textbänden finden sich zu jeder Rosenabbildung eine botanische Bestimmung und die Beschreibung ihrer Merkmale, anschließend folgen die Geschichte der Rose und ihrer Entdeckung. Der letzte Band enthält außerdem ein Rosenglossar und eine 200 Titel umfassende Bibliographie. Zeitgleich mit der auf nur fünf Exemplare limitierten GroßfolioAusgabe wurde eine kleine Folio-Ausgabe veröffentlicht.

Die Göttinger Exemplare gelangten in den Erscheinungsjahren über die Straßburger Buchhandlung Treuttel, Hauptlieferantin für französische Werke, in den Besitz der Universitätsbibliothek. Redoutés kunstvolle Darstellungen der Rosen sind weithin bekannt und genießen noch heute eine besondere Beliebtheit. Vom Kunstdruck bis zur Vorlage für Postkarten und Briefpapier werden Redoutés Rosenmotive vielfältig reproduziert.

(AK) 


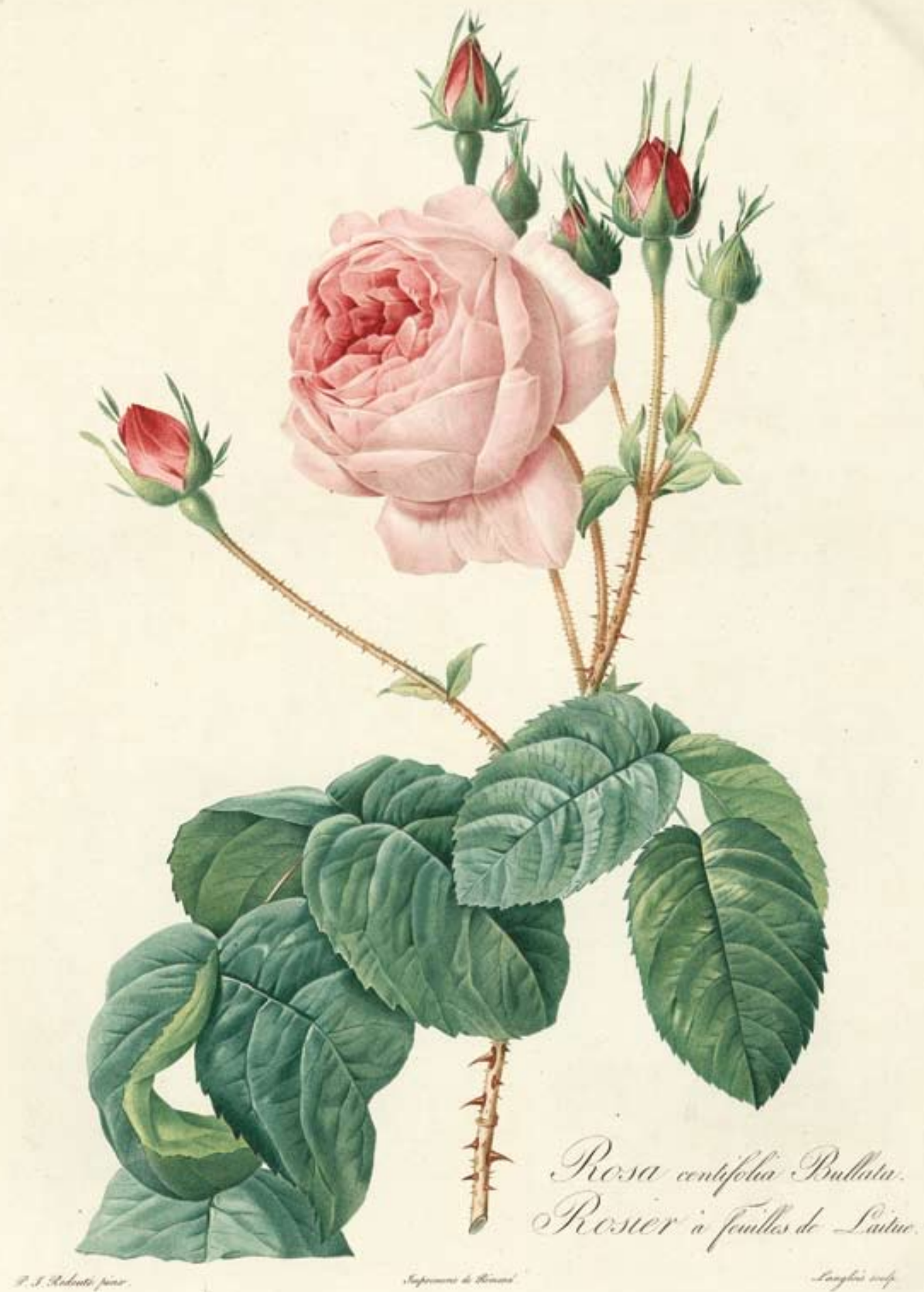




\section{Eine „überköstliche Ballade“}

Gottfried August Bürger:

Lenore.

Papierhandschrift,

Göttingen [?], 9. September 1773.

Signatur: $8^{\circ}$ Cod. Ms. philol. 206 Cim.

Provenienz: Antiquariat Wilhelm Zentner, Prag 1925

Gottfried August Bürger (1747-1794) war ein bedeutender Dichter der Sturm-undDrang-Epoche, der mit seiner kraftvollvolkstümlichen, manchmal derben und oft sozialkritischen Dichtung in die Literaturgeschichte eingegangen ist. Lenore, die Ballade von der jungen Soldatenbraut, die ihrem im Krieg gefallenen Geliebten ins Grab folgt, gehört heute ebenso zum Kanon wie jene Ballade von der armen, durch einen adligen Strolch verführten Tochter des Pfarrers von Taubenhain. Weitere bedeutende Werke Bürgers sind das Gedicht Der Bauer. An seinen Durchlauchtigen Tyrannen oder die (anonym bearbeiteten) Erzählungen vom Lügenbaron Münchhausen (s. Nr. 13). Zu Lebzeiten allerdings musste sich der von persönlichem Unglück verfolgte Herausgeber des Göttinger Musenalmanachs neben Lob auch immer wieder herbe Kritik seiner Dichtung anhören. Am schlimmsten traf ihn das rundweg negative (und leider überaus einflussreiche) Urteil Friedrich Schillers, der 1791 bei Bürger die Kunst des Idealisierens und Veredelns vermisste - eine Kunst, die Bürgers Dichtungskonzept in keiner Weise entsprochen hat. Von Schillers Kritik erholte sich Bürger nie, er starb vereinsamt und verarmt wenige Jahre später.

Die unglaublich erfolgreiche Lenore war der Höhepunkt in Bürgers Balladenschaffen und ließ ihn zum Begründer der deutschen Kunstballade werden. Die Handschrift, die wahrscheinlich aus dem Nachlass von Johann Heinrich Voß (1771-1826) stammt und 1925 über einen Düsseldorfer Bankier sowie einen Prager Antiquar für 5.000 Goldmark in den Besitz der Göttinger Bibliothek gelangt ist, besteht aus vier Lagen, d. h. acht Blättern. Blatt 4 ist in Falznähe abgeschnitten und ersetzt worden. Blatt $4^{\mathrm{r}}$ trägt drei Strophen, ansonsten stehen auf Blatt $1^{\mathrm{r}}$ bis $7^{\mathrm{v}}$ zwei Strophen, die mit Ausnahme der letzten beiden von Bürger nachträglich nummeriert worden sind. Blatt $8^{r}$ enthält eine Nachschrift Bürgers, die Hinweise zum Druck der dialogischen Teile des Gedichts gibt. Blatt $8^{\mathrm{v}}$ ist leer. Die Niederschrift stellt somit eine Zwischenstufe zwischen der Urfassung und der 1774 im Musenalmanach veröffentlichten Version dar. Einzelne Worte sind unterstrichen und mit darüber stehenden eigenhändigen Korrekturen versehen. Am Rand finden sich kritische Bemerkungen von Heinrich Christian Boie (1744-1806), dem Mitbegründer des Göttinger Hainbundes und engen Freund und Berater Bürgers. Zusammen mit Bürgers Briefwechsel gewährt die Handschrift einen fast lückenlosen Einblick in den Schaffensprozess seiner „überköstlichen Ballade“, der „unsterblichen Lenora“. 


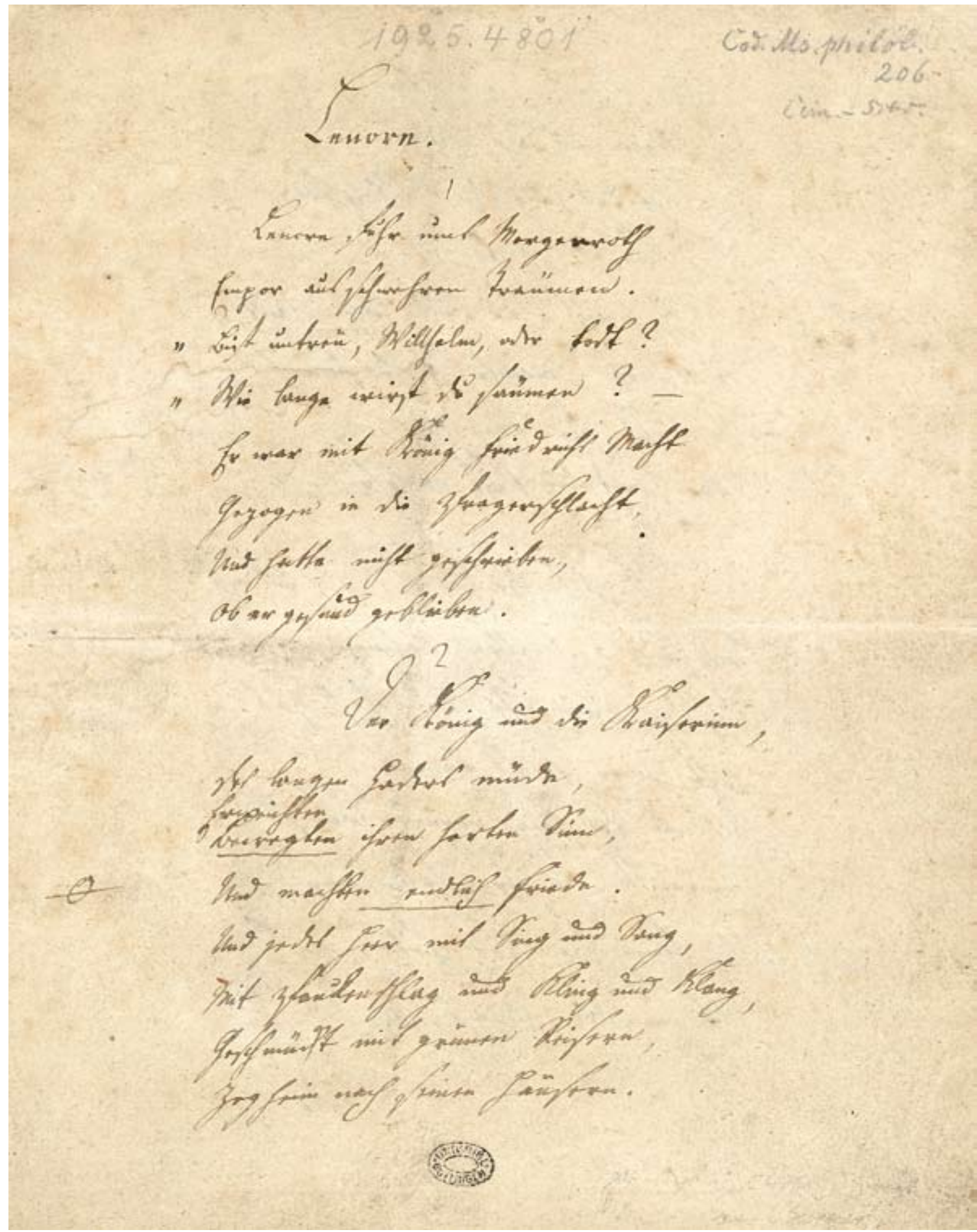




\section{Die Wiedergewinnung des Mittelalters im Viktorianismus}

Geoffrey Chaucer:

The works of Geoffrey Chaucer now newly imprinted. Ed. by F. S. Ellis. Ornamented with pictures designed by Eduard Burne-Jones, and engraved on wood by W. H. Hooper. Printed by W. Morris. Hammersmith: Kelmscott Press, 1896.

Signatur: $2^{\circ}$ Poet. Angl. 4346 Rara

Provenienz: Antiquariat Bernard Quaritch, London 1961

In seinem Todesjahr legte der englische Kunsthandwerker, Dichter und Sozialreformer William Morris (1834-1896) eine Ausgabe der Werke Geoffrey Chaucers (um 1343-1400) vor, des bedeutendsten Dichters der mittelenglischen Literatur, die als Kelmscott Chaucer berühmt wurde. Morris, der sich seit seiner Oxforder Studienzeit lebhaft für die mittelalterliche Kunst und Literatur, für Handschriften und Wiegendrucke interessierte, betrachtete die materielle und ästhetische Qualität industriell gefertigter Produkte seiner Zeit als Niedergang und trachtete danach, die handwerklichen und künstlerischen Traditionen des späten Mittelalters wiederzubeleben. Seit 1861 betrieb er eine Werkstatt für Inneneinrichtungen, die dem Arts and Crafts Movement wesentliche Impulse verlieh; 1891 gründete er die Kelmscott Press, die bis 1898 bestand. Ihr charakteristisches Aussehen erhielten die hier gedruckten 53 Werke durch die Verwendung von Schriften, die in Anlehnung an Wiegendrucktypen entworfen worden waren, und von üppigen, im Sinne des Präraffaelitentums bzw. des Jugendstils gestalteten Initialen, Holzschnittbordüren und Holzschnittillustrationen. Der in fünfjähriger Arbeitszeit entstandene Kelmscott Chaucer gilt als Höhepunkt der Tätigkeit der Kelmscott Press. Er ist in der Chaucer Type gesetzt, einem kleineren gotischen Schrifttyp, und vereint nicht weniger als 87 opulente Holzschnittillustrationen, deren Vorlagen von dem präraffaelitischen Künstler und Studienfreund Morris' Edward Burne-Jones (1833-1898) stammen. Die Gesamtauflage belief sich auf 438 Exemplare.
Bereits 1854, noch während der Oxforder Studienzeit, hatten Morris und Burne-Jones zusammen Chaucers Canterbury Tales gelesen. Die um 1478 erschienenen, unvollendet gebliebenen Erzählungen schildern eine Reise von dreißig Pilgern von London nach Canterbury zum Grab des heiligen Thomas Becket. Um die Reise zu verkürzen, erzählen sie einander Geschichten. Spiegeln die erzählenden Personen bei aller ihrer Individualität die mittelalterliche Ständehierarchie, so bieten ihre Erzählungen selbst das Spektrum der im Mittelalter verbreiteten Literatur von der derben Schwankliteratur bis zum höfischen Roman dar. Aufgeschlagen ist der Beginn des berühmten Prologs, in dessen ersten Zeilen das Erwachen der Natur im Frühling geschildert wird. Die Holzschnittillustration zeigt den Dichter in kontemplativer, inspirierter Pose inmitten einer üppigen Frühlingslandschaft mit zwitschernden Vögeln und blühenden Pflanzen. 


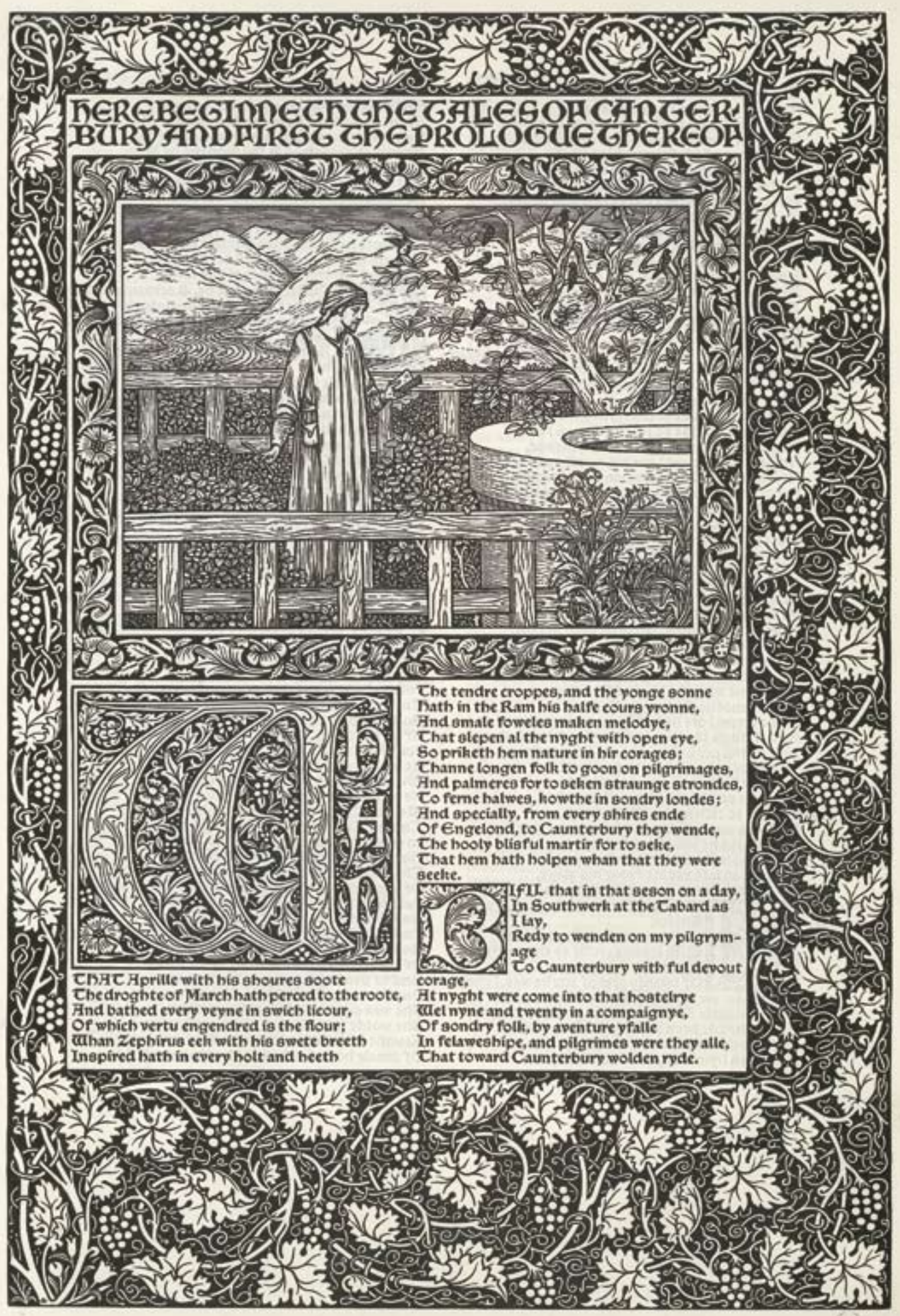




\section{Eines der schönsten deutschen Bücher des 20. Jahrhunderts}

Publius Vergilius Maro:

Eclogen und Georgica in der Ursprache und deutsch. Band 1: Die Eclogen.

Weimar: Cranach-Presse, 1926.

Signatur: $4^{\circ}$ Auct. Lat. II, 7660 Rara

Provenienz: Galerie Gerd Rosen, Berlin 1961

Der gebürtige Hamburger Harry Graf Kessler (1868-1937) hat wie nur wenige andere mit einer Vielzahl an Aktivitäten und in einem weit gespannten Netzwerk von Freunden und Bekanntschaften das kulturelle und politische Leben seiner Zeit mit geformt, ohne selbst dauerhaft in der vordersten Reihe der öffentlich wahrgenommenen Protagonisten gestanden zu haben. Nach einem Jurastudium widmete sich Kessler ganz der Kunst und gehörte schon mit 25 Jahren dem Redaktionsstab der berühmten Kunstzeitschrift Pan an. In Weimar versuchte er, mit namhaften Künstlern und Literaten ein fortschrittliches, weltoffenes Kulturprogramm zu installieren, scheiterte jedoch am Widerstand konservativer Kreise. Kessler pflegte engen Kontakt zum Insel-Verlag, gründete den Deutschen Künstlerbund, war nach dem Ersten Weltkrieg deutscher Gesandter in Warschau, gehörte zu den Mitbegründern der Deutschen Demokratischen Partei und veröffentlichte zukunftsweisende Gedanken über den Aufbau einer politischen Weltorganisation.

Neben diesen vielfältigen Verpflichtungen führte Kessler die Geschäfte seiner CranachPresse (so benannt nach der Straße in Weimar, in der Kessler gewohnt hatte). Mit diesem Unternehmen stellte er sich in die Tradition der Privatpressen, die sich bereits am Ende des 19. Jahrhunderts zur Aufgabe gemacht hatten, dem zur Massenware gewordenen Handelsgut „Buch“ den künstlerisch gestalteten, handwerklich perfekten Druck gegenüber zu stellen. Mit der Gestaltung und Herstellung von Büchern hatte sich Kessler schon vor der
Gründung seiner Presse intensiv beschäftigt, seine Kontakte zu Schriftschneidern, Illustratoren, Literaten und Verlegern kamen ihm jetzt sehr zugute. Schon sehr früh interessierte er sich für Vergil, doch erst in den 20er Jahren konnte er das Projekt vorantreiben und fertigstellen. Die eigens angefertigte Schrifttype orientierte sich an der Antiquaschrift, die Nicolaus Jenson 1470 in Venedig benutzt hatte. Für den Buchschmuck gewann Kessler den französischen Künstler Aristide Maillol (1861-1944), den er mit viel Überredungskunst und List zur Gestaltung der Abbildungen und Verzierung der Initialen brachte. Der Aufwand lohnte sich. Es entstand eines der schönsten deutschen Bücher des 20. Jahrhunderts, das schon 1927 auf der BuchkunstAusstellung in Leipzig prämiert wurde. Hergestellt wurden von der deutschen Ausgabe (es gab auch eine französische und eine englische) acht Exemplare auf Pergament, 36 Stücke auf Seidenpapier und 250 Drucke auf Büttenpapier. Die Universitätsbibliothek Göttingen besitzt das nummerierte Exemplar 195. 


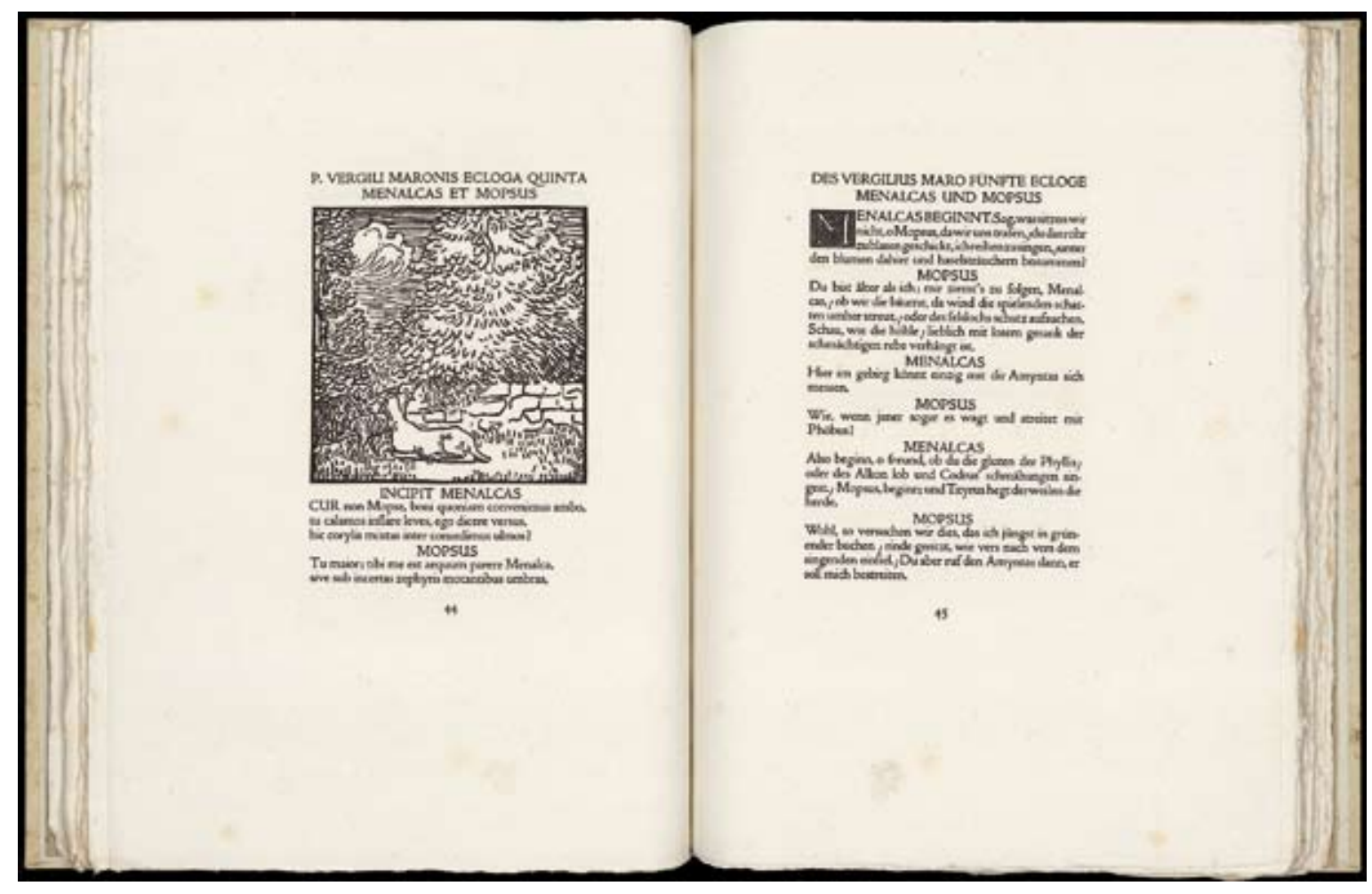




\section{Kapitel 6}

\section{Von adliger Herkunft}

Das Renommee der Göttinger Universitätsbibliothek bewog eine ganze Reihe hochgestellter Persönlichkeiten, Fürsten wie Könige, zu wertvollen Geschenken. So stiftete Georg Prinz von Waldeck (1747-1813), der Bruder des regierenden Fürsten Friedrich von Waldeck, der Bibliothek im Mai 1794 zwanzig Wiegendrucke, vorwiegend Autoren der klassischen Antike und des Humanismus. Wenige Jahre später, im Januar 1801, wurden aus der Bibliothek der in Arolsen residierenden Fürsten von Waldeck 180 alte Drucke nach Göttingen gesandt - diesmal allerdings leider nicht als Geschenke. Das im Zugangsbuch der Bibliothek genannte „Verzeichniß der im Jan. 1801 von Arolsen an die Univers. biblioth. verkauften Bücher“ führt unter anderem 23 Inkunabeln auf, meist die geläufigen Autoren der Spätantike und des Mittelalters. Dass die fraglichen Bücher tatsächlich aus der Fürstlich Waldeckschen Bibliothek stammen, wird erhärtet durch das Supralibros auf dem Augustinus-Band von 1467 (s. Nr. 54): Unter einer Fürstenkrone sind die Initialen „G[eorg von] W[aldeck]“ eingeprägt.

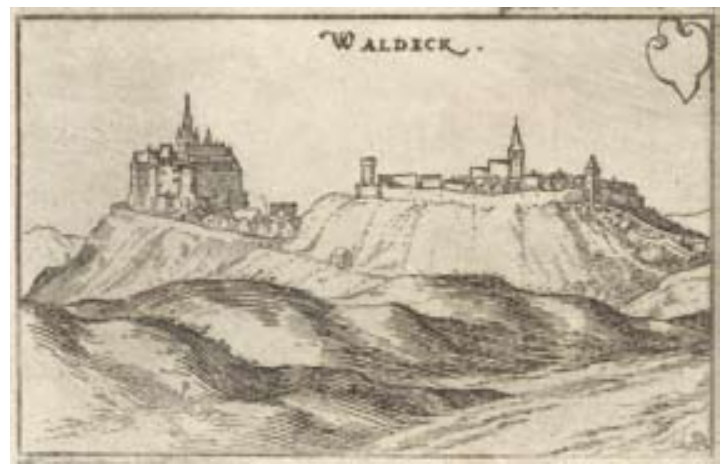

Schloss Waldeck bei Arolsen.

Unter den 1794 übereigneten Drucken des Prinzen von Waldeck befand sich auch eine lateinische Fassung der Vorlesungen des Aristoteles über die Natur oder Physik, die aus der Bibliothek des ungarischen Königs Matthias Corvinus (1443-1490) stammte (s. Nr. 48). Auf mitunter verschlungenen und nicht immer rekonstruierbaren Wegen trafen auch weitere Werke aus den Bibliotheken illustrer adliger Vorbesitzer in Göttingen ein, so für die englische Königin Elizabeth I. (1533-1603), den französischen König Ludwig XIV. (1638-1715) oder Napoléon Bonaparte (1769-1821) gefertigte wertvolle Einbände. In ihrer prunkvollen Gestaltung heben sie sich deutlich von den zumeist schlichten braunen Kalbsleberbänden ab, in die die Göttinger Bibliothek ihre für den alltäglichen wissenschaftlichen Gebrauch bestimmten Neuerwerbungen binden ließ.

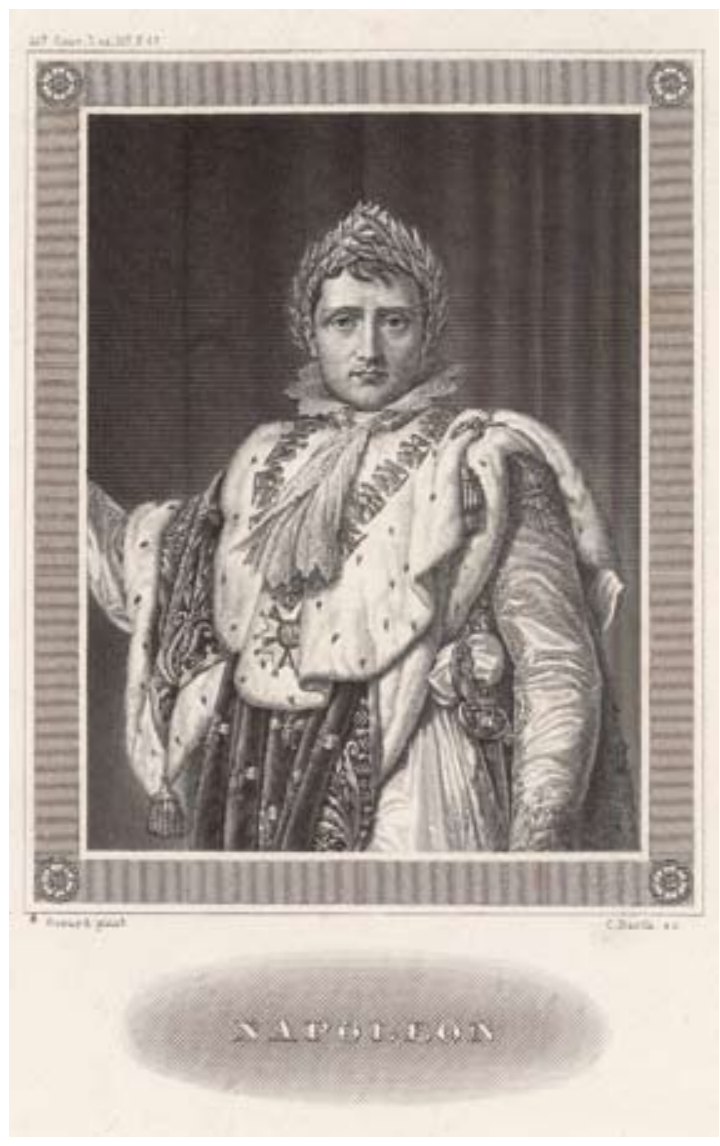

Napoléon Bonaparte (1769-1821). 


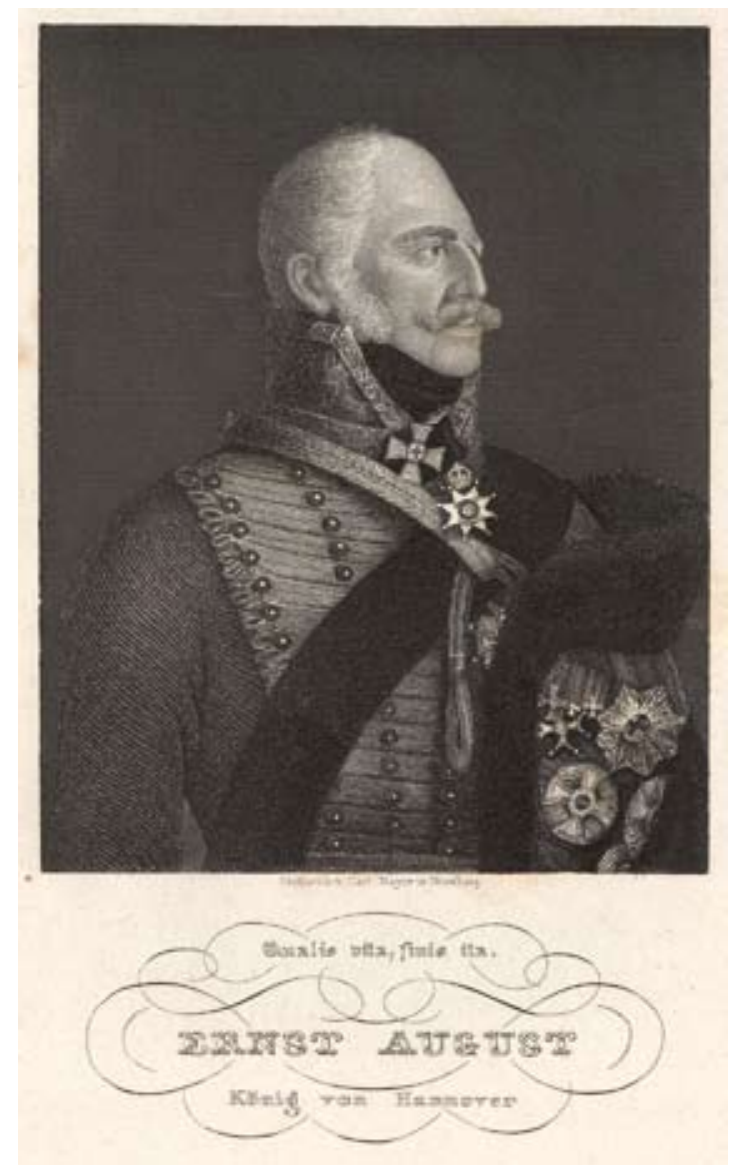

König Ernst August I. von Hannover (1771-1851).

Schließlich ließen es sich die regierenden Landesherren nicht nehmen, ihre Universität mit Geschenken zu bedenken. Die Eingliederung Göttingens in das während der Herrschaftszeit Napoléon Bonapartes gegründete Königreich Westfalen hatte für die Bibliothek - neben der ungleich größeren Bedeutung der Überführung von Helmstedter Beständen (s. Kapitel 3) - immerhin den Vorteil, dass König Jérôme Bonaparte (1784-1860) die Bibliothek anlässlich seiner Besuche mit Buchgeschenken versorgte (s. Nr. 52). Und nach der Restituierung des Königreiches Hannover, dem die Leinestadt nach 1814 wieder angehörte, machte ihr der nicht nur wegen seiner Amtsenthebung der Göttinger Sieben (1837) eher unbeliebte König Ernst August I. immerhin wertvolle botanische Zeichnungen zum Geschenk (s. Nr. 5).

(SG) 


\section{Matthias Corvinus - ein königlicher Bibliophile}

Aristoteles:

Physicorum libri VIII per Johannem Argyropylum traducti, lateinisch.

Pergamenthandschrift,

Italien, 15. Jahrhundert.

Signatur: $2^{\circ}$ Cod. Ms. philol. 36 Cim.

Provenienz: Fürst Georg zu Waldeck und Pyrmont, 1794.

Die in Italien im 15. Jahrhundert entstandene Handschrift gehörte zu der Bibliothek des bibliophilen ungarischen Königs Matthias Corvinus (1443-1490), die im ausgehenden Mittelalter eine der größten Privatbibliotheken ihrer Zeit war. In der unteren Zierleiste prangt das Wappen des Königs, umgeben von den Buchstaben M und A für „Matthias Augustus“. Es handelt sich um eine lateinische Fassung der Vorlesungen des Aristoteles über die Natur oder Physik, die um 1460 in Italien entstanden ist. Im Göttinger Handschriften-Katalog findet sich die Bemerkung: „Der Hauptwerth der Handschrift besteht in ihrer Ausstattung und ihrer Geschichte.“ Auffällig ist zum einen die Gleichmäßigkeit und Genauigkeit der Schrift, einer humanistischen Minuskel. Auf dem ersten Textblatt der Handschrift (Bl. $3^{r}$ ) findet sich eine aufwändig gemalte Zierleiste aus weißem Rankenwerk auf blauem Grund, die mit Putten, Vögeln, Faltern und einem Hasen ausgeschmückt ist.

Die Bibliothek des Königs Matthias bestand fast ausschließlich aus wertvollen illuminierten Renaissance-Handschriften, enthielt aber nur wenige gedruckte Bücher. Nach dem Tod des Königs wurde der Bestand stark dezimiert, und besonders bei der Befreiung Ofens von den Türken 1686 wurden viele wertvolle Stücke vernichtet. In den Bibliotheken Europas sind bisher 107 lateinische Handschriften in 33 Bibliotheken bekannt, die auf die Bibliotheca Corviniana zurückzuführen sind. Im 16. Jahrhundert gelangte die Aristoteles-Handschrift in den Besitz einer Familie namens von Haym in Reichenstein in Österreich. Mehr als 200 Jahre später gab Christian Gottlob Heyne (1729-1812) eine schriftliche Beurteilung über die Handschrift ab. In einem Brief vom 22. Februar 1782 an den Besitzer der Corvine, Georg Prinz von Waldeck, nahm er zu der Handschrift Stellung. Der Prinz machte die Corvine im Jahre 1794 der Königlichen Universitätsbibliothek Göttingen zum Geschenk.

Die Physik des Aristoteles (384-322 v. Chr.) fasst in acht Büchern die wesentlichen naturphilosophischen Überlegungen des griechischen Philosophen zusammen; sie kann gleichsam als Vorwort zur Gesamtheit seiner naturwissenschaftlichen Schriften angesehen werden. Seine Definitionen von Begriffen wie Ort, Leere und Zeit, von Stoff und Form, aber insbesondere seine Gedanken zur Bewegung haben das naturwissenschaftliche Denken bis hin zu Galileo Galilei (1564-1642) bestimmt. 


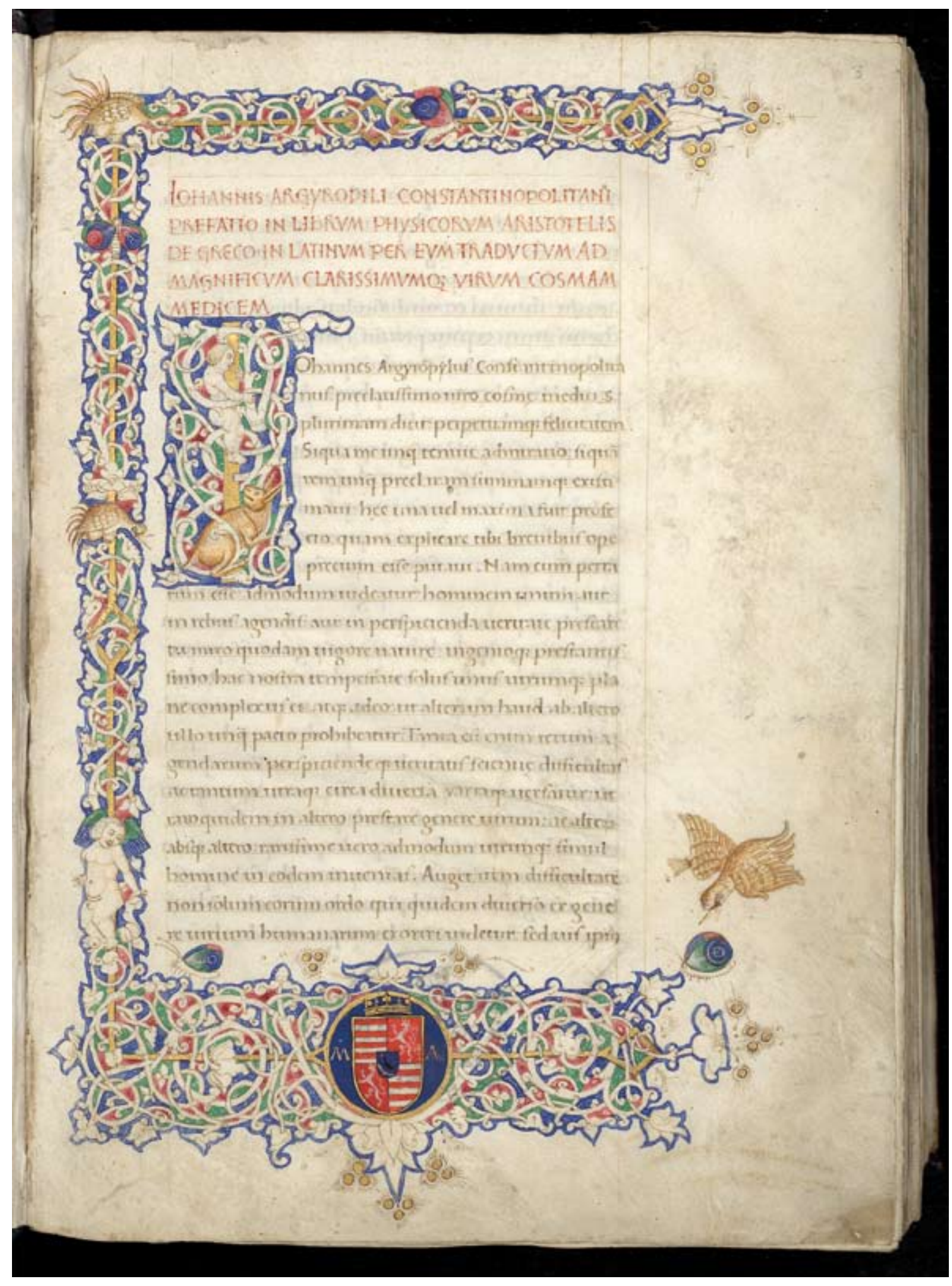




\section{Ein Schelm, wer Böses dabei denkt}

The statutes and ordinaunces of the most noble order of Saint George named the Gartyer.

Pergamenthandschrift,

England, um 1580.

Signatur: $8^{\circ}$ Cod. Ms. hist. 769 Cim.

Provenienz: Elisabeth I., Auktion Thomas Osborne, 1754

Der im Jahre 1348 von Edward III.

(1327-1377) gegründete Hosenbandorden (The Order of the Garter) ist der älteste und höchste englische Orden. Sein Emblem (ein blaues Strumpfband) und Motto („Honi soit qui mal y pense“) sind erstmals Ende 1347 als persönliches Abzeichen des Königs nachweisbar. Um die Gründung des Ordens ranken sich viele Legenden, von denen die HofballLegende am weitesten verbreitet ist. Ihr zufolge sei beim Tanz Edwards III. mit der Gräfin von Salisbury das Strumpfband der Gräfin zu Boden gefallen, woraufhin der König es sich mit den Worten „Honi soit qui mal y pense“ an das Knie gebunden habe. Unbestritten ist demgegenüber, dass die Ordensstiftung die Intention verfolgte, auf „ewige Zeiten“ die Loyalität der Ritterschaft gegenüber dem Königshause zu sichern. Auf der Basis der schriftlich fixierten und von den Gründungsmitgliedern besiegelten, in der Folgezeit mehrfach reformierten Statuten entwickelte sich ein kontinuierliches Ordensleben, das heute noch in der Zeremonie des Garter Day seinen Ausdruck findet. Träger des Ordens sind neben dem König und dem Prince of Wales bis zu 24 weitere, nur vom Monarchen zu bestimmende Ritter, um das Land verdiente Persönlichkeiten. Seit 1987 sind auch Frauen als Vollmitglieder zugelassen.

1754 erwarb die Göttinger Bibliothek auf einer Auktion Thomas Osbornes eine ausgesprochen schöne Pergamenthandschrift mit den Statuten des Hosenbandordens, die wahrscheinlich aus der Zeit um 1580 stammt. Die Handschrift ist in einen hellbraunen Kalbs- lederband eingebunden, der die Wappensupralibros Elizabeths I. (1533-1603) mit den für den englischen Einbandstil üblichen Rahmungen (Panels) trägt. Das in der Mitte des Einbandes angebrachte, vergoldete Wappen der Königin und ihre Initialen ER (Elisabeth Regina) sind mit dem Motto des Hosenbandordens verwoben. Vermutlich handelt es sich um ein für ein neues Mitglied des Ordens bestimmtes Exemplar - auf welchen Wegen es stattdessen zu Osborne gelangte, ist bislang unbekannt geblieben.

(SG/KN) 


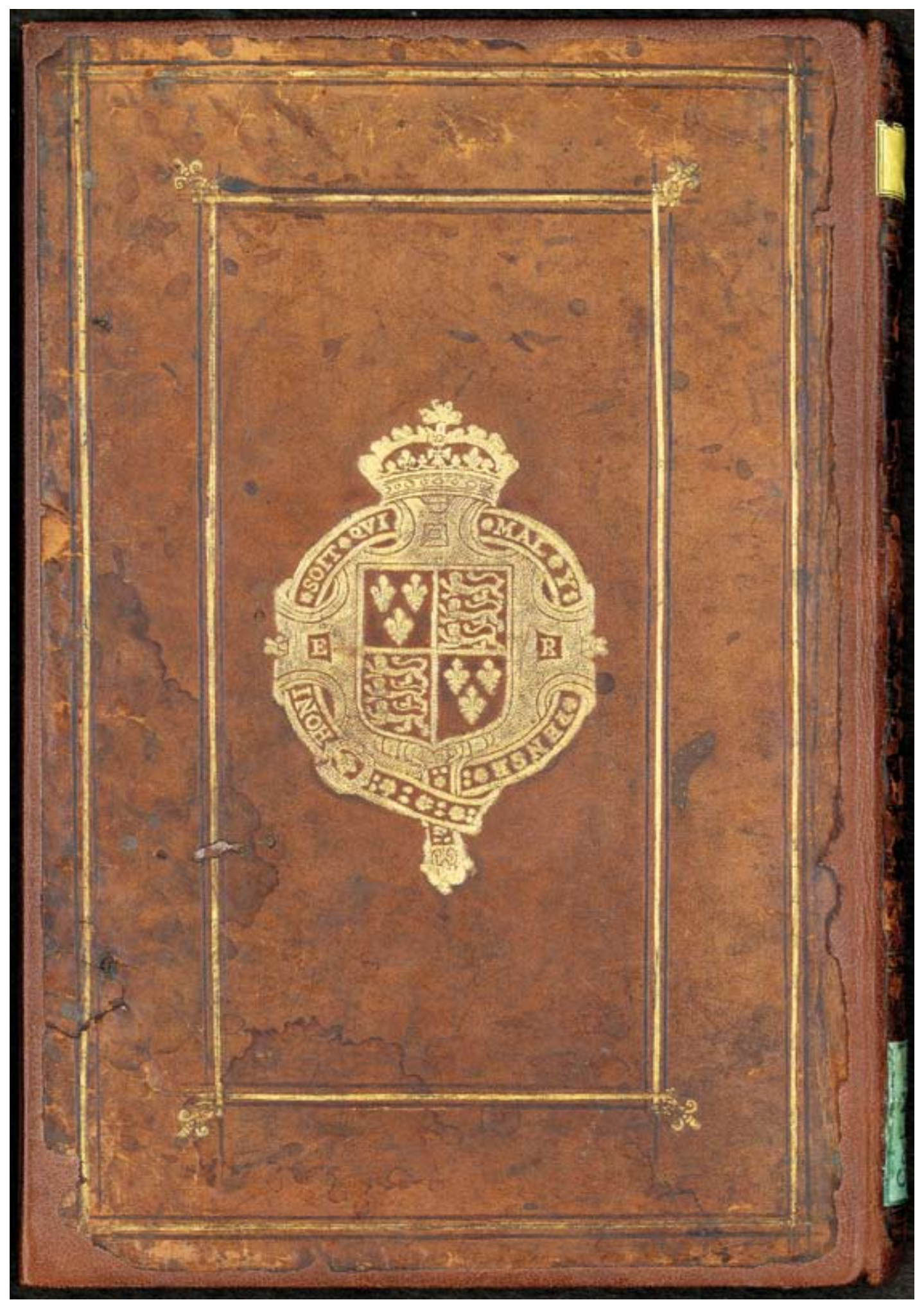




\section{Der Sonnenkönig und der Bücherfreund: ein Einbandvergleich}

Marcus Tullius Cicero:

Opera. Hrsg. Alexander Minutianus. P. I-IV.

Mailand: Guillaume Le Signerre, [1498].

Signatur: $2^{\circ}$ Auct. lat. II,2: 1.2 Inc.

Provenienz: Pietro Antonio Crevenna, Auktion Amsterdam 1790

Die erste Gesamtausgabe der Werke Ciceros (106-43 v. Chr.) erschien erst gegen Ende der Inkunabelzeit im Jahre 1498 in Mailand, während die Drucke einzelner Schriften bereits in den sechziger Jahren auf den Markt kamen und besonders in Italien und Deutschland sehr populär waren. In der Renaissance war Cicero der am meisten gelesene klassische Autor, und aus diesem Grund haben seine Reden und Briefe, aber auch seine politischen und philosophischen Werke inhaltlich und formal tiefere Spuren hinterlassen als die irgendeines anderen Schriftstellers der Antike.

Im hier gezeigten Exemplar sind die Teile I bis IV der Erstausgabe der Werke Ciceros auf zwei Bände verteilt, die beide in rotes, goldverziertes Maroquinleder eingebunden sind. Beide zeigen auf den Deckeln einfache Rahmen aus dreifachen Goldlinien; die Buchrücken haben sechs Bünde. Die unterschiedliche Herkunft wird erst bei genauerer Untersuchung der beiden Rücken deutlich. Bei Band 1 liegt in den fünf Feldern zwischen den Bünden ein Zierstück, welches zwei in sich verschlungene „L“ mit einer aufgesetzten Krone aufweist. Dieses Ornament wurde für die Einbände des französischen Königs Ludwig XIV. (1638-1715) verwendet. Hinweise auf den Besitzer von Band 2 sind mehrfach im äußeren Buchschmuck versteckt. Zum einen findet sich auf dem Buchrücken zwischen den Bünden fünfmal ein Zierstück, das hier aus einer Krone und dem Monogramm „JBC“ zusammengesetzt ist; im Deckel ist im Mittelfeld ein prächtiges Wappensupralibros mit einer Schlange eingeprägt. Dass es sich bei dem Vorbesitzer um den Wirtschaftspolitiker und Büchersammler Jean Baptiste Colbert (1619-1683), den Begründer des Merkantilismus, handelt, macht auch eine handschriftliche Eintragung auf Bl. 2a deutlich (,Bibliotheca Colbertina“). Colbert hat sich einen Namen als Reorganisator der königlichen Bibliothek gemacht und Ludwig XIV. vermutlich auch beim Aufbau seiner Bibliothek unterstützt.

Da kaum anzunehmen ist, dass der König und sein Minister das zweibändige Werk unter sich aufgeteilt haben, kann man heute nur darüber spekulieren, wo die beiden jeweils fehlenden Bände sich befinden, ob sie gar in einer anderen Bibliothek eine zweite komplette Ausgabe bilden. Auf jeden Fall hat Pietro Antonio Crevenna (1735-1792), ein aus Mailand gebürtiger und in Amsterdam ansässiger Kaufmann, Geschick bewiesen, als er die beiden Bände für seine große Inkunabelsammlung erwarb. Schon 1774 musste er einen Teil der Sammlung aus finanziellen Gründen wieder abstoßen, was noch übrig blieb, kam schließlich 1790 unter den Hammer. 


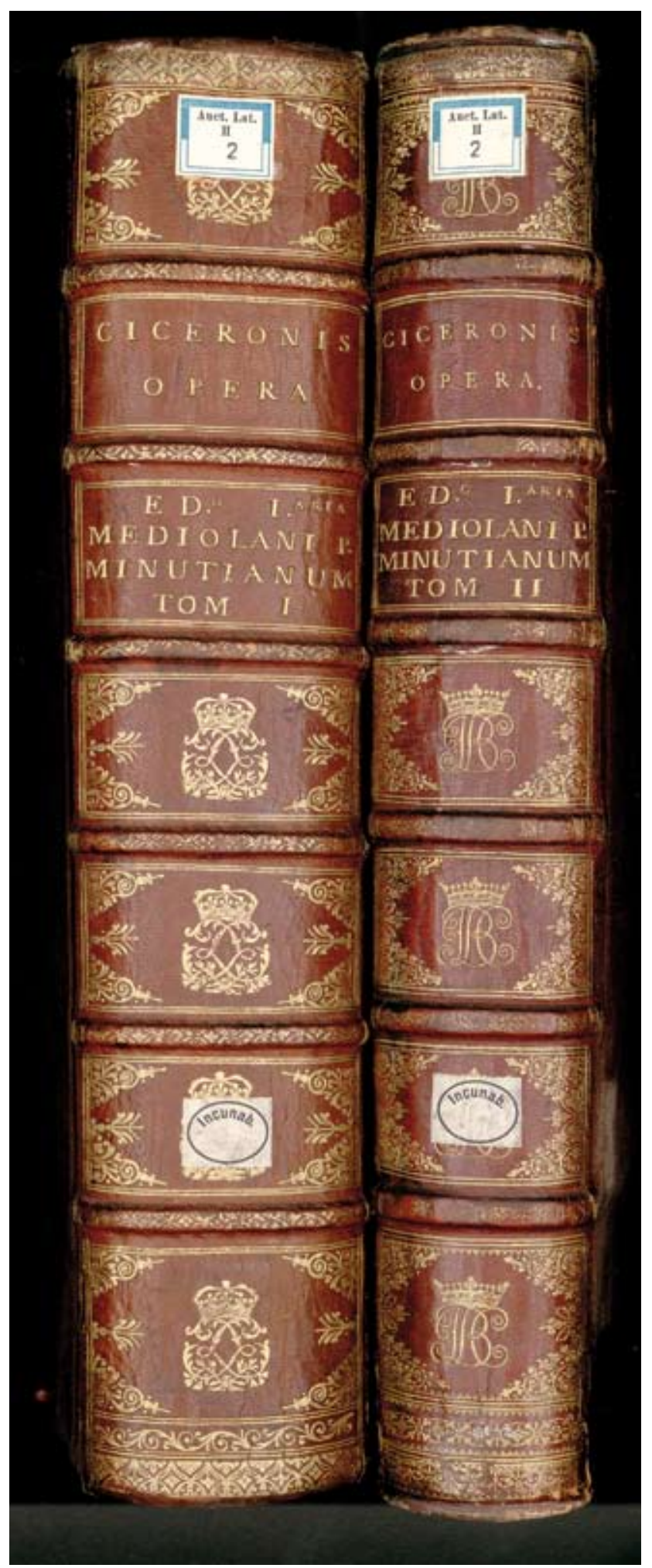




\section{Aus Napoleons Bibliothek}

Jean Nicolas Corvisart des Marets:

Essai sur les maladies et les lésions organiques du coeur et des gras vaisseaux. 2. éd.

Paris: H. Nicole, 1811.

Signatur: $8^{\circ}$ Med. pract. 788/60 Rara

Provenienz: Johann Friedrich Blumenbach

Baron Jean-Nicolas Corvisart des Marets (1755-1821) war Mediziner aus Leidenschaft. Gegen den Willen seiner Eltern, die ihn gerne als Juristen gesehen hätten, studierte er mit Erfolg das Fach seiner Wahl und bekleidete danach verschiedene Positionen, u.a. die des Chefarztes am Hospice de la Charité. Von 1795 an hatte er den Lehrstuhl für innere Medizin an der neu gegründeten École de Santé in Paris inne, die sich zur bedeutendsten Medizinschule Europas entwickelte. Schwerpunkt seiner Forschungen wurde die Kardiologie, wobei ihm eine Verbesserung diagnostischer Verfahren besonders wichtig war. Zum Leibarzt Napoleons wurde er 1804, er begleitete den Korsen 1805 nach Italien und 1809 nach Österreich. In diesen Jahren arbeitete er an dem Essai sur les maladies et les lésions organiques du coeur et des gras vaisseaux, der 1806 erschien. 1811 kam eine zweite, verbesserte und vermehrte Auflage heraus.

Ein Exemplar davon fand den Weg in die zu ihrer Blütezeit viele Zehntausende Bücher umfassenden Bibliotheken Napoleons und erhielt dafür - wie auch unzählige andere Druckwerke, meistens Geschenke an den Kaiser - einen angemessenen Einband. Die Deckel wurden mit rotem Maroquinleder bezogen und - ganz klassisch - mit Gold geprägt. Eingefasst von Streicheisenlinien und floralen Ornamenten prangt im Zentrum sowohl des vorderen als auch des hinteren Deckels ein Wappensupralibros des französischen Kaisers. Vergoldungen zeigen außerdem die Steh- und Innenkanten des Bandes.
Innen wurde himmelblaue Seide für Spiegel und Vorsatz benutzt. Der Buchblock ist dreiseitig vergoldet. Der flexible Rücken ist in sechs Felder aufgeteilt, die Trennlinien deuten dabei die Bünde an.

Die Büchersammlungen Napoleons, deren Betreuung seit 1806 von einer zentralen Bibliotheksverwaltung organisiert wurde, sind nicht als Ensemble erhalten geblieben. Die Mehrzahl der Bücher wurde nach dem Sturz des Kaisers auf den verschiedensten Wegen in alle Welt verstreut. Nicht wenige davon waren Maroquinbände, trugen Initialen oder, wie das vorliegende Exemplar, das Wappen Bonapartes. Daneben hatte der Kaiser aber auch wesentlich einfachere Einbände ohne weitere Verzierungen besessen. Der hier gezeigte, vom Buchbinder nicht signierte Band kam als Geschenk des Professors der Naturwissenschaften Johann Friedrich Blumenbach (1752-1840) in die Göttinger Bibliothek. 


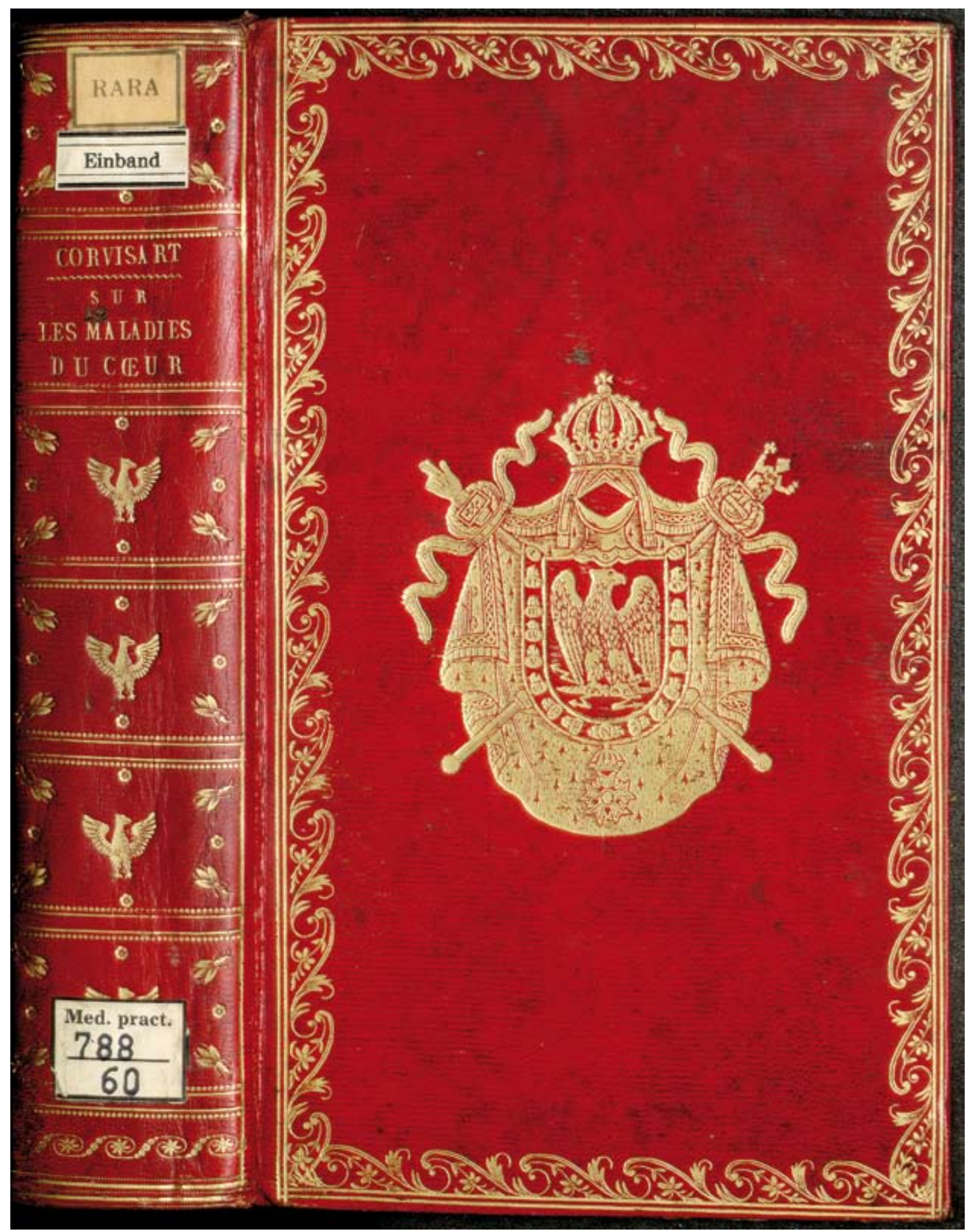




\section{Ein Geschenk königlicher Freigebigkeit}

[Carl von Rechberg, Georges Bernard Depping]:

Les peuples de la Russie, ou description des moeurs, usages et costumes des diverses nations de l'empire de Russie. Accompagnée de figures coloriées. Bd. 1. Paris 1812. Signatur: gr. $2^{\circ}$ Hist. Russ. 150/5

Provenienz: Jérôme Bonaparte, 1813

Im Jahre 1813 wurde in den Göttingischen gelehrten Anzeigen ein besonderes „Prachtwerk..., das wir als ein neues Geschenk königlicher Munifizenz verehren“, angekündigt. Erhalten hatte es die Göttinger Universitätsbibliothek, wie die panegyrisch geprägte Einleitung der Rezension berichtet, „am 4. April, demselben Tage, welcher der hiesigen Universität durch die abermahlige Anwesenheit Seiner Majestät, unseres Allergnädigsten Königes, und durch Höchstihre lange, und an Beweisen königlicher Huld und Theilnahme an der Blüthe unserer Lehranstalt reiche Unterredung mit dem auf der Bibliothek versammelten Corps der Professoren, auf immer unvergesslich bleiben wird“. Der Schenker des Buches war Jérôme Bonaparte (1784-1860), der Anlass der Schenkung sein fünfter - und letzter - Besuch in der Hauptstadt des Leinedepartements; das Werk selbst schließlich beschäftigte sich ausgerechnet mit den Völkern eines Landes, das den militärischen Niedergang der napoleonischen Herrschaft einleitete: mit Russland, dem Schauplatz des militärischen Fiaskos der Grande Armée des Jahres 1812.

Militärische Inhalte freilich spielten in dem königlichen Geschenk keine Rolle; vielmehr galt das Interesse seines Verfassers, des Grafen Carl von Rechberg (1775-1847), ganz einer ethnographischen Darstellung des Vielvölkerstaates in Wort und Bild. Dabei folgt seine Gruppierung der Völker des Russischen Reiches in slavische, finnische und tatarische Ethnien sowie in Völker unbekannten Ursprunges und eingewanderte Bevölkerungs- gruppen Klassifikationen, die von Johann Gottlieb Georgi (1738-1802) entwickelt worden waren. Die ersten drei Gruppen sind im ersten von zwei Bänden dargestellt; besonderes Augenmerk gilt dabei dem russischen Volk, dessen Trachten, religiöse Bräuche und Alltagsvergnügungen ausführlich beschrieben werden. Es ist nicht feststellbar, welchen Anteil an den Texten, die Standardwerken der Zeit folgen, Rechberg besitzt, welchen der deutsch-französische Historiker Georges Depping (1784-1853), der den Text bearbeitet hat. Von ungleich größerer Bedeutung als der 124-seitige Textteil des Bandes jedoch sind die ihn begleitenden 48 Kupferblätter, die im Sinne eines Genrebildes typische Trachten und Lebenssituationen der einzelnen Völker abbilden. Der Kunstliebhaber Rechberg hatte die Entwürfe von Emel'jan M. Karneev (1780-ca. 1839) erworben, der sie auf einer Russlandreise angefertigt hatte; sie wurden von K. Wagner und anderen Künstlern handkoloriert. Stolz vermerkt die Rezension in den Göttingischen Gelehrten Anzeigen, dass das Werk somit ,zu den prächtigsten, die in unsern Tagen erschienen sind“, gehöre. Aufgeschlagen ist die Darstellung eines Ringspiels. 


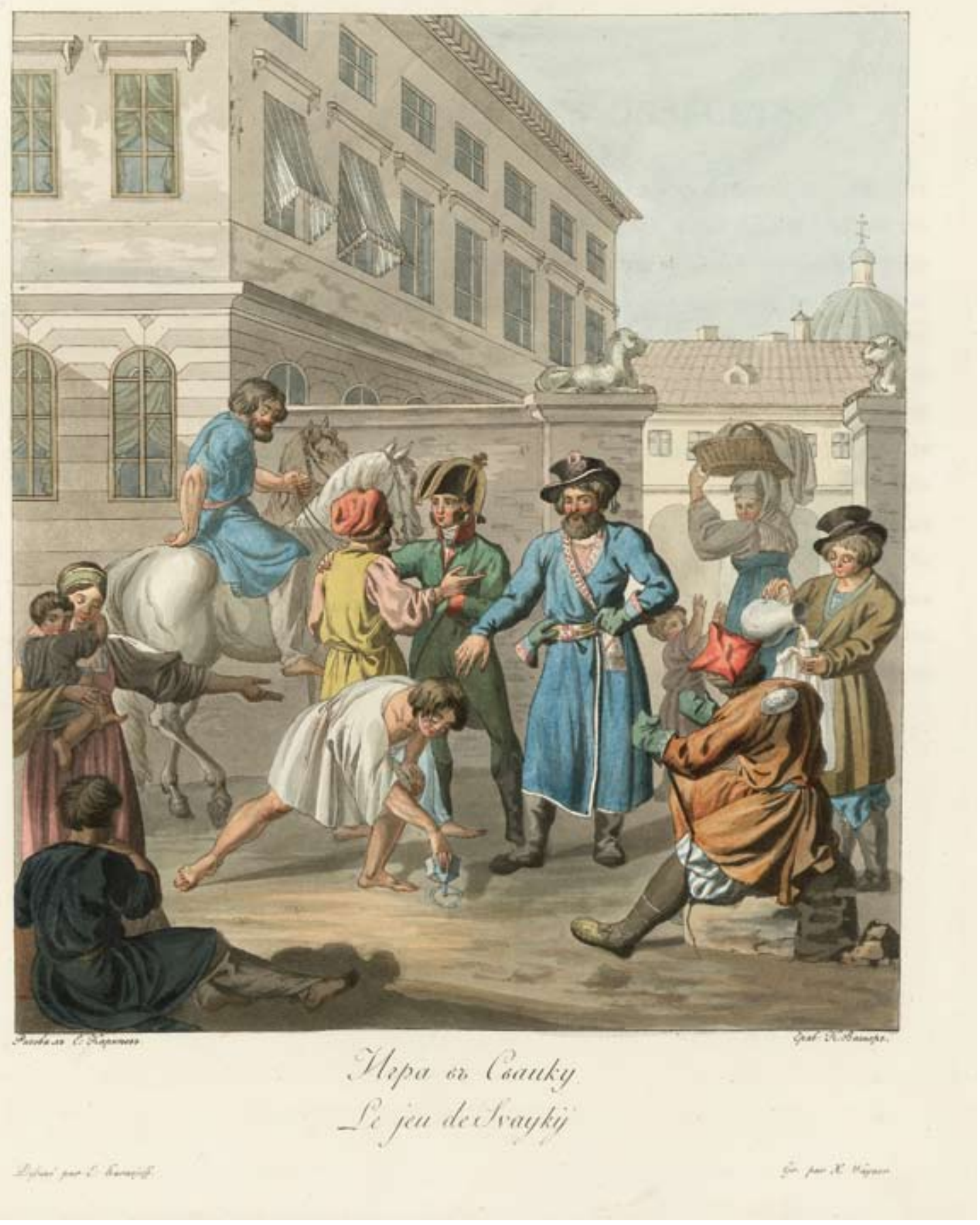




\section{Orchideen als Geschenk des Königs Ernst August I. von Hannover}

Franz Andreas Bauer:

Plants (Orchideous) found near Port Jakson, New Holland, by Captain Paterson.

Signatur: $2^{\circ}$ Cod. Ms. hist. nat. 94:13

Provenienz: Ernst August I. von Hannover, 1842

Franz Andreas Bauer (1758-1840) wurde in Feldsberg in Niederösterreich geboren, wo der Vater Lukas Bauer als Hofmaler des Fürsten Liechtenstein wirkte. Wie seine Brüder Joseph Anton und Ferdinand Lukas zeichnete er sich durch ein außerordentlich hohes Zeichen- und Maltalent aus, insbesondere bei der Darstellung von Pflanzen. Schon im Alter von 13 Jahren lieferte er Zeichnungen von Pflanzen für wissenschaftliche Veröffentlichungen. Später arbeitete er zunächst als Blumenmaler für Fürstenhäuser und dann als Nachfolger seines Bruders Ferdinand als Pflanzenmaler für den Wiener Botaniker Nikolaus Joseph von Jacquin (1727-1817). Für diesen lieferte Bauer einige Abbildungen für dessen Werk Icones plantarum rariorum. 1788 kam er nach London, wo der Naturforscher und Direktor der Royal Botanical Gardens in Kew, Sir Joseph Banks (1743-1820), sein außerordentliches Talent erkannte und ihn als Botanikmaler für die Königlichen Gärten gewann. In Kew war Bauer für den Rest seines Lebens tätig. Obwohl seine Arbeiten künstlerisch immer etwas im Schatten seines weit gereisten Bruders Ferdinand (1760-1826) standen, war Bauer als wissenschaftlicher Maler jedoch auf Grund seiner unübertroffen exakten - das Mikroskop war sein wichtigstes Hilfsmittel - Darstellungsweise berühmt. Besonders schön und bekannt sind seine Habitusdarstellungen u.a. von Strelitzien. Daneben hat sein Werk eine hohe wissenschaftliche Bedeutung, vor allem seine mykologischen und anatomischen Zeichnungen beispielsweise von der Keimung und Entwicklung des Weizens und verschiedener Getreidekrankheiten.
Die Originalzeichnungen Bauers kamen nach seinem Tod zum Teil an das Britische Museum, zum Teil wurden sie 1841/1842 von König Ernst August I. von Hannover (1771-1851) der Universitätsbibliothek Göttingen überlassen. Unter den letzteren befindet sich der ausgestellte Band VIII aus den Skizzenbüchern, der auf 22 Tafeln Orchideen aus Port Jackson, New Holland (heute gehörig zu Sydney, New South Wales, Australien) darstellt. Am Schluss des Bandes gibt ein Blatt Informationen über Größe, Blütezeit und weitere Merkmale der dargestellten Pflanzen. Aufgeschlagen ist Blatt 2 mit der Spezies Diuris. Die Informationen auf dem Erläuterungsblatt ergänzen hierzu, dass die Pflanzen in natürlicher Größe dargestellt seien und im Oktober blühten. Die Gattung Diuris kommt mit mehr als 40 Spezies in Australien verbreitet vor und wird dort als „Donkey Orchid“ (Eselsorchidee) bezeichnet. 


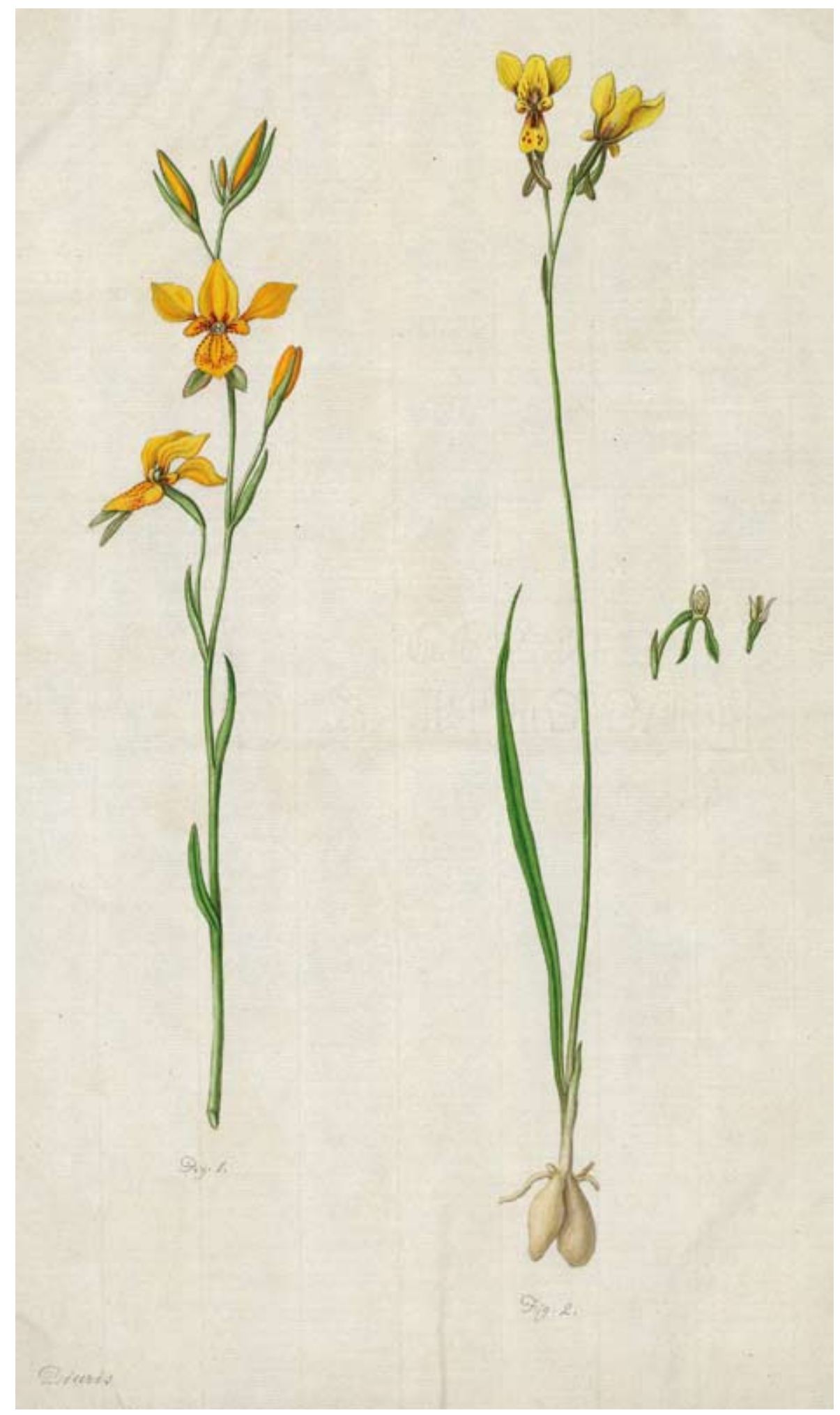




\title{
54 Das dritte in Italien gedruckte Buch
}

\author{
Aurelius Augustinus: \\ De civitate Dei. \\ [Subiaco: Konrad Sweynheym und Arnold Pannartz], 12. VI. 1467. \\ Signatur: $2^{\circ}$ Patr. Lat. 164/21 Inc. \\ Provenienz: Fürstlich Waldecksche Bibliothek, Arolsen 1801
}

Aurelius Augustinus (345-430) war eine der prägendsten Persönlichkeiten unter den frühen Kirchenvätern. Geboren als Sohn eines heidnischen Vaters und einer christlichen Mutter in Numidien (Nordafrika), fand er erst nach längeren Irrungen unter dem Eindruck der Predigten des Bischofs Ambrosius von Mailand (um 340-397) zum Christentum. Nach einem dem Studium und der inneren Einkehr gewidmeten Leben, das ihn von Italien wieder zurück in seine nordafrikanische Heimat führte, wurde er zum Presbyter geweiht und schließlich zum Bischof von Hippo Regius in Nordafrika ernannt. Augustinus starb beim Angriff der Vandalen auf seine Stadt im Jahre 430.

Der Anlass für sein Hauptwerk Über den Gottesstaat war die Plünderung Roms durch das Gotenheer Alarichs und die in diesem Zusammenhang aufgeworfene Frage, ob nicht das Christentum am Fall Roms schuld sei, weil die Römer sich nach der Aufgabe der alten Götter zunehmend der neuen Religion hingegeben hätten. Augustinus tritt in den ersten fünf Büchern dieser Auffassung entgegen und sucht zu belegen, dass es Selbstsucht und Sittenlosigkeit gewesen seien, die den Untergang Roms herbeigeführt hätten. In den folgenden fünf Büchern handelt er von der Verwerflichkeit des Heidentums und der Unzulänglichkeit der alten Philosophie. Das Gottesreich selbst ist das Thema der letzten zwölf Bücher, in denen dem weltlichen Staat das Reich Gottes in Form der Kirche Christi gegenübergestellt wird. Mit dem Werk findet die christliche Kultur der Spätantike zum ersten Mal ihren philosophischen Ausdruck. Das augustinische Denken, das Streben nach Gotteserkenntnis und Gottesliebe hat die christliche Lehre bis zum Zeitalter der Scholastik entscheidend geprägt.

Der erste Ort, an dem in Italien Bücher gedruckt worden sind, war das Kloster Santa Scolastica in Subiaco. Hier stellten die beiden deutschen Kleriker Konrad Sweynheym († 1475) und Arnold Pannartz († um 1476) im Jahre 1464 ihre Druckpressen auf, vermutlich auf Vermittlung des deutschen Kardinals Nikolaus von Kues, der wünschte, dass die „heilige Kunst“ auch in Italien ausgeübt werde. Als ihr drittes Werk verließ die Abhandlung des Augustinus die Werkstatt. Die auffallend schönen, von Hand ausgemalten Initialen sind übrigens in verschiedenen Exemplaren des Drucks anzutreffen. 


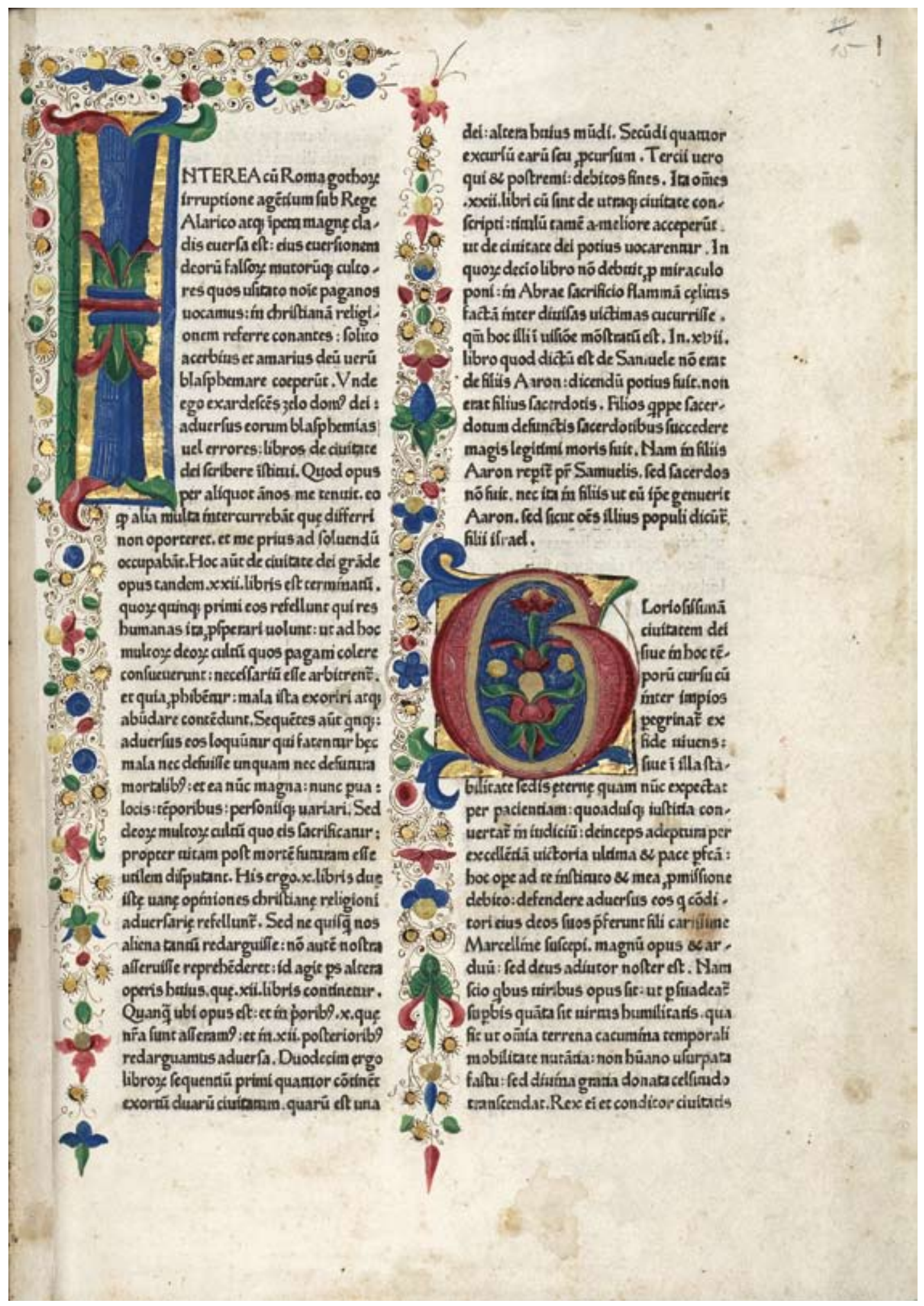




\section{Attische Nächte}

Aulus Gellius:

Noctes Atticae.

Rom: In domo Petri de Maximis [= Konrad Sweynheym und Arnold Pannartz], 11. IV. 1469.

Signatur: $4^{\circ}$ Auct. Lat. V, 3983 Inc.

Provenienz: Prinz Georg von Waldeck, 1794

Der römische Grammatiker Aulus Gellius (um 125-170) begann mit der Redaktion und Niederschrift seiner Materialsammlung in den „langen Winternächten“ seines Aufenthaltes in Athen - was den zunächst etwas merkwürdig anmutenden Titel des Werkes erklärt. Gellius hatte eine beeindruckende Sammlung von Notizen, Exzerpten, Zitaten aus allen möglichen Büchern und Quellen angelegt, einen umfänglichen Zettelkasten, den er im Jahre 170 in Buchform zusammenstellte. Die moderne Literaturwissenschaft nennt ein solches Vorgehen heute „Buntschriftstellerei“ und kennt eine ganze Reihe von Beiträgern zu dieser Gattung, die durchaus auch als eine entfernte Verwandte der Enzyklopädie angesehen werden kann. In der Regel werden die Attischen Nächte heute auch so benutzt: als eine Art „Steinbruch“ für die unterschiedlichsten altertumswissenschaftlichen Themen.

Gellius' Werk ist aufgrund seines frühen Todes ein Fragment geblieben; auch in Aufbau und Komposition wirkt es ein wenig fragmentarisch. Im zwölften Buch beispielsweise folgt auf ein Traktat des Philosophen Favorinus über den Wert der Muttermilch eine kritische Auseinandersetzung mit der Enniusund Cicero-Kritik des Seneca, und an diese schließt sich ein Exkurs über die Herkunft des Wortes lictor an.
Zahlreiche weitere Beispiele belegen, dass es sich hier um eine recht willkürlich zusammengestellte Anthologie aus griechischen und römischen Schriftstellern handelt. Man mag die Technik vergleichen mit Lichtenbergs Sudelbüchern; in der Tat hat ja der Göttinger Professor einem seiner Notizbücher den Titel Noctes gegeben.

Die erste Ausgabe wurde von den beiden italienischen Erstdruckern Konrad Sweynheym und Arnold Pannartz in Rom gedruckt. Herausgeber der Noctes Atticae war der Gelehrte Theodoros Gazes, der eine größere Zahl der Druckerzeugnisse von Sweynheym und Pannartz anonym herausgab, hier aber namentlich erwähnt ist. Das Buch ist nicht nur als Erstausgabe des Enzyklopädisten Aulus Gellius von Interesse, sondern auch, weil es den ersten Druck in griechischer Sprache enthält: einen Abschnitt im Umfang von einem Blatt und drei Zeilen aus dem platonischen Dialog des Gorgias. Möglicherweise kam es den beiden Druckern hier hauptsächlich darauf an, Erfahrungen im Druck mit griechischen Lettern zu sammeln. 


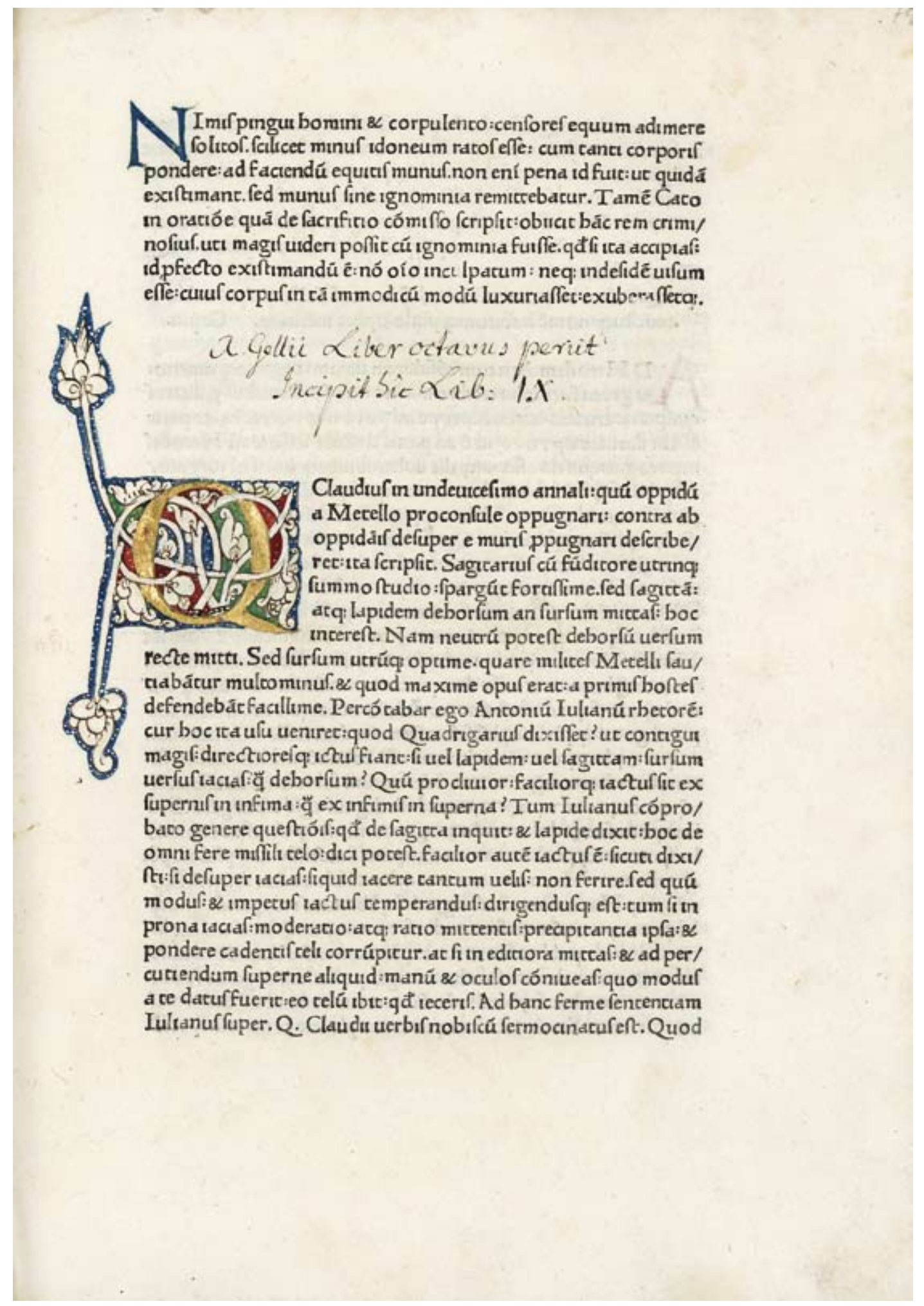




\section{Das Breviarium Windeshemense im Kloster Volkhardinghausen}

Breviarium Windeshemense.

Antwerpen: Gerard Leeu, 1488.

Signatur: $8^{\circ}$ Cod. Ms. theol. 235c

Provenienz: Friedrich von Waldeck, 1799

Das vom Gottesdienst unabhängige offizielle Gebet, das für Kleriker und Mönche obligatorisch war, richtete sich schon im frühen Mittelalter nach festgelegten Gebetsstunden. Zunächst waren das die Terz (gegen 9 Uhr), Sext (gegen 12 Uhr) und Non (gegen $15 \mathrm{Uhr}$ ), und später kamen nach und nach die Matutin bzw. Laudes zum Sonnenaufgang, die Prim bei Tagesanbruch und das Complet als Tagesschlussgebet nach Sonnenuntergang hinzu. Im römischen Brevier haben sich dann die folgenden sieben Horen oder Gebetsstunden durchgesetzt: Matutin mit Laudes, Prim, Terz, Sext, Non, Vesper und Complet. Im Brevier sind alle für das Stundengebet notwendigen Texte versammelt: Es enthält Bibeltexte, Szenen aus Heiligenlegenden, Auszüge aus den Kirchenvätern, Hymnen und Ähnliches und ist nach der Ordnung des Kirchenjahres - man unterscheidet den Sommerteil (Pars aestivalis) und den Winterteil (Pars hiemalis) - und nach den Gebetsstunden eingeteilt.

Das Breviarium Windeshemense wurde für die Kongregation im holländischen Kloster Windesheim bei Zwolle gedruckt. Es enthält außer dem Winterteil ein Kalendarium sowie ein Psalterium mit Commune Sanctorum. Der aus Gouda stammende Gerard Leeu druckte von 1487 bis zu seinem Tode im Jahr 1492 in Antwerpen. Unter seinen Drucken finden sich außergewöhnlich viele kleinformatige Ausgaben, wie das Breviarium Windeshemense von 1488.
An den Anfangsseiten der Hauptkapitel sind sogenannte Blattweiser angebracht, die das Auffinden einer bestimmten Textseite erleichtern sollen - kleine, an den Blatträndern angeklebte Lederknötchen. Der kalbslederne Einband ist mit Streicheisenlinien und mit verschiedenen Stempelprägungen geschmückt, die es erlauben, seinen Hersteller zu ermitteln: Der Einband wurde im 15. Jahrhundert in der Werkstatt des Jordanus zu Volkhardinghausen, in der Nähe des fürstlichen Schlosses Arolsen, angefertigt. In dem kleinen Dorf befand sich seit dem 13. Jahrhundert ein Nonnenkloster, das Mitte des 15. Jahrhunderts in ein Augustiner-Chorherrenstift umgewandelt wurde. Dieses Stift schloss sich an die von Holland ausgehende Windesheimer Kongregation an, so dass ein Breviarum nach Windesheimer Ritus hier durchaus zu erwarten ist. Aus dem Kloster in Volkhardinghausen gingen zahlreiche Handschriften und Bücher in den Besitz der Fürsten von Waldeck über, und 1799 schenkte Friedrich von Waldeck der Göttinger Universitätsbibliothek das Breviarium. 


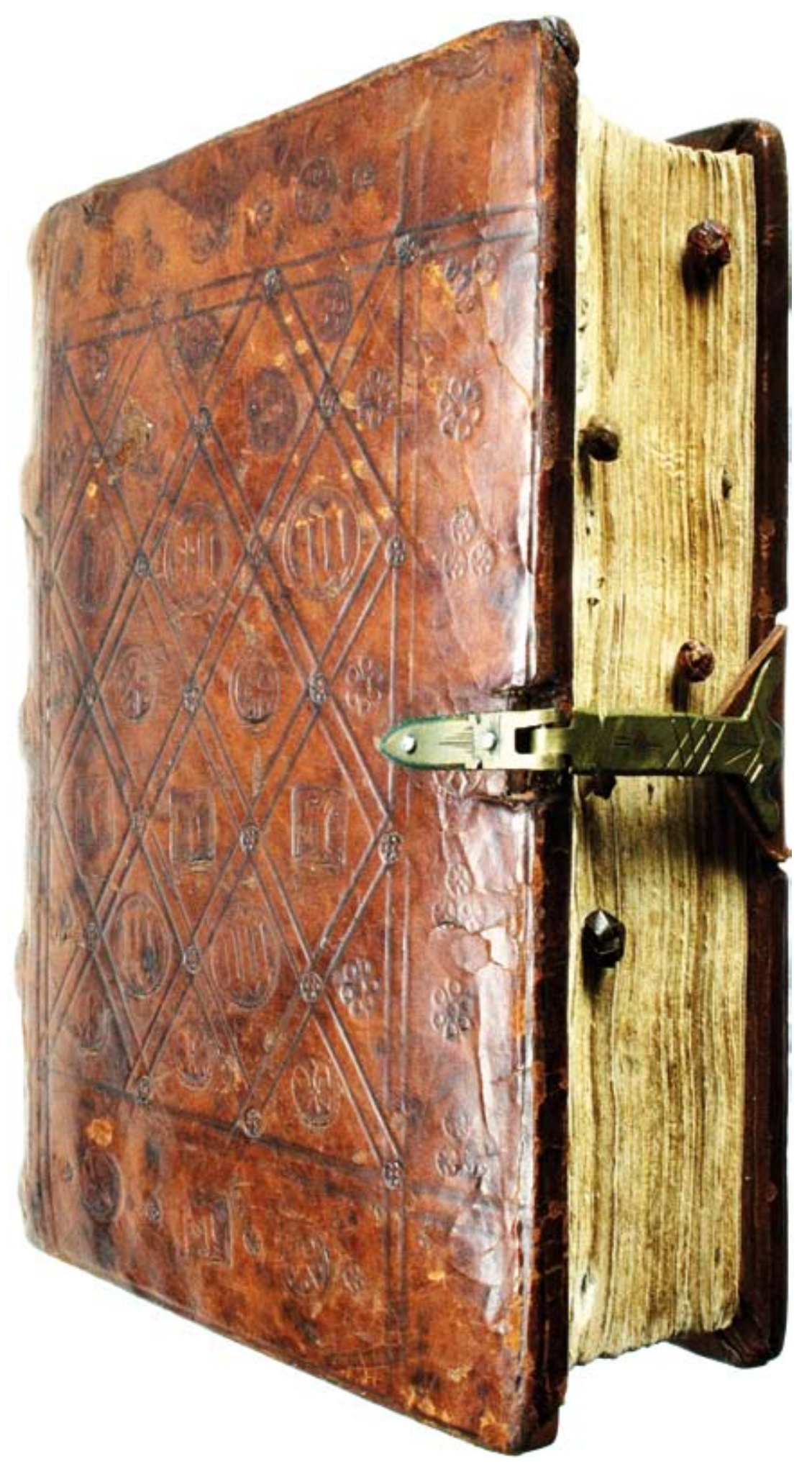




\section{Sensationsmeldung aus Polen}

Newe zeyttung aus Polen von wunderlichen geschichten ynn Polen Vngern und Behemen, auch von andern landen.

Leipzig: Michael Blum, 1527.

Signatur: $8^{\circ}$ Hist. Cesk. I, 3005 (2)

Provenienz: Fürstlich Waldecksche Bibliothek, Arolsen 1801

Der Begriff „Zeytung“ bedeutete im Mittelalter „aktuelle Nachricht“, und erst im 16. und 17. Jahrhundert wurde „Zeitung“ im heutigen Wortsinn für unterschiedliche Gattungen des Tagesschrifttums verwendet. Bei den „Newen Zeytungen“ handelt es sich also nicht um periodische Einblattdrucke oder Druckschriften, sondern um Berichte zu besonderen Ereignissen, die nur bei Bedarf herauskamen und oftmals an ein spezielles Publikum gerichtet waren. Ein beliebter Gegenstand waren „erschröckliche“ Begebenheiten wie Naturkatastrophen (Kometen), Teufelsaustreibungen, Missgeburten oder Ketzerverbrennungen. Zur Illustration der Meldung waren die Berichte mit Holzschnitten, später mit Kupferstichen illustriert. Auch Herrschaftshäuser nutzten das neue Medium und beauftragten fürstliche Schreiber, die über repräsentative Ereignisse wie adlige Hochzeiten und Todesfälle berichteten oder über Pläne zur Aufrüstung und Kriegsführung. Die „Sensationsblätter“ wurden auf Märkten und Messen von fliegenden Händlern vorgelesen und verkauft. Die älteste bekannte gedruckte Sensationsmeldung dieser Art trägt den Titel Newe Zeytung vom orient vnnd auffgange und stammt vermutlich aus dem Jahr 1502. Hier wurde erstmals der heute so geläufige Begriff „Zeitung“ verwendet.

Das vorgestellte Beispiel einer Newen zeyttung aus Polen berichtet von ,wunderlichen geschichten/ynn Polen Vngern und Behemen“ aus dem Jahre 1527. Offenbar kam es in Polen zu einer Naturkatastrophe der besonderen Art: „Eytel große Hewschrecken“ fielen in das Land ein, bedeckten Himmel und Erde und fraßen nicht nur alles Viehfutter, sondern auch das Korn auf den Feldern. Das Vieh sei tausendfach entweder verhungert oder wahnsinnig geworden. Erst nach einem Kälteeinbruch seien die Insekten, die dem Titelholzschnitt zufolge die Größe von ausgewachsenen Raben gehabt haben müssen, zugrunde gegangen. Als Spätfolge fürchtet der Autor eine weitere Plage: Würmer mit vier Flügeln, von denen zwei grau und zwei golden seien. Am Ende seines Bericht versichert er: „Und dis alles solt yhr fur eyne warheyt glewben / und fur keyne fabel halten / Denn es eyne grosse tewrung ym lande gemacht hat / Gott fug es zu dem besten Geben“. Erstaunlich ist hier nicht die Sensationsmeldung selbst, sondern die Art der Berichterstattung, deren Elemente bis heute in der Regenbogenpresse zu finden sind: Übertreibung des tatsächlichen Geschehens, Bildmanipulation, Beteuerung des Wahrheitsgehalts und Verdächtigung eines fremden Ursprungs der Plage: Ein Wind, der die Heuschrecken von der Türkei aus ins Land getrieben habe, ist schuld!

(KN/HR) 


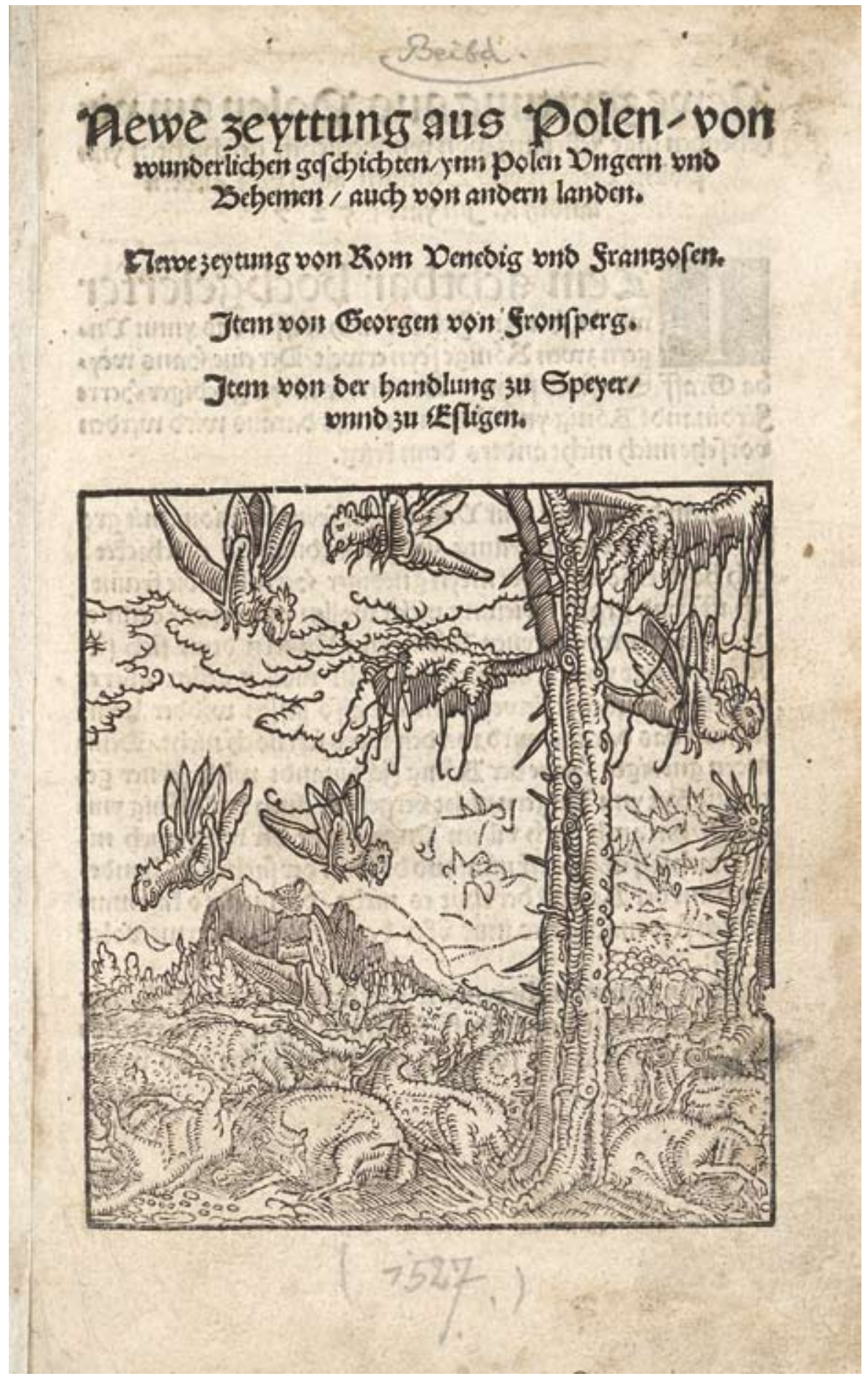




\section{Kapitel 7}

\section{Göttinger Gelehrte}

Noch in den ersten Jahrzehnten des 18. Jahrhunderts war es durchaus üblich, dass die Professoren einer Universität sich nicht etwa auf eine zentrale Bibliothek stützten, sondern zu Zwecken der Lehre und Forschung eigene Büchersammlungen anlegten, die die Grundlage ihrer wissenschaftlichen Tätigkeit bildeten. Ähnlich war es zunächst in Göttingen: So war der Kurator der Georgia Augusta Gerlach Adolph Freiherr von Münchhausen (1688-1770) in den Gründungsjahren der Universität eigens darauf bedacht, Professoren mit möglichst umfassenden Privatbibliotheken nach Göttingen zu berufen, um eine bestmögliche Informationsversorgung vor Ort aufbauen zu können. Mit der dank großzügiger finanzieller Mittel rasch vorangetriebenen Bestandsvermehrung der Universitätsbibliothek schwand die Notwendigkeit, eigene - in der Regel kostspielige - Handbibliotheken zusammenzutragen. Im Laufe des 18. Jahrhunderts verkleinerten sich die Göttinger Gelehrtenbibliotheken und wurden in der Regel nach dem Tode ihrer Besitzer an die Universitätsbibliothek veräußert.

Eine der ersten Erweiterungen des Bestandes der Göttinger Bibliothek ging freilich auf einen noch zu Lebzeiten des Besitzers veranlassten Ankauf zurück: Im Jahre 1754 ging die mit mehr als 3.000 Kartenblättern überaus reiche Kartensammlung des Johann Michael Franz (1700-1761) an die Universitätsbibliothek über. Sie bedeutete eine wichtige Ergänzung des Grundstockes der Kartensammlung, der im wesentlichen aus etwa 2.000 Karten der Bibliotheca Buloviana bestand. Der Geograph und Verleger Franz war nach dem Tode des Kartenverlegers Johann Christoph Homann im Jahre 1730 gemeinsam mit Johann Georg Ebersberger vom Geschäftsführer zum Erben des - nunmehr „Homännische Erben“ genannten - Verlages aufgestiegen. Unter seiner Federführung hatte sich 1746 die Kos- mographische Gesellschaft gegründet. 1754 wurde Franz auf den für ihn neu eingerichteten geographischen Lehrstuhl nach Göttingen berufen, wo er 1761 starb.

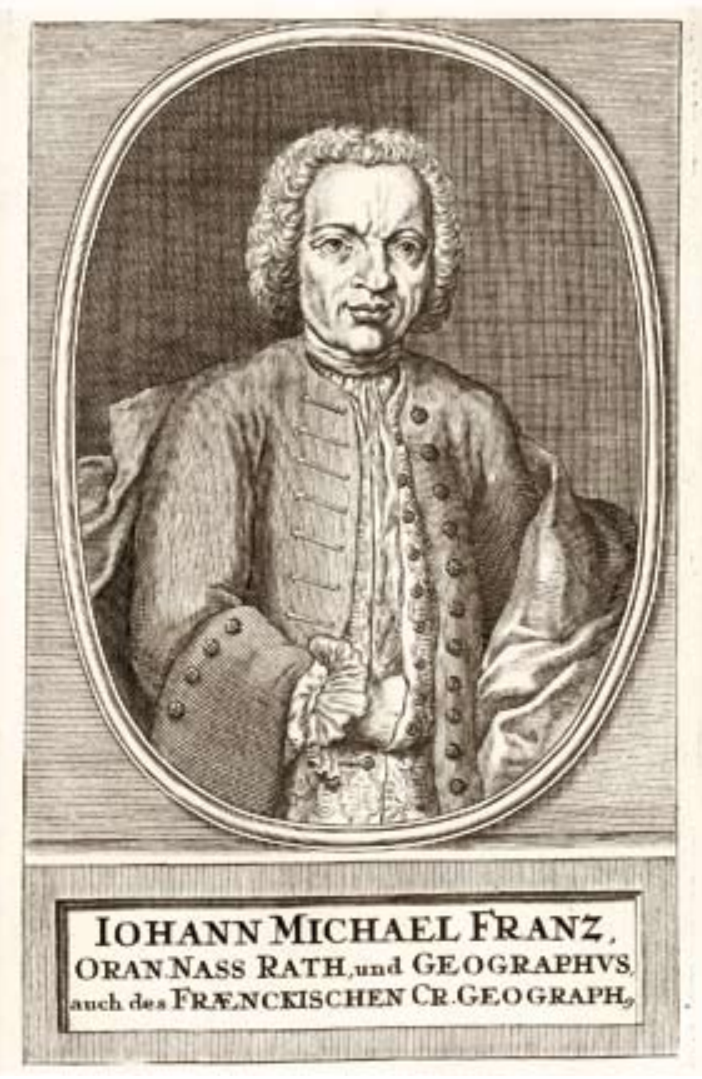

Johann Michael Franz (1700-1761).

Zehn Jahre nach diesem Ankauf, im August 1764, wurde die Bibliothek des Professors der Klassischen Philologie und ersten Bibliothekars der Universitätsbibliothek Johann Matthias Gesner (1691-1761) in Göttingen versteigert. Die Bibliothek erwarb insgesamt 729 Titel, darunter 23 Inkunabeln, dem Interessengebiet des Vorbesitzers entsprechend fast ausschließlich Autoren der klassischen und christlichen Antike. Gesner war wie sein Nachfolger Christian Gottlob Heyne ein Vertreter des Neuhumanismus, so dass in seiner Bibliothek die Altertumswissenschaften einen 
Schwerpunkt bildeten. Die Ausgaben griechischer und lateinischer Schriftsteller aus der Frühdruckzeit waren daher in diesem Bestand besonders zahlreich.

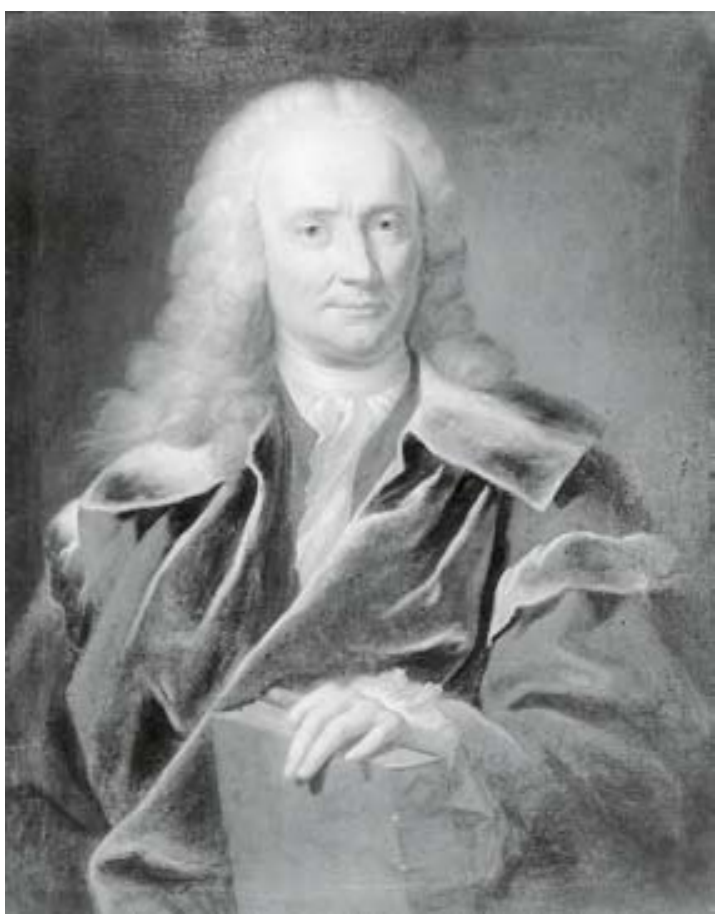

Johann Matthias Gesner (1691-1761).

Wiederum zehn Jahre später, in den Jahren 1773/74, wurde die umfangreiche Bibliothek des Juristen Georg Christian Gebauer (1690-1773) verkauft. Seine Bibliotheca Germanica, die rund 3.500 Drucke der älteren deutschen Literatur aus allen Gebieten enthielt, wurde komplett aufgekauft, ebenso wie eine zweite Sammlung des bibliophilen Juristen, die Collectio canticorum, die etwa 300 ältere Gesangbücher umfasste.

Weitere Erwerbungen aus Bibliotheken Göttinger Gelehrter werden in diesem Kapitel an Einzelbeispielen dargestellt, darunter der Verkauf des Insektenbuchs der Maria Sibylla Merian durch Johann Friedrich Blumenbach (1752-1840). Zum Abschluss werden
Beispiele aus der Gauß-Bibliothek, dem etwa 1.500 Titel umfassenden erhaltenen Teil der Privatbibliothek des Mathematikers und Naturwissenschaftlers Carl Friedrich Gauß (1777-1855), und aus der Schlözer-Stiftung, der Hinterlassenschaft des Historikers und Publizisten August Ludwig von Schlözer (1735-1809) und seiner Nachkommen, vorgestellt.

(SG)

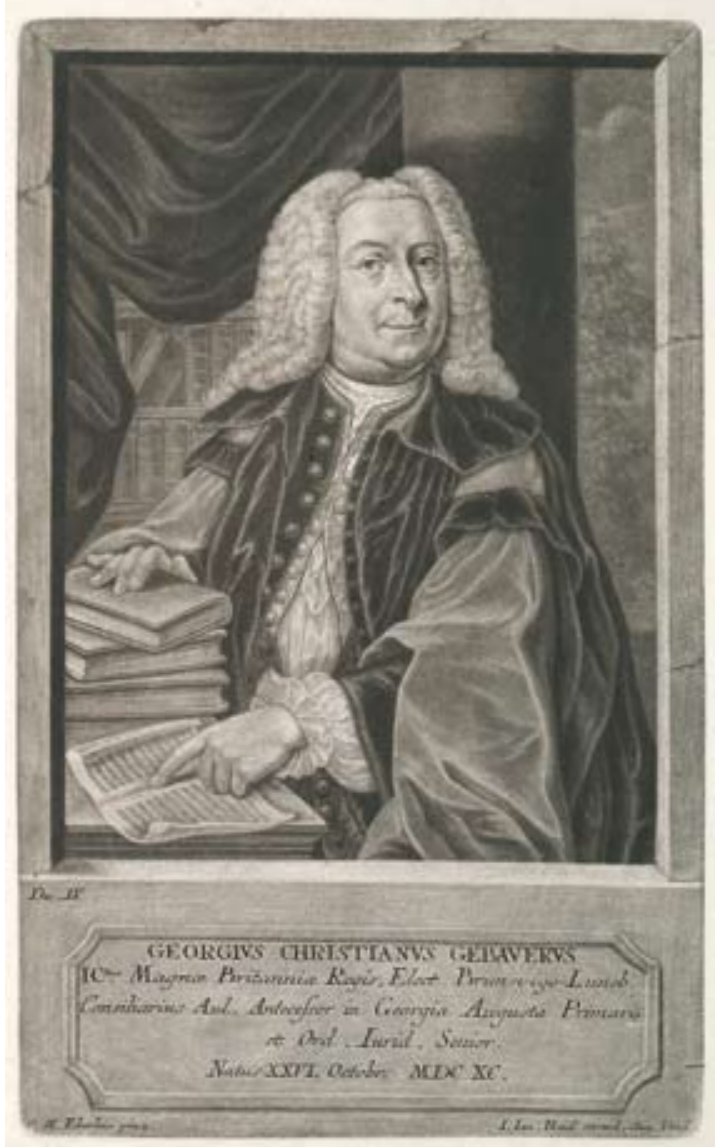

Georg Christian Gebauer (1690-1773). 


\section{Ein Blick durch das Fernrohr - Astronomie in Nürnberg}

Johann Gabriel Doppelmayr:

Atlas novus coelestis.

Nürnberg: Homännische Erben, 1742.

Signatur: gr. $2^{\circ}$ Astr. I, 1962 Rara

Provenienz: Johann Michael Franz, 1754

Der Nürnberger Mathematiker und Naturwissenschaftler Johann Gabriel Doppelmayr (1677-1750) bereiste nach seinem Studium in Altdorf und Halle verschiedene Städte in Deutschland, den Niederlanden und England. Nach seiner Rückkehr 1704 wirkte er als Professor für Mathematik und Physik in Nürnberg, wo er bis zu seinem Tod blieb. 1710 wurde er außerdem zum Direktor der Nürnberger Sternwarte ernannt. Doppelmayr begann seine kartographische Tätigkeit, indem er vor allem Himmelskarten für den Nürnberger Verleger Johann Baptist Homann (1664-1724) entwarf, die den verschiedenen Atlanten des Verlages beigegeben wurden.

Erst 1742 wurde dann von den Homännischen Erben der Atlas novus coelestis herausgegeben, für den Doppelmayr 30 Karten zeichnete. Der prächtig ausgestattete Band enthält Darstellungen des Sonnensystems, der Planetenbewegungen, der Sternbilder und eine Mondkarte. Die sorgfältig ausgeführten Kupferstiche sind von allegorischen Darstellungen eingerahmt. Doppelmayr vertrat die Überzeugung, dass eine gute Karte nur durch das Zusammenwirken von Künstlern und Mathematikern entstehen könne. Eine Karte sei ein Kunstwerk, das auf mathematischem Grund erwachsen sei.

Dank der Sternkarten wurde die Astronomie einem weiten Benutzerkreis zugänglich. Der Österreicher Peter Anich (1723-1766) benutzte 1755/56 diese Karten bei der Anfertigung seines großen Himmelglobus. Auch wenn die Karten aus dem Atlas novus coelestis die astronomische Wissenschaft nicht grundsätzlich bereicherten, trugen sie doch erheblich zur Popularisierung des Kopernikanischen Weltbildes bei. Wissenschaftsgeschichtlich bedeutend ist eine Weltkarte aus dem Atlas, auf der Doppelmayr 142 Ortspositionen mit ihren astronomisch bestimmten geographischen Koordinaten anführt. Mit astronomischen Hilfsmitteln sind genaue Positionsbestimmungen auf der Erde möglich. Genaue und verbindliche geodätische Bezugspunkte fehlten zur damaligen Zeit jedoch in Deutschland. Doppelmayr weckte mit seiner Karte das Bewusstsein für die Wichtigkeit der Landvermessung als Grundlage für eine exakte topographische Kartendarstellung. Unter seiner Anleitung entstanden in Nürnberg ebenfalls zahlreiche Erd- und Himmelsgloben, die der Kupferstecher Johann Georg Puschner (1680-1749) anfertigte. 


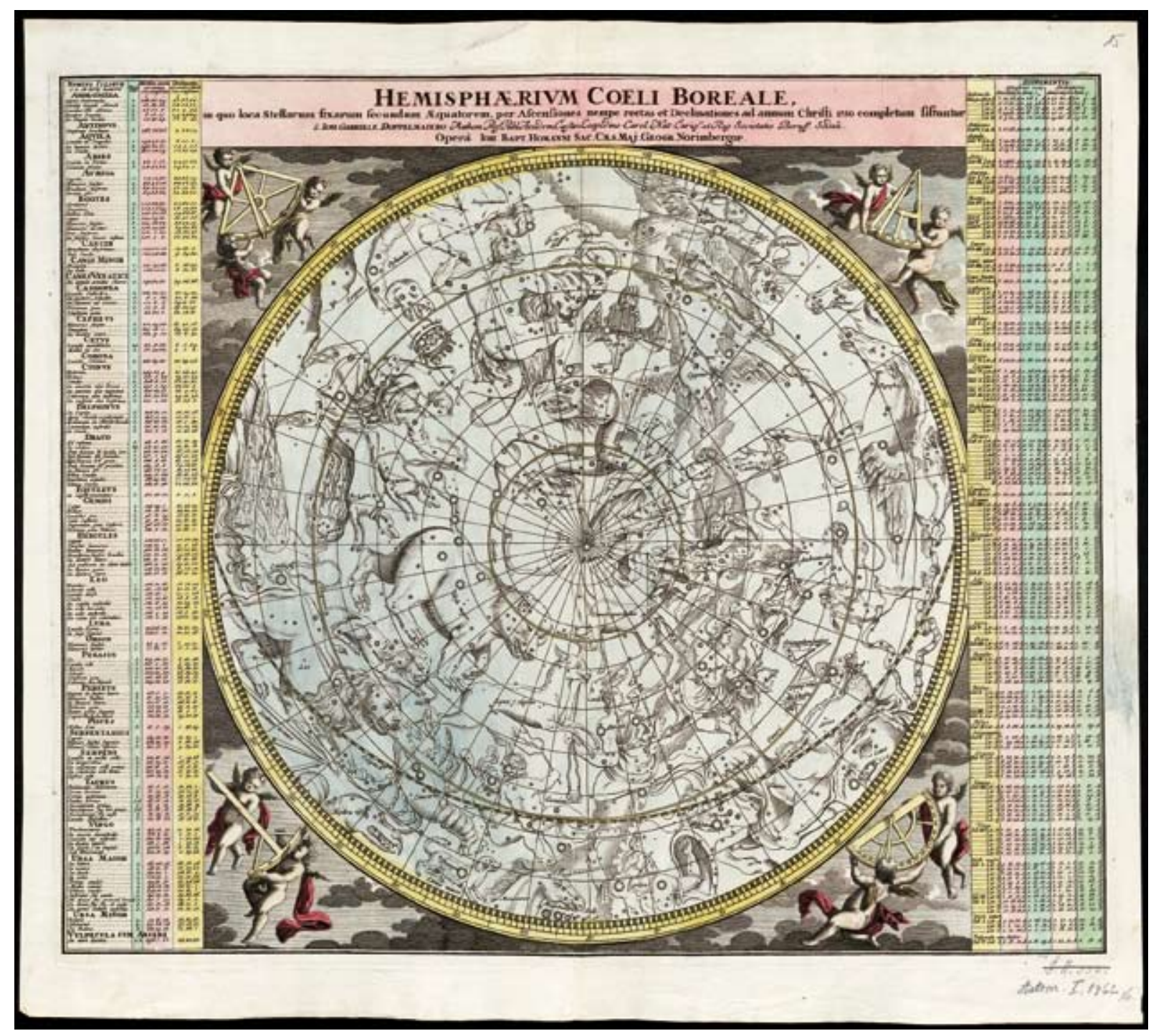




\section{Der erste moderne Geschichtsatlas}

Johann Matthias Hase:

Atlas historicus comprehendens imperia maxima seu monarchias orbis antiqui historice, chronologice et geographice.

Nürnberg: Homännische Erben, 1750.

Signatur: gr. $2^{\circ}$ Geogr. 307 Rara

Provenienz: Johann Michael Franz, 1754

Den Höhepunkt der geschichtskartographischen Publikationen des Verlages Homännische Erben bilden die historischen Karten des Johann Matthias Hase (1684-1742). Der Sohn eines Augsburger Mathematiklehrers studierte zunächst Theologie in Helmstedt und seit 1704 Mathematik an der Universität Leipzig. 1719 wurde er als Professor für Mathematik an die Universität Wittenberg berufen, wo er fast 23 Jahre lang wirkte. Hase wurde von Johann Michael Franz als Autor für die Erstellung von historischen Karten für den Verlag angeworben. Infolge seines besonderen Interesses an der politisch-territorialen Geschichte des europäischen, nordafrikanischen und asiatischen Raumes begann Hase schon relativ früh, sich mit der geschichtskartographischen Darstellung dieser Gebiete zu beschäftigen. Seine historischen Karten bilden einen Wendepunkt in der Geschichtskartographie. Hase beschränkt sich - ganz im Sinne der Geschichtsauffassung der Aufklärung - als einer der ersten auf seinen Karten nicht auf Europa und den Mittelmeerraum, sondern bezieht außereuropäische Weltreiche in seine Betrachtungen mit ein und führt die Karten bis in die jüngste Zeitgeschichte.

Johann Matthias Hase wollte seine jahrzehntelangen Forschungen über die Großreiche der Weltgeschichte mit einem umfangreichen Werk krönen. Sein plötzlicher Tod im Jahre 1742 vereitelte das Vorhaben. Auf Initiative von Johann Michael Franz veröffentlichte der Verlag der Homännischen Erben mit einiger Verzögerung 1750 die bereits fertig gestellten sieben Karten, die das Römisch-Deutsche
Reich betrafen. Diese Karten umspannen eine Zeit von mehr als 900 Jahren, nämlich vom Tod Karls des Großen (814) bis zu Karl VI. (1736).

Aus Kostengründen wurde für alle sieben Karten nur eine einzige Kupferplatte angefertigt. Daher sind auf jeder Karte die gleichen Beschriftungen vorhanden. Die sieben Karten unterscheiden sich lediglich durch das mit der Hand angelegte Kolorit voneinander. Um die einzelnen Farben den entsprechenden Territorien zuordnen zu können, wurde jeder Karte eine eigene Farberklärung beigegeben, so dass jedes Blatt aus zwei Teilen besteht: aus einer Kupferstich-Karte und aus einer Kupferstich-Farbenerklärung jeweils mit Handkolorit. Auf Hases Geschichtskarten kommt den mit der Hand aufgetragenen Farben eine derart zentrale Bedeutung zu, dass ohne sie eine Vermittlung des Karteninhalts gar nicht möglich wäre. Dementsprechend sorgfältig und exakt musste das Kolorit auf die Drucke aufgetragen werden. 


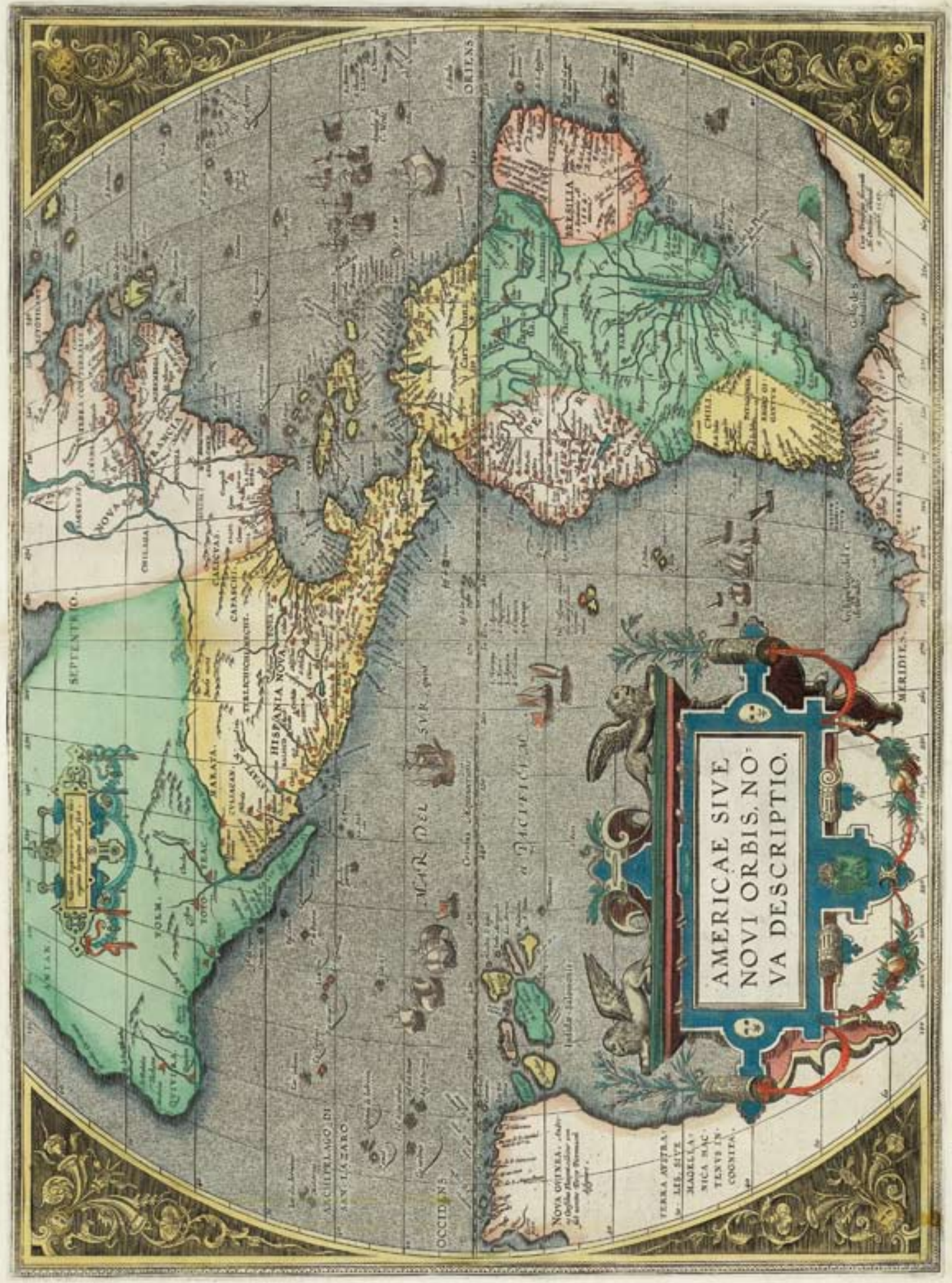




\section{Eine Weltkugel-Fabrik in Göttingen?}

Acta Societatis Cosmographicae seu Minorum Scriptorum a Membris Societatis publicandi Instituti Cosmographici causa editorum in unum Volumen Collectio, facta Anno 1754, quo exspiravit huius Societatis Directorium Norimbergense, ad Musas idque Goettingenses felicissimis Auspiciis emigravit. Nürnberg: Kosmographische Gesellschaft, 1754.

Signatur: $4^{\circ}$ Geogr. 662 Rara und $4^{\circ}$ Geogr. 663 Rara

Provenienz: Johann Michael Franz, 1754

Johann Michael Franz (1700-1761), Mitinhaber des Verlages Homännische Erben, erkannte um 1740, dass sich ohne eine umfassende, staatlich finanzierte Datenaufnahme die Kartographie nicht weiterentwickeln könne. Da der Verlag aus eigener Kraft keine Abhilfe schaffen konnte, gründete Franz einen privaten Verein, die Kosmographische Gesellschaft, mit dem Ziel, das öffentliche Bewusstsein zu ändern und damit den Weg für eine staatlich finanzierte kartographische Stelle zu ebnen. Diese Kosmographische Gesellschaft bestand aus nur wenigen Mitgliedern, die fast alle für den Verlag Karten zeichneten. Seit 1750 folgten diese Wissenschaftler Rufen an die Universität Göttingen: zunächst der Astronom Tobias Mayer, fünf Jahre später der Mathematiker Georg Moritz Lowitz und Franz selbst. Man hatte letzterem in Göttingen eine Finanzierung der Kosmographischen Gesellschaft in Aussicht gestellt, wofür er seine Verlagshälfte mitzubringen versprach. Doch seine Reise nach Göttingen musste heimlich geschehen, und eine Übersiedlung des Verlages verhinderte der Rat der Stadt Nürnberg, als die hohe Verschuldung von Franz offenbar wurde.

In enger Zusammenarbeit mit der Kosmographischen Gesellschaft wollten Franz und Lowitz eine Globenproduktion ins Leben rufen, die alle bisher bekannten Globen an Qualität weit übertreffen sollte. Von dem Verkauf der Globen erwartete Franz einen Gewinn, den er in die Kartenproduktion des Verlages investieren wollte. Für ein derart anspruchsvolles Unternehmen wurde eine längere Vorbereitungszeit vorgesehen. In dieser Zeit wurden verschiedene Werbeschriften verteilt, die vor allem dazu dienten, Subskribenten für die Finanzierung des Projektes der „Weltkugel-Fabrik“ zu gewinnen, und es fanden sich auch genügend Interessierte, die bereit waren, im Vorhinein Geld zu investieren. Lowitz’ Ansprüche an die Qualität der Globen waren jedoch so hoch, dass die Produktion nicht in Gang kam. Zehn Jahre nach der ersten Ankündigung der Globen forderten die Subskribenten ihr eingezahltes Geld zurück. Franz hatte diese Gelder jedoch längst in andere Projekte investiert. Lowitz beendete daraufhin die Arbeiten an den Globen und verließ 1767 enttäuscht Göttingen, um einem Ruf nach St. Petersburg zu folgen. Die Kosmographische Gesellschaft in Göttingen brachte aufgrund der zu hoch gesetzten Ansprüche in Verbindung mit der finanziellen Zerrüttung von Franz anstatt eines Quantensprungs in der Kartographie lediglich einige kleinere programmatische Schriften zustande. 


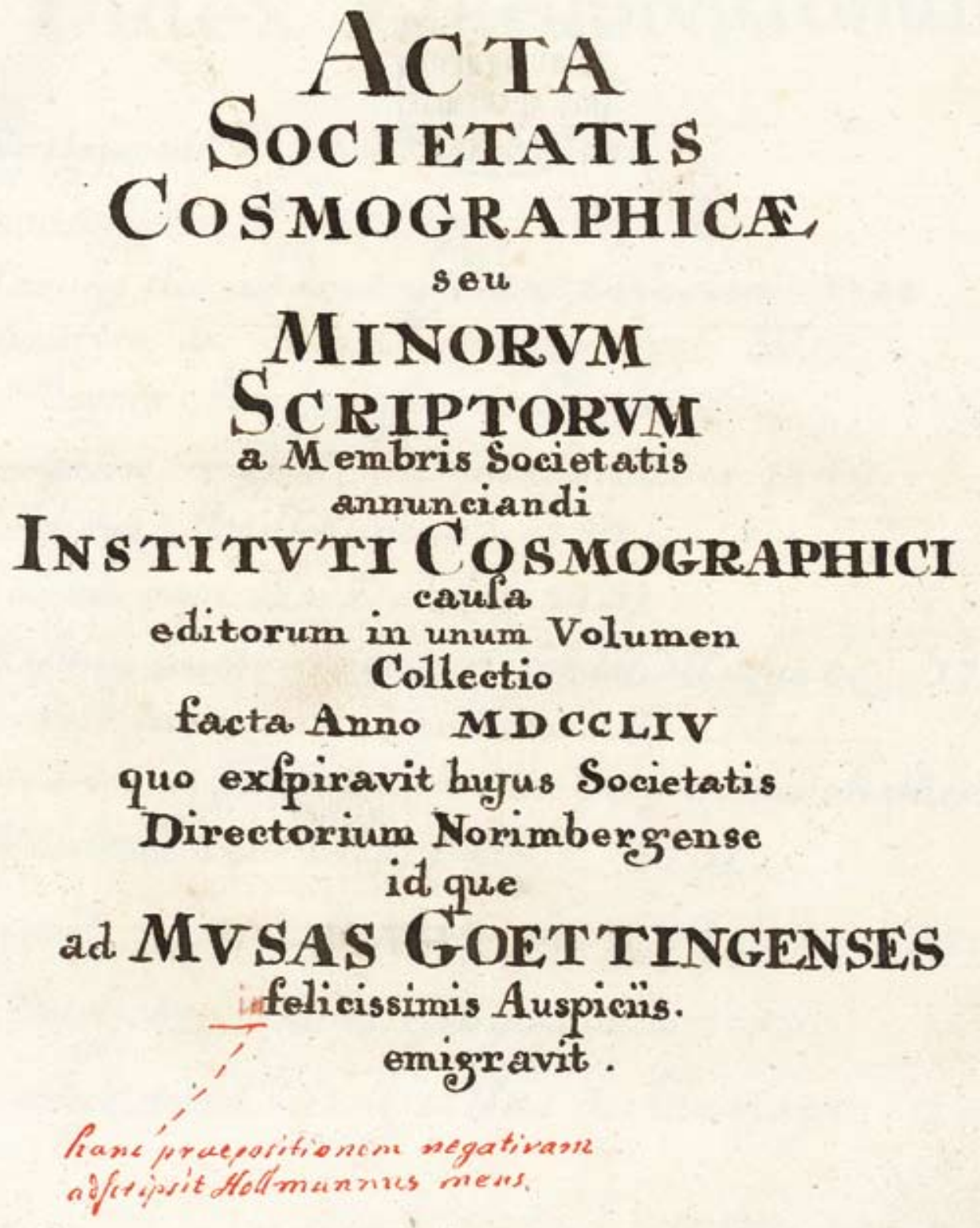




\section{Der Sammelatlas des Verlages Homann}

Atlas von Deutschland und angrenzender Gebiete.

Nürnberg: Homännische Erben, 1761.

[Mit Titelblatt: „Atlas Germaniae Specialis“ von Johann Baptist Homann, 1735.]

Signatur: gr. $2^{\circ}$ Geogr. 222 Rara

Provenienz: Johann Michael Franz, 1761

Der Homännische Verlag ist berühmt für sein umfangreiches Atlasangebot. Diese Atlanten unterscheiden sich von den heutigen nicht nur hinsichtlich des Kartenbildes, sondern auch durch einen anderen Herstellungsprozess. Der Verlag stellte für die Atlanten keine eigenen Karten her; sämtliche Karten wurden sowohl für die Zusammenstellung der Atlanten verwendet als auch einzeln verkauft. Der Großteil der Drucke von den Stadtkarten bis zu den Weltkarten gehört zu den zeittypischen politisch-historischen Karten allgemeinen Informationsgehaltes, eine ganze Reihe von Darstellungen widmet sich aber speziellen Themen, wie Geschichtskarten, Postroutenkarten, Gewässerkarten, Sprachenkarten und Entfernungstabellen.

Von den Atlas-Titelblättern und Inhaltsverzeichnissen wurde eine wesentlich größere Anzahl auf Vorrat gedruckt als von den Karten. Ein Verlagsatlas entstand, wenn sich der Kunde den Atlas beim Verlag oder bei einem gut sortierten Händler individuell zusammenstellen ließ. Der Atlas wurde üblicherweise ungebunden angeboten. Während von Titel und Inhaltsverzeichnis ein Vorrat für mehrere Jahre gedruckt wurde, veränderte der Verlag ständig das eine oder andere Kartenblatt. Da immer die aktuellsten Versionen der Karten für die Atlanten verwendet wurden, erhielt der Kunde in der Regel einen Atlas, dessen Karten aktueller waren, als es die Datierung des Titelblattes angab. Im vorliegenden Fall beträgt die Diskrepanz zwischen Erscheinungsjahr auf dem prächtigen Titelblatt und der jüngsten Karte 36 Jahre.
Im Homännischen Verlag wurden umfangreiche Atlanten mit allen verfügbaren Karten herausgegeben. Die Atlanten und ihre Karten verkauften sich so gut, dass der Verlag ständig in neue Karten für erweiterte Atlasausgaben investieren konnte. Mit zunehmendem Umfang kamen aber auch kleinere Zusammenstellungen auf den Markt, nicht nur, um auch weniger kaufkräftige Kunden anzusprechen, sondern auch wegen der Handlichkeit. Die letzte zweibändige Atlaszusammenstellung aller Karten enthielt einen ersten Band mit 150 Karten aller nichtdeutschen Gebiete und einen zweiten Band mit 125 Deutschlandkarten. Die Ausgliederung der Deutschlandkarten in einem eigenen Band erfolgte erstmals im Atlas Germaniae specialis 1735. 


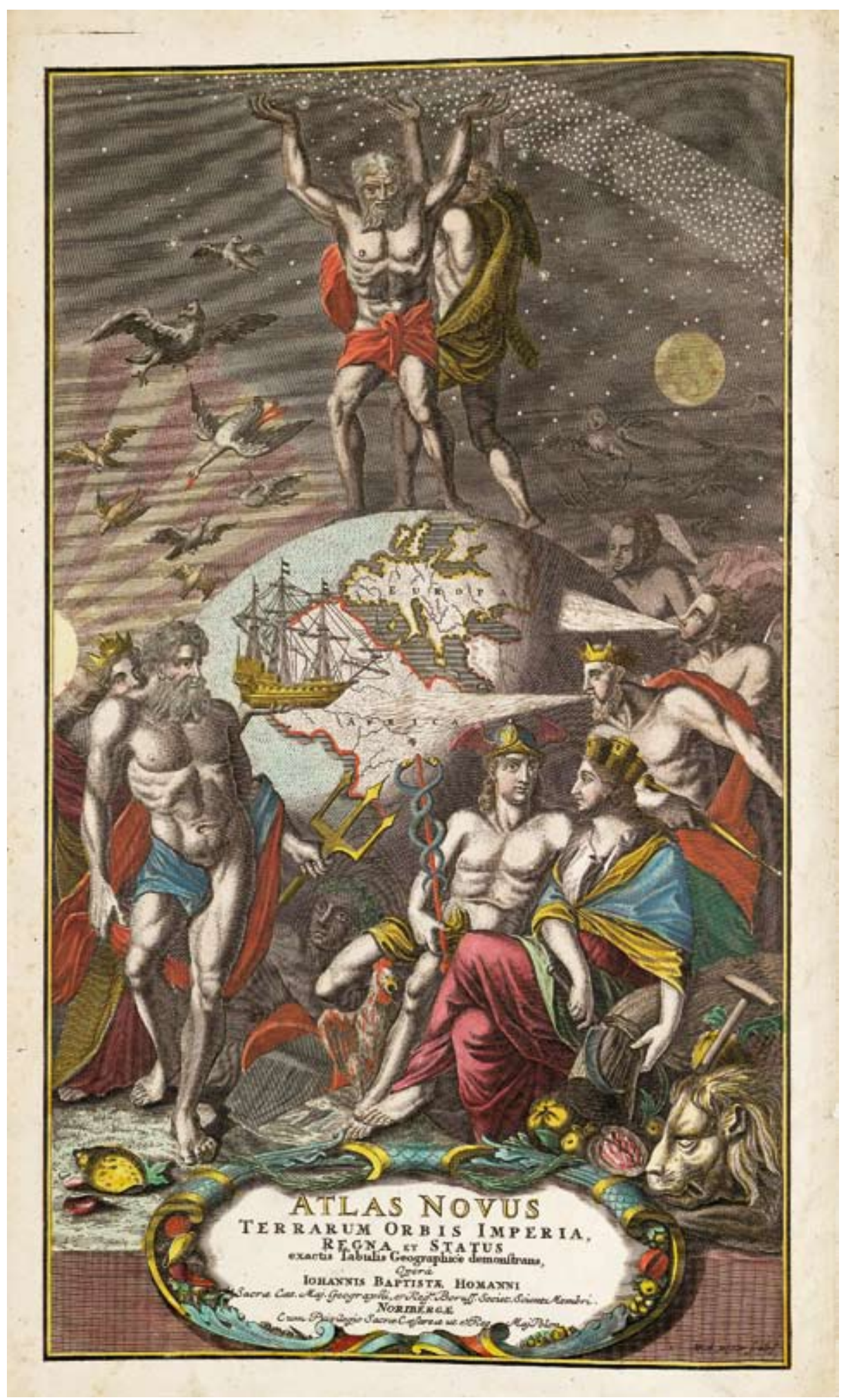




\section{Die Institutiones oratoriae in Nicolas Jensons Antiqua}

Marcus Fabius Quintilianus:

Institutiones oratoriae.

Venedig: Nicolas Jenson, 21. V. 1471.

Signatur: $4^{\circ}$ Auct. Lat. IV, 3474 Inc.

Provenienz: Johann Matthias Gesner, 1764

Marcus Fabius Quintilianus (35-um 96) fasste in den zwölf Büchern der Institutiones oratoriae die gesamte Erfahrung seiner jahrzehntelangen Tätigkeit als Rhetoriklehrer zusammen. Quintilian unterrichtete u.a. am römischen Kaiserhof und propagierte eine möglichst natürliche Redeweise, womit er sich gegen die gängige, sehr gekünstelte Rhetorik seiner Zeitgenossen wandte. Durch seine fundierten Ausführungen erwarb Quintilian auch bei den Humanisten hohes Ansehen. Viele Gelehrte wurden von ihm direkt oder indirekt beeinflusst und schulten ihr Sprachgefühl an den Schriften des antiken Redelehrers.

Eine der typographisch schönsten Ausgaben der Institutiones oratoriae brachte 1471 Nicolas Jenson (1420-1481) in Venedig auf den Markt. Der in Frankreich geborene Jenson lernte den Buchdruck bei Gutenberg kennen und begann nach dessen Tod eine sehr erfolgreiche Karriere als Schriftschneider, Drucker und Buchhändler in Italien. Mit den ab 1470 entstandenen Schriften hat Jenson die Buch- und Schriftästhetik nicht nur seiner Zeit nachhaltig geprägt. Seine schönste Schrifttype ist die hier zu sehende kräftige und lebendige Antiqua. Diese Schriftfamilie wurde in den romanischen Sprachgebieten schon in der Renaissance bevorzugt, während die vor allem im deutschen Sprachraum benutzten gebrochenen Schriften deutlich weniger verbreitet waren. Gründe dafür gibt es viele, nicht zuletzt politische. Doch die Antiquaschriften, allen voran die Jenson-Antiqua, stehen auch für ein Programm: Im ebenmäßigen, leicht lesbaren und perfekt ausgewogenen Schriftbild spiegeln sich Klarheit und Freiheit des Denkens, auch wenn man dabei dem Irrtum aufsaß, die Antiquaschrift gehe unmittelbar auf antike Schriftvorbilder zurück. Tatsächlich basiert sie auf Schriften der karolingischen Zeit.

Nicolas Jensons Antiqua inspiriert die Typographen bis heute. Auch Harry Graf Kessler ließ für seine Cranach-Presse diese Schrift nachschneiden und druckte damit u.a. seine Vergilausgabe von 1926 (s. Nr. 47). Aufgeschlagen ist der Beginn von Buch 1 der Institutiones. Das Exemplar aus dem Besitz von Johann Matthias Gesner, der es selbst im Jahr 1736 geschenkt bekam, ist nur unvollständig und wenig sorgfältig rubriziert. Um so mehr kann jedoch die wunderbare Schrift wirken. 


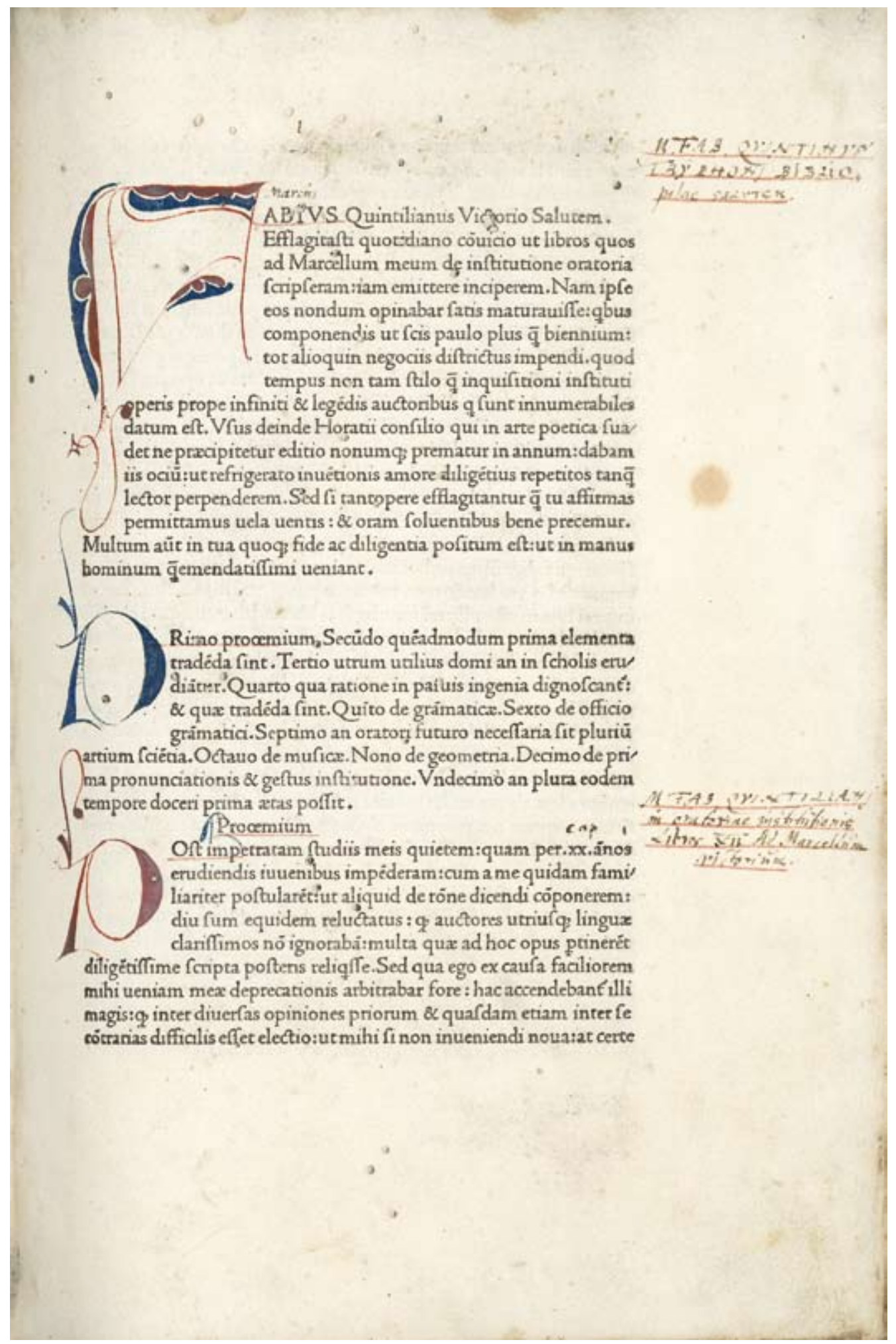




\section{Humanistische Studienausgabe des Horaz}

Quintus Horatius Flaccus:

Opera, lateinisch.

Venedig: Filippo Pincio, 1495 oder 1505.

Signatur: $4^{\circ}$ Auct. Lat. III, 348 Inc.

Provenienz: Johann Matthias Gesner, 1764

Das Leben des römischen Dichters Quintus Horatius Flaccus (67 v. Chr. -8 v. Chr.) wurde entscheidend von den politischen Umwälzungen seiner Zeit geprägt. Der Sohn eines freigelassenen Sklaven aus Venusia erlebte den Aufstieg Caesars und den Untergang der römischen Republik, die Bürgerkriege und die Errichtung des Prinzipates durch Augustus. Der junge Horaz erhielt eine überdurchschnittliche Bildung und war ehrgeizig; in den politischen Wirren erlebte er manche Erfolge, aber auch Tiefpunkte seiner Karriere. Eine dauerhafte Konsolidierung in seinem Leben trat erst mit dem Zugang zum Kreis des Maecenas durch Vermittlung von Vergil ein. Horaz war jetzt nicht nur ein angesehener und materiell abgesicherter Dichter, sondern gehörte auch zum Kreis jener Künstler, die die augusteische Kultur entscheidend mitprägen sollten. Als anerkannter Poet und Vertreter der klassischen römischen Literatur stand Horaz von Beginn an im Mittelpunkt des Interesses bei der Wiederentdeckung antiker Autoren durch die Humanisten in der Renaissance. Neben den Bemühungen um die Herstellung eines möglichst authentischen Textes stand für die Philologen der beginnenden Neuzeit die Abfassung von Kommentaren im Zentrum ihrer Arbeit.

In der hier gezeigten Ausgabe sind außer dem Horaz-Text gleich vier Kommentare enthalten, von denen zwei noch aus antiker Zeit, zwei aus der Renaissance stammen. Die Texterklärungen von Pomponius Porphyrio und Pseudo-Acro sind die einzig erhaltenen Kommentare zu Horaz aus der Antike, obwohl es zahlreiche Werke dieser Art gegeben haben muss. Die umfangreichen Anmerkungen neuerer Zeit stammen von Antonius Mancinellus und Christophorus Landinus. So wie diese Ausgabe, eine typische Studienausgabe der Renaissance, sahen auch viele andere Werkausgaben der Zeit aus: Einige wenige Textzeilen des antiken Autors werden von umfangreichen Erläuterungen eingerahmt, wie hier beim Anfang der 15. Ode aus dem 2. Odenbuch. Horaz prangert darin die übertriebene Liebe zum Luxus in seiner Gegenwart an und lobt die ,gute alte Zeit”, die Bescheidenheit und Sparsamkeit der Vorfahren. Begleitet wird der Beginn des Gedichtes von einer Abbildung, die das einfache Landleben zeigt, für die Römer zu allen Zeiten ein Ideal der Lebensführung.

Der Druck stammt aus der Werkstatt des venezianischen Druckers Filippo Pincio (1490-1530), der die Herstellung des Werkes für Benedictus Fontana übernommen hat. Venedig hatte sich am Ende des 15. Jahrhunderts zu einer Hochburg der Renaissance entwickelt, in der das Buchwesen eine herausragende Bedeutung einnahm. Nirgendwo sonst gab es so viele Buchdrucker, nirgendwo sonst so viele kaufkräftige Kunden und wissenschaftlich interessierte Leser. 
CArgomeritam.

ODES.XV.

CANT. Dinat hac ode xdificioge fuxuriamagri.n.illis occupati minus populo neceffaria fuppeditabảs

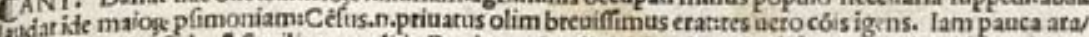

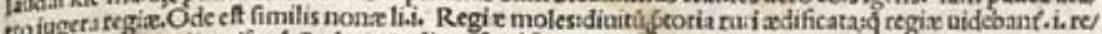

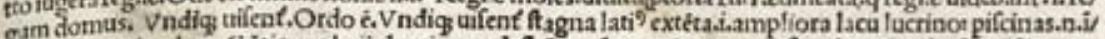
gelligit. Lucrino lacu.Cótiguus bsiis lacrinus adeft finusitraqué auernus eftut ingt Strabo li.y. Plisquog:

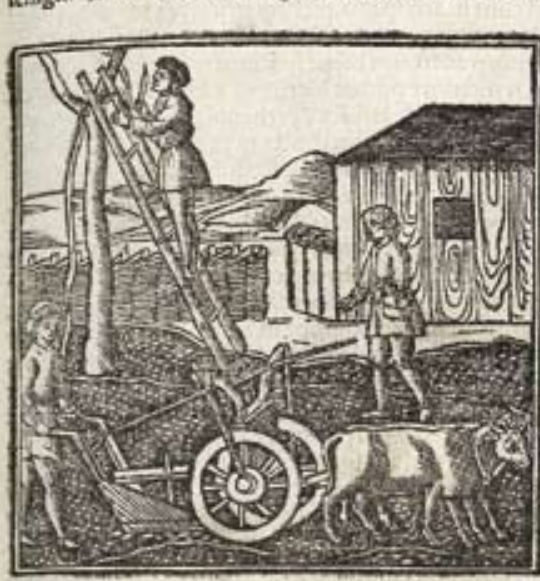

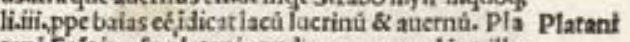
tani.Erát in ufa platani apud romanosacel in uilia: uel i hortis urbanisiad umbras iambulationú : qué ufum docuerút Athenx in pliopecio r xaroo át Platos latitudo dit.rs $\lambda$ a rusto dilato.plata dixius in luuej Platino malể ibi. Frótonis platani. Calebsi.fine uitib?p me Calebo taphorä̉nó iung unf.n.platano uites: ga ut fcri.Pli. Iucunda cft unovera platanisçđ̆ craffa. Cretibé aŭt dì

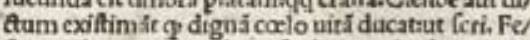
ftus. Vlmos cuincetshoc eft plures erút platani uo luptatis gfa confitx ö ulmicû uitibus. Nariam.i. odoges Óliuetissubi f ferít oliueta. Fertilibusınác enimfublatis inde oless uio'atia \& fimilia ibidécó fexebant ad uoluptaté SX odoregtam. IQtus: folarcs radiosad f falmina itelligit:laurus n.non tangit ful mineat fcribít Pli.lib.xy. Non ita romuli. Ordoé. Non ita ṕfcriptum aufpiciis romuli \& itonfi cato// nis \& uetçe norma. Non ita p̂fcriptum.i. jeeptum.

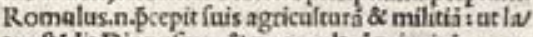
tc oftédit Dionyfius : á nos multa i principio geor.

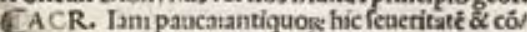
tiné ia laudar : É querit de putas laxuria feculi quo

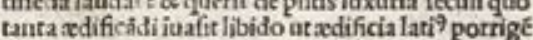

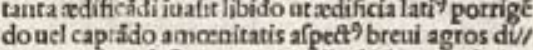
cat a rônimbus defuturos. Vndị latiusanon latius extéctaffed latius uifent trä̧ino in latimdinéfed in al titudiné potius extéderen' porrigédo faftidias ut lu crinus baiag lac undis olpiceret. Platannfo ca. eui.ul.Plures eruit ingt platani funt magis ad amcenitaté deábulationis pofitax ga almi utiles uitibus \& neceffarix funthinc notat li xum pńtis tpissuel gimyrtus aut ulolaria anteferan tur oliuetis:plufog odor copia ä fruttus cutent:cex Íbs aút uitious uỉdanideo olinerú dixit fertile prio

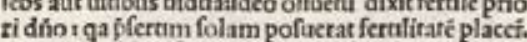
Tumf piffa.r.l. ifructuof́a ét laurus:aut ad excladé dos umbra faa folis atdores pofitan ant cette gaio i' niridaris Ifitituebat:ag feruidiss iatib? falminú crede bat effe contraria. Excludet ittusscontra maiorum laboriofam fragalemg uitam Romuli vel Catonis

dicit laxum prxfentem. Prxfcriptumiprzctptâ. Euinect ulmos/tum uiolaria/\&:

Myrtus/\&omnis copianarium

Spargent oliuetisodorem

Ferrilibus domíno priori.

Tumf fiffa ramís laurea feruidos

Excluderictus,noníta romuli

Prafcriptum/\&intonficatonis

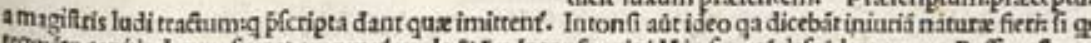

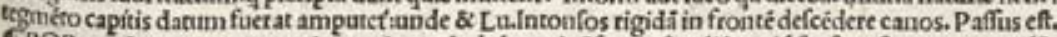

CPOR. Iam pauca aratro iugerathac odede luxuria ffents feculi loquififenfus eft autemitanta libido êt hoc tempore latius porrigetndi zedificiatut breuidefuturi fint agri. Vndiq latius uifent extenta lucrino

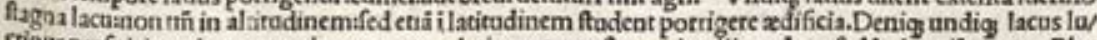
crinus prof́picietur in campaniasnon autem latius extenta ftagna intelligendumfed latius uifentat. Pla/ tanufq celcbs euincet ulmosiczlibem platanum ait elegantertquoniam econtrario maritari arbores dicun tureguibus uites iunganturaper hoc autem fignificat nó nifil luxuri 2 \& ambitiofis uoluptatibas fuderi.Pla/ tanus autem in ambalacris cohferiturande fructus nullas eft. Copia nariumsodorem dixit. Spargent olinetisshoc eft ubioliueta fuerunt. Significat autem futurum utolex arbores uertant ad conferuendas ibi myrtos \& uiolas \&c.qux fant odori \& uolaptati. Non ita romuli prxécriptum \& intonficatonis.'Aufpi cis uterumg normaipraferiptum \& joceptum di a magiftris ladi qui fcripta pueris dant f́cipiuntog imita// n. Intonfum autem Catonem aitaquia neteres pgter feueritatem hiffuti erant.

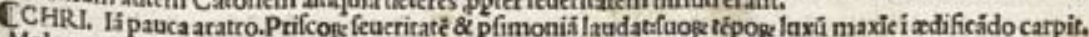
Moles regix:ully iftar regiogr xdificiog?. Moles aút fm Pompeiú p magnitudine ponitufed tá molirí \&

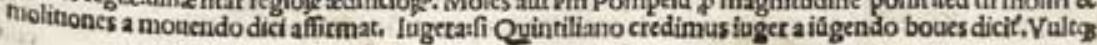




\section{Die Erde im Universum}

Johannes de Sacro Bosco:

Sphaera mundi.

[Leipzig: Martin Landsberg oder Konrad Kachelofen, um 1502].

Signatur: $8^{\circ}$ Astr. I, 986 Inc.

Provenienz: Johann Matthias Gesner, 1764

Über das Leben des Johannes de Sacro Bosco (um 1195-1256) ist nicht all zu viel bekannt; vermutlich wurde er in Yorkshire geboren und studierte in Oxford. Nach weiteren Studienjahren an der Universität Paris wurde er dort Professor der Mathematik, war aber auch als Astronom tätig. Er verfasste um 1230 sein bedeutendstes Werk, Tractatus de Sphaera oder Sphaera mundi, in dem er kosmographische Theorien des Ptolemaeus mit arabischen Quellen zusammenfasste. Zentrales Thema ist die Erde und ihre Position im Universum. Die astronomischen Erkenntnisse des Johannes de Sacro Bosco waren für die nächsten 400 Jahre bestimmend, und dies erklärt den Erfolg des Werks in der Inkunabelzeit: Vom Erstdruck im Jahre 1472 (durch den Erstdrucker Andreas Belfortis in Ferrara) bis zum Jahre 1500 erschien das Werk in 30 Ausgaben. Wegen seiner herausragenden Bedeutung für die mittelalterliche Astronomie wurde ein Mondkrater nach de Sacro Bosco benannt. Auch als Mathematiker erwies er sich als Wegbereiter für die Neuzeit, da er einer der ersten Europäer war, der sich für die Verwendung von arabischen Ziffern in der Mathematik einsetzte.

Die hier gezeigte Ausgabe der Sphaera mundi wurde vermutlich um das Jahr 1502 in Leipzig gedruckt. Da der Druck weder datiert noch mit Angaben zu den Druckern versehen ist, kann nur eine Analyse der Drucktypen die Werkstatt bestimmen helfen. Danach scheint der Druck in Leipzig das Licht der Welt erblickt zu haben, und zwar entweder bei Konrad Kachelofen († 1529) oder bei Martin Landsberg († 1523). Kachelofen war schon im 15. Jahrhundert der erfolgreichste Drucker in Leipzig, wo er zunächst als Kaufmann, Papierhändler und Inhaber einer Weinschenke wirkte. Aus seiner Werkstatt stammen zahlreiche theologische, philosophische und pastorale Schriften, und gleichzeitig versorgte er die Angehörigen der Leipziger Universität mit Literatur. Der aus Würzburg stammende Martin Landsberg hatte in Leipzig studiert und 1485 dort seine erste Druckerei eröffnet. Auch er bediente den Bedarf der Universität und publizierte unter anderem klassische Texte, in denen Platz für handschriftliche Ergänzungen gelassen war. Eine Reihe der Leipziger Professoren unterstützte Landsberg als Herausgeber und Korrektoren. Nach der in Sphaera Mundi verwendeten Auszeichnungstype, der Schrift also, die für Hervorhebungen oder Überschriften verwendet wurde, scheint der Druck um 1502 in einer der beiden Werkstätten entstanden zu sein. 


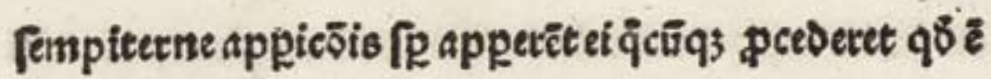

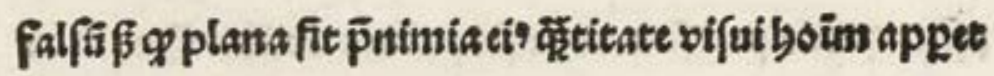

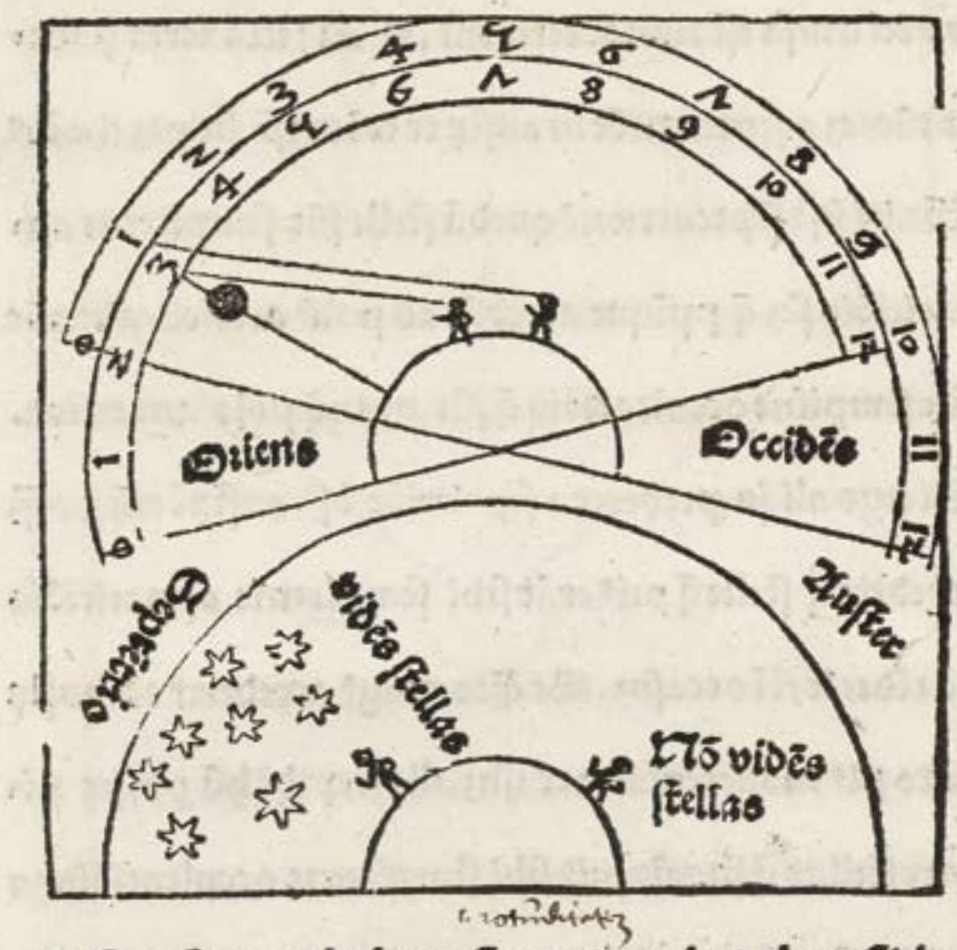

pot zom 0 ingas danta Q a cagtian

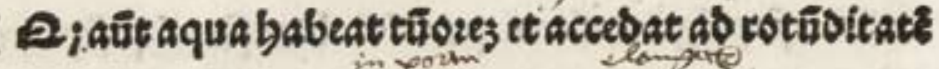
in form

Fiepts. Ponat figni intlittore maze atereatnanis a pos

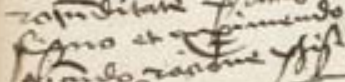

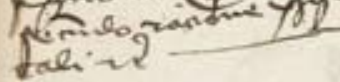

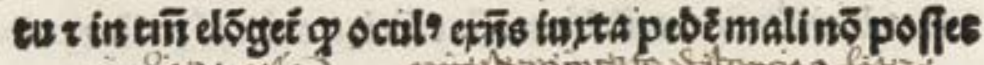
vibere figntir / f tante vero nauf ociulus eiurdèctiftentis

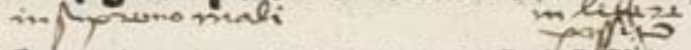

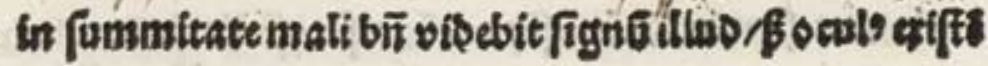




\section{Ein Rechtsbuch von europäischem Rang}

Eike von Repgow:

Landrecht u. a., niederdeutsch. [Der Sachsenspiegel.]

Leipzig: [Moritz Brandis], 30. VIII. 1488.

Signatur: $4^{\circ}$ Jus Germ. I, 4711 Inc.

Provenienz: Georg Christian Gebauer, 1773/74

Das älteste deutsche Rechtsbuch des Mittelalters wurde um 1224 von Eike von Repgow (um 1180/1190 - nach 1233) verfasst. Der anhaltinische Schöffe hatte zunächst eine - nicht überlieferte - lateinische Fassung des sächsischen Rechts zusammengestellt (um 1220) und diese auf Geheiß seines Lehnsherrn in das Niederdeutsche übertragen. Noch zu Eikes Lebzeiten wurde sie mehrfach überarbeitet und ergänzt. Nach seiner eigenen Aussage nannte Eike sein Buch Sachsenspiegel, weil darin das Recht der Sachsen erblickt werden kann, ,alse an eneme spegele de vrowen / er antlite scowen“.

Der Sachsenspiegel enthält das Landrecht, eine Zusammenfassung des um 1220 herrschenden Gewohnheitsrechtes der freien Sachsen aller Stände, und das Lehnsrecht, das vor allem die besonderen Rechtsfragen des sächsischen Adels behandelt. Als erste schriftliche Niederlegung von Rechtssätzen in deutscher Sprache und Garant der Rechtseinheit breitete er sich rasch von seinem ursprünglichen Geltungszentrum Magdeburg aus und erfasste - nicht zuletzt in Umarbeitungen und Übersetzungen - große Teile Europas, die Hansestädte des Nordostens und Nordwestens, weite Teile des heutigen Polen und Russland, Holland und Seeland. Seinen größten Einfluss erlangte das Werk im Süden des deutschen Sprachraums, wo es zum Vorbild für den um 1275 aufgeschriebenen Deutschenspiegel und anschließend für den Schwabenspiegel wurde. Als Rechtsquelle blieb der Sachsenspiegel bis weit in die Neuzeit hinein offiziell gültig: In Sachsen selbst war er bis zum Inkrafttreten des Sächsischen Bürgerlichen Gesetzbuches im Jahre 1865, in Anhalt und Thüringen bis zur Schaffung des Bürgerlichen Gesetzbuches für das Deutsche Reich im Jahre 1900 in Kraft. Das Lehnsrecht blieb formal gar bis zur Gründung der Weimarer Republik maßgeblich. Noch heute liegt der Sachsenspiegel in mehr als 200 Handschriften und Fragmenten vor. - Gezeigt wird der das Werk einleitende Holzschnitt, der den deutschen Kaiser und die sieben Kurfürsten abbildet.

(HR/SG) 


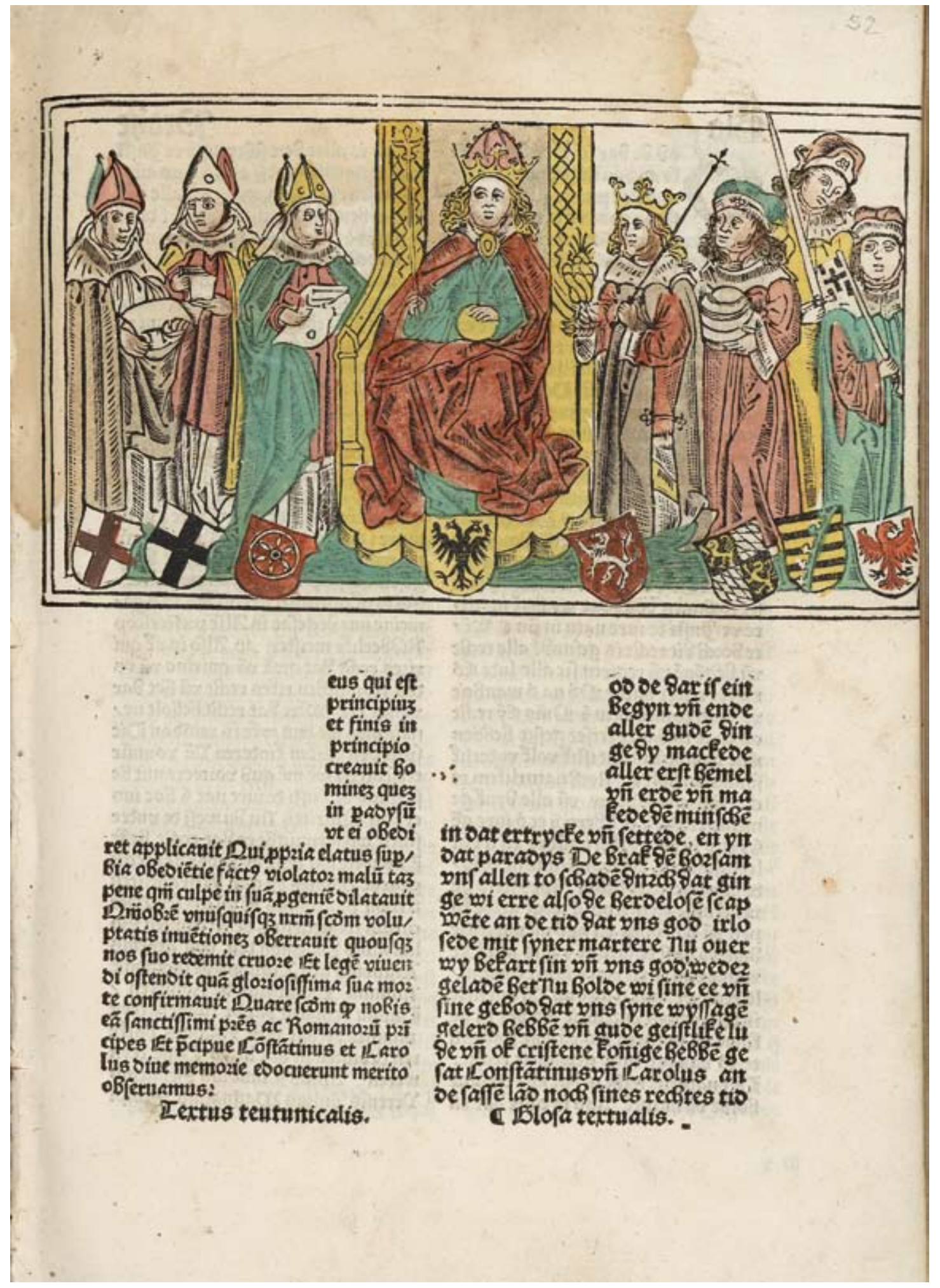




\section{Ein Bestseller der Frühdruckzeit}

Sebastian Brant:

Das Narrenschiff.

Reutlingen: [Michael Greyff], 23. VIII. 1494.

Signatur: $8^{\circ}$ Poet. Germ. II, 2114 Inc. Rara

Provenienz: Georg Christian Gebauer, 1773/74
Sebastian Brant (1457-1521) studierte in Basel klassische Sprachen und Rechtswissenschaften und lehrte danach in seiner Heimatstadt Straßburg Recht, seit 1484 auch Poesie. Einer Fülle wichtiger öffentlicher Ämter zum Trotz fand er dennoch die Zeit für umfangreiche wissenschaftliche und dichterische Arbeiten: Juristische und historischgeographische Schriften und Editionen gehen ebenso auf Brant zurück wie lateinische und volkssprachliche Gedichte oder Übersetzungen antiker Autoren. Sein Hauptwerk und zugleich sein größter Erfolg ist die Moralsatire Das Narrenschiff, dessen Erstausgabe am 11. Februar 1494 von Johann Bergmann in Basel gedruckt wurde. Das Buch schildert in einem 112 Kapitel umfassenden Katalog die Torheiten der Menschheit. Die Narren begeben sich auf eine Schiffsreise in ihr Vaterland Narragonien. In der Folge werden sämtliche Narrentypen in Einzelkapiteln vorgeführt. Den Kapiteln ist jeweils ein Motto vorangestellt, das den Inhalt des sich anschließenden Textes zusammenfasst; ihm folgt in der Regel ein Holzschnitt, der diesen Inhalt illustriert. Die insgesamt 105 Holzschnitte stammen zu fast drei Vierteln von dem jungen Albrecht Dürer (1471-1528). Nicht nur die sieben Todsünden Hoffart, Wollust, Völlerei, Neid, Trägheit, Geiz und Zorn, sondern auch sonstige menschliche Schwächen werden in satirischer Weise der Lächerlichkeit preisgegeben.
Das Narrenschiff war das erfolgreichste deutschsprachige Werk vor Goethes Werther und begründete die bis ins 18. Jahrhundert lebendige Gattung der Narrenliteratur. Die 1497 von Brants Schüler Jakob Locher (1471-1528) verfasste lateinische Version machte das Werk auch zu einem europäischen Erfolg, so dass bald Übersetzungen in die Volkssprachen folgten: Insgesamt zwölf Übersetzungen in vierzig unterschiedlichen Ausgaben machten das Buch zu einem literarischen Bestseller der Frühdruckzeit. Im Göttinger Exemplar der dritten Ausgabe, die von dem Reutlinger Erstdrucker Michael Greyff gedruckt wurde, sind einige fehlende Blätter durch die entsprechenden Blätter aus der ersten Ausgabe ersetzt. Aufgeschlagen ist ein Holzschnitt, der die Wollust thematisiert: Er zeigt eine Frau, die sich auf der Straße anbietet. 


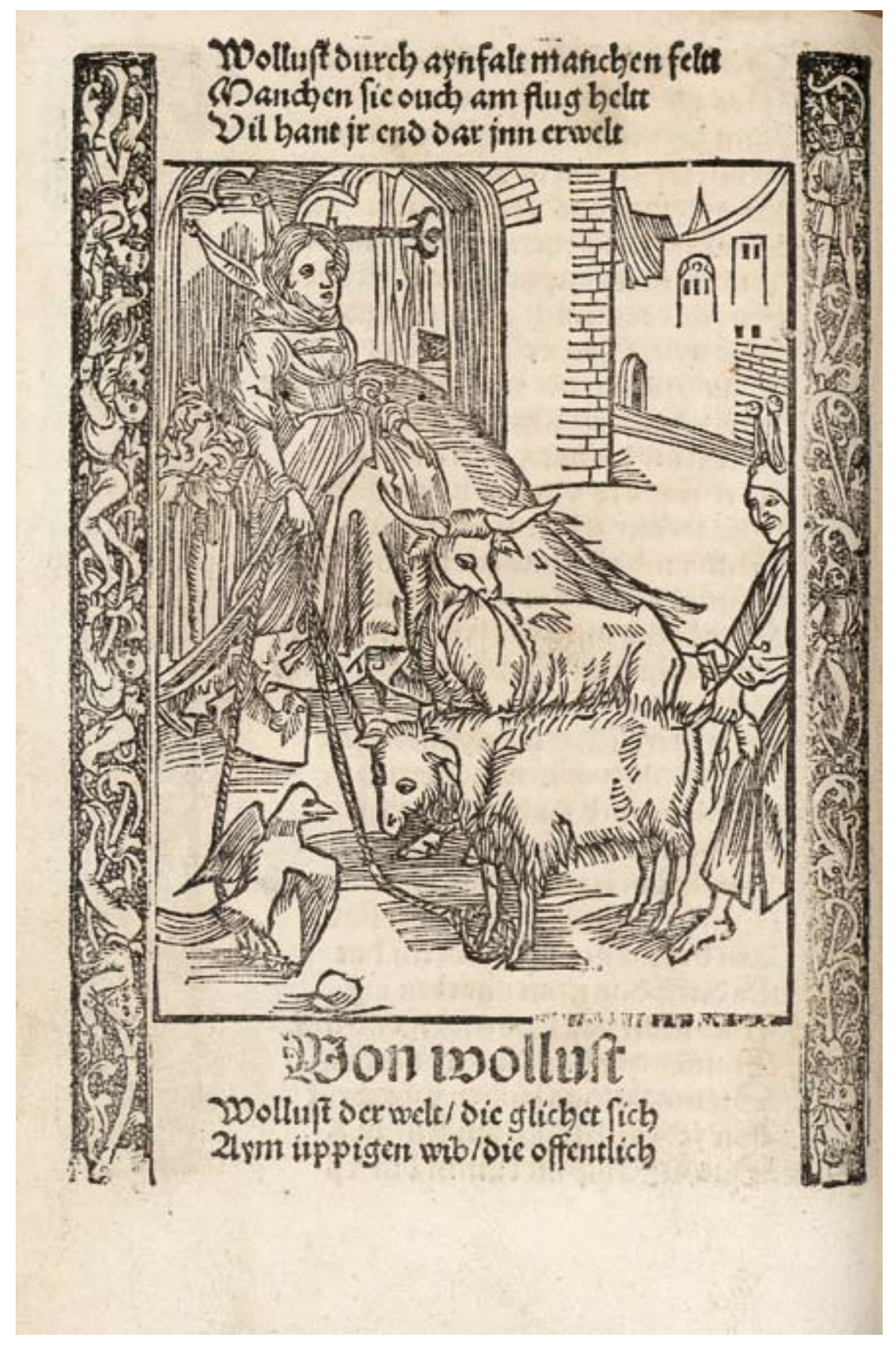




\section{Die Peinliche Gerichtsordnung}

Des allerdurchlauchtigsten, großmächtigsten, unüberwindlichsten Kaiser Karls des Fünften und des Heiligen Römischen Reichs peinliche Gerichtsordnung.

Mainz: Ivo Schöffer, Februar 1533.

Signatur: $4^{\circ}$ Jus crim. I, 1410 Rara

Provenienz: Georg Christian Gebauer, 1773/74

Ein illustrierter Gesetzestext war im 16. Jahrhundert nichts Ungewöhnliches. Rechtsordnungen wie die Peinliche Gerichtsordnung Kaiser Karls V. (1500-1558), auch Carolina genannt, wurden bebildert - zur Abschreckung. Schon im Titelholzschnitt zeigt das Werk ein einschüchterndes Ensemble von Folterinstrumenten: Rad, Daumenschrauben, Streckwerkzeuge und andere. Die Rechtsprechung strafte an Leib und Leben - an die Freiheitsstrafe war noch nicht zu denken. In moderner Terminologie ist die Carolina eine Strafprozessordnung und ein Strafgesetzbuch. Sie enthält Bestimmungen zur Besetzung eines Gerichts, legt fest, wie ein Gerichtsverfahren auszusehen habe und wie welche Delikte bestraft werden sollten.

Die Bedeutung der Carolina für die Rechtsgeschichte ist gewaltig: Sie ist das erste für das gesamte Heilige Römische Reich Deutscher Nation geltende Strafgesetzbuch und sollte der Rechtsvereinheitlichung dienen. Auf den genauen Wortlaut des Gesetzes konnten sich die Vertreter der Reichskreise nur schwer einigen, doch schließlich wurde es 1532 verabschiedet. Das Druckprivileg erhielt der Mainzer Drucker Ivo Schöffer (um 1500-1555), der im Februar 1533 die Erstausgabe vorlegte. Bis 1559 fertigten er und seine Erben elf weitere Ausgaben. Als Vorbild für den Text und die (wenigen) Illustrationen der Carolina diente die Bambergische Halsgerichtsordnung, die erstmals 1507 bei Johann Pfeil in Bamberg gedruckt wurde. Von wem die Holzschnitte der Carolina stammen, ist bislang nicht eindeutig ermittelt.
Vermutlich stammen die Vorzeichnungen von Martin Kaldenbach und die Holzschnitte von dem Holzschneider Fritz Hammer.

Auch auf die Sprachentwicklung nahm die Carolina Einfluss. Der genaue Gesetzestext fußte ursprünglich auf einem lateinischen Entwurf juristischer Gelehrter, der anschließend in das Deutsche übertragen wurde. Johann Freiherr zu Schwarzenberg und Hohenlandsberg (1463/65-1528), Hofmeister des Bischofs von Bamberg, nahm sich dieser Aufgabe an und machte die Carolina so zu einem Sprachdenkmal: Begriffe wie „Abtreibung“ oder Wendungen wie „Rechtsmittel einlegen“ und „auflaufende Kosten“ gehören seitdem zu unserem Sprachgebrauch. Nicht erhalten hat sich allerdings die Bedeutung des Wortes „peinlich“, das, abgeleitet von lateinisch „poenae“, für „Strafe“ stand. 


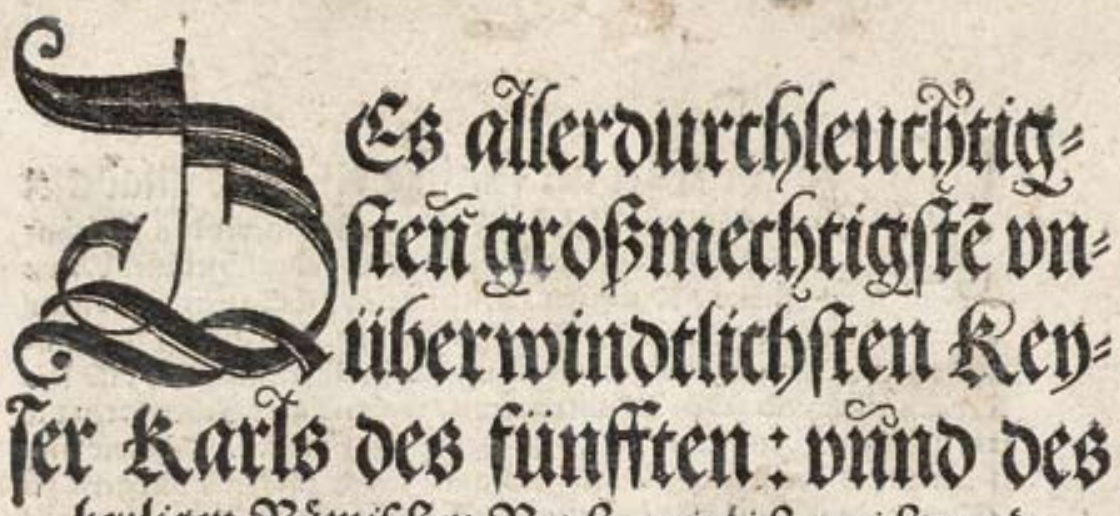

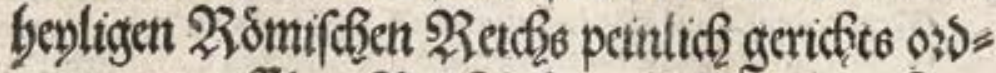

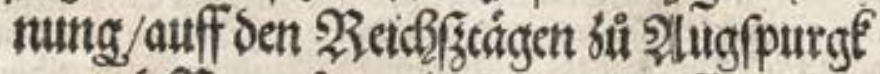

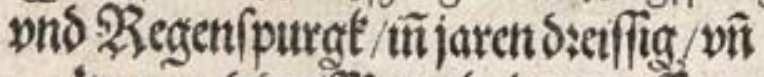
stwey vns seciffig gebalten/auff= gerticht wnd befdaloffen.

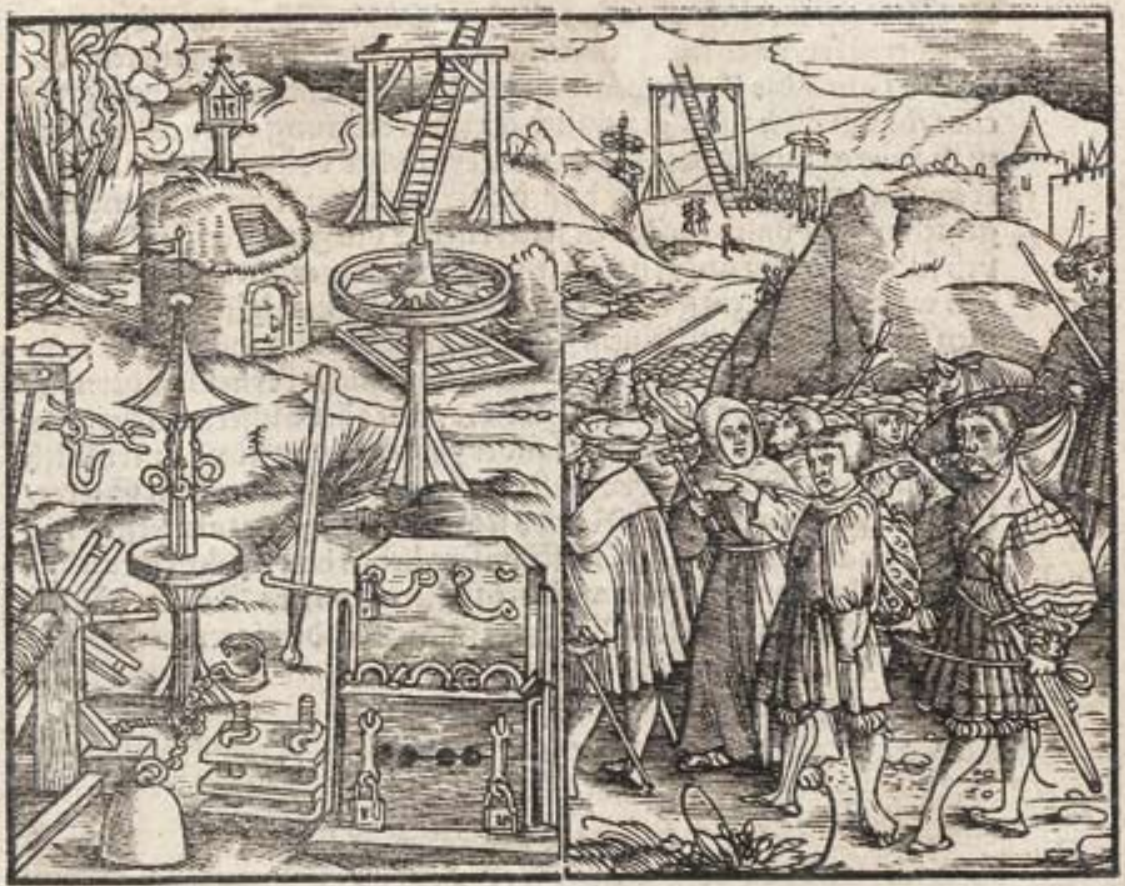

Cum gratia et prituilegio gimperioli. 


\section{Das schönste Gesangbuch der Lutherzeit}

Geystliche Lieder. Mit einer newen vorrhede D. Mart. Luth.

Leipzig: Valentin Bapst, 1545.

Signatur: $8^{\circ}$ Poet. Germ. II, 2515 Rara

Provenienz: Georg Christian Gebauer, 1773/74

Dem systematischen Aufbau einer evangelischen Frömmigkeit dienten seit dem Frühjahr 1529 Gemeindegesangbücher, deren Lieder von Martin Luther zusammengestellt und teilweise selbst verfasst worden waren, unter ihnen für das deutsche Kirchenlied so wichtige Texte wie „Aus tiefer Not schrei ich zu dir“, „Ein feste Burg ist unser Gott“ oder auch „Vom Himmel hoch, da komm ich her“. Das erste erhaltene lutherische Gesangbuch wurde 1533 bei Josef Klug ( $†$ 1552) in Wittenberg gedruckt. Die in den folgenden zwölf Jahren erschienenen Wittenberger Ausgaben wurden 1545 durch die von Valentin Bapst († 1556) in Leipzig gedruckten Geystlichen Lieder und ihre Nachfolgewerke abgelöst. Sowohl das Wittenberger als auch das Leipziger Gesangbuch sollten „eine fast unabsehbare Wirkung auf die Gesangbuchentwicklung der Folgezeit“ (Jenny) haben und selbst römischkatholische Gesangbücher beeinflussen.

Das Bapstsche Werk von 1545, das letzte zu Lebzeiten Luthers in den Druck gegebene Gesangbuch, gilt als das umfangreichste und am schönsten ausgestattete seiner Zeit; das einzige vollständig erhaltene Exemplar ist im Besitz der Niedersächsischen Staats- und Universitätsbibliothek. Nicht nur die klare Schrifttype und die sauber geschnittenen Noten, sondern auch die ornamentalen Seitenrandleisten und die Holzschnittillustrationen des Monogrammisten HA lassen seinen besonderen künstlerischen Wert erkennen. Luther selbst, von Bapst um eine neue Vorrede gebeten, gab in diesem letzten Beitrag zum kirchlichen Singen - ohne sich einen
Seitenhieb gegen die römische Kirche zu versagen - seiner Anerkennung dieser Leistung Ausdruck: „Darumb thun die drucker sehr wol dran / das sie gute lieder vleissig drucken / und mit allerley zierde / den leuten angeneme machen / damit sie zu solcher freude des Glaubens gereitzt werden / und gerne singen. Wie denn dieser druck Val[en]tin Bapsts / sehr lustig zugericht ist / Gott gebe / das damit dem Römischen Bapst der nichts denn heulen / trawern und leid in aller welt hat angericht / durch seine verdampte / untregliche und leidige gesetze / grosser abbruch und schaden geschehe / Amen.“

Das Buch enthält in zwei Teilen, den „Geistlichen Liedern“ und den „Psalmen und Geistlichen Liedern“, insgesamt 128 Kirchenlieder, dazu Gebete und illustrierte Psalmen, die sich inhaltlich eng auf die ihnen zugeordneten Lieder beziehen. Aufgeschlagen ist ein Holzschnitt, der Psalm 18, Vs. 6 illustriert. 


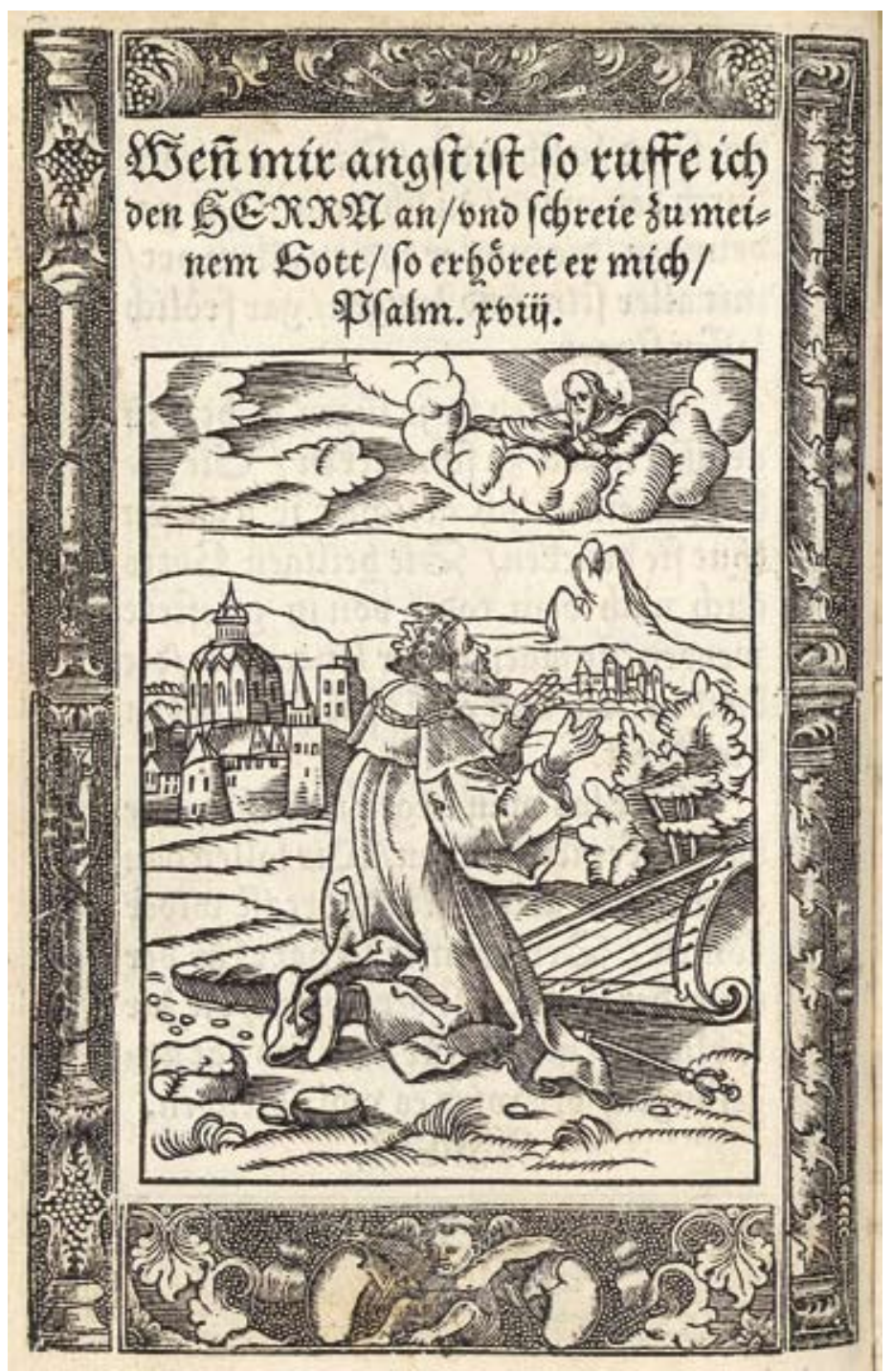




\section{Meistergesänge von Hans Sachs in eigener Hand}

Hans Sachs:

Meistergesänge.

Papierhandschrift, Nürnberg, 1554.

Signatur: $8^{\circ}$ Cod. Ms. philol. 194 Cim.

Provenienz: Georg Christian Gebauer, 1773/74
Hans Sachs (1494-1576), ein Nürnberger Schuhmacher und Freizeitpoet, lebt in unserer heutigen Zeit fort als Meistersinger. Daran hat vor allem Richard Wagner seinen Anteil, der den frühneuzeitlichen städtischen Handwerker-Dichtern vom Schlage des Hans Sachs in der Oper Die Meistersinger von Nürnberg ein romantisiertes Denkmal gesetzt hat. Tatsächlich nimmt der Meistersang im Schaffen von Sachs einen großen Raum ein: Er dichtet im Laufe seines Lebens über 4.000 Meisterlieder. Aber auch als Komödienund Tragödienautor sowie als Verfasser von Fastnachtspielen, geistlichen und weltlichen Liedern, Spruchgedichten und Prosadialogen tat sich Sachs hervor, so dass er als der vielseitigste Dichter seiner Zeit gelten muss. Bei seiner Stoffauswahl bediente sich Sachs aus vielerlei Quellen. Die biblischen Geschichten fanden ebenso Eingang in sein Werk wie die antike und zeitgenössische Geschichtsschreibung; die antike Literatur war für ihn ein so reichhaltiger Schatz wie die mittelalterliche oder die zeitgenössische. Daneben war das politisch-religiöse Zeitgeschehen sehr bedeutsam für seine Dichtung. Er kam schon früh in Kontakt mit den Lehren Luthers und betätigte sich ab 1523 als eifriger Verfechter der Reformation, die in Nürnberg (nicht zuletzt durch ihn) fortan eine Hochburg hatte.

Die in der vorliegenden Handschrift zusammengestellten 203 Meisterlieder gehören ebenfalls den verschiedensten Themenbereichen an: „dar in den sint vil schriftlicher par aus altem und newem testament... auch vil schoner \& warhaftiger weltlicher histori auch aus den poeten und philosophen fabel und sitliche ler und der gleichen vil gueter stampaney guet schwenck und possen“. Sie wurde als Auftragswerk von Sachs eigenhändig angefertigt. Die einzelnen Lieder sind im Wesentlichen nach den Erfindern der ihnen zugrunde liegenden Töne (Weisen) geordnet. Jedes Lied ist mit Jahr, Tag und Monat der Entstehung verzeichnet. Es finden sich zu Beginn des Bandes ein Vorwort von Hans Sachs mit einer Zueignung an den Nürnberger Hafner Hans Leutzdörfer (vor 1533-1571) und ein Register der Lieder, das vom Meistersinger Benedict von Watt (1569-1616) um sechs eigene Gesänge ergänzt wurde. Die Blätter mit diesen Liedern sowie das Blatt 289 mit dem letzten Lied von Sachs fehlen.

Aufgeschlagen ist Blatt 48: Antwort auf alle Strafer. Es handelt sich um ein Schulgedicht gegen die „Strafer“ (d.h. Satiren), die bei den Zunftgenossen von Hans Sachs beliebt waren. Der Text ist „Im kurzen thon Muglings“ zu singen. 


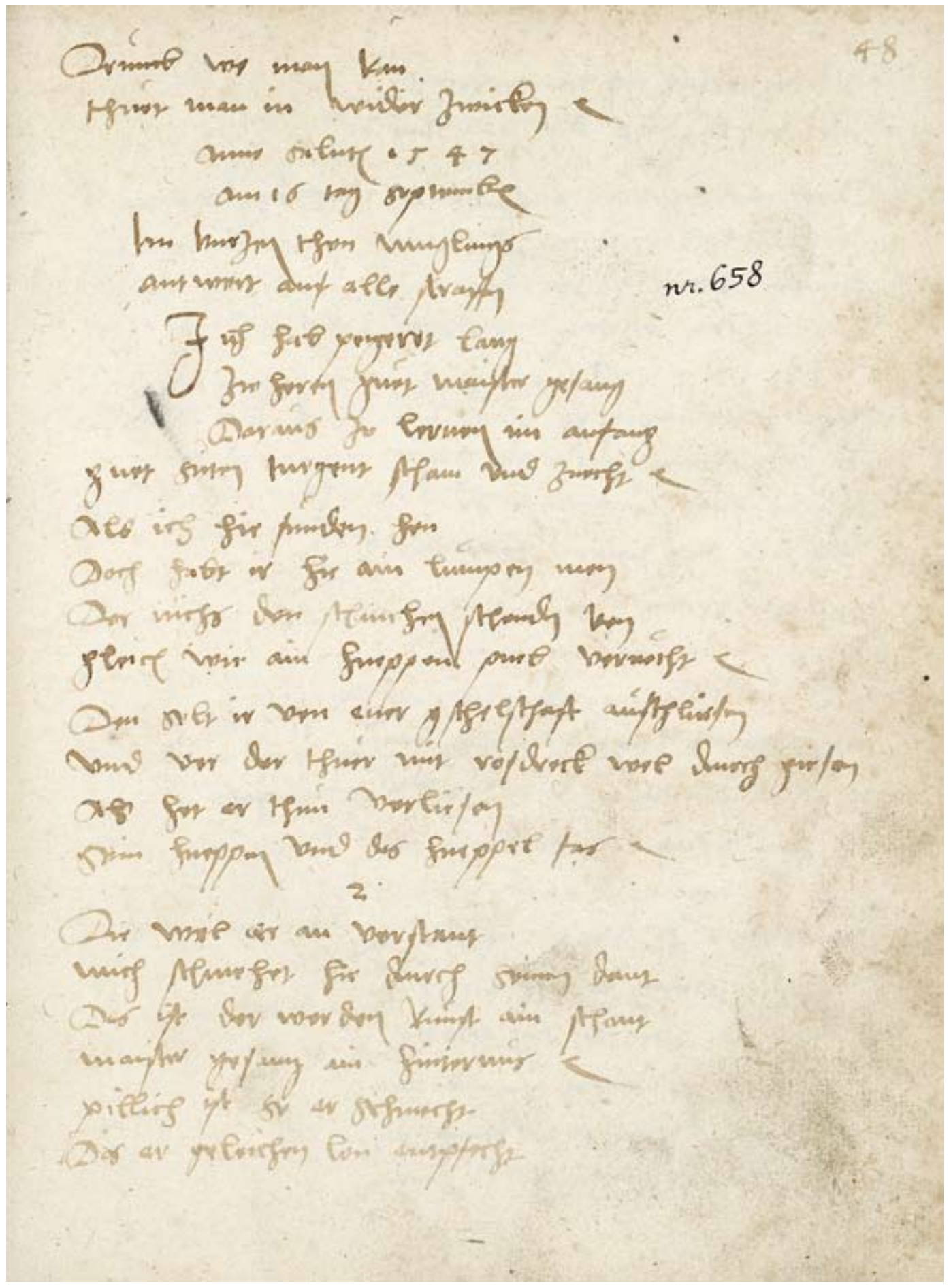




\section{mittelalterlichen Rittertums}

Jean Froissart:

Chroniques de France, d'Angleterre, d'Escoce. Band 4.

Paris: Antoine Vérard, [um 1499].

Signatur: $2^{\circ}$ Hist. Gall. un. II, 2310 Inc.

Provenienz: Hofrätin Richter, 1780

Der französische Hofdichter und Geschichtsschreiber Jean Froissart (1337-um 1410) schilderte in den vier Bänden seiner Chronik die Ereignisse der jüngeren Zeitgeschichte seit 1325. Dabei konnte er auch auf eigene Erfahrungen und Einblicke zurückgreifen, denn ein ununterbrochenes Reiseleben führte ihn an sämtliche wichtigen europäischen Höfe, auch an den englischen und den spanischen. Während Froissart für die Jahre 1325 bis 1356 im wesentlichen eine Chronik des Lütticher Kanonikers Jean le Bel als Vorlage diente, der er eigenes Material hinzufügte, war er nach 1369 somit in der Lage, ausschließlich selbst gesammelte Aufzeichnungen zu verwenden. Der vierte, unvollendete Band entstand am Hof Albrechts von Bayern und beschreibt den Zeitraum zwischen 1388 und 1400. Im Mittelpunkt stehen die Wirren am französischen Hof nach 1390 und die Vorgeschichte der Absetzung des englischen Königs Richard II., aber auch weitere wichtige Ereignisse der europäischen Geschichte werden in breiter Anlage einbezogen.

Froissarts Werk wurde wegen seiner lebendigen Schilderung der ersten Hälfte des Hundertjährigen Krieges zwischen England und Frankreich berühmt. Sein Hauptaugenmerk richtete der häufig als ,größter Chronist des Mittelalters“ gefeierte Dichter auf kriegerische Ereignisse, die Beschreibung ritterlicher Taten und die Charakterisierung großer Helden, wobei er zahlreiche stilistische und stoffliche Anregungen aus der höfischen Literatur verarbeitete. Als Ideal galt Froissart das zu seiner Zeit schon zum Mythos gewordene mittelalterliche Rittertum, das er mit seiner Chronik wieder zum Leben erwecken wollte.

Erstmalig wurden die Chroniques im Jahre 1499 von Antoine Vérard in Paris veröffentlicht. Vérard war als Drucker von Stundenbüchern bekannt geworden: In seiner Druckerei entstanden mehr als 200 Ausgaben, die durch ihren zierlichen Satz, elegante Randleisten und filigrane Illustrationen bald zu begehrten Sammelobjekten wurden. Die Chroniques sind in nur wenigen Bibliotheken mit allen vier Bänden nachgewiesen. In Deutschland ist das Werk neben Göttingen nur in Weimar vorhanden. Pergamentexemplare wie das vorliegende sind jedoch in deutschen Bibliotheken sonst überhaupt nicht anzutreffen. - Aufgeschlagen ist die ganzseitig gemalte Illustration einer Turnierszene. Sie gehört zu den schönsten Beispielen französischen Buchschmucks, die der Göttinger Bestand zu bieten hat. 


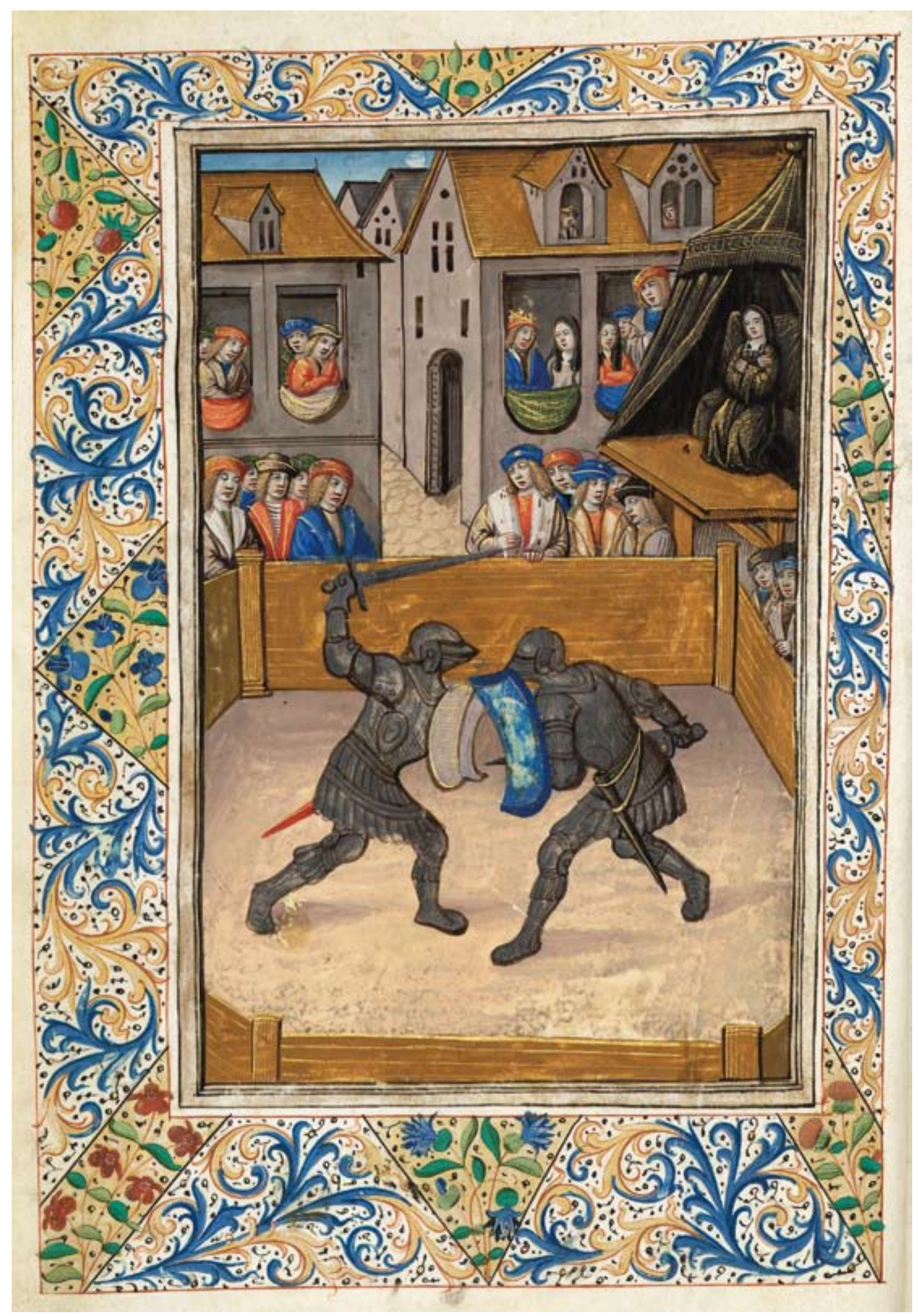




\section{Das Insektenbuch der Maria Sibylla Merian}

Maria Sibylla Merian:

Metamorphosis insectorum surinamensium. Amsterdam: Maria Sibylla Merian, um 1705. Signatur: gr. $2^{\circ}$ Hist. nat. zool. VI, 3904 Rara

Provenienz: Johann Friedrich Blumenbach, 1786
In Amsterdam erschien 1705 ein eindrucksvolles Werk über die Entdeckungen einer entomologischen Forschungsexpedition in die niederländische Kolonie Surinam. Die Metamorphosis insectorum surinamensium der Forscherin und Künstlerin Maria Sibylla Merian (1647-1717) entstand nach einer zweijährigen Reise (1699-1701) in den Nordosten Südamerikas. Merian, Tochter des berühmten Künstlers und Verlegers Matthäus Merian d. Ä. (1593-1650), lernte bereits in ihrem Elternhaus das Zeichnen, die Aquarellmalerei, das Zubereiten von Farben, das Stechen von Kupferplatten und das Drucken. Als Dreizehnjährige begann sie am Beispiel der Seidenraupe das Studium der Insekten. Ihre erste Veröffentlichung war das dreiteilige Blumenbuch mit je 12 Kupfertafeln (1675-1680). Ihre erste insektenkundliche Arbeit, Der Raupen wunderbare Verwandlung und sonderbare Blumennahrung, erschien in zwei Teilen mit je fünfzig Tafeln 1679 und 1683. Merian verwendete bereits dort ein besonderes Darstellungsprinzip, auf welches sie später in ihrem Werk über Insekten zurückgriff: Neben den einzelnen Entwicklungsstadien von Schmetterlingen auf einer Illustration bildet Merian die verschiedenen Insektenarten um die jeweilige Nährpflanze $\mathrm{ab}$.

Während ihres von 1685 bis 1690 dauernden Aufenthaltes bei den Labadisten, einer protestantischen Gemeinschaft auf Schloss Waltha in Westfriesland, entwickelte Merian ihr Interesse an tropischen Pflanzen und Insekten. Die anschließende, mit eigenen Mitteln finanzierte Forschungsreise nach Surinam unternahm sie zusammen mit ihrer Tochter Dorothea Maria. Bei ihren Expeditionen in den Urwald sammelten und beobachteten sie Insekten und zeichneten deren Entwicklungsstadien und Futterpflanzen auf kleine Pergamentblätter. Hinweise auf die jeweilige ornamentale, kulinarische und medizinische Verwendung von Pflanzen und Tieren erhielt Merian von den Einheimischen.

Trotz anfänglicher finanzieller Schwierigkeiten konnte Merian das Kupferstichwerk mit sechzig Tafeln publizieren. Bei ihrer Gesamtdarstellung verzichtete sie auf eine perspektivische Illustration der Objekte und auf eine maßstabsgetreue Wiedergabe der Größenverhältnisse. Den Eindruck der Dreidimensionalität erzielte Merian durch sorgfältige Modellierung mit Farben. Im Vorwort widmet sie ihr Buch sowohl den „Kennern der Kunst“ als auch den „Liebhabern der Insekten“. Die Universitätsbibliothek erwarb 1786 Merians Kunstwerk von dem Göttinger Professor der Medizin und Inspektor der Naturaliensammlung Johann Friedrich Blumenbach (1752-1840).

\section{(AK)}




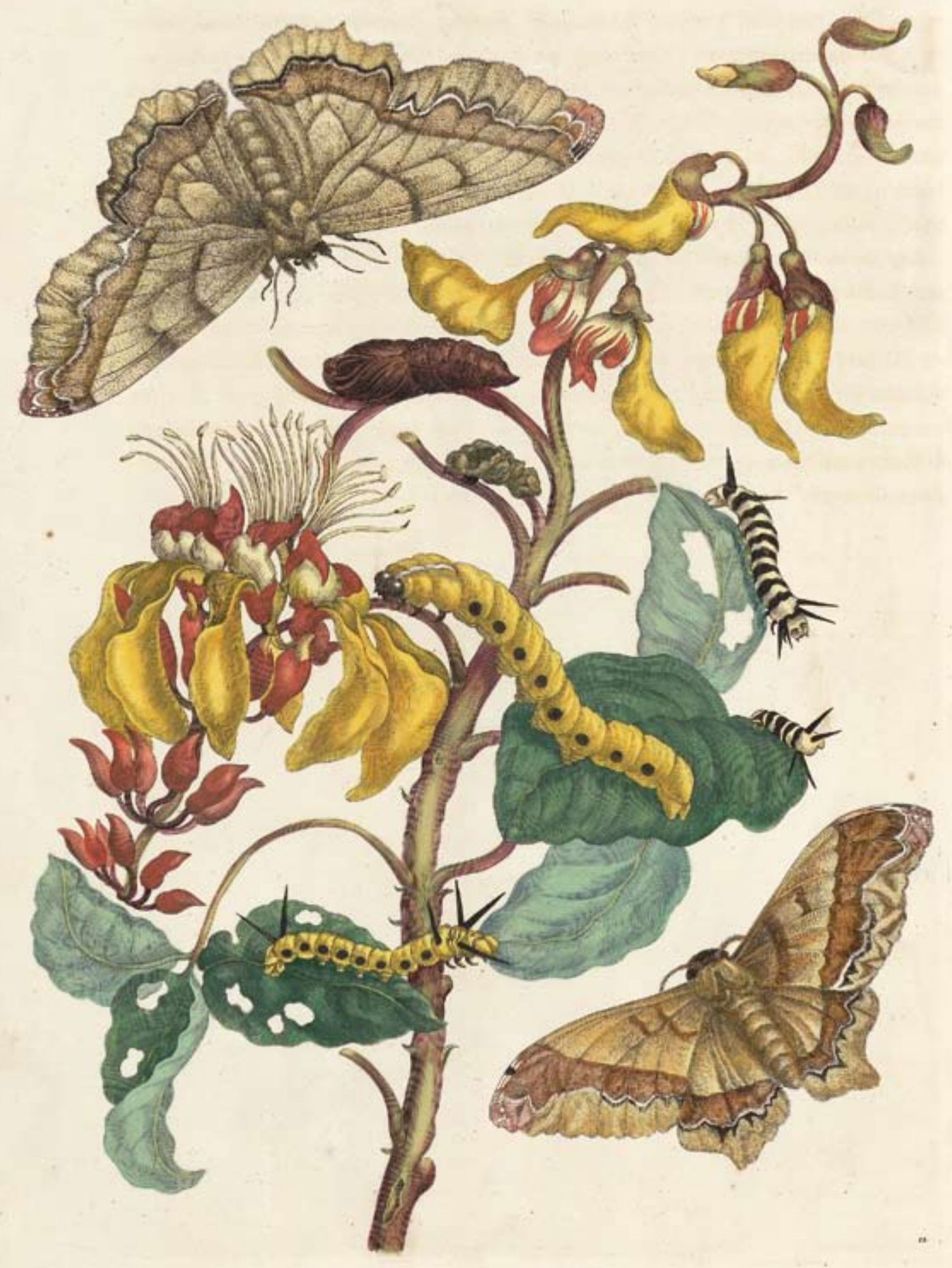




\section{Terenz - ein beliebter}

\section{römischer Komödiendichter}

Publius Terentius Afer:

Comoediae.

Pergamenthandschrift,

Italien, 15. Jahrhundert.

Signatur: $2^{\circ}$ Cod. Ms. philol. 110 Cim.

Provenienz: Lüder Kulenkamp, 1796

Nur sechs Werke sind von dem Dichter Publius Terentius Afer (um 190 v. Chr. - nach 160 v. Chr.) überliefert. Dennoch zählt er zu den wichtigsten lateinischen Autoren im republikanischen Rom. Das verdankt er nicht nur dem Umstand, dass er neben Plautus der einzige Komödiendichter dieser Epoche ist. Sein Leben und Werk reflektieren außerdem die Jahrzehnte der römischen Machtexpansion mit ihren Konsequenzen. Geboren wurde Terenz in Nordafrika bei Karthago, das damals von Rom schon zweimal geschlagen, aber noch nicht endgültig zerstört war. Als Sklave kam er nach Rom, wo er eine gute Ausbildung und Kontakte bis in die höchsten Kreise erwarb. Rom dehnte in jenen Jahren seine Sphäre nicht nur nach Süden, sondern auch nach Osten aus und kam gleichzeitig in engen Kontakt zu den Staaten Griechenlands und vor allem deren Kultur. Terenz nahm all das in sein Werk mit auf. Vorlage für seine Komödien waren die Stücke des griechischen Dichters Menander, aber er kopierte sie nicht einfach, sondern adaptierte sie für ein gebildetes römisches Publikum. Das trifft auch für sein jüngstes Stück zu, dessen Beginn in der ausgestellten Handschrift zu sehen ist. Es heißt Adelphen, wurde 160 uraufgeführt und hat vor allem die Frage nach der richtigen Erziehung zum Inhalt. Bezeichnend ist nun, dass Terenz der im Stück lange favorisierten liberalen Erziehung am Ende in einem bei Menander fehlenden Schluss auch die Vorzüge eines strengeren Regimentes gegenüberstellt: wohl ein Tribut an traditionelle römische Werte, die der hellenistischen Lebensart kritisch begegneten.

Wegen seiner kultivierten Sprache und kunstfertigen Behandlung des Stoffes war Terenz zu allen Zeiten ein beliebter Autor. Schon in der Antike, aber auch während des Mittelalters wurde er viel gelesen und kommentiert. Die Humanisten schätzten ihn ebenso wie später Ariost, Molière oder Goethe.

Die in Italien im 15. Jahrhundert entstandene Handschrift ist in einer sauberen Humanistenschrift geschrieben und enthält einige Randglossen mit Kommentaren zum Haupttext. Den Anfang jeder Komödie zieren HalbfigurInitialen, die Personen des Stückes zeigen. Wie Eintragungen im vorderen Deckel zeigen, war die Handschrift im 16. Jahrhundert im Besitz eines Leipziger Apothekers und Stadtbaumeisters namens Johann Hu(t)ter († 1552), der das biblische Alter von 114 Jahren erreicht haben soll. Seit 1771 gehörte sie dem Göttinger Professor der Philosophie Lüder Kulenkamp (1724-1794), dessen Bibliothek im Mai 1796 versteigert wurde. 


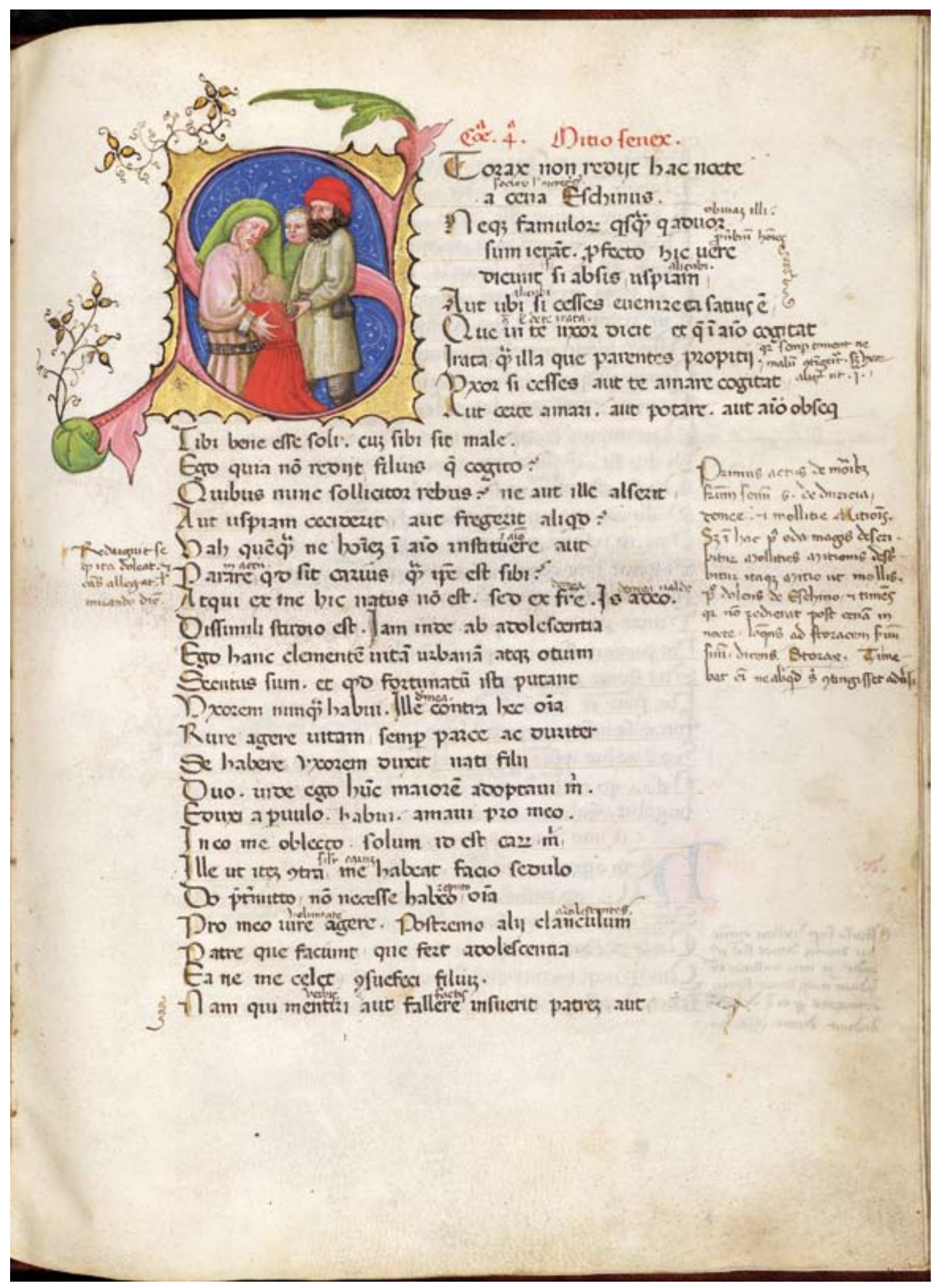




\section{der Pflanzenwelt von ganz Russland}

Peter Simon Pallas:

Flora Rossica seu stirpium Imperii Rossici per Europam et Asiam indigenarum descriptiones et icones: iussu et auspiciis Catharinae II. Augustae. T. 1, P. 1. [Tafelband].

St. Petersburg: Weitbrecht, 1784.

Signatur: gr. $2^{\circ}$ Hist. nat. bot. V, 6075:1,1 Taf. Rara

Provenienz: Johann Beckmann, 1811

Peter Simon Pallas (1741-1811) gehört zu den großen Naturforschern des 18. Jahrhunderts; seine Forschungsschwerpunkte waren die Zoologie und die Botanik. Im Jahre 1767 wurde er an die St. Petersburger Akademie der Wissenschaften berufen und mit der Planung und Leitung einer der „physicalischen“ Akademie-Expeditionen beauftragt, die ihn zwischen 1768 und 1774 in den Ural, den Altai, das Baikalgebiet und die Steppen um Astrachan und Zarizyn führte. Von 1793 bis 1794 unternahm er eine zweite große Forschungsreise durch Südrussland auf die Krim, wo er seinen Wohnsitz nahm. 1810 kehrte er nach Berlin zurück, wo er im Folgejahr starb.

Unter Pallas' 17 botanischen Arbeiten stellt die Flora Rossica als eine der ersten und wichtigsten Übersichten über die Pflanzenwelt des Russischen Reiches das ambitionierteste und umfangreichste Werk des Naturforschers dar. Im Auftrag Katharinas der Großen (1729-1796; reg. 1762-1796) begonnen, setzte es sich zum Ziel, die gesamte Pflanzenwelt des europäischen und asiatischen Teils Russlands systematisch zu beschreiben und auf etwa 600 Tafeln darzustellen. Nach ersten Teillieferungen, die 1784 und 1778 bei J. J. Weitbrecht in St. Petersburg erschienen, konnte erst nach Pallas’ Tod, im Jahr 1815, der erste Teil des zweiten Bandes bei C. G. Schöne in Berlin verlegt werden. Dass das Werk letztlich unvollendet blieb, mag zu einem Teil auch in der gewaltigen Fülle des zu bearbeitenden Materials begründet gewesen sein: Nicht nur das eigene gesammelte botanische Material musste ausgewertet werden, sondern auch das seiner Vorgänger und Kollegen an der Akademie der Wissenschaften. Nicht zuletzt oblag es Pallas, die Anfertigung der von Karl Friedrich Knappe (1745-1808), einem Lehrer der Pflanzenmalerei an der St. Petersburger Kunstakademie, stammenden Zeichnungen, die Herstellung der Stiche und ihre Kolorierung zu beaufsichtigen.

Über die allen Mühen zum Trotz fertiggestellten Lieferungen konnte Pallas nicht frei verfügen, da sie der Zarin als Geschenke dienten. Er konnte es aber erreichen, dass einige Exemplare an wissenschaftliche Institutionen und Gelehrte gelangten, so auch an den Göttinger Professor für Ökonomie und Studienfreund des Naturforschers aus Göttinger Studientagen Johann Beckmann (1739-1811), den der erste Teil der ,prächtigen Flora Rossica“ 1785 erreichte. Nach Beckmanns Tod erwarb die Göttinger Universitätsbibliothek sein Exemplar ,anno 1811 d. 21. Dez. von den Erben des seel. HofR. Beckmann's“. 


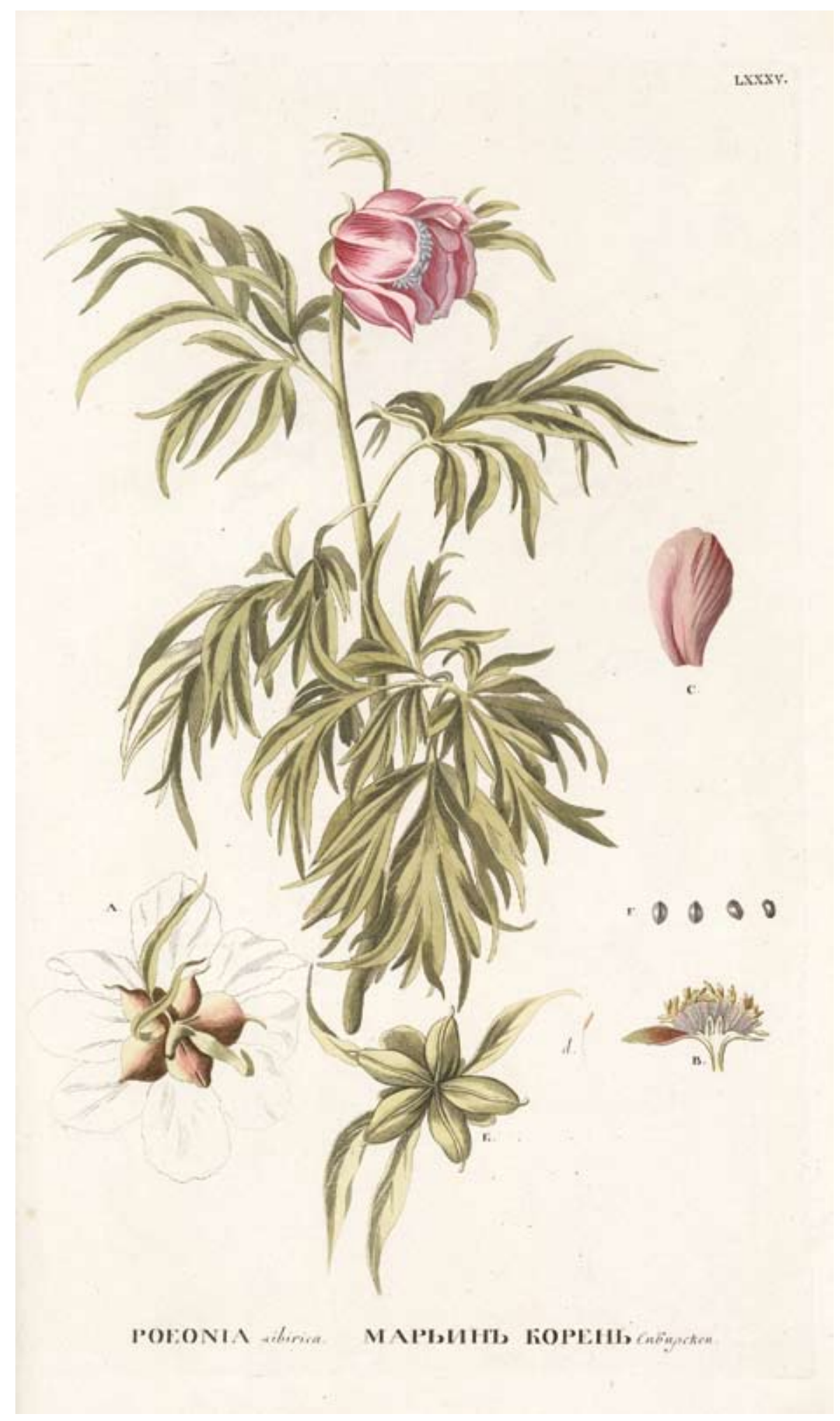




\section{Entzifferung von Keilschriften aus Persien}

Georg Friedrich Grotefend:

De cuneatis, quas vocant, inscriptionibus Persepolitanis legendis et explicandis relatio.

Papierhandschrift, um 1802/1803.

Signatur: $2^{\circ}$ Cod. Ms. hist. 37a: VIIIa Cim.

Provenienz: Ernst Ludwig von Leutsch, 1878

Georg Friedrich Grotefend wurde 1775 in

Hannoversch Münden geboren und starb

1853 in Hannover. Als Gymnasiallehrer war er in Göttingen, Frankfurt am Main und seit 1821 als Direktor des Lyzeums in Hannover tätig. Seine Interessenschwerpunkte waren die lateinische Sprache und die Alte Geschichte. Bleibenden Ruhm hat er sich jedoch als Außenseiter der Orientalistik erworben, wobei ihm seine philologischen Kenntnisse und Neigungen sehr zugute kamen. Bis zu diesem Zeitpunkt waren die überlieferten Dokumente der alten persischen Sprache noch nicht entschlüsselt. Obwohl der Forschung schon im 18. Jahrhundert Schriftzeichen bekannt gemacht worden waren, waren alle Bemühungen um ihre Deutung vergeblich geblieben. Da unterhielten sich 1802 bei einem sommerlichen Spaziergang Grotefend und sein Freund Johann Dominicus Fiorillo (1748-1821) über die Frage, ob die Schrift einer unbekannten Sprache nur aus sich selbst, also ohne Hilfsmittel und Kenntnis des Inhalts, gedeutet werden könne. Grotefend bejahte, der skeptische Fiorillo forderte den Beweis.

Das ist die von Grotefend selbst überlieferte Vorgeschichte zu einer sprachgeschichtlichen Sensation: der Entzifferung der altpersischen Keilschrift, bzw. eines Teiles davon, in kürzester Zeit. In der wissenschaftlichen Welt wurde das allerdings nur über kurze, zusammenfassende Nachrichten rezipiert, die an verschiedenen Stellen erschienen. Die Ausführungen Grotefends, die all dem zu Grunde lagen, blieben zunächst unpubliziert. Sie waren 1802 und 1803 während der eigentlichen Entschlüsselungsarbeit entstanden und wurden der Göttinger Gesellschaft der Wissenschaften als Manuskript vorgelegt. Über den Kreis der anwesenden Akademiemitglieder hinaus wurden sie nicht bekannt. Erst 1893 gab Wilhelm Meyer im Nachrichtenorgan der Gesellschaft die so bedeutenden Dokumente heraus - allerdings auf der Basis von Kopien, die er im Archiv der Gesellschaft vorfand. Das Original des frühesten Aufsatzes von Grotefend wurde im Bestand der Niedersächsischen Staats- und Universitätsbibliothek erst 1974 von Prof. Dr. Riekele Borger entdeckt. Grotefend beschrieb darin, wie er nach heutigem Wissen annähernd richtig - die altpersische Namensform der AchämenidenKönige Dareios, Xerxes, Hystaspes sowie den Titel König erkannte. Die Keilschrift, Ende des 4. Jahrtausends v. Chr. von den Sumerern als Bilderschrift benutzt, hatte sich in die Richtung zu einer Silbenschrift entwickelt und wurde - regional unterschiedlich - auch noch parallel zu den späteren Buchstabenschriften verwendet. Im Unterschied zu den frühen Keilschriften, die einen Vorrat von mehreren hundert bis zu etwa 2.000 Zeichen benötigten, kam das Altpersische mit rund 40 Schriftzeichen aus. 


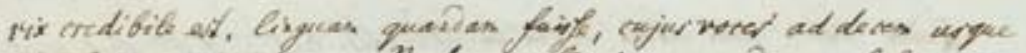

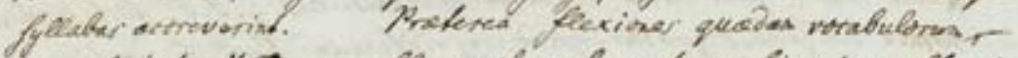

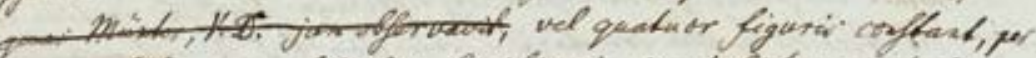

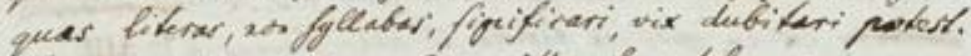

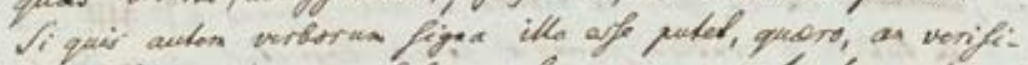

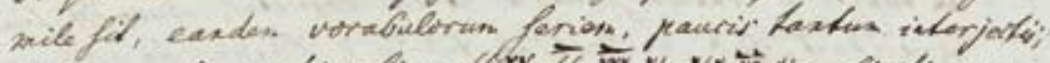

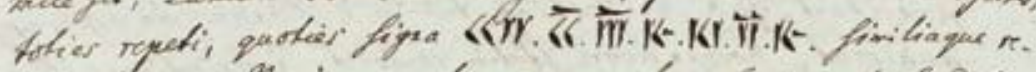

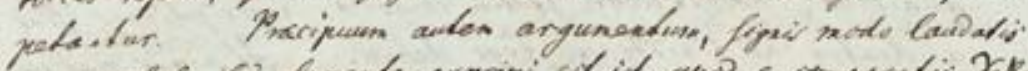

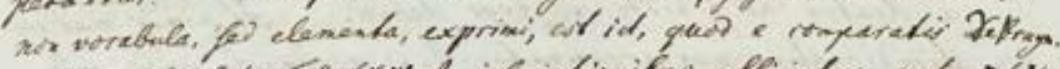

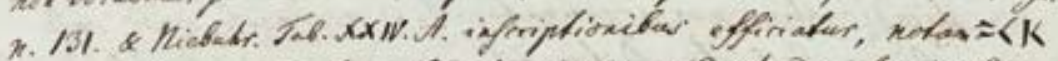

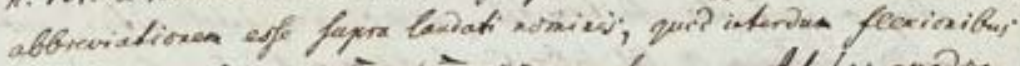

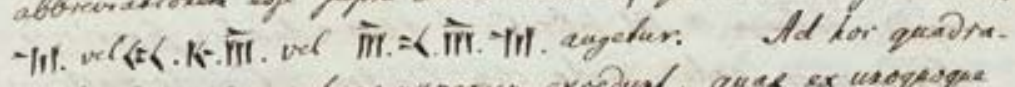

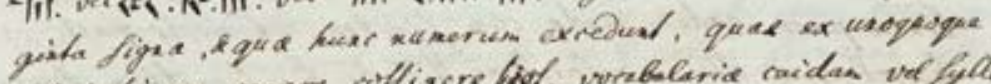

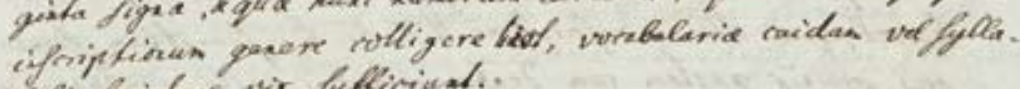

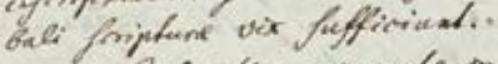

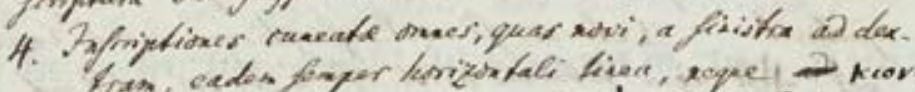

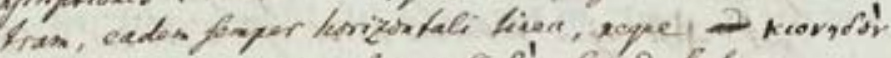

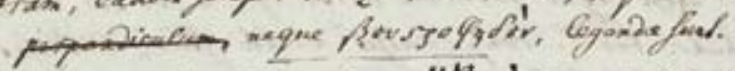

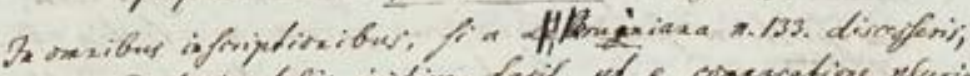

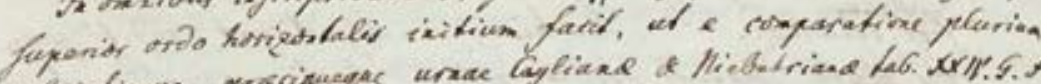

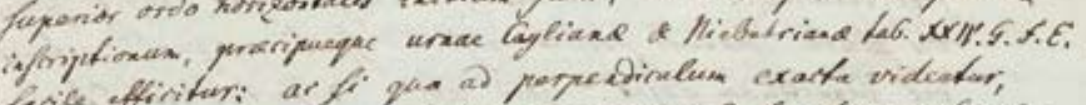

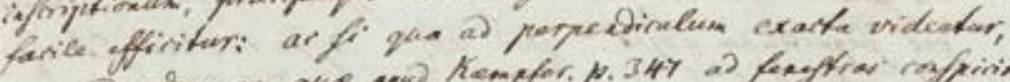

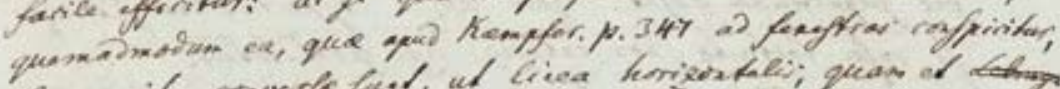

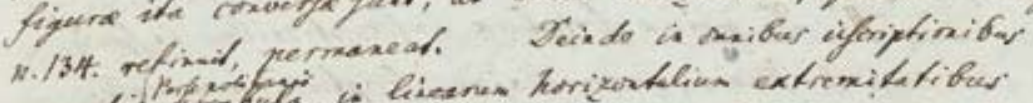

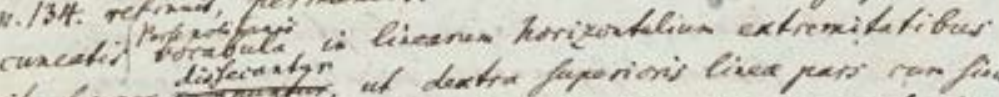

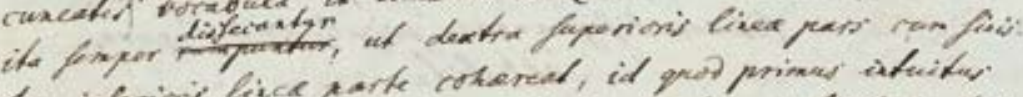

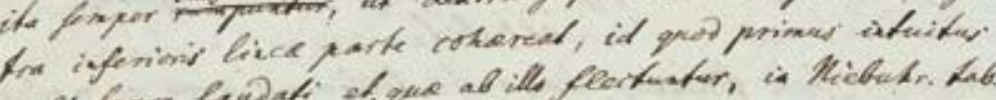

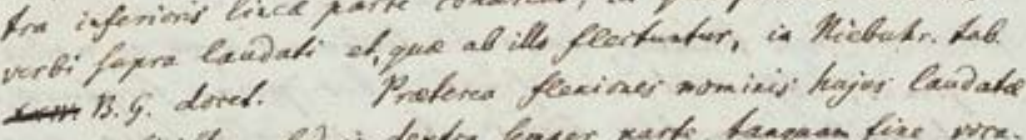

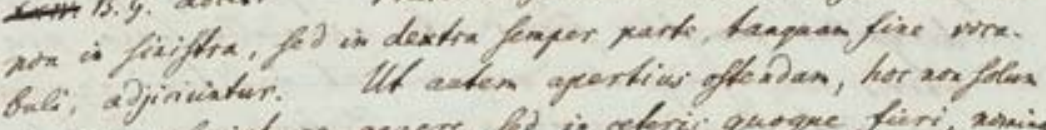

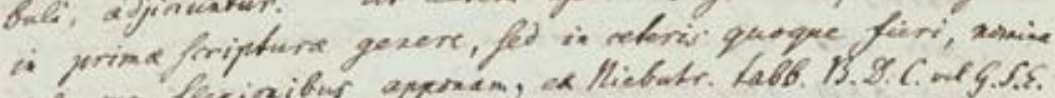

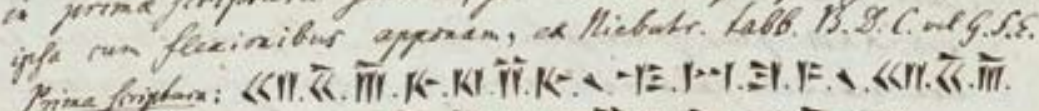

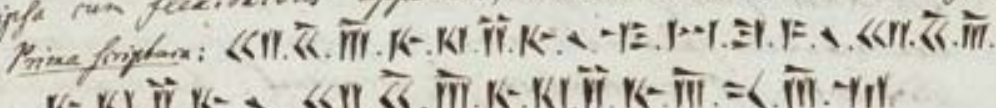

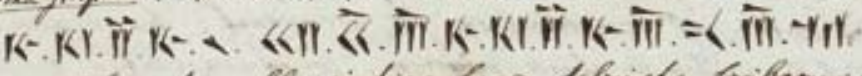

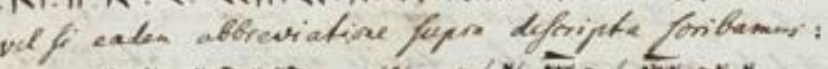

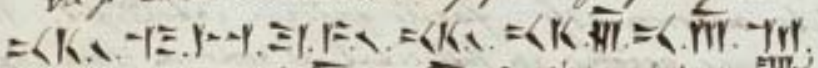

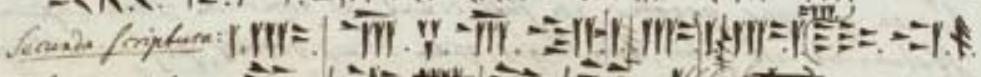

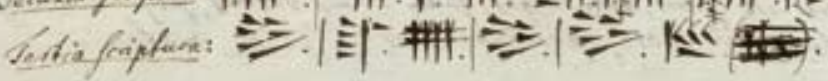




\section{Die Revolution der Himmelssphären}

Nikolaus Kopernikus:

De revolutionibus orbium coelestium libri VI.

Nürnberg: Johann Petreius, 1543.

Signatur: $4^{\circ}$ Gauß-Bibliothek 1442 Rara

Provenienz: Carl Friedrich Gauß (1803), Universitäts-Sternwarte 1977

Das Werk des polnischen Priesters und Astronomen Nikolaus Kopernikus (1473-1543)

De revolutionibus orbium coelestium beendete die 2.000 Jahre alte aristotelische Sicht auf das Universum und bildete den Anfang einer neuen Forschungstradition in der Astronomie und Physik, mit der Namen wie Galileo Galilei, Johannes Kepler und Isaac Newton verbunden sind. Die Bedeutung des Werks liegt sowohl auf praktischer als auch auf theoretischer Ebene.

In praktischer Hinsicht sind die von Kopernikus beobachteten astronomischen Daten wichtig. Im frühen 16. Jahrhundert stellte sich das Datum für Ostern - das gemäß dem Konzil von Nizäa (325 n. Chr.) am ersten Sonntag nach dem ersten Vollmond nach dem Frühlingsäquinoktium stattfinden sollte - immer früher ein, was an dem aus der Antike stammenden System der astronomischen Berechnung lag, das damals benutzt wurde. 1514 rief Papst Leo X. ein Laterankonzil zusammen und bat Kopernikus um Vorschläge, wie der Julianische Kalender reformiert werden könne, um den Zeitpunkt der Frühlings-Tagundnachtgleiche mit einem Vollmond zu koordinieren und dafür Sorge zu tragen, dass Ostern wieder im Frühling gefeiert werden konnte. Unter dem Vorsitz des deutschen Jesuiten Christoph Flavius aus Bamberg (1537-1612) reformierte die katholische Kirche den Julianischen Kalender auf der Grundlage von Kopernikus' exakteren Berechnungen der Position der Erde und anderer Himmelskörper. Papst Gregor XIII. präsentierte den neuen Kalender, der seither als Gregorianischer bezeichnet wird, in seiner päpstlichen Bulle Inter Gravissimas am 24. Februar 1582.

Kopernikus’ verbesserte Berechnungen für das Osterdatum basierten jedoch auf einer revolutionären Neuerung. An Stelle des geozentrischen Universums, das von Aristoteles und dem Astronomen Ptolemäus (um 150 n. Chr.) entworfen worden war, konstruierte Kopernikus ein heliozentrisches Universum - die Planeten rotieren um die Sonne herum, wie die Abbildung zeigt - und legte dies auch seinen Berechnungen zugrunde. Der Heliozentrismus stellte nicht nur alte Autoritäten in Frage, er widersprach auch der Bibel, die an verschiedenen Stellen von der Bewegungslosigkeit der Erde spricht. Zunächst war die Kirche bereit, die Sonne im Zentrum der Welt als eine Hypothese zu betrachten. Aber mit den Entdeckungen von Johannes Kepler und besonders Galileo Galilei schien die heliozentrische Sichtweise eher als sicher denn als hypothetisch zu gelten. Die Kirche setzte deshalb De revolutionibus orbium coelestium 1616 auf den Index der verbotenen Bücher (auf dem es noch stand, als Gauß sein Exemplar 1803 erwarb); aber sie verwendete Kopernikus' Berechnungen weiter zur Bestimmung des Ostertermins.

(KMO) 


\section{NICOZAI CORERNICI}

net, in quo terram cum orbe lunari tanquam epicyclo contineri diximus. Quinto loco Venus nono menfe reducitur.; Sextum deniç̧ locum Mercurius tenet, octuaginta dierum fpacio circü currens, In medio uero omnium refider Sol, Quis enim in hoc

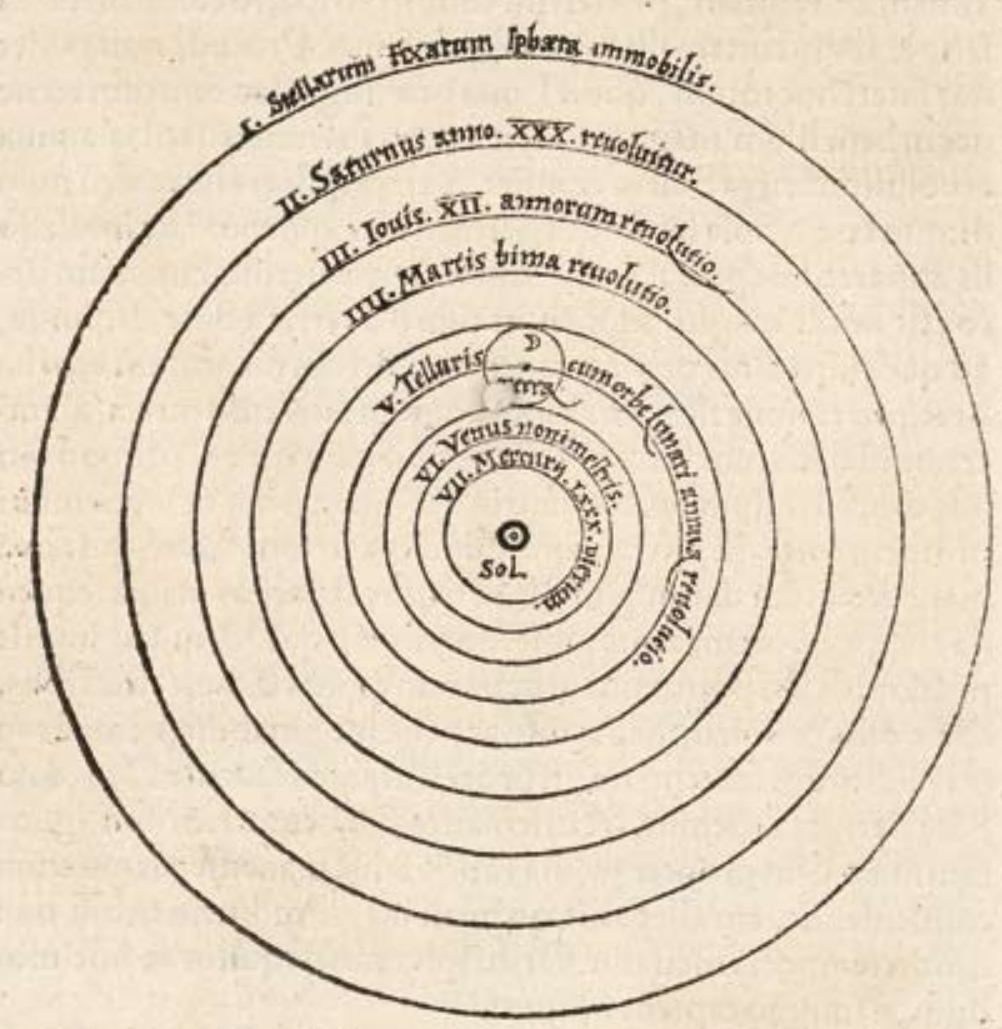

pulcherrimo templolampadem hanc in alio uel melioril loco po neret, quàm unde totum fimul pofsit illuminare: Siquidem non inepte quidam lucernam mundi, alri mentem, alïrectorem uo= cant. Trimegiftus uifibilem Deum, Sophoclis Electra intuentē omnia.Ita profecto tanquam in folio re gali Sol refidens circum agentem gubernat Aftrorum familiam. Tellas quoç minime fraudatur lunari minifterio, fed ut Ariftoteles de animalibus ait,maximã Luna cũ terra cognationẽ habet. Concipit intereaà Soleterra , \& impregnatur annuo partu. Inuenimus igitur fub 


\title{
der allererste zu seyn ...“
}

\author{
Alexander I.: \\ Adelsbrief für August Ludwig Schlözer mit kaiserlichem Siegel. \\ St. Petersburg, 30. V. / 11. VI. 1804. \\ Signatur: Schlözer-Stiftung, Gegenstände, AL I \\ Provenienz: Schlözer-Stiftung, 1939/40
}

Voller Genugtuung empfahl sich am 2. Februar 1805 ,der Pfarrersohn von Gaggstadt, August Ludwig Schlözer, ... als Ritter des kaiserl. russischen Wladimir Ordens und noch außerdem als Mitglied des russischen Erbadels, folglich als von Schlözer“ dem Reichsfürsten Karl von Hohenlohe-Kirchberg. Der ehemalige hohenlohisch-kirchbergische Untertan Schlözer (1735-1809) hatte allen Grund, stolz auf das in seinem Leben Erreichte zu sein, galt er doch zu seiner Zeit als überragende Autorität auf dem Gebiet der russischen Geschichte im deutschen Sprachraum und hatte damit einen Status inne, den seine Nobilitierung durch Zar Alexander I. (1777-1825; reg. 1801-1825) im Jahre 1804 auf das Sinnfälligste bestätigte. Nach seinem Göttinger Studium der Philologie und Orientalistik 1761 war Schlözer als Gehilfe des russischen Reichshistoriographen Gerhard Friedrich Müller nach St. Petersburg gekommen und bereits im Folgejahr zum AdjunktProfessor der Akademie der Wissenschaften, 1765 zum ordentlichen Professor der Geschichte ernannt worden. 1767 kehrte er endgültig nach Göttingen zurück, wo er seit 1770 als ordentlicher Professor der Philosophie tätig war. Seine zahlreichen Übersetzungen und Rezensionen forschungsrelevanter russischsprachiger Publikationen, Sammlungen authentischer russischer Staatsdokumente und Veröffentlichungen von staatskundlichen Nachrichten über Russland machten Schlözer zu einem der wichtigsten Exponenten des russisch-deutschen Wissenstransfers; seine quellenkritisch begründeten Editionen russischer Chroniken stellten einen Meilenstein innerhalb der Geschichtswissenschaft dar. So war es denn auch sein Lebenswerk, die Edition der aus dem frühen 12. Jahrhundert stammenden Nestor-Chronik (1802-1809), die den Anlass für seine Nobilitierung bildete. Dass Schlözer sich seiner eigenen Bedeutung mehr als bewusst war („Ich habe die seltne, vielleicht der Nachwelt unbegreifliche Ehre, der allererste zu seyn, der Eine von den Tausend geschriebenen Russischen Chroniken zu Druck gebracht hat.“) und dass er, wie Martin Peters rekonstruiert hat, seine Nobilitierung selbst initiierte und energisch vorantrieb, tut seiner Leistung keinen Abbruch.

Mit dem auf Pergament geschriebenen, von Alexander I. unterzeichneten Adelsbrief wird Schlözers Erhebung in den erblichen russischen Adelsstand bestätigt. Aufgeschlagen ist das erste Blatt der mehrseitigen Urkunde, das vollständig von Ehrentiteln des Zaren eingenommen wird. Über dem Text ist der zaristische Doppeladler abgebildet; der Text ist von einem breiten Ornamentstreifen umrahmt, der mit den Wappen der Gouvernements des Russischen Reiches verziert ist. 


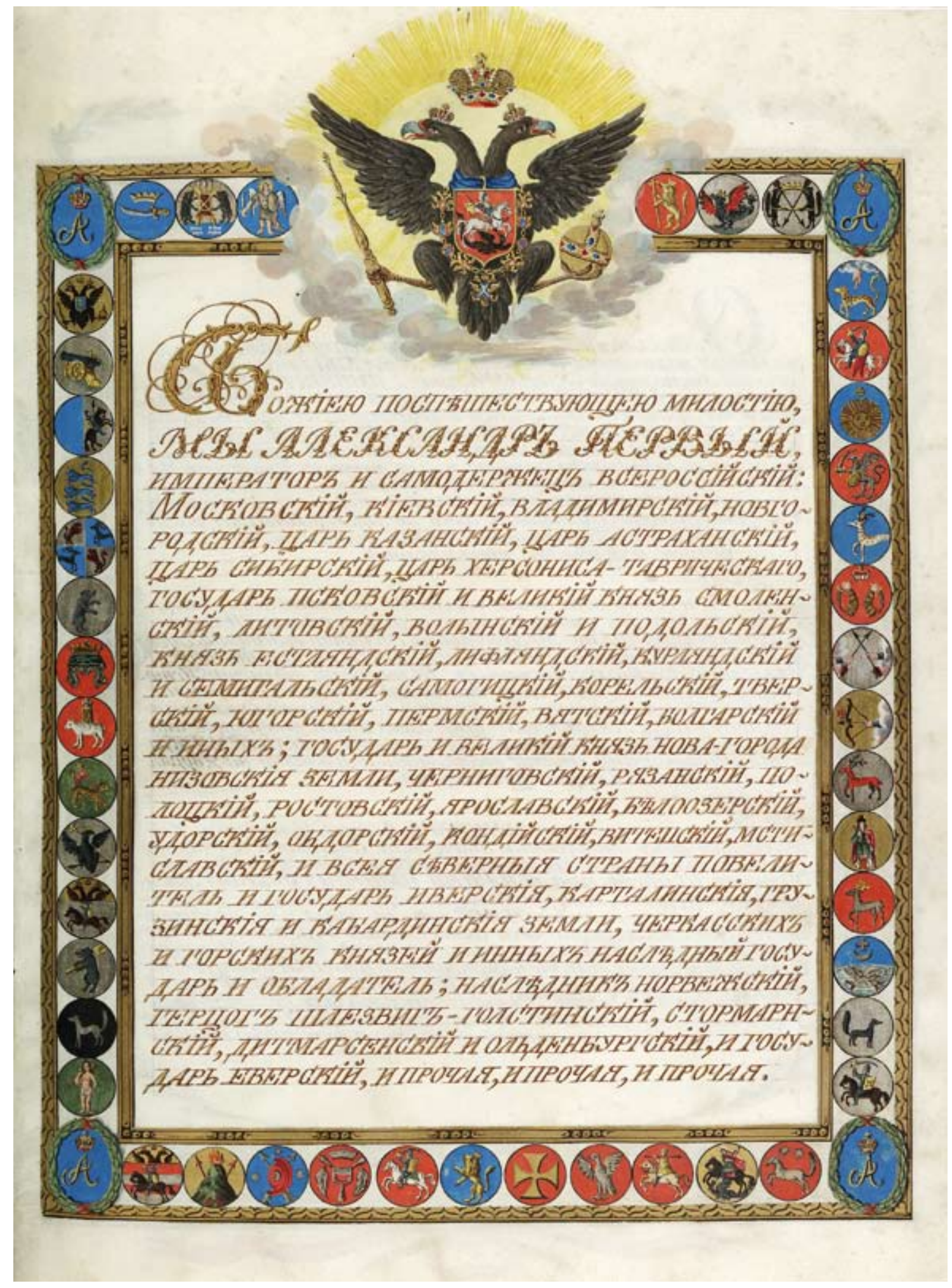




\section{Kapitel 8}

\section{Auswärtige Wissenschaftler}

Dank ihrer großzügigen Mittelausstattung im 18. Jahrhundert konnte die Göttinger Universitätsbibliothek in großem Umfang nicht nur den Grundbedarf einer Universalbibliothek unter den jährlichen Neuerscheinungen decken; sie war darüber hinaus in der Lage, noch vorhandene Lücken zu schließen und antiquarische Erwerbungen zu tätigen, die zur allmählichen Verdichtung der historischphilologischen Quellenliteratur des 15. bis 17. Jahrhunderts führten. Besonders ergiebig in dieser Hinsicht waren Bibliotheken auswärtiger Gelehrter, die nach 1750 zum Verkauf kamen. Selbst wenn diese Gelehrtenbibliotheken nach Inhalt und Umfang sehr unterschiedlich waren, so trugen sie dennoch dazu bei, die Göttinger Bibliothek bis zum Ende des 18. Jahrhunderts zur größten wissenschaftlichen Gebrauchsbibliothek in Deutschland zu machen.

Der Leipziger Professor der Poesie, Logik und Metaphysik Johann Christoph Gottsched (1700-1766) ist besonders durch die Herausgabe ästhetisch-literarhistorischer Zeitschriften (z.B. Die vernünftigen Tadlerinnen) und durch die Veröffentlichung einiger grundlegender Lehrbücher zur deutschen Literatur (z.B. Versuch einer Critischen Dichtkunst vor die Deutschen) hervorgetreten. Auf der Auktion seiner Bibliothek am 13. Juli 1767 in Leipzig wurden zwar nur zehn Titel in acht Bänden ersteigert, aber darunter waren vier Inkunabeln aus dem Bereich der älteren deutschen Literatur. Gottsched hatte seine literaturwissenschaftliche und literaturpflegerische Tätigkeit aus der Gegenwart in die Vergangenheit übertragen: Er stellte einen Nöthigen Vorrath zur Geschichte der deutschen Dramatischen Dichtkunst von 1450 an zusammen und sammelte für seine Privatbibliothek alte deutsche Literaturdenkmäler. Die erste gedruckte Ausgabe von Wolfram von Eschenbachs Parzival, gedruckt von Mente- lin in Straßburg 1477, ist ein hervorragendes Beispiel für Gottscheds Vorrath. Mit dieser Auktion des Jahres 1767 begann die Göttinger Bibliothek, systematisch frühe Ausgaben deutschsprachiger Literatur zu sammeln.

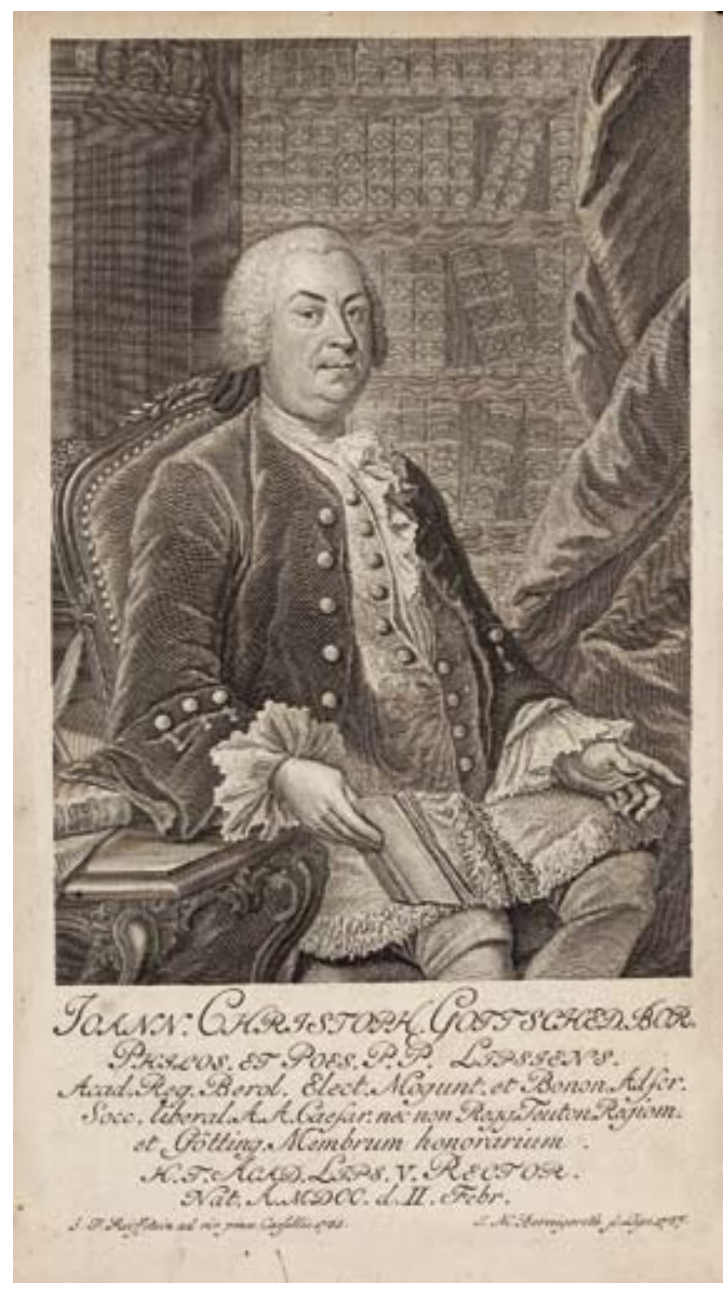

Johann Christoph Gottsched (1700-1766).

28 Jahre nach seinem Tode wurde 1769 der zweite Teil der Büchersammlung des Altdorfer Professors Christian Gottlieb Schwarz (1675-1751) verkauft: 61 Handschriften und 1.011 Drucke (davon 138 undatierte Ausgaben, 612 datierte Inkunabeln, 260 Drucke des 16. und ein Druck des 17. Jahrhunderts). Schwarz war seit 1709 Professor der Be- 
redsamkeit, Poesie und Geschichte an der Universität Altdorf, an der er 42 Jahre lang lehrte. Der Schwerpunkt seiner Bibliothek lag in ihrem Bestand an Wiegendrucken, wie es auch der Verkaufskatalog formuliert: „,...continens codices manuscriptos vetustos et libros saeculo XV ab incunabulis impressos....". Die Göttinger Bibliothek erwarb 55 Nummern (40 Titel), darunter 39 Inkunabeln, die am 15. März 1770 in der Bibliothek eintrafen. Von besonderem Wert unter den Wiegendrucken war die erste Ausgabe des Eunuchus von Terenz in deutscher Sprache, die Conrad Dinckmut 1486 in Ulm druckte.

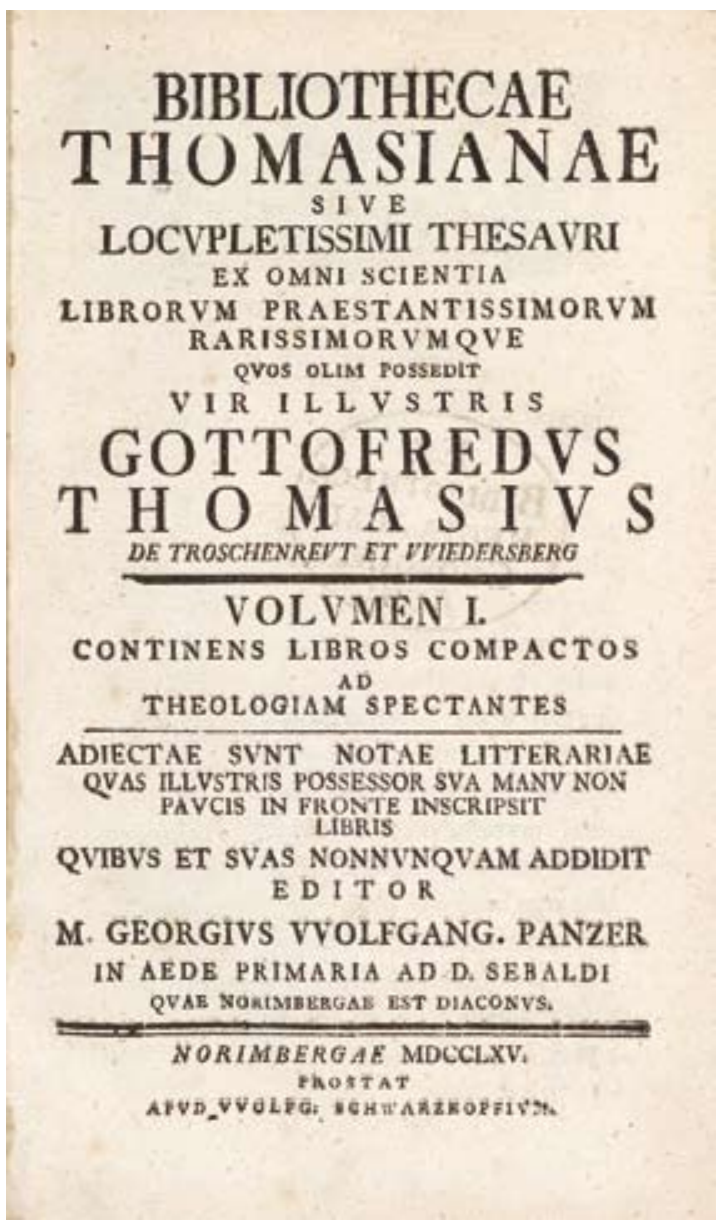

Katalog zur Bibliothek von Gottfried Thomasius (1660-1746).
Insgesamt acht Jahre, von 1765 bis 1773, dauerte der Verkauf der umfangreichen Bibliothek des Nürnberger Mediziners und Polyhistors Gottfried Thomasius (1660-1746), des Bruders des berühmten Hallenser Juristen Christian Thomasius (1655-1728). Es handelte sich um eine riesige Privatbibliothek universalen Charakters (29.844 Nummern, davon 253 Handschriften) mit vielen Raritäten vor allem aus dem Bereich der älteren deutschen Literatur. Göttingen hat aus dieser Sammlung 1770 neben vielen anderen Werken 175 Inkunabeln erworben. Bemerkenswert sind die zahlreichen deutschsprachigen, oft mit Holzschnitten geschmückten Ausgaben. Diese Erwerbung war der erste umfangreiche Zuwachs an Wiegendrucken seit Gründung der Göttinger Bibliothek.

Am 27. November 1776 erwarb die Universitätsbibliothek auf der Auktion der Büchersammlung des Helmstedter Professors Rudolf Anton Fabricius 33 Inkunabeln. Diese zweite Ergänzung der Inkunabelsammlung im Jahre 1776 enthielt vorwiegend wissenschaftlichtheologische Werke, Literatur des Humanismus sowie erbauliche Schriften mittelalterlicher Autoren. Zu letzteren zählt Stephan Fridolins Schatzbehalter der wahren Reichtümer des Heils aus der Werkstatt des Großverlegers Anton Koberger in Nürnberg. Am Ende dieses Kapitels werden Einzelerwerbungen aus den Bibliotheken verschiedener Gelehrter vorgestellt, darunter Johan Lundblad aus Lund (1792) und Heinrich Philipp Conrad Henke aus Helmstedt (1811). 
Wolfram [von Eschenbach]:

Parzival.

[Straßburg:] [Johann Mentelin], 1477.

Signatur: $4^{\circ}$ Poet. Germ. I, 8883 Inc. Rara

Provenienz: Johann Christoph Gottsched, 1767

Das Heldenepos Parzival des Wolfram von Eschenbach (um 1170-ca. 1220) zählt zu den wohl umfangreichsten, gedankentiefsten und meistgelesenen Werken des Mittelalters. Zwischen 1200 und 1210 als Auftragsdichtung für den fränkischen oder thüringischen Adel entstanden, wurde die fast 25.810 Verse umfassende Erzählung aus dem Stoffkreis der keltischen Sagen um König Artus in mehr als 80 Handschriften und Fragmenten überliefert. Geschildert wird - mit viel Humor, Erzählfreude und symbolischer Hintergründigkeit - die Geschichte eines jungen Toren, Parzival, und seine Entwicklung zum vorbildlichen Ritter. Wolfram berichtet von Parzivals Vater Gahmuret, Parzivals Suche nach dem Gral und den Abenteuern seines Verwandten und Freundes Gawan. Dabei konstruiert er ein spannendes Gewebe von in die Handlungen verstrickten Geschichten um die Gralssippe, den Gral und die Artusritter und behandelt religiöse Themen wie Sünde, Buße und Gnade.

Wolfram, der sich vermutlich nach dem mittelfränkischen Ort Eschenbach bei Ansbach benannte, durchsetzte seine Werke mit zahlreichen, oft ironischen Kommentaren. Für den Parzival bearbeitete er den Perceval (1180/90) Chrétien de Troyes. Die Erstausgabe des Werkes wurde 1477 bei Johann Mentelin (um 1410-1478) gedruckt, von dem auch die erste gedruckte deutsche Bibel (1466) stammt. Als Vorlage diente Mentelin wohl eine bebilderte Handschrift aus der Werkstatt Diebold Laubers, die sich im Besitz des Bischofs Ruprecht von Pfalz-Simmern (1440-1478), des Mäzens des Druckers, befand. Vermutlich handelt es sich dabei um das heute in Heidelberg befindliche Exemplar (Cpg 339). Im Druck Mentelins fällt allerdings das völlige Fehlen einer bildlichen Ausgestaltung auf. Vielmehr wurde jeweils Raum gelassen, um Bilder und Initialen von Hand nachtragen lassen zu können: Kleine Platzhalter für die Positionen der Initialen und viel versprechende Bildüberschriften für die auszugestaltenden Szenen zeugen von dieser Absicht. Der Parzival war das letzte Werk, das Mentelins Offizin vor seinem Tod verließ. Obgleich Angaben zum Druckort und Drucker fehlen, konnte ihm das Werk anhand der von ihm verwendeten Antiqua-Drucktype zugewiesen werden. Erst im 18. Jahrhundert sollte es zu einem Neudruck kommen. 


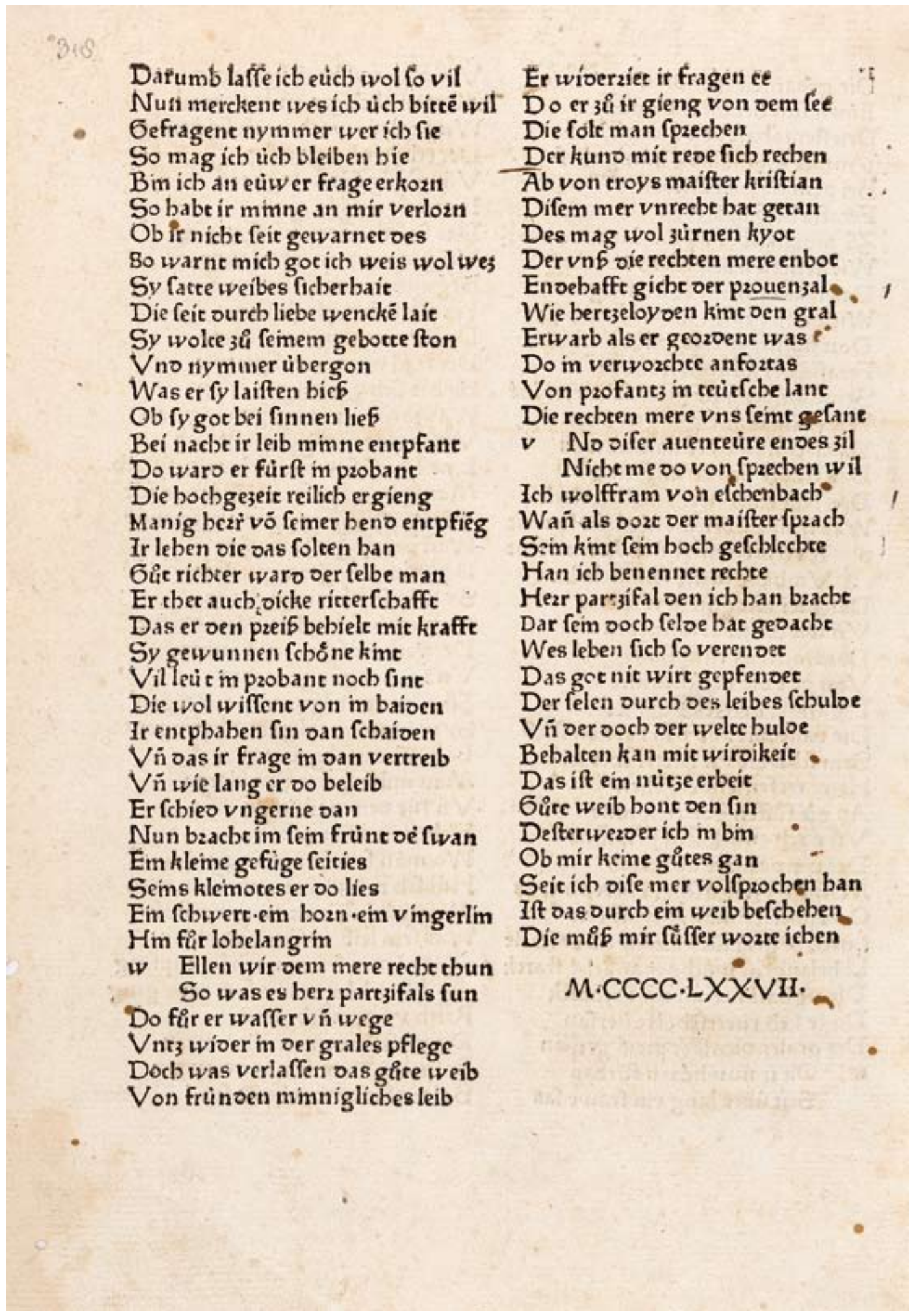




\section{Ein ergetzung der gesunden / ein trost hoffnung vnd hilff den krancken}

Johannes de Cuba:

Gart der Gesundheit.

Augsburg: Johann Schönsperger, 22. VIII. 1485.

Signatur: $4^{\circ}$ Mat. med. 34/65 Inc.

Provenienz: Johann Christoph Gottsched, 1767

Seit der ausgehenden Antike vermittelten Kräuterbücher das Wissen der Ärzte über die Heilkraft der Pflanzen; mit der Erfindung des Buchdrucks wurden sie zu heilkundlichen Volksbüchern. Der Gart der Gesundheit ist das berühmteste Werk dieser Art und zugleich das wohl bedeutendste illustrierte naturwissenschaftliche Buch des Spätmittelalters. Seine Vorlage bildet ein Herbarius des italienischen Arztes Mattheus Platearius (* 1161), den der Mainzer Drucker und ehemalige Mitarbeiter in der Gutenbergschen Offizin Peter Schöffer im Jahre 1484 unter dem Titel Hortus sanitatis mit einem Umfang von 348 Seiten und 150 Holzschnitten herausbrachte. Das Werk war derart erfolgreich, dass Schöffer bereits im Folgejahr, am 28. März 1485, auf Anregung des Mainzer Domdekans Bernhard von Breidenbach (ca. 1440-1497) eine deutsche Fassung besorgte, die nicht nur mit einem Umfang von 720 Seiten und 379 Holzschnitten, sondern auch inhaltlich ihr Vorgängerwerk weit übertraf. Der Gart der Gesundheit bot das gesamte medizinischpharmakologische Wissen des 15. Jahrhunderts dar und beschrieb Heilanwendungen von Pflanzen, Tieren und Mineralien.

Den wissenschaftlichen Kommentar verfasste der „meyster in der ercznei gelert“ Johannes de Cuba (aus Kaub am Rhein), der seit September 1484 Stadtarzt in Frankfurt am Main war. Die Holzschnitte, die dem Utrechter Künstler Erhard Reuwich zugeschrieben werden, bedeuten mit ihrer naturnahen Darstellung einen Wendepunkt in der Geschichte der botanischen Buchillustration. Dass mit einem solchen Werk ein gutes Geschäft zu machen war, erkannte rasch auch der Augsburger Drucker Johann Schönsperger (1455-1521). Nur fünf Monate nach Erscheinen der Mainzer Erstausgabe legte er am 22. August 1485 einen Nachdruck vor, in dem sämtliche Mainzer Holzschnitte nachgeschnitten waren. Mit diesem Raubdruck war das Geschäft von Peter Schöffer zunichte gemacht, der keine weitere Neuauflage mehr vorlegte, während Schönsperger bis zum Jahre 1502 insgesamt acht Auflagen veröffentlichte.

$(\mathrm{HR} / \mathrm{KN})$ 


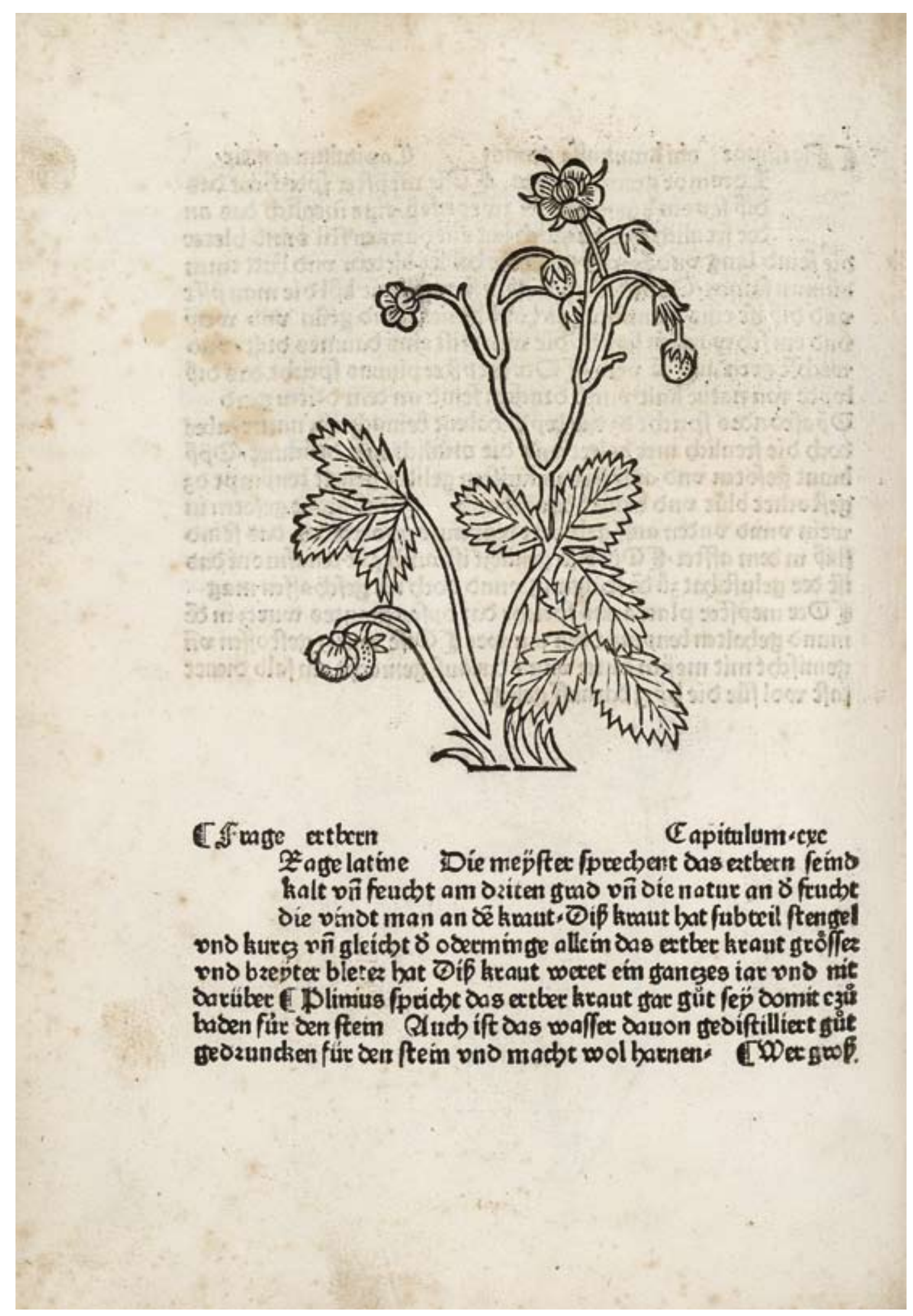


Aesopus:

Vita et Fabulae, lateinisch u. deutsch. Ulm: Johann Zainer d. Ä., [um 1476].

Signatur: $4^{\circ}$ Fab. Rom. I, 5245 Inc.

Provenienz: Gottfried Thomasius, 1770

Die mündliche Überlieferung von Fabeln reicht mindestens bis in das 7 . Jahrhundert v. Chr. zurück; dennoch gilt Aesop, der große Geschichtenerzähler der Griechen (um 600 v. Chr.), als Ahnherr dieser Gattung. Über seine Herkunft und sein Leben ist fast nichts bekannt. Die von ihm geschaffene Sammlung wurde von einer Reihe späterer römischer Fabeldichter (Phaedrus, Babrius, Avianus) nachgedichtet und ergänzt. Im Mittelpunkt der kurzen, pointiert berichteten Handlung stehen zumeist Tiere, aber auch Pflanzen, Götter und Heroen, Menschen des Alltags oder historische Personen, die stets so auftreten, dass sofort eine Übereinstimmung mit allgemeinmenschlichen Verhaltensweisen erkannt werden kann. Auf diese Weise dient die erzählte Geschichte als einprägsames Beispiel einer Moral oder Lebensweisheit. Neid und Geiz, Habsucht und Eitelkeit, Hochmut und Fressgier und immer wieder die Dummheit werden bloßgestellt und entlarvt. Gerade wegen ihres belehrenden Charakters und der leicht verständlichen Anwendung auf die alläglichen Erfahrungen des Menschen sind die Fabeln des Aesop über die Jahrtausende hinweg lebendig geblieben.

Die erste gedruckte Übersetzung der griechisch-römischen Fabeln war eine lateinisch-deutsche und mit mehr als $200 \mathrm{Holz}$ schnitten versehene Fassung, die der Ulmer Humanist und Stadtarzt Heinrich Steinhöwel (1412-1478) um 1476 herausbrachte (vermutlich eines der ersten zweisprachig gedruckten Bücher überhaupt). Drucken ließ er seine Übertragung bei Johann Zainer, dem seit 1472 in Ulm wirkenden Bruder des Augsburger Erstdruckers Günther Zainer. In der Folgezeit sollte Steinhöwel weitere deutsche Übersetzungen humanistischer Werke bei Johann Zainer herausgeben, darunter Boccaccios De claribus mulieribus.

Der berühmte Ulmer Aesop ist eines der Hauptwerke der deutschen Buchillustration im 15. Jahrhundert; mit ihm begann „,der hundertjährige Siegeslauf der ... Fabel durch die europäischen Sprachlandschaften“ (Schirokauer). Der erste der zahlreichen Nachdrucke erschien bereits im Folgejahr bei Günther Zainer in Augsburg; die ersten der vielen Übersetzungen folgten nur wenige Jahre darauf: in das Französische (1484), Englische (1484), Niederländische (1485), Spanische (1487) usw. Von der vorliegenden ersten Ausgabe des Ulmer Aesop sind nur insgesamt zehn Exemplare bekannt, sechs davon befinden sich in Deutschland. 


\section{Liber}

in foner ktankbait: ‘o ftùnoê fie wor fynem nol'vî grúbtent ín/ vino 200 oltent nit bín $y$. ID o frage 8 leo sen ainen fuchs $/ 20$ ar vmb fie nit bin yn gien: gen jů im. Ontwolurt ger fucbs: oaz ift oarumb/oz woir vil fpuz fenbê zì oir bin yn gan/aber kaine bez zoiber vb. Qlfo fol ain 20 yfer man fich wor aignê fchaben of frem iem fchaben bersaren. 20 ann mit ben gexsaltigen mag ficb oer vnoez vno ainfăltig lyche in gefebăffe wermifchen /aber fchaden ono on trủro wermyoen ift ủber fchrosăr

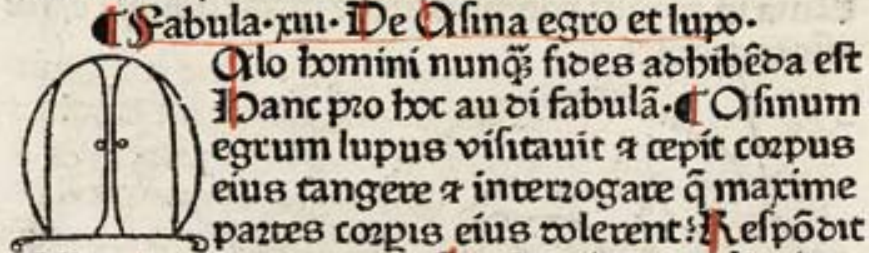
afellus iquas tu tangis. Sic bomines mali etiam fi pzodeffe fe fingũe $x$ bene loqui fimulatozie velint magis nocere feftinent.

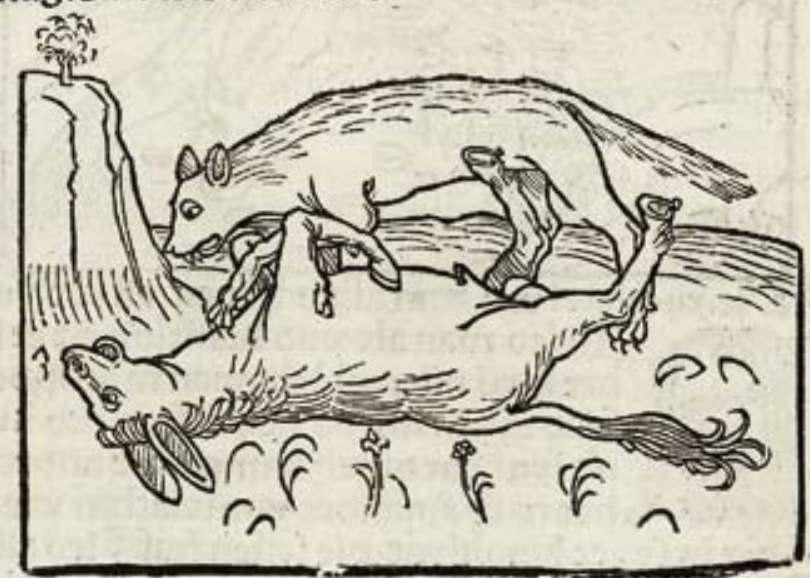




\section{Die Abenteuer des Marco Polo - eine Erfindung?}

Marco Polo:

Das Buch des edlen Ritters und Landfahrers Marco Polo.

Nürnberg: Friedrich Creussner, 1477.

Signatur: $4^{\circ}$ Itin. I, 2268 Inc.

Provenienz: Gottfried Thomasius, 1770

Marco Polo wurde im Jahr 1254 als Sohn des Kaufmanns Niccolò Polo in Venedig geboren. Sein Vater widmete sich vor allem dem Handel mit dem Nahen Osten. Niccolò Polo unternahm nach 1260 zusammen mit seinem Bruder Matteo Polo ausgedehnte Reisen nach Kleinasien, die sie 1266 sogar bis an den Hof des Großkhans in Peking führten. Vom Jahr 1271 an begleitete der erst 17 Jahre alte Marco Polo seinen Vater und seinen Onkel auf einer diplomatischen Mission, die sie im Auftrag Papst Gregors X. erneut zum Hof des Kaisers von China führen sollte. Die Männer reisten in dreieinhalb Jahren von Venedig über Jerusalem, Persien, Afghanistan, die Seidenstraße und die Wüste Gobi nach Peking, wo sie im Jahr 1275 ankamen. Hier traf Marco Polo angeblich den mongolischen Herrscher Kublai Khan, der ihm verschiedene diplomatische Missionen übertrug, die ihn nach Tibet und in andere Provinzen des riesigen Reiches führten. Der Aufenthalt der drei venezianischen Gesandten am Hofe des Großkhans sollte bis zum Jahre 1291 dauern, und die Rückreise nahm weitere vier Jahre in Anspruch.

Schon zu Lebzeiten Marco Polos wurden wesentliche Teile seiner Berichte für nicht wirklichkeitsgetreu gehalten, und einige seiner Zeitgenossen bezweifelten deren Wahrhaftigkeit sogar vollständig. Als Marco Polo 1298 nach einer Seeschlacht in Genuesische Gefangenschaft geriet, diktierte er offenbar einem Mitgefangenen seinen Bericht, dessen erste Fassung in französischer Sprache unter dem Titel Le Livre des merveilles du monde abgefasst war. Im 14. Jahrhundert verbreitete sich der Text in Handschriften rasch auch in italienischer Sprache unter dem Titel Il milion - möglicherweise die Kurzform des Spitznamens der venezianischen Familie Polo „Emilione“. Noch heute sind etwa 150 Handschriften erhalten. Der deutsche Erstdruck des Reiseberichts stammt aus der Werkstatt des Nürnberger Druckers Friedrich Creussner, der ihm 1477 den Titel Das Buch des edlen Ritters und Landfahrers Marco Polo gab. Auch in der neueren Forschung sind starke Zweifel an der Authentizität des Werks geäußert worden. Zum einen finden zahlreiche auffällige Erscheinungen des täglichen Lebens in China keinerlei Erwähnung (Tee, die Schriftzeichen, die chinesische Mauer), zum andern erwähnt der Bericht Einzelheiten, die nachweislich falsch sind. Das vernichtende Urteil eines Fachmannes lautet daher: „der kolossalste Schwindel der globalen Entdeckungsgeschichte“ (Dietmar Henze). Dennoch kann dem Buch eine Wirkung auf die Beziehungen zwischen Europa und Asien nicht abgesprochen werden.

(KN/HR) 


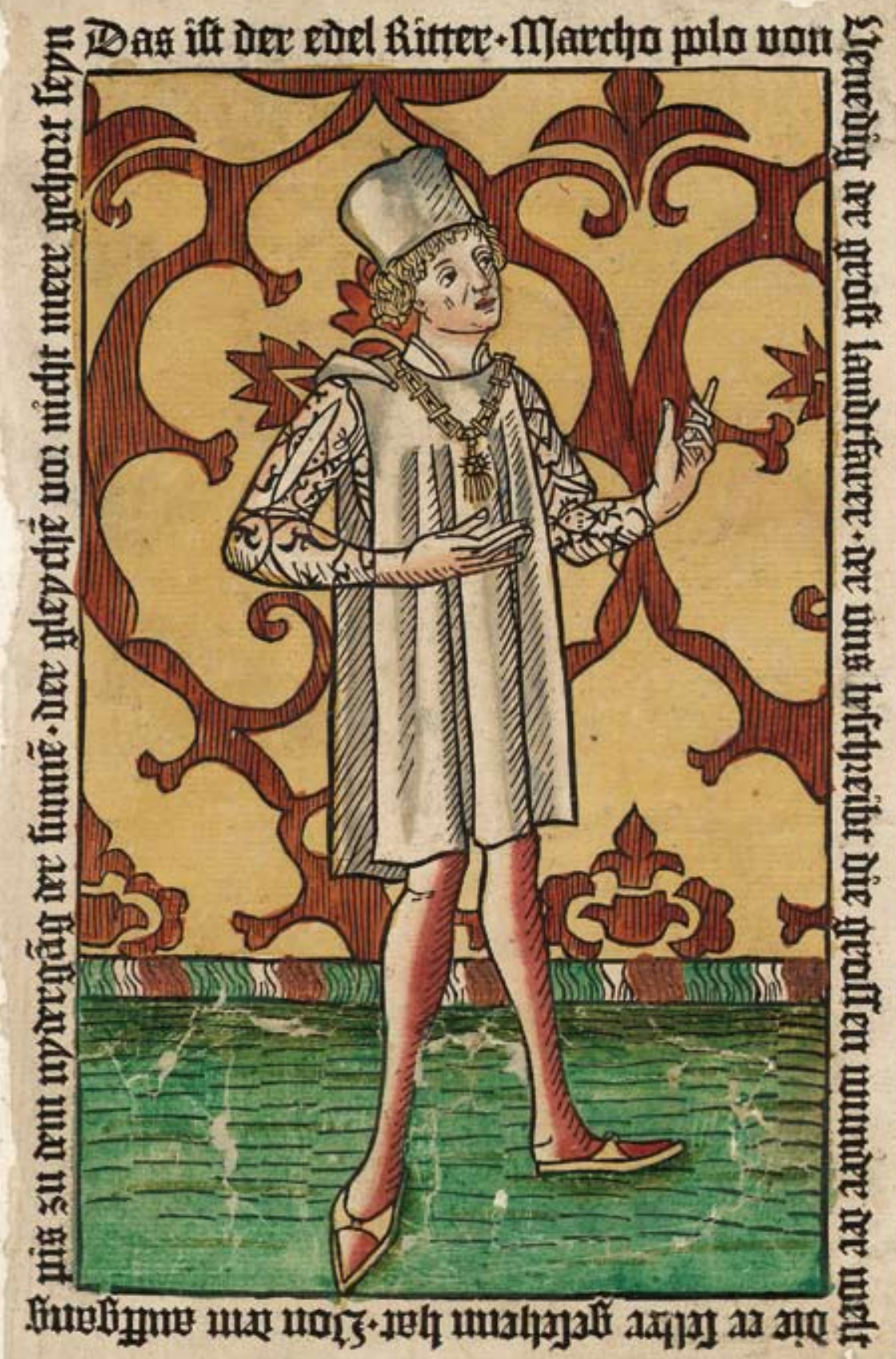




\section{Die Weisheit der alten Weisen}

Johannes de Capua:

Directorium humanae vitae, deutsch.

Ulm: Lienhart Holl, 28. V. 1483.

Signatur: $4^{\circ}$ Fab. Rom. I, 1730 Inc. Rara

Provenienz: Gottfried Thomasius, 1770

Das Buch der Beispiele oder der Weisheit der alten Weisen zeigt eine Verwandtschaft $\mathrm{zu}$ orientalischen Fabelsammlungen wie dem indischen Pañcatranta, in denen menschlich handelnde Tiere auftreten, deren Beispiele den Leser oder Zuhörer kluges, wohlbedachtes und auch gutes Verhalten lehren sollen. In der zweiten Hälfte des 13. Jahrhunderts wurde der Stoff von Johannes de Capua unter dem Titel Directorium humanae vitae in einer lateinischen Fassung zusammengestellt, die durch den Geistlichen Rat Antonius von Pforr aus Rottenburg am Neckar um 1470 ins Deutsche übersetzt wurde. Antonius widmete das Werk Graf Eberhard im Bart von Württemberg, dessen Name als (im Vergleich zu Fyners Ausgabe verstümmelten) Akrostichon „EBERHART GRAF“ aus den Holzschnittinitialen der Vorrede herauszulesen ist. Im Hauptteil des Werkes erzählt der Weise Sendebar auf Bitten des indischen Königs Dißles Geschichten, die als byspel, glychnuß, fabel dienen und rechtes Verhalten und Lebensklugheit lehren wollen.

Die Erstausgabe der Übersetzung wurde vermutlich im Jahre 1481 von Conrad Fyner in Urach gedruckt und mit insgesamt 128 Holzschnitten ausgestattet. Noch prachtvoller aber ist die vorliegende zweite Ausgabe gestaltet, die der Ulmer Drucker Lienhart Holl ,auff den xxviij. tag des mayenß“ 1483 vorlegte. Die 126 Holzschnitte dieser Ausgabe übertreffen den Erstdruck in jeder Hinsicht - es sind Meisterwerke der deutschen Buchillustration, die im Göttinger Exemplar zudem sehr sorgfältig und mit erstaunlichen Farbnuancen koloriert wurden. Lienhart Holl druckte von seinem Erstdruck einige Exemplare auf Pergament und brachte - vermutlich wegen des Verkaufserfolges - schon zwei Monate nach der Erstveröffentlichung eine unveränderte Neuauflage des Buchs der Beispiele auf den Markt, dem ein Jahr später die dritte, durch ein Register erweiterte Ausgabe folgte. Die Abbildung gehört zum Ende des dritten Kapitels und illustriert den Abschluss des Gerichtsverfahrens gegen den Übeltäter Dymna, der auf Befehl des Königs hingerichtet wird, weil er zum Schaden anderer eigenen Vorteil erzielen wollte. 


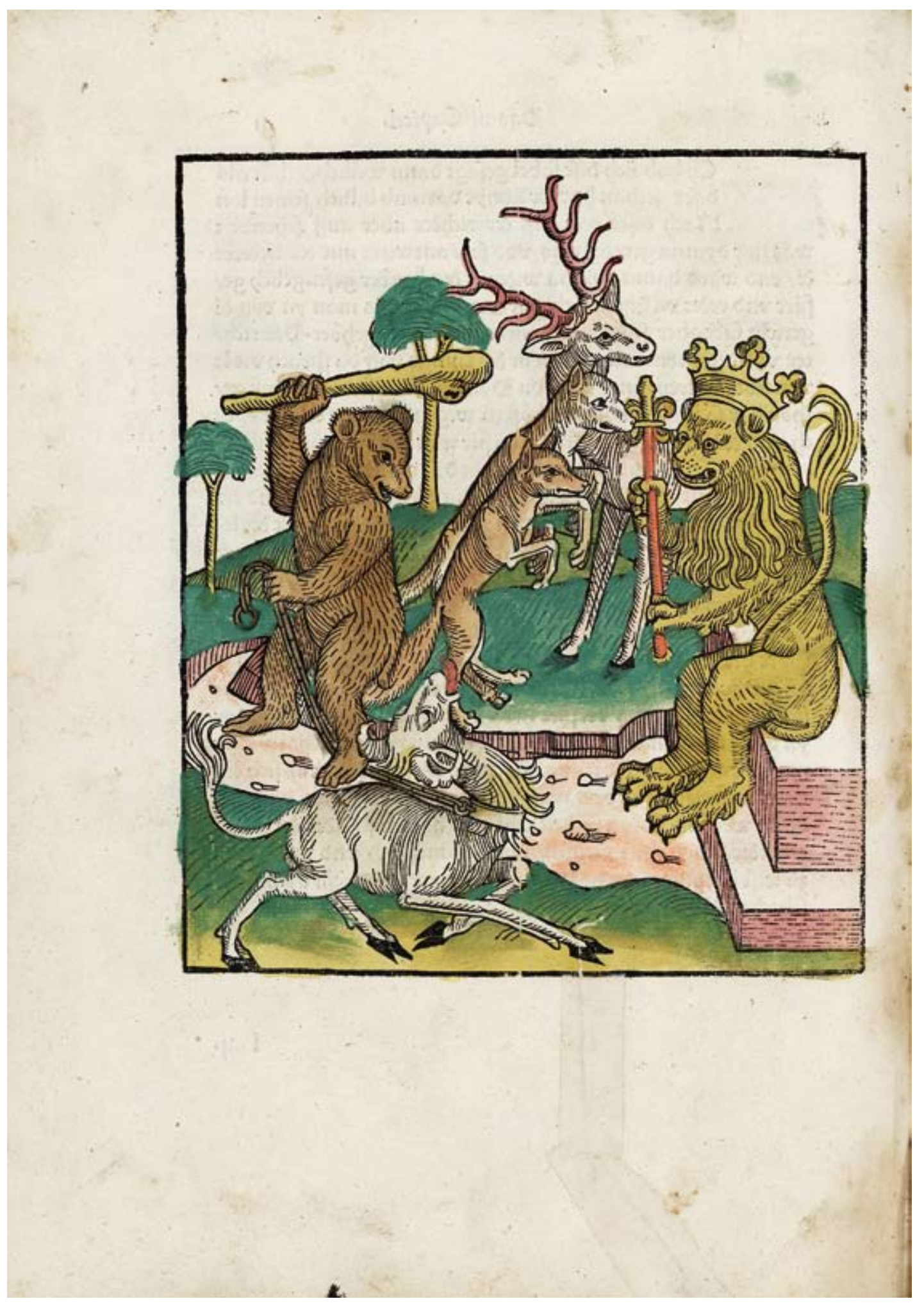




\section{Helden und Heiden}

Das Heldenbuch.

[Straßburg: Johann Prüss d. Ä., um 1484/85].

Signatur: $4^{\circ}$ Poet. Germ. I, 2140 Inc. Rara

Provenienz: Gottfried Thomasius, 1770
Als „Heldenbücher“ werden im heutigen Sprachgebrauch Ausgaben der mittelhochdeutschen Heldenepik bezeichnet. Die älteste überlieferte Handschrift dieser Literaturgattung stammt aus der Zeit um 1300; sie enthält Fragmente aus dem Ortnit, dem Wolfdietrich, dem Eckenlied und der Virginal. Alle weiteren überlieferten Zeugnisse sind erst im letzten Drittel des 15. Jahrhunderts entstanden. Unmittelbare Vorläuferin des ersten Drucks ist eine wahrscheinlich um 1480 entstandene Handschrift des Straßburger Goldschmieds Diebolt von Hanowe (Wirkungsjahre ca. 1470/80), die einst im Besitz der Straßburger Seminarbibliothek war und 1870 verbrannte. Dem Text ist eine Vorrede in Prosa vorangestellt, die einen summarischen Überblick über die wichtigsten Gestalten und Stoffe der mittelalterlichen deutschen Heldendichtung gibt.

Der ohne Angabe von Drucker, Druckort und Drucktermin veröffentlichte Erstdruck ist, wie typographische Vergleiche nahe legen, wohl Johann Prüss dem Älteren in Straßburg zuzuschreiben. Er enthält den Ortnit, den Wolfdietrich, den Rosengarten und den Laurin.

Das Werk ist mit 230 Holzschnitten von 156 Druckstöcken versehen - eine Zahl, die nur von wenigen Inkunabeln erreicht wird. Sie illustrieren auf eingängige Weise die dramatischsten und oft genug blutrünstigen Einzelheiten der Erzählungen. Bis zum Ende des 16. Jahrhunderts wurden insgesamt sechs Ausgaben des Heldenbuchs gedruckt, darunter als zweite Ausgabe eine des professionellen Nachdruckers Johann Schönsperger (1455-1521), die 1491 in Augsburg erschien.
Aufgeschlagen ist ein Holzschnitt aus dem Wolfdietrich, der, aus einer alten, in weiter Verzweigung überlieferten Erzähltradition stammend, zu einem der großen literarischen Erfolge des ausgehenden Mittelalters wurde. Unermüdlich werden Riesen, Drachen und andere Ungeheuer unschädlich gemacht, Frauen gefreit, hunderte von Heiden verstümmelt, getötet oder auch getauft - bis Wolfdietrich am Ende eines ereignisreichen und doch tugendhaften Lebens zu einem vorbildlichen Mönch wird. 
vicfercic Wolfoieterich mit Baloemar oem rifen in oem walo/oer ein [shelin frans bet/vno über alle baum aufissiens/pno fcblüs im jü oot ]

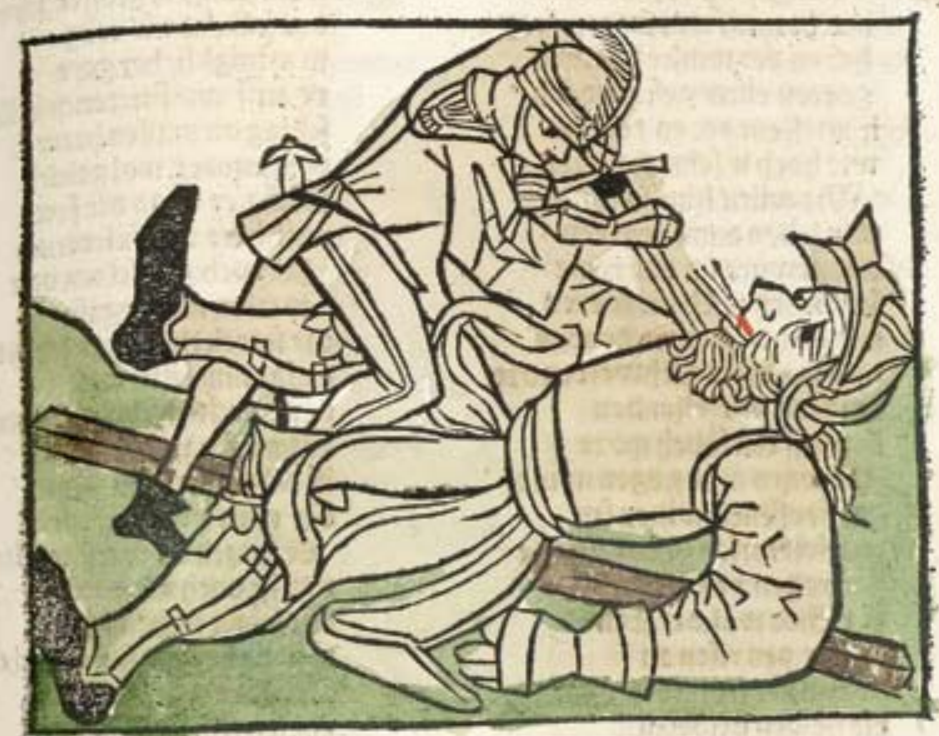

et mas ciner groffen wenoe an (eimer groffe geleich) ver teufffel oich tie febenve fprasblwolf berz oictereich Ou bifcoes tetiffels bziloer ein vincfieger cjag vno bif cém recbe wale luost für war icboir oas fas "8 waro níe weibes kimne fola: $800 \mathrm{er}$ fosros (ie vic); fir wer oes teiffels senos Was asfeu kime vil tumbes fiezacb oa ocr fratcke man

ou baft ein feraffe krumbes gerittenourch oen tan ich gib oir voz oer fefte 3wep geteilt inkureser fune vnokicfefe ou nit oas befte cu wirtfefein vngefunt nusib mir bie ;ü zolle ein füfs ooer ém bante oaskino icb oir bie folle oas milf biefcin meím $p$ fane fo fpzachoer riff vnrcime fas an wie wiltuleben ou mŭfr mir pe oas cine nocb but jü jolle geben 


\section{Irrungen und Wirrungen}

Giovanni Boccaccio:

Il Filocolo, deutsch.

Metz: Kaspar Hochfeder, 26. VIII. 1499.

Signatur: $4^{\circ}$ Fab. Rom. III, 1579 Inc.

Provenienz: Gottfried Thomasius, 1770

Der Filocolo (um 1340/45) ist das Erstlingswerk Giovanni Boccaccios (1313-1375). Der abenteuerliche Prosaroman verarbeitet einen damals in ganz Europa populären Stoff, der in Frankreich in der Mitte des 12. Jahrhunderts unter dem Titel Floir et Blancheflor entstanden war. „Die erbarmenswerten Abenteuer des verliebten Florio und seiner Biancofiore“" führten die beiden von Amor selbst zusammengeführten Protagonisten, deren Liebe der spanische König, der Vater Florios, entgegensteht, durch allerlei Gefahren und Abenteuer von Verona nach Alexandrien, von Neapel wieder nach Ägypten und schließlich nach Rom, wo endlich die prächtige Hochzeit stattfindet. Wiederholt müssen die Götter in allerhöchster Not eingreifen, um die Liebenden zu retten; der Verkauf in die Sklaverei bzw. in den Harem eines Sultans, Einkerkerung und Verurteilung zum Feuertod, Schiffsbrüche und falsche Todesnachrichten sind nur einige der vielen Gefahren, die ihnen drohen. Der Liebesroman mischt auf nahezu wahllos anmutende Weise christliche, antike und höfische Elemente, und Boccaccio nutzt die Gelegenheit, um seine Kenntnisse der griechischen und römischen Mythologie unter Beweis zu stellen. Die griechische Sprache allerdings beherrschte er nur unzulänglich: Erst aus der in einer venezianischen Ausgabe von 1537 verwendeten Titeländerung Il filopono (aus griechisch philoponos) ist erkenntlich, dass er mit dem Titel Il filocolo wohl den sich abmühenden Liebenden zu bezeichnen trachtete.
Kaspar Hochfeder, der Drucker der ersten deutschen Ausgabe des Filocolo, war seit etwa 1473 in der polnischen Königs- und Universitätsstadt Krakau tätig. Als ausgesprochener „Wanderdrucker“ ließ er sich dann von 1490 bis 1499 in Nürnberg nieder, von 1499 bis 1502 in Metz, von 1502 bis 1505 in Krakau. Schließlich war er von 1508 bis 1517 wieder in Metz tätig. Dort druckte er zwei deutsche Ausgaben des Filocolo. 


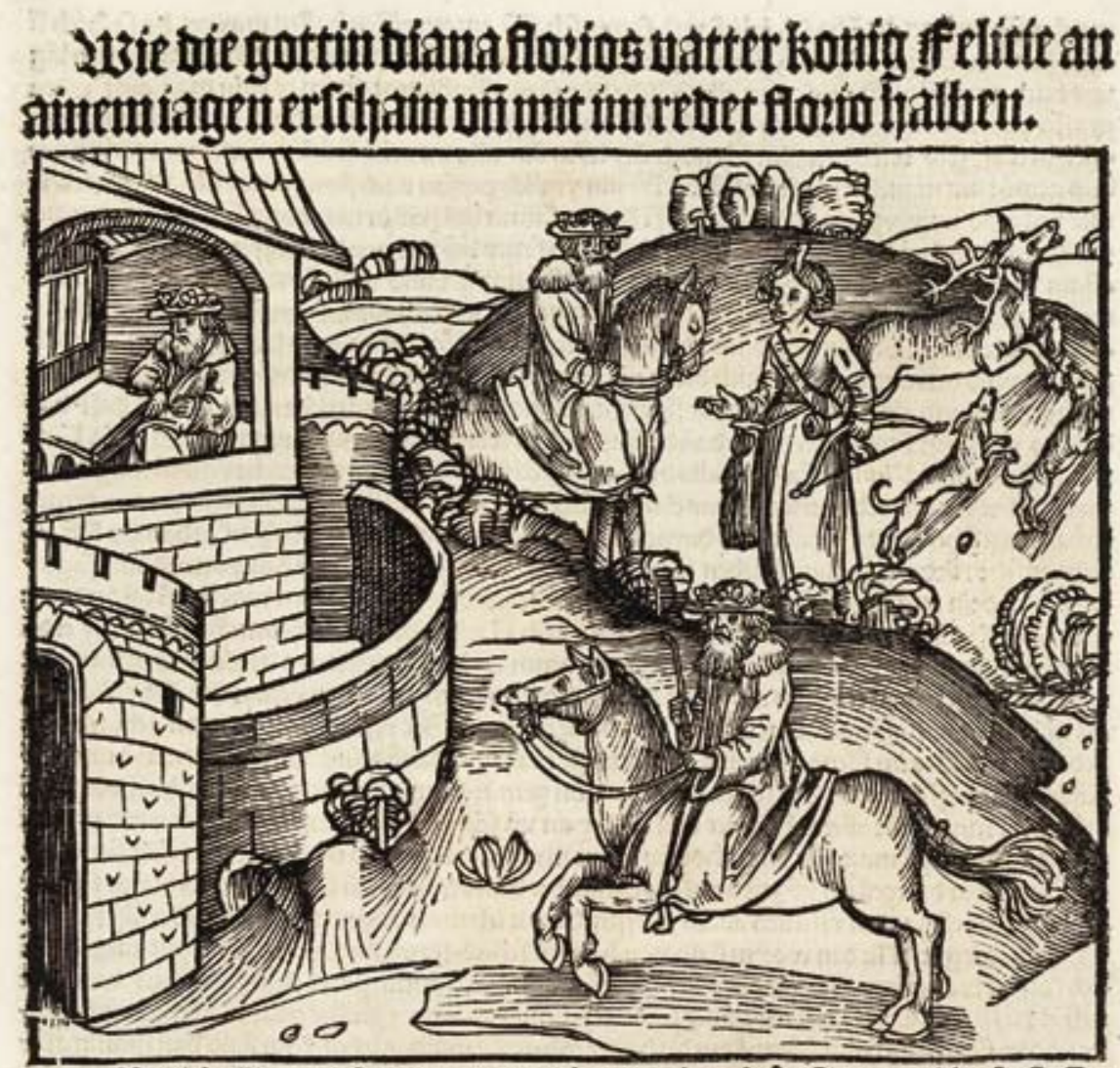

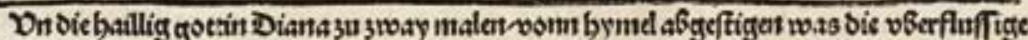

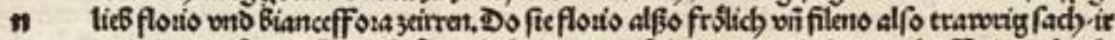

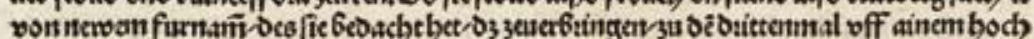

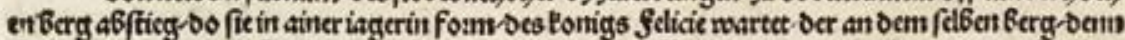

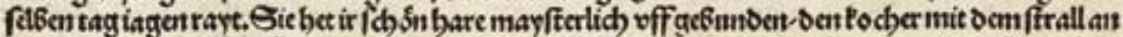

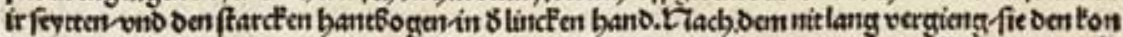

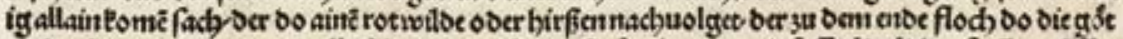

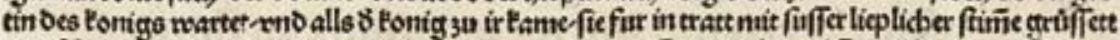

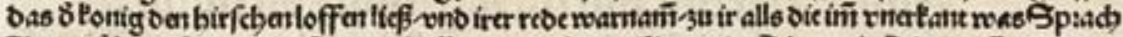

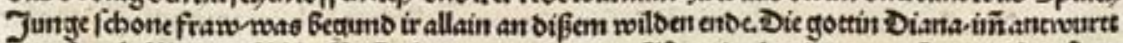

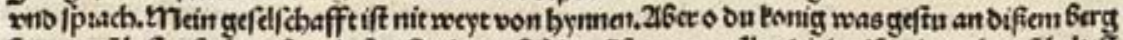

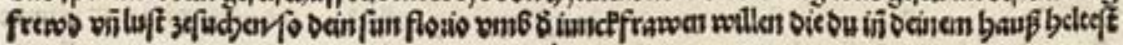




\section{Das Leiden Christi - der Schatz des Menschen}

Stephan Fridolin:

Schatzbehalter der wahren Reichtümer des Heils.

Nürnberg: Anton Koberger, 8. XI. 1491.

Signatur: $4^{\circ}$ Theol. mor. 142/29 Inc.

Provenienz: Rudolf Anton Fabricius, 1776
Stephan Fridolin (um 1430-1498) war Prediger, Lektor und Franziskanermönch in Bamberg, Mainz, Basel und Nürnberg, wo er als geistlicher Betreuer des Klarissenklosters wirkte. Neben einem Buch von den Kaiserangesichten, das Kaiserbildnissen auf antiken römischen Münzen gewidmet ist, einigen Predigtsammlungen und allegorischen Werken veröffentlichte er im Jahre 1491 sein wichtigstes Werk, den Schatzbehalter der wahren Reichtümer des Heils. Die ,auff frag un[d] bitt etlicher andechtiger person“ verfasste Erbauungsschrift war dezidiert an Laien gerichtet. Die im Hauptteil des Werkes dargebotenen 100 Gedanken über das Leiden und Sterben Christi fordern dazu auf, die Werke und Martern des Gottessohnes „mit $\mathrm{scha[m],} \mathrm{mit} \mathrm{mitleiden} \mathrm{und} \mathrm{danckberkeit“} \mathrm{zu}$ betrachten und als Genugtuung für alle Sünde und Erlösung der Gläubigen zu begreifen. Die Passion und das Kreuzesgeschehen gelten so als Schrein- oder Schatzbehalter-des menschlichen Heils.

Der Schatzbehalter ist das einzige Werk Fridolins, das bereits zu seinen Lebzeiten in gedruckter Form veröffentlicht wurde. Mit einem Umfang von 352 Blatt und 96 ganzseitigen Holzschnitten aus der Werkstatt von Michael Wolgemut (1437-1519) und Wilhelm Pleydenwurff ( $\uparrow$ 1494) bei Anton Koberger (ca. 1440-1513) erschienen, gilt es als Höhepunkt in der Geschichte der Nürnberger Druckerei. Das Buch, von dem heute weltweit knapp 140 Exemplare nachweisbar sind, verließ in mindestens vier unterschiedlichen Ausstattungen die Offizin. Die Holzschnitte des Göttinger Exemplars sind unkoloriert geblieben, so dass ihre künstlerische Wirkung zur vollen Entfaltung kommen kann. Eng auf den Text bezogenen, stellen sie die ständige Präsenz des Leidens Christi im gesamten Weltgeschehen seit der Erschaffung der Erde heraus. So ist auch zu erklären, dass sie sich mehrheitlich auf das Alte Testament und den präexistenten Christus bzw. auf das Leben Christi bis zum Geschehen auf dem Ölberg beziehen, während die Passionsschilderungen der Evangelien in nur fünfzehn Holzschnitten verarbeitet werden. Aufgeschlagen ist eine Abbildung, die Christus als ,arzet und heylmacher“ zeigt: Ihm, der körperliche und seelische Leiden heilte und sich selbst als Arznei gab, wurde von den Juden vorgeworfen, die Menschen zu verderben.

(HR/SG) 


\section{Décie neununotreyfligift figur;}

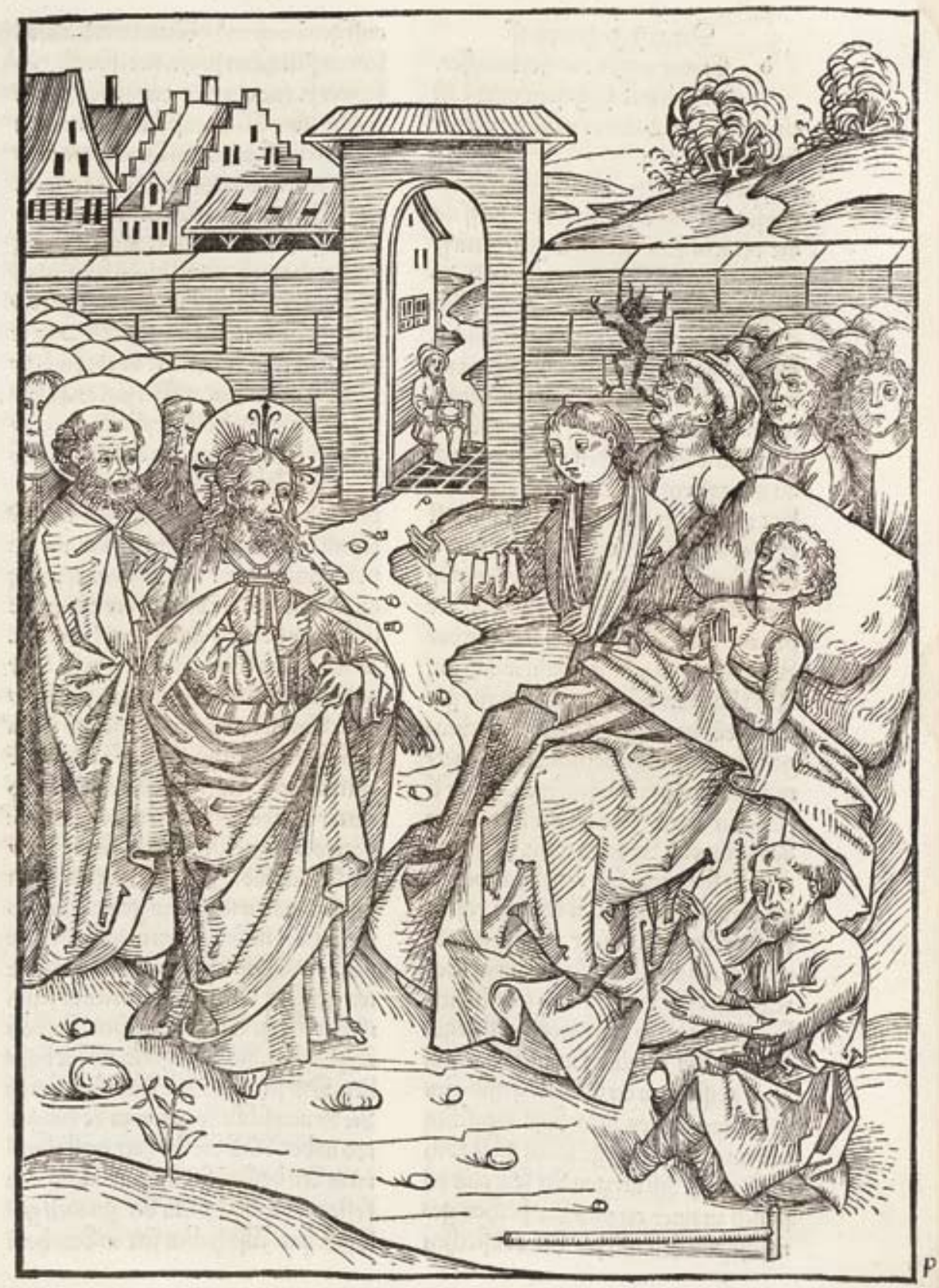




\section{Das Emblembuch Peters des Großen}

Symbola et emblemata, iussu atque auspiciis Sacerrimae Suae Majestatis Augustissimi ac Serenissimi Imperatoris Moschoviae... Petri Alexeidis ...

Amsterdam: H. Wetstein, 1705.

Signatur: $8^{\circ}$ Hist. subs. 4352 Rara

Provenienz: Rudolf Anton Fabricius, 1776

1697/98 unternahm Peter der Große (1672-1725; reg. 1682/89-1725) eine als „Große Gesandtschaft“ bekannt gewordene Reise nach Westeuropa, die ihn auch in die Niederlande führte. Hier erwarb der junge Zar Kenntnisse und Einsichten, die seine radikale Umgestaltung Russlands zur militärischen Großmacht und zu einem modernen Staatsgefüge nach westeuropäischem Vorbild maßgeblich beeinflussten. Noch während seines Aufenthaltes in der niederländischen Hauptstadt stattete Peter der Große dortige Drucker mit dem Privileg aus, russische Bücher zu drucken. Als einer von etwa zwanzig bekannten frühen russischen Amsterdamer Drucken erschien im Jahre 1705 - vom Zar persönlich in Auftrag gegeben - die Emblemenzyklopädie Symbola et emblemata. Woher rührt das Interesse Peters des Großen an der Publikation dieses ersten russischen Emblembuches? Während seines Aufenthaltes in Amsterdam hatte der Zar, wie Hippisley rekonstruiert hat, Daniel de la Feuilles umfangreiche siebensprachige Emblemkompilation Devises et emblemes anciennes et modernes (Amsterdam 1691) erworben. In einer Zeit, in der die Verwendung der Emblematik in der Heraldik, bei offiziellen Feierlichkeiten wie Feuerwerken und Illuminationen, in der Gebäude- und Landschaftsarchitektur und anderen Bereichen allgegenwärtig war, erkannte Peter der Große sofort die Eignung des Werkes für Zwecke der russischen höfischen und militärischen Repräsentation und beauftragte den polnischen Übersetzer und Druckagenten Elias Kopijewski damit, eine auch dem fremder Sprachen nicht mächtigen Russen verständliche Fassung herzustellen.
Nach Kopijewskis Weggang aus Amsterdam im Jahre 1702 wurden die Symbola et emblemata bei Hendrik Wetstein gedruckt. Sie umfassen 840 durchnummerierte, kreisförmig umrandete Emblemata mitsamt ihrer Inskriptionen in acht Sprachen, nach ihrem niederländischen Titel an erster Stelle der russischen, an letzter Stelle der deutschen Sprache; ihnen folgt ein einfaches alphabetisches Register der Inskriptionen in lateinischer Sprache. Die ersten 708 Embleme gehen direkt auf de la Feuilles Sammlung zurück, während die übrigen 132 Embleme weitere Quellen haben. Wie von Peter dem Großen intendiert, wurde die Auflage vielfach von russischen Kunsthandwerkern erworben, die sie als Gestaltungsvorlage verwendeten. Insbesondere aber im Rahmen des forcierten Aufbaus der russischen Flotte fanden die Symbola et emblemata (und auch ihr Vorgängerwerk) reiche Verwendung.

Aufgeschlagen sind die Embleme Nr. 205 bis 210, deren erstes einen von einem Ast auffliegenden Adler mit der russischen Inskription „Ne glasom no dělami moimi“ (Nicht durch meine Stimme, sondern durch meine Taten) zeigt. Mit diesem Emblem wurde das russische Kriegsschiff „Alter Adler“ geschmückt, das im Jahre 1709 vom Stapel lief. 


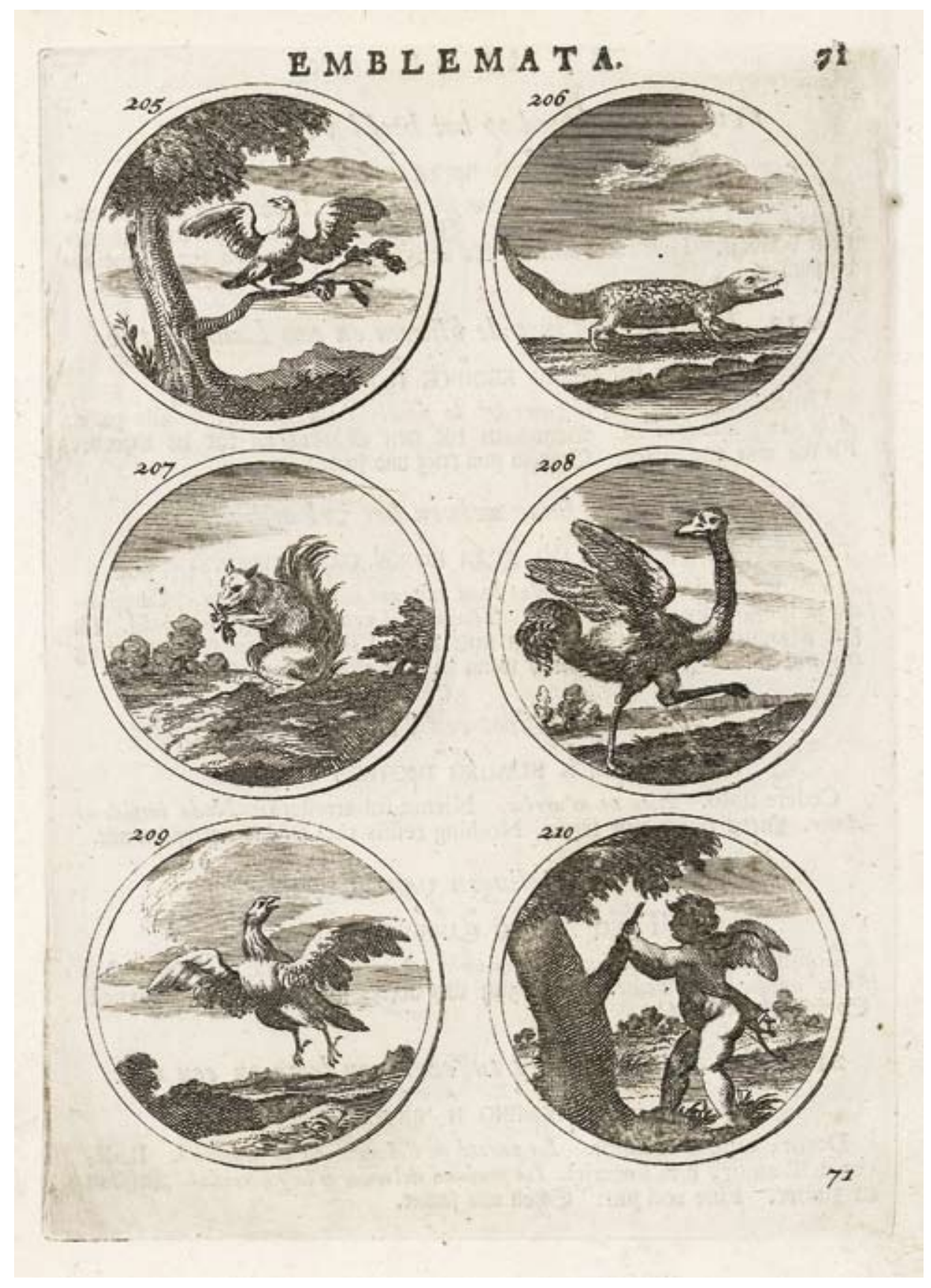




\section{Der erste Druck eines antiken Schauspiels in einer Volkssprache}

Publius Terentius Afer:

Eunuchus, deutsch.

Ulm: Conrad Dinckmut, 1486.

Signatur: $4^{\circ}$ Auct. Lat. I, 4202 Inc.

Provenienz: Christian Gottlieb Schwarz, 1769/70
Die antike Komödie Eunuchus des römischen Dichters Publius Terentius Afer (ca. 190 v. Chr. - nach 160 v. Chr.) wurde 161 v. Chr. bei den Megalensischen Spielen von der Schauspieltruppe des Lucius Ambivius Turpio uraufgeführt. Das Publikum nahm das Stück mit Begeisterung auf. Bereits am ersten Spieltag musste es zweimal wiederholt werden und brachte insgesamt die Riesensumme von 8.000 Sesterzen ein. Der Kern des Schauspiels liegt in den Bemühungen der Hetäre Theis, das Mädchen Pamphila, welches als Kind entführt und als Sklavin verkauft wurde, wieder mit seiner Familie zusammenzuführen. Um diesen Handlungsstrang bauen sich zwei unterschiedliche Liebesgeschichten auf. In der ersten wetteifern der Soldat Thraso und der Jüngling Phadria um die Gunst der Hetäre Theis. Thraso bietet ihr die Sklavin Pamphila als Geschenk für die Abwendung von Phadria. Dieser wiederum sendet ihr einen Eunuchen als Liebesbeweis. Zeitgleich verliebt sich Chaerea, der Bruder von Phadria, in die vermeintliche Sklavin Pamphila. Mittels der Kleidung des Eunuchen gelangt er in ihre Nähe und verführt sie. Als sich herausstellt, dass Pamphila eine Freigeborene ist, darf Chaerea seine Geliebte heiraten. Der prahlerische Thraso ist der doppelte Verlierer des Stücks: Er verliert nicht nur die teuer erkaufte Sklavin, sondern auch die Gunst der Theis, die sich Phadria zuwendet. Die wirkungsvolle Intrigen- und Wiedererkennungskomödie verzichtet auf derb-lustige oder reißerische Anspielungen. Die Glaubwürdigkeit und die humane Gesinnung der handelnden Personen machten dieses Schauspiel zu allen
Zeiten erfolgreich. Ihr Verfasser Terenz, ein wichtiger Vertreter der altlateinischen Komödie, gehörte im Altertum und im Mittelalter zu den beliebtesten Schriftstellern.

Die deutsche Übersetzung des Eunuchus stammt von dem vermögenden, humanistisch gebildeten Ulmer Patrizier Hans Neithart. Dieser veranlasste und finanzierte den Druck durch Conrad Dinckmut. In der Schlussschrift heißt es kurz: „Dise Comedia hat Hanns Nythart zu Vlm lasse trucken den Cunrad Dinckmut“. Das Werk ist mit 28 ganzseitigen Holzschnitten verziert. In der Vorrede wird deutlich, dass diese Illustrationen Originalschöpfungen sind, an deren Gestaltung Neithart maßgeblich beteiligt war. Der deutsche Eunuchus ist der erste Druck eines antiken Schauspiels in einer Volkssprache und die erste illustrierte Ausgabe eines Schauspiels. Die Ausgabe erschien im Jahr 1486 und stellt den Höhepunkt der Druckertätigkeit der Dinckmutschen Offizin dar.

$(\mathrm{HR} / \mathrm{KN})$ 
xxxi

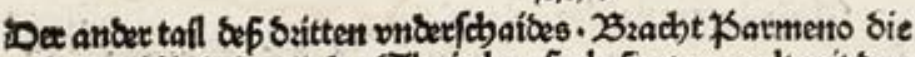

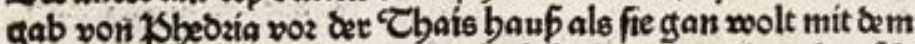

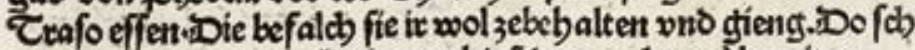

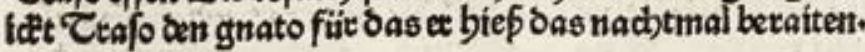

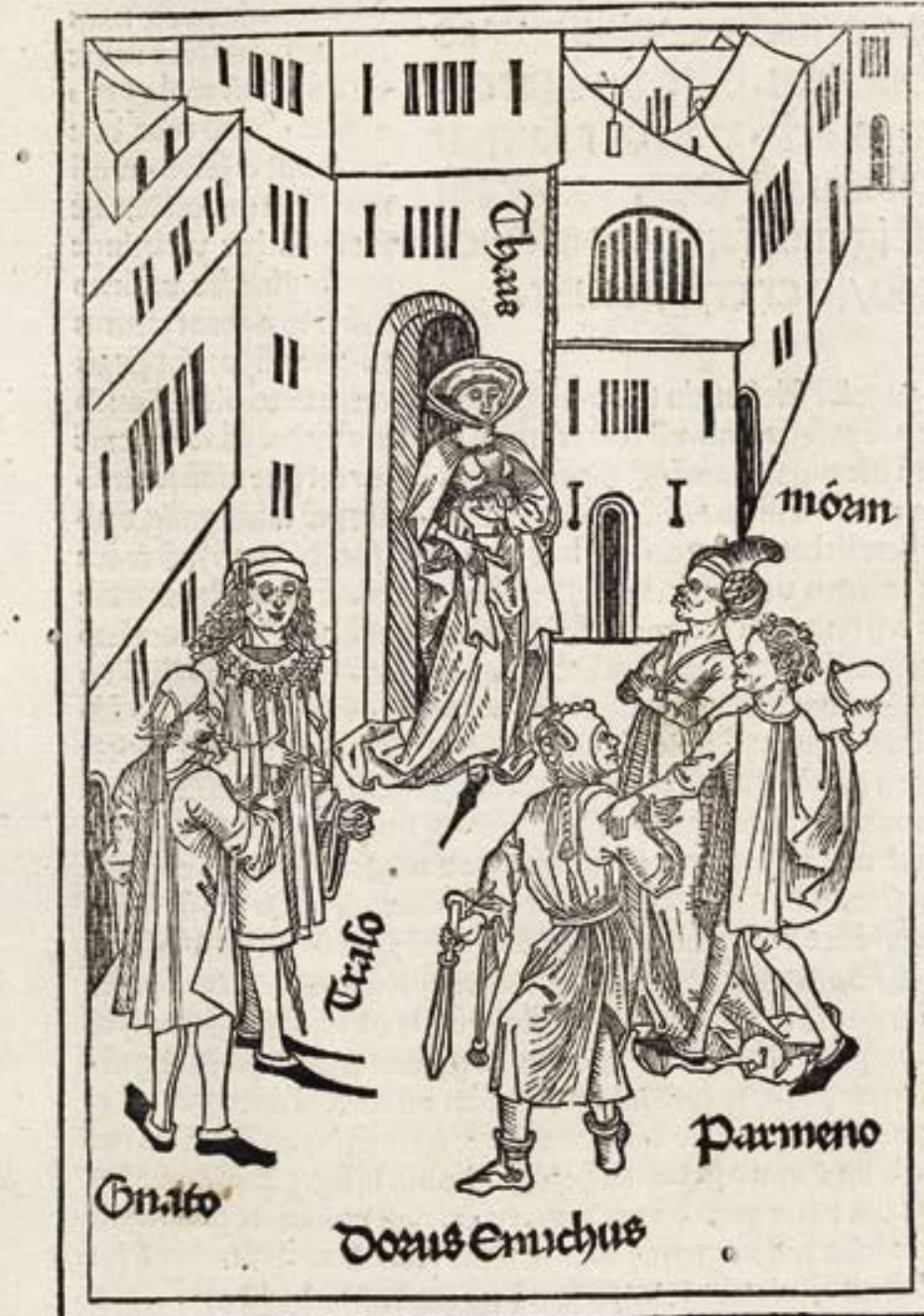

fii 


\section{Das Ilfelder Evangeliar - vom Tegernsee in den Südharz}

Evangelia, lateinisch.

Sedulius Scottus: Collectaneen.

Pergamenthandschrift,

Tegernsee und Norddeutschland, 2. Hälfte des 11. Jahrhunderts.

Signatur: $4^{\circ}$ Cod. Ms. Cod. theol. 38 Cim.

Provenienz: Heinrich Philipp Konrad Henke, 1810/1811

Evangeliare enthalten den vollständigen

Text der vier Evangelien, dem im Mittelalter zumeist sogenannte Kanontafeln vorangestellt wurden, in denen inhaltlich übereinstimmende Textstellen aus den Evangelien in Konkordanztabellen aufgelistet sind. Bei dem vorliegenden Evangeliar aus dem 11. Jahrhundert ist vor den Kanontafeln noch ein Text des irischen Dichters Sedulius Scottus (Wirkungszeit 848-874) zu finden, der aber ursprünglich nicht mit dem Evangeliar verbunden war. Paläographische Untersuchungen ergaben, dass die fünf Handschriften im Evangeliar im Wesentlichen von Schreibern aus dem im Jahr 978 neu gegründeten Kloster Tegernsee stammen.

Nach seiner Anfertigung in Süddeutschland könnte das Evangeliar in ein norddeutsches Kloster gelangt sein, wo der Buchschmuck, die Kanontafeln und die ganzseitigen Bilder der Evangelisten Markus, Lukas und Johannes beigefügt wurden (eine Darstellung des Evangelisten Matthäus ist nicht vorhanden). Auf dem vorderen Einbanddeckel findet sich der Eintrag „Ilefelt“, so dass es nicht unwahrscheinlich ist, dass der Bestimmungsort des noch ungeschmückten Evangeliars das 1189 gestiftete Prämonstratenserkloster Ilfeld im Südharz gewesen war. Die drei Evangelistenbilder sind mit Sicherheit erst nachträglich in den Kodex eingefügt worden, was auch dadurch bestätigt wird, dass die Rückseiten der Miniaturen frei geblieben sind. Auf diesen Bildern sind die Evangelisten häufig schreibend mit einem Schriftband oder einem Kodex dargestellt. Der auf einem
Sessel mit Kissen sitzende Evangelist Lukas ist hier damit beschäftigt, den Textbeginn seines Evangeliums in eine geöffnete Handschrift zu schreiben, die auf einem Pult ruht. Die verzwickte Entstehungsgeschichte des Buches wird zusätzlich dadurch kompliziert, dass die aufgeschlagene Schriftseite auf dem Lukas-Bild eine Minuskelschrift zeigt, die mit keiner der fünf in dem Kodex enthaltenen Handschriften übereinstimmt. Dennoch belegt das Ilfelder Evangeliar eindrucksvoll, dass schon im Mittelalter jedes Buch seine eigene Geschichte hat.

Die Handschrift stammt aus dem Nachlass des Theologen Heinrich Philipp Konrad Henke (1752-1809), dessen Bibliothek im Jahre 1810 versteigert wurde. Sie enthielt 124 Handschriften und mehr als 14.000 gedruckte Bücher, aus denen die Göttinger Bibliothek 25 Handschriften und knapp 300 Drucke erwerben konnte. 


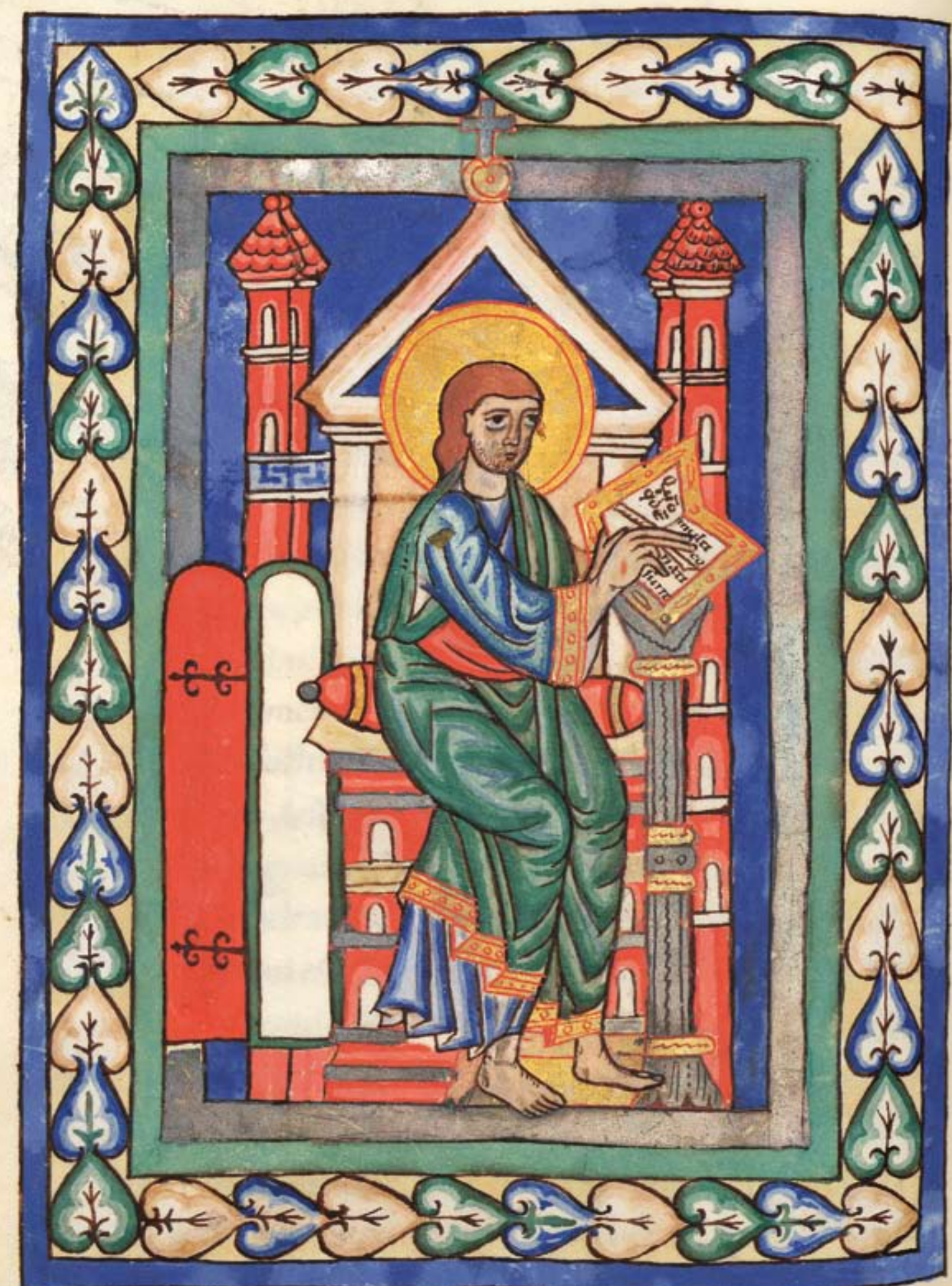




\section{Ein kaiserliches Schreibmeisterbuch}

L'art d'écrire.

Pergamenthandschrift, Deutschland, 17. Jahrhundert.

Signatur: $4^{\circ}$ Cod. Ms. philos. 27 Cim.

Provenienz: Johan Lundblad, 1792

Kalligraphie ist im Zeitalter unübersehbar vieler Schriftfonts für den Computer und dem offenbar unaufhaltsamen Verschwinden ganzer Schriftfamilien wie den Frakturschriften eine fast verlorene Kunst. „Schreiben können“" war natürlich auch in früheren Zeiten zunächst eine unterschiedlich weit verbreitete Grundfertigkeit, über die große Teile der Bevölkerung mehr schlecht als recht verfügten. Trotzdem gab es zu jeder Zeit ein Bewusstsein dafür, dass auch Schriftzeichen unter dem Gestaltungswillen des Künstlers wie ein Bild oder ein Bauwerk zum Kunstobjekt werden können. Zuständig dafür waren die Schreibmeister. Als Gattung haben die Schreibmeisterbücher ihre Wurzeln im Geist des Humanismus, auch wenn natürlich schon mittelalterliche Schreiber zum Teil großartige kalligraphische Fähigkeiten an den Tag gelegt hatten. Von ihnen unterschieden sich die neuzeitlichen Schreibmeister dadurch, dass sie sich ihrer Arbeit mit theoretischem Wissen über Geometrie und Ästhetik näherten. Die ersten Vertreter der Gattung kommen entsprechend aus dem 16. Jahrhundert. Wichtige Vorarbeiten stammten von so namhaften Wissenschaftlern und Künstlern wie Luca Pacioli und Albrecht Dürer. Das von solchen Größen erreichte Niveau konnte die Gattung aber nicht durchgängig halten, und in zahlreichen Musterbüchern trieben schon bald abenteuerliche Akrobatik und filigrane Schnörkelei ihr Unwesen. Aber immer gab es auch den Willen zur Reform und zur Überwindung unerwünschter Auswüchse. Virtuosität wurde dann wieder in den Dienst der Sache gestellt, und die Sache waren Briefvorlagen, offizielle
Dokumente, Erbverträge, Neujahrswünsche, Einladungen usw.

Eine weitere, ganz wesentliche Nutzung von Schreibmeisterbüchern erfolgte in den Zentralen der politischen Macht. In den Schreibstuben der Höfe gab es stets Bedarf an Schriftvorlagen, die für die Abfassung von offiziellen Dokumenten aller Art gebraucht wurden. In diesen Kontext gehört auch das vorliegende Schriftmusterbuch. Es kann zeitlich und inhaltlich dem Umkreis des kaiserlichen Hofes im 17. Jahrhundert bzw. den Kaisern Ferdinand I. oder Ferdinand II. zugeordnet werden, diente also vermutlich als Musterbuch in der kaiserlichen Kanzlei oder war zumindest dafür gedacht. Für diesen vornehmen Zweck spricht nicht zuletzt der wertvolle Beschreibstoff Pergament, auf dem die Schriftbeispiele kunstvoll und aufwändig ausgeführt wurden. 


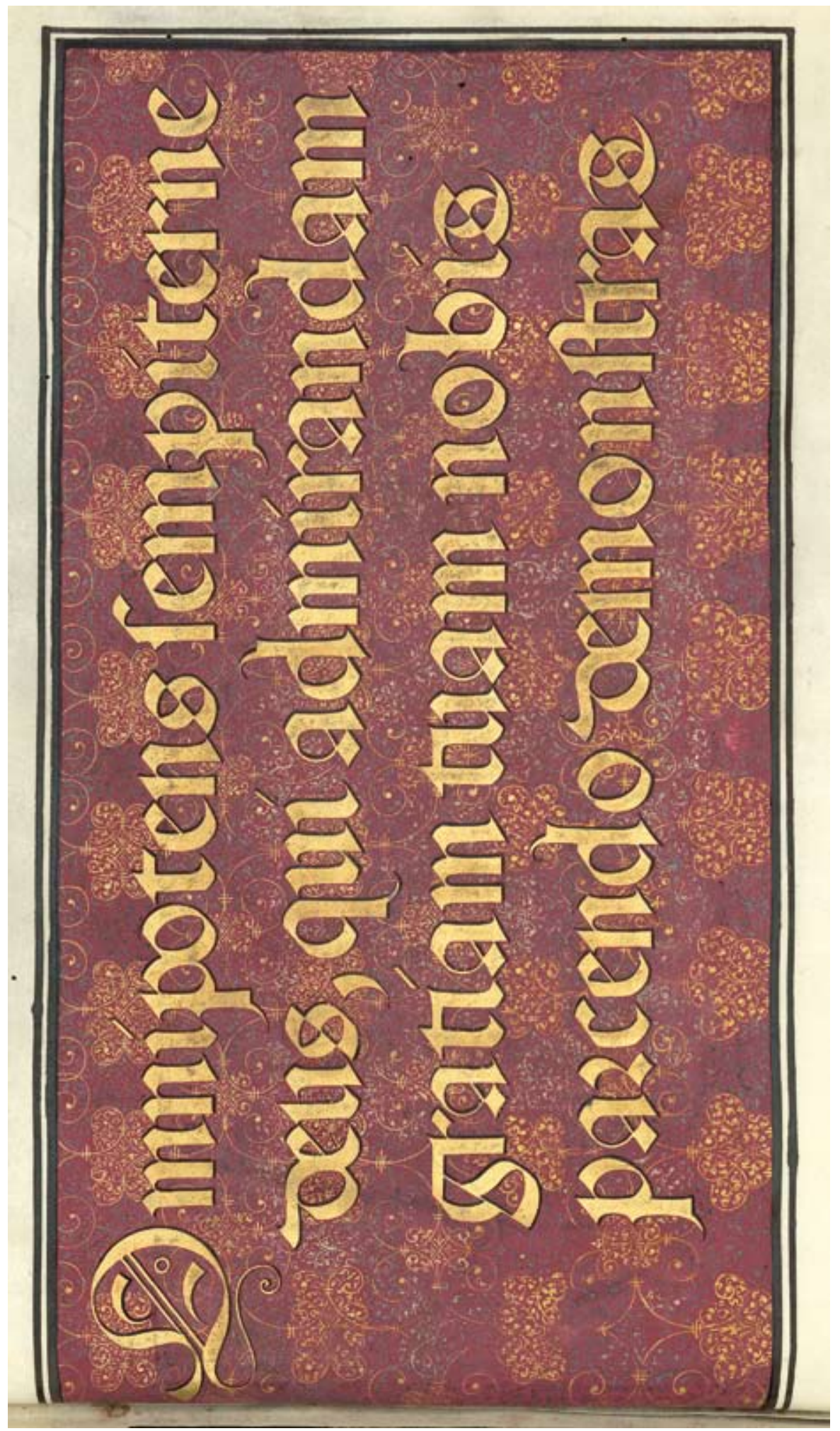




\section{Kapitel 9}

\section{Aus den Bibliotheken privater Büchersammler}

Eine besonders interessante Konstellation kann immer dann entstehen, wenn ganze Sammlungen oder große Teile daraus aus privater Hand in Bibliotheken übernommen werden. Der Reiz besteht dann darin, in der Sammlung die Persönlichkeit des früheren Eigentümers, seine Vorlieben und Ansichten in der Bibliothek (wieder-)erkennen zu können. In den allermeisten Fällen sind von früheren Privatbibliotheken heute nur noch Verzeichnisse, zumeist Verkaufskataloge erhalten. Auch sie sind eine eminent wichtige Quelle für die Geschichte des privaten Büchersammelns mit all ihren Facetten. Die Göttinger Universitätsbibliothek besitzt eine stattliche Sammlung davon. Die Kataloge, einst Informations- und Einkaufsgrundlage für Bibliothekare und mit entsprechenden Akzessionsbemerkungen versehen, sind heute eine Fundgrube für die Aufhellung vieler Aspekte der Buchhandels- und Wissenschaftsgeschichte, unabhängig davon, ob es sich um gedruckte Verzeichnisse oder handgeschriebene Inventarlisten handelt. Aber es ist doch etwas anderes, die Bücher selbst dafür zur Hand zu haben, denn über zahlreiche exemplarspezifische Elemente wie Einband, Marginalien, etc. steht in den Katalogen mit ihren zumeist sehr kurz gefassten Titelbeschreibungen in der Regel nichts. In den Beständen der Universitätsbibliothek sind viele Sammlungen aus privatem Besitz aufgegangen: große und kleine, hochkarätige und weniger bedeutende, repräsentative Ensembles und Gebrauchsbibliotheken.

Zu den herausragenden Kollektionen aus Privatbesitz zählt zweifellos die Sammlung des kurbraunschweigisch-lüneburgischen Hofrats und Geheimen Kanzlei-Sekretärs Friedrich Wilhelm von Duve. Duve besaß eine umfangreiche Sammlung alter Drucke, von denen ein Teil - so auch Caxtons Mirror of the World - aus der Bibliothek Harley stammte.
Der handschriftliche Katalog der Duveschen Bibliothek verzeichnet Drucke $a b$ incunabulis artis typographicae usque ad annum 1510 und nennt insgesamt 704 Titel, davon 504 Inkunabeln, so dass die außergewöhnlich reichhaltige Sammlung mit Recht den Titel Monumenta typographica trägt. 383 Frühdrucke gelangten daraus 1781/82 als dritte und letzte der umfangreicheren Inkunabelerwerbungen der Heyne-Zeit nach Göttingen. Alle Wissensgebiete sind in der Sammlung vertreten, besonders zahlreich sind die Drucke antiker Autoren, etwa eine prächtig illuminierte frühe Ausgabe von Ciceros De officiis (Rom: Sweynheym und Pannartz 1469), die zweite Ausgabe von Caesars Kommentaren (Venedig: Jenson 1471) sowie die erste, vierte, fünfte und sechste Edition der Cosmographia des Ptolemaeus. Eine besondere Rarität stellen schließlich die beiden Caxton-Drucke dar, die aus der Harley-Sammlung stammen: The Dicts or sayings of the philosophers und The Mirror of the World, die englische Version des Werkes von Gossuin de Metz.

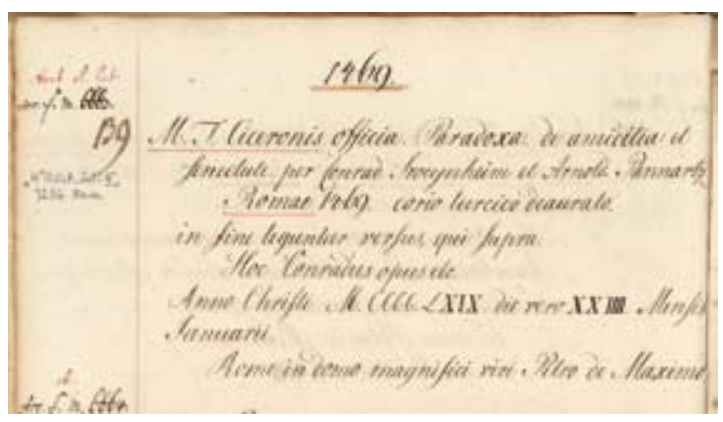

Katalog zur Bibliothek von Friedrich Wilhelm von Duve (1707-1785).

Wenige Jahre zuvor, am 19. April 1776, wurde die Büchersammlung des Rektors Johann Heinrich Stuß (* 1686 in Grone) in Gotha verkauft. Der gedruckte Katalog enthielt mehr als 1.750 Nummern, wovon die Göttinger Bibliothek 40 Nummern (63 Titel) erwerben 
konnte. Darunter befanden sich immerhin 33 Inkunabeln, und zwar vorwiegend theologisch-philosophische Werke des Mittelalters.

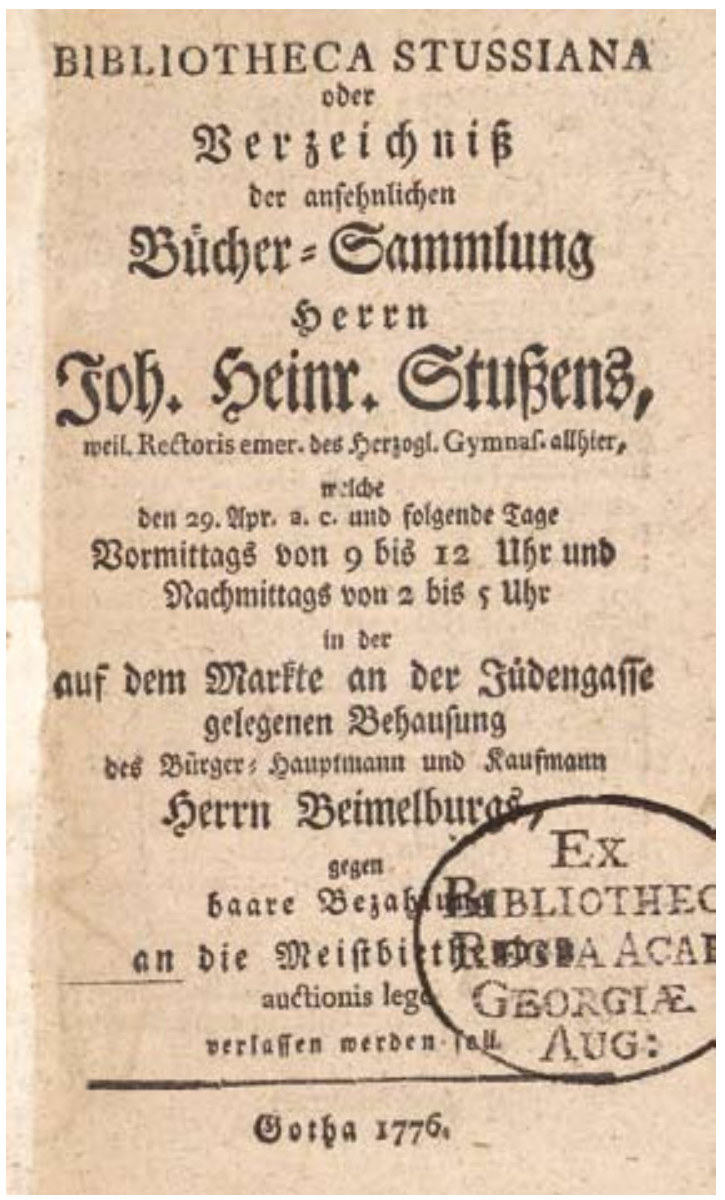

Auktionskatalog der Bibliothek Johann Heinrich Stuß.

Die Darstellung zur Chirurgie, die von dem Straßburger Arzt und Apotheker Hieronymus Brunschwig verfasst wurde, steht für die zahlreichen zusätzlichen Wissensgebiete, die in der Sammlung vertreten sind. Das hier erkennbare, sehr weit angelegte Sammlungsinteresse wird durch die Biographie aus der Feder seines Sohnes bestätigt: Stuß hing „auch bald seiner Begierde nach, einen eigenen Schatz von Büchern sich zu sammlen, und opferte derselben oftmals Bequemlichkeiten und Vortheile auf, besonders bey den häufigen Auctionen in Gotha. Er sahe seine Bücher für seine Güter, und ihre Verfasser für seine Freunde und Gesellschafter an. ... Jedesmal aber halfen ihm seine Bücherkenntniß und sein Gedächtniß, die Quellen, Nachrichten und Materialien, die er brauchte, geschwinde $\mathrm{zu}$ finden. Weil er nun auf diese Weise immer aus einem Felde der Gelehrsamkeit in das andere Lustreisen that, so bauete er sich zwar in keinem eigentlich an, war aber auch in keinem fremd“. 


\section{Der vierte Bibeldruck}

Biblia, lateinisch.

Mainz: Johannes Fust und Peter Schöffer, 14. VIII. 1462.

Signatur: $2^{\circ}$ Bibl. I, 6002 Inc. Rara

Provenienz: Friedrich Wilhelm von Duve, 1782

Nach dem Bruch mit Johannes Gutenberg führte Johannes Fust die Arbeit der Druckerei in Mainz fort mit Hilfe von Gutenbergs Mitarbeiter Peter Schöffer, der im Streit zwischen Fust und Gutenberg auf Fusts Seite getreten war und der technische Leiter der neuen Firma wurde. Schöffer stammte aus Gernsheim am Rhein, wo er um 1425 geboren wurde. In Erfurt immatrikulierte er sich für Theologie und Recht, betätigte sich jedoch danach als Schreiber und wirkte unter anderem als Kalligraph in Paris. 1452 stieß er zu Gutenberg, dessen wichtigster Schüler er wurde. Auch wenn die Details nur schwer zu ermitteln sind, so deutet doch viel darauf hin, dass Schöffer die Erfindungen Gutenbergs sehr eigenständig und konstruktiv weiterentwickelte. Das gilt nicht nur für die technischen Aspekte des neuen Handwerks. Auch bei der Gestaltung neuer Schriften zeigte sich Schöffer einfallsreich und stilsicher. Nicht zuletzt die Perfektion des Mainzer Psalters mit seinen vielen innovativen Elementen zeigt die Meisterschaft des Gutenbergschülers. Zu den prächtigen liturgischen Drucken dieser Jahre gehört auch die sogenannte 48zeilige Bibel von 1462. Für sie hatte Schöffer eine sehr schöne Gotico-Antiqua hergestellt, die gefälliger und leichter lesbar war als die konservative Textura der B42. Berühmt ist dieses Buch auch für das erste in einem Druckwerk enthaltene Signet der Produzenten. Fust und Schöffer begründeten damit eine sehr wirkungsmächtige Tradition in der Buchgeschichte. Ihre Erzeugnisse waren im Gegensatz zu denen Gutenbergs - damit nicht mehr anonym. Das deutet vor allem auf ein gut ausgeprägtes Selbstbewusstsein hin. In der Tat wusste Schöffer, was er konnte, und
Pnis boc opufculü Artificiola adimuêtione mp̉mendi feu caractery.andi-abfq calami exaracoin. ma cautate $M$ oguntī lic effigiatū. qad cuffobia corinduftric por ] ofiç fuift caué st Betrü fchoiflior be gernffxym cleriai oi: otrof eiuldem eft confunanuz. Anno ovii. ()). ccce.lxï. ] nvigria aflumpäisvirgomario.

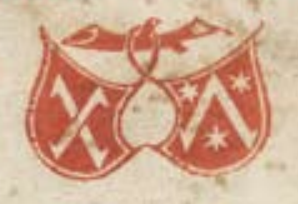

wurde darin durch seinen anhaltenden Erfolg auch regelmäßig bestätigt. Er ist einer der wenigen Frühdrucker, die mit handwerklichem Können, einer glücklichen Hand bei der Auswahl der Texte und kaufmännischem Geschick eine glänzende Karriere machten. Nach dem Tode Fusts 1466 und der Heirat mit dessen Tochter war er seit 1476 alleiniger Inhaber des erfolgreichen Unternehmens und engagierte sich - wiederum mit günstigem Ausgang - auf ganz anderen Geschäftsfeldern. Insgesamt hat Schöffer rund 250 Werke gedruckt und dabei das Niveau stets hoch gehalten. Als er kurz nach der Jahrhundertwende starb, waren drei seiner Söhne in seine Fußstapfen getreten und ebenfalls im Druckgewerbe tätig.

Das Göttinger Exemplar der B48 gehört mit dem Catholicon des Johannes Balbus zu den ältesten und wertvollsten Stücken der Sammlung Duve. Es hat einen Einband aus rotem Maroquin mit einer Vergoldung, die an den Harleian Style erinnert, doch stammt es wahrscheinlich nicht aus der Sammlung Harley.

(HR/JM) 


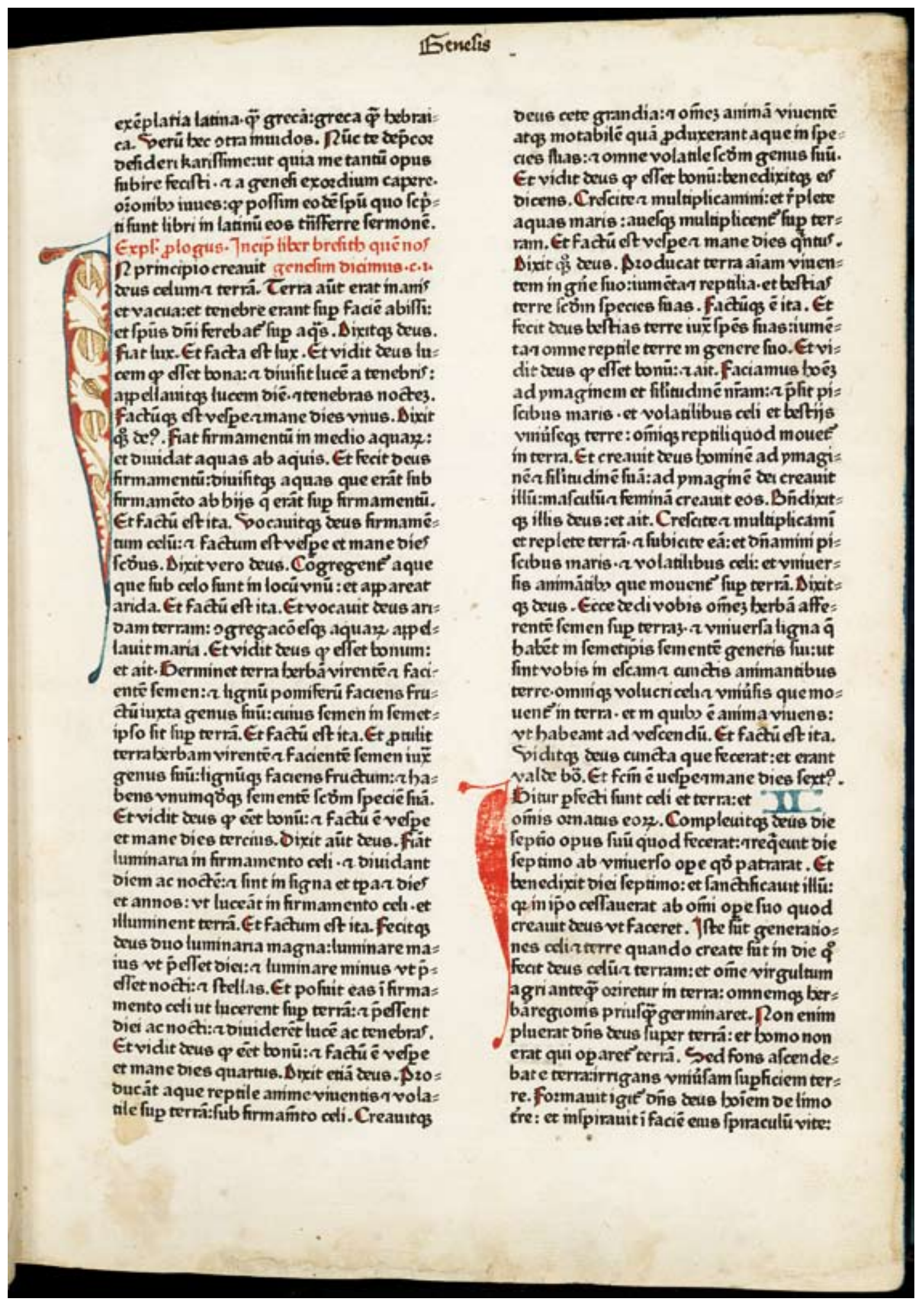




\section{Das Gute und das Nützliche}

Marcus Tullius Cicero:

De officiis etc.

Rom: Konrad Sweynheym und Arnold Pannartz, 24. I. 1469.

Signatur: $4^{\circ}$ Auct. Lat. II, 3236 Inc. Rara

Provenienz: Friedrich Wilhelm von Duve, 1782

In seinem letzten Werk De officiis, das er zwischen Oktober und Dezember 44 v. Chr. verfasst hat, stellt Cicero die Pflichten des Menschen aus ethisch-philosophischer Sicht dar. Das aus drei Büchern bestehende Werk, das dank seiner Lebendigkeit und seines inneren Reichtums einen großen Einfluss auf die Nachwelt ausgeübt hat, behandelt das Sittlich-Gute (honestum) im ersten Buch, das Nützliche (utile) im zweiten, und im dritten Buch diejenigen Situationen, in denen honestum und utile im Widerstreit liegen. Seine Beispiele, wie sich ehrenvolles Handeln auch im Gegensatz zum scheinbar Nützlichen durchhalten lässt, gewinnt Cicero aus der römischen Geschichte, indem er diesen Konflikt bei Cato oder den Scipionen beschreibt. Das Werk entstand vor dem Hintergrund einer Zeit der ,starken Männer“ - Pompeius und Caesar, Antonius und Octavian - in der Cicero selbst aus der aktiven Politik verdrängt war und einen Ausgleich in der philosophischen Schriftstellerei suchte. Die tiefe Einsicht des Werkes, die Sensibilität des Autors, sein Bemühen, aus griechischem Denken und römischem Handeln neue Maßstäbe zu erarbeiten und Verhaltensregeln für sich und andere zu entwickeln, verleihen dem Werk eine Menschlichkeit, die nur in wenigen Werken der Antike so unmittelbar zu erfahren ist wie in Ciceros De officiis.
Unter allen in der Inkunabelzeit gedruckten klassischen Autoren steht Cicero eindeutig an der Spitze. Fast die Hälfte aller Cicero-Drucke ging aus italienischen Pressen hervor. Die hier gezeigte erste Ausgabe von De officiis in der italienischen Gruppe wurde von den römischen Erstdruckern Konrad Sweynheym und Arnold Pannartz gedruckt, zwei Jahre nachdem sie ihre Buchdruckerei von Subiaco nach Rom verlegt hatten. Aus ihren in Rom gedruckten Werken selbst ist zu entnehmen, dass die beiden Drucker ihre Pressen im Hause der Brüder Petrus und Franciscus de Maximis (de Massimi - in der Nähe des Campo del Fiore) betrieben. Das vorliegende Exemplar von De officiis zeigt auf $\mathrm{Bl} .2^{\mathrm{r}}$ eine eindrucksvolle Ausmalung des Rankenwerks, das einen geschlossenen Rahmen um den Text bildet. 


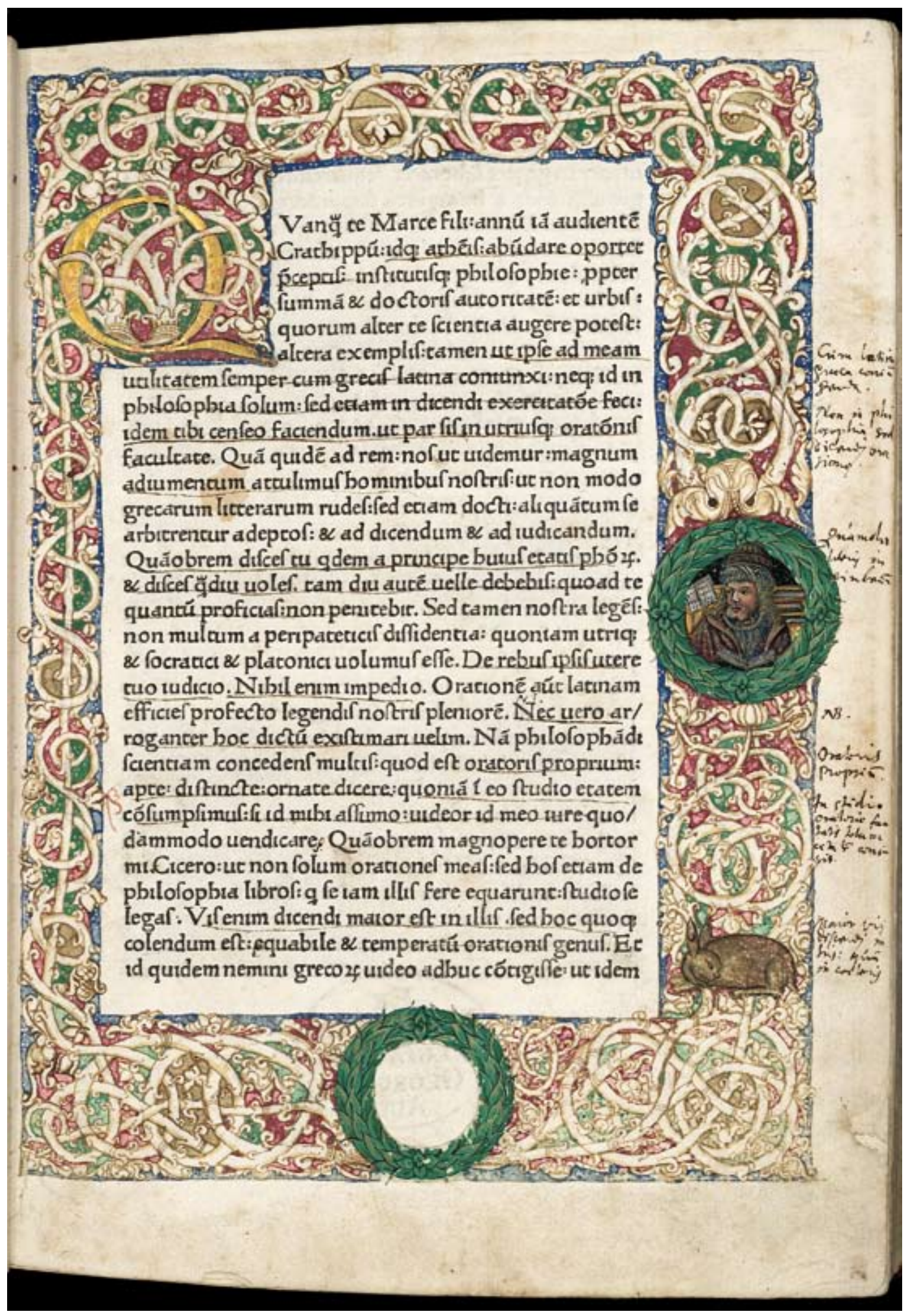




\section{Der erste deutsche Weltatlas}

Claudius Ptolemaeus:

Cosmographia, lateinisch.

Ulm: Lienhart Holl, 16. VII. 1482.

Signatur: $2^{\circ}$ Auct. graec. V, 4145 Inc. Rara

Provenienz: Friedrich Wilhelm von Duve, 1782
Im 2. Jahrhundert verfasste der alexandrinische Gelehrte Claudius Ptolemaeus eine theoretisch fundierte Darstellung der bekannten Welt in acht Büchern. Während die Erstausgabe der Cosmographia des Ptolemaeus 1475 noch ohne Landkarten gedruckt wurde, erschienen von 1477 bis zum Ende der Inkunabelzeit in Deutschland und Italien insgesamt sechs Ausgaben des ptolemaeischen Werkes mit Landkarten-Holzschnitten. Man kann diese Editionen deshalb schon als Atlanten bezeichnen. Die im Jahre 1482 in Ulm von Lienhart Holl gedruckte Ausgabe der Cosmographia ist der erste Weltatlas, der nördlich der Alpen hergestellt wurde, und mit seinen 32 Karten die bis dahin umfangreichste Ptolemaeus-Ausgabe. Sogar der Künstler, der die Holzstöcke für die Kartenbilder schuf, ist bekannt. Die doppelseitige Weltkarte ist mit „Insculptum est per Johannem Schnitzer de Armßheim" signiert: die erste namentlich gekennzeichnete Karte der Druckgeschichte. Johannes stammte aus Rheinhessen und war in Ulm als Formschneider tätig; der Beiname „Schnitzer“ ist nicht als Familienname, sondern als Berufsbezeichnung (Formschneider) zu verstehen. Als Urheber auch aller anderen Karten in Holls Ausgabe verrät ihn sein konsequent falsch geschriebenes Versal-,„N“.
Die Landkarten haben eine charakteristische trapezförmige Projektion, als deren Erfinder der deutsche Geistliche Nikolaus Germanus anzusehen ist. Im 15. Jahrhundert hat er in Italien für mehrere Fassungen des Ptolemaeus Karten in dieser Form entworfen. Die Darstellung der Gebirge, Gewässer und Landesgrenzen ist für die Zeit von erstaunlicher Exaktheit. Die sorgfältig kolorierten Karten, einige schöne Initialen am Beginn der Vorrede und des Textes, „Maiblumeninitialen“ und die italienisch anmutenden Einfassungsleisten um die Begleittexte machen den Ulmer Weltatlas zu einem typographischen Meisterwerk. Die Sorgfalt, mit der Lienhart Holl bei seinem Atlas zu Werke ging, zeigt sich neben der künstlerischen Ausstattung auch darin, dass er sich das Papier für den Druck aus Mailand besorgte und eigens für den Ptolemaeus eine übergroße, gut lesbare Antiqua-Type anschaffte. Trotzdem brachte dieser erste große Druck seiner Offizin nicht den gewünschten Erfolg. Er musste sich stark verschulden und einige Jahre später Bankrott anmelden.

$(\mathrm{HR} / \mathrm{JM})$ 


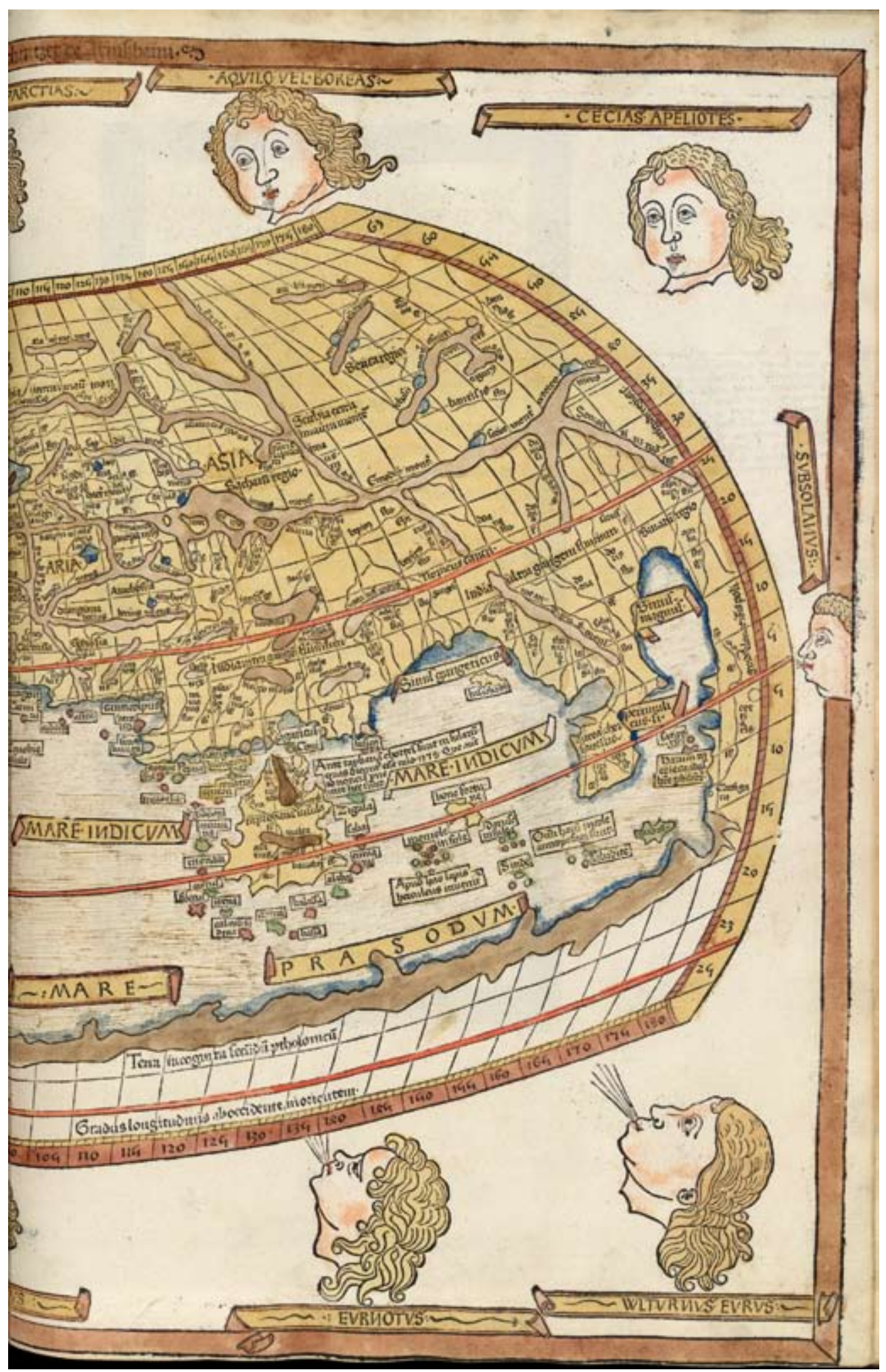




\section{Das erste in England gedruckte Buch}

Dicta philosophorum, englisch.

Westminster: William Caxton, 18. XI. 1477 [vielmehr um 1479].

Signatur: $4^{\circ}$ Philos. I, 6940 Inc. Rara

Provenienz: Friedrich Wilhelm von Duve, 1782

Vergleichsweise spät wandte sich der englische Erstdrucker William Caxton (1422-1491) der Kunst des Buchdrucks zu: Nach einer Lehre bei einem wohlhabenden Londoner Tuchhändler ließ er sich zunächst in Brügge als Kaufmann nieder, wo er einige Zeit der Gilde der englischen Kaufleute vorstand. Nachdem er 1469 von der Herzogin Margarete von Burgund den Auftrag erhalten hatte, die Receuils des histoires de Troye des Raoul Lefèvre († um 1467) ins Englische zu übertragen, vollendete er seine Aufgabe zwei Jahre später in Köln. In dieser Stadt erlernte er auch in der Werkstatt des Schriftgießers und Druckers Johann Veldener aus Utrecht das Druckereihandwerk. Die in Brügge um 1474 gedruckte Übersetzung The recueyll of the historyes of Troy ist das erste gedruckte Buch in englischer Sprache. 1476, mit mehr als 50 Jahren, zog Caxton nach England zurück und richtete in der Stadt Westminster seine erste Druckerei ein. Hier erschien am 18. November 1477 die Erstausgabe des Werkes The Dicts or sayings of the philosophers, eine umfangreiche Sammlung der wichtigsten Aussagen klassischer und orientalischer Philosophen der Antike und des Mittelalters. Die Übersetzung aus der französischen Vorlage stammt von Antony Woodville, dem Second Earl Rivers (1440-1483), Bruder der Gattin Edwards IV. und Erzieher der Kronprinzen; der Text wurde von Caxton, wie er selbst berichtet, kritisch durchgesehen und um einige von Rivers nicht übertragene Aussagen des Sokrates über die Frauen ergänzt.
Die hier vorliegende zweite Ausgabe wurde, obgleich sie dasselbe Druckdatum wie die Erstauflage trägt, vermutlich um 1479 veröffentlicht. Von dieser zweiten Ausgabe sind, abgesehen von einem Fragment, nur noch fünf Exemplare bekannt, von denen das Göttinger das einzige außerhalb Englands ist. Caxton druckte insgesamt etwa 90 Bücher, davon 74 in englischer Sprache. Etwa zwanzig fremdsprachige Werke übersetzte er selbst ins Englische. Besondere Verdienste hat er sich durch zahlreiche Ausgaben der Werke spätmittelalterlicher englischer Dichter erworben, vor allem mit Geoffrey Chaucers Canterbury Tales (1478). 


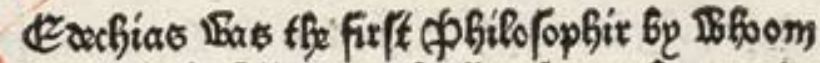
thozugh the Ibil ano? pleafer of ourr forde goor?

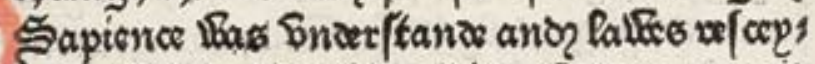

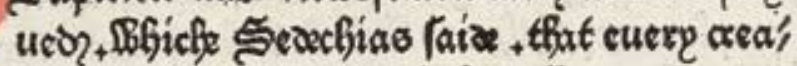

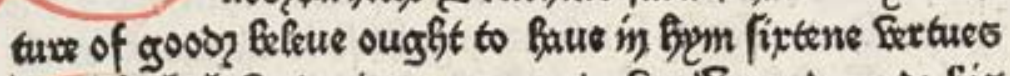
Ele firtt fertue is to osex ano? finolfe goon ano? fis !

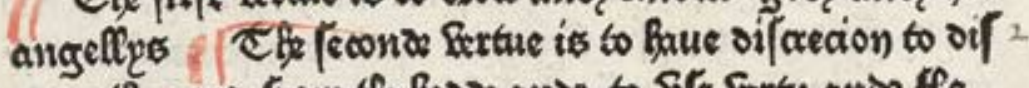

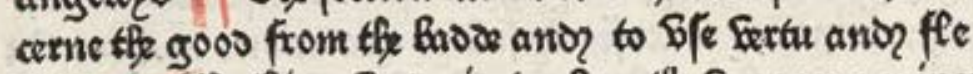

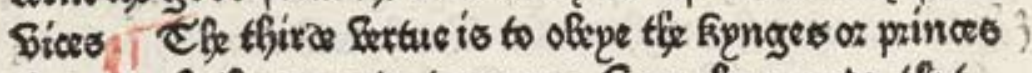
that goon hatf orrepneor to reegne fpon Gem ano? that

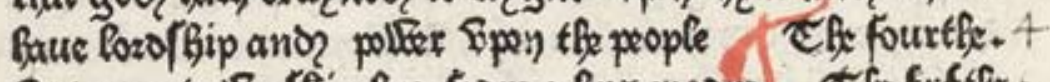

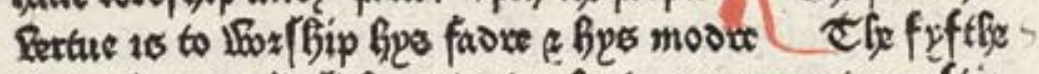
Sertue is to $20+$ J ult tolp ano truclp to eucrp areature aftir

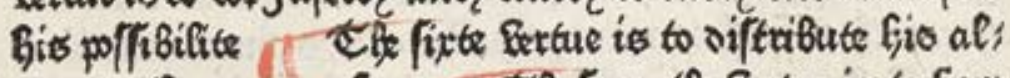
mes to the port people. If Ele feuentle fertuc is to fiepte antor of enx (traungers ano? pilgepmes (t) epg set fer tue is to Bpnos ano? atermine Gim felf to ferue onr foras

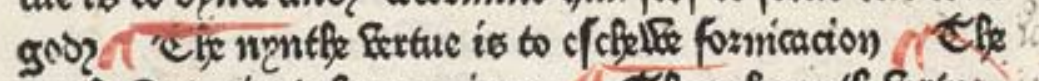

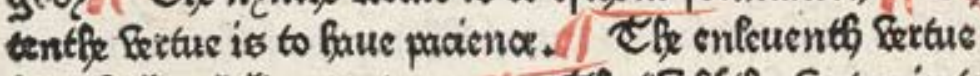

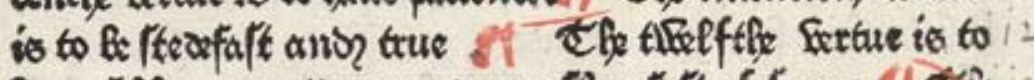

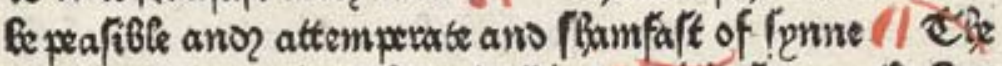

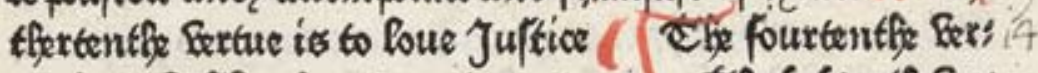

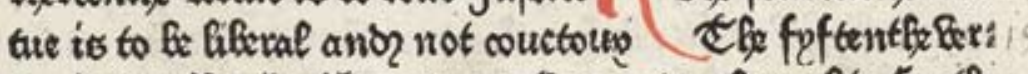
tur is to offer lacxifices to our loto goor almpghte for sfe

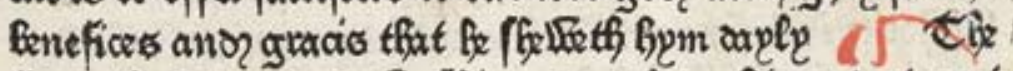
firtentfe fertue is to Ifort (bip goon almpghtp antor to put

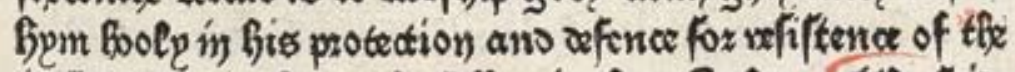

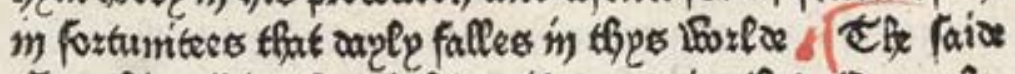
Soxchias faim that riggtas it aparteineth to the pople

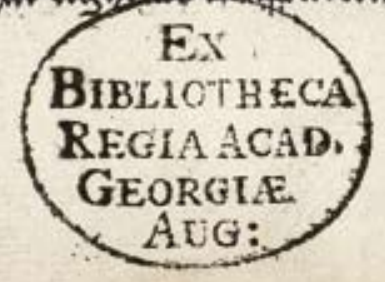




\section{Der Spiegel der Welt: eine volkstümliche Enzyklopädie}

Gossuin de Metz:

L’Image du monde, englisch.

Westminster: W. Caxton, [nach 8. III. 1480/81].

Signatur: $4^{\circ}$ Hist. un. II, 42 Inc. Rara

Provenienz: Friedrich Wilhelm von Duve, 1782

Das Werk geht zurück auf den französischen Schriftsteller Gossuin de Metz (13. Jahrhundert), der in dem didaktischen Epos seine Kenntnisse in der Geographie, Kosmogonie, Astronomie und Meteorologie zusammengetragen hat. Enzyklopädien dieses Typs waren im Mittelalter sehr weit verbreitet; das Werk ist in zahlreichen Handschriften erhalten und übte auf eine Reihe von spätmittelalterlichen Schriftstellern einen erheblichen Einfluss aus. Der englische Erstdrucker William Caxton übersetzte und druckte die hier vorliegende erste englische Ausgabe im Auftrag des Kaufmanns Hugh Bryce, Alderman der Stadt London. The Mirror of the World ist das erste illustrierte Buch, das in England gedruckt wurde. Im ersten Abschnitt des Werks finden sich Bemerkungen zur Astronomie und zur Beschaffenheit der Welt. Es wird deutlich gemacht, dass die Erde keine Scheibe, sondern rund sei: Es ist möglich, dass ein Mensch um die Erde herumgeht ,lyke as a flye goth round about a round apple.“

Im englischen Königreich fasste der Buchdruck erst relativ spät Fuß. In mehr als 70 Städten in acht Ländern Europas bestanden schon Druckereien, als William Caxton 1476 in Westminster die erste englische Presse einrichtete (Caxton hatte das Druckerhandwerk in den Jahren 1471 und 1472 in der Stadt Köln erlernt). Deshalb ist es nicht verwunderlich, dass es nur verhältnismäßig wenige englische Inkunabeldrucke gibt: Bis zum Ende des 15. Jahrhunderts sind kaum mehr als 370 - zumeist übrigens volkssprachliche Werke erschienen. Die erkennbare Nähe zum niederländischen Wiegendruck zeigt sich darin, dass die drei bedeutendsten englischen Drucker der Inkunabelzeit - William Caxton, Wynkyn de Worde und Richard Pynson - die in Holland weit verbreitete Bastarde als Drucktype verwendeten. Der Frühdruck in England war nicht nur für die Verbreitung der volkssprachlichen Texte von großer Bedeutung, er trug auch ganz maßgeblich zur Ausbreitung eines sprachlichen Standards bei, denn bis zum Beginn des 15. Jahrhunderts war die englische Literatur noch stark dialektal geprägt.

Das Göttinger Exemplar des Mirror of the World enthält auf dem Schlußblatt die handschriftliche Eintragung „Roberte ... Spensar ... 1525“. Das Buch wurde später in die berühmte Sammlung Harley aufgenommen, mit der es 1743 in den Besitz des Londoner Buchhändlers Thomas Osborne gelangte, der den Harley-Bestand ab 1747 einzeln abgab. Dadurch geriet der Caxton-Druck in den Besitz des Hofrats Friedrich Wilhelm von Duve in Hannover. 


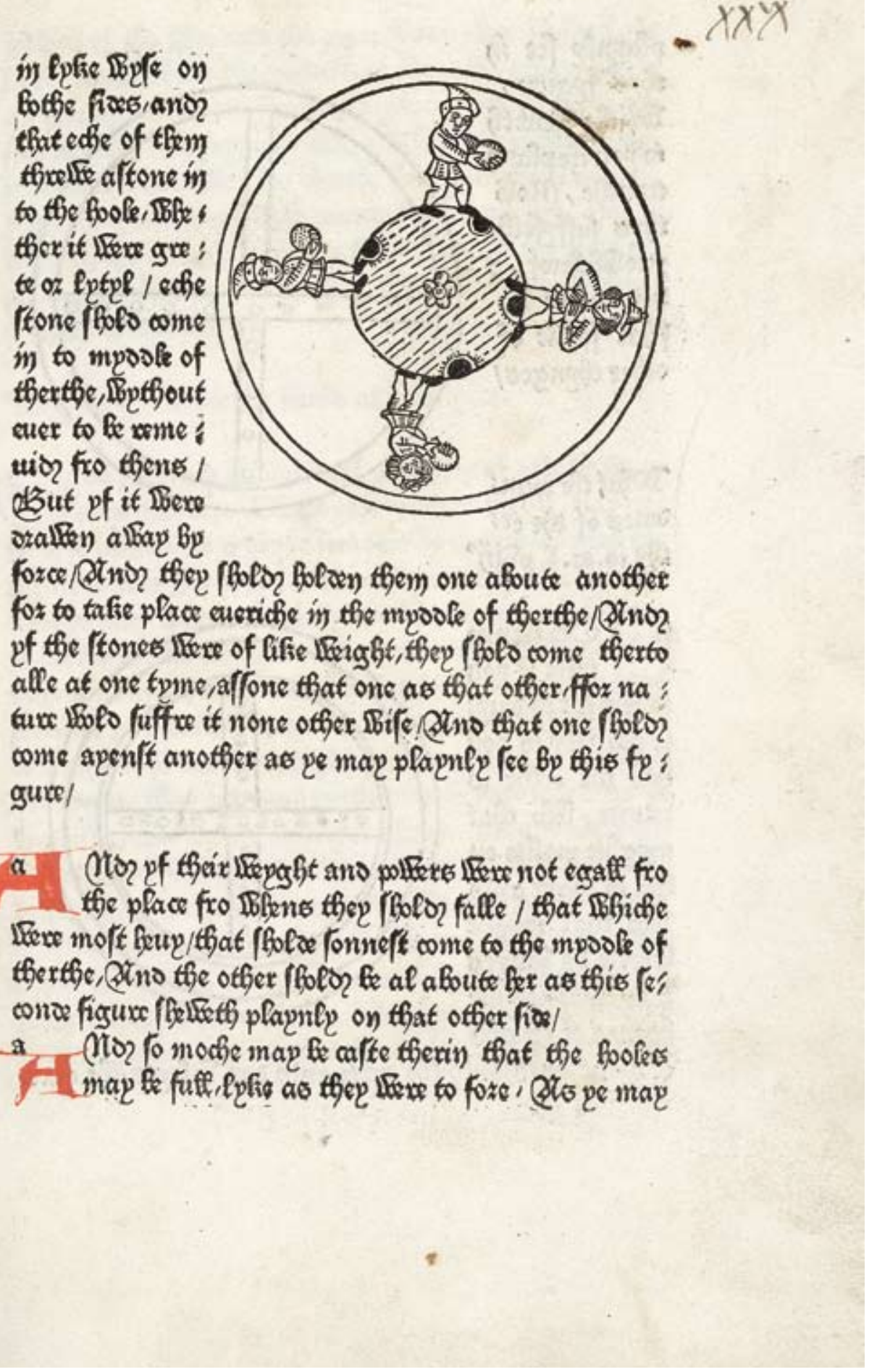




\section{Italienische Vergil-Handschrift}

Publius Vergilius Maro:

Opera.

Pergamenthandschrift,

Italien, 15. Jahrhundert.

Signatur: $8^{\circ}$ Cod. Ms. philol. 116 Cim.

Provenienz: Johann Georg Wilhelm Köhler, 1792

Mit der Erfindung des Buchdrucks unter Verwendung beweglicher Lettern durch Gutenberg und der raschen Ausbreitung dieser Technik in anderen europäischen Ländern verschwand die herkömmliche Art der mittelalterlichen Buchherstellung keineswegs von der Bildfläche. Lange Zeit standen gedruckte Bücher und handschriftlich vervielfältigte Kodizes nebeneinander und gelegentlich in direkter Konkurrenz zueinander. So ist es keineswegs erstaunlich, dass um 1470 herum noch Handschriften in der hier gezeigten Art entstanden. Über das Zustandekommen der Handschrift wissen wir das Folgende aus der lateinischen Schlussschrift, die heute zwar kaum noch lesbar ist, aber schon im 18. Jahrhundert von den damaligen Besitzern der Handschrift wiedergegeben wurde: Der Priester Georg aus Novara habe diese Werke Vergils in Rom bei der Basilika des Apostels Petrus, das meiste aber bei der Heiligen Kirche des berühmten Märtyrers Georg im Land von Bergamo abgeschrieben, als Paul II. Papst (1464-1471) und Christoforo Moro Doge der Republik Venedig (1462-1471) waren. Damit ist der Zeitpunkt der Entstehung auf die Jahre zwischen 1464 und 1471 einzugrenzen. Georg stellte auf 210 Pergamentblättern die größeren und kleineren Werke Vergils zusammen, fügte auch Vergil zugeschriebene Gedichte der Anthologia Latina hinzu. Auffallend sind die im Vergleich zu anderen italienischen Handschriften eher ungewöhnlichen Initialen. Ihre individuellen Verzierungen zeigen zumeist florale Elemente oder erinnern an Edelsteine, wie hier zu sehen ist: An dem in einem Quadrat eingeschriebenen großen „A“ rankt

ein Weinstock, eingefasst von geometrischen Verzierungen. Diese Initiale markiert den Beginn des ersten Buches der Aeneis Vergils, des römischen Nationalepos. Vergil schilderte in diesem Werk die Flucht des Helden Aeneas aus Troia und seine abenteuerliche Reise bis nach Italien. Von ihm leiteten die Römer ihre Herkunft ab. Die kleinere Initale „A“ darüber leitet ein kurzes Gedicht ein, das aus einer kleinen Folge von Versen aus der Anthologia Latina stammt. Zu jedem Buch der Aeneis sind hier kurze, dem römischen Dichter Ovid zugeschriebene Inhaltsangaben in Gedichtform verfasst.

Im 18. Jahrhundert gehörte die Handschrift der in Ansbach und Jena ansässigen Familie Köhler. 1792 übernahm sie die Universitätsbibliothek. Christian Gottlob Heyne erwähnte sie in der Einleitung zu seiner Vergilausgabe. 


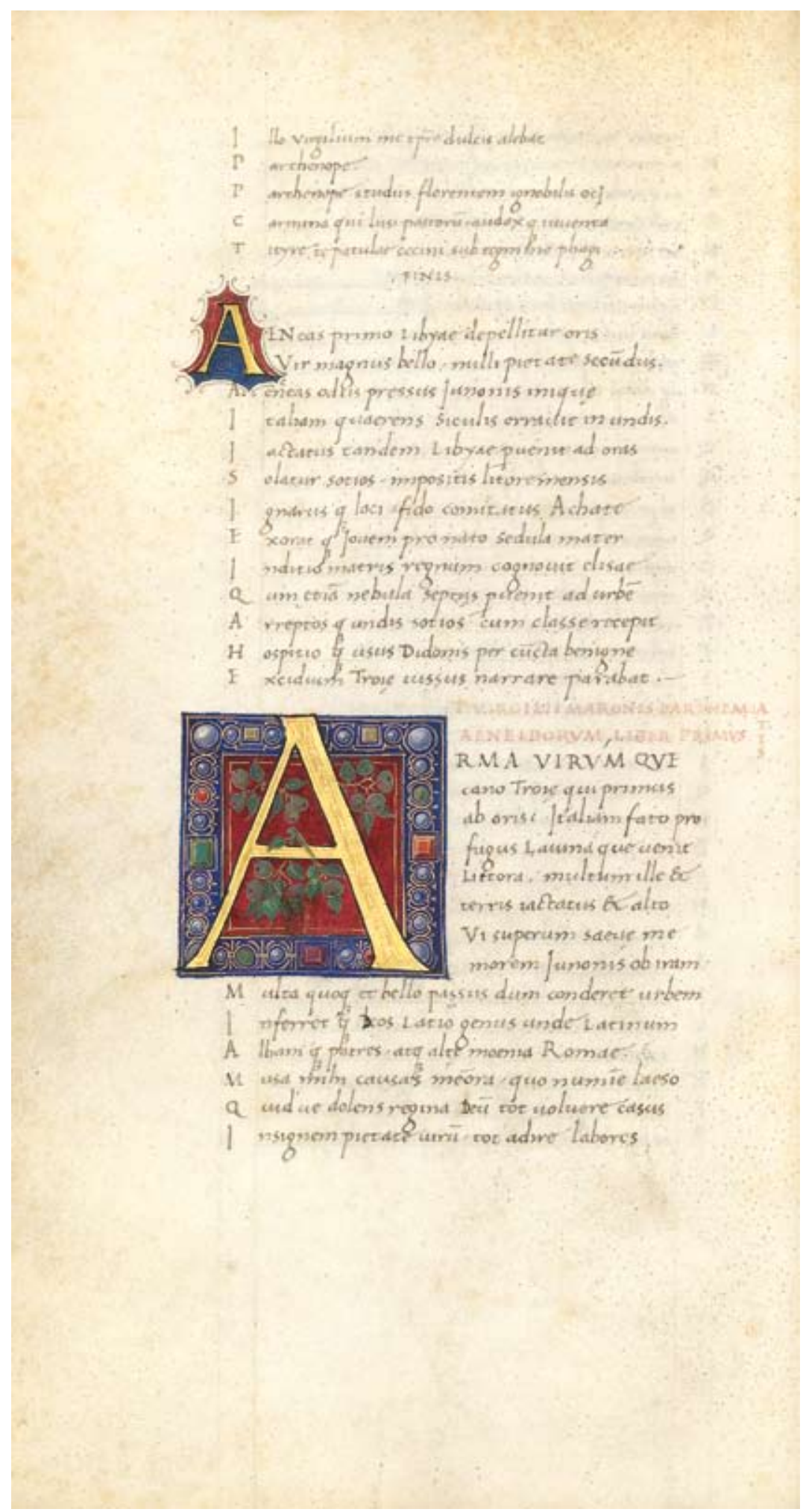




\section{Eine hussitische Bildsatire aus dem 15. Jahrhundert}

Illuminierter Hussitenkodex, tschechisch.

Papierhandschrift,

Böhmen, 2. Hälfte 15. Jahrhundert.

Signatur: $2^{\circ}$ Cod. Ms. theol. $182 \mathrm{Cim}$.

Provenienz: David Gottfried Schoeber, 1776
Der durchgängig illuminierte, in tschechischer Sprache verfasste Kodex gehört zu den wenigen erhaltenen bildnerischen Werken des frühreformatorischen Hussitentums. Die 43 Papierblätter umfassende Handschrift entstand vermutlich in den 60er Jahren des 15. Jahrhunderts im Auftrag eines Vertreters der Utraquisten. Sie ist eine von nur zwei bisher bekannten Bildsatiren, die den Gegensatz zwischen dem unverdorbenen Urchristentum und der verderbten zeitgenössischen Kirche gestalten. Die zweite Handschrift, den Jenaer Kodex, seit 1548 im Besitz der Jenaer Universitätsbibliothek, übergab Wilhelm Pieck anlässlich seines ersten Staatsbesuches 1951 in der Tschechoslowakei nach Prag; sie wird seitdem im dortigen Nationalmuseum verwahrt. Beide Werke gehen auf ältere Vorlagen zurück, die ihrerseits auf Schriften des hussitischen Gelehrten Nikolaus von Dresden fußen, vor allem auf dessen Traktat Tabulae veteris et novi coloris seu cortina de antichristo (1412).

In didaktischer Zielsetzung stellt die Handschrift dem tugendhaften Leben Christi und seiner Jünger, aber auch anderer biblischer Gestalten und Heiliger, den verfehlungsreichen Lebenswandel der zeitgenössischen Geistlichkeit gegenüber; angeprangert werden etwa das weltliche Besitz- und Machtstreben der Kirche, der Missbrauch ihrer Autorität, die Unkeuschheit des Klerus, Kleiderordnung und Idolatrie. Die einfachen, derben, spärlich kolorierten Federzeichnungen beschränken sich zumeist auf die Darstellung einer knapp umrissenen Szene, in der handelnde Personen im Mittelpunkt stehen. Ihnen sind kurze Texte beigegeben, Zitate aus der Bibel und anderen Schriften sowie knappe Erläuterungen und Glossen zur dargestellten Handlung. Historisch verbürgt ist ein Bericht über den Mord eines Priesters an seinem eigenen Kind (Bericht Zděnek Kostkas auf dem außerordentlichen Landtag zu Prag 1462); außerdem enthält der Kodex dokumentarische Schilderungen aus der hussitischen revolutionären Bewegung.

Aufgeschlagen ist $\mathrm{Bl}$. 35 , das den unkeuschen Lebenswandel der Ordensgemeinschaften zum Inhalt hat: ,Viele scheinen den Menschen heilig zu sein, doch vor Gott sind sie verdammt“, wie eine an zentraler Stelle des Bildes angebrachte Inschrift lautet. In der Mitte eines Klostergartens sitzen eng umschlungen ein Mönch und eine Nonne. Links von ihnen steht der „Baum des sündigen Verlangens der Nonnen“, aus denen Nonnen sich Mönche, rechts von ihnen der „Baum der Unzucht der Mönche“, aus denen Mönche sich Nonnen schütteln. Auf dem gegenüberliegenden $\mathrm{Bl}$. 34v ist Joseph dargestellt, der sich der ihn am Kleidersaum ziehenden Gattin des Potiphar widersetzt (vgl. 1 Mose 39). 


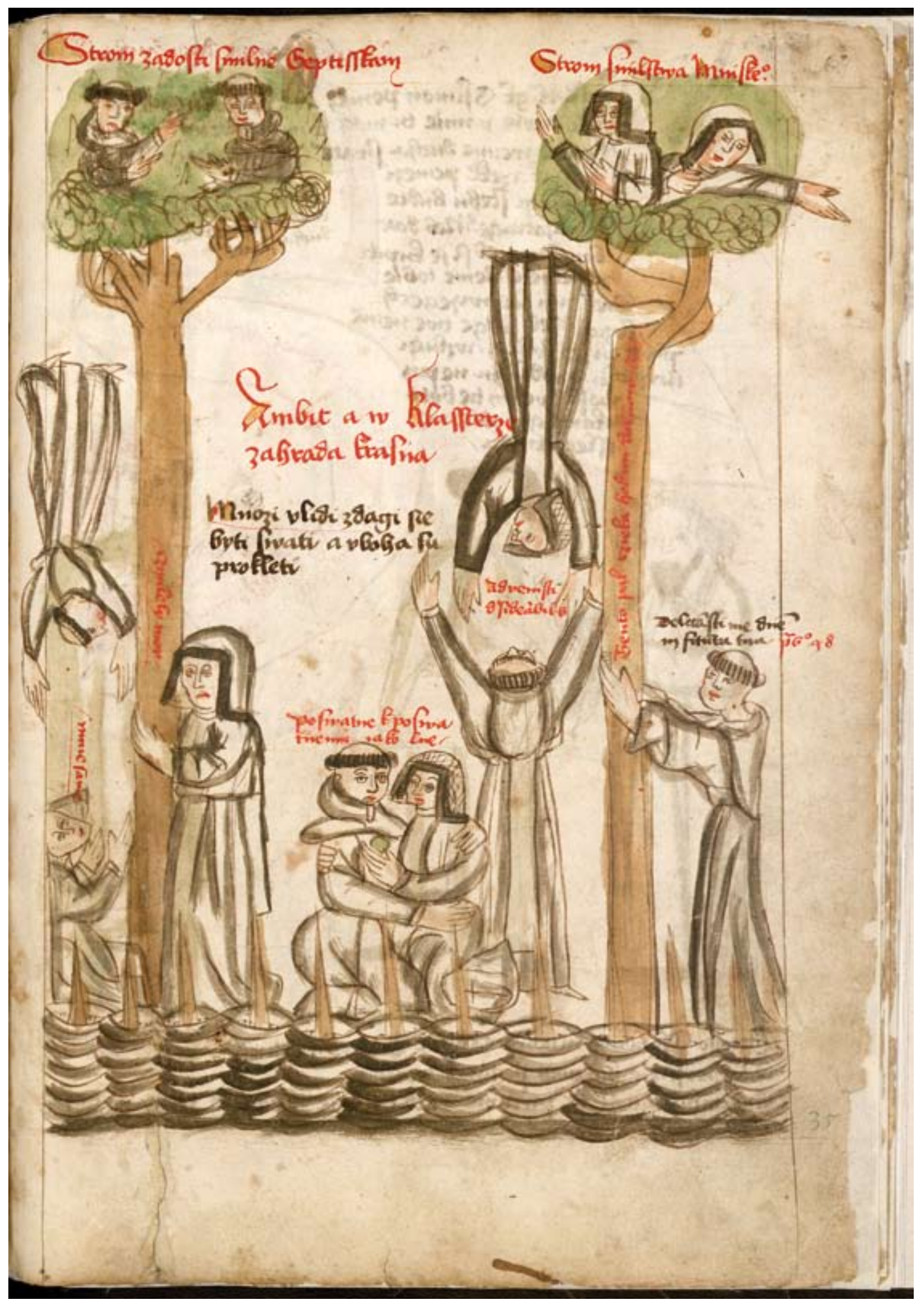




\section{Vom Sturz berühmter Männer}

Giovanni Boccaccio:

De casibus virorum illustrium, englisch. London: Richard Pynson, 27. I. 1494.

Signatur: $4^{\circ}$ Hist. un. I, 1285 Inc. Rara

Provenienz: H. G. Goltermann, 1837

Der aus Suffolk stammende John Lydgate (ca. 1370-ca. 1450) verbrachte den Großteil seines Lebens seit etwa 1385 als Mönch, seit 1397 als Priester in der Benediktiner-Abtei Bury St. Edmunds. Vermutlich durch ein Studium in Oxford umfassend gebildet und als großer Bewunderer seines Zeitgenossen Geoffrey Chaucer (um 1343-1400) selbst literarisch ambitioniert, schuf er im Auftrag oder mit der Unterstützung der Könige Heinrich IV., Heinrich V. und Heinrich VI., vor allem aber seines Gönners Humphrey, Herzog von Gloucester, des einflussreichen Sohnes Heinrichs IV., ein umfangreiches dichterisches Werk, das ihn zum im 15. Jahrhundert produktivsten englischen Schriftsteller werden ließ. Anregungen für seine Werke entnahm Lydgate Standardwerken der mittelalterlichen Literatur: So diente ihm Guido de Columnis (1210-1287) Historia destructionis Troiae als stoffliche Hauptquelle des Troy Book (1412-1420) und - über weitere Prosabearbeitungen - der altfranzösische Roman de Thèbes als Anregung für The Siege of Thebes (1421), eine Huldigung an sein Vorbild Chaucer. Zwischen 1431 und 1438/39 war Lydgate im Auftrag des Herzogs von Gloucester mit einem Werk beschäftigt, das mit 36.365 Verszeilen eine selbst für seine Maßstäbe gewaltige und tatsächlich seine umfangreichste Arbeit bleiben sollte. The Fall of Princes, auf der Grundlage einer französischen Prosaübertragung Laurent de Premierfaits (1409) verfasst, stellt eine Versübersetzung von Giovanni Boccaccios (1313-1375) De casibus virorum illustrium (1356-1360) dar. Lydgates Interesse galt einem Buch, das einen
Höhepunkt innerhalb der mittelalterlichen De-Casibus-Literatur darstellt und bis zum 16. Jahrhundert eine höhere Bekanntheit als Boccaccios Meisterwerk, der Novellenzyklus Il Decamerone, genoss. Das Werk schildert in neun Büchern das Schicksal berühmter Männer und Frauen aus der Mythologie und Geschichte, die von höchster Macht in tiefstes Unglück stürzen, und verleiht so dem mittelalterlichen Topos vom Glücksrad der - im Werk selbst als Figur auftretenden - Fortuna sinnfälligen Ausdruck.

Den Druck der englischen Erstausgabe besorgte der aus der Normandie stammende Richard Pynson (1449-1529), der um 1490 in London zu drucken begann und bereits wenige Jahre später mit seinem Konkurrenten, dem Caxton-Nachfolger Wynkyn de Worde († 1532), das englische Druckwesen dominierte. Aufgeschlagen ist eine Holzschnittillustration zum Aufstieg und Fall des alttestamentarischen Königs Saul.

(SG) 


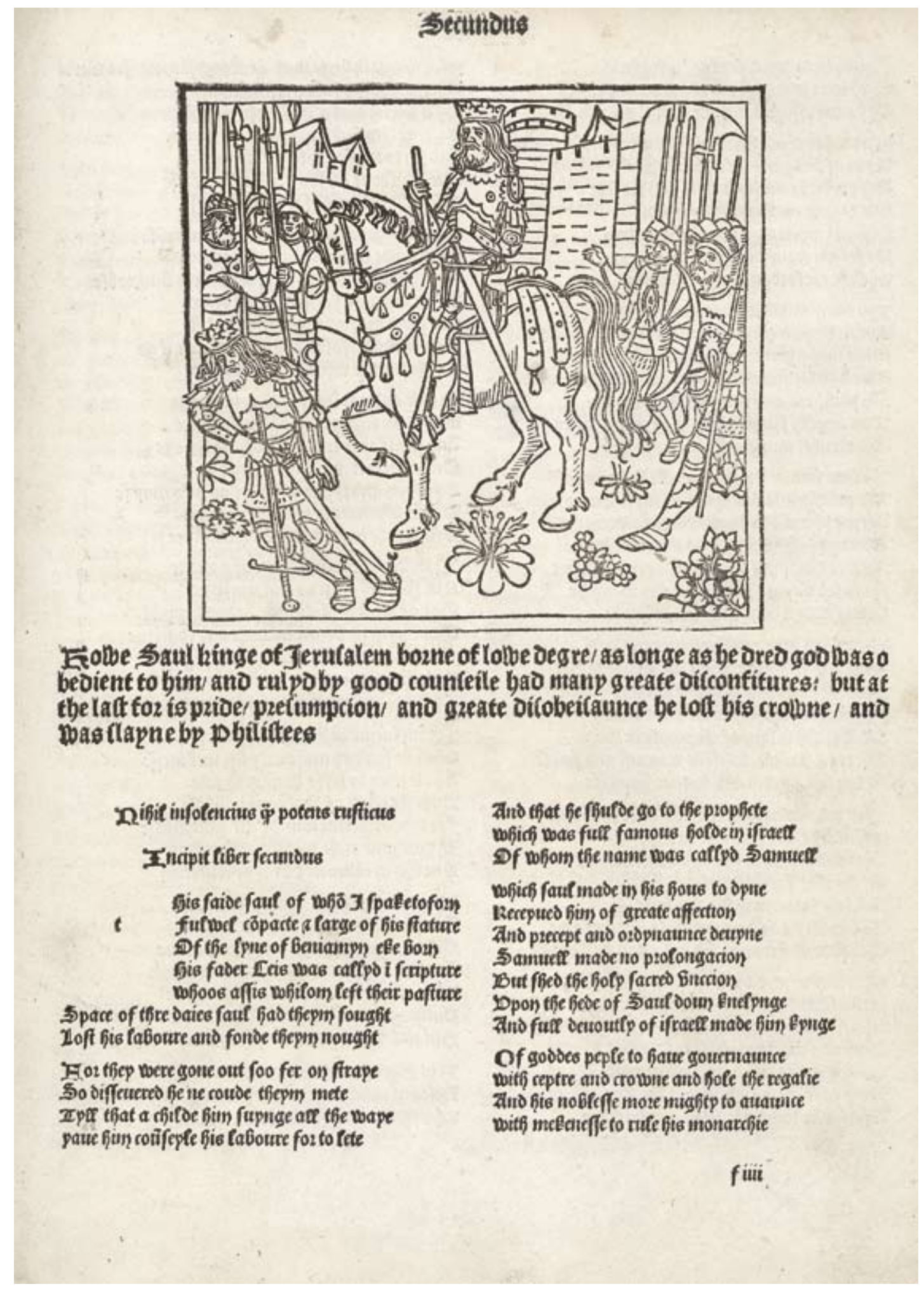




\section{Das erste wissenschaftliche Lehrbuch in der Wundarzneikunde}

Hieronymus Brunschwig:

Chirurgia.

Straßburg: Johann Grüninger, 4. VII. 1497.

Signatur: $4^{\circ}$ Med. chir. I, 13060 Inc.

Provenienz: Johann Heinrich Stuß, 1776

Der Straßburger Wundarzt Hieronymus

Brunschwig (1450-1512) hat sich auf verschiedenen Gebieten Verdienste erworben:

Im Jahre 1500 erschienen zwei Arbeiten zur Arzneimittelkunde, der Liber destillandi de simplicibus und der Liber pestilentialis de venenis epidimie. Als Brunschwigs pharmakologisches Hauptwerk gilt der 1512 gedruckte Liber de arte distillandi de compositis (s. Nr. 37). Mit seiner bereits im Jahre 1497 bei dem Straßburger Drucker Johann Grüninger verlegten Chirurgia entstand ,das erste deutsche Lehrbuch in der Wundarzneikunde, das Anspruch auf Wissenschaftlichkeit erheben konnte“ (Probst). Das Werk besteht aus sieben Traktaten, die in systematischer Anordnung typische Verletzungserscheinungen beschreiben und Anweisungen zu ihrer Therapie geben. Seine Kapitel sind den ethischen Maximen des Arztberufes, der allgemeinen und der speziellen Chirurgie, stumpfen Verletzungen, Knochenbrüchen, Verrenkungen und der Arzneikunde gewidmet. Sie beinhalten auch die Behandlung von Verletzungen, die durch Leibesstrafen, Folter und - sofern der Patient sie überlebt hatte - Hinrichtungen wie das Rädern oder Henken entstanden waren. Den Ausführungen sind exakt ausgeführte, im Göttinger Exemplar kolorierte Holzschnitte beigefügt. Sie stellen zumeist eine Begegnung des Arztes bzw. einer Gruppe von Medizinern und eines Patienten mit einer jeweils spezifischen Verletzung dar. Im Falle des gezeigten Holzschnittes, der dem Traktat über Themen der speziellen Chirurgie entnommen ist, steht zu hoffen, dass er dazu dient, einen summarischen Überblick über den Inhalt des
Kapitels zu geben. Es behandelt Kopfwunden mit und ohne Schädelverletzungen, Gesichtsund Halsverletzungen sowie verschiedene Wunden an Armen, Rumpf, Bauchorganen, Beinen, Füßen und Zehen.

Der große Erfolg der Chirurgia veranlasste den Augsburger Nachdrucker Johann Schönsperger dazu, bereits im Dezember 1497 einen Nachdruck vorzulegen, der einige Korrekturen des Originals beinhaltete. Grüningers Antwort bestand darin, seine Ausgabe der Chirurgia durch Brunschwigs Traktat von der Anatomia zu ergänzen, um so die Verkaufsaussichten des Plagiats zu verringern.

(SG/HR) 


\section{İas XVI capitel bes ozitten tractat;}

\section{预as XVI. capitel oís oríten tractat; 2vurt}

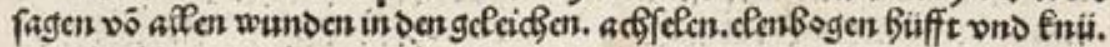

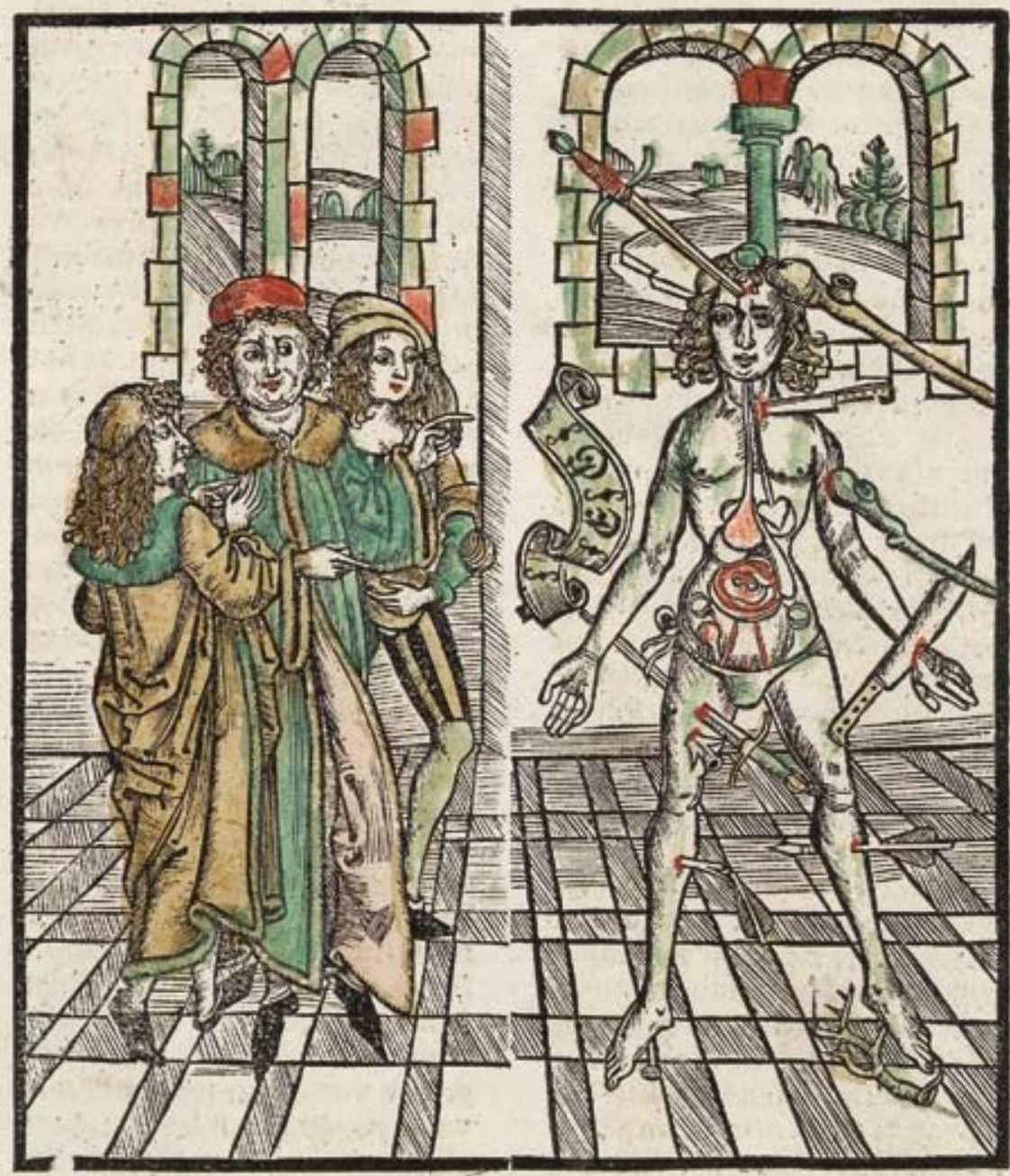

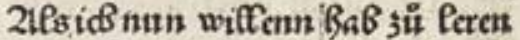
von affen wumben-vnd yie 3uifette. su curicen vnd $a b$;

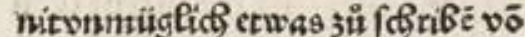
Gen fabelen ier temaine f ferer Pie Sergofert $\bar{c}$ Oifer funft. pii nuir offe 


\section{Kapitel 10}

\section{In Dankbarkeit verbunden - Schenkungen Ehemaliger}

Im Jahre 1772 traf in Göttingen ein Schreiben aus Russland ein, das folgenschwere Konsequenzen haben sollte: Der russische Baron Georg Thomas von Asch (1729-1807), der von 1747 bis 1750 an der Georgia Augusta Medizin studiert hatte und in Russland zu hohen Ämtern im russischen Gesundheitswesen aufgestiegen war, brachte seine tiefe Dankbarkeit der Hochschule und ihrer Bibliothek gegenüber zum Ausdruck: „C’est avec une satisfaction toute particulière ... que je me rapelle avoir été il y a vingt demi ans, citoyen de Votre illustre academie: que c'est aux leçons des hommes les plus célèbres de ces temps là ainsi qu'au libre accès dans Votre Bibliothèque que je dois les connoissances qui m’ont fait parvenir ... au grade de Premier Medecin de l'Armée Impériale de Russie". Mit diesem Brief sandte Asch als Zeichen seiner Verbundenheit eine erste Kiste mit Büchern und Handschriften nach Göttingen. Die Sendung bildete den Beginn einer bis zum Tode Aschs währenden Korrespondenz mit Christian Gottlob Heyne, in deren Verlauf der Alumnus der Göttinger Universität eine Vielzahl von seltenen und kostbaren Büchern und Drucken, Handschriften, Karten (unter ihnen unikale Karten der russischen Sibirienexpeditionen), Kunstwerken und Forschungsgegenständen aller Art nach Göttingen sandte. Sie verdanken sich den weitreichenden Beziehungen des russischen Mediziners zu einem regelrechten Netzwerk von im Russischen Reich wirkenden Wissenschaftlern, aber auch seiner eigenen Tätigkeit als Generalstabsarzt während des 1 . Russisch-Türkischen Krieges. Die in der Universitätsbibliothek ursprünglich als Bibliotheca Aschiana aufgestellten etwa 2.000 Bücher, 1883/84 in den allgemeinen Bestand eingearbeitet, bilden den größten Teil der Schenkungen und begründeten den Ruf der Göttinger Bibliothek als einer einzig- artigen Sammlung der slawischen Literatur des 18. Jahrhunderts. So erscheint es kaum übertrieben, wenn Heyne in seinem Nachruf auf Asch vermerkt: „Immer wenn uns die Meldung erreichte, dass neue Schätze ... bereitet und abgesandt waren, dann haben schon alle gejubelt, - welche Erwartungen, welche Ungeduld. Wenn sie ankamen, wie groß war dann die Bewunderung der Freigebigkeit dieses Mannes, wie haben sie ihn gelobt. Durch die ganze Akademie ist dann dieses Lob gedrungen“.

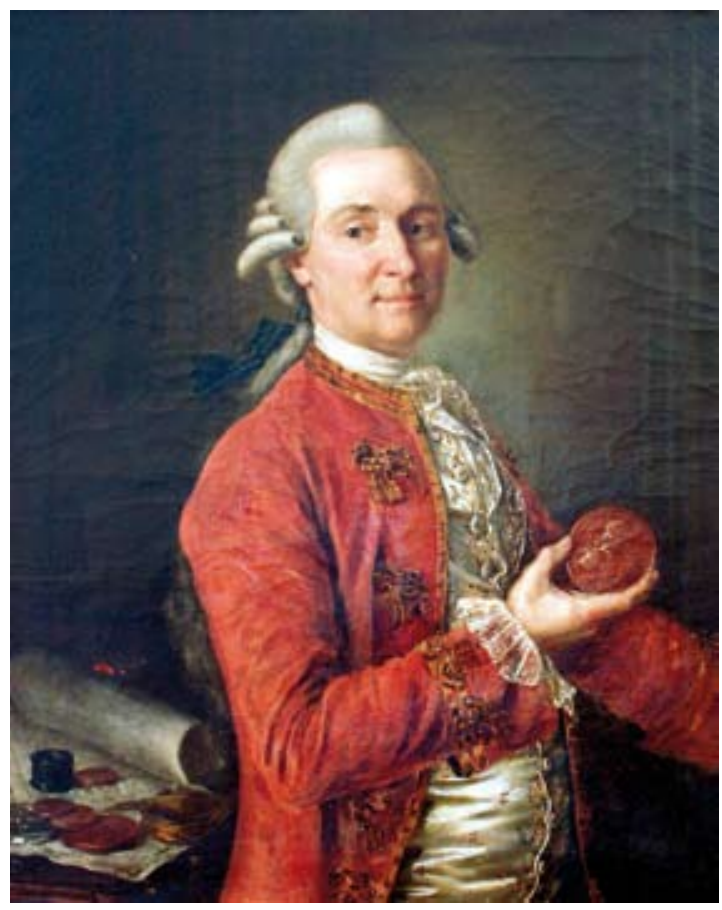

Georg Thomas von Asch (1729-1807).

Asch sollte zwar der (bislang) größte Förderer der Göttinger Universitätsbibliothek, aber selbstredend nicht ihr einziger bleiben. So erfuhr die Kartensammlung der Bibliothek im Jahre 1887 eine beträchtliche Erweiterung. Fünf Jahre vor seinem Tod hatte ihr der 
Direktor der Bremer Navigationsschule Arthur Breusing (1818-1892) seine Sammlung kostbarer Atlanten und Karten zum Geschenk gemacht. Die Sammlung ging auf sein starkes Interesse an der Geschichte der Geographie und Kartographie zurück, einem Themengebiet, zu dem er zahlreiche Veröffentlichungen verfasste. Breusing hatte von 1841 bis 1847 an der Georgia Augusta studiert und sich neben mathematischen und astronomischen Studien auch der Philologie und anderen Wissensgebieten gewidmet. 1861 war er hier zum Doktor der Philosophie promoviert worden.

Im beginnenden 20. Jahrhundert war es der amerikanische Bankier John Pierpont Morgan (1837-1913), dem die Göttinger Bibliothek wertvolle Bestandszuwächse verdankt. Der aus einer wohlhabenden Bostoner Familie stammende Morgan studierte 1856 Mathematik und Chemie an der Göttinger Universität, die er nach eigenem Bekunden für „the greatest and finest in Germany" hielt. Nach seiner Rückkehr in die Vereinigten Staaten begann seine beispiellose Karriere als Bankier, die ihn schließlich zu einem der wohlhabendsten und einflussreichsten Männer im Lande machte. Schon früh begann er, sein Vermögen in den Ankauf wertvoller Kulturgüter aus Europa zu investieren, und ließ aufwändig gestaltete Kataloge seiner Sammlungen anfertigen. Größere Summen seines Vermögens verwandte Morgan zugunsten künstlerischer Projekte. So ermöglichte er dem Photographen Edward Sheriff Curtis (1868-1952) die Drucklegung seines Werkes The North American Indian. Als Gegenleistung erhielt John Pierpont Morgan 25 Exemplare der limitierten Auflage, von denen er die meisten an Bibliotheken verschenkte. Das Exemplar mit der Nr. 8 ging an die Göttinger
Bibliothek. Im Jahre 1912 veranlasste Morgan schließlich, dass der Bibliothek ein Scheck über $\$ 50.000$ zugewiesen werden solle. Mit dem Kapital, das einem Gegenwert von knapp 200.000 Reichsmark entsprach, wurde 1913 an der Bibliothek die John Pierpont Morgan Foundation begründet, deren Zinsen der Anschaffung amerikanischer und englischer Bücher dienen sollten. In einer Zeit, in der es kaum möglich war, den Literaturbedarf der Universität zu befriedigen, konnte so die seit dem 18. Jahrhundert entstandene, außergewöhnlich reichhaltige Sammlung angloamerikanischer Literatur weiter aufgebaut werden: Zwischen 1913 und 1920 wurden mehr als 2.500 Titel erworben, darunter auch eine Reihe antiquarischer Ergänzungen. Leider sollte sich die Stiftung als kurzlebig erweisen: Die Zeichnung von Kriegsanleihen auf das Kapital im Ersten Weltkrieg, die Inflation der Zwischenkriegsjahre und die Verwendung des Geldes für Sammlungen des Winterhilfswerkes im Zweiten Weltkrieg dezimierten das Stiftungsvermögen immer mehr. Das verbleibende Sondervermögen wurde 1967 aufgelöst.

Ihre wichtigste Schenkung der Nachkriegszeit erhielt die Göttinger Bibliothek im Jahre 1953 mit der Sammlung des 1951 verstorbenen Ministerialdirektors Oskar Mulert (1881-1951), des früheren Präsidenten des Deutschen und Preußischen Städtetages. Die Oskar-und-IlseMulert-Stiftung enthält etwa 1.000 Drucke der Reformationszeit und mehrere Inkunabeln, darunter drei hochdeutsche Bibeln des 15. Jahrhunderts. Zusammen mit den Autographa Lutheri (s. Kap. 11) bilden sie eine der umfassendsten Spezialsammlungen von zeitgenössischen Ausgaben Luthers.

(SG/HR) 


\section{Das iranische Königsbuch}

Firdausī:

Šāhnāma.

Papierhandschrift, Persien, Jahr 1030 der Hiğra (= 1620/21).

Signatur: $2^{\circ}$ Cod. Ms. Asch 79

Provenienz: Georg Thomas von Asch, 1790

Vor einem Jahrtausend schuf Abu-'1-Qāsim Firdausī (940 - 1020), der vielleicht berühmteste Dichter der neupersischen Sprache, das Schahname (šāhnāma) oder Königsbuch. Dieses Epos erreicht in manchen Handschriften die Zahl von etwa 60.000 Doppelversen und überragt so dem Umfang nach alles, was in Epen anderer Sprachen überliefert ist. Bis heute gilt es vielen Iranern als wesentliches Zeugnis ihrer Kultur. Einer wohlhabenden Familie aus Tus im Nordosten Irans entstammend widmete sich Firdausī der Sammlung und Dichtung des epischen Stoffes, wobei er sich auf schriftliche und mündliche Traditionen stützte. Er reiht sich damit ein in eine im Laufe des 10. Jahrhunderts entstandene Bewegung, deren Bestreben es war, anknüpfend an vorislamische Traditionen die mythische und historische Geschichte Irans vor dem Islam wieder ins Bewusstsein zu rufen. Nach eigenem Zeugnis arbeitete er 35 Jahre an seinem Werk, das zum Maßstab der seit zwei Jahrhunderten aufblühenden neupersischen Literatur wurde.

Mit Ausnahme weniger Teile, in denen sich Firdausī auf arabische Quellen stützt, weist das Schahname weit weniger sprachliche Einflüsse des Arabischen auf als die neupersische Literatur allgemein. So verhält es sich auch mit der Episode, die die hier abgebildete Miniatur (fol. 217') illustriert: Der Herrscher Irans Kai Husrau tötet Afrasiyāb, König des Reiches Turan und zugleich sein Großvater.

Jetzt ist von Gott der Vergeltung Tag Gott lohnt das Böse mit bösem Schlag. Er traf ihm den Nacken mit indischem Stahl Und warf den finsteren Leib zu Tal.

So überträgt in Nachbildung des persischen Metrums Friedrich Rückert (1788-1866) den entscheidenden Moment. Firdausī besingt zahllose Taten der Könige und Helden Irans, doch gelingt es ihm, den handelnden Personen individuelle Züge zu verleihen. Oft verknüpft er mit den einzelnen Episoden moralische Schlussfolgerungen.

Die seit dem 14. Jahrhundert häufig mit Miniaturen versehenen Handschriften des Schahname dokumentieren die Entwicklung der persischen Malerei. Die Illustrationen unserer Handschrift weisen durchgehend einen klaren, von gemessenem Rhythmus getragenen Stil auf. Das Werk hebt sich klar von zeitgenössischen Schahname-Illustrationen ab. Die kunsthistorische Einordnung ist jedoch erst noch zu leisten. Die Herkunft der Handschrift lässt sich über Georg Thomas von Asch bis nach Transkaukasien verfolgen, wo sie der bekannte Kaukasusreisende Christian Rudolf Ehlich (1744-1793) erwarb. Joseph von Görres (1776-1848) nahm diese Handschrift zur Grundlage seiner frühen deutschen Bearbeitung des Epos (Berlin 1820). 


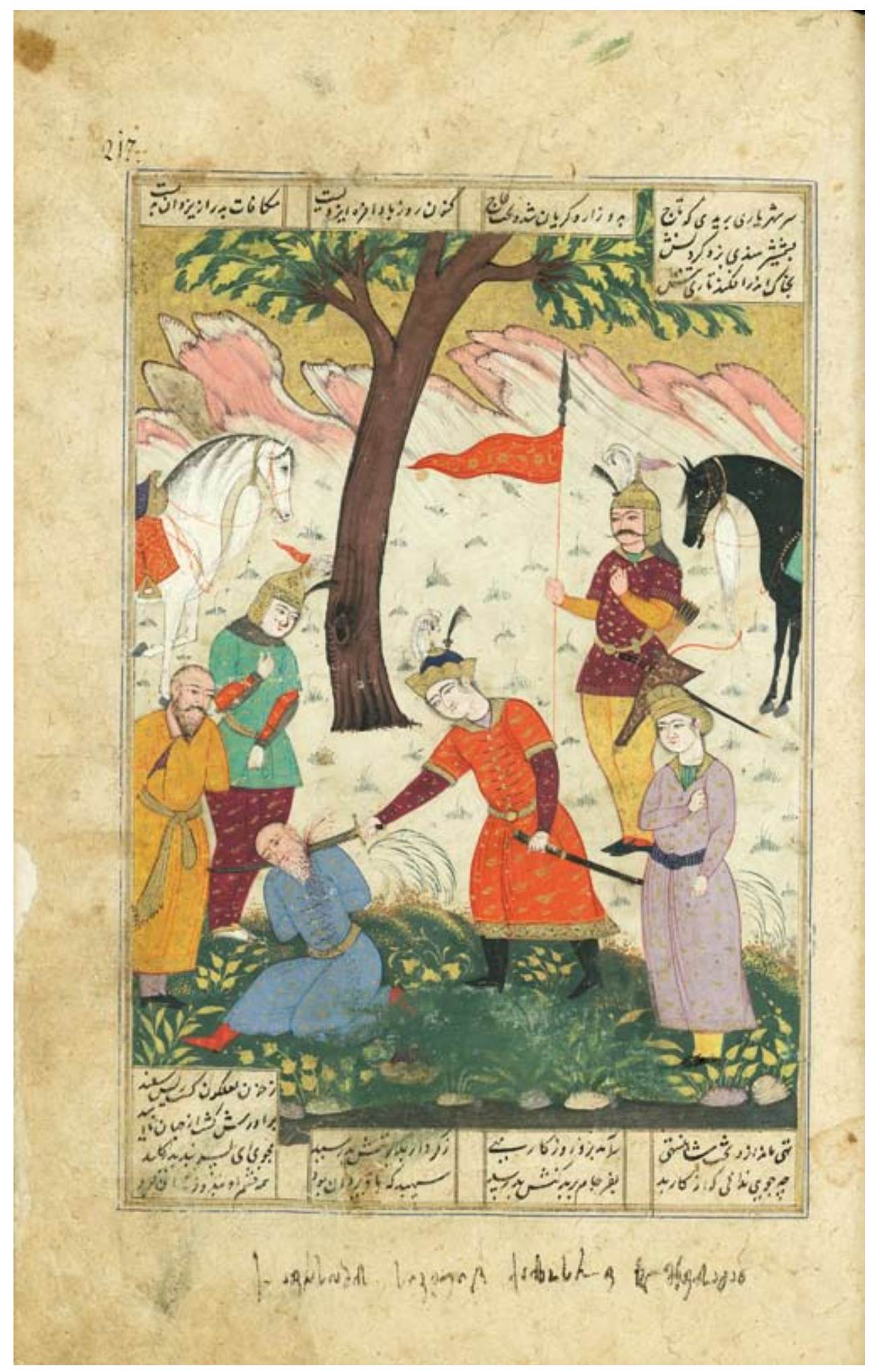




\section{der ersten Kamtschatka-Expedition}

Petr Avraamovič Čaplin:

Sija karta sočinisja v sibirskoj èkspedicii pri komande flota capitana Beringa ot Tobol'ska do Čjukockago ugla. [Diese Karte wurde während der sibirischen Expedition unter dem Kommando des Flottenkapitäns Bering von Tobolsk bis zum Tschuchotskischen Bogen verfasst].

Aquarellierte Federzeichnung, Russland um 1729.

Signatur: gr. $2^{\circ}$ Cod. Ms. Asch 246

Provenienz: Georg Thomas von Asch, 1777

Kurz vor seinem Tode erteilte Peter der Große (1672-1725, reg. 1682/89-1725) dem dänischen Kapitän Vitus Bering (1680-1741) den Auftrag zu erforschen, ob es eine Nordostpassage oder eine Landverbindung zwischen Sibirien und Nordamerika gebe. Im Februar 1725 brach die 34-köpfige erste Kamtschatka-Expedition von St. Petersburg über Tobolsk und Jakutsk nach Ochotsk auf. Die Bewältigung des mehr als 6.000 Kilometer umfassenden Landweges von der russischen Hauptstadt bis zur Ostküste nahm zwei Jahre in Anspruch. Von Kamtschatka aus stach Bering nordwärts in See. Er segelte durch die Meerenge zwischen Asien und Amerika, scheiterte jedoch bei seinem Versuch, seine Aufgabe zweifelsfrei zu lösen. Bering kehrte 1730 nach St. Petersburg zurück, um Bericht zu erstatten, und schlug vor, eine weitere Forschungsreise durchzuführen. Die anschließende, zwischen 1733 und 1743 andauernde zweite Kamtschatka-Expedition sollte zum vermutlich größten Expeditionsunternehmen der Geschichte werden.

Obgleich die Detailergebnisse der ersten (wie auch der zweiten) Kamtschatka-Expedition unter strengster Geheimhaltung standen, gelangten immer wieder Kenntnisse ins Ausland - so auch eine um 1729 vom Leutnant zur See Petr Čaplin $(† 1765)$ handgezeichnete Karte, die Asch 1777 nach Göttingen sandte. Ein ähnliches Werk hatte Bering seinem Rapport an das St. Petersburger Admiralitätskollegium beigefügt. Die Karte, die kartographische und ethnologische Informationen

verbindet, ist das wissenschaftshistorisch wichtigste und auch schönste Einzelstück der Göttinger Kartensammlung. Sie zeigt die Gegenden zwischen Tobolsk und Kamtschatka und neben einem genaueren Umriss der Küste Kamtschatkas auch zehn schwarz umrandete farbige Zeichnungen mit Vertretern der Ethnien des Gebietes (von links nach rechts, oben nach unten): einen Samojeden mit Schneeschuhen, eine Jakutin, eine Rentier-Tungusin sowie einen Rentier-Tungusen, einen Korjaken mit Schneeschuhen und Bogen, einen Kurilen mit Pfeil und Bogen, einen Tschuktschen mit einem Vogel, einen Kamtschadalen auf einem Hundeschlitten sowie einen Tungusen mit Köcher und Bogen und eine Tungusin mit einem Fisch. Auf der linken Seite der Karte befindet sich die Titelkartusche, an deren Rand - unter dem zaristischen Doppeladler die Begegnung von Vertretern der Zivilisation (rechts) und der „Wildnis“ (links: fellbekleidete Frau, unbekleideter Mann) abgebildet ist. Darunter befinden sich Zeichnungen von Tieren und Gegenständen, die für das Leben der Bevölkerung Sibiriens von Bedeutung sind. In zwei Kreise schließlich sind Hinweise von üblichen Bestattungsweisen eingezeichnet.

(SG) 


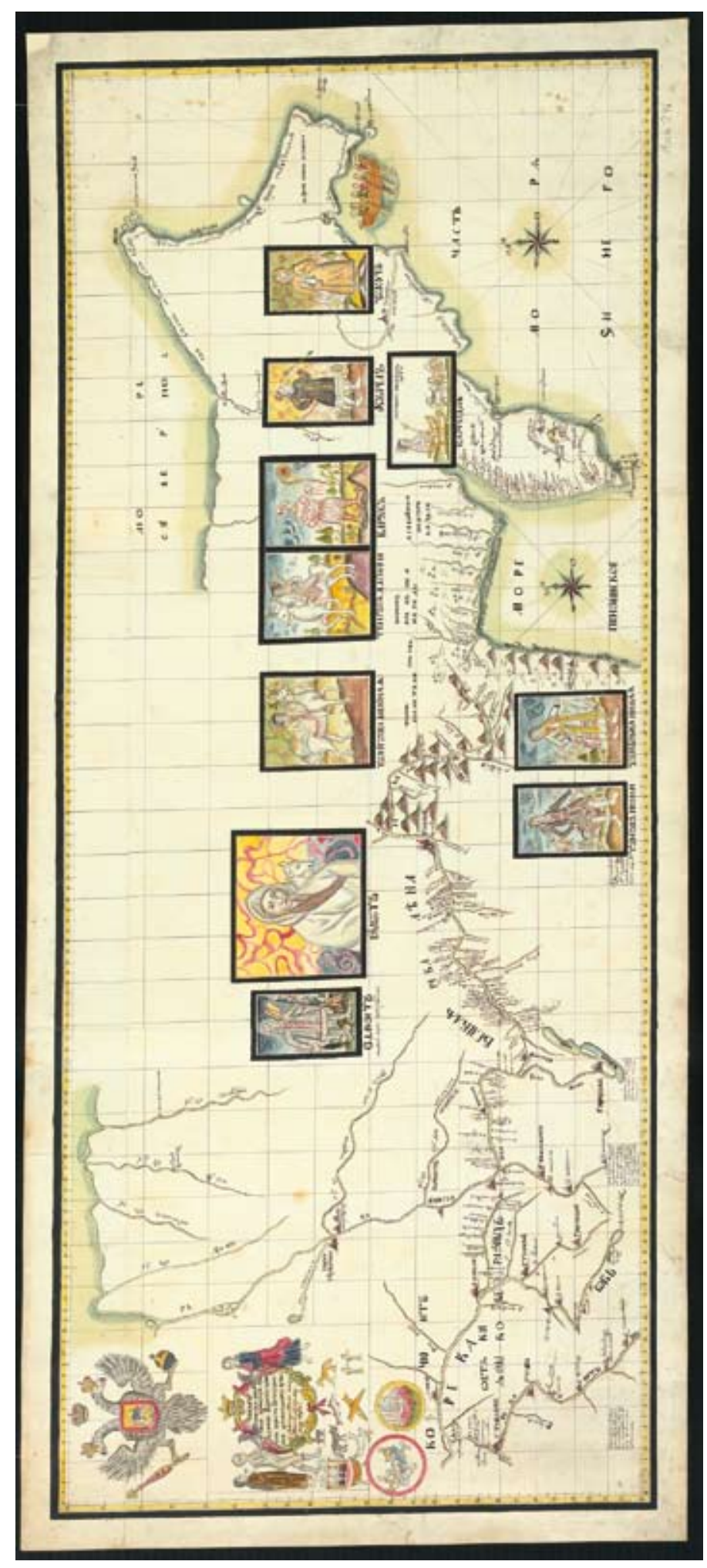




\section{Frühe Panoramaansichten von St. Petersburg}

Michail Ivanovič Machaev (Vorzeichner) und Efim Grigor'evič Vinogradov (Stecher):

Prospekt v verch po Nevě rěkě ot Admiraltejstva i Akademii Nauk k vostoku.

[Ansicht newaaufwärts von der Admiralität und der Akademie der Wissenschaften nach Osten.]

Aus: Plan stoličnago goroda Sanktpeterburga s izobraženiem znatnejšich onago prospektov

izdannyj trudami Imperatorskoj Akademii nauk i chudožestv. [Plan der Hauptstadt St. Petersburg

mit der Darstellung ihrer vornehmsten Prospekte, herausgegeben von der Kaiserlichen Akademie

der Wissenschaften und der Künste]. [St. Petersburg 1753].

Radierung und Kupferstich von zwei Platten, ca. 1350 x 500 mm

Signatur: gr. $2^{\circ}$ Hist. Russ. 430/71 Rara

Provenienz: Georg Thomas von Asch, 1806

Zum 50-jährigen Stadtjubiläum St. Petersburgs erschien 1753, in der Regierungszeit

Elisabeths I. (1709-1761, reg. 1741-1761), ein Album mit einem großen Plan und zwölf Veduten der russischen Hauptstadt. Anliegen dieser großangelegten Edition der Akademie der Wissenschaften war es, einen Überblick über die noch junge russische Hauptstadt mit topographisch wie architektonisch genauen Panoramaansichten zu verbinden. Sämtliche Vorlagen für die Vedutenserie stammen von dem an der Akademie angestellten Maler, Zeichner und Stecher Michail Ivanovič Machaev (1718-1770), zu dessen Mitarbeitern mehrere Stecher zählten. Das Werk zeigt die noch im Entstehen begriffene Metropole, deren Ansichten sich in vielerlei Hinsicht von dem heute bekannten Stadtbild unterscheiden. Im Jahre 1703 legte Peter der Große den Grundstein der Peter- und Pauls-Festung, 1712 erklärte er seine Neugründung bereits zur neuen russischen Hauptstadt. Ihr rasantes, durchaus auch durch erzwungene Umzüge des Adels und des Beamtentums bedingtes Wachstum - 1710 zählte die Stadt 8.000, gegen Ende des 18. Jahrhunderts bereits 250.000 Einwohner - wurde von einer allmählichen Verdrängung der frühen Holzdurch repräsentative Steinbauten begleitet. Von 1714 bis 1741 galt das Gesetz, dass sämtliche Steinbauten des Landes auschließlich in St. Petersburg ausgeführt werden und im übrigen Russland unterbleiben mussten.

Unter der Herrschaft Elisabeths I., der Tochter Peters des Großen, prägte der Hofarchitekt Bartolomeo Francesco Rastrelli (1700-1771) mit seinen Bauten nachhaltig das St. Petersburger Stadtbild. Sein „russischer Barock“, der russische und westeuropäische Formen verbindet, wurde bald in ganz Russland tonangebend.

Gezeigt wird das zweite Panorama der Vedutenserie, das von Efim Grigor'evič Vinogradov (1725-1769) gestochen wurde. Auf der linken Seite ist im hinteren Bildbereich die Peter-Pauls-Festung mit der von 1712 bis 1733/34 erbauten Peter-Pauls-Kathedrale zu sehen, im vorderen Bildbereich am - noch unbefestigten - Flussufer das Gebäude der 1725 eröffneten Akademie der Wissenschaften mit einem ins Wasser ragenden hölzernen Podest, dem „Theater für Feuerwerke und Illuminationen“. Auf der rechten Seite liegt das Schlossufer vom Sommergarten bis zum offenen Hof des von 1732 bis 1736 von Rastrelli errichteten Winterpalastes. Der Anblick dieser Uferseite wurde durch spätere Um- und Neubauten stark verändert (so wurde der heute noch bestehende Bau des Winterpalastes von 1754 bis 1762 von Rastrelli ausgeführt). Auf der Newa herrscht reger Schiffsverkehr; auf der linken Seite ist ein Boot zu sehen, das Steinblöcke transportiert. 


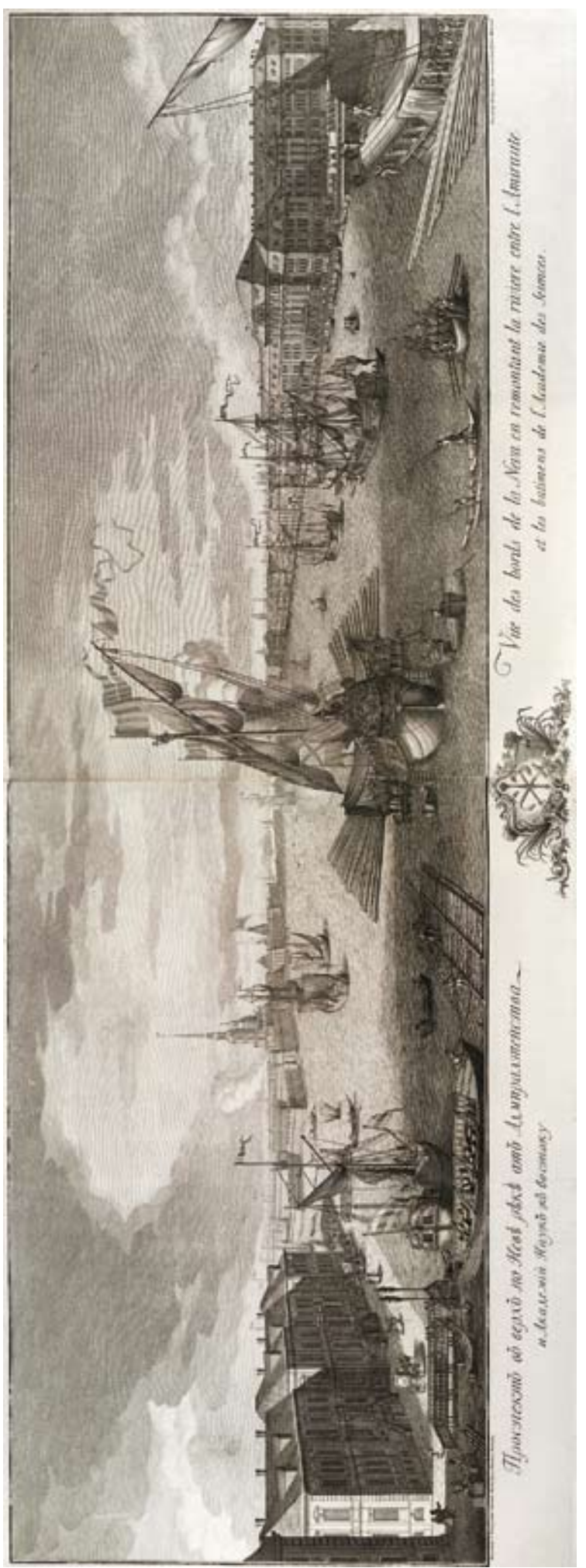




\section{Eine Karte aus der Frühzeit der russisch-japanischen Beziehungen}

Karta sočinennaja morskich sudov kompanejšika jakutskogo kupca Pavla Sergeeva Lebedeva Lastočkina, peredovšikom ego, irkutskim kupcom Dmitreem Jakovlevym Šabalinym, v bytnost' svoju na ostrove Atkize, sentjabrja 6 dnja 1779 godu. [Karte, entworfen von dem Vormann des Kompagnons der Seeschiffe, des Jakutsker Kaufmanns Pavel Sergeevič Lebedev-Lastočkin, dem Irkutsker Kaufmann Dmitrij Jakovlevič Šabalin, bei seinem Aufenthalt auf der Insel Atkis am 6. September 1779.]

Farbige Zeichnung, Russland, um 1779

Signatur: gr. $2^{\circ}$ Cod. Ms. Asch 283

Provenienz: Georg Thomas Asch

Nach der fast völligen Ausrottung der wertvollen Pelztiere in Ostsibirien geriet im Laufe des 18. Jahrhunderts die zwischen der Halbinsel Kamtschatka und dem japanischen Hokkaidō gelegene Inselkette der Kurilen verstärkt in das Gesichtsfeld der großen russischen Pelzhändler. 1777 rüsteten die Kaufleute Grigorij Šelichov und Pavel LebedevLastočkin gemeinsam eine Handelsreise zu den Kurilen aus; eine kleinere Gruppe setzte nach Hokkaidō (das sie Atkis nannten) über. Der große Erfolg der Expedition bewegte die Pelzhändler dazu, ihr Schiff mit Ivan Antipin als Kapitän und dem Irkutsker Kaufmann Dmitrij Šabalin als Vormann 1778 erneut auszuschicken. Am 5. Oktober erreichte das Schiff Urup; Anfang 1779 setzten Antipin und Šabalin mit 45 Mann in sieben Booten nach Hokkaidō über. Ihre dortigen Versuche, mit den Japanern Handelsbeziehungen anzuknüpfen, bleiben allerdings erfolglos, so dass sie am 15. September nach Urup zurückkehrten. Anfang 1780 ereignete sich in der Region ein großes Erd- und Seebeben, das weitere Unternehmungen zunichte machte. Dieser wirtschaftliche Misserfolg führte dazu, dass die russischen Handelsreisen zu den Kurilen für einige Zeit ins Stocken gerieten.

Über die Begegnung der Russen und der Japaner informiert eine handgezeichnete Karte Šabalins, eines der seltenen frühen Zeugnisse über das zu dieser Zeit hermetisch abgeschlossene Inselreich. Sie ergänzt eine entsprechende Schilderung in einer Beschreibung der Kurilen, die der Leiter der Irkutsker Navigationsschule Michail Tatarinov 1782 an die St. Petersburger Akademie der Wissenschaften schickte und deren deutsche Übersetzung Peter Simon Pallas 1783 unter dem Titel „Neue Beschreibung der Kurilischen Inseln“ in den Neuen Nordischen Beyträgen veröffentlichte: „Da Antipin auf Matmai war, erschienen die Japaneser beym russischen Lager am 5. September 1779 in einer Art von Procession. Voran gieng ein Japaneser mit einer großen, gelb geschäffeten Muskete auf der Schulter ... dann folgte der Oberbefehlshaber in weiten Hosen, einem kurzen ausgenähten Obergewandt, mit einem Fächel in der Hand, zwey kurzen Säbeln an der Seite, und auf Klotzschuhen, wie die Weiber in Holland auf der Straße tragen, einhergehend ... Antipin gieng mit dem Steuermannslehrling Putinzof, und dem Vormann Schebalin zu ihnen, um sie zu begrüßen, und ihnen die Ursach seiner Ankunft anzuzeigen ... Der Japanische Kaufmann erwiederte darauf, sie hätten keine andre Waaren bey sich, als Provisionen, Branntwein, Tabak, und könnten also keinen Tausch anbieten." Offizielle Beziehungen sollten Russland und Japan erst 1855 aufnehmen. 


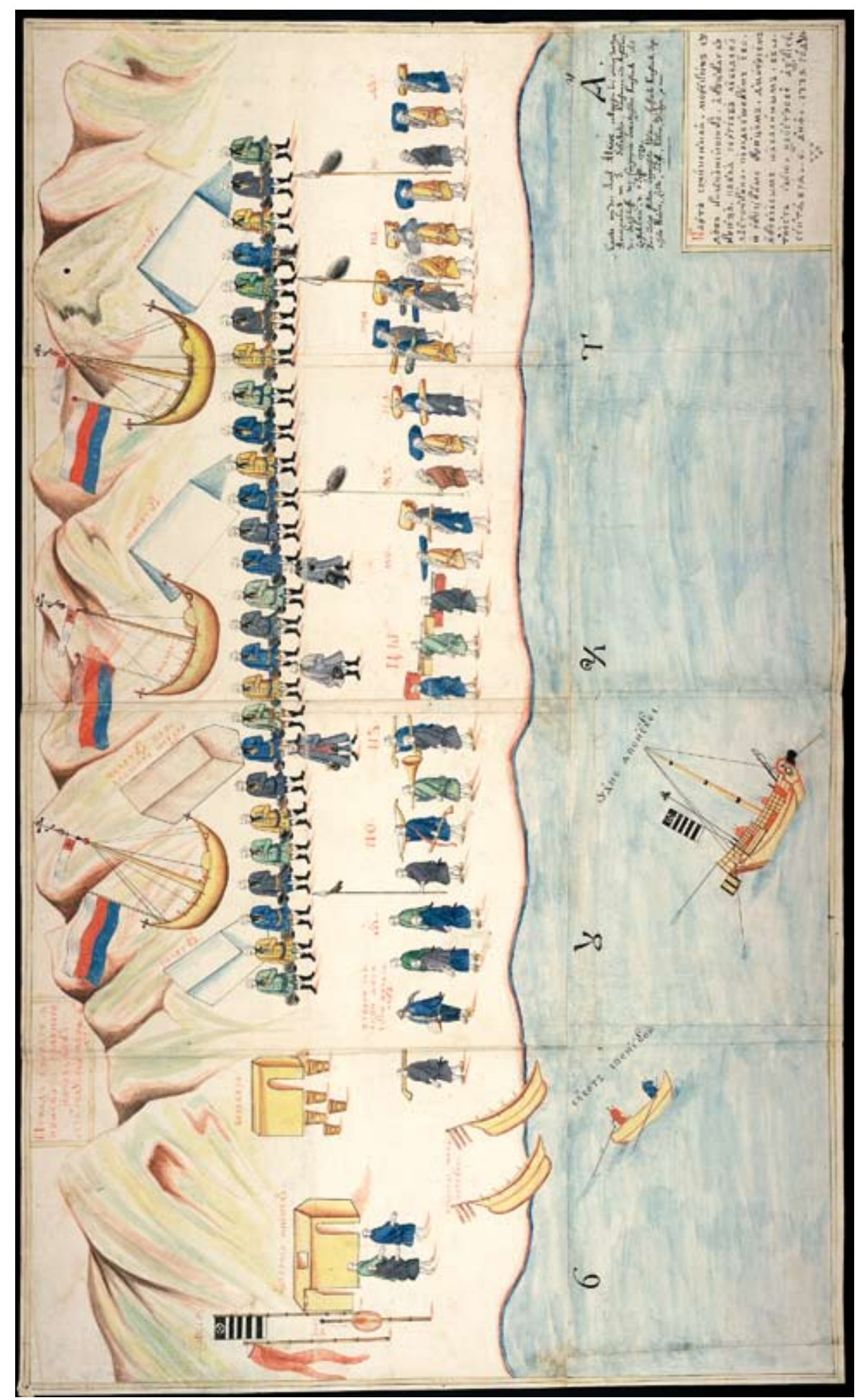




\section{Das Weltbild der Renaissance}

Cornelis de Jode:

Speculum Orbis Terrarum.

Antwerpen: Arnold Coninx, 1593.

Signatur: $2^{\circ}$ Geogr. $155^{\mathrm{d}}$ Rara

Provenienz: Arthur Breusing, 1887

Die Familie de Jode gehört zu jenem Kreis von Kupferstechern aus den nördlichen Provinzen der Niederlande, die in Antwerpen eine erfolgreiche Karriere als Kupferstich- und Kartenhändler sowie als Verleger machten. Gegründet von Gerard de Jode (1509-1591) wurde der Verlag nach dessen Tod von seiner Witwe und seinem Sohn Cornelis (1568-1600) weitergeführt. Haupteinnahmequelle des Geschäftes war zunächst der Handel mit Kupferstichen, später kamen lose Kartenblätter hinzu. Die schnelle Verbreitung geographischer Kenntnisse führte dazu, dass Karten immer beliebter wurden. Durch das Kopieren von Kartenwerken bedeutender Kartographen hat de Jode entscheidend dazu beigetragen, dass eine Reihe von heute in ihren Originalausgaben nicht mehr erhaltenen kartographischen Werken bekannt blieb.

Ausgestellt ist die zweite und gleichzeitig letzte Ausgabe des Speculum Orbis Terrarum, herausgegeben von Cornelis de Jode mit zum Teil neuen oder revidierten Kartenblättern. Die Erstausgabe 1578 erfolgte noch durch Gerard de Jode, dessen Karten größtenteils schon ab den 1570er Jahren als Einzelblätter im Handel waren. Das an Ortelius verliehene Privileg zur Herausgabe eines Weltatlas Theatrum Orbis Terrarum verhinderte erfolgreich das Erscheinen des Speculum vor 1578. Obwohl de Jodes Atlas, was die dekorative Gestaltung anbelangt, wahrscheinlich die gefälligsten aller Renaissancekarten enthält, konnte er sich dennoch kommerziell nicht gegen das bereits bestens eingeführte Konkurrenzwerk von Abraham Ortelius behaupten.
Alle Darstellungen sind von versierten Kupferstechern sorgfältig ausgeführt, und zwar von den Brüdern Joannes und Lucas van Doetecum, die ein neues, besonders für Karten geeignetes Ätzverfahren entwickelt hatten. Mit der ornamentalen Umrahmung, den prächtigen Kartuschen, dem reichen figuralen Schmuck sowie den Sagentieren entsprachen die Tafeln ganz dem Zeitgeschmack.

Nach dem Tod von Cornelis de Jode wurde das Geschäft aufgelöst. Die Druckplatten gingen an Jan Baptist Vrients (1552-1610), der bereits die Verlagsrechte von Ortelius Theatrum Orbis Terrarum durch eine Erbschaft erhalten hatte. Er verhinderte weitere Auflagen des Speculum, um den Verkauf des Ortelius-Atlas zu steigern. Aufgrund der geringen Auflagen ist der Atlas de Jodes heute selten. 


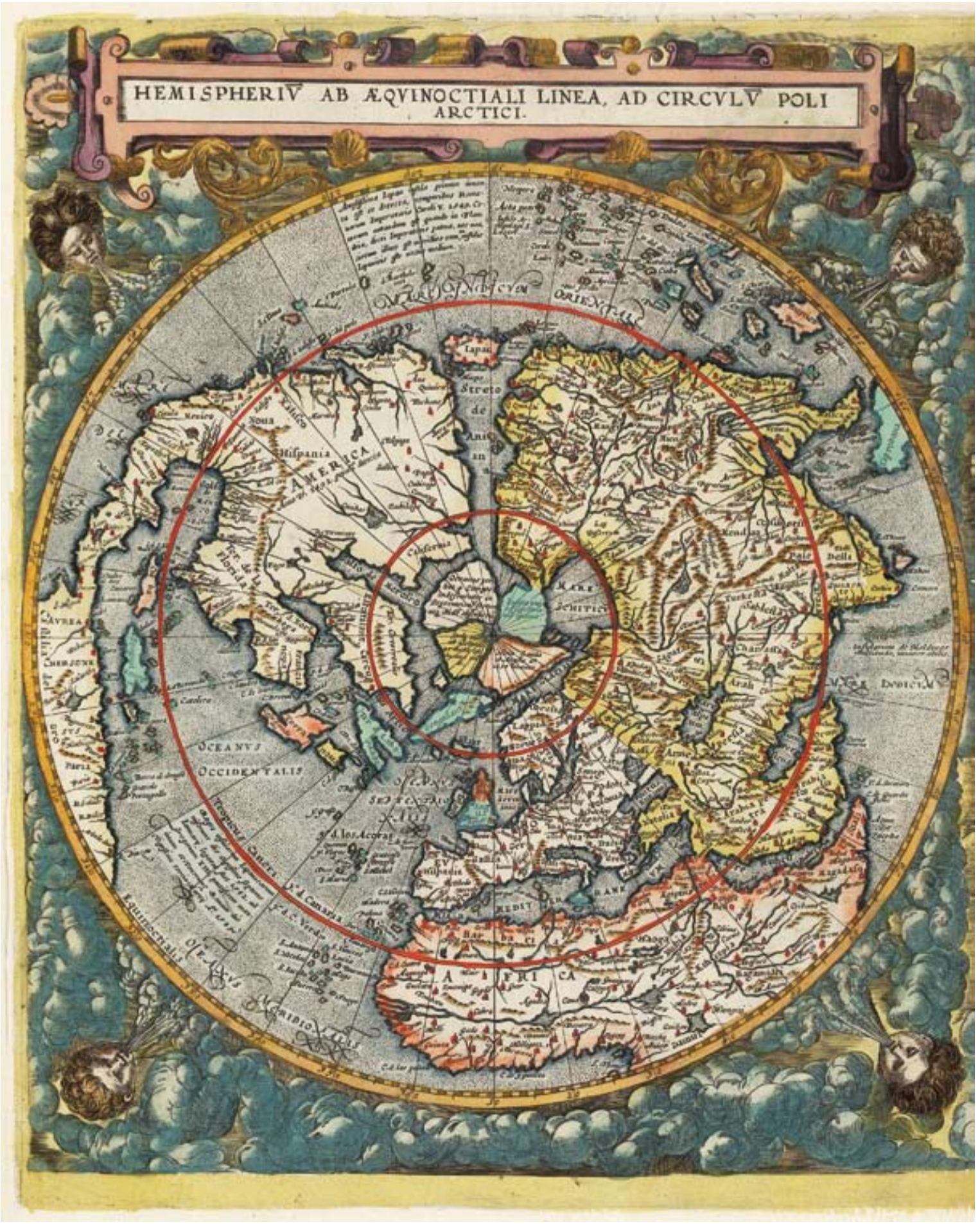




\section{Die ganze Welt in einem Buch - der erste große Weltatlas}

\author{
Abraham Ortelius: \\ Theatrum Orbis Terrarum. \\ Antwerpen: Officina Plantiniana, 1595. \\ Signatur: $2^{\circ}$ Geogr. $153^{\mathrm{d}}$ Rara \\ Provenienz: Arthur Breusing, 1887
}

geblich den Entwicklungsgang der Kartographie. Die südlichen Niederlande blieben im 17. Jahrhundert das Zentrum der Kartenherstellung.

Das im Renaissancestil ausgeführte Titelblatt gibt die vier Kontinente allegorisch als Frauengestalten wieder: Europa als Kaiserin mit Weltkugel und Kreuz, Asien als Priesterin, Afrika als Negerin und schließlich Amerika, das erstmals als gleichberechtigter Erdteil erscheint, als nackte Barbarin. Daneben steht noch eine Büste der Magellanica mit einer Fackel, womit das fiktive Südland und Feuerland symbolisiert werden sollten. 


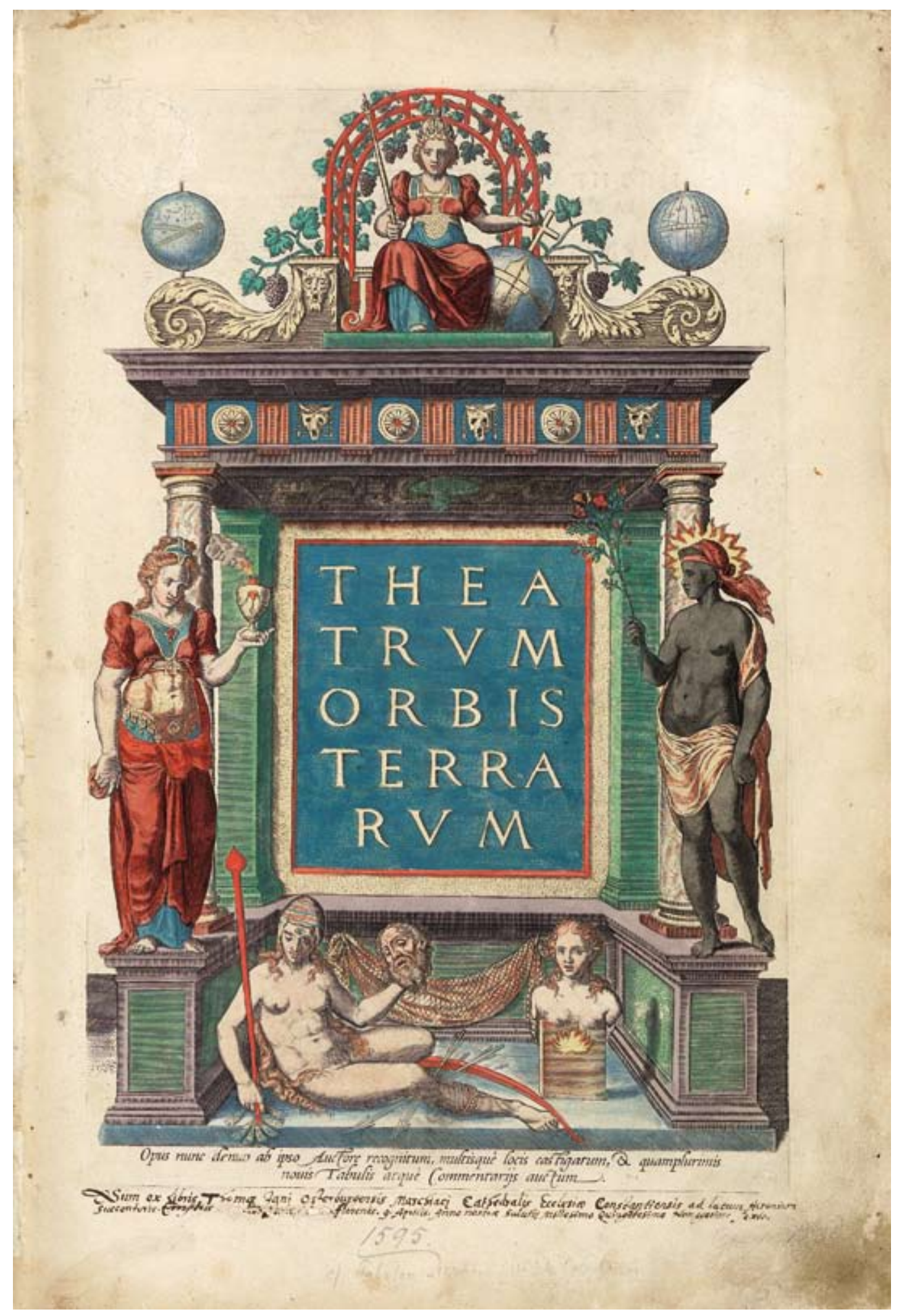




\section{Großformatige Katzenbilder}

Daniel Giraud Elliot:

A Monograph of the Felidae or family of the cats. London: Selbstverlag, 1883.

Signatur: gr. $2^{\circ}$ Hist. nat. zool. X, 3555

Provenienz: Pierpont Morgan Foundation

Daniel Giraud Elliot (1835-1915) war ein einflussreicher und sehr erfolgreicher amerikanischer Zoologe. Der Gründer des American Museum of Natural History in New York wirkte als Kurator für Zoologie in Chicago, bekleidete die Position des Vizepräsidenten der von ihm mitbegründeten Zoologischen Gesellschaft Frankreichs sowie die des Präsidenten der American Ornithologists' Union. Der vielfach ausgezeichnete Elliot besaß mehrere Mitgliedschaften naturwissenschaftlicher Akademien und wurde mit Ehrungen verschiedener Vereinigungen überhäuft. Aber nicht nur als Wissenschaftler und Wissenschaftsorganisator zeichnete sich Elliot aus, zugleich verfügte er über künstlerisches Talent und machte sich um die Herstellung und Herausgabe von zoologischen Abbildungswerken verdient. Mit dem Anspruch einer Weiterführung des Erbes des großen amerikanischen Vogelkundlers Audubon entstanden unter seiner Leitung die prächtigen, großformatigen Tafelbände über Fasane und Paradiesvögel. Der gut betuchte Elliot setzte dafür eigene Mittel in großem Umfang ein. Anerkennung und Bedeutung in der Wissenschaft brachte seinen Editionen aber vor allem die Mitarbeit der unumstritten bedeutendsten Tiermaler und -lithographen seiner Zeit ein. Elliot gewann insbesondere Joseph Wolf und Joseph Smit, die aus jeder Vorlage eine hinreißende, lebensechte Darstellung von Tieren schaffen konnten. Mit ihrer Arbeit über die Familie der Katzen schufen alle zusammen ein Standardwerk der Zoologie, das mit seinen Darstellungen verbindlich für Identifikation und Benennung von Katzen werden sollte, ein Desiderat seiner Zeit. Elliot selbst sichtete bzw. beschaffte sich in Amerika und Europa die verfügbaren Vorlagen, verglich und vereinheitlichte auf dieser Basis das gesammelte Material. Von Hand nachkolorierte Lithographien präsentierten dann das Ergebnis aller Forschungen und zeigten die Tiere in ihrer natürlichen Umgebung, ergänzt um Beschreibungen und Literaturhinweise.

Die Abbildung zeigt den im südlichen Afrika vorkommenden Serval, der mit 70 bis $100 \mathrm{~cm}$ Körperlänge zu den kleineren Katzen gehört. Das schlanke Tier wirkt mit seinen langen Beinen sehr elegant und kann bis zu 20 Jahre alt werden. Auffallend sind seine großen Ohren. Sein Fell ist sehr wertvoll, entsprechend stark wird der Serval gejagt. Wie auch die anderen Galeriewerke Elliots konnte die Universitätsbibliothek Göttingen den Band über die Katzen aus Mitteln der Pierpont Morgan Foundation erwerben. 


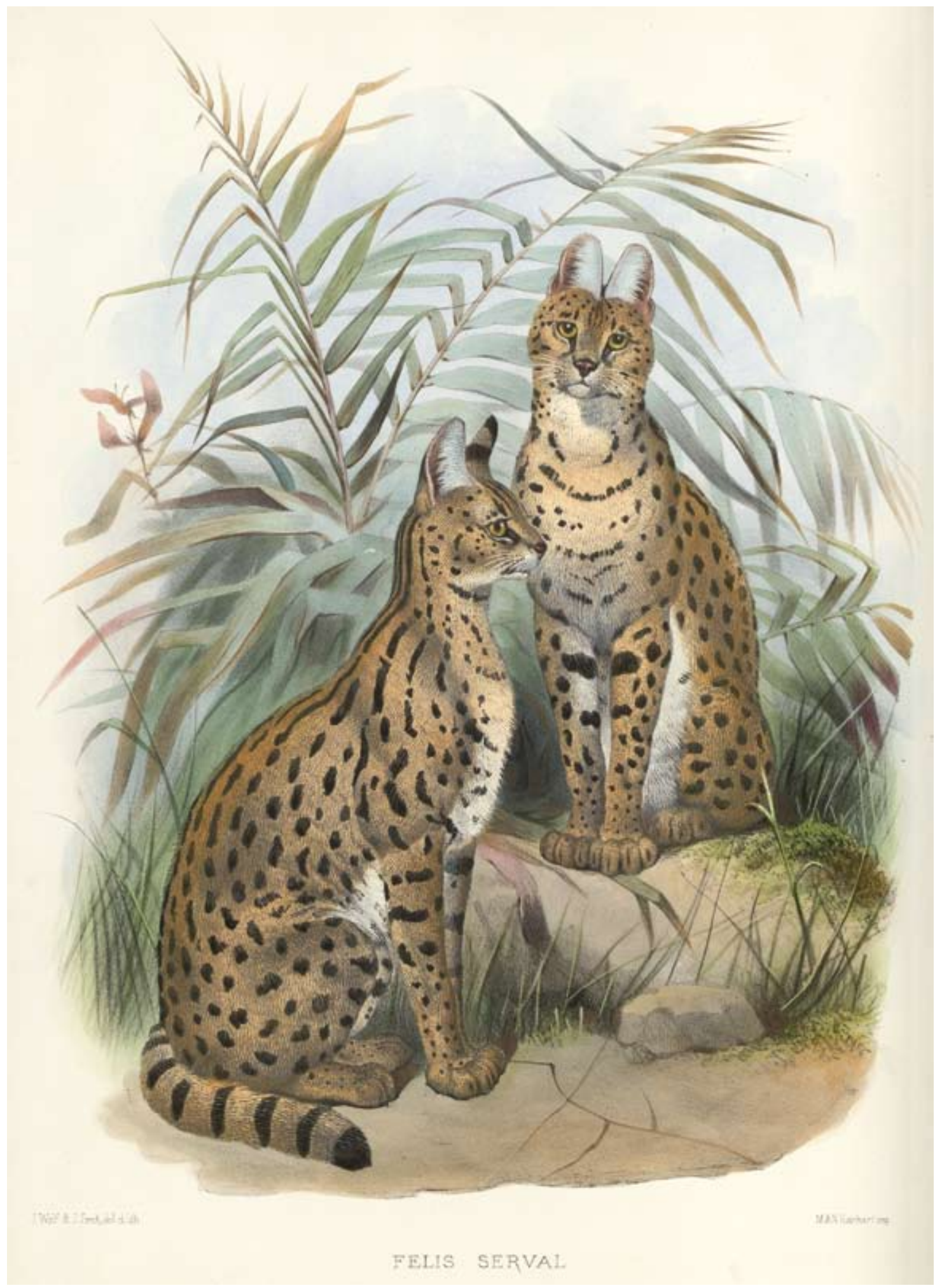




\section{Ein üppig ausgestatteter Inkunabelkatalog}

Catalogue of manuscripts and early printed books from the libraries of William Morris, Richard Bennett, Bertram, fourth Earl of Ashburnham, now forming portion of the library of J. Pierpont Morgan. Bd. 1.

London : Chiswick Press, 1907

Signatur: HSD-LS Zi ${ }^{\mathrm{a}} 70=2^{\circ}$ Hist. lit. libr. XI, 7560: 1

Provenienz: John Pierpont Morgan, 1908

John Pierpont Morgan erwarb zwischen 1890 und dem Vorabend des 1 . Weltkriegs eine ganze Reihe von Privatbibliotheken in Europa, so dass nach und nach eine bemerkenswert breit gefächerte Bibliothek mit einer erstaunlichen Anzahl von kostbaren Handschriften und Frühdrucken entstand. Heute besitzt die John Pierpont Morgan Library in New York eine Sammlung von 2.700 Inkunabeln, darunter zahlreiche Unikate, bedeutende Erstausgaben klassischer Autoren und Werke der berühmtesten Drucker der Inkunabelzeit. Der sorgfältig gestaltete dreibändige Katalog zu dieser Sammlung entstand zwischen 1907 und 1913, und er wurde als Privatdruck bei der Chiswick Press in London in nur 175 Exemplaren auf handgeschöpftem Papier gedruckt. Zusätzlich gab es fünf auf Pergament gedruckte Vorzugsexemplare. An der Herstellung des Katalogs waren die namhaftesten Fachleute für den europäischen Frühdruck beteiligt: Alfred W. Pollard (1859-1944), Montague Rhodes James (1862-1936) und Edward Gordon Duff (1863-1924).

Angelegt ist der Katalog nach dem geographisch-chronologischen Prinzip: Die Haupteinteilung bilden die Länder - im ersten Band folgen auf die Blockbücher die Kapitel Deutschland, Österreich und die Schweiz, innerhalb der Länder folgen die Druckorte in chronologischer Abfolge aufeinander (angefangen mit Mainz), und innerhalb des Druckortes sind die Inkunabeln chronologisch angeordnet. Insgesamt folgt der Katalog damit dem Aufbau des Catalogue of the Books printed in the XVth Century now in the
British Museum, für dessen erste drei Bände (1908-1913) ebenfalls A. W. Pollard verantwortlich zeichnete.

Neben den sorgfältigen und ausführlichen Beschreibungen der Inkunabeln sind die ausgezeichneten Faksimile-Wiedergaben in dem Katalog bemerkenswert: Gelegentlich vergessen selbst geübte Betrachter, dass hier nicht ein Holzschnitt aus dem 15. Jahrhundert zu sehen ist, sondern ein Nachdruck, dessen Qualität dem Original sehr nahe kommt. Voller Stolz bemerkt Pollard im Vorwort zum ersten Band: „Every illustration appears in immediate connection with the book to which it relates, and yet it will hardly be contended that the beauty of the catalogue itself has been in any way damaged." Dies zeigt auch die aufgeschlagene Seite mit der Beschreibung der Erstausgabe von Hartmann Schedels Weltchronik (s. Nr. 2) auf der linken Seite und dem ganzseitigen Holzschnitt mit Papst Pius II. und Kaiser Friedrich III. auf der rechten Seite. 


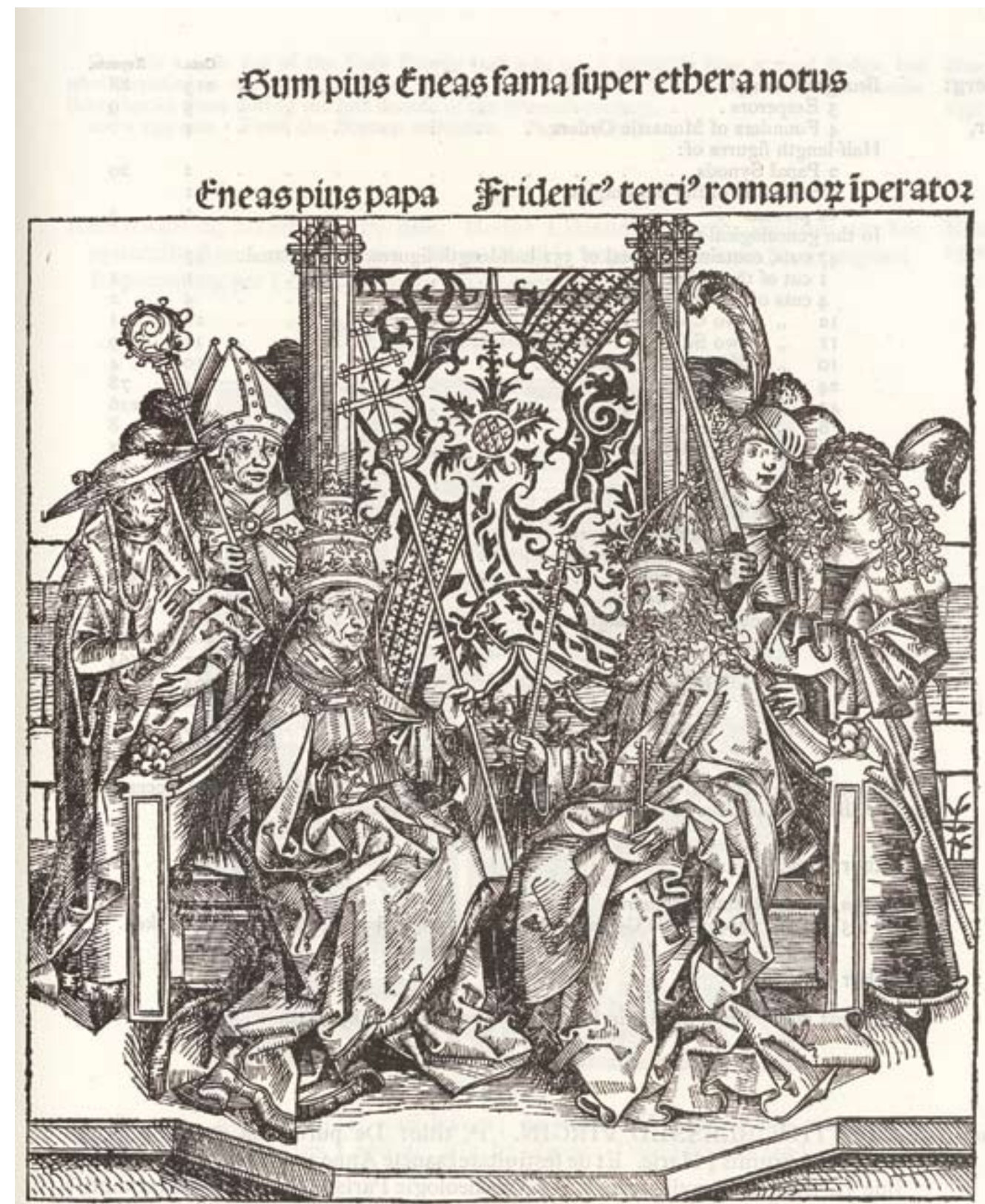

\section{Zorcere pzoftzatis fcit nobiliska IL In quoq3 fac fimlequifquis regnabis in ozbe}

182. SCIIEDEL: LHER CHRONICARUM. NUREMBERG: ANTON KOBERGER, 1493. (LEAF NUMBERED 267, VETSO.) 


\section{Fotografien der Indianer Nordamerikas}

Edward Sheriff Curtis:

The North American Indian: Being a series of volumes picturing and describing the Indians of the United States and Alaska.

Cambridge, Mass.: 1907-1930.

Signatur: gr. $2^{\circ}$ Hist. Am. II, 12 Rara und $4^{\circ}$ Hist. Am. II, 12 Rara

Provenienz: Pierpont Morgan Foundation

Edward Sheriff Curtis (1868-1952) stammte aus einfachen Verhältnissen. Er scheint sich aber schon früh autodidaktisch mit der Fotografie befasst zu haben und eröffnete 1897 ein expandierendes Fotostudio. Als Curtis zu Beginn des 20. Jahrhunderts auf seinen ausgedehnten Reisen durch den nordamerikanischen Kontinent mit dem Aufbau einer umfangreichen Fotodokumentation begann, war die Verdrängung der „native Americans“ bereits in vollem Gange. Über Jahrzehnte hinweg waren sie aus ihren angestammten Siedlungsgebieten vertrieben, ihrer Lebensgrundlage beraubt und schließlich in Reservaten angesiedelt worden. Ihre Bevölkerungszahl war stark rückläufig und erreichte um 1920 mit 350.000 ihren tiefsten Stand. Sie schienen tatsächlich eine „vanishing race“ zu sein, wie es Curtis auf einem seiner Bilder nannte.

Mit seinen Aufnahmen plante der Fotograf, Eindrücke aus dem Leben der indianischen Völker festzuhalten, so lange dies noch möglich war. Doch Curtis, der mit über 2.200 Fotos die umfangreichste Sammlung an Aufnahmen zu diesem Thema anzulegen begann, sah lediglich das, was er sehen wollte. Gerade in seinen frühen Fotografien spiegelt sich eher eine zeittypische Betrachtungsweise ,der Indianer“ als die Realität. Eine romantisierende Sicht, verbunden mit dem Gestaltungswillen des fotografierenden Künstlers, schuf zwar stimmungsvolle, atmosphärische Momentaufnahmen, blendete aber die harte Wirklichkeit weitgehend aus. Die Tatsache, dass zahlreiche indianische Völker mit ganz eigenen Kulturen, Sprachen und Lebensweisen um ihr
Überleben kämpften, trat hinter dem Ideal des echten, traditions- und naturverbundenen Indianers zurück.

Während der 25 Jahre, in denen Curtis über 80 verschiedene Stämme besuchte, lernte der Fotograf viel über die Menschen, die er ablichtete. Und im selben Maß, in dem seine Fotos an dokumentarischem Wert gewannen, erfuhr er mehr Achtung und Unterstützung durch die Indianer selbst. Es ist tragisch, dass die Öffentlichkeit zu dieser Zeit, Ende der zwanziger Jahre des 20. Jahrhunderts, das Interesse an Curtis' Werk bereits verloren hatte. Als Autor und Indianerforscher findet Curtis erst in jüngerer Zeit stärkere Beachtung. Die Zeitgenossen reagierten noch sehr unterschiedlich auf sein Projekt. Den etablierten Ethnologen und Anthropologen war Curtis' Tätigkeit suspekt. Der Fotograf konnte keine akademische Ausbildung vorweisen, war aber bekannter als mancher Professor. Die Wissenschaftler an den amerikanischen Universitäten wollten Kunst und Wissenschaft streng getrennt sehen. Die Abbildung entstammt einer von 20 Mappen, die Curtis zur Ergänzung der 20 Textbände zwischen 1907 und 1930 publizierte. Die Mappen mit den über 700 großformatigen Fotodrucken sind in Deutschland vollständig nur in der Niedersächsischen Staats- und Universitätsbibliothek Göttingen nachweisbar. 


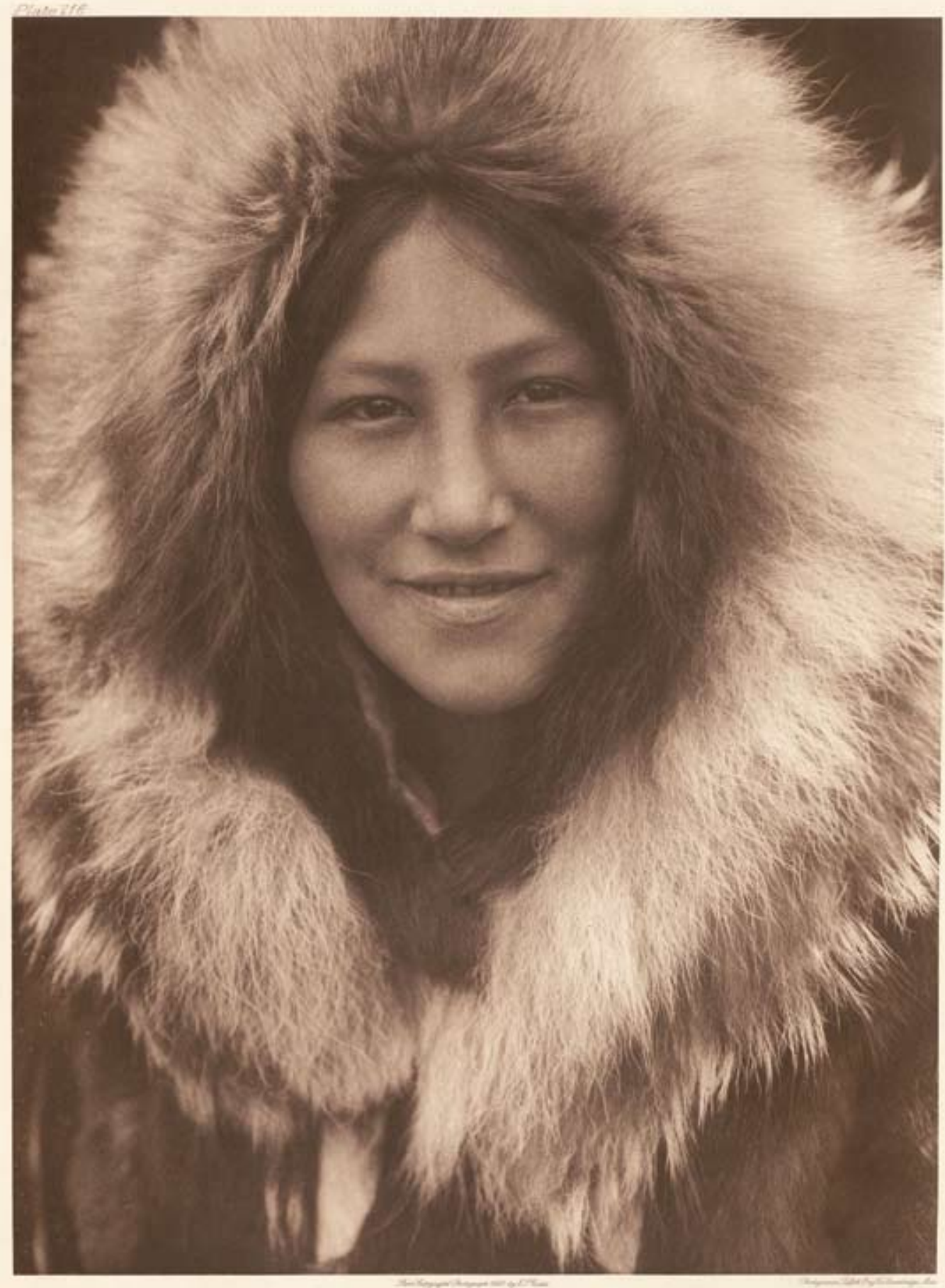

6ha-moATak 


\section{Die erste illustrierte deutsche Bibel}

Biblia, deutsch.

Augsburg: [Günther Zainer, 1475/76].

Signatur: $2^{\circ}$ Mulert 152

Provenienz: Oskar und Ilse Mulert-Stiftung, 1953

Bereits 56 Jahre vor Erscheinen des Lutherschen Septembertestamentes und 68 Jahre vor der Publikation seiner Gesamtausgabe der Heiligen Schrift druckte Johannes Mentelin (um 1410-1478) in Straßburg 1466 die erste hochdeutsche Vollbibel. Seinem Werk liegt eine Übersetzung zugrunde, die der Mitte des 14. Jahrhunderts entstammt und die damit zur Zeit ihres Drucks sprachlich veraltet war; Syntax und Phraseologie schlossen sich eng an die lateinische Vorlage der Vulgata an. Wahrscheinlich wurde der Text als Hilfsmittel zum besseren Verständnis der lateinischen Bibel oder auch zur Vorbereitung auf die (lateinischen) Lesungen im Gottesdienst benutzt. Sämtliche weiteren hochdeutschen Bibeldrucke vor Luther hängen direkt oder indirekt von ihm ab. Als der Augsburger Erstdrucker Günther Zainer ( $†$ 1478), der vermutlich in der Werkstatt Mentelins ausgebildet worden war, um 1475/76 seine Ausgabe der Heiligen Schrift - die nunmehr dritte hochdeutsche Bibel - vorlegte, griff auch er auf den Text der Mentelin-Bibel zurück, unterzog ihn dabei aber einer grundlegenden Revision und Modernisierung. Kolumnentitel, Blattzählung und Kapitelüberschriften, die in der MentelinBibel noch handschriftlich eingefügt worden waren, wurden hier teils in Rot mitgedruckt.

Sieht man von der gleichzeitig erschienenen Ausgabe von Jodocus Pflanzmann in Augsburg ab, so schuf Zainer mit dieser Ausgabe auch die erste deutsche illustrierte Bibel. Am Beginn der Vorreden setzte er die für ihn charakteristischen Maiglöckchen-Initialen, am Beginn der Bibelbücher Bildinitialen, die im Innern des Buchstabenkörpers Szenen aus dem nachfolgenden Text enthalten oder seine theologischen Kernaussagen veranschaulichen. Von späteren deutschen Bibelausgaben des Göttinger Inkunabelbestands ist noch die Koberger-Bibel von 1483 hervorzuheben. Sowohl wegen der Textverbesserungen als auch wegen der Abbildungen aus den niederdeutschen Kölner Bilderbibeln wurde sie zu der am weitesten verbreiteten deutschen Bibel vor Luther.

(HR/SG) 


\section{TEin Enre bat oas gebert Salomonise Vno bebet an oic vorke in ten weiffagen IIfaiam.}

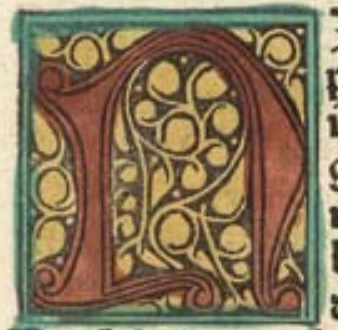

Ilemãt fo s? ficht oie pro: pheten bno íxe bŭcher bñ ine gfebrift oas oie féno gefchosiben vnterfchepeen mit kurtzen claulélin vî bef́chlief wozt? dxer maf ces gervichtes exs woorts Oex fol nit o3 wănen oas fra alfo feind gee bunien mit fölicher aufmeflung bei oe be bzeifchen. Auch) foll pemant wănen o3 oie

CDic vortean batent cin ence. Vns bebet an ser peopłee praias.

\section{CDD as erif aspirel.}

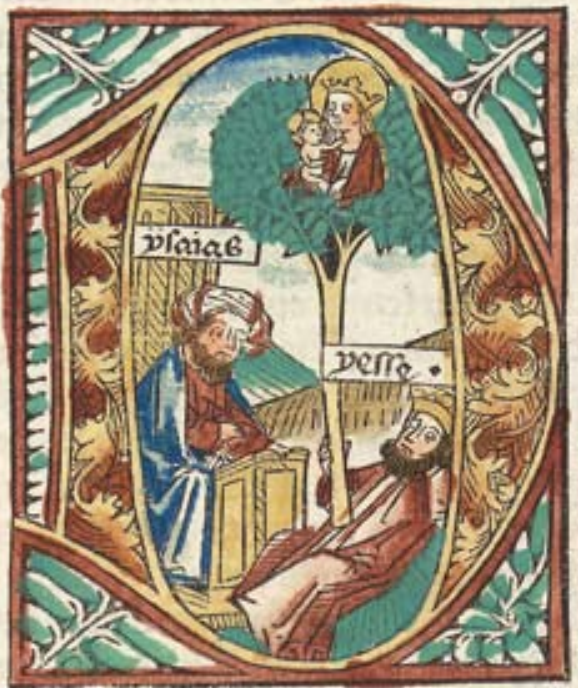

Ile geficlst pfaias oxs fun Omos die ex (ach) úb iubam vî úb íbel rufalem in oen tagen Dzic joatb/ an Alchas ขที ezechie oer kunig iuba. Ir bi melbŏzent vî ou erbe empfacb mit wen ozen - wann ext berze batt geceot. İcb bab exzogê fün. bñ bab fper hŏ bet- aB (p baben micl) verfcl)mábt. DiDer acbs eckant feinen befitzer. ono oer efel ove krúpp feines berzen. M ber jfrabel see erkant micl) 


\section{Die Luther-Bibel niederdeutsch}

De Biblie uth der uthlegginge Doctoris Martini Luthers yn dyth düdesche vlitich uthgesettet mit sundergen underrichtingen alse men seen mach.

[Mit Summarien hrsg. von Johannes Bugenhagen].

Lübeck: Ludwig Dietz, 1533.

Signatur: $2^{\circ}$ Mulert 143

Provenienz: Oskar und Ilse Mulert-Stiftung, 1953

Mit der Verwendung der sächsischen Kanzleisprache in seiner hochdeutschen Übersetzung des Neuen Testamentes 1522 hatte Martin Luther (1483-1546) die Hoffnung verbunden, einen im gesamten deutschen Sprachraum verständlichen Text vorzulegen. Tatsächlich überschätzte er die Verbreitung dieser Varietät: In oberdeutschen Städten wurde es üblich, dem Werk Luthers mitteldeutsch-oberdeutsche Glossarien beizulegen; im norddeutschen Raum entstanden gar eigene niederdeutsche Fassungen. Die erste niederdeutsche Vollbibel nach der Übersetzung Luthers erschien im Jahre 1533 in Lübeck und kam damit der ersten Gesamtausgabe der hochdeutschen Luther-Übersetzung, die 1534 in Wittenberg gedruckt wurde, um ein halbes Jahr zuvor. Entstanden war sie unter der Leitung des Wittenberger Stadtpfarrers und Universitätsprofessors Johannes Bugenhagen (1485-1558), eines engen Vertrauten Luthers, der sich in seiner Eigenschaft als Reformator zahlreicher norddeutscher Städte und Territorien von 1530 bis 1532 in Lübeck aufhielt, um dort die neue reformatorische Kirchenordnung einzusetzen. Vermutlich in dieser Zeit entstand der Plan, eine niederdeutsche Fassung der Heiligen Schrift herzustellen; sie wurde bei dem zwischen 1529 und 1534 in Lübeck tätigen Rostocker Drucker Ludwig Dietz († 1559) in Auftrag gegeben, der außer der Vollbibel auch eine niederdeutsche Psalterausgabe (1533) herstellte. Der von 59 Holzschnitten Erhard Altdorfers begleitete Text enthält außer den Vorreden und Glossen Luthers auch Vorreden und Summarien Bugenhagens sowie die vorher nicht im Druck erschienenen Apokryphen.

Das Werk steht in der bereits vorreformatorischen Tradition eines niederdeutschen geistlichen Schrifttums, die sich u.a. in vier zwischen 1478 und 1522 in Köln, Lübeck und Halberstadt gedruckten niederdeutschen Bibelübersetzungen der Vulgata manifestiert. Vor allem aber aufgrund der reformatorischen Schriften, welche die Volkssprache zur Sprache des kirchlichen Lebens erhoben, stieg die Zahl der niederdeutschen Drucke im 16. Jahrhundert sprunghaft an. Allein bis zum Jahre 1545 erschienen vier weitere Vollbibeln und etwa 90 Einzelausgaben der Heiligen Schrift in niederdeutscher Sprache. Erst im Laufe des 17. Jahrhunderts wurde der endgültige Wechsel zum Hochdeutschen vollzogen. 


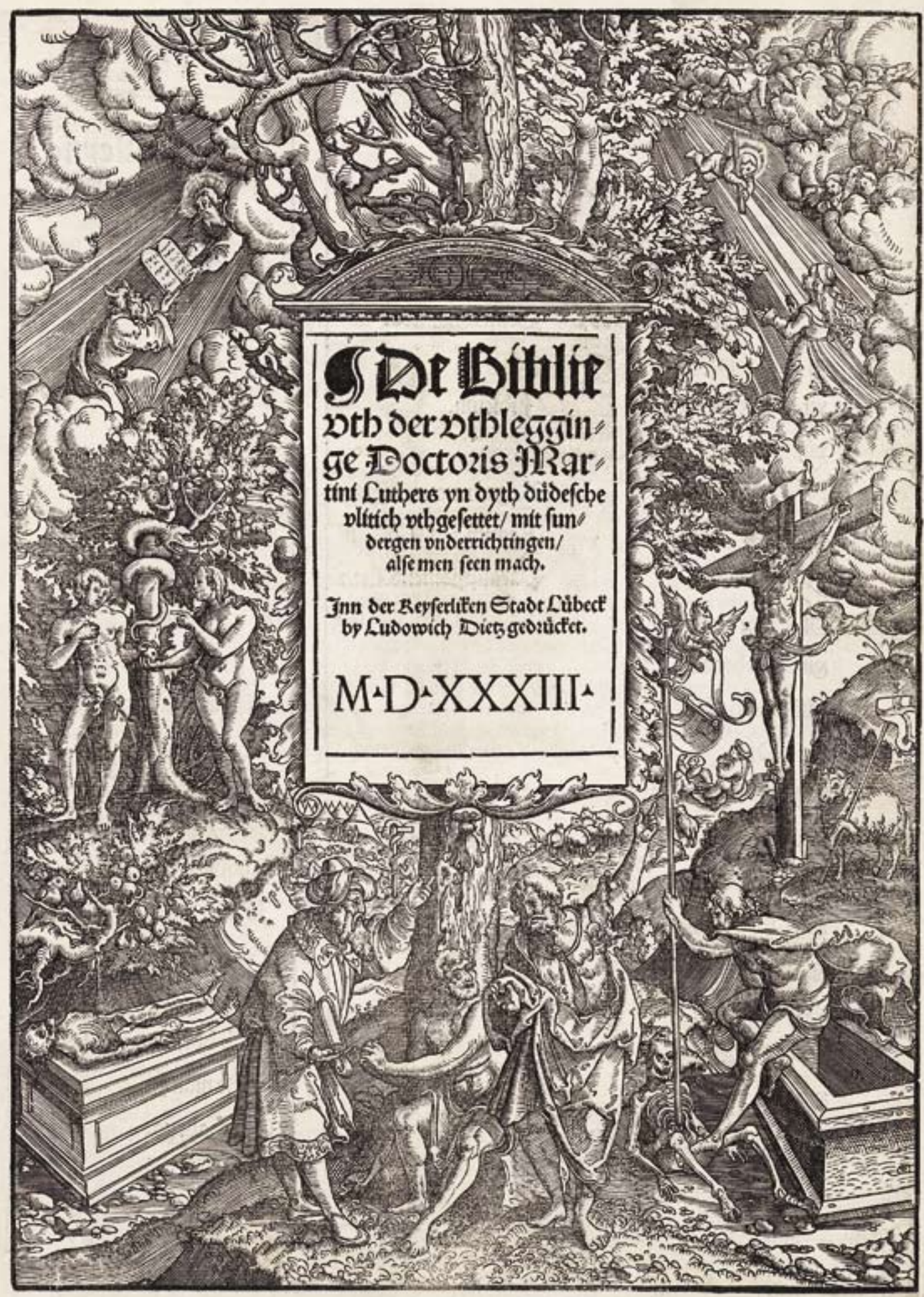




\section{Von Florenz nach Göttingen}

Gianfrancesco Poggio Bracciolini:

De varietate fortunae.

Pergamenthandschrift,

Florenz, 1450.

Signatur: $4^{\circ}$ Cod. Ms. theol. $136 \mathrm{Cim}$.

Provenienz: Georg Erich Barnstorf, Mitte 18. Jahrhundert

Gianfrancesco Poggio Bracciolini

(1380-1459) schrieb sein Buch über die

Wechselfälle des Schicksals zwischen März

1447 und Februar 1448. Karriere hatte der aus einfachen Verhältnissen stammende Student der alten Sprachen in den Diensten verschiedener Päpste gemacht. Schon mit 22 wurde er apostolischer Sekretär bei Bonifatius IX., und diese Position behielt er auch unter den Nachfolgern auf dem Stuhl Petri. Poggio nahm am Konzil von Konstanz (1414-1418) teil und übernahm in den letzten Jahren seines Lebens die Leitung der florentinischen Kanzlei der Medici. Zeitlebens blieb Poggio seiner Liebe zu den antiken Autoren und zum Altertum treu. Ständig war er auf der Suche nach noch nicht wiederentdeckten klassischen Texten und kümmerte sich um deren Vervielfältigung und Übersetzung, wobei ihm die Sache auch schon mal einen Diebstahl wert war. Dessen ungeachtet sind seine humanistischen Leistungen unbestritten. Da er auch den mehrjährigen Aufenthalt in Konstanz für seine Forschungen nutzte und zahlreiche Bibliotheken der Region besuchte, brachte er als einer der ersten das Denken und die Ziele der italienischen Humanisten nach Mitteleuropa.

Poggio hat sich auch als Autor einen Namen gemacht. Im vorliegenden Traktat griff er ein seit der Antike wohlbekanntes Thema auf, über das sich auch schon andere Zeitgenossen verbreitet hatten. In einem fiktiven Dialog mit dem Humanisten Antonio Loschi geht es um die Unzuverlässigkeit des Glücks. Neu dabei ist bei Poggio, dass er auf die üblichen Exempla der ferneren Vergangenheit verzichtet und
Beispiele aus den letzten 100 Jahren ausführt. Mit Exkursen und erzählenden Passagen gewinnt Poggios Werk damit den Rang einer zeithistorischen Abhandlung.

Die Göttinger Handschrift ist ein wichtiger Zeuge für die Überlieferung des Textes. Sie wurde 1450 in Florenz von Gherardo di Giovanni del Ciriagio angefertigt. Typisch florentinisch ist die Art des Buchschmucks, vor allem aber zeigt die (hier nicht abgebildete) Ausmalung von Blatt $1^{\mathrm{r}}$ das Wappen der Familie d'Este. Möglicherweise war Lionello d'Este erster Eigentümer der Handschrift. Auf nebenstehender Abbildung ist der eigentliche Beginn des Textes nach der Vorrede zu sehen. Georg Erich Barnstorf, der zu den ersten Studenten in Göttingen gehörte und sein Medizinstudium hier begann, brachte das Stück aus Italien nach Göttingen mit. Über Vermittlung des hiesigen Professors Jakob Wilhelm Feuerlein kam die Handschrift in die Universitätsbibliothek. 


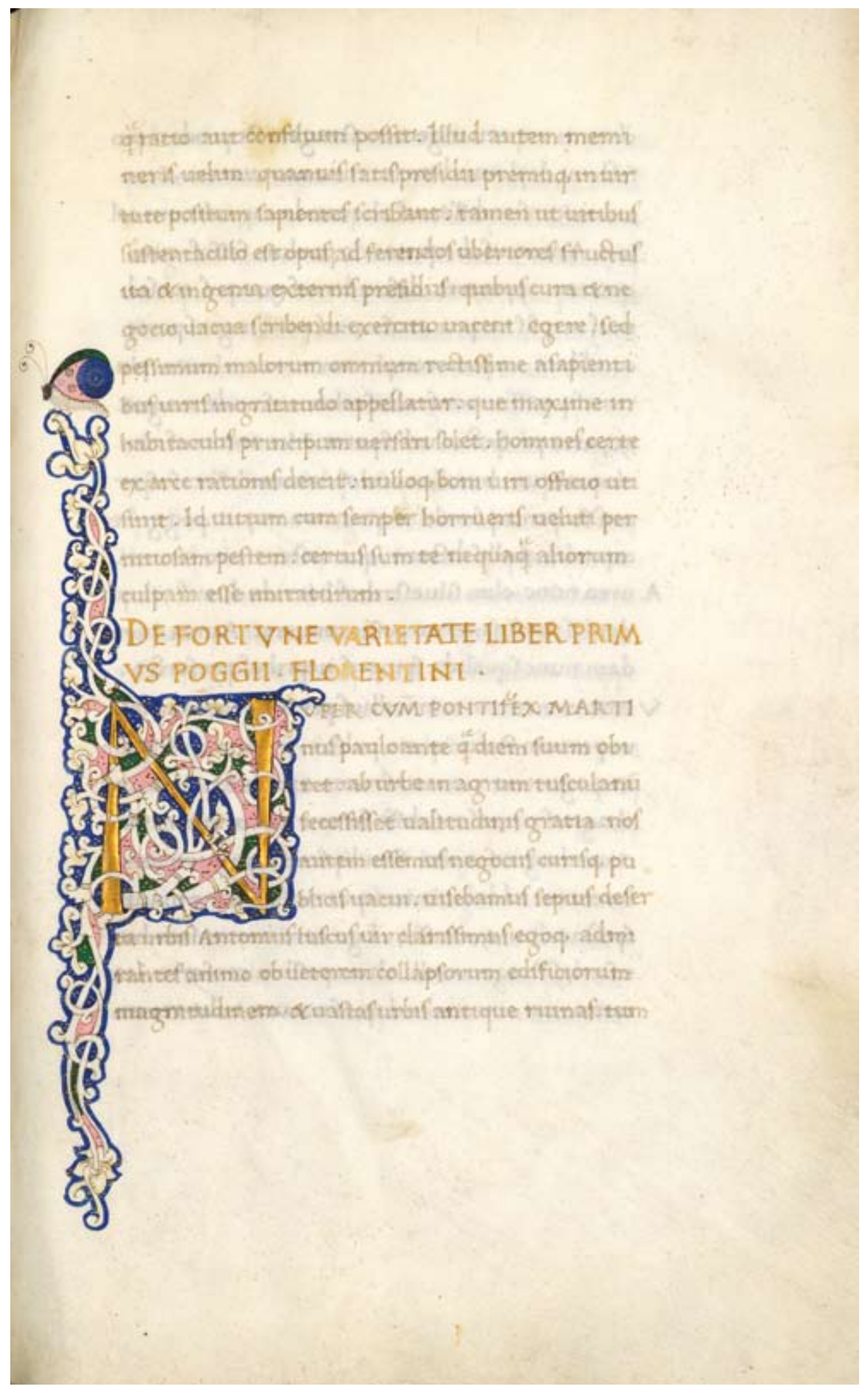




\section{Erstdruck der Resultate der ersten amerikanischen Volkszählung}

Return of the whole number of persons within the several districts of the United States. Philadelphia: Childs and Swaine, 1791.

Signatur: $8^{\circ}$ Hist. Am. II, 1661 Rara

Provenienz: Christoph Daniel Ebeling, 1797

Die erste Volkszählung in den USA begann am Montag, den 2. August 1790, wenig mehr als ein Jahr nach der Ernennung von George Washington (1732-1799) zum Präsidenten. Der Kongress wies die Verantwortlichkeit für die Zählung der Einwohner den Marshals der jeweiligen Staatsbezirke zu. Nach dem Gesetz für die Volkszählung mussten alle Haushalte besucht und dafür abgeschlossene Zeitpläne aufgestellt werden. Die sechs Befragungen im Jahr 1790 ermittelten den Namen des Familienoberhauptes und die Anzahl der im Haushalt lebenden Personen. Als Grundlage dienten folgende Kriterien:

- Number of houses

- Number of families

- Free white males of 16 years and upwards (zur Bestimmung des industriellen und militärischen Potentials des Landes)

- Free white males under 16 years

- Free white females

- All other free persons

- Slaves

- Total number

- Total of each town

Die erste Volkszählung ergab, dass die Nation aus weniger als vier Millionen Einwohnern einschließlich der 750.000 Sklaven bestand. (Die Bevölkerungszahl heute liegt bei 281,4 Millionen). Die Indianer als Ureinwohner des Landes tauchten in keiner Statistik auf. Die Bevölkerungsdichte der weißen Einwohner betrug 1,7 Personen pro Quadratkilometer, 97 Prozent der Bevölkerung wohnten in Orten mit weniger als 8.000 Einwohnern und die Hälfte der Amerikaner war unter 17 Jahre alt. Die meisten Einwohner lebten an der Ostküste. Ihr Wohlstand war bescheiden, aber weit gleichmäßiger verteilt als in der Alten Welt und als heute.

Der Erstdruck der Resultate der ersten amerikanischen Volkszählung trägt den handschriftlichen Namenszug von Thomas Jefferson (1743-1826). In seiner Funktion als Secretary of State signierte Jefferson die für die Kongressmitglieder bestimmten Exemplare. Der liberale Aufklärer Jefferson gilt als einer der einflussreichsten Staatsdenker der USA. 1776 verfasste er im Auftrag des Kongresses die Unabhängigkeitserklärung der Vereinigten Staaten von Amerika. Sie beinhaltet die Freiheit des Einzelnen und Gleichheit aller Menschen sowie die Gewaltenteilung in Legislative, Judikative und Exekutive. 1790-1793 wirkte er unter George Washington als Außenminister. Nach seiner Amtszeit als dritter Präsident der Vereinigten Staaten (1801-1809) nahm Jefferson als politischer Berater weiterhin Einfluss auf das politische und gesellschaftliche Leben des Landes.

(KN/DW) 


\section{$\left[\begin{array}{lll}5^{6} & ]\end{array}\right.$}

Schedule of the wbole number of perfons in the territory of the United States of America, South of the River Obio, as taken on the laft Saturday of Fuly 1791, by the Captains of the Militia witbin the limits of their refpective diftricts.

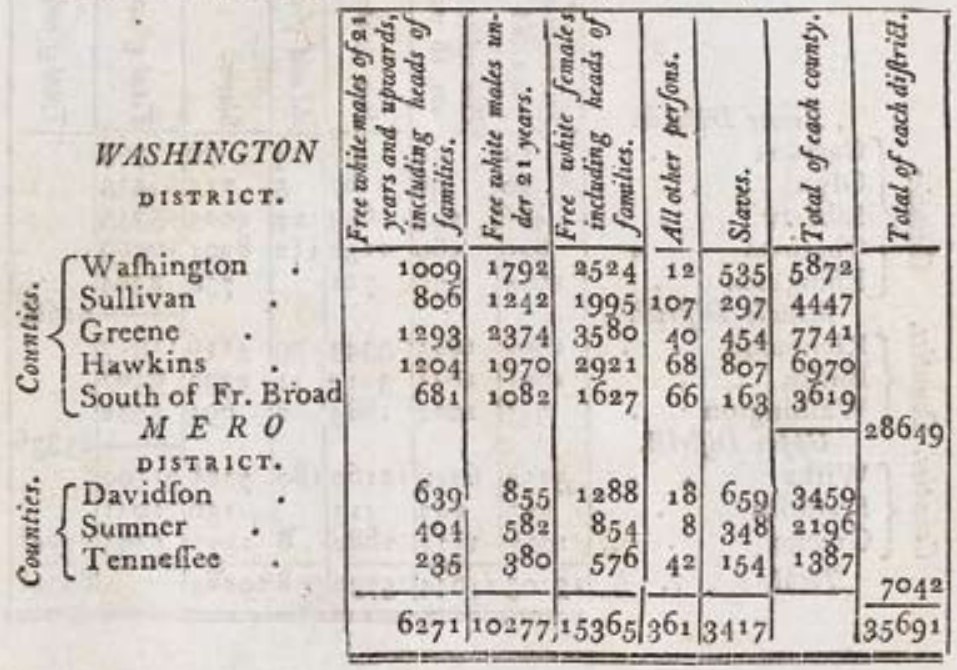

Note. There are feveral Captains who have not as yet returned the Scheduies of the numbers of their diftricts, namcly : In Greene County, threc-in Davidfon, one-and South of French-Broad, one diftriet.

$$
\text { September 19th, } 179 \text { r. }
$$

$\mathrm{W}^{\mathrm{m}}: \mathrm{BLOUN}$ T.

By the Governor;

DANIEL SAITH, Secretary.

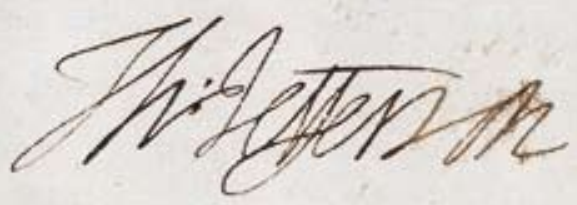




\section{Kaiserbiographien in einer italienischen Handschrift}

Gaius Suetonius Tranquillus:

De vita et moribus Caesarum.

Pergamenthandschrift,

Italien, um 1480.

Signatur: $2^{\circ}$ Cod. Ms. philol. $161 \mathrm{Cim}$.

Provenienz: Johannes Christoph August Blauel, 1837

Diese prachtvolle Handschrift enthält die Kaiserbiographien Suetons (ca. 75-ca. 150), der am römischen Kaiserhof Karriere gemacht und verschiedene Sekretariatsstellen bekleidet, vor allem die Leitung der kaiserlichen Kanzlei mitsamt ihrer Korrespondenz beaufsichtigt hatte - eine sehr einflussreiche und mit Blick auf seine anschließende Betätigung als Schriftsteller zentrale Position. Den Wert seiner Darstellungen zu den Herrschern von Caesar bis Domitian macht der Reichtum an Details aus, die der Bücherwurm Sueton Plinius nennt ihn scholasticus - akribisch sammelnd und dokumentierend referierte. Der Fülle an Information steht freilich ein Minimum an Einsicht gegenüber. Sueton war kein großer Historiker, sondern beflissener Biograph mit der „Sichtweise eines Kammerdieners“. Immerhin ist sein Werk aber unterhaltend und befriedigte zu allen Zeiten ein gewisses voyeuristisches Interesse der Leserschaft.

Die um 1480 herum entstandene Handschrift ist in mehrfacher Hinsicht ein herausragendes Werk und eines der Glanzstücke der Bibliothek. Maßgeblich beteiligt war an ihrer Herstellung der paduanische Kalligraph Bartolomeo Sanvito, der am Ende des 15. Jahrhunderts in Rom im Umfeld des Pomponius Laetus, eines Pioniers auf dem Gebiet der Forschungen zur Antike und Begründer eines Accademia genannten Kreises von Altertumsfreunden, nachzuweisen ist.
Von zeitloser Schönheit und unglaublicher Frische sind bis heute die Zierseiten der Handschrift, von denen die 12 Biographien jeweils eingeleitet werden. Darauf sind regelmäßig der Name des Kaisers als Überschrift, der Beginn des Textes mit einer kunstvollen Zierinitiale und die Wiedergabe eines Münzportraits angeordnet. Benutzt wurden von Sanvito die Farben Gold, Ultramarinblau, Weinrot, Olivgrün und Purpurviolett. Es entspricht dem in der Accademia gepflegten Geist, wenn hier der Versuch unternommen wird, einen antiken Text mit authentischen, passenden Elementen zu schmücken. Dazu zählen die nach der Art einer römischen capitalis quadrata ausgeführten Initialen, vor allem aber die Münzbilder der Kaiser. Und in der Initiale „E“, mit der die Nerobiographie beginnt, erkennt man ein weiteres Antikenzitat: einen bocksbeinigen, bärtigen und gehörnten Pan, für den wahrscheinlich eine der Panfiguren der Sammlung Della Valle in Rom als Vorbild diente. Die qualitätvolle Handschrift wurde 1837 aus dem Besitz des Pfarrers Blauel (1766-1862) aus Obernjesa für einen nicht genannten Preis angekauft. Blauel hatte übrigens als Student in Göttingen bei Christian Gottlob Heyne gewohnt. 


\section{क्य И}

NERO DOMITI

VS CAESAR.

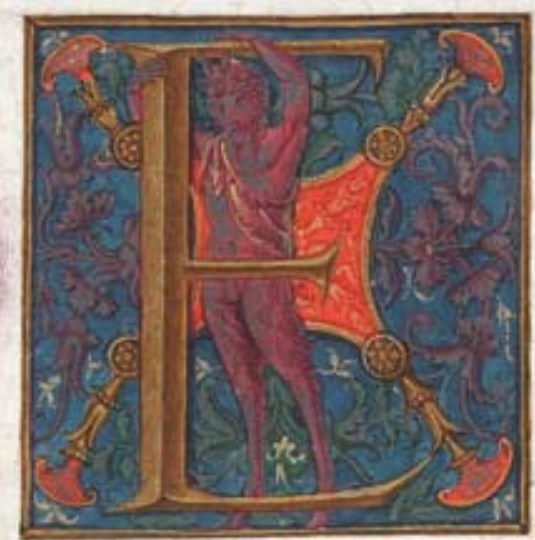

$X$ GENTE DOMI

TIA DVAE FAMI

LIAE CLARVE

RVNT: CAIVINO

RVM: ET AENEO 


\section{Eine solide Abstammung sichert die Zukunft}

Adelsbrief des Juan de Salcedo aus Atienza (Provinz Guadalajara, Spanien). Pergamenthandschrift, Spanien, 2. III. 1585.

Signatur: $2^{\circ}$ Cod. Ms. hist. $635^{\mathrm{m}}$ Cim.

Provenienz: H.W. Förster, nach 1894

Der in der Regierungszeit Philipps II. entstandene Adelsbrief ist eine reich illustrierte Pergamenthandschrift mit schwarzem, ehemals goldgepresstem Ledereinband. An einer gelbroten Schnur hängt das Bleisiegel des Königs. Juan de Salcedo, für den diese Urkunde erstellt worden ist, stammt aus einer alten Adelsfamilie der Stadt Atienza in der Provinz Guadalajara. Dem jungen Juan geht es in der Urkunde darum, seinen Blutsadel auf Grund seines Stammbaums nachzuweisen und sich rechtlich durch den König bestätigen zu lassen.

Die hier gezeigte Seite $18^{v}$ des Adelsbriefes ist inhaltlich und künstlerisch von großem Interesse. Es geht einerseits um die stammbaummäßige Absicherung der direkten Vorfahren väterlicherseits des Juan de Salcedo. Ein namentlich nicht genannter Zeuge bestätigt, dass Antonio de Salcedo und Catalina Goncales de Heredia Juans Eltern waren und dass Francisco de Salcedo wiederum eheliches Kind von Pedro de Salcedo (Urgroßvater von Juan) und Maria de Contreras war. Die Wappen der väterlichen Linie und die der Groß- und Urgroßmutter erscheinen in der Umrahmung des Textes. Andererseits fallen die Figuren aus der dämonischen Bildwelt des Hieronymus Bosch (um 1450-1516) auf, die die Wappen halten. Imitationen Boschs wie diese wurden zwar während des ganzen 16. Jahrhunderts produziert, doch warum ziert ein solches Bild einen Adelsbrief? Man mag an die Tradition der Drôlerien in Randleisten mittelalterlicher Handschriften denken und an eine Art stilistischer Aktualisierung der grotesken Einfälle, an ein originelles Zitat. Doch die Höllenwelt Boschs ist eben nicht grotesk, sondern die als real geglaubte, wenn auch visionäre Folge eines Lebens in Sünde. Weshalb also dieses Zitat? Juan de Salcedo, der eine Bestätigung seines Erbadels durch Philipp II. erwartete, wird in Text und Bild versucht haben, sich den König gewogen zu machen. Aber kann man sich Ihre allerkatholischste Majestät mit einem auf dem Rücken liegenden und sein Hinterteil zeigenden Dämon gewogen machen (Mitte der oberen Leiste)? Die Antwort ist: Ja, wenn man aus einem Gemälde zitiert, das sich im Besitz des Königs befindet. Philipp II. war ein geradezu manischer Sammler von Werken Boschs (oder was dafür gehalten wurde). Fray José de Sigüenza berichtet darüber in seiner Historia de la Orden de San Jerónimo (1605), und die Inventare der königlich spanischen Sammlungen legen eindringlich Zeugnis ab von der Leidenschaft, die Philipp II. für Gemälde Boschs hegte.

Wir werden daher die Miniatur von Seite $18^{\mathrm{v}}$ als Huldigung des Bittstellers an den Kunstgeschmack seines Königs verstehen dürfen: gleichsam als ästhetische Wurst, die nach der nützlichen Speckseite Adelsbrief geworfen wurde.

$(\mathrm{GU} / \mathrm{HF})$ 


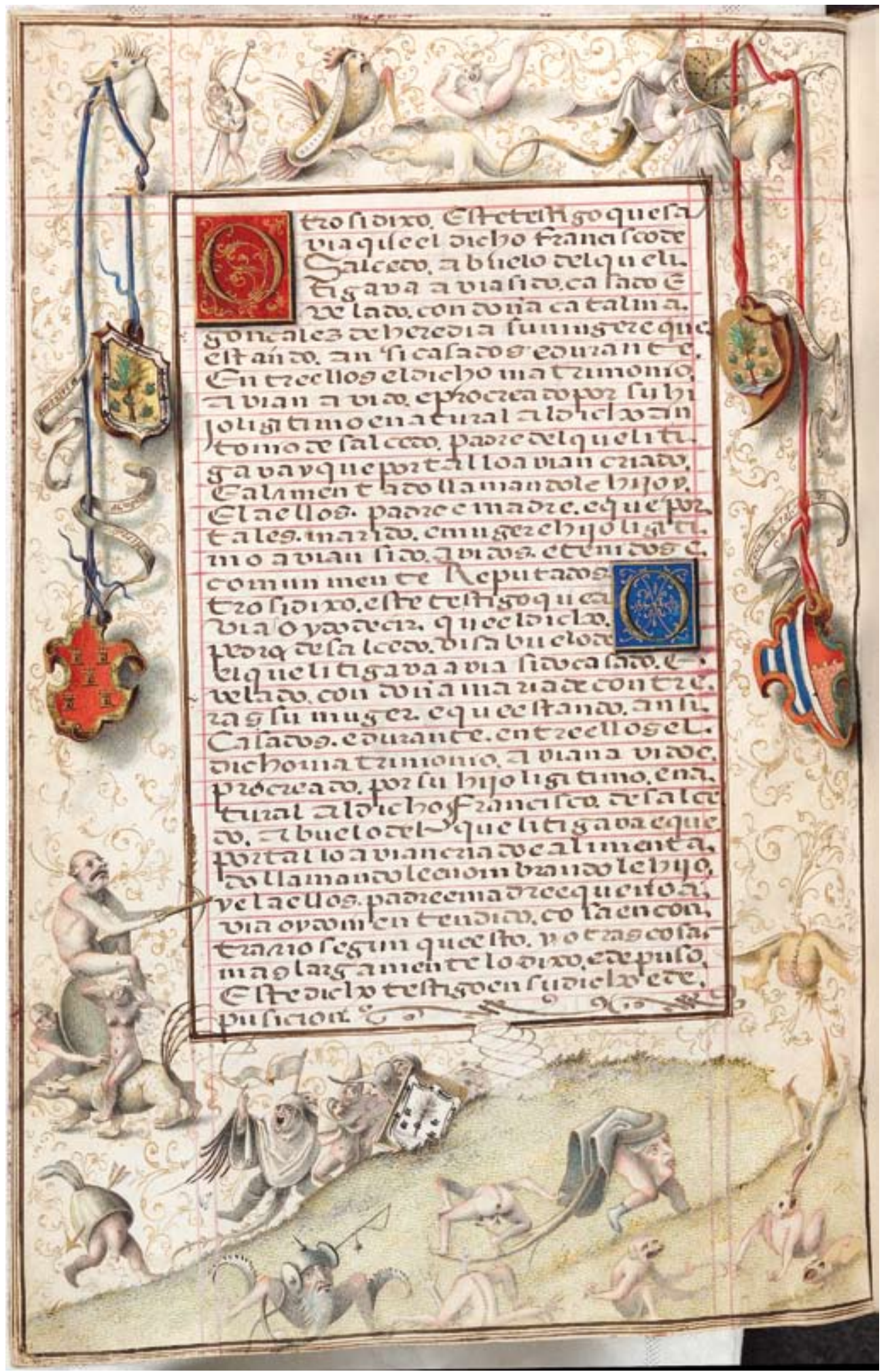




\section{Autographa Lutheri}

Die Göttinger Universitätsbibliothek besitzt einen umfangreichen Bestand an Drucken, die mit der Person Martin Luthers als Verfasser, Übersetzer oder Herausgeber verknüpft sind und während des 16 . Jahrhunderts gedruckt wurden. Insgesamt handelt es sich um ca. 1.300 Ausgaben seiner Schriften, deren größter Teil die Signatur „Autographa Lutheri“ trägt. Mit dem Begriff „Autographa“ sind hier nicht eigenhändige Schriftstücke, sondern Erstdrucke und Frühdrucke gemeint, die bis 1546 erschienen sind. Dieser Kernbestand an Lutherdrucken wurde seit dem 18. Jahrhundert aus ganz unterschiedlichen Quellen erworben, und etwa um das Jahr 1830 wurden diese Drucke in einer eigenen Signaturgruppe zusammengefasst. Der handschriftliche Katalogband 141 des Systematischen oder Realkatalogs der Bibliothek erfasst die Lutherdrucke nach Formaten und innerhalb des Formats chronologisch. Auch heute noch werden antiquarisch oder auf Auktionen erworbene Lutherdrucke in diesen Katalog unter der Signatur „Autographa Lutheri“ mit einer Bandzahl eingetragen, wobei gleichzeitig eine maschinenlesbare Katalogisierung des Titels erfolgt.

Neben den „Autographa Lutheri“" finden sich zahlreiche gedruckte Lutherschriften in der Signaturgruppe „Oskar und Ilse Mulert Stiftung“ (s. Kapitel 10), eine Sammlung mit etwa tausend Drucken aus der Reformationszeit, von denen knapp die Hälfte als Lutherdrucke eingestuft werden kann. Weitere Einzeldrucke Luthers sind in den Literaturgruppen „Theologia“ und „Historia ecclesiastica“ zu 


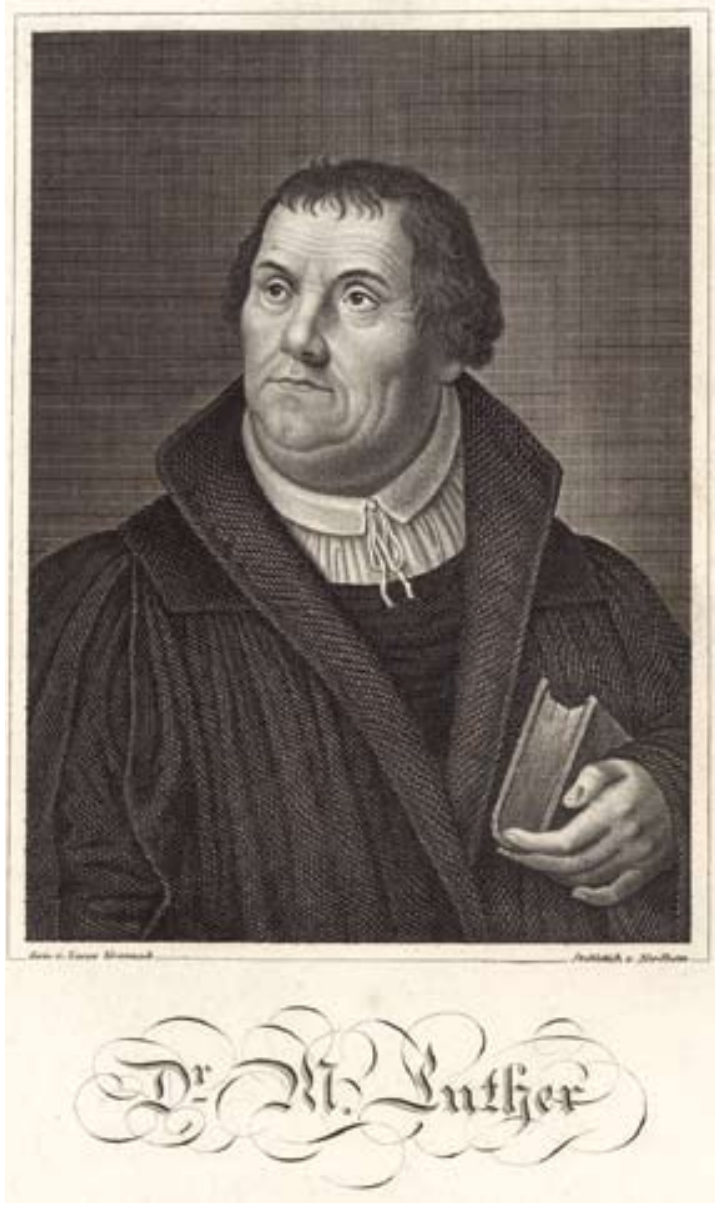

finden. Insgesamt ist die Göttinger Sammlung von Lutherdrucken eine der bedeutendsten ihrer Art in Deutschland, so dass im Jahr 1967 ein gedruckter Katalog dieses Sonderbestands von Helmut Kind veröffentlicht wurde (Die Lutherdrucke des 16. Jahrhunderts und die Lutherhandschriften der Niedersächsischen Staats- und Universitätsbibliothek Göttingen). $\mathrm{Zu}$ den wertvollsten Erwerbungen der letzten zehn Jahre in der Gruppe der Lutherdrucke zählt die dritte Ausgabe des Kleinen Katechismus (1536), von der nur dieses eine Exemplar erhalten geblieben ist.

(HR) 


\section{Von der babylonischen Gefangenschaft}

Martin Luther:

De captivitate Babylonica ecclesiae.

Wittenberg: Melchior Lotter d. J., 1520.

Signatur: $8^{\circ}$ Aut. Luth. 81

Provenienz: Autographa Lutheri

In rascher Folge veröffentlichte Martin Luther (1483-1546) im Jahre 1520 drei Schriften, die aufgrund ihrer herausragenden Bedeutung für seine Lehre als „reformatorische Hauptschriften“ bezeichnet werden: An den christlichen Adel deutscher Nation von des christlichen Standes Besserung (August 1520), De captivitate Babylonica ecclesiae (Oktober 1520) und Von der Freiheit eines Christenmenschen (November 1520). In der umfangreichsten dieser Schriften, die Luther in lateinischer Sprache verfasste, mithin an die Gelehrten und Theologen gewandt, beschäftigt er sich mit theologischen Fragestellungen. Luther wendet sich in scharfer polemischer Haltung gegen die traditionelle Lehre von den sieben Sakramenten der Taufe, Firmung, Eucharistie, Buße, Ehe, Priesterweihe und Letzten Ölung und lässt ihrer lediglich drei zu: Taufe, Eucharistie und (in eingeschränktem Maße) Buße. Durch das Papsttum, das Luther, auf die Babylonische Gefangenschaft Israels Bezug nehmend, mit dem Reiche Babylon gleichsetzt, und seine Hinwegsetzung über das Wort Gottes seien die Sakramente „in elende Gefangenschaft geraten, und die Kirche ist all ihrer Freiheit beraubt“". Im Mittelpunkt seiner Ausführungen steht die Abendmahlslehre, die durch die Verweigerung des Laienkelches, die Transsubstantationslehre und die Lehre von der Messe als gutem Werk und Opfer in dreifache Gefangenschaft geraten sei.
Das Werk trug in erheblichem Maße zu einer Polemisierung um die Gestalt Luthers und seiner Lehre bei: Der Häresievorwurf gegen den Reformator wurde in der Folgezeit wiederholt eben an der Babylonica festgemacht. Als einer der prominentesten Verteidiger der römischen Kirche wandte sich König Heinrich VIII. von England (1491 - 1547; reg. 1509-1547) mit seiner Schrift Assertio septem sacramentorum adversus Martinum Lutherum (1521) öffentlich gegen Luther. Sie trug ihm auf Veranlassung von Papst Leo X. den Ehrentitel „Defensor fidei“ ein - wenige Jahre bevor Heinrich VIII. selbst in einen folgenreichen Konflikt mit dem Papsttum geraten sollte. 


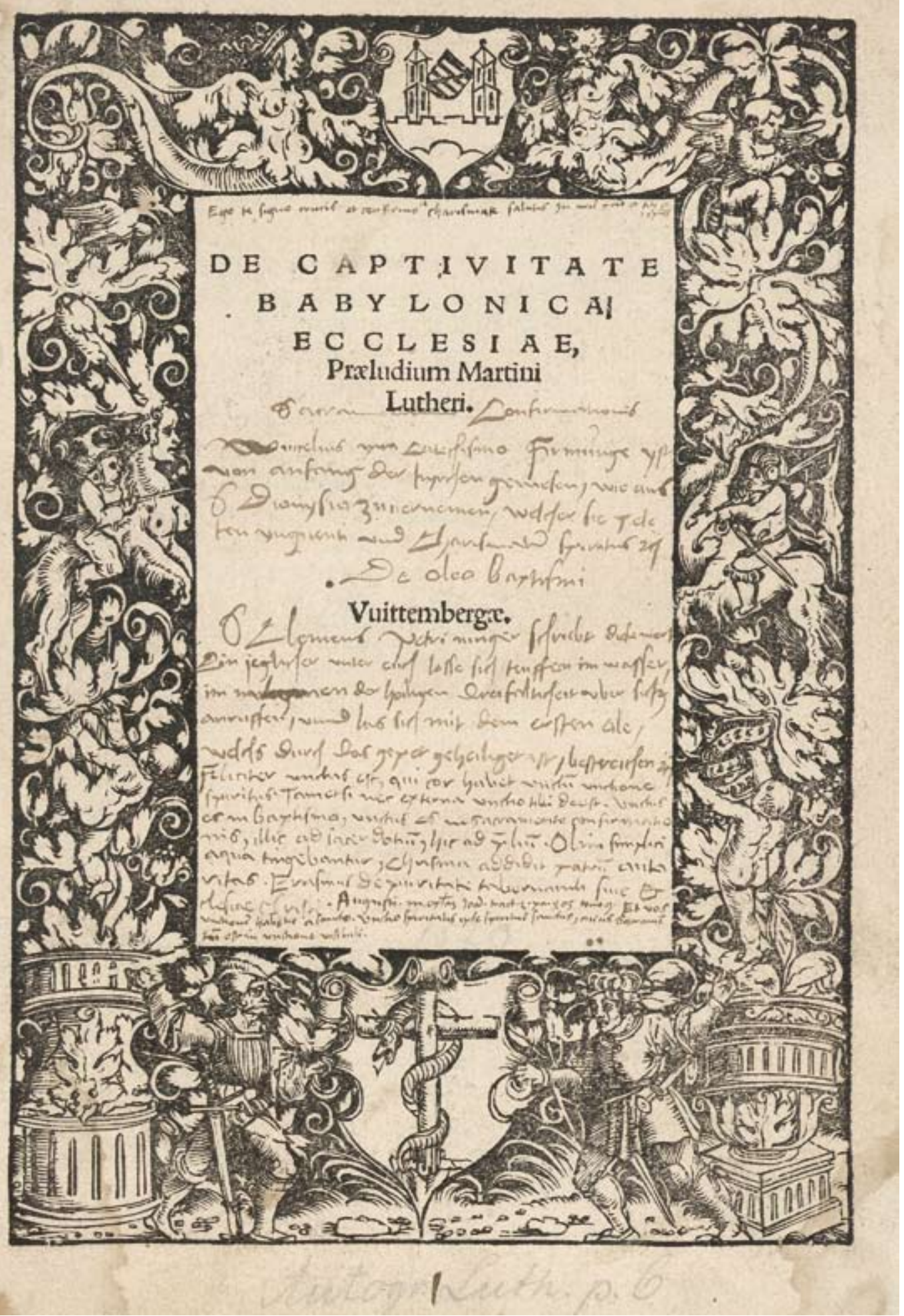




\section{Das Septembertestament}

[Martin Luther:]

Das Newe Testament Deutzsch.

Wittenberg: Melchior Lotter d. J., 1522.

Signatur: $4^{\circ}$ Bibl. II, 1922 Rara

Provenienz: Autographa Lutheri

Mitte Dezember 1521 begann Martin Luther (1483-1546) auf der Wartburg mit der Übersetzung des Neuen Testamentes in das Hochdeutsche, die er bereits Ende Februar 1522 abschloss und unmittelbar nach seiner Rückkehr nach Wittenberg im März 1522 mit dem Professor für Hebraistik und Gräzistik Philipp Melanchthon (1497-1560) redigierte. Als Quelle stand Luther die 1519 in Basel in zweiter Auflage erschienene Ausgabe des griechischen Urtextes mit lateinischer Übertragung und Anmerkungen des Erasmus von Rotterdam zur Verfügung. Ergänzend fügte er Vorreden und zahlreiche erläuternde Randglossen hinzu. Die den biblischen Text beschließende Offenbarung des Johannes wurde mit 21 ganzseitigen Holzschnitten aus der Werkstatt Lucas Cranach d. Ä. (1472-1553) versehen, die sich eng an Albrecht Dürers vierzehn Holzschnitte zur Apokalypse (1498-1511) anschlossen. Nach fünfmonatiger Druckzeit in der Offizin von Melchior Lotter d. J. im Verlag von Lucas Cranach d. Ä. und Christian Döring am 29. September 1522, rechtzeitig zum Beginn der Leipziger Herbstmesse, erschienen, wurde dem Werk ein überwältigender Erfolg zuteil: Trotz eines Stückpreises von etwa anderthalb Gulden, der dem Dreimonatsgehalt eines Schulmeisters entsprach, war die Erstauflage von ca. 3.000 Exemplaren binnen dreier Monate vergriffen, und bereits im Dezember desselben Jahres folgte eine zweite, verbesserte Auflage.

Luthers Werk - nach Teilübersetzungen des Alten Testamentes erschien 1534 die erste Vollbibel in seiner Übertragung - steht keines- falls am Beginn der deutschsprachigen Bibelübersetzung: Bereits vor 1522 gab es nicht weniger als vierzehn hochdeutsche Vollbibeln. Ihre Wirkung blieb jedoch aufgrund ihres veralteten, eng die lateinische Vorlage der Vulgata imitierenden Sprachbildes eingeschränkt. Luthers Absicht war es demgegenüber, gemäß seiner Lehre von der Heiligen Schrift als der höchsten Autorität in Glaubensdingen einen Text vorzulegen, der auch Laien verständlich war. Im Sinne des Humanismus wandte er sich den griechischen und hebräischen Urtexten zu, legte seiner Übersetzung die überregional verbreitete sächsische Kanzleisprache zugrunde und erhob die Sinngemäßheit seiner Formulierungen als Übersetzungsprinzip. Wie sehr er damit einem weitverbreiteten Interesse entgegenkam, beweist der Erfolg seines Unterfangens: Bis zu Luthers Tod 1546 sollten mehr als 300 hochdeutsche Bibelausgaben mit einer Gesamtauflage von über einer halben Million Exemplaren erscheinen, eine für die Frühzeit des Buchdruckes ungeheure Menge. Als sprachliches Kunstwerk und Meilenstein innerhalb der Standardisierung des heutigen Hochdeutschen ist die Lutherbibel auch außerhalb der Religionsgeschichte von herausragender Bedeutung.

Aufgeschlagen ist eine Offenbarung 9, Vs. 1-12 begleitende Illustration: Aus dem Rauch des Brunnens des Abgrundes steigen gepanzerte und mit Stacheln bewehrte Heuschrecken mit menschlichen Antlitzen, die alle Menschen quälen, die nicht das Siegel Gottes tragen.

(SG) 


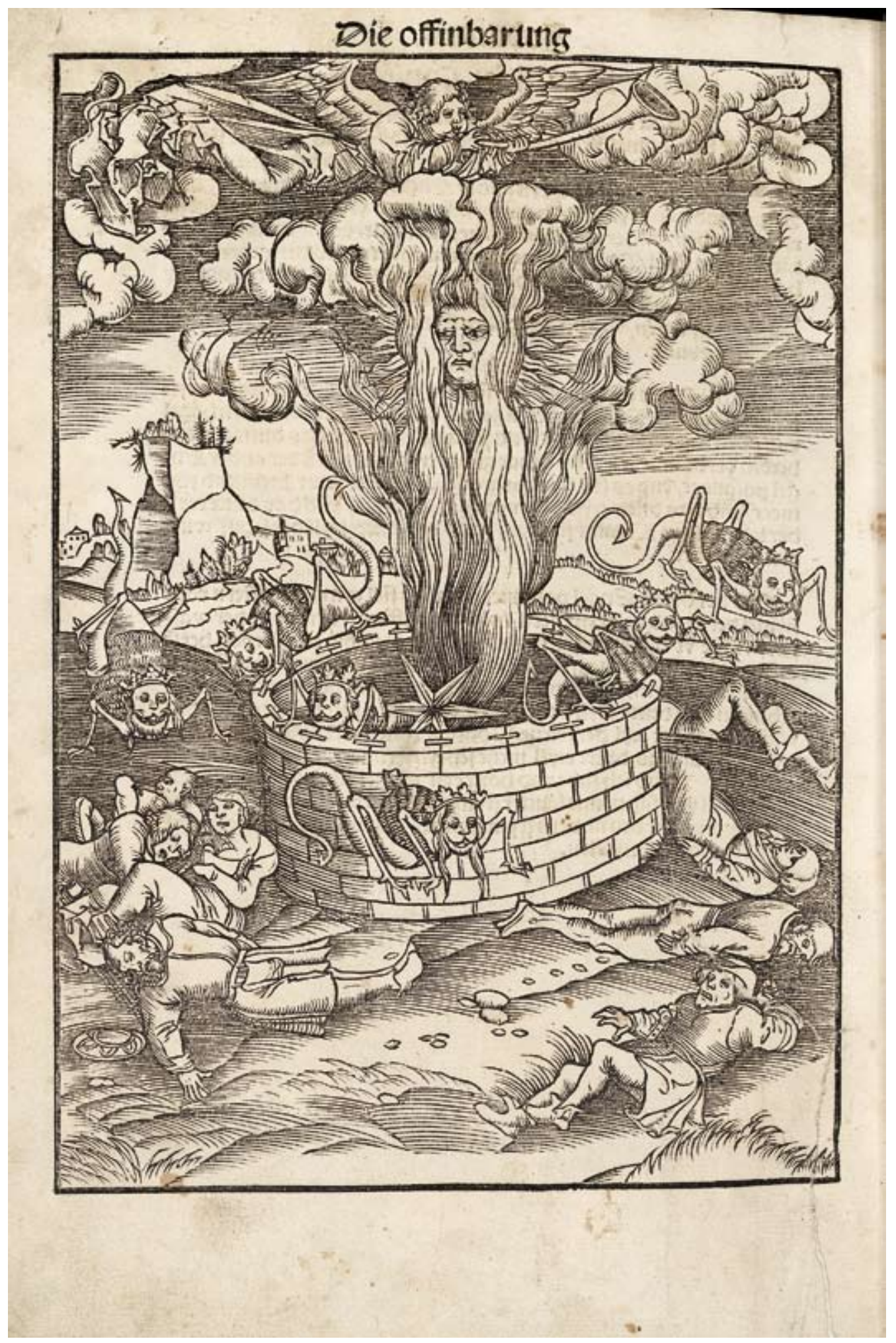




\section{Der kleine Katechismus}

Enchiridion: Der kleine Catechismus für die gemeine Pfarher vnd Prediger

Wittenberg: Nickel Schirlentz, 1536.

Signatur: $8^{\circ}$ Aut. Luth. 1432

Provenienz: Autographa Lutheri

Der Kleine Katechismus Martin Luthers gehört zu den Bekenntnisschriften des Reformators, gleichsam zum Grundgerüst des lutherischen Glaubens. In dem Text fasste Luther die wesentlichen Elemente der christlichen Lehre knapp zusammen mit dem Ziel, dass die Kinder sie in der Schule auswendig lernen können. Der Katechismus enthält in Frage und Antwort Aussagen zu den zehn Geboten, dem Glaubensbekenntnis, dem Vaterunser, der Taufe, der Beichte und dem Abendmahl. Die Dialogform war aus der lateinischen Literatur übernommen und erwies sich als besonders förderlich für die Verbreitung der reformatorischen Ideen. Von Beginn an war der 1529 erstmalig gedruckte Katechismus als Lehrschrift für den christlichen Unterricht gedacht, und deshalb erschienen bis 1543 insgesamt elf Auflagen des Textes. Wegen ihres intensiven Gebrauchs im Unterricht existieren von diesen ersten elf Auflagen heute nur noch 15 Exemplare, und von der dritten Auflage aus dem Jahr 1536 hat sich nur dieses eine Stück erhalten. Das Werk wurde in Wittenberg von Nicolaus Schirlentz gedruckt, es ist mit insgesamt 24 Holzschnitten nach Lucas Cranach und mit zweifarbig gedruckten Holzschnitteinfassungen verziert.

Nicolaus oder Nickel Schirlentz ließ sich 1521 in Wittenberg nieder und druckte neben dem Kleinen Katechismus in Hoch- und Niederdeutsch unter anderem die niederdeutsche Ausgabe des Alten Testaments (1525) und zahlreiche Flugschriften der Reformatoren. Die Bibliothek erwarb den seltenen Druck 1996 beim Stuttgarter Antiquariat.
Der Kleine Katechismus ist eines der wenigen Lehrbücher des kirchlichen Religionsunterrichts, das in mehr oder weniger unveränderter Form auch heute noch Verwendung findet. Auf dem Titelblatt ist zu lesen, dass das Buch in erster Linie für die ,gemeinen Pfarrherren und Prediger“ bestimmt sei, aber im Vorwort richtet sich Luther auch an die „Hausväter“ und empfiehlt, ,dass sie sich täglich im Katechismus, so der ganzen Heiligen Schrift eine kurze Summa und Auszug ist, wohl üben und den immer treiben wollen“. Damit zeigt sich die Intention des Reformators, das Buch nicht nur für den schulischen, sondern insgesamt für den christlichen Glaubensunterricht einzusetzen. Die Niedersächsische Staats- und Universitätsbibliothek besitzt heute eine Sammlung von mehr als 1.300 Lutherdrucken. Von den meisten der insgesamt ca. 3.900 Ausgaben ist der Erstdruck vorhanden. 
Das SArrantent set beiligen Eauffe/gBic baffels bigge eirr 3 ants vater faitrens gefinto fol einfeltighich firs baltert.

\section{Die Sigur, Yratthej XXVIIr}

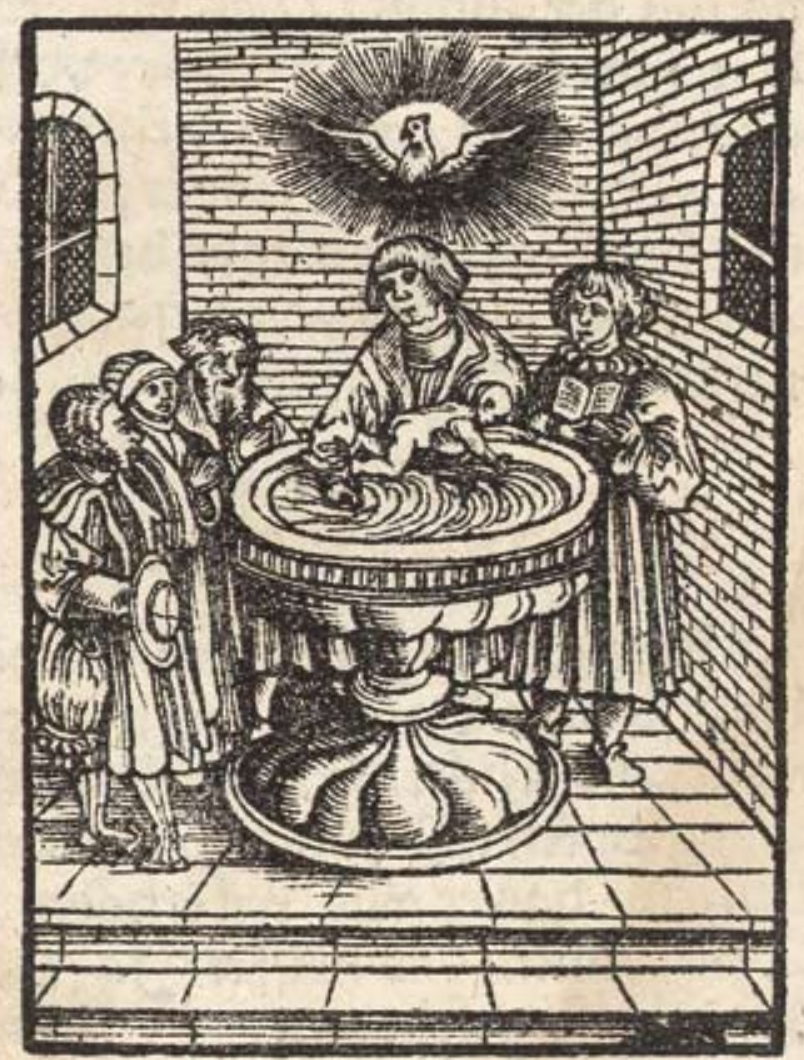




\section{Kapitel 12}

\section{Die Sammlung Deutscher Drucke des 18. Jahrhunderts}

So bedeutend die Bereicherung des Bibliotheksbestandes durch den Zugang von Einzeltiteln, ganzen Sammlungen oder Teilen daraus in der Vergangenheit gewesen ist, so wichtig ist der Hinweis darauf, dass seltene, wichtige und schöne historische Drucke auch heute und in Zukunft einen Platz in den Bücherregalen der Universitätsbibliothek finden können. Ein Weg dahin ist schon vor Jahren durch die Teilnahme der Bibliothek an einem kooperativen Erwerbungsprogramm mit nationalbibliothekarischem Anspruch frei gemacht worden. Seit 1989/90 ist die Niedersächsische Staats- und Universitätsbibliothek Göttingen Partner in der Arbeitsgemeinschaft Sammlung Deutscher Drucke mit dem Auftrag, fehlende Werke des 18. Jahrhunderts aus dem deutschsprachigen Raum auf dem Markt zu beschaffen und einem interessierten Publikum zur Verfügung zu stellen. Dieser besondere Sammelauftrag basiert auf einer 1983 von Bernhard Fabian vorgetragenen Konzeption: Um in Deutschland das Fehlen einer gewachsenen Nationalbibliothek wie zum Beispiel in England oder Frankreich zu kompensieren, sollten einige, an historischen Beständen besonders reiche Bibliotheken mit der Ergänzung ihrer Sammlungen und der Bildung einer „verteilten“ Sammlung des gedruckten Kulturgutes aus dem deutschen Sprachraum beauftragt werden. Partner des arbeitsteiligen Unternehmens sind bis heute die Bayerische Staatsbibliothek München (1450-1600), die Herzog-August-Bibliothek Wolfenbüttel (1601-1700), die Niedersächsische Staats- und Universitätsbibliothek Göttingen (1701-1800), die Universitätsbibliothek Johann Christian Senckenberg Frankfurt/Main (1801-1870), die Staatsbibliothek zu Berlin - Preußischer Kulturbesitz (1871-1912) und die Deutsche National- bibliothek Frankfurt/Main, Leipzig, Berlin (ab 1913). Mit beträchtlichem Einsatz hat die Stiftung Volkswagen während der ersten fünf Jahre die Finanzierung übernommen und damit nicht nur eine solide Basis geschaffen, sondern auch kräftige Impulse für die Weiterführung des Projektes gegeben.

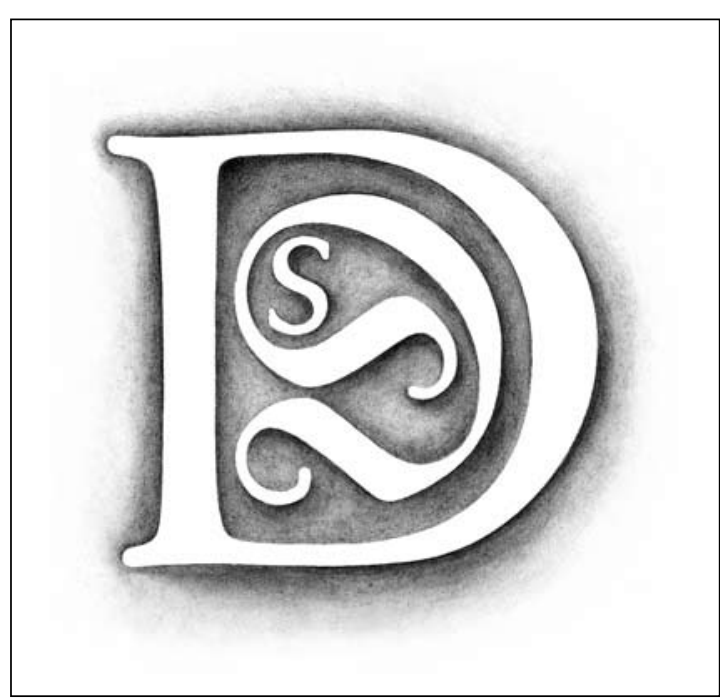

Logo der Arbeitsgemeinschaft Sammlung Deutscher Drucke.

Zum Erfolg können diese gemeinsame Anstrengung nur kontinuierliche Arbeit und ein langer Atem führen. Aufmerksame Beobachtung des Buchmarktes, intensive Kenntnis eigener Bestände, sorgfältige Bewertung der Objekte und nicht zuletzt ausreichende finanzielle Möglichkeiten sind die notwendigen Voraussetzungen für das große Ziel. Dennoch ist allen Beteiligten klar, dass eine lückenlose Dokumentation aller Druckwerke aus über 500 Jahren noch viel Zeit und Aufwand benötigen wird. Aber nicht ohne Stolz kann die Arbeitsgemeinschaft darauf verweisen, dass sie die Marke von 100.000 erworbenen Titeln schon hinter sich gelassen hat. 
Darin enthalten sind auch die Göttinger Anschaffungen für das 18. Jahrhundert, mit denen die in der Bibliothek schon vorhandenen Titel regelmäßig ergänzt werden: Häufig handelt es sich dabei um ursprünglich fremdsprachige Literatur in deutschen Übersetzungen, auf deren Beschaffung im Zeitalter einer europäisch denkenden „Gelehrtenrepublik“ zu Gunsten einer Erwerbung des Originals verzichtet wurde, sogenannte graue Literatur, Gebrauchsliteratur oder Belletristik. Jede Anschaffung verbessert - vor Ort und darüber hinaus - die Versorgung mit historischen Dokumenten und schließt eine kleine Lücke im „kulturellen Gedächtnis“.

(JM) 


\section{Seltene Farben- und Pflanzenpracht}

Joannis Martyn:

Historia Plantarum Rariorum - Beschreibung seltener Pflanzen.

Nürnberg: Andreas Bieling, 1752.

Signatur: DD 90 D 33286 Rara

Provenienz: Sammlung Deutscher Drucke des 18. Jahrhunderts, 1990

In der Vorrede der Historia Plantarum Rariorum, erstmals gedruckt in London 1728, gab der Autor Joannis Martyn kund, er sei ,auf die Gedancken gekommen: ich würde den Liebhabern der Kräuterkunde keinen unangenehmen Dienst erweisen, wenn ich dem Mangel der Abbildungen durch die geschickte Hand eines vortrefflichen Künstlers abzuhelffen trachtete, und dergleichen mit beygefügter Beschreibung gemein machte.“ Es war in der Tat kein „unangenehmer Dienst“, den er der Nachwelt erwies. Zusammen mit dem Künstler Jacob van Huysum, Bruder des berühmten holländischen Blumenmalers Jan van Huysum, betrat er 1728 mit seiner Darstellung einiger seltener Pflanzen, die vom Kap der Guten Hoffnung, aus Nordamerika und aus Westindien stammten, drucktechnisches Neuland. Als einer der ersten setzte er den Mehrfarbendruck ein, wobei zwei und mehr Farben auf einmal von einer einzigen Metallplatte stammten. Seine Veröffentlichung war überdies eines der ersten botanischen Werke in Farbendruck überhaupt. „Dieses aber ist nun auf eine neue, und wie ich hoffte so zierlich als nützliche Weisse geschehen; indem die Abbildungen mit ihren natürlichen Farben abgedruckt worden. Denn gleichwie viele Kleinigkeiten beschrieben werden, welche der Mahler übersiehet: also kann hingegen die Mahlerkunst die Mannigfaltigkeit der Farben am besten darstellen.“
Mit 50 teilweise von Hand in Feinheiten nachdekorierten, in farbiger Mezzotino-Technik gedruckten Tafeln und einer großen, der Vorrede vorangestellten Vignette, ebenfalls in Mezzotinto, entstand so in England eines der ersten Prachtwerke der Botanik. In Deutschland nahm sich der Porträt- und Miniaturmaler Johann Daniel Meyer aus Nürnberg der Aufgabe an, eine zweite Ausgabe dieses Werks herauszugeben (aus dem oben zitiert wurde). 1752 ging die Beschreibung Seltener Pflanzen ihrer Fürtrefflichkeit wegen von neuem herausgegeben durch Johannes Daniel Meyer: Miniatur Mahler mit einem deutsch-lateinischen Paralleltext bei Andreas Bieling in Nürnberg in Druck. Die Nachstiche Meyers, die sich durch eine außerordentliche Sorgfalt in der Wiedergabe aller Einzelheiten auszeichnen, zeigen als genaue Kopien der Originale die verschiedenen Aspekte der jeweiligen Pflanze vom Samen über die Blüte bis zur Frucht, einschließlich einzelner Blütenbestandteile und Wurzeln. Unterhalb der Abbildungen erscheinen gedruckt die lateinischen Namen der Pflanzen, die in den Texten zu den Platten I-L bezüglich ihrer Herkunft und Entdeckung, ihres Aussehens, ihrer Standortbedingungen, ihrer Aussaat-, Blüteund Erntezeit, ihrer möglichen Verwendung in der Heilkunde und sonstiger Besonderheiten genauestens beschrieben werden. 


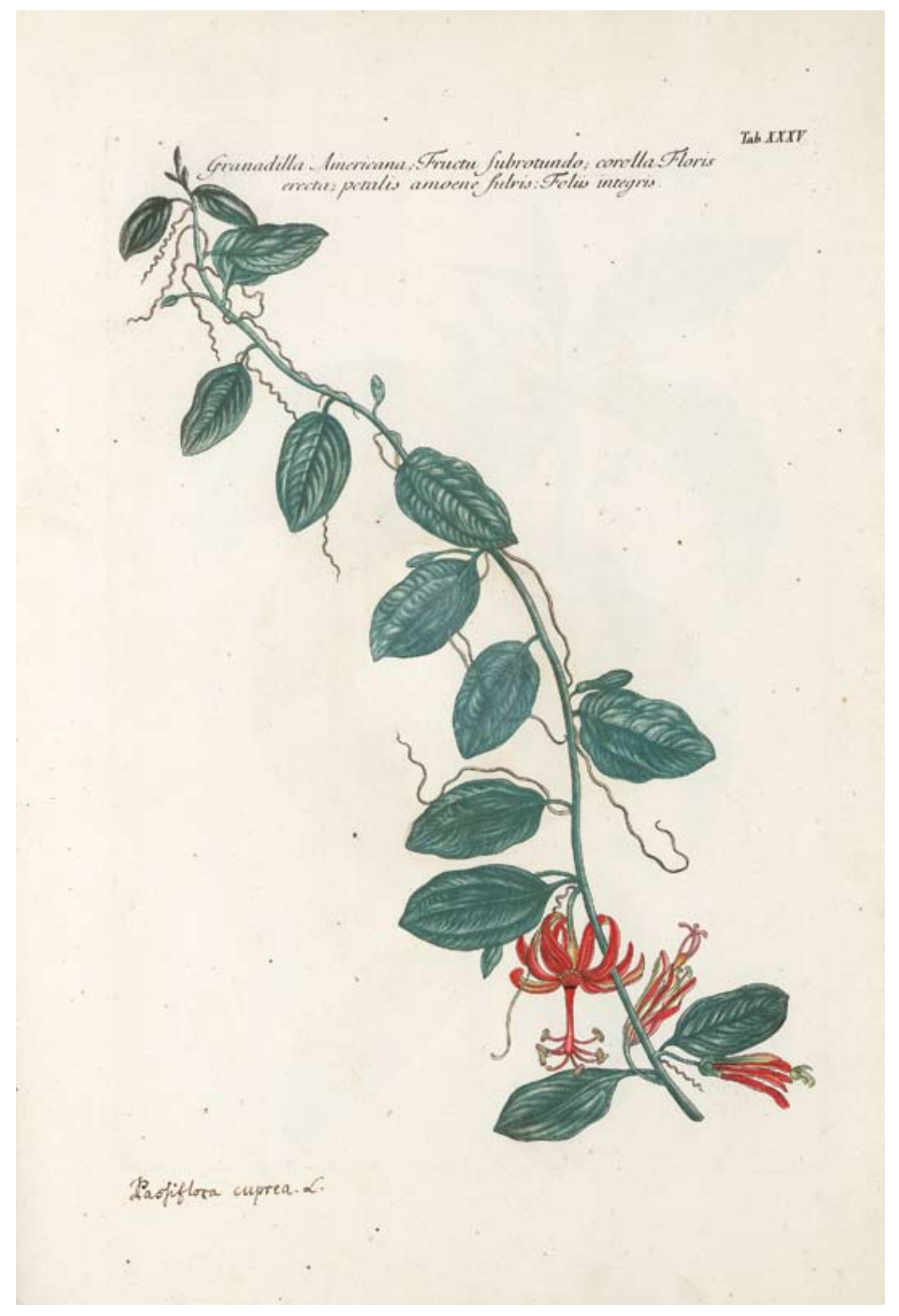




\section{Die wunderbaren Verwandlungen Ovids}

Publius Ovidius Naso:

Verwandlungen. In Kupfern vorgestellt, und mit nöthigen Erläuterungen versehen. Wien: Ignaz Alberti, 1791.

Signatur: DD 91 A 33260 Rara

Provenienz: Sammlung Deutscher Drucke des 18. Jahrhunderts, 1991

„Obschon wir Jahrtausende über die Zeit der Fabeln hinaus sind; so hat sich doch ihr Andenken bis diese Stunde noch sehr lebhaft erhalten. Wir pflanzen sie in den Werken der Dichtkunst, des Griffels, Pinsels und Meißels fort...“ (Vorrede Ovids Verwandlungen, 1791). Die Metamorphosen des römischen Dichters Ovid (43 v. Chr.-17/18 n. Chr.) zählen zu den beliebtesten und wirkungsmächtigsten Werken antiker Autoren. Ihr Einfluss auf die europäische Literatur-, Kunst- und Kulturgeschichte kann kaum hoch genug eingeschätzt werden. In fünfzehn Büchern und rund 12.000 Versen wird von den Lieben und Intrigen der Götter und ihrem Eingreifen in die irdische Sphäre berichtet. In einem Kranz von Erzählungen um den ständigen Wandel, dem alles Belebte und Unbelebte unterworfen ist, spannt Ovid den Bogen von der Schöpfung der Welt bis zur Apotheose Julius Cäsars und zur Verherrlichung des Kaiserreichs.

Eine Fülle von Übertragungen in die Volkssprachen, Bearbeitungen und Kommentaren zeugt von einer nahtlosen Vermittlung seines Werks in allen Kulturen. Mit Beginn des Buchdrucks eroberte es sogleich den Markt. Seine Geschichten galten nicht nur als Vorbild der Erzählkunst, Hort enzyklopädischen Wissens und moralischer Werte; sie boten zudem ein enormes Motiv-Repertoire, aus dessen Vorrat Künstler jeder Profession jahrhundertelang schöpften. Die Metamorphosen waren so zum Inspirationsquell für mythologische Darstellungen geworden, und textbegleitende Druckgrafik - Holzschnitte, später Kupferstiche und Radierungen -, populäre Serien und Kopien ließen einen riesigen Fundus gewisser Darstellungstypen entstehen: eine Art Vorlagensammlung für bildende Künstler. So orientiert sich auch die dreibändige Wiener Ausgabe Ovids Verwandlungen. In Kupfern vorgestellt, und mit nöthigen Erläuterungen versehen, 1791 von einer Gesellschaft in Wien herausgegeben und bei Ignaz Alberti gedruckt, an einem französischen Prachtdruck von 1767. Im Jahr 1791 gab es überdies eine mit Albertis Druck nahezu identische Ausgabe, gedruckt bei Schwalbacher in Wien; aber Albertis Werk enthielt im Vergleich mit der Ausgabe seines Konkurrenten sieben zusätzliche Textseiten.

Vor jedem Kapitel findet sich in dieser Ausgabe ein Kupferstich mit erklärender Bildunterschrift, der Wesentliches der Haupthandlung darstellt. Die insgesamt 139 Tafeln mit drei Titelstichen, unten rechts signiert, stammen von den Graveuren Benedicti, Stöber, Mansfeld, Bauer, Grüner, Mark, Stenger, Ponheimer, Schindelmayer, Gerstner, Blaschke, Peni, Conti und Antropp. Zusammen schufen sie eines der Hauptwerke der Wiener Stecherschule und der klassizistischen Stechkunst in Wien überhaupt. 


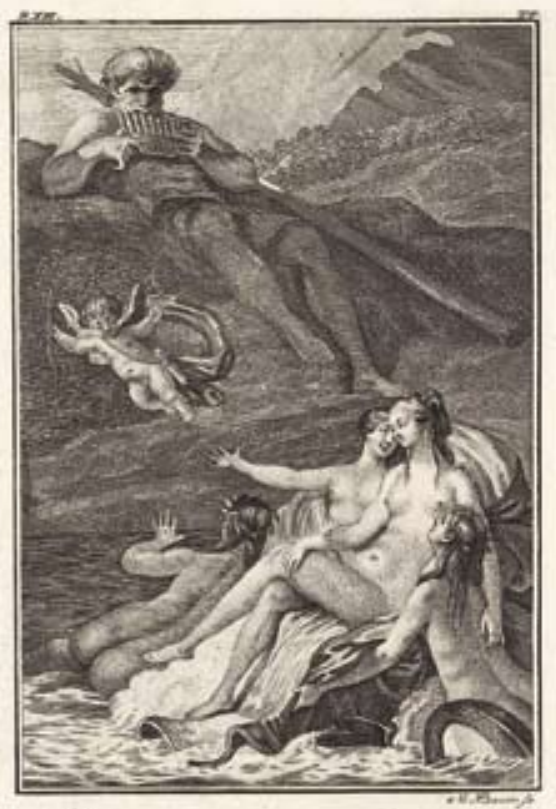

$0000000000000 \times 0 \times \times \times 0000000 \times 2$

v.

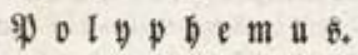

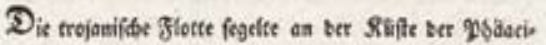
fden Snfet bin, unb lanbete cntlid ju Evirus, 10000

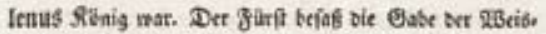
fagung, unt fagte seber sen Frejanern alle abenteuer ito

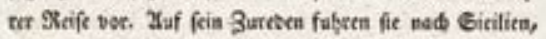

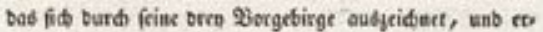
reidten ned in ter Stacte ten bofen ven Bancla. In ber rediten Geite sicer Stupt ift tie Meerenge von Ecolla, unb an ber linfen jene ven (S)arybsis; pwen firrdeterlis

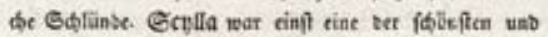

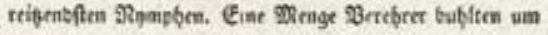

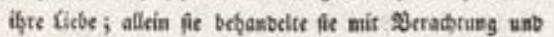




\section{Die Franzosen und der Bär}

Friedrich von Hagedorn, Johann Wilhelm Ludwig Gleim, Magnus Gottfried Lichtwer:

Fabeln.

Winterthur: Heinrich Steiner u. Compagnie, 1777.

Signatur: DD 94 A 328 Rara

Provenienz: Sammlung Deutscher Drucke des 18. Jahrhunderts, 1994

Die zahlreichen Abbildungen in der vorliegenden Fabelsammlung stammen von dem Schweizer Johann Rudolf Schellenberg (1740-1806). Schon während seiner Schulzeit zeigte der in Basel geborene Enkel des Malers Rudolf Huber eine ausgeprägte künstlerische Neigung und Begabung für die Malerei. Obwohl seit einem Sturz von der Schaukel an einer lebenslänglichen Gedächtnisschwäche leidend setzte Schellenberg seinen Weg als Zeichner und Maler fort. Unterstützt wurde er darin von Johann Geßner, der ihn auf die Idee brachte, naturhistorische Abbildungen zu wissenschaftlichen Zwecken anzufertigen. Schellenberg meisterte diese Aufgabe sehr gut, arbeitete sich gleichzeitig in das Gebiet der Radierkunst ein. Seine ersten Arbeiten zeigen dabei nicht nur sein Talent, sondern auch Humor und einen Hang zum Satirischen. Seinen Unterhalt verdiente er sich nun mit der Herstellung von Abbildungen zu Romanen und Erzählungen, Erbauungsschriften und Reisewerken.

Zahlreiche Illustrationen lieferte er für Neujahrsblätter, deren lange Folge im Übrigen auch sehr gut den Geschmackswandel der Zeit dokumentieren kann. Der Beruf brachte unter anderem Bekanntschaft und schließlich Freundschaft mit Chodowiecki mit sich. Schellenberg illustrierte auch Bibelausgaben und beteiligte sich an dem so wichtigen Abbildungsmaterial für Lavaters Physiognomik. Zu seinen besten Werken gehören die Tafeln für den Verleger Heinrich Steiner, der auch die hier gezeigte Fabelsammlung herausbrachte. Für jede der 20 Fabeln entwarf er eine ganzseitige Illustration und brachte darin jede Menge schweizerisches Lokalkolorit unter. Die Chodowiecki gewidmete Ausgabe von 1777 enthielt Fabeln von Hagedorn, Gleim und Lichtwer. Hagedorn war als Fabeldichter recht erfolgreich und beliebt. Während er die Geschichten und Motive zumeist aus älteren und jüngeren Vorlagen schöpfte, entwickelte er für die Darstellung einen ganz eigenen, leichten Erzählstil. Diesen imitierte Gleim in seinen 1756 erschienenen Fabeln. 1748 brachte Lichtwer seine Fabeln heraus, auch er um den modernen, französischen Duktus bemüht.

Die Abbildung gehört zur achten Fabel Die Bärenhaut und zeigt eine Szene, in der zwei Franzosen dem Bär begegnen, dessen Fell sie erbeuten wollen. Das Vorhaben misslingt, einer der Männer rettet sich auf einen Baum, der andere stellt sich tot, da „Bären selten Todte fressen“. Die Moral ist klar: Man soll das Fell des Bären nicht verteilen, bevor man ihn erlegt hat. 


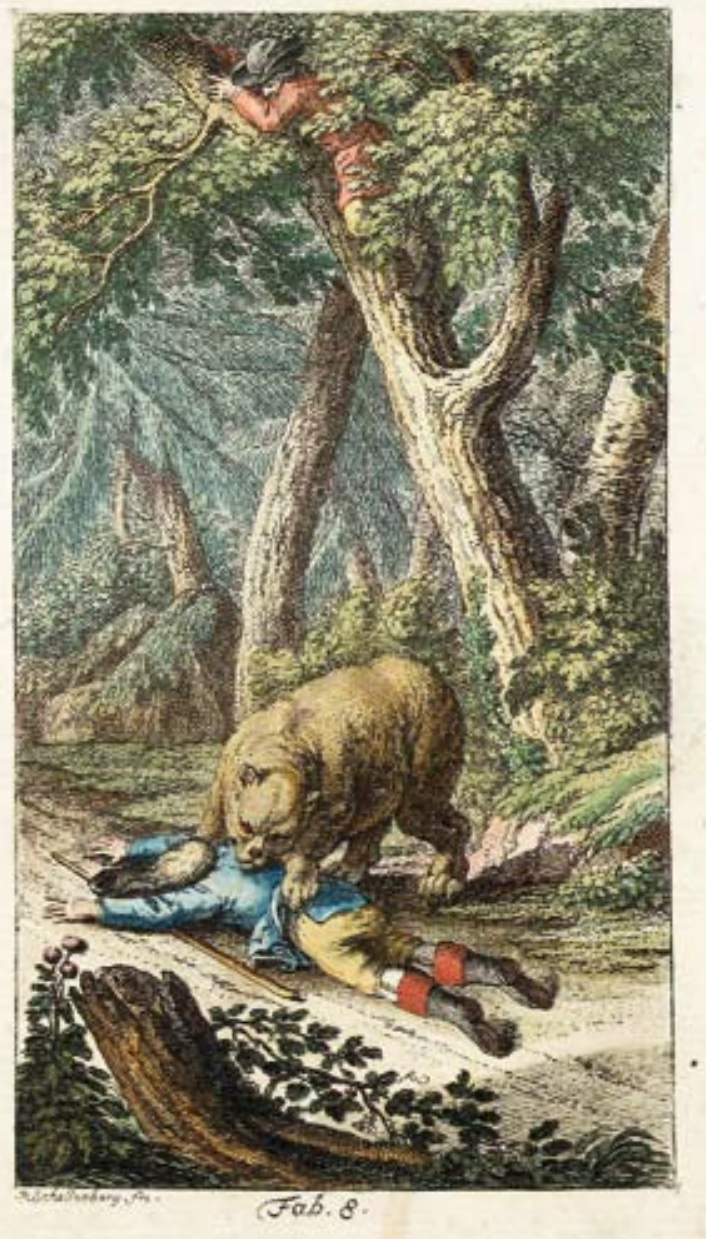




\section{Trattners Musterbuch}

Johann Thomas Trattner:

Abdruck von denjenigen Röslein und Zierrathen, welche sich in der K.K. Hofschriftgiesserey bey Johann Thomas Trattnern dermalen befinden.

Wien 1760.

Signatur: DD 94 A 487 Rara

Provenienz: Sammlung Deutscher Drucke des 18. Jahrhunderts, 1994

Der Verleger und Buchhändler Johann Thomas Trattner (1717-1798) hatte sich vom einfachen Buchdrucker in einer kleinen Offizin (Werkstatt) in Wien zu einem ,typographischen Großunternehmer“ entwickelt. Im Verlauf seiner Karriere expandierte er auch in Bereiche des Buchhandels und der Papierproduktion. Mit seinem Unternehmen baute er in Österreich ein wahres Netzwerk von Filialen und aufeinander bezogenen Geschäftszweigen auf. Dazu gehörten außerdem eine Schriftschneiderei, eine Gießerei, eine Kupferstecherei und eine Buchbinderei. Neben Geschäftstüchtigkeit, Innovationsbereitschaft und Fleiß verhalfen ihm besonders die Beziehungen zur Kaiserin Maria Theresia und die Kontakte zu wichtigen Personen aus dem jesuitischen und universitären Milieu zu seinem herausragenden Erfolg. Sein eigener Wahlspruch „LABORE ET FAVORE“ (Mit Arbeit und Gunst) macht dies deutlich. Mit Förderung durch die österreichische Kaiserin entwickelte er sich zum privilegierten Hofbuchhändler mit zahlreichen, zum Teil auf 20 Jahre zugestandenen Privilegien für seine Produktion.

Sein Erfolg zeigte sich nicht zuletzt in der Erhebung in den Adelstand (Johann Thomas Edler von Trattner). Trattners Plan war die „allgemeine Verbreitung der Kultur in den kaiserlich königlichen Staaten durch wohlfeile Lieferung der Bücher für alle Fälle der Wissenschaften“. Dafür wollte er die nützlichsten wissenschaftlichen Werke der Zeit systematisch nachdrucken und in einer typographisch ansprechenden Reihe zu ein- heitlichen und zu verhältnismäßig günstigen Preisen anbieten. Zur Qualitätssicherung beschäftigte er mehrere Korrektoren und führte den Stücklohn im Buchdruck ein. Absatz fördernd war zudem die Tatsache, dass er es außerordentlich gut verstand, seinen Drucken ein gefälliges Aussehen zu geben, wie an vorliegendem Schrifttypen-Buch deutlich wird. Sein Erfolg war allerdings auch begleitet von der Kritik an ihm als „Nachdrucker-Fürst“ und als Raubdrucker.

Insgesamt gab Trattner vier Schriftmusterbücher heraus. Anhand der Schriftproben konnten die Druckereien und Schriftgießereien ihren Kunden das Repertoire an verschiedenen Typen zeigen. Bücher dieser Art wurden in den Druckereien „verbraucht“, nicht mehr aktuelle Schriftproben vernichtet, so dass sie heute kaum noch auftauchen, was den Wert dieses fast verlagsfrischen Exemplars noch zusätzlich erhöht. Das Buch enthält Antiqua- und Frakturschriften, griechische und hebräische Typen, verschiedene Typen von Musiknoten, Kalenderzeichen, medizinische Zeichen, algebraische Zeichen, gebrochene Ziffern sowie einen Fundus an Zierstücken, Ornamenten und Symbollettern. 


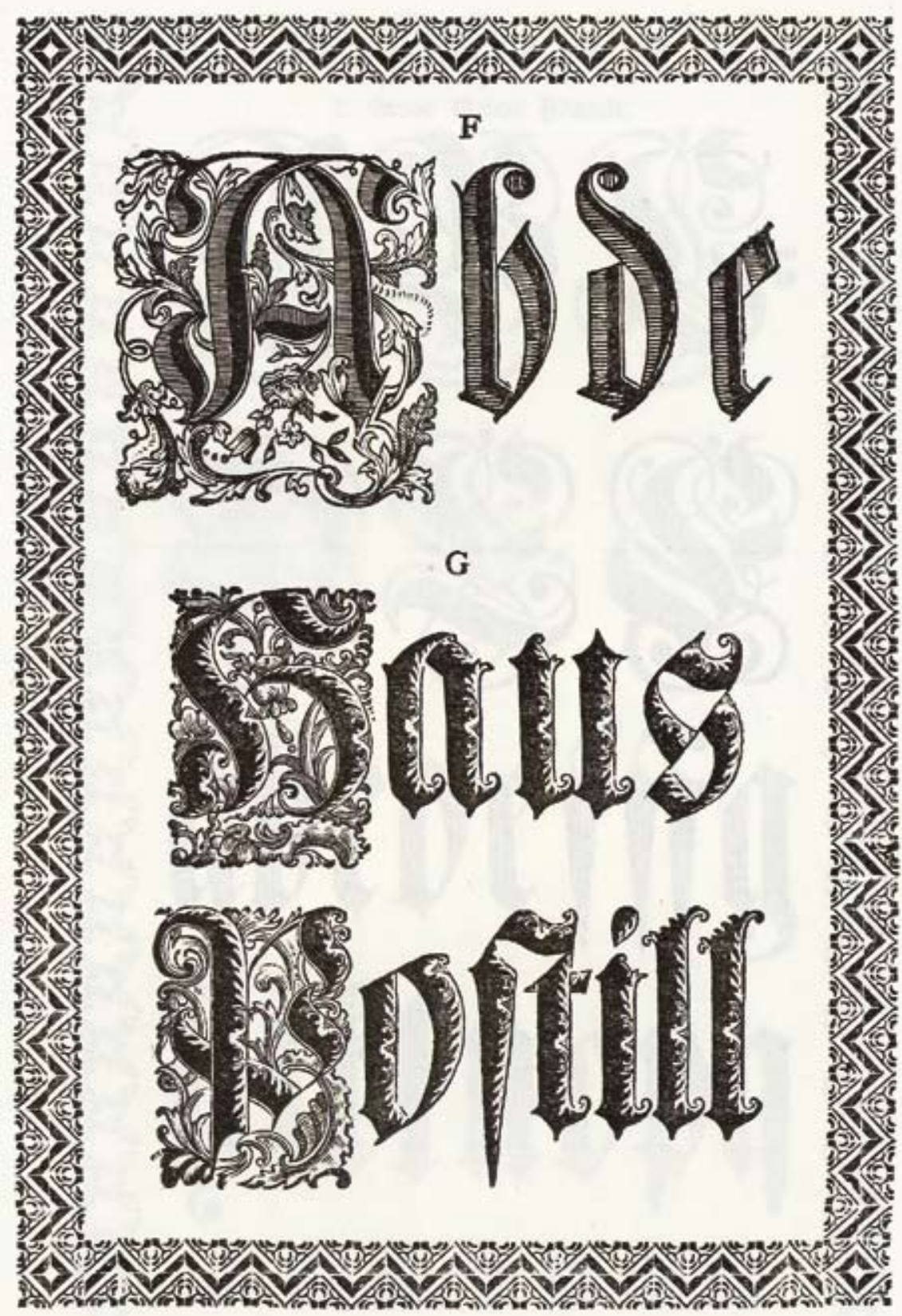




\section{Deutsches Staats- und Lehnsrecht im Schmuckeinband}

Christoph Kramer:

Abhandlungen aus dem deutschen Staatsrechte, 2 Bände.

Wien 1771-1773.

Signatur: DD 2000 A 5: 1 und 2 Einband-Rara

Provenienz: Sammlung Deutscher Drucke des 18. Jahrhunderts, 2000

Christoph Kramer war kaiserlich-königlicher Rat und ordentlicher Professor des deutschen Staats- und Lehnsrechts an den kaiserlichköniglichen theresianischen und savoyischen Ritterakademien in Wien. Basierend auf den Inhalten seiner Vorlesungen publizierte er im vorliegenden Werk ausführliche Erörterungen zu allerlei staatsrechtlichen Fragen seiner Zeit. Band 1 enthält unter anderem Ausführungen zu den kaiserlichen Majestätsrechten oder zum Verhältnis zwischen dem Reich und den Reichsständen. Auch Band 2 geht nach dem gleichen Schema vor und problematisiert unter anderem die Rechtsstellung des Kaisers in Kirchensachen.

Obwohl es sich also um ein klassisches juristisches Lehrbuch handelt, das in erster Linie für die Ausbildung des fachlichen Nachwuchses, vielleicht auch zur schnellen Orientierung für den praktizierenden Juristen gedacht war und eindeutig zur Gattung der Gebrauchsbücher zählt, ist es mit einigem Aufwand eingebunden worden. Für beide Bände wurden mittelbraune Kalbsledereinbände gefertigt, in die vergoldete Motive geprägt wurden. Vorder- und Rückendeckel sind dabei jeweils mit einer den Kanten folgenden doppelten Linie verziert, von denen die äußere nach außen weisende Zacken zeigt. An die Linien, die mit einer Rolle geprägt wurden, sind dann florale Motive mit zwei unterschiedlichen Stempeln anfügt worden. Ein Stempel wiederholt sich auf den Geraden, der zweite Stempel kam in den Ecken zum Einsatz. Deutlich ist zu sehen, dass die Aufteilung der Längsseiten keine Probleme machte. Der Stempel passt genau fünf Mal in die Reihe. An den kürzeren Seiten konnte er zwei Mal gesetzt werden, wobei jeweils ein Stempel etwas „verlängert“ werden musste, um eine Lücke in der Verzierung zu vermeiden.

Beide Bände haben feste Rücken: Der Lederbezug ist flächig mit dem Buchblock verbunden, der auf fünf echten Bünde geheftet ist. Dadurch entstehen sechs Rückenfelder, die verziert bzw. mit Schildchen für Titel und Bandzählung beklebt sind. Auch die Stehkanten der Bände sind geprägt, allerdings ist hier die Vergoldung fast vollständig verloren gegangen. Dagegen ist der dreiseitige Goldschnitt noch makellos erhalten. Zur Verdeckung minimaler Vergoldungsfehler, die auch bei starker Pressung durch die Faltung der Papierbögen leicht entstehen können, ist vor dem handgestochenen Kapital jeweils eine kleine Linie gepunzt worden.

(JM/KN) 


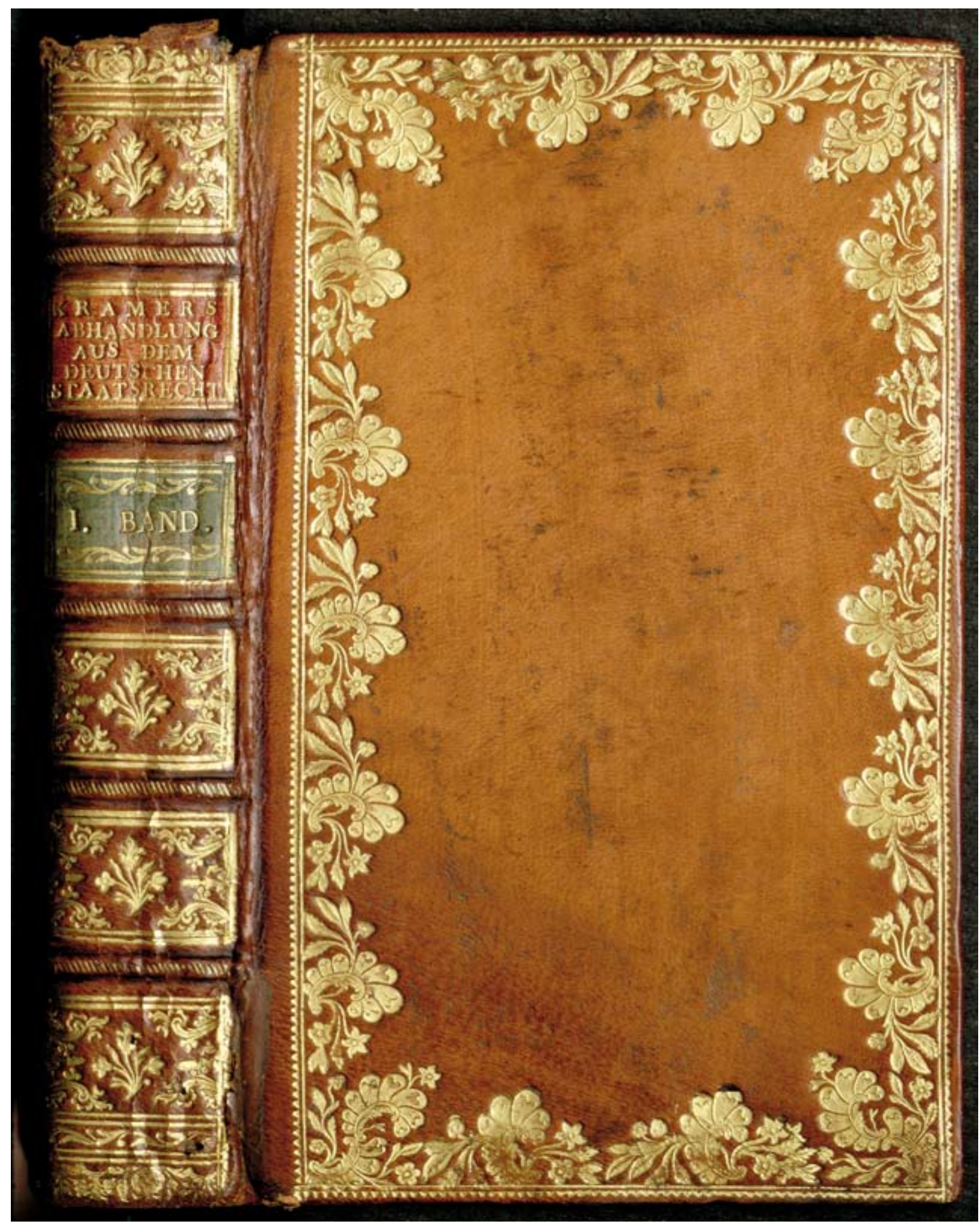




\section{Kapitel 13}

\section{Wissenschaftliche Nachlässe}

Die Niedersächsische Staats- und Universitätsbibliothek besitzt heute eine Sammlung von rund 360 Nachlässen und Teilnachlässen, von denen der weitaus größte Teil von Professoren der Göttinger Universität stammt und damit die historisch enge Verbindung zwischen Universität und Bibliothek auf besondere Weise betont. Schon früh begann die Bibliothek ihre Sammeltätigkeit in diesem Bereich. Bereits im 18. Jahrhundert gelangten die nachgelassenen Materialien des Juristen und Statistikers Gottfried Achenwall (1719-1772), des Orientalisten und Bibliothekars Johann David Michaelis (1717-1791) und des Juristen Georg Ludwig Böhmer (1715-1797) in den Bestand. Für die Erwerbung dieser Nachlässe setzte sich der langjährige Bibliotheksdirektor Christian Gottlob

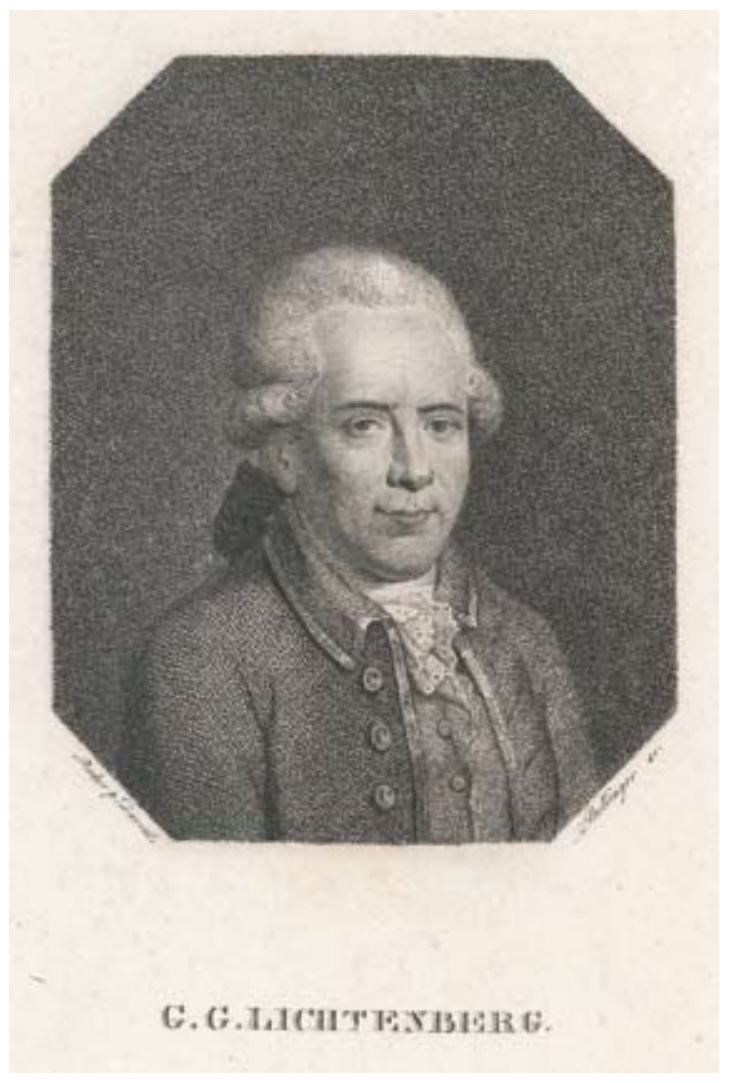

Georg Christoph Lichtenberg (1742-1799).

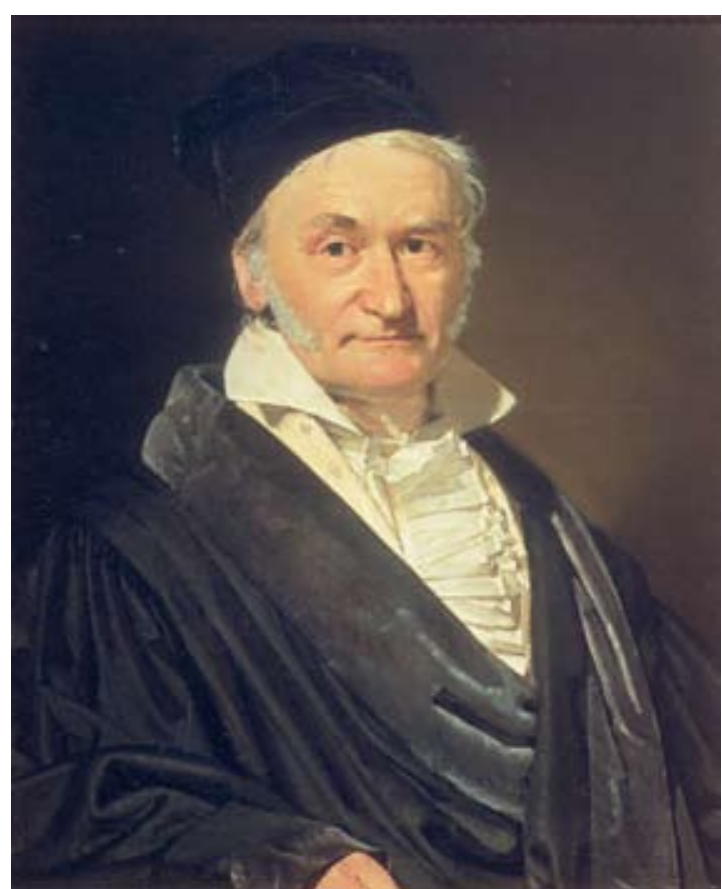

Carl Friedrich Gauß (1777-1855).

Heyne (1729-1812) ein. Bis heute wird der Nachlassbestand systematisch ergänzt; allein in den letzten zwanzig Jahren wuchs er um etwa 90 Nachlässe oder Teilnachlässe. Grundsätzlich sind alle wissenschaftlichen Disziplinen vertreten, aber die Gruppe der Mathematikernachlässe ragt sowohl der Zahl als auch der Bedeutung nach aus dem Gesamtbestand heraus. Insgesamt stellen die Nachlässe eine wichtige Ergänzung zum Bestand des Universitätsarchivs dar, das die Instituts- und Universitätsakten bewahrt und erschließt.

Die wissenschaftlichen Nachlässe sind fast ausschließlich auf dem Wege des Geschenks in die Bibliothek gekommen. Sie werden von den Erben manchmal unmittelbar nach dem Ableben des Nachlassers, manchmal auch erst Jahrzehnte später angeboten. Mit der Übereignung übernimmt die Bibliothek nicht nur die Verpflichtung, den Nachlass zu erschließen und der wissenschaftshistorischen Forschung 


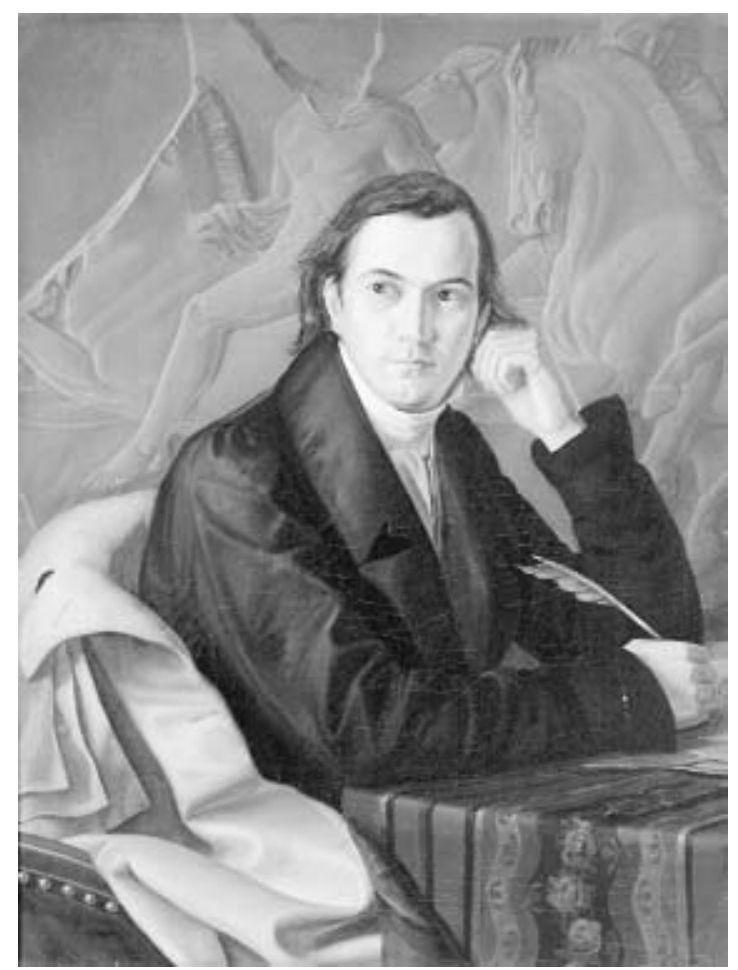

Karl Otfried Müller (1797-1840).

zugänglich zu machen. Wo immer möglich versucht sie auch, Einzelautographen auf dem Markt als Ergänzung zu kaufen. Vier Beispiele mögen diesen Teil der Sammeltätigkeit der Göttinger Bibliothek veranschaulichen: ein satirisches Gedicht Georg Christoph Lichtenbergs (1742-1799) über Göttingen, Notizen mit dem Telegraphenalphabet Carl Friedrich Gauß’ (1777-1855), ein Abschnitt aus dem Reisetagebuch des

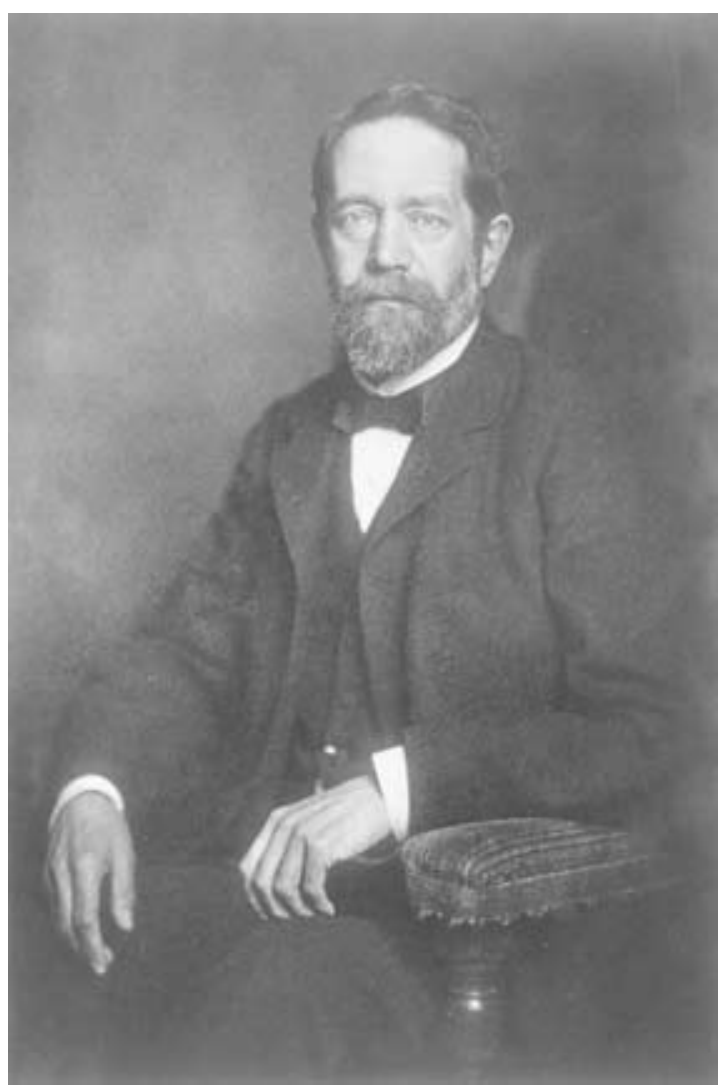

Felix Klein (1849-1925).

Altertumswissenschaftlers Karl Otfried Müller (1797-1840) und schließlich Briefe Albert Einsteins an den Göttinger Mathematiker Felix Klein (1849-1925).

(HR) 


\section{Ein spöttischer Blick auf die Universitätsstadt Göttingen}

Georg Christoph Lichtenberg:

„Seitdem mein Kutscher und mein Schicksal ...“. Satirisches Gedicht über Göttingen.

Eigenhändige Handschrift,

Göttingen, Mai 1769.

Signatur: Cod. Ms. Lichtenberg IV, 10 (B1.1)

Provenienz: Georg Christoph Lichtenberg, um 1900

Georg Christoph Lichtenberg (1742-1799) nahm sein Studium in Göttingen im Sommersemester des Jahres 1763 auf und schrieb sich für die Naturwissenschaften und die Mathematik ein. Göttingen war drei Jahrzehnte nach der Gründung der Georgia Augusta immer noch eine kleine Provinzstadt, die außerhalb der Universität für einen Studenten kaum geistige Anregungen bot. Die Einwohnerzahl ging als Folge des Siebenjährigen Kriegs um etwa 2.500 Personen zurück und lag 1763 bei etwa 6.000 Personen. Lichtenberg beendete sein Studium im Jahre 1767 und lernte auf einer Englandreise 1770 König Georg III. kennen. Die Verbindung zum Hof war der Karriere des jungen Fachgelehrten förderlich: Er wurde kurz nach Ende der Reise zum außerordentlichen Professor an die Universität Göttingen berufen. Bereits während seines Studiums begann er, in Notizbüchern Beobachtungen, Pläne zu Veröffentlichungen und sonstige Gedanken festzuhalten. Diese „Sudelbücher“ waren es, die ihn nach seinem Tode als Satiriker und Aphoristiker berühmt machten. In einem kurz nach Ende seines Studiums verfassten Gedicht, das als „Schreiben an einen Freund“ charakterisiert ist, gibt Lichtenberg eine spöttische Schilderung Göttingens als „geistliches Schlaraffen Ländgen“:
Seitdem mein Kutscher und mein Schicksal Mich, Theuerster, aus deinem Blick stahl Leb' ich in diesem Vaterstädtgen Von manchen Hefften und Tracktätgen, Berühmt in allerley Bedeutung Durch Würste, Bibliotheck und Zeitung Durch Professorn und Regenwetter, Und breite Stein und Wochenblätter; Durch junge Herrn aus allen Reichen Der Welt, und Mädgen und dergleichen. Du kennst zwar schon aus einem Bändgen Dieß geistliche Schlaraffen Ländgen Wo Wahrheit kommt von selbst geflogen Bald mit der Haut bald abgezogen Zuweilen künstlich Skeletirt Zuweilen gantz französ'sch candirt Und wo man folglich um gelehrt $\mathrm{Zu}$ werden nur sich recht aufsperrt. Der Preiß ist für so viel und so schön Vier Theler vier und zwanzig Groschen. (Viel mehr kost'ts was der Leib indes iss't, Wenns auch nur trocken brod und Käß ist:) Doch wirst Du vieles noch vermissen, Was man hier weiß und nicht will wissen. Professorn schreiben nur qua tales Und dann wer Hencker weiß denn alles? 


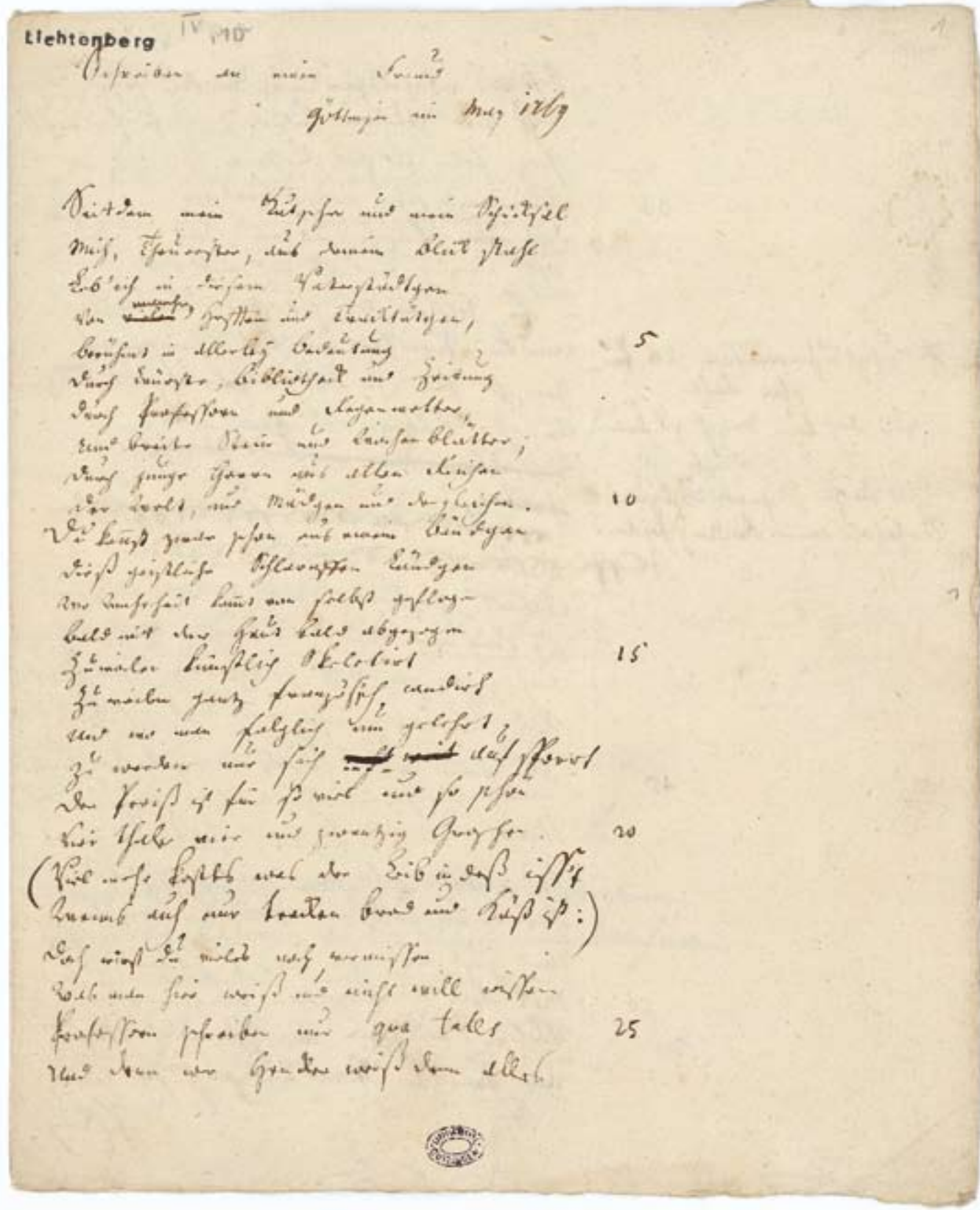




\section{Die erste auf telegraphischem Wege übermittelte Nachricht}

Carl Friedrich Gauß:

Telegraphenalphabet.

Notizblatt.

Signatur: Cod. Ms. Gauß Physik 6, Bl. $1^{\mathrm{v}}$ und $2^{\mathrm{r}}$

Provenienz: Carl Friedrich Gauß, 1856

Im Jahre 1833 nahmen Carl Friedrich Gauß (1777-1855) und Wilhelm Eduard Weber (1804-1891) in Göttingen den ersten elektromagnetischen Telegraphen in Betrieb und übertrugen erstmalig Signale und Nachrichten auf elektromagnetischem Wege. Die über einen Kilometer lange Telegraphenleitung führte vom Physikalischen Kabinett über die Dächer und Türme der Stadt zur Sternwarte. Weber und Gauß waren damit Pioniere einer Technologie, die gemeinsam mit dem aufkommenden Eisenbahnwesen zu enormen Veränderungen des Verkehrs- und Wirtschaftslebens im 19. Jahrhundert führte, und legten damit auch den Grundstein für die modernen Kommunikationstechnologien.

Aus ihren Versuchen zur Bestimmung des Erdmagnetismus und ihren Experimenten zur Erforschung des elektrischen Stroms hatten sie zuvor Instrumente entwickelt, die es ermöglichten, die Abweichung einer beweglich aufgehängten Magnetnadel (als Empfänger) nach links oder rechts unter der Einwirkung von durch Induktion hervorgerufenen Stromstößen (Sender) zu beobachten. Zuerst wurden um Ostern 1833 Versuche mit einfachen Stromstößen über die von Weber gespannte Leitung unternommen, aber bereits im Sommer wurden zwischen Physikalischem Kabinett und Sternwarte Phrasen ausgetauscht. Die Übermittlung eines Buchstabens hat anfangs - aufgrund der Schwingungsdauer der großen Magnetnadeln - ca. 1 Minute gedauert. Als Resultat der Weiterentwicklungen an den Apparaten gelang es Gauß und Weber, die Zeichenübertragungsrate auf bis zu 9 Zeichen pro Minute zu erhöhen. Zur Übermittlung der Nachrichten hatte Gauß Telegraphiercodes entwickelt, in denen Buchstaben und Zahlen als Kombinationen von Rechts-LinksAusschlägen der Magnetnadel verschlüsselt wurden. Eine der ersten 1833 übermittelten Phrasen könnte der Sinnspruch „Wissen vor Meinen, Sein vor Scheinen" gewesen sein, wie die im Nachlass erhalten gebliebene Notiz von Gauß mitsamt dem zugehörigen Telegraphenalphabet zeigt. Dafür benötigten Gauß und Weber nach der Notiz auf dem Blatt „30 Buchstaben, 41/2 Minuten“.

Gauß und Weber waren sich der Tragweite ihrer Erfindung bewusst und haben versucht, diese der Öffentlichkeit zukommen zu lassen, jedoch wurde ihre Zusammenarbeit dadurch beendet, dass Weber als einer der Göttinger Sieben 1837 seines Amtes enthoben wurde. Das Telegraphenalphabet kam 1856 nach dem Tode von Gauß mit seinem handschriftlichen Nachlass an die Universitätsbibliothek Göttingen. 


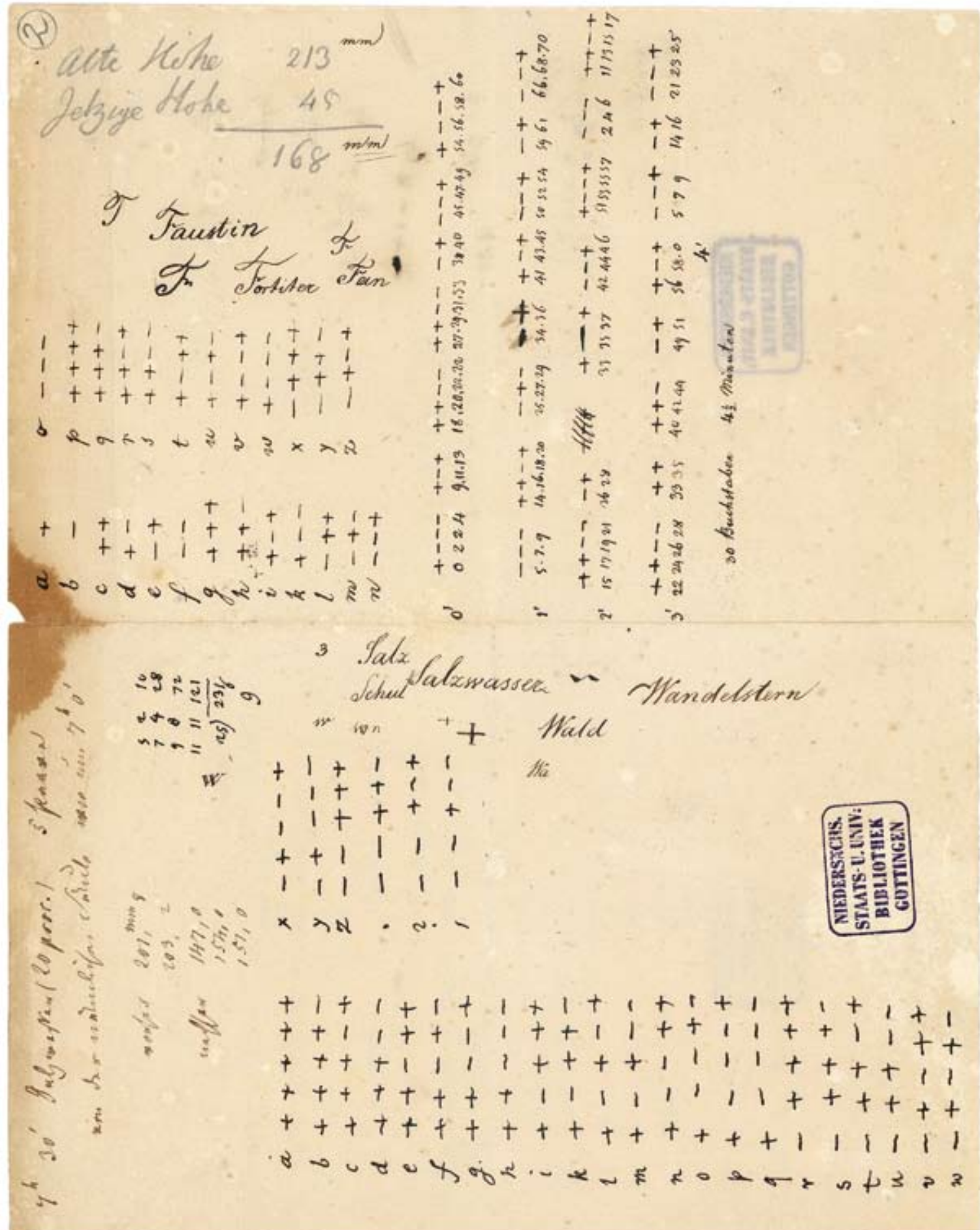




\section{Karl Otfried Müller - Philologe, Archäologe, Althistoriker}

Karl Otfried Müller:

Tagebuch der Italienreise.

Papierhandschrift, Italien, 1839.

Bl. 31' : Eintrag Montalto, 20. November 1839.

Signatur: Cod. Ms. K. O. Müller 7, 2a

Provenienz: Karl Otfried Müller, 1926

Als Verfechter einer universalen historischen Betrachtung des Altertums hat Karl Otfried Müller (1797-1840) in den nur wenig mehr als zwanzig Jahren seines Gelehrtenlebens in ganz unterschiedlichen Bereichen grundlegende Werke, teilweise die ersten Gesamtdarstellungen geschaffen, deren Wirkung bis in die Gegenwart fortdauert. Müller stammte aus einer schlesischen Pastorenfamilie und verbrachte seine Kindheitsjahre in Brieg und in Ohlau. Zu Ostern 1814 begann er an der wenige Jahre zuvor gegründeten Universität Breslau ein breit angelegtes Studium, das sich unter dem Einfluss von Ludwig Friedrich Heindorf aber zunehmend auf historischphilologische Studien ausrichtete. Nach zwei Jahren wechselte er an die Berliner Universität und hörte hier Friedrich Schleiermacher und Karl Solger, Friedrich August Wolf und Philip Buttmann. Sein wichtigster Lehrer in der Klassischen Philologie war allerdings August Boeckh, unter dem Müller in unermüdlichem Arbeitseifer und Forschungsdrang die Grundlage für sein universales Wissen in seinem Studiengebiet legte. Er schloss sein Studium 1817 mit einer Dissertation über die Geschichte der Insel Ägina ab.

Im Juli 1819 erhielt Müller den Ruf auf eine außerordentliche Professur an der Georgia Augusta in Göttingen und wurde schon 1823 zum ordentlichen Professor ernannt; zugleich nahm ihn die Göttinger Sozietät der Wissenschaften als Mitglied auf. 1832 erfolgte die Ernennung zum Hofrat, mit der die hannoversche Landesregierung seine großen Verdienste für die Lehre und Forschung an der Göttinger Universität würdigte. Im Spätsommer 1839 konnte Müller den lang gehegten Plan verwirklichen, die antiken Stätten Italiens und Griechenlands zu besuchen. Von dieser Reise kehrte Müller nicht zurück. Beim Kopieren von Inschriften in Delphi zog er sich eine schwere Hirnentzündung zu, an deren Folgen er am 1. August 1840 starb. Sein Grab fand er auf dem Kolonoshügel im Norden Athens, wo noch heute eine Grabstele an ihn erinnert.

Das Blatt aus Müllers Reisetagebuch zeigt den Ponte dell'Arcobaleno bei Montalto di Castro in Etrurien. Die Brücke stammt aus dem ersten vorchristlichen Jahrhundert und überspannt den Fluss Fiora in einer Höhe von 30 Metern.

$(\mathrm{HR} / \mathrm{JM})$ 


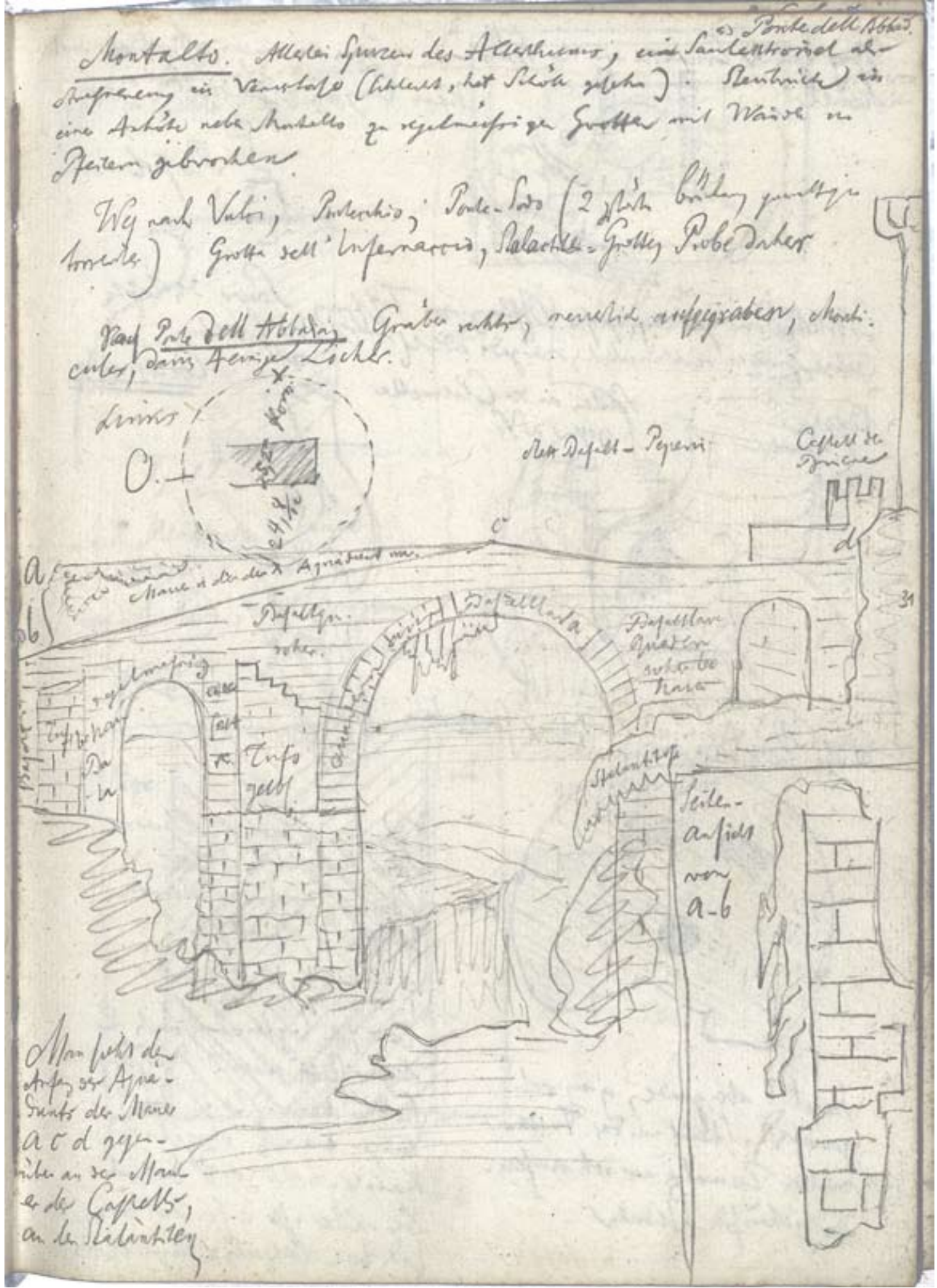




\title{
124 Einstein zur Habilitation von Emmy Noether
}

\author{
Albert Einstein: \\ 18 eigenhändige Briefe an Felix Klein. \\ Berlin u. a., 1918. \\ Signatur: Cod. Ms. Klein 22 B \\ Provenienz: Nachlass Felix Klein, 1926
}

\begin{abstract}
Albert Einstein (1879-1955) hatte am 20. März 1916 seine allgemeine Relativitätstheorie in den Annalen der Physik veröffentlicht. Die Korrespondenz mit dem Göttinger Mathematiker Felix Klein (1849-1925) aus dem Jahre 1918 behandelt zentrale Fragen der allgemeinen Relativitätstheorie wie Gravitation, Elektromagnetismus, Verteilung von Materie und Energie. Darüber hinaus erörtern die beiden Gelehrten die Anwendung von mathematischen Methoden auf die Grundlagenforschung in der Physik. Felix Klein entfaltete in Göttingen nicht nur in der mathematischen Forschung vielseitige Aktivitäten. Er sorgte dafür, dass David Hilbert (1862-1943) einen Ruf an die Georgia Augusta erhielt, setzte sich für die Förderung der Naturwissenschaften und der Mathematik durch die Industrie ein und regte die Gründung der Deutschen Mathematiker-Vereinigung an. Obwohl längst nicht so bekannt wie Einstein, gilt er als einer der bedeutendsten Mathematiker seiner Zeit.
\end{abstract}

In einem Brief vom 27. Dezember 1918 gratuliert Einstein Klein zu dessen 50-jährigem Doktorjubiläum: „Für uns alle ist es ein schöner Anblick, wenn wir auf die 50 Jahre glücklicher Arbeit zurücksehen, die Sie durchlebt haben; solch ein Rückblick muss für Sie selbst ein Erlebnis reinster Befriedigung sein.“ Am Ende des Briefs kommt Einstein auf den eigentlichen Anlass seines Schreibens zu sprechen. Er bittet Felix Klein eindringlich, sich um die Erteilung der Lehrbefugnis für die begabte Göttinger Mathematikerin Emmy Noether (1882-1935) zu bemühen. David Hilbert und Felix Klein hatten sich während des 1 . Weltkriegs vergeblich um Noethers Habilitation bemüht - an preußischen Universitäten waren damals nur Männer zur Habilitation zugelassen. Einstein schreibt: „Beim Empfang der neuen Arbeit von Frl. Noether empfinde ich es wieder als grosse Ungerechtigkeit, dass man ihr die venia legendi vorenthält. Ich wäre sehr dafür, dass wir beim Ministerium einen energischen Schritt unternähmen.“ Ein Jahr später gestattete das Ministerium die Durchführung des Habilitationsverfahrens, aber trotz glänzender Forschungsergebnisse blieb Emmy Noether eine Universitätskarriere verwehrt. Am 25. April 1933 wurde sie aus politischen Gründen auf der Basis des Gesetzes zur Wiederherstellung des Berufsbeamtentums beurlaubt, und ein halbes Jahr später entzog man ihr die Lehrbefugnis. Es gelang ihr, 1934 eine Anstellung als Gastprofessorin am Bryn Mawr College in Pennsylvania zu erhalten. Emmy Noether starb 1935 im Alter von 53 Jahren an den Folgen einer Tumorerkrankung. 


\section{Hodn werester Jen rollege!}

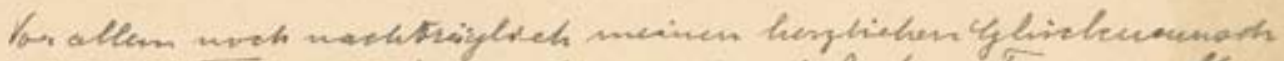

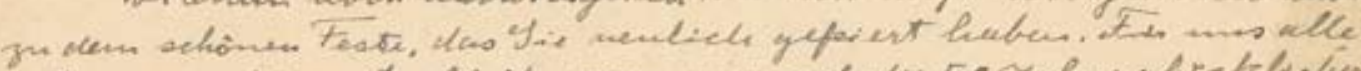

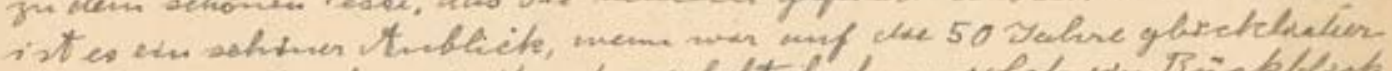

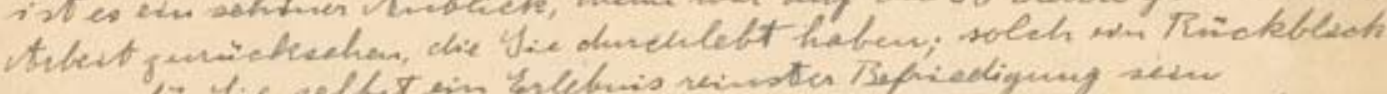

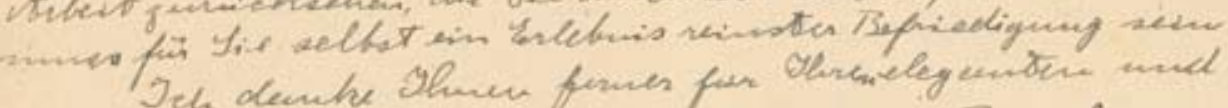

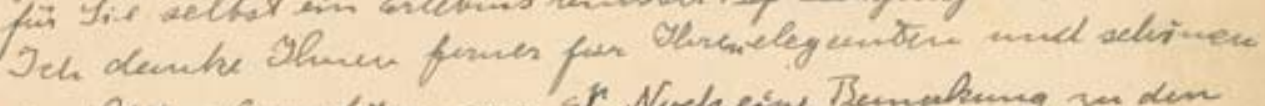

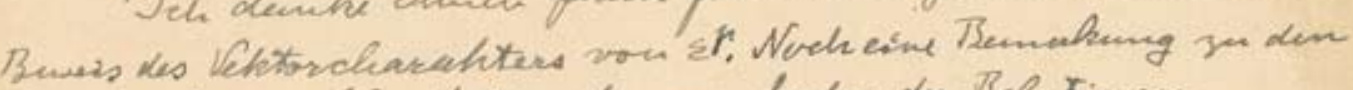

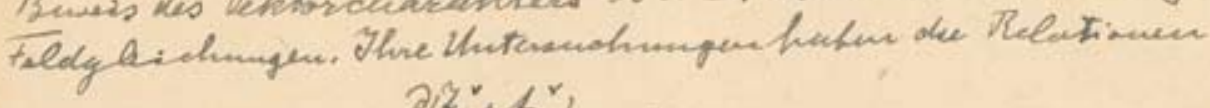

$$
\frac{\partial z_{2}^{2}+h_{2}^{2} \mid}{\partial x_{0}}=0
$$

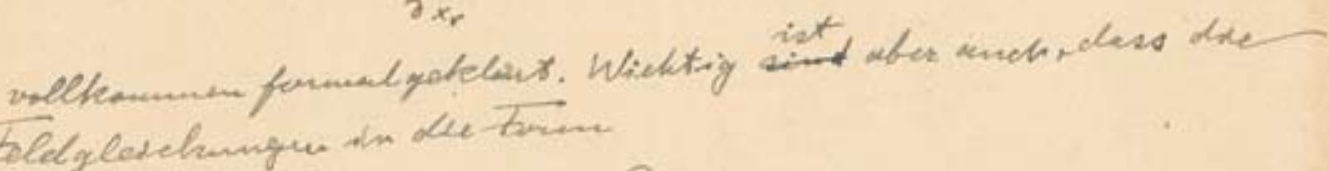
beldgledehangur in dee taries

$$
z_{u r}+\frac{1}{u_{r}}=8 w_{r}
$$

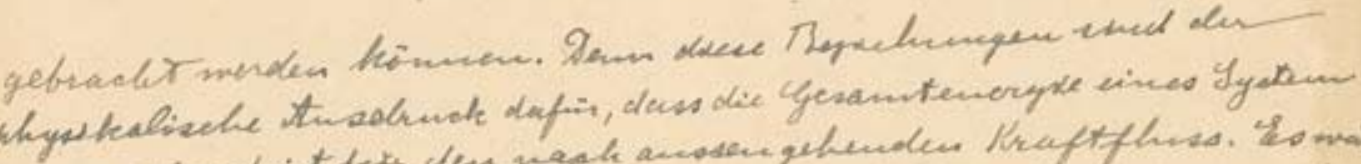

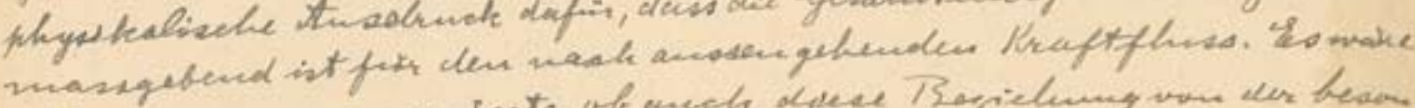

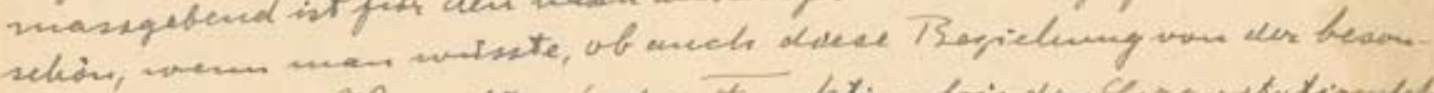

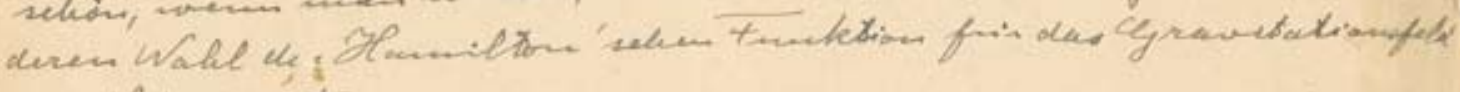
mabhinging ist.

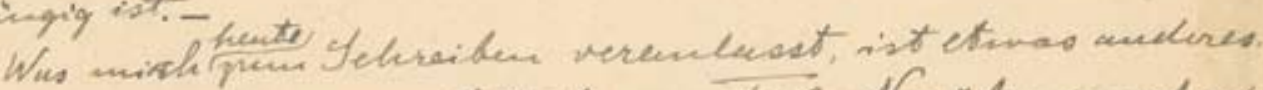

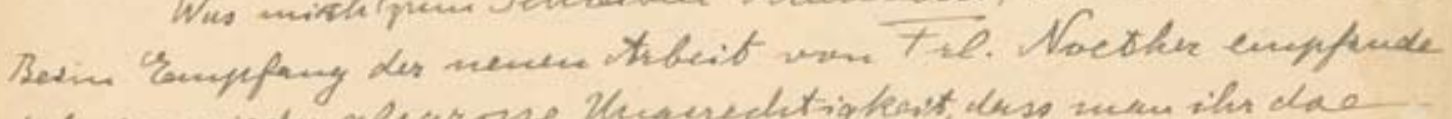

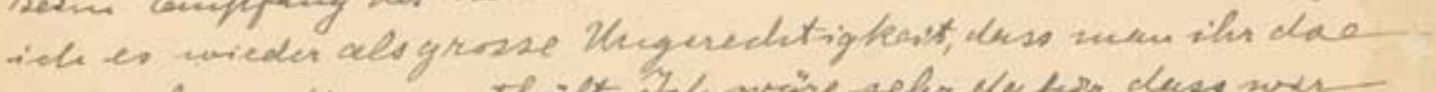

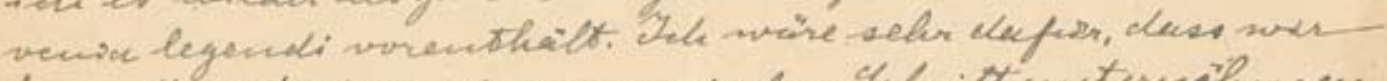

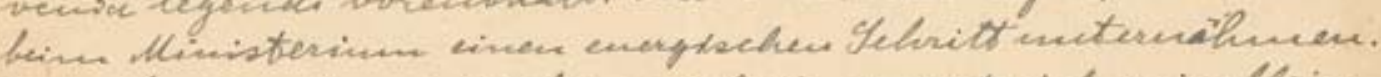

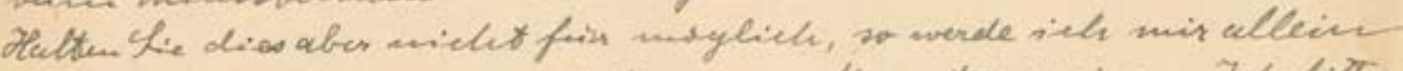

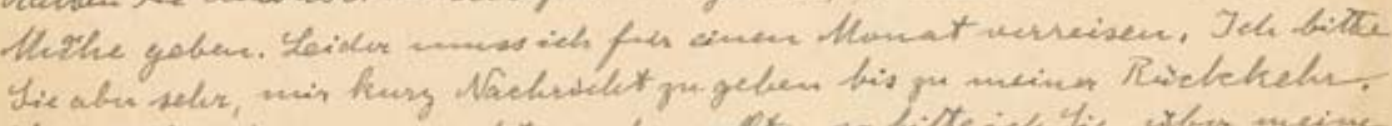

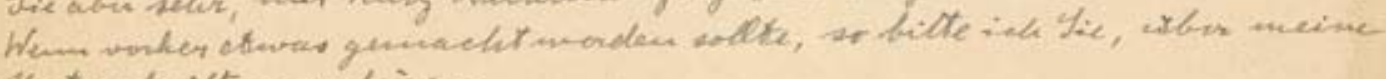

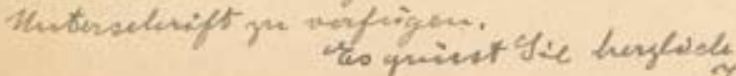




\section{Register der Verfasser, Anonyma, Drucker, Vorbesitzer und Provenienzen}

Name

Aesopus Exponat-Nr.

Alexander I., Zar 79

Andreae, Hieronymus

Aristoteles

Art d'écrire.

Asch, Georg Thomas von.

Atlas von Deutschland...

Augustinus, Aurelius

Autographa Lutheri

Bapst, Valentin

Barnstorf, Georg Erich

Bauer \& Treuttel

Bauer, Franz Andreas

Beckmann, Johann

Bellifortis

Biblia, deutsch.

Biblia, lateinisch

Biblia, niederdeutsch.

Birgitta

Blauel, Johannes Christoph August

Blum, Michael

Blumenbach, Johann Friedrich

Boccaccio, Giovanni

Bracciolini, Gianfrancesco Poggio

Brahe, Tycho

Brandis, Lukas

Brandis, Moritz

Brant, Sebastian

Braun, Johann Bartholomäus

Breidenbach, Bernhard von

Breusing, Arthur.

Breviarium Windeshemense

Brito Freire, Francisco de

Brunschwig, Hieronymus

Bülow, Joachim Hinrich von

Bürger, Gottfried August.

Burman, Pieter d. J.

Čaplin, Petr Avraamovič

Caymox

Caxton, William

Chaucer, Geoffrey

Cicero, Marcus Tullius
.. 76

10. 34

48

88

98-101

61

54

113-115 .. 68

109

42

53

73

Einführung 107

1. 17.89

108

27

.111

57

51. 71

83. 96

109

21. 22

... 23

65

66

11

102. 103

.56

14

37. 97

1-6

13. 45

.. 36

.. 99

28

92.93

46

50. 90
Name

Exponat-Nr.

Colonna, Francesco......................................... 33

Coninx, Arnold.............................................. 102

Corvisart des Marets, Jean-Nicolas................. 51

Costa, Stephanus .............................................. 24

Cranach, Lucas d. Ä......................................... 9

Creussner, Friedrich ...................................... 80

Crevenna, Pietro Antonio .............................. 50

Curtis, Edward Sheriff ............................... 106

De Jode, Cornelis ........................................ 102

De modo confitendi et penitendi ..................... 25

Depping, Georges Bernard.............................. 52

Dessalines d'Orbigny, Alcide......................... 16

Dicta philosophorum, englisch ..................... 92

Dieterichsche Buchhandlung ......................... 43

Dietterlin, Wendelin ..................................... 28

Dietz, Ludwig ............................................. 108

Dinckmut, Conrad.......................................... 86

Doppelmayr, Johann Gabriel ........................ 58

Dürer, Albrecht....................................... 10. 34

Duve, Friedrich Wilhelm von ....................89-93

Ebeling, Christoph Daniel........................... 110

Eike von Repgow .......................................... 65

Einbände . 49-51. 56. 120

Einbeck, Alexanderstift............................23-26

Einstein, Albert ............................................ 124

Elisabeth I. ..................................................... 49

Elliot, Daniel Giraud.................................... 104

Enchiridion: Der kleine Catechismus ......... 115

Ernst August I. von Hannover.......................... 53

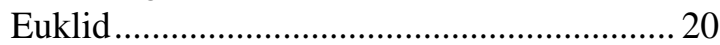

Eulenspiegel .................................................. 41

Evangelia, lateinisch .................................. 87

Fabricius, Rudolf Anton........................... 84. 85

Fallours, Samuel ............................................ 6

Fechtbuch ....................................................... 4

Feyerabend, Sigmund .................................... 41

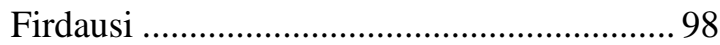

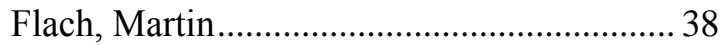

Flacius, Matthias ............................................ 19

Flora Picta ........................................................ 11

Förster, H. W. .......................................... 112

Frankfurt, Wissenschaftliche Gesellschaft ..... 12 
Franz, Johann Michael .............................58-61

Fridolin, Stephan........................................... 84

Friedrich von Waldeck ................................... 56

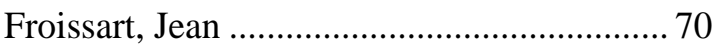

Fust, Johannes ......................................... 17. 89

Gauß, Carl Friedrich ............................. 75. 122

Gebauer, Georg Christian..........................65-69

Gellius, Aulus................................................. 55

Georg von Braunschweig-Lüneburg ................ 3

Georg Prinz von Waldeck ......................... 48. 55

Gerichtsordnung, Peinliche............................ 67

Gesner, Johann Matthias .......................... 62-64

Ghotan, Bartholomäus ................................... 27

Gleim, Johann Wilhelm Ludwig ................ 118

Goethe, Johann Wolfgang von ...................... 43

Goltermann, H. G. ....................................... 96

Gossuin de Metz ............................................ 93

Gottfried, Johann Ludwig .............................. 30

Gottsched, Johann Christoph ................. 77.78

Greyff, Michael............................................... 66

Grotefend, Georg Friedrich .......................... 74

Grüninger, Johann ..................................... 37. 97

Gutenberg, Johannes .................................... 17

Hagedorn, Friedrich von ............................. 118

Hamilton, William........................................... 42

Hannover, Königliche Bibliothek .................... 7

Hase, Johann Matthias .................................. 59

Heinrich Julius, Herzog zu

Braunschweig-Lüneburg......................... 21. 22

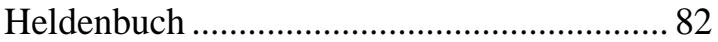

Helmstedt, Universitätsbibliothek............ 17. 19

Henke, Heinrich Philipp Konrad .................. 87

Hildesheim, Gymnasialbibliothek............ 21. 22

Hochfeder, Kaspar ......................................... 83

Holl, Lienhart ........................................... 81. 91

Horatius Flaccus, Quintus ............................. 63

Hu(t)ter, Johann .......................................... 72

Hussitenkodex .............................................. 95

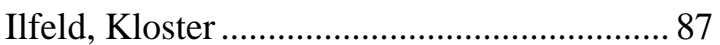

Jacobus de Breda.............................................. 25

Jefferson, Thomas ........................................ 110

Jenson, Nicolas ............................................ 62
Jérôme Bonaparte ......................................... 52

Johannes de Capua ........................................... 81

Johannes de Cuba.............................................. 78

Johannes de Sacro Bosco ................................ 64

Jordanus zu Volkhardinghausen..................... 56

Josephus, Flavius ........................................... 23

Juan de Salcedo.............................................. 112

Kachelofen, Konrad ...................................... 64

Karl V., Kaiser.............................................. 67

Kessler, Harry Graf ........................................... 47

Klammer, Gerhard ....................................14-16

Klein, Felix .................................................. 124

Koberger, Anton ........................................... 2. 84

Köhler, Johann Georg Wilhelm...................... 94

Kolumbus, Christoph .................................... 36

Kopernikus, Nikolaus .................................... 75

Kosmographische Gesellschaft ..................... 60

Kramer, Christoph........................................ 120

Krause, Melchior.......................................... 39

Kulenkamp, Lüder ......................................... 72

Kyeser, Konrad ...............................Einführung

Landsberg, Martin ........................................... 64

Lavalle, Martinus de ....................................... 24

Le Signerre, Guillaume................................... 50

Leeu, Gerard .................................................. 56

Leutsch, Ernst Ludwig von ........................... 74

Lichtenberg, Georg Christoph...................... 121

Lichtwer, Magnus Gottfried........................ 118

Lieder, Geystliche ............................................. 68

Lotter, Melchior d. J..............................113. 114

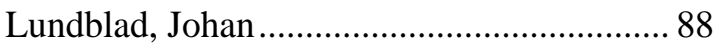

Lüneburg, Michaeliskloster ......................27-30

Luther, Martin ............................... 9. 68. 113-115

Lydgate, John .............................................. 96

Machaev, Michail Ivanovič......................... 100

Manutius, Aldus ................................................. 33

Marchand, Guy ............................................. 36

Martyn, Joannis......................................... 116

Matthias Corvinus ........................................... 48

Meermann, Petrus ............................................. 35

Mellinger, Johannes ........................................ 5

Mentelin, Johann.............................................. 77 
Merian, Maria Sibylla ................................... 71

Merian, Matthäus d. Ä. 30

Morgan Foundation...

104. 106

Morgan, John Pierpont 105

Morris, William .46

Mulert-Stiftung 107. 108

Müller, Karl Otfried 123

Münchhausen, Börries von ........................... 13

Musterbuch, Göttinger . 18

Nachlässe 121-124

Napoleon Bonaparte 51

Nettis, Johannes 40

Newton, Isaac. .. 7

Nieuhof, Joan 15

Nürnberg, Stadtbibliothek............................. 20

Officium Beatae Mariae Virginis .................. 35

Oporinus, Johannes .......................................... 40

Order of the Garter.......................................... 49

Ortelius, Abraham ......................................... 103

Ortuin, Gaspard. ... 32

Osborne, Thomas 31-34. 49

Ovidius Naso, Publius. 117

Palladio, Andrea 29

Pallas, Peter Simon .73

Pannartz, Arnold 54. 55.90

Pappe 38

Peter I., der Große, Zar 85

Petreius, Johann 75

Pfintzing, Melchior ............................................ 8

Phalaris.......................................................... 26

Pincio, Filippo. .63

Plantiniana, Officina 103

Polo, Marco 80

Prüss, Johann d. Ä........................................... 82

Ptolemaeus, Claudius...................................... 91

Pynson, Richard ............................................. 96

Quaritch, Bernard........................................... 46

Quintilianus, Marcus Fabius ......................... 62

Raspe, Rudolf Ernst ...................................... 13

Ratdolt, Erhard................................................. 20

Rechberg, Carl von ....................................... 52

Redouté, Pierre-Joseph ............................... 44
Return of the whole number of persons...... 110

Rhau-Grunenberg, Johann ........................... 9

Richter, Hofrätin ............................................. 70

Ries, Adam ..................................................... 39

Rolewinck, Werner........................................ 31

Rosen, Gerd.................................................... 47

Rösslin, Eucharius.......................................... 38

Rudolf II., Kaiser ...................................... 21. 22

Šabalin, Dmitrij Jakovlevič ......................... 101

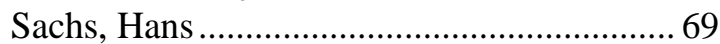

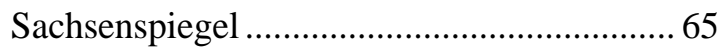

Sacramentarium Fuldense............................ 19

Sammlung Deutscher Drucke ............... 116-120

Schedel, Hartmann .......................................... 2

Schirlentz, Nickel...................................... 115

Schlözer, August Ludwig von ........................ 76

Schlözer-Stiftung ............................................ 76

Schlüter, Philipp August von ............................ 1

Schoeber, David Gottfried ............................. 95

Schöffer, Ivo.................................................... 67

Schöffer, Peter.......................................... 17. 89

Schönsperger, Johann................................... 8. 78

Schwarz, Christian Gottlieb ........................... 86

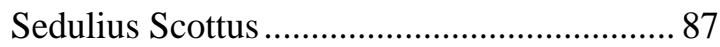

Septembertestament ...................................... 114

Stammbuch .................................................... 3

Stoy, Johann Siegmund................... Einführung

Stuß, Johann Heinrich ................................... 97

Suetonius Tranquillus, Gaius ........................111

Sweynheym, Konrad.......................... 54. 55. 90

Symbola et emblemata ..................................... 85

Talhoffer, Hans..................................................... 4

Terentius Afer, Publius............................... 72. 86

Thanner, Jacob ................................................ 26

Thomasius, Gottfried .......................... 79-83. 95

Trattner, Johann Thomas............................... 119

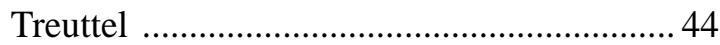

Uffenbach, Johann Friedrich Armand.. 8-11. 18

Uffenbach, Zacharias Conrad von ................ 12

Veldener, Johann ................................................ 31

Vérard, Antoine............................................ 70

Vergilius Maro, Publius ........................... 47. 94 
Exponat-Nr.

Vesalius, Andreas ............................................ 40

Vinogradov, Efim Grigor'evič .................... 100

Waldeck, Fürstliche Bibliothek................ 54. 57

Wolfram von Eschenbach .............................. 77

Zainer, Günther ........................................... 107

Zainer, Johannes d. Ä...................................... 79

Zentner, Wilhelm ............................................ 45 


\section{Verzeichnis der Beiträger}

$\begin{array}{ll}\text { AK } & \text { Andrea Kölbl } \\ \text { AT } & \text { Arnulf Timm } \\ \text { DW } & \text { Diana Walz } \\ \text { GU } & \text { Gerd Unverfehrt } \\ \text { HF } & \text { Heinz Fuchs } \\ \text { HK } & \text { Helmut Kind } \\ \text { HR } & \text { Helmut Rohlfing } \\ \text { HZ } & \text { Horst Zehe } \\ \text { JI } & \text { Jens Ilg } \\ \text { JM } & \text { Joachim Migl } \\ \text { JMb } & \text { Jens Mittelbach } \\ \text { KH } & \text { Katharina Habermann } \\ \text { KMO } & \text { Kathryn M. Olesko } \\ \text { KN } & \text { Kathrin Nordmeyer } \\ \text { MS } & \text { Mechthild Schüler } \\ \text { SG } & \text { Silke Glitsch } \\ \text { SK } & \text { Stefanie Krinninger } \\ \text { WE } & \text { Wilfried Enderle } \\ \text { WS } & \text { Werner Schwartz }\end{array}$


Der Ausstellungskatalog „Göttinger Kostbarkeiten - Handschriften, Drucke und Einbände aus zehn Jahrhunderten“ zeigt 125 schöne, außergewöhnliche und besonders wichtige Werke der Niedersächsischen Staats- und Universitätsbibliothek Göttingen. Die Auswahl ihrer Schätze vermittelt einen Eindruck von dem erstaunlichen Reichtum und der außerordentlichen Vielfalt der Bestände einer Bibliothek, die bereits im 18. Jahrhundert Vorbild für Bibliotheksgründungen in Deutschland, in Europa und in Amerika wurde. Zugleich bietet sie einen anschaulichen Einblick in die Erwerbungsgeschichte der Bibliothek und zeigt, aus welch unterschiedlichen Quellen die Göttinger Bibliothekare gezielt und systematisch einzelne Titel oder ganze Sammlungen erwarben, auf welch verschlungenen und mitunter abenteuerlichen Wegen Handschriften und Bücher ihren Weg nach Göttingen fanden, um einen Bestand von einzigartiger Dichte zu bilden. 